Studien zum Wirtschaftsstrafrecht - Neue Folge

Julian Sigmund

\title{
Strafrecht gegen \\ Korruption im Sport?
}

Erscheinungsformen des Match Fixing und Legitimation ihrer Kriminalisierung über die $\S \S 265 c$, 265d StGB 
Studien zum Wirtschaftsstrafrecht - Neue Folge

Begründet von

Prof. em. Dr. Dr. h. c. mult. Klaus Tiedemann, Universität Freiburg i.Br.

Prof. em. Dr. Dr. h. c. mult. Bernd Schünemann,

Ludwig-Maximilians-Universität München

Herausgegeben von

Prof. em. Dr. Dr. h. c. mult. Bernd Schünemann,

Ludwig-Maximilians-Universität München

Prof. Dr. Thomas Rönnau,

Bucerius Law School Hamburg

Prof. Dr. Roland Hefendehl,

Universität Freiburg i.Br.

Band 18 
Julian Sigmund

Strafrecht gegen Korruption im Sport?

Erscheinungsformen des Match Fixing und Legitimation ihrer Kriminalisierung über die $\S \S 265 c$, 265d StGB 
The book processing charge was funded by the Baden-Württemberg Ministry of Science, Research and Arts in the funding programme Open Access Publishing and the University of Freiburg.

Die Deutsche Nationalbibliothek verzeichnet diese Publikation in der Deutschen Nationalbibliografie; detaillierte bibliografische Daten sind im Internet über http://dnb.d-nb.de abrufbar.

Zugl.: Freiburg, Univ., Diss., 2020

u.d.T.: Strafrecht gegen Match Fixing? Erscheinungsformen und Legitimation ihrer Kriminalisierung über die $\S \S 265 c$, 265d StGB

1. Auflage 2021

(c) Julian Sigmund

Publiziert von

Nomos Verlagsgesellschaft mbH \& Co. KG

Waldseestraße 3-5 | 76530 Baden-Baden

www.nomos.de

Gesamtherstellung:

Nomos Verlagsgesellschaft mbH \& Co. KG

Waldseestraße 3-5 | 76530 Baden-Baden

ISBN (Print): 978-3-8487-8098-3

ISBN (ePDF): 978-3-7489-2516-3

DOI: https://doi.org/10.5771/9783748925163

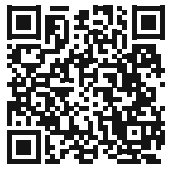

Onlineversion Nomos elibrary

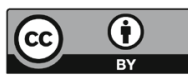

Dieses Werk ist lizensiert unter einer Creative Commons Namensnennung 4.0 International Lizenz. 
Meinen Eltern und Julia 


\section{Vorwort}

Die vorliegende Arbeit wurde im Sommersemester 2020 von der rechtswissenschaftlichen Fakultät der Albert-Ludwigs-Universität Freiburg als Dissertation angenommen. Rechtsprechung und Literatur konnten in der vorliegenden leicht überarbeiteten und aktualisierten Fassung bis Anfang Dezember 2020 berücksichtigt werden.

Mein erster Dank gilt meinem Doktorvater Herrn Professor Dr. Roland Hefendehl. Er hat die Entstehung dieser Arbeit von der Themenfindung bis zur Veröffentlichung mit Engagement, Fürsorge und instruktiven Anregungen gefördert. Indem er mich während meiner langjährigen Tätigkeit am Institut für Kriminologie und Wirtschaftsstrafrecht der Universität Freiburg vertrauensvoll in vielfältige Forschungs- und Lehrprojekte eingebunden hat, verhalf er mir überdies zu zahlreichen wertvollen Erfahrungen und schärfte mein kritisches Denken nicht nur in Bezug auf die Legitimation des Strafrechts. Seine integrative Institutsleitung stiftete auch unter den Mitarbeiterinnen und Mitarbeitern einen über den fachlichen Austausch hinausgehenden Zusammenhalt und ermöglichte es, das Institut als mehr zu begreifen als nur einen Arbeitsplatz.

Für die zügige Erstellung des Zweitgutachtens, das einige in die finale Überarbeitung eingeflossene Denkanstöße beinhaltete, bin ich Herrn Professor Dr. Gerson Trüg sehr verbunden. Mein Dank gebührt außerdem Herrn Professor Dr. Thomas Rönnau sowie Herrn Prof. em. Dr. Dr. h.c. mult. Bernd Schünemann für ihr Einverständnis in die Aufnahme der Arbeit in die von ihnen mitherausgegebene Schriftenreihe.

Inhaltlich wie formal profitierte diese Arbeit von der Mühe, die Steffen Lindemann und Patrick Steinmetz für die Durchsicht einzelner Kapitelentwürfe aufgebracht haben. Im Wissen um ihren juristischen und sportbezogenen Sachverstand bestärkte mich ihr differenziertes Feedback, veranlasste mich an manchen Stellen aber auch zu präziseren Neufassungen und gewinnbringenden Folgeüberlegungen.

Da sich der Wert dieser Arbeit für mich persönlich im Rückblick immer auch in den während ihres Entstehungsprozesses am Institut entstandenen oder vertieften Freundschaften ausdrücken wird, möchte ich mich zudem bei Jutta Bader, Annika Gronke, Laura Diebold, Jorge Cabrera und Matthias Schaum bedanken. Sich nahezu täglich mit derart klugen, humorvollen und hilfsbereiten Menschen sowohl über die Herausforderungen einer 
Promotion als auch über die Kuriositäten des Universitätsbetriebes austauschen zu können, empfand ich als großes Glück.

In tiefer Dankbarkeit blicke ich schließlich auf die umfassende Unterstützung, die ich durch meine Eltern und meine Freundin Julia erfahren habe. Mit Geduld, treffenden Ratschlägen und einem untrüglichen Gespür für meine Stimmungslagen und Bedürfnisse haben sie mich durch die Höhen und Tiefen der vergangenen Jahre begleitet, meine Sorgen immer wieder durch Ermutigung zerstreut und mitunter eigene Wünsche zurückgestellt. Die Gewissheit ihrer Anteilnahme und bedingungslosen Zuneigung war Antrieb dieser Arbeit und Grund ihres Gelingens. Ihnen ist sie daher gewidmet.

Berlin, im Februar 2021 


\section{Inhaltsverzeichnis}

Abkürzungsverzeichnis

Einführung

A. Problemstellung 23

B. Gang der Untersuchung 28

Teil 1: Die Straftatbestände der $\$ \mathbb{S} 265 \mathrm{c}, 265 \mathrm{~d}$ StGB als

Untersuchungsgegenstand 31

A. Gesetzgebungshistorischer Hintergrund 32

B. Zum Inhalt der Vorschriften im Einzelnen 35

I. Tatbestandsmerkmale der $\$ \$ 265 \mathrm{c}, 265 \mathrm{~d}$ StGB 36

1. Übereinstimmung in Aufbau, Täterkreis und Tathandlungsalternativen $\quad 36$

2. Unrechtsvereinbarung und subjektive Anforderungen des Sportwettbetrugs gemäß $₫ 265$ c StGB

3. Unrechtsvereinbarung und subjektive Anforderungen der Manipulation berufssportlicher Wettbewerbe gemäß $\$ 265 \mathrm{~d}$ StGB

II. Besonders schwere Fälle ( $\$ 265 \mathrm{e} \mathrm{StGB})$ und flankierende prozessuale und strafanwendungsrechtliche Anpassungen

Teil 2: Phänomenologische und strafrechtliche Grundlagen von Manipulationen im Sport

A. Phänomenologie der Sportmanipulationen 47

I. Begriffsklärung 48

1. Herleitung der Begriffsbestimmung und offene Definition der Sportmanipulation 48

2. Verhältnis zur Korruption im Sport $\quad 50$

3. Verhältnis zu Match Fixing 52 
II. Erscheinungsformen der Sportmanipulationen und am Anwendungsbereich der $\$ \$ 265 \mathrm{c}, 265 \mathrm{~d}$ StGB orientierte

Abgrenzungen

1. Abgrenzung der erfassten direkten

Wettbewerbsmanipulation zur indirekten

Sportkorruption

2. Abgrenzung der erfassten gegnerbegünstigenden Schlechtleistung zur Manipulation zum eigenen Wettbewerbsvorteil

3. Abgrenzung der erfassten Schlechtleistung zu außersportlichen Zwecken zur sportimmanent motivierten Leistungsreduzierung

a) Schonung von Kräften als sportimmanenter Zweck der Leistungsreduzierung

b) Indirekte Belohnung von Niederlagen durch den Wettbewerbsmodus

c) Die sog. „Stallorder" als Grenzfall

d) Sportinterner Umgang und Spiegelung der Differenzierung in den $\$ \mathbb{S} 265 \mathrm{c}, 265 \mathrm{~d}$ StGB

4. Abgrenzung der erfassten Bestechungsprämien von eigens erstrebten Wettgewinnen und der Weitergabe von Insiderinformationen aus Gefälligkeit

5. Unterscheidung nach Motivlage des Vorteilsgebers 68

a) Bestechungsprämie zwecks Wettgewinnen 68

b) Bestechungsprämie zwecks sportlicher Erfolge $\quad 73$

6. Zusammenfassung

III. Bedingungsfaktoren von Match Fixing und

Erklärungsansätze

1. Bedingungsfaktoren 77

a) Entwicklung und Zustand des Sportwettenmarkts $\quad 77$

aa) Wachstumsexplosion infolge Deregulierung und neuer Technologien

bb) Ableitung für die Gefahr des Match Fixing

b) Kommerzialisierung des Sports

aa) Kennzahlen

bb) Ableitungen für die Gefahr des Match Fixing

c) Verbandsinterne Verfolgung und Sanktionierung von Match Fixing 
2. Erklärungsansätze auf Grundlage der ökonomischen Kriminalitätstheorie

a) Ansätze auf Basis der Annahme der Rational Choice $\quad 92$

b) Theoretische Ableitungen für die Manipulationsanfälligkeit bestimmter Sportarten und empirische Belege

c) Grenzen und Potenziale $\quad 100$

IV. Ausmaß des Match Fixing

1. Methodische Probleme einer Quantifizierung

2. Hellfeld

3. Dunkelfeld

V. Ergebnis

B. Strafrechtliche Ausgangslage: Reaktionsmöglichkeiten auf die erfassten Sportmanipulationen

I. Strafbarkeit durch manipulatives Wettkampfverhalten

1. Betrugsstrafbarkeit des Sportlers durch Schlechtleistung im Wettkampf ( $\$ 263$ StGB)

a) Zum Nachteil des eigenen Vereins bzw. der Teamkollegen

b) Zum Nachteil eines konkurrierenden Drittvereins

c) Zum Nachteil der Zuschauer

d) Zum Nachteil des Veranstalters

2. Betrugsstrafbarkeit des Schiedsrichters durch Schlechtleistung im Wettkampf ( $\$ 263 \mathrm{StGB})$

a) Zum Nachteil des betroffenen Vereins

b) Zum Nachteil des Verbands

c) Zum Nachteil der Zuschauer

3. Zwischenergebnis

II. Strafbarkeit durch vorangehende Manipulationsabsprache

1. Strafbarkeit wegen Bestechung bzw. Bestechlichkeit ( $\$ 299$ StGB)

a) Sportakteure als Angestellte oder Beauftragte eines Unternehmens

b) Bevorzugung beim Bezug von Waren im geschäftlichen Verkehr

c) Zwischenergebnis

2. Strafbarkeit wegen Untreue ( $\$ 266$ StGB)

a) Missbrauch einer Verfügungs- oder

Verpflichtungsbefugnis und Verletzung einer

Vermögensbetreuungspflicht 
b) Vermögensnachteil

c) Zwischenergebnis

III. Strafbarkeit durch Folgehandlungen im Zusammenhang mit Sportwetten

1. Strafbarkeit des Wettspielers wegen Betrugs zum Nachteil des Wettanbieters ( $\$ 263$ StGB)

a) Täuschung 136

b) Vermögensschaden 139

c) Zwischenergebnis 146

2. Strafbarkeit des Wettspielers wegen Computerbetrugs zum Nachteil des Wettanbieters ( $\$ 263$ a StGB)

3. Strafbarkeit des Wettspielers wegen Betrugs zum Nachteil der redlichen Wettteilnehmer ( $\$ 263$ StGB) $\quad 148$

4. Beteiligung des Sportakteurs

IV. Ergebnis und Abgleich mit dem Anwendungsbereich der $\mathbb{S} 265 \mathrm{c}, 265 \mathrm{~d}$ StGB

I. Reduzierung des gesetzgeberischen Handlungsermessens im konkreten Fall

1. Kriminalisierungspflicht kraft internationaler Vereinbarungen

2. Kriminalisierungshindernis in Form des grundrechtlichen Schutzbereichs der Autonomie des Sports (Art. 9 GG)

a) Eingriff in einen materiell strafrechtsfreien Bereich

b) Entwertung der zugesicherten Verbandsgerichtsbarkeit und prozessuale Konflikte

aa) Schwächung der Sportgerichtsbarkeit durch prozessuale Konflikte

bb) Zwangsläufiger Verstoß gegen den Grundsatz der Doppelbestrafung

3. Zwischenergebnis

II. Allgemeine strafrechtsbezogene Begrenzungskonzepte

1. Strafrechtsimmanent fundierte Begrenzungskonzepte

a) Rechtsgutslehre

aa) Darstellung

bb) Kritik 
cc) Wertung

b) Sonstige strafrechtsimmanent fundierte

Begrenzungskonzepte

aa) Darstellung 175

bb) Kritik und Wertung 176

2. Verfassungsrechtliche Begrenzungskonzepte 178

a) Überprüfung materieller Strafnormen durch das Bundesverfassungsgericht

aa) Darstellung 179

bb) Kritik und Wertung 182

b) Sonstige verfassungsrechtliche Begrenzungskonzepte 186

aa) Darstellung 186

bb) Kritik und Wertung 187

3. Integrative Ansätze einer Strafrechtsbegrenzung 188

a) Schärfung des Verhältnismäßigkeitsgrundsatzes durch den Rechtsgutsbegriff

b) Ergänzende Begrenzungskriterien

III. Zusammenfassung und Folgen für den weiteren Verlauf der Untersuchung

B. Rechtsgut

I. Unzureichende Legitimierungsgründe

1. Der Sport als solcher

2. Bekämpfung von Korruption

3. Erweiterung prozessualer Befugnisse

4. Überwindung von Nachweisschwierigkeiten

II. Analyse der vorgebrachten Rechtsgüter

1. Quellen

a) Gesetzgebungsmaterialien 201

b) Wissenschaftliche Rezeption 204

2. Integrität des Sports 205

a) Allgemeines Begriffsverständnis 205

aa) Integrität 205

bb) Sport 206

b) Bestehender strafrechtlicher Integritätsschutz 207

c) Die spezifische Konkretisierung der Integrität des Sports als strafrechtlich zu schützendes Rechtsgut durch den Gesetzgeber

aa) Der zugrunde gelegte Sportbegriff 
bb) Anknüpfungspunkt und

Wirkungszusammenhang der sportspezifischen Integrität

(1) Das Sportethos als spezifischer Wertekodex

(2) Die gesamtgesellschaftliche Bedeutung des Sports als Wertevermittler

(3) Die gesamtgesellschaftliche Bedeutung des Sports als Wirtschaftsfaktor

cc) Zusammenfassung und Einordnung in das "Integritätsstrafrecht"

d) Prüfung der Integrität des Sports und ihrer

Bestandteile an den Kriterien eines materialisierten Rechtsgutsbegriffs

aa) Fairness

(1) Fair Play im Sport

(2) Fairness als (Straf-)Rechtsbegriff

(3) Vergleich und Einordnung des Gesetzentwurfs

(4) Kritik

(5) Zwischenergebnis

bb) Leistungsbereitschaft

cc) Vertrauen der Allgemeinheit in die Integrität des Sports

(1) Voraussetzungen eines legitimen strafrechtlichen Vertrauensschutzes

(2) Konkrete Einordnung und Kritik

(3) Zwischenergebnis

e) Zusammenfassung

3. Vermögen

4. Wettbewerb

a) Schutz des Sports als durch Wettkampfregeln konstituierte Institution

b) Schutz des Sports als wirtschaftlicher Wettbewerb

c) Zwischenergebnis 
C. Verhältnismäßigkeit 280

I. Geeignetheit 282

1. Hinsichtlich der Integrität des Sports 284

a) Allgemeine Untauglichkeit des Strafrechts zum Schutz der Integrität des Sports

aa) Systembedingte Untauglichkeit zur Förderung sportethischer Werte

bb) Konkretisierte Zweifel an der generalpräventiven Wirkung des Strafrechts bei Match Fixing

cc) Zwischenergebnis

b) Tatbestandsspezifische und deliktsstrukturelle Merkmale

aa) Tatbestandliche Verkürzungen des

Anwendungsbereiches

(1) Ausschluss tauglicher Täter

(2) Einschränkung auf Manipulationen leistungssportlicher bzw. berufssportlicher Wettbewerbe

(3) Einschränkung auf Manipulationen zugunsten des Wettbewerbsgegners

bb) Ausgestaltung als abstraktes Gefährdungsdelikt

(1) Grundlagen des abstrakten Gefährdungsdelikts und Notwendigkeit einer rechtsgutsabhängigen Differenzierung

a) Die Unterkategorie des Kumulationsdelikts

ß) Die Unterkategorie des Vorbereitungsdelikts

(2) Hinreichende Gefahrenwirkung der einzelnen Tathandlungen der $\$ \$ 265 c, 265 d$ StGB

(3) Verletzungswirkung über den Kumulationsgedanken

(4) Einseitig bleibende Tathandlungen als Kumulations- oder Vorbereitungsdelikte?

2. Hinsichtlich des Vermögensschutzes

a) Vermögensschutz durch $\$ 265$ c StGB

b) Vermögensschutz durch $\$ 265 \mathrm{~d}$ StGB 
II. Erforderlichkeit

1. Hinsichtlich der Integrität des Sports

a) Selbstregulierung durch die Sportverbände

aa) Schutzwirkung verbandlicher

Präventionsmaßnahmen

(1) Schulungs- und Informationsprogramme

(2) Überwachung des Sportwettenmarkts durch Frühwarnsysteme

(3) Wettverbote für Sportakteure

(4) Schieds-, kampf- und wertungsrichterbezogene Maßnahmen

(5) Kritik des widersprüchlichen Verhaltens

(6) Zwischenergebnis

bb) Ordnungs- und Strafgewalt der Verbände

(1) Rechtsgrundlagen und Verfahren

(2) Eingriffsintensität verbandsinterner Sanktionen

(3) Rechtsgutsbezogene Wirksamkeit verbandsinterner Sanktionen

(a) Fehlen strafprozessualer Ermittlungsbefugnisse

( $\beta$ ) Beschränkte Bindungswirkung

(Y) Machtlosigkeit gegenüber der Organisierten Kriminalität

(ठ) Signalwirkung der Kriminalstrafe

(4) Zwischenergebnis

b) Soziale Kontrolle und Substitute der

Norminternalisierung

c) Etablierung des Ordnungswidrigkeitenrechts

d) Veränderte staatliche Regulierung des Sportwettenmarkts

aa) Intendierter Integritätsschutz durch den Glücksspielstaatsvertrag

bb) Ausbleibender Vollzug und zweifelhafte

Geeignetheit

cc) Verbesserter Integritätsschutz durch alternative Regulierungsmodelle

2. Hinsichtlich des Vermögensschutzes
a) Effektivierung des strafrechtlichen
Vermögensschutzes durch $\$ 265$ c StGB? 
b) Außerstrafrechtlicher Vermögensschutz im Berufssport

3. Zwischenergebnis

III. Angemessenheit

1. Hinsichtlich der Integrität des Sports

2. Hinsichtlich des Vermögensschutzes

a) Ausmaß der Vorverlagerung und Ausgleich in $\$ 265 \mathrm{c}$ StGB

b) Ausreichend objektiv-abstrakte Gefährdung in $\$ 265 \mathrm{~d}$ StGB

c) Proportionalität von Tatbestand und Strafrahmen

3. Zwischenergebnis

IV. Ergebnis

D. Bestimmtheitsgrundsatz

I. Adressatenkreis und persönlicher Anwendungsbereich

1. Sportler

2. Einem Trainer gleichgestellte Personen

II. Berufssportlicher Wettbewerb i.S.d. $\$ 265$ d StGB 


\section{Abkürzungsverzeichnis}

$\mathrm{aA}$

abl.

Abs.

AEUV

$\mathrm{aF}$

$\mathrm{AO}$

ARD

Art.

AT

ATP

Aufl.

BDR

BGB

BGB1.

$\mathrm{BGH}$

BR-Drs.

BT

BT-Drs.

BT-PIPr.

BVerfG

bzw.

ca.

CAS

CDU andere Ansicht

ablehnend

Absatz

Vertrag über die Arbeitsweise der Europäischen Union in der Fassung der Bekanntmachung vom 9. Mai 2008, zuletzt geändert durch Änderungsbeschluss vom 11. Juli 2012

alte Fassung

Abgabenordnung in der Fassung der Bekanntmachung vom 1. Oktober 2002 (BGBl. I S. 3866), zuletzt geändert durch Gesetz vom 21. Dezember 2019 (BGB1. I S. 2875)

Arbeitsgemeinschaft der öffentlich-rechtlichen Rundfunkanstalten der Bundesrepublik Deutschland

Artikel

Allgemeiner Teil

Association of Tennis Professionals

Auflage

Bund Deutscher Radfahrer

Bürgerliches Gesetzbuch in der Fassung der Bekanntmachung vom 2. Januar 2002 (BGBl. I S. 42), zuletzt geändert durch Gesetz vom 26. März 2019 (BGBl. I S. 541)

(deutsches) Bundesgesetzblatt (zitiert nach Band, Jahr und Seite)

Bundesgerichtshof

Drucksachen des Bundesrats (zitiert nach Jahr und Nummer)

Bundestag / Besonderer Teil

Drucksachen des Deutschen Bundestages (zitiert nach Wahlperiode und Nummer)

Plenarprotokoll des Deutschen Bundestages (zitiert nach Wahlperiode und Nummer)

Bundesverfassungsgericht

Beziehungsweise

circa

Court of Arbitration for Sport

Christlich Demokratische Union Deutschlands 
CSU

Christlich Soziale Union Deutschlands

ders.

derselbe

DFB

Deutscher Fußballbund

DFL

Deutsche Fußballliga

DHB

Deutscher Handballbund

DOSB

Deutscher Olympischer Sportbund

ebd.

ebenda

Einl.

EMRK

etc.

Einleitung

etc.
EU
EuGH
f./ff.
FIFA
FDS
Fn.
FS
GG

$\mathrm{GmbHG}$

Europäische Menschenrechtskonvention in der Fassung der Bekanntmachung vom 22. Oktober 2010 (BGBl. II S. 1198), zuletzt geändert durch EMRK-Protokoll vom 24. Juni 2013 (BGBl. 2014 II S. 1034)

et cetera

Europäische Union

Europäischer Gerichtshof

folgende/fortfolgende

Fédération Internationale de Football Association

Fraud-Detection-System

Fußnote

Festschrift

Grundgesetz für die Bundesrepublik Deutschland vom 23. Mai 1949 (BGBl. S. 1), zuletzt geändert durch Gesetz vom 15. November 2019 (BGBl. I S. 1546)

\begin{tabular}{|c|c|}
\hline GmbHG & $\begin{array}{l}\text { Gesetz betreffend die Gesellschaften mit beschränkter Haftung in } \\
\text { der Fassung der Bekanntmachung vom 20. Mai } 1898 \text { (RGBl. } \\
\text { S. 846), zuletzt geändert durch Gesetz vom 17. Juli } 2017 \text { (BGBl. I } \\
\text { S. 2446) }\end{array}$ \\
\hline GlüStV & $\begin{array}{l}\text { Staatsvertrag zum Glücksspielwesen in Deutschland vom 15. De- } \\
\text { zember } 2011 \text { (GVB1. } 2012 \text { S. 318, 319, 392) }\end{array}$ \\
\hline $\mathrm{hM}$ & herrschende Meinung \\
\hline Hrsg. & Herausgeber \\
\hline ICSS & International Centre for Sports Security \\
\hline IRIS & Institut de Relations internationales et stratégiques \\
\hline ITF & International Tennis Federation \\
\hline IOC & International Olympic Committee \\
\hline i.S.d. & im Sinne des \\
\hline i.V.m. & in Verbindung mit \\
\hline
\end{tabular}




\begin{tabular}{|c|c|}
\hline krit. & Kritisch \\
\hline LG & Landgericht \\
\hline LV & Landesverfassung \\
\hline MINEPS & $\begin{array}{l}\text { International Conference for Ministers and Senior Officials Re- } \\
\text { sponsible for Physical Education and Sport }\end{array}$ \\
\hline $\mathrm{mwN}$ & mit weiteren Nachweisen \\
\hline NBA & National Basketball Association \\
\hline NCAA & National Collegiate Athletic Association \\
\hline NFL & National Football League \\
\hline Nr. & Nummer \\
\hline OLG & Oberlandesgericht \\
\hline OWiG & $\begin{array}{l}\text { Gesetz über Ordnungswidrigkeiten in der Fassung der Bekannt- } \\
\text { machung vom 19. Februar } 1987 \text { (BGBl. I S. 602), zuletzt geändert } \\
\text { durch Gesetz vom 9. Dezember } 2019 \text { (BGBl. I S. 2146) }\end{array}$ \\
\hline Rn. & Randnummer \\
\hline RuVO & Rechts- und Verfahrensordnung \\
\hline s. & Siehe \\
\hline S. & Seite \\
\hline SPD & Sozialdemokratische Partei Deutschlands \\
\hline sog. & sogenannte $(r)$ \\
\hline StGB & $\begin{array}{l}\text { 13. November } 1998 \text { (BGBl. I S. 3322), zuletzt geändert durch } \\
\text { Art. } 1 \text { des Gesetzes vom 3. März } 2020 \text { (BGBl. I. S. 431) }\end{array}$ \\
\hline StPO & $\begin{array}{l}\text { Strafprozessordnung in der Fassung der Bekanntmachung vom } \\
\text { 7. April } 1987 \text { (BGBl. I S. 1974), zuletzt geändert durch Art. } 2 \text { des } \\
\text { Gesetzes vom 3. März } 2020 \text { (BGBl. I S. 431) }\end{array}$ \\
\hline u. a. & unter anderem/anderen \\
\hline UCI & Union Cycliste Internationale \\
\hline UEFA & Union of European Football Associations \\
\hline UNESCO & United Nations Educational, Scientific and Cultural Organization \\
\hline $\begin{array}{l}\text { Var. } \\
\text { VDV }\end{array}$ & $\begin{array}{l}\text { Variante } \\
\text { Vereinigung der Vertragsfußballspieler e.V. }\end{array}$ \\
\hline VGH & Verwaltungsgerichtshof \\
\hline vgl. & Vergleiche \\
\hline Vor. & Vorbemerkung \\
\hline WpHG & $\begin{array}{l}\text { Gesetz über den Wertpapierhandel in der Fassung der Bekannt- } \\
\text { machung vom 9. September } 1998 \text { (BGBl. I S. 2708), zuletzt geän- } \\
\text { dert durch Gesetz vom 27. März } 2020 \text { (BGBl. I S. 543) }\end{array}$ \\
\hline
\end{tabular}


Abkürzungsverzeichnis

z. B.

zum Beispiel

$\mathrm{ZPO}$

Zivilprozessordnung in der Fassung der Bekanntmachung vom 5. Dezember 2005 (BGBl. I S. 3202), zuletzt geändert durch Gesetz vom 12. Dezember 2019 (BGBl. I S. 2633)

zust.

zustimmend 


\section{Einführung}

\section{A. Problemstellung}

$\mathrm{Ob}$ als Gegenstand morgendlicher Zeitungslektüre, verbindendes Gesprächsthema in Mittagspausen, Wartezimmern oder Nahverkehrszügen oder Anlass abendlicher Zusammenkünfte im Freundeskreis vor Bildschirmen oder auf Stadiontribünen: der globalisierte Spitzensport ist zu einem zentralen Bestandteil unserer Alltagskultur geworden. In einer zunehmend komplexen und undurchsichtigen Welt verspricht er Orientierung durch vermeintlich klare Maßstäbe von gut und schlecht, von Erfolg und Misserfolg, auf die sich Menschen über soziale und nationale Trennlinien hinweg verständigen können. Neben dem als Fan erfahrbaren Zusammengehörigkeitsgefühl einer gemeinsamen emotionalen Anteilnahme bieten die Rollenverteilung von Favorit und Außenseiter, die Belohnung von Anstrengung und Beharrlichkeit, aber auch die gelegentliche Abhängigkeit des Erfolgs von glücklichen Zufällen Identifikationsmuster, die sich unmittelbar auf das eigene Leben übertragen lassen. Längst haben die Industrie und die Organisationseinheiten der populären Sportarten das sich hieraus ergebende Potenzial erkannt und den Spitzensport durch mediale Vermarktung zu einer milliardenschweren Unterhaltungsdienstleistung ausgebaut, die zahlreiche Möglichkeiten der wirtschaftlichen Verwertung eröffnet. In Deutschland trägt der Sektor Sport bereits mit 2,3 \% zum gesamten Bruttoinlandsprodukt bei. ${ }^{1}$

Eine derart breitflächige Verankerung des Spitzensports verleiht manipulativen Eingriffen in seine Wettkämpfe unweigerlich eine gesellschaftliche Dimension, was bereits die auf entsprechende Meldungen verlässlich folgende öffentliche Empörung bezeugt. Wurde diese über Jahre hinweg vor allem durch die Aufdeckung prominenter Dopingfälle ausgelöst, scheint sie sich zuletzt zunehmend an einer anderen Manipulationsform zu entflammen: dem sog. Match Fixing. Der Begriff beschreibt die oftmals auf einer vorangehenden Absprache beruhende Herbeiführung eines bestimmten Wettkampfergebnisses durch absichtliche Schlechtleistung eines am Wettkampf unmittelbar beteiligten Sportakteurs. Prinzipiell in jeder Sportart denkbar kann diese etwa im absichtlichen Vergeben eines Elfme-

1 Ablert/an der Heiden/Repenning Sportsatellitenkonto 2016, S. 8. 
ters oder Freiwurfs, einer unzureichenden Verteidigungsleistung in entscheidenden Spielsituationen oder der Aussprache gänzlich unbegründeter Feldverweise durch einen Schiedsrichter bestehen.

Hierzulande ist das Phänomen untrennbar verbunden mit zwei Geschehnissen im Fußball, die als „Manipulationsskandale“ in die deutsche Sportgeschichte eingingen. In der Spielzeit 1970/1971 wurden von verschiedenen Funktionsträgern sich im Abstiegskampf befindlicher Vereine Bestechungsprämien an Spieler gegnerischer Teams gezahlt, damit diese in kommenden Punktspielen bestimmte Resultate herbeiführten, die den Vereinen der jeweiligen Vorteilsgeber den Verbleib in der Bundesliga sichern sollten. Und im Jahr 2005 gab der Schiedsrichter Robert Hoyzer zu, gegen Sach- und Geldzuwendungen auf den Ausgang verschiedener unter seiner Leitung ausgetragener Fußballspiele durch bewusste Fehlentscheidungen eingewirkt zu haben, um seinen Auftraggebern finanzielle Gewinne aus Sportwetten zu verschaffen.

Stets reduziert ein derartiges Spielverhalten die Qualität des dargebotenen sportlichen Wettkampfes. Match Fixing entzieht dem Sport große Teile seiner Faszination, die sich aus seiner Unvorhersehbarkeit und der Grundannahme ergibt, mehrere Athleten wetteiferten unter Aufbietung ihrer maximalen Leistungsfähigkeit. Gleichzeitig eröffnen Manipulationsabsprachen sowohl für die ausführenden Sportakteure in Form zugesagter Bestechungsprämien als auch für initiierende Außenstehende in Form für den manipulierten Wettkampf verfügbarer Sportwetten die Aussicht auf beträchtliche finanzielle Gewinne. Entsprechend alarmiert zeigen sich hohe Funktionsträger internationaler Sportverbände und bezeichnen Match Fixing in drastischer Rhetorik als „neuen Kampf, dem man sich stellen muss“2 bzw. „Krebsgeschwür, das es auszumerzen gilt“. ${ }^{3}$

Offenbar fühlte sich auch der deutsche Strafgesetzgeber zur Mitwirkung an Gegenmaßnahmen aufgefordert. Unter Verweis auf den notwendigen Schutz der Integrität des Sports sowie betroffener Vermögensinteressen stellte er mit den am 19.4.2017 in Kraft getretenen Vorschriften des Sportwettbetrugs $(\$ 265 \mathrm{c}$ StGB) und der Manipulation von berufssportlichen Wettbewerben $(\$ 265 \mathrm{~d} \mathrm{StGB})$ erstmals ein auf eine Spielmanipulation ge-

2 So Jacques Rogge als Präsident des Internationalen Olympischen Komitees (IOC) bei einer Pressekonferenz im Jahr 2011, www.espn.com/olympics/story/_/id/67683 58/jacques-rogge-says-match-fixing-gambling-big-fights-sports.

3 So Gianni Infantino als Generalsekretär des europäischen Fußballverbandes UEFA bei einer Pressekonferenz im Jahr 2013, www.uefa.org/about-uefa/legal-justice/new s/newsid=1912418.html. 
richtetes korruptives Verhalten im Sport als solches unter Strafe. Dies mag auf den ersten Blick nicht weiter verwundern. Schließlich scheint sich ein gesellschaftlich vielfältig bedeutsamer Bereich mit einer gravierenden Bedrohung konfrontiert zu sehen, die der medialen Berichterstattung zufolge nicht selten von systematisch und verdeckt operierenden kriminellen Organisationen („Wett-Mafia“) ausgeht. ${ }^{4}$ Außerdem lassen sich die geschaffenen Straftatbestände sowohl im Sinne des durch das Anti-Doping Gesetz von 2015 eingeleiteten Integritätsschutzes im Sport als auch hinsichtlich der verstärkten Implementierung eines berufsspezifischen Korruptionsstrafrechts ${ }^{5}$ durchaus als konsequente Fortführung eines legislatorischen Konzepts deuten.

Bei erweiterter Betrachtung von Gesetzgebungshistorie und gesellschaftlicher Rezeption des Spitzensports erstaunt die Einführung der $\$ \mathbb{S} 265 \mathrm{c}$, 265d StGB allerdings doch. Die spezifische Kriminalisierung wettkampfbezogener Verhaltensweisen durchbricht eine über Jahrzehnte andauernde Enthaltsamkeit des Strafrechts in Bezug auf den Sport. Unter dem beständigen Eindruck auf die verfassungsrechtliche Garantie der Autonomie des Sports (Art. 9 GG) verweisender Sportverbände überdauerte diese Zurückhaltung mehrere Aufsehen erregende Manipulationsserien und rechtspolitische Vorstöße. Die Erhebung der Integrität des Sports zu einem strafrechtlich geschützten Gut erfolgt nun gerade zu einem Zeitpunkt, an dem bestimmte Indizien sowohl deren reale Existenz als auch deren Relevanz für den Spitzensport und seine gesellschaftlichen Funktionen zunehmend in Zweifel ziehen.

Gerade die Sportverbände selbst haben zuletzt nämlich jenseits von Dopingskandalen und Fällen des Match Fixing zur Infragestellung eines den Sport überwölbenden, vorbildhaften Wertekodex beigetragen. Mit ihren bereits im Verfahrensablauf undurchsichtigen Entscheidungen zur Vergabe bedeutender Sportturniere an autoritäre Staaten konterkarieren sie die

4 In der einschlägigen medialen Berichterstattung scheint der Begriff der „Wett-Mafia" mittlerweile notorisch und von konkreten Fällen gelöst als Synonym der diffusen Bedrohung des Sports durch wettbedingtes Match Fixing verwendet zu werden, s. die Analyse der Darstellung von Match Fixing in den Printmedien mit vielen Beispielen bei Kalb/Herrmann/Emrich, in: Emrich/Pierdzioch/Pitsch (Hrsg.), Falsches Spiel, 2015, S. $109 \mathrm{ff}$.

5 Vgl. nur die allesamt innerhalb der 18. Legislaturperiode des Deutschen Bundestages neu gefassten bzw. eingeführten Straftatbestände der Mandatsträgerbestechung $(\$ 108 \mathrm{e}$ StGB), der Bestechlichkeit und der Bestechung im Gesundheitswesen ( $\$ \$ 299 \mathrm{a}, 299 \mathrm{~b}$ StGB) sowie den Veränderungen bei der Amtsträgerbestechung ( $\mathbb{S} \mathbb{1 1}$ Abs. 1 Nr. 2a, 335a StGB). 
Werte von Transparenz, Leistungsprinzip, Toleranz und Entfaltungsfreiheit, die ihre Wettbewerbe transportieren sollen. Bei den jüngsten Weltmeisterschaften im Fußball in Russland 2018 und in der Leichtathletik in Katar 2019 drängte die vielstimmige öffentliche Kritik an Vergabe und Organisationsmängeln die Berichterstattung über die sportlichen Leistungen beinahe in den Hintergrund. Zudem hinterfragt der vielerorts ermöglichte Einstieg von Großinvestoren in Sportvereine den Anspruch der sportlichen Chancengleichheit. Und die inzwischen umfangreich vollzogene Verflechtung von Verbänden, Sportvereinen und prominenten Protagonisten mit der Glücksspielindustrie und Wettanbietern ${ }^{6}$ schafft in Form von möglichem Suchtverhalten und Geldnöten zumindest mittelbar Anreize für die verbal verurteilten Spielmanipulationen. Auch wenn diese Beispiele nicht die sportliche Auseinandersetzung selbst betreffen, beeinträchtigen sie doch deren öffentliche Wahrnehmung und erschweren eine Definition dessen, was als Integrität des Sports zu schützen wäre. ${ }^{7}$

Darüber hinaus wirft die von bisherigen Manipulationsfällen weitgehend unbeeindruckte Popularität des Spitzensports die noch grundsätzlichere Frage auf, ob es einer wie auch immer im Einzelnen ausgefüllten Wettbewerbsintegrität in einem zur milliardenschweren Unterhaltungsindustrie ausgebauten Spitzensport überhaupt bedarf. Womöglich basieren die gesellschaftlichen und wirtschaftlichen Funktionen des Sports in Wahrheit allein auf dessen Produktion von in gewisser Weise stets unbegreiflichen Mythen. ${ }^{8}$ Dann würde es aber genügen, die Integrität von Akteuren und Wettbewerben als bloßes Ideal in ein Narrativ einzubinden, das auch aus der gelegentlich aufgedeckten diesbezüglichen Unzulänglichkeit von Sportakteuren und ihrer kollektiven Verstoßung Zusammengehörigkeitsgefühle herstellt und die entstehende Lücke an Identifikationsmustern umgehend durch die Einführung neuer Helden auszufüllen versteht.

6 Allein in der Fußball-Bundesliga lassen sich aktuell 13 Vereine von privaten Sportwettanbietern sponsern. Der Verband der deutschen Profiligen DFL unterhält seit 2018 eine Premiumpartnerschaft mit dem Wettanbieter Tipico. Der konkurrierende Anbieter bwin sponsert derweil den Deutschen Fußball Bund (DFB), die deutsche Nationalmannschaft, die Frauen-Bundesliga sowie die 3. Liga. In Werbespots verschiedener Anbieter treten zahlreiche namhafte ehemalige und aktuelle Fußballnationalspieler wie Joshua Kimmich, Lukas Podolski, Bastian Schweinsteiger oder Oliver Kahn auf. Eindrücklich zur Verflechtung Haberl Wetten dass...?, Süddeutsche Zeitung Magazin vom 14.3.2019, sz-magazin.sueddeutsche.de/sport/sportwett en-fussball-werbung-tipico-bwin-86974? reduced=true.

7 S. auch Momsen KriPoZ 2018, 21.

8 So etwa Gebauer, in: Caysa (Hrsg.), Sportphilosophie, 1997, S. 290 ff., der vom Spitzensport als einer Mythen-Maschine spricht. 
Die bereits bei einer ersten Annäherung aufblitzende Ambivalenz der Integrität des Sports und ihr Spannungsverhältnis zu dessen fortschreitender Kommerzialisierung können eine grundlegende Skepsis gegenüber einer an diesen beiden Aspekten anknüpfenden Aktivierung des Strafrechts hervorrufen. Braucht es ein berufsspezifisches Korruptionsstrafrecht zur Sicherung des schwer greifbaren Wertekodex eines gesellschaftlichen Teilbereichs, der trotz des auf sich gezogenen öffentlichen Interesses doch ohne unmittelbaren Einfluss auf die individuellen Freiheitsräume der großen Mehrheit der Bevölkerung bleibt? Schlösse eine dem organisierten Sport tatsächlich aus der Vereinsfreiheit des Art. 9 GG verfassungsrechtlich zukommende Kompetenz zur autonomen Ausformung und Überwachung dieses Kodex eine parallele strafrechtliche Verhaltenssteuerung nicht von vornherein aus? Und selbst wenn nicht: ist staatlichen Straftatbeständen gegen Match Fixing in der von eigenen Verhaltensanforderungen geprägten „normativen Sonderwelt“ des Sports überhaupt eine generalpräventive Wirkung zuzutrauen?

Derart grundlegende Zweifel an der Notwendigkeit und Effektivität einer strafrechtlichen Adressierung des Match Fixing setzen sich bezüglich ihrer konkreten Ausformung fort: Führen die bisweilen auch untereinander kollidierenden Schutzgüter der Integrität und des Vermögens bei der Beschreibung der Tathandlungen nicht zwangsläufig zu einem Abstraktionsniveau, das ein für beide Schutzgüter gleichermaßen erkennbares Gefährdungspotenzial nahezu zwangsläufig vermissen lassen muss? Und gelingt angesichts der bereichsweise fließenden Übergänge von Spitzen-, Amateur- und Breitensport eine hinreichend bestimmte tatbestandliche Eingrenzung des strafbaren Bereiches, die bezüglich der verfolgten Schutzgutskonzeption schlüssig wirkt?

Hinter diesen Fragen formiert sich eine Gegenposition zur getroffenen Kriminalisierungsentscheidung, deren Skepsis nicht nur den vom Gesetzgeber im Zusammenhang mit den $\$ \$ \$ 265$ c, 265d StGB vorgebrachten Leitmotiven und Erwartungen gilt, sondern bis zu tiefer gelegenen Schichten der allgemeinen Strafrechtsausrichtung durchdringt. Ihr zufolge basiert die nun gesetzgeberisch festgestellte Schnittfläche der jahrelang berührungslos nebeneinander stehenden Kreise Sport und Strafrecht weniger auf einem infolge der gewachsenen Bedeutung und neuer Gefährdungsformen zu konstatierenden Hineinragen des Sports in den eingehegten Bereich des Strafbaren als vielmehr umgekehrt auf einer fortschreitenden Ausdehnung des Strafrechts durch die Preisgabe von Begrenzungsparametern. Doch handelt es sich bei den geschaffenen Tatbeständen gegen Match Fixing tatsächlich primär um den bloßen Ausfluss einer allgemeinen Kri- 


\section{Einfübrung}

minalisierungstendenz, die sich durch die behauptete Schutzwürdigkeit institutioneller Zusammenhänge und nahezu willkürliche Erfassung abstrakter Gefahren kennzeichne?

In jedem Fall wird deutlich: An den $\$ \mathbb{S} 265 \mathrm{c}$, 265d StGB entzündet sich eine vielschichtige Kontroverse, die sich von konkreten Fragen der Tatbestandsfassung über eine mögliche verfassungsrechtliche Straffreistellung des Sports bis hin zur Uneinigkeit über die allgemeine Ausrichtung des Strafrechts erstreckt. So nachdrücklich derart mehrdimensionale Streitfragen nach einer eingehenden und differenzierten Überprüfung der Legitimität der Tatbestände verlangen, so unweigerlich stellen sie diese vor methodische Herausforderungen. Die vielfältigen Kritikpunkte, in denen sich die Geltendmachung konkreter Unzulänglichkeiten der $\$ \$ \$ 265$ c, 265d StGB und eine schon im Grundsatz abweichende Auffassung von den allgemeinen Legitimationsbedingungen strafrechtlicher Tatbestände mitunter vermischen, sind gemäß ihrer Zielrichtung und ihrem Hintergrund zu ordnen. Sofern sie einer grundsätzlich strafrechtskritischen Haltung entstammen, sind sie ihrerseits begründungsbedürftig und können nicht ohne weiteres an die $\$ \$ 265 c$, 265d StGB herangetragen werden. Wenn es aber gelingt, die Einwände in einen übergeordneten und fundierten Maßstab einzubinden, dessen einzelne Prüfungsstufen ihrem spezifischen Gehalt eine allgemeingültige kritische Relevanz verleihen, lassen sich aus ihrer Bewertung verbindliche Aussagen über die Legitimation der $\$ \$ 265 \mathrm{c}$, 265d StGB ableiten.

\section{B. Gang der Untersuchung}

Dieses Erfordernis schlägt sich auch im Gang der Untersuchung nieder, der die zentrale Fragestellung nach der Legitimation der $\$ \$ 265$ c, 265d StGB anhand eines verfassungsrechtlich ableitbaren Prüfungsmaßstabes unter Rückgriff auf phänomenologische Erkenntnisse zur gesellschaftlichen Bedeutung des Sports im Allgemeinen und den tatbestandlich erfassten Manipulationsabsprachen im Besonderen zu beantworten versucht.

Der Einführung des Untersuchungsgegenstands dient dabei die deskriptive Darstellung der durch gemeinsame und abweichende Tatbestandsvoraussetzungen ausgeformten jeweiligen Anwendungsbereiche der $\$ \$ 265 \mathrm{c}$, $265 \mathrm{~d}$ StGB, die von einer Zusammenfassung entstehungsgeschichtlicher Hintergründe sowie prozessualer und strafanwendungsrechtlicher Implikationen flankiert wird (Teil 1). 
Jedoch kann die Bewertung ihrer Legitimation ohne Kenntnis von Erscheinungsformen und Entstehungsbedingungen des kriminalisierten Verhaltens und ohne Befassung mit seiner bisherigen strafrechtlichen Erfassung nicht gelingen. Der Legitimationsprüfung vorgeschaltet ist daher ein grundlegendes Kapitel, das sich dem weiten Feld der Sportmanipulationen phänomenologisch nähert und vor Einführung der spezifischen Tatbestände bestehende strafrechtliche Reaktionsmöglichkeiten untersucht (Teil 2). Im Rahmen einer phänomenologischen Beleuchtung des kriminalisierten Verhaltens entlang der tatbestandlichen Eingrenzungen der $\$ \$ 265 c, 265 d$ StGB werden die strafrechtlich adressierten Spielmanipulationen dabei zunächst von anderen Manipulationsformen im Sport abgegrenzt und exemplifiziert (A. I. und A. II.). Zu der auf diese Weise fokussierten und sich nach Motivationsstruktur der Akteure noch einmal aufspaltenden Fallgruppe des korruptionsbasierten Match Fixing werden anschließend Bedingungsfaktoren beschrieben und die aus ihnen abgeleiteten sportartspezifischen Gefährdungslagen und allgemeinen Erklärungsansätze diskutiert (A. III.). Am Ende dieses kriminologisch ausgerichteten Abschnitts wird anhand der Auswertung von amtlichen Statistiken und Dunkelfeldforschung die tatsächliche Ausbreitung der tatbestandlich adressierten Spielmanipulationen zu bestimmen versucht (A. IV.). Sodann wird das regelmäßig mehraktige Vorgehen bei vereinbarten Spielmanipulationen auf strafrechtlich relevante Anknüpfungspunkte jenseits der $\$ \$ 265 c$, 265d StGB untersucht, wobei ein Schwerpunkt auf der vom Bundesgerichtshof bereits zweimalig angenommene Betrugsstrafbarkeit durch die Platzierung einer Sportwette auf einen zuvor manipulierten Wettkampf liegt (B). Hierdurch kann das genaue Ausmaß der durch die spezifischen Tatbestände geschaffenen strafrechtlichen Erweiterung abgebildet und den im Gesetzgebungsverfahren geltend gemachten Strafbarkeitslücken nachgespürt werden.

Die Analyse der Legitimation der überprüften Tatbestände (Teil 3) gliedert sich in die Herleitung eines allgemeinen Prüfungsmaßstabes für die Bewertung der Legitimation strafrechtlicher Tatbestände und dessen ausführliche Anwendung auf die $\$ \$ 265 c, 265 \mathrm{~d}$ StGB. Auf der Grundlage einer Würdigung strafrechtsimmanenter, verfassungsrechtlicher und integrativer Begrenzungskonzepte werden also zunächst zentrale Legitimationsbedingungen herausgestellt, deren kritisches Potenzial sich normativ verankern lässt (A.). Sie erfordern eine eingehende Auseinandersetzung mit den vorgeblich geschützten Gütern und der Weise ihres jeweils tatbestandsstrukturell realisierten Schutzes. Hierzu wird insbesondere das neu geschaffene Rechtsgut der Integrität des Sports zunächst in seiner gesetzge- 


\section{Einfübrung}

berischen Konzeption skizziert und in einzelne Bestandteile unterteilt, ehe es den für ein strafrechtliches Schutzgut als maßgeblich befundenen Anforderungen gegenübergestellt wird (B.). Im Abgleich beider Tatbestände mit den Prüfungsstufen des Verhältnismäßigkeitsgrundsatzes wird sodann ausgehend von ihrer Deliktsstruktur die bereichsspezifische Wirkweise der konkreten strafrechtlichen Verbote im Hinblick auf die geschützten Güter bewertet, mit der Effektivität sonstiger strafrechtlicher oder sportverbandlicher Maßnahmen gegen Match Fixing verglichen und einerseits zur Bedeutung der Schutzgüter, andererseits zur mit strafrechtlichen Eingriffen einhergehenden Beschränkung von Freiheitsrechten ins Verhältnis gesetzt (C.). Ferner wird die Bestimmtheit der Tatbestände untersucht (D.).

Die zu den einzelnen Prüfungsfragen gefundenen Ergebnisse werden abschließend in eine Bewertung der Legitimation der $\$ \$ 265$ c, 265d StGB überführt, die vor dem Hintergrund der übergeordneten Kontroverse um die Ausrichtung des Strafrechts eingeordnet und mit Handlungsempfehlungen an den organisierten Sport verbunden wird, die der künftigen Reduzierung von Spielmanipulationen dienen. 


\section{Teil 1: Die Straftatbestände der $\$ \$ 265$ c, 265d StGB als Untersuchungsgegenstand}

Gegenstand dieser Arbeit sind die mit dem 51. Strafrechtsänderungsgesetz beschlossenen und mit Wirkung zum 19. April 2017 ins StGB aufgenom-

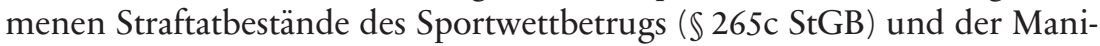
pulation von berufssportlichen Wettbewerben ( $\$ 265 \mathrm{~d} \mathrm{StGB}) .{ }^{9}$ Ausweislich ihrer Begründung dienen sie dem Schutz der Integrität des Sports und des Vermögens. ${ }^{10}$ Als normative Richtschnur der folgenden phänomenologischen Auseinandersetzung mit Match Fixing und Bezugspunkt der kritischen Bewertung der Legitimation der durch sie etablierten Kriminalisierung werden die Tatbestände zunächst in ihrer Entstehungsgeschichte (dazu A.) und sodann in ihren materiellen Voraussetzungen und verfahrensrechtlichen Auswirkungen (dazu B.) beschrieben. Dieser deskriptiven Einführung werden die gegenständlichen Vorschriften in ihrer seit Inkrafttreten gültigen Fassung vorangestellt:

\section{§265c Sportwettbetrug}

(1) Wer als Sportler oder Trainer einen Vorteil für sich oder einen Dritten als Gegenleistung dafür fordert, sich versprechen lässt oder annimmt, dass er den Verlauf oder das Ergebnis eines Wettbewerbs des organisierten Sports zugunsten des Wettbewerbsgegners beeinflusse und infolgedessen ein rechtswidriger Vermögensvorteil durch eine auf diesen Wettbewerb bezogene öffentliche Sportwette erlangt werde, wird mit Freiheitsstrafe bis zu drei Jahren oder mit Geldstrafe bestraft.

(2) Ebenso wird bestraft, wer einem Sportler oder Trainer einen Vorteil für diesen oder einen Dritten als Gegenleistung dafür anbietet, verspricht oder gewährt, dass er den Verlauf oder das Ergebnis eines Wettbewerbs des organisierten Sports zugunsten des Wettbewerbsgegners beeinflusse und infolgedessen ein rechtswidriger Vermögensvorteil durch eine auf diesen Wettbewerb bezogene öffentliche Sportwette erlangt werde.

(3) Wer als Schieds-, Wertungs- oder Kampfrichter einen Vorteil für sich oder einen Dritten als Gegenleistung dafür fordert, sich versprechen lässt oder annimmt, dass er den Verlauf oder das Ergebnis eines Wettbewerbs des organisierten Sports in regelwidriger Weise beeinflusse und infolgedessen ein rechtswidriger Vermögensvorteil durch eine auf diesen Wettbewerb bezogene öffentliche Sportwette erlangt werde, wird mit Freiheitsstrafe bis zu drei Jahren oder mit Geldstrafe bestraft.

(4) Ebenso wird bestraft, wer einem Schieds-, Wertungs- oder Kampfrichter einen Vorteil für diesen oder einen Dritten als Gegenleistung dafür anbietet, verspricht oder gewährt, dass er den Verlauf oder das Ergebnis eines Wettbewerbs des organisierten Sports in regelwidriger

9 BGBl. 2017 I S. 815.

10 BT-Drs. 18/8831, S. 10. 
Weise beeinflusse und infolgedessen ein rechtswidriger Vermögensvorteil durch eine auf diesen Wettbewerb bezogene öffentliche Sportwette erlangt werde.

(5) Ein Wettbewerb des organisierten Sports im Sinne dieser Vorschrift ist jede Sportveranstaltung im Inland oder im Ausland,

1. die von einer nationalen oder internationalen Sportorganisation oder in deren Auftrag oder mit deren Anerkennung organisiert wird und

2. bei der Regeln einzuhalten sind, die von einer nationalen oder internationalen Sportorganisation mit verpflichtender Wirkung für ihre Mitgliedsorganisationen verabschiedet wurden.

(6) Trainer im Sinne dieser Vorschrift ist, wer bei dem sportlichen Wettbewerb über den Einsatz und die Anleitung von Sportlern entscheidet. Einem Trainer stehen Personen gleich, die aufgrund ihrer beruflichen oder wirtschaftlichen Stellung wesentlichen Einfluss auf den Einsatz oder die Anleitung von Sportlern nehmen können.

\section{\$265d Manipulation von berufssportlichen Wettbewerben}

(1) Wer als Sportler oder Trainer einen Vorteil für sich oder einen Dritten als Gegenleistung dafür fordert, sich versprechen lässt oder annimmt, dass er den Verlauf oder das Ergebnis eines berufssportlichen Wettbewerbs in wettbewerbswidriger Weise zugunsten des Wettbewerbsgegners beeinflusse, wird mit Freiheitsstrafe bis zu drei Jahren oder mit Geldstrafe bestraft.

(2) Ebenso wird bestraft, wer einem Sportler oder Trainer einen Vorteil für diesen oder einen Dritten als Gegenleistung dafür anbietet, verspricht oder gewährt, dass er den Verlauf oder das Ergebnis eines berufssportlichen Wettbewerbs in wettbewerbswidriger Weise zugunsten des Wettbewerbsgegners beeinflusse.

(3) Wer als Schieds-, Wertungs- oder Kampfrichter einen Vorteil für sich oder einen Dritten als Gegenleistung dafür fordert, sich versprechen lässt oder annimmt, dass er den Verlauf oder das Ergebnis eines berufssportlichen Wettbewerbs in regelwidriger Weise beeinflusse, wird mit Freiheitsstrafe bis zu drei Jahren oder mit Geldstrafe bestraft.

(4) Ebenso wird bestraft, wer einem Schieds-, Wertungs- oder Kampfrichter einen Vorteil für diesen oder einen Dritten als Gegenleistung dafür anbietet, verspricht oder gewährt, dass er den Verlauf oder das Ergebnis eines berufssportlichen Wettbewerbs in regelwidriger Weise beeinflusse.

(5) Ein berufssportlicher Wettbewerb im Sinne dieser Vorschrift ist jede Sportveranstaltung im Inland oder im Ausland,

1. die von einem Sportbundesverband oder einer internationalen Sportorganisation veranstaltet oder in deren Auftrag oder mit deren Anerkennung organisiert wird,

2. bei der Regeln einzuhalten sind, die von einer nationalen oder internationalen Sportorganisation mit verpflichtender Wirkung für ihre Mitgliedsorganisationen verabschiedet wurden, und

3. an der überwiegend Sportler teilnehmen, die durch ihre sportliche Betätigung unmittelbar oder mittelbar Einnahmen von erheblichem Umfang erzielen.

(6) $\$ 265$ c Absatz 6 gilt entsprechend.

\section{A. Gesetzgebungshistorischer Hintergrund}

Der Einführung der $\$ \$ 265$ c, 265d StGB im Jahr 2017 ging eine ein Jahrzehnt andauernde rechtspolitische Diskussion voran, in deren Verlauf auf 
verschiedenen legislatorischen Ebenen einschlägige Entwürfe eingebracht und verworfen wurden, ehe eine bemerkenswerte Kehrtwende in der Haltung der Regierungsparteien den Weg ebnete. Einen ersten Versuch zur Implementierung der strafrechtlichen Erfassung von Sportmanipulationen jenseits des Dopings unternahm im Jahr 2007 die Bundestagsfraktion Bündnis 90/Die Grünen, die im Rahmen eines Änderungsantrages zum damaligen Entwurf eines Dopingbekämpfungsgesetzes dieses um einen Tatbestand des Sportbetrugs ergänzen wollte, der die Einwirkung eines Schieds- oder Wertungsrichters auf einen wirtschaftlich bedeutenden sportlichen Wettbewerb durch wissentlich falsche Entscheidungen pönalisierte. ${ }^{11}$ Mit Verweis auf verfassungsrechtliche Bedenken und seitens angehörter Staatsanwälte geäußerte Zweifel an der Praktikabilität der Vorschrift wurde der Antrag von der Großen Koalition aus CDU, CSU und SPD abgelehnt. ${ }^{12}$

In der Folgezeit fiel insbesondere das Bundesland Bayern mit nachdrücklichen legislatorischen Bestrebungen auf. Im Jahr 2009 legte das dortige Justizministerium den Referentenentwurf eines Gesetzes zur Bekämpfung des Dopings und der Korruption im Sport vor (sog. Sportschutzgesetz), dessen in $\$ 6$ vorgesehener Tatbestand der Bestechlichkeit und Bestechung im Sport sich in Aufbau und Terminologie eng an die Strafvorschrift des $\$ 299$ StGB anlehnte, dabei Teilnehmer, Trainer eines Teilnehmers oder Schiedsrichter eines sportlichen Wettkampfes einbezog und die Zusage dessen unlauterer Beeinflussung voraussetzte. ${ }^{13}$ Auch wenn der Entwurf im Bundesrat gar nicht erst beraten worden war, knüpfte Bayern im März 2014 hieran unmittelbar an und entwarf ein Gesetz zum Schutze der Integrität des Sports, dessen in $\$ 4$ wiederum enthaltener Tatbestand der Bestechlichkeit und Bestechung im Sport der Version aus 2009 weitgehend glich. Er enthielt lediglich eine innerhalb des Tatbestands vorgenommene Beschreibung des gegenständlichen sportlichen Wettbewerbs, anstatt hierfür auf eine dem Gesetz vorangestellte zentrale Definition zu verweisen. ${ }^{14}$

$\mathrm{Zu}$ diesem Zeitpunkt hatte sich jedoch die ablehnende Haltung der nach wie vor von den Unionsparteien geführten Bundesregierung bereits

11 BT-Drs. 16/5938, S. 1.

12 BT-PIPr. 16/108, S. 11075; dazu auch Reinhart SpuRt 2016, 235 f.

13 Bayerischer Referentenentwurf eines Sportschutzgesetzes vom 30.11.2009, www.justiz.bayern.de/media/entwurf_sportschutzgesetz_30112009.pdf.

14 Diskussionsentwurf eines Gesetzes zum Schutz der Integrität des Sports der Landesregierung Bayern vom 12.3.2014, www.justiz.bayern.de/media/pdf/gesetze/spo rt.pdf. 
gedreht. Nachdem sie im Bundestag noch im Jahr 2011 eine Kleine Anfrage nach einer möglichen Bekämpfung von Korruption und Manipulation im Sport mittels spezifischer Straftatbestände unter Rückgriff auf die 2007 hiergegen vorgebrachten Argumente abermals zurückgewiesen hatte, enthielt der 2013 zwischen CDU, CSU und SPD geschlossene Koalitionsvertrag die Zielvereinbarung, innerhalb der kommenden Legislaturperiode eine strafrechtliche Regelung gegen Spielmanipulationen zu schaffen. ${ }^{15}$ Zwar wurde der offenkundige Sinneswandel vordergründig auch mit den jüngsten internationalen Entwicklungen wie der „Berliner Erklärung“ der 5. UNESCO-Weltsportministerkonferenz vom 30. Mai 2013 oder den im Sommer 2013 begonnenen Verhandlungen über ein Abkommen des Europarates gegen die Manipulation von Sportwettbewerben begründet, die ihre Mitgliedstaaten zu einem entschiedenen Vorgehen gegen Sportmanipulationen aufgefordert hätten. Aufgrund deren weitgehender rechtlicher Unverbindlichkeit ${ }^{16}$ lässt sich die Aufnahme der Schaffung entsprechender Straftatbestände in die rechtspolitische Agenda der Koalition aber wohl eher als Entgegenkommen von CDU und SPD gegenüber dem Drängen der CSU auffassen, die die spätere Umsetzung dann auch sogleich für sich reklamierte. ${ }^{17}$

Zeitlich etwas versetzt zum prioritär vorangetriebenen Anti-Doping-Gesetz wurde am 3. November 2015 schließlich der vom Bundesjustizministerium erarbeitete Referentenentwurf eines „Gesetzes zur Änderung des Strafgesetzbuch - Strafbarkeit von Sportwettbetrug und der Manipulation von berufssportlichen Wettbewerben" präsentiert, ${ }^{18}$ der eine durchaus ambivalente öffentliche Rezeption erfuhr. Während die Strafrechtspraxis und -wissenschaft überwiegend fundamentale Kritik übten, ${ }^{19}$ erfuhr der Entwurf von zentralen Sportverbänden grundsätzliche Zustimmung, die ihre

15 Koalitionsvertrag zwischen CDU, CSU und SPD für die 18. Legislaturperiode vom 27.11.2013, S. 138.

16 Dazu ausführlich s. unten Teil 3 A. I. 1.

17 So auch Reinhart SpuRt 2016, 235 (236f.); vgl. etwa die in einer Bundesratssitzung im Anschluss an den Beschluss des Gesetzes abgegebene Erklärung des damaligen bayerischen Staatsministers Bausback, in der er den Gesetzesbeschluss erfreut langjähriger bayerischer Beharrlichkeit zuschreibt, BR-PIPr 956, S. 206.

18 Referentenentwurf des Bundesministeriums für Justiz und Verbraucherschutz zur Strafbarkeit des Sportwettbetrugs und der Manipulation berufssportlicher Wettbewerbe vom 3.11.2015, www.bmjv.de/SharedDocs/Gesetzgebungsverfahren /Dokumente/Ref_Spielmanipulation.pdf?_blob=publicationFile\&v=2.

19 S. nur die diesbezüglichen Stellungnahmen des Deutschen Anwaltsvereins (Nr. 12/2016), des Deutschen Richterbundes (Nr. 2/2016) sowie der Bundesrechtsanwaltskammer (Nr. 8/2016). 
über Jahrzehnte vehement vertretene Ablehnung nahezu jeder Art staatlicher Eingriffe in die Autonomie des Sports bereits beim Anti-Doping-Gesetz aufgegeben hatten. ${ }^{20}$ Von den Einwänden unbeeindruckt brachte die Bundesregierung am 20. Juni 2016 einen im Vergleich zum Referentenentwurf nur marginal geänderten Regierungsentwurf im Bundestag ein. ${ }^{21}$ Dieser wurde in Plenarsitzungen vom 7. Juli 2016 sowie 9. März 2017 beraten und trotz massiver Kritik einzelner Abgeordneter am parlamentarischen Umgang mit dem Gesetzentwurf ${ }^{22}$ mit den Stimmen der Regierungsfraktionen CDU/CSU und SPD bei geschlossener Enthaltung der Fraktion Die Linke und Gegenstimmen der Fraktion Bündnis 90/Die Grünen angenommen. ${ }^{23}$ Nach der Erklärung des Verzichts auf Anruf des Vermittlungsausschusses durch den Bundesrat ${ }^{24}$ wurde das Gesetz am 18. April 2017 im Bundesgesetzblatt verkündet und trat am Folgetag in Kraft. ${ }^{25}$

\section{B. Zum Inhalt der Vorschriften im Einzelnen}

Die Änderung des StGB umfasste neben der Einfügung der $\$ \$ 265 c$, 265d StGB auch diejenige der Folgevorschrift $\$ 265$ e StGB, die in der typischen Art eines Regelbeispiels den für die Grundtatbestände der $\$ \$ 265 \mathrm{c}, 265 \mathrm{~d}$ StGB vorgesehenen Strafrahmen für besonders schwere Fälle anhebt. Im ursprünglichen Referentenentwurf war darüber hinaus in $\$ 265 \mathrm{f} \mathrm{StGB}$ eine Regelung zur Kennzeichnung der $\$ \mathbb{S} 265 \mathrm{c}$, 265d StGB als Antragsdelikt vorgesehen gewesen, die jedoch im weiteren Verlauf des Gesetzgebungs-

20 S. die gemeinsame Stellungnahme von Deutschem Olympischen Sportbund (DOSB), Deutschem Fußballbund (DFB) und Deutscher Fußballliga (DFL) zum Entwurf BT-Drs. 18/8831 vom 15.1.2016, S. 2.

21 BT-Drs. 18/8831.

22 Diese richtete sich gegen den jeweils erst zu spätabendlicher Uhrzeit de facto unter Ausschluss der Öffentlichkeit erfolgenden Aufruf des entsprechenden Tagesordnungspunktes und die verzögerte Übersendung des Protokolls einer vom Rechtsausschuss zwischenzeitlich durchgeführten Anhörung sachverständiger Experten, s. die Einlassung des MdB Hahn während der Zweiten Beratung im Bundestag, BT-PIPr. 18/221, S. 22251.

23 BT-PIPr. 18/221, S. 22256.

24 BR-PIPr. 956, S. 174B.

25 BGBl. 2017 I S. $815 \mathrm{ff}$. 
verfahrens wieder gestrichen wurde. ${ }^{26}$ Das gleiche Schicksal ereilte $₫ 265 f$ StGB ein zweites Mal, als die dort im Regierungsentwurf verankerte gesonderte Regelung der Voraussetzungen des erweiterten Verfalls ${ }^{27}$ im Zuge des Gesetzes zur Reform der strafrechtlichen Vermögensabschöpfung vom 13. April $2017^{28}$ obsolet wurde. Im Schlepptau der neuen materiellen Straftatbestände wurden außerdem punktuelle Erweiterungen in strafverfahrens- und strafanwendungsrechtlicher Hinsicht vorgenommen.

\section{Tatbestandsmerkmale der $\$ \mathbb{S} 265 \mathrm{c}, 265 \mathrm{~d}$ StGB}

Eine Skizzierung des Regelungsgehalts der Straftatbestände der $\$ \$ 265 c$, 265d StGB offenbart zunächst zahlreiche Übereinstimmungen der beiden Vorschriften. Eine solche betrifft bereits den identischen Strafrahmen von Geldstrafe bis Freiheitsstrafe von bis zu drei Jahren, der demjenigen der vorstehenden Delikte des Kapitalanlage- $(\$ 264$ a StGB) und des Kreditbetrugs ( $\$ 265$ b StGB) sowie der Korruptionsdelikte der $\$ \$ 299$ ff., 331 Abs. 1, 333 Abs. 1 StGB entspricht, hinter demjenigen des Betrugs gemäß $\$ 263$ StGB (Freiheitsstrafe bis fünf Jahre) jedoch zurückbleibt. Auch gesetzgebungstechnisch und deliktsstrukturell zeigt sich eine weitgehende Ähnlichkeit, die in einem gemeinsamen Abschnitt aufgezeigt wird, ehe getrennt voneinander auf spezifische tatbestandliche Merkmale und Bezugspunkte eingegangen wird.

1. Übereinstimmung in Aufbau, Täterkreis und Tathandlungsalternativen

Beide Vorschriften bestehen aus sechs Absätzen, deren jeweiliges Regelungsziel sich ebenso gleicht wie der grammatikalische Satzbau. Die tatbestandliche Grundstruktur der $\$ \$ 265 c$, 265d StGB weist dabei an mehreren Stellen charakteristische Merkmale eines Korruptionsdelikts auf, die sie von ihrem systematischen Deliktsumfeld erkennbar abheben und ihre systematische Einordnung in den 22. Abschnitt des StGB durchaus überra-

26 Referentenentwurf des Bundesministeriums für Justiz und Verbraucherschutz zur Strafbarkeit des Sportwettbetrugs und der Manipulation berufssportlicher Wettbewerbe vom 3.11.2015, S. 5, www.bmjv.de/SharedDocs/Gesetzgebungsverfa hren/Dokumente/Ref_Spielmanipulation.pdf?_blob=publicationFile\&v=2; die Streichung begrüßend Krack ZIS 2016, 540 (550); Rübenstabl JR 2017, 333 (338).

27 BT-Drs. 18/8831, S. 5.

28 BGBl. 2017 I S. 872 ff. 
schend wirken lassen. ${ }^{29}$ In einer von den $\$ \$ 299 \mathrm{ff}$., $331 \mathrm{ff}$. StGB bekannten Trennung in Nehmer- bzw. Geberseite enthalten die jeweiligen Absätze 1 bis 4 selbständige Tatbestände mit einer deckungsgleichen Beschreibung von tauglichem Täterkreis und Tathandlung, die von Legaldefinitionen in den jeweiligen Absätzen 5 und 6 ergänzt werden. Dabei regeln die Absätze 1 für Sportler und Trainer und 3 für Schieds-, Wertungs- und Kampfrichter die Strafbarkeit abschließend aufgezählter Sportakteure als einer qualifizierten Personengruppe wegen Bestechlichkeit. Den Kreis der tauglichen Täter kennzeichnet insofern die Fähigkeit, auf den Verlauf oder das Ergebnis eines Sportwettbewerbs unmittelbar Einfluss nehmen zu können. ${ }^{30}$ Die Tatbestände in den Absätzen 2 und 4 stellen hingegen in spiegelbildlicher Fassung die aktive Bestechung eines solchen Sportakteurs durch einen Dritten ohne besondere Tätereigenschaft unter Strafe.

Die Nehmer- und Geberseite kennzeichnenden Tathandlungen bestehen in beiden Strafvorschriften bei den Sportakteuren im Fordern, SichVersprechen-Lassen oder Annehmen eines Vorteils, bei den von jedermann erfüllbaren Tatbeständen im Anbieten, Versprechen oder Gewähren eines solchen. Tathandlungsalternativen und der Vorteil als Tatobjekt decken sich somit mit den erwähnten Korruptionsdelikten des StGB und sollen auch entsprechend ausgelegt werden. ${ }^{31}$ Unter einem Vorteil ist eine unentgeltliche Leistung materieller oder immaterieller Art zu verstehen, auf die der Sportakteur oder der begünstigte Dritte keinen Rechtsanspruch hat und die seine wirtschaftliche, rechtliche oder auch nur persönliche Lage objektiv messbar verbessert. ${ }^{32}$ Auch immaterielle oder wettbewerbsimmanente Zuwendungen unterfallen dieser Auslegung. Eine Geringwertigkeitsgrenze muss nicht übertroffen werden. ${ }^{33}$

Neben diesen identischen Teil der jeweiligen objektiven Tatbestände tritt das ebenfalls korruptionstypische Erfordernis einer geschlossenen, im Falle des bloßen Forderns bzw. Anbietens eines Vorteils zumindest einsei-

29 Krit. zur systematischen Verortung Jaleesi Kriminalisierung, S. 111 ff.; Valerius Jura 2018, 777 (779); Satzger Jura 2016, 1142 (1153 f.).

30 BT-Drs. 18/8831, S. 13. Um der zunehmenden Ausdifferenzierung dieser Fähigkeit im professionellen Sport Rechnung zu tragen, erweitert $\$ 265$ c Abs. 6 S. 2 StGB den Kreis tätertauglicher Akteure noch über die explizit angeführten Rollen hinaus auf mit bestimmten Kompetenzen ausgestattete Sportdirektoren, Sponsoren und Teamärzte, s. BT-Drs. 18/8831, S. 18; Satzger Jura 2016, 1142 (1146).

31 BT-Drs. 18/8831, S. 15.

32 BGH NJW 2003, 2996 (2997 f.); Schönke/Schröder/Eisele $\$ 299$ Rn. 18.

33 BT-Drs. 18/8831, S. 15. 
tig angestrebten Unrechtsvereinbarung zwischen Sportakteur und Vorteilsgeber. Der gesetzliche Terminus „als Gegenleistung dafür“ bringt die finale Verknüpfung von Vorteil und einer zugesagten Handlung des Sportakteurs zum Ausdruck. Ihm soll der Vorteil gerade um einer künftigen manipulativen Beeinflussung eines bestimmten sportlichen Wettbewerbs willen zu Gute kommen. Als derartige Beeinflussung des Wettbewerbs gelten alle Verhaltensweisen vor oder während desselben, die darauf abzielen, seinen Verlauf zu manipulieren und die Unvorhersehbarkeit des Wettbewerbsgeschehens aufzuheben oder einzuschränken. ${ }^{34}$

Sofern Spieler oder Trainer in die Unrechtsvereinbarung involviert sind, muss die Beeinflussung gemäß den jeweiligen Absätzen 1 und 2 zugunsten des unmittelbaren Wettbewerbsgegners erfolgen. Dies ist gegeben, wenn die vereinbarte Manipulationshandlung diesem irgendwie geartete Vorteile im Wettbewerb verschaffen soll. ${ }^{35}$ Anreize für die Beeinflussung eines Wettbewerbs zu eigenen Gunsten wie beispielsweise das Angebot von Siegprämien sind nicht erfasst. ${ }^{36}$ Eine explizite Regelwidrigkeit der Einwirkung ist nicht erforderlich. Besetzen Schieds-, Wertungs- oder Kampfrichter die Rolle des Vorteilsempfängers, hat die Beeinflussung gemäß den jeweiligen Absätzen 3 und 4 hingegen in regelwidriger Weise zu erfolgen.

Im von der geplanten Beeinflussung betroffenen Wettbewerbstyp, weiteren Beschränkungen der relevanten Beeinflussungen sowie in gegebenenfalls zusätzlichen Bezugspunkten der Unrechtsvereinbarung weichen die $\$ \mathbb{S} 265 \mathrm{c}, 265 \mathrm{~d}$ StGB hingegen voneinander ab. Eine sorgfältige Darstellung der jeweiligen Bezugspunkte der Unrechtsvereinbarung ist unerlässlich, da sie den spezifischen Kern des tatbestandlichen Unrechts bildet. Denn ob es im Anschluss an die Absprache tatsächlich zur Umsetzung der zugesagten Manipulation kommt, ist für die Strafbarkeit nach beiden Vorschriften unerheblich. Vollendung tritt bereits mit Abschluss der Unrechtsvereinbarung bzw. mit Abgabe einer hierauf gerichteten Erklärung ein.

34 BT-Drs. 18/8831, S. 14.

35 BT-Drs. 18/8831, S. 16.

36 BT-Drs. 18/8831, S. 16; allgemein zur rechtlichen Bewertung vereinsfremder Siegprämien Bach JR 2008, 57. 
2. Unrechtsvereinbarung und subjektive Anforderungen des Sportwettbetrugs gemäß $\$ 265$ c StGB

Zielpunkt der Unrechtsvereinbarung muss zunächst die Beeinflussung von Verlauf oder Ergebnis eines Wettbewerbs des organisierten Sports sein. Ein Wettbewerb des organisierten Sports kennzeichnet sich gemäß Abs. 5 durch einen organisatorischen Zusammenhang mit einer nationalen oder internationalen Sportorganisation und die Geltung eines von dieser verbindlich erlassenen Regelwerks. Eine sonderlich selektive Eingrenzung ist mit diesen Merkmalen freilich nicht verbunden. Erfasst werden sowohl einzelne Wettkämpfe wie Meisterschaftsspiele oder Endläufe als auch verbundene Veranstaltungen wie Turniere, Meisterschafts- oder Qualifikationsrunden, die von einem auf eine einzelne Sportart bezogenen Weltfachverband, Kontinental-, National- oder Regionalverband oder einem sportartübergreifenden Verband selbst oder in dessen Auftrag durchgeführt werden, ohne dass es dabei auf ein bestimmtes Leistungsniveau ankommt. ${ }^{37}$ Ausgeschlossen werden rein privat organisierte Sportveranstaltungen wie Firmenläufe oder Sportfeste sowie Wettbewerbe des Schulsports. $^{38}$

Eine Eingrenzung erfährt der Kreis in Betracht kommender Sportwettbewerbe durch das Erfordernis eines auf sie bezogenen Angebots öffentlicher Sportwetten, durch die ein rechtswidriger Vermögensvorteil erlangt werden kann. Dies beschränkt den Bereich des Strafbaren zunächst auf den Leistungssport. Mittelbar erhält der Anwendungsbereich der Vorschrift hierdurch jedoch einen in Abhängigkeit von der Popularität einer Sportart stehenden, selektiven Zuschnitt. Denn während das über das Internet nutzbare, öffentliche Sportwettenangebot sich in populären Sportarten wie Fußball mittlerweile auch auf unterklassige Ligen und Wettbewerbe erstreckt, an denen Jugendliche oder Amateure beteiligt sind, ${ }^{39}$ enthält es Wettmöglichkeiten für Wettkämpfe in Randsportarten wie Fechten oder Turnen allenfalls im Rahmen seltener Großveranstaltungen wie Olympischen Spielen oder Weltmeisterschaften und verengt den tatbestandlichen Anwendungsbereich diesbezüglich damit auf einen schmalen Ausschnitt des nationalen oder internationalen Spitzensports.

$\mathrm{Ob}$ auch das mögliche Erlangen eines rechtswidrigen Vermögensvorteils mittels einer öffentlichen und wettbewerbsbezogenen Sportwette durch

37 BT-Drs. 18/8831, S. 19.

38 BT-Drs. 18/8831, S. 19.

39 Swoboda/Bohn JuS 2016, 686 (688f.). 
den Vorteilsgeber oder einen Dritten - ein Wettgewinn des Sportakteurs selbst würde keine Bestechungsprämie motivieren - einen Teil der Unrechtsvereinbarung bildet, ist umstritten. Der Wortlaut der Norm legt dies freilich nahe. Die grammatikalische Verknüpfung von „beeinflusse“ und „erlangt werde“ mittels des gleichstellenden „und infolgedessen“ lässt sich nur im Sinne einer Einbeziehung nicht nur der Beeinflussung des Wettbewerbs, sondern auch der Erzielung eines wettbedingten Vermögensvorteils in die Unrechtsvereinbarung deuten. Kritischen Stimmen zufolge werde aber gerade hierdurch das eine Unrechtsvereinbarung typischerweise prägende Äquivalenzverhältnis außer Kraft gesetzt. Bereits die Platzierung einer Wette durch den Vorteilsgeber als Bedingung eines sich hieraus entwickelnden Vermögensvorteils entziehe sich dem Einflussbereich des Sportakteurs, so dass dieser allenfalls Gegenstand des Vorsatzes sein könne. ${ }^{40}$ Als Teil des vom Sportakteur als Gegenleistung zum Vorteil Versprochenen könne einzig die Beeinflussung des Wettbewerbs gelten; andernfalls bliebe $\$ 265$ c StGB faktisch ohne Anwendungsbereich. ${ }^{41}$

Tatsächlich vermag es der Sportakteur nicht, den Vorteil zuzusichern. Er kann durch seine Manipulation lediglich die grundsätzliche Möglichkeit für dessen Erlangung eröffnen. Die Manipulationszusage stellt insofern lediglich eine Vorbereitungshandlung eines möglichen späteren Betrugs zu Lasten des Wettanbieters bei der Wettplatzierung dar. Und doch ergibt sich gerade aus deren Verknüpfung der spezifische Unrechtsgehalt der Tat, so dass die auf der verabredeten Manipulation aufbauende Sportwette nicht lediglich eine vom Tätervorsatz umfasste außertatbestandliche Folge, sondern Gegenstand der Unrechtsvereinbarung selbst sein muss. ${ }^{42}$ Bei gleichzeitiger Respektierung von gesetzgeberisch intendierter Aufnahme des rechtswidrigen Vermögensvorteils in die Unrechtsvereinbarung ${ }^{43}$ und korruptionstypischer Gegenseitigkeit ist der missverständliche Wortlaut ${ }^{44}$ demnach so auszulegen, dass das Äquivalenzverhältnis selbst zwar nicht erweitert wird, es aber bereits in objektiv erkennbarer Weise in den Dienst

40 Vgl. Krack wistra 2017, 289 (294); Jaleesi Kriminalisierung, S. 233 ff.; ähnlich Kubiciel WiJ 2016, 256 (264).

41 So zumindest Stam NZWiSt 2018, 41 (44).

42 Schönke/Schröder/Perron $\$ 265$ c Rn. 18.

43 BT-Drs. 18/8831, S. 16.

44 Noch schärfer in der Ablehnung Jaleesi Kriminalisierung, S. 233 f.; einen klarstellenden Formulierungsvorschlag unterbreitet Kubiciel WiJ 2016, 256 (264). 
einer Sportwette mit Vermögensvorteil gestellt werden muss. ${ }^{45}$ Diese Zweckbestimmung muss über ihre Einbindung in den bedingten Vorsatz hinaus bereits Gegenstand einer zwischen den Beteiligten der Absprache ausdrücklich oder konkludent getroffenen Einigung sein. ${ }^{46}$ Das Vorteilsangebot des Gebers hat demnach etwa seinem äußeren Erscheinungsbild nach zum Ausdruck zu bringen, dass die als Gegenleistung gewollte Manipulation zum Zweck eines unberechtigten Wettgewinns angestrebt wird. ${ }^{47}$

Bezugspunkte der Unrechtsvereinbarung sind somit die Beeinflussung des Verlaufs oder Ergebnisses eines Wettbewerbs des organisierten Sports zugunsten des Wettbewerbsgegners oder in regelwidriger Weise, durch die mittels einer auf den manipulierten Wettbewerb bezogenen öffentlichen Sportwette ein rechtswidriger Vermögensvorteil erlangt wird. Ob es im Anschluss zu einer tatsächlichen Wettplatzierung oder gar der Auszahlung eines Wettgewinns kommt, ist genauso irrelevant wie die spätere Ausführung der zugesagten Wettbewerbseinwirkung. ${ }^{48}$

In subjektiver Hinsicht ist ein bedingter Vorsatz bezüglich aller objektiven Tatbestandsmerkmale und somit auch eine auf eine Sportwette bezogene Tätervorstellung zu fordern. Der Sportakteur muss bei der Absprache mit einer Ausnutzung der von ihm zugesagten Manipulation für eine betrügerische Wettplatzierung zumindest rechnen und sie billigend in Kauf nehmen, wobei sich die Feststellung eines solchen Eventualvorsatzes entlang der Frage orientieren könne, ob aus Sicht der an der Absprache Beteiligten nur der Wettvertragsabschluss einen nachvollziehbaren wirtschaftlichen Sinn für die Vorteilsgewährung ergibt. ${ }^{49}$ Eine genauere Vorstellung von Ort, Zeit und Form der Wettplatzierung ist nicht zu verlangen. ${ }^{50}$ Dem Vorteilsgeber muss die Wettbewerbsbeeinflussung zumindest in groben Umrissen bekannt sein. ${ }^{51}$

45 SK-StGB/Rogall $\$ 265$ c Rn. 10; Schönke/Schröder/Perron $\$ 265$ c Rn. 18; Rübenstahl JR 2017, 264 (273); in diese Richtung auch Stellungnahme der Bundesrechtsanwaltskammer Nr. 8/2016, S. 8.

46 BeckOK-StGB/Bittmann/Nuzinger/Rübenstabl \$265c Rn. 43; Löffelmann recht + politik 2/2016, 1 (2).

47 Rübenstabl JR 2017, 264 (273).

48 BT-Drs. 18/8831, S. 16.

49 BT-Drs. 18/8831, S. 17 mit Verweis auf BGHSt 51, $165 \mathrm{ff}$.

50 BT-Drs. 18/8831, S. 17; MüKo-StGB/Schreiner $\$ 265$ c Rn. 29, 41.

51 Dazu Schönke/Schröder/Perron $\$ 265$ c Rn. 25. 
3. Unrechtsvereinbarung und subjektive Anforderungen der Manipulation berufssportlicher Wettbewerbe gemäß $\$ 265 \mathrm{~d}$ StGB

Wenngleich auch für die in $\$ 265 \mathrm{~d}$ StGB enthaltenen Tatbestände die vorteilsbezogene Gegenleistung in der gegnerbegünstigenden bzw. regelwidrigen Beeinflussung eines Sportwettbewerbs bestehen muss, werden an den Inhalt der erforderlichen Unrechtsvereinbarung in gewisser Hinsicht abweichende Anforderungen gestellt. Durch den offensichtlichen Verzicht auf den Bezug der getroffenen Absprache zu einer Sportwette und die Irrelevanz der hinter ihrer Initiierung stehenden Gründe wird der tatbestandliche Anwendungsbereich zunächst erweitert. Im Hinblick auf die Art des von der zugesagten Manipulation betroffenen Wettbewerbs und der genauen Form der manipulativen Einwirkung sorgen zusätzliche qualitative Voraussetzungen hingegen für eine Eingrenzung im Vergleich zu $\$ 265 \mathrm{c}$ StGB. Bezugspunkt der Manipulation muss stets der Verlauf oder das Ergebnis eines berufssportlichen Wettbewerbs sein. Darüber hinaus hat sie im Falle ihrer Zusage durch einen Spieler oder Trainer gemäß $\$ 265$ d Abs. 1 und 2 StGB nicht nur den Wettbewerbsgegner zu begünstigen, sondern zudem in wettbewerbswidriger Weise zu erfolgen.

Die Legaldefinition in $\$ 265$ d Abs. 5 StGB beschreibt berufssportliche Wettbewerbe als Teilmenge der Wettbewerbe des organisierten Sports i.S.d. $\$ 265$ c Abs. 5 StGB. ${ }^{52}$ Die hinzukommenden spezifischen Merkmale bestehen in der organisatorischen Zurechnung des Wettbewerbs zu einem Sportbundesverband, wodurch von regionalen Sportorganisationen veranstaltete Wettbewerbe (im Fußball etwa Spiele der Regional- und Landesligen) ausscheiden, sowie in der überwiegenden Teilnahme von Sportlern, die durch ihre sportliche Betätigung unmittelbar oder mittelbar Einnahmen von erheblichem Umfang erzielen. Letzteres soll entsprechend der gleichlautenden Voraussetzung in $\$ 4$ Abs. 7 Nr. 2 AntiDopG anzunehmen sein, wenn die Mehrzahl der an dem Wettbewerb teilnehmenden Sportler durch die sportliche Betätigung wiederholt wirtschaftliche Vorteile erlangt. ${ }^{53}$ Als ausreichend dauerhafte Einnahmequelle werden regelmäßige Antritts- und Preisgelder, Leistungen der Sportförderung oder eine arbeitsvertragliche Vergütung bzw. Besoldung betrachtet. Zum Maßstab ihrer Erheblichkeit enthalten weder Gesetzestext noch -begründung nähere Anga-

52 Dies betont auch BT-Drs. 18/8831, S. $21 \mathrm{f}$.

53 BT-Drs. 18/8831, S. 22. 
ben. ${ }^{54}$ Doch selbst wenn man die diesbezügliche Schwelle niedrig ansetzte und in Anlehnung an den gesetzlichen Mindestlohn in Deutschland einen aus der sportlichen Betätigung generierten Mindestverdienst von 1.500 Euro pro Monat verlangte, 55 dürfte das Erfordernis der Berufssportlichkeit durchaus hochklassige Wettkämpfe wie deutsche Meisterschaften in Randsportarten (z.B. Judo, Volleyball, Fechten ${ }^{56}$ ) oder Stadtmarathonläufe ausschließen.

Das eingefügte Erfordernis einer wettbewerbswidrigen Beeinflussung bewirkt keine gravierende Verschiebung der von der (intendierten) Unrechtsvereinbarung in Bezug genommenen Manipulationsform im Vergleich zu $\$ 265$ c StGB, da die große Mehrheit gegnerbegünstigender Manipulationen bereits für sich genommen als wettbewerbswidrig verstanden wird. ${ }^{57}$ Es soll vielmehr als spezifisches Korrektiv dienen, um eine schmale Gruppe manipulativer Einwirkungen vom Tatbestand auszunehmen, bei der ein gewährter wettbewerbsimmanenter Vorteil mit einer Manipulation verknüpft wird, die zumindest dem mittelbaren Ziel eines eigenen sportlichen Erfolgs dient. ${ }^{58}$ Die Zusage wettbewerbsimmanenter Vorteile gegen mittelbar den eigenen sportlichen Erfolg bezweckende Wettkampfhandlungen, die vornehmlich unter Akteuren mit unmittelbarer Einflussmöglichkeit auf den Wettbewerb getroffen werden dürfte, ${ }^{59}$ wird offenbar als zu sporttypisch für eine strafrechtliche Erfassung verstanden. Als Beispiel benennt die Gesetzesbegründung die zwischen zwei Kontrahenten getroffene wechselseitige Zusicherung einer Leistungsreduzierung, die in einem für beide im weiteren Wettbewerbsverlauf vorteilhaften Unentschieden mündet. ${ }^{60}$ Für die von Schieds-, Wertungs- oder Kampfrichtern zugesagte Manipulation verbleibt es gemäß den Absätzen 3 und 4 wie in $\$ 265$ c Absätze 3 und 4 beim Erfordernis der Regelwidrigkeit. Ob es tatsächlich zu

$54 \mathrm{Zu}$ einem möglichen Verstoß gegen den Bestimmtheitsgrundsatz aus Art. 103 Abs. 2 GG s. Teil 3 D.

55 So Stam NZWiSt 2018, 41 (46); näher zur Herleitung dieses Orientierungswerts s. Teil 3 D. II.

56 Nach einer Studie aus dem Jahr 2018, die auf einer Befragung von 1.087 Athleten beruht, die sich in einem Bundeskader befanden und von der deutschen Sporthilfe gefördert wurden, kommen Judoka, Volleyballspieler bzw. Fechter gerade einmal auf ein durch den Sport erzieltes durchschnittliches Bruttoeinkommen von monatlich 1.232 Euro, 1.266 Euro bzw. 603 Euro, Breuer/Wicker/Dallmeyer/Ilgner Lebenssituation von Spitzensportlern und -sportlerinnen in Deutschland, S. 35.

57 BT-Drs. 18/8831, S. 21.

58 BT-Drs. 18//8831, S. 21.

59 S. BT-Drs. 18/8831, S. 21.

60 BT-Drs. 18/8831, S. 21. 
einer manipulativen Einwirkung des Sportakteurs kommt, ist ohne Bedeutung.

In subjektiver Hinsicht decken sich die Anforderungen im Wesentlichen mit denjenigen des $\$ 265$ c StGB, wobei die Tätervorstellung selbstverständlich keinen Bezug der Vereinbarung zu einer Sportwette erfassen muss. Bedingter Vorsatz reicht aus, muss sich aber auch auf die Wettbewerbswidrigkeit der Manipulation und den berufssportlichen Charakter des Wettbewerbs beziehen. Gerade letzteres kann die Strafverfolgung bei Wettbewerben, die nicht ausschließlich von offensichtlich gut verdienenden Profisportlern bestritten werden, vor Nachweisschwierigkeiten stellen. ${ }^{61}$

II. Besonders schwere Fälle ( $\$ 265$ e StGB) und flankierende prozessuale und strafanwendungsrechtliche Anpassungen

Ergänzt werden die Tatbestände der $\$ \$ 265 c$, 265d StGB durch eine Regelung zu besonders schweren Fällen $(\$ 265$ e StGB), die die Sanktionierung aus einem angehobenen Strafrahmen von drei Monaten bis zu fünf Jahren Freiheitsstrafe nach sich ziehen. Die beiden einen besonders schweren Fall indizierenden Regelbeispiele betreffen die Gewährung eines Vorteils großen Ausmaßes (Nr.1) bzw. ein täterschaftliches Handeln, das gewerbsmäBig oder als Mitglied einer Bande erfolgt, die sich zur fortgesetzten Begehung von Taten nach den $\mathbb{S}$ 265c, 265d StGB zusammengeschlossen hat (Nr. 2). Inhaltlich gleichen die angeführten Regelbeispiele damit größtenteils denjenigen eines besonders schweren Falls der Bestechlichkeit und Bestechung im geschäftlichen Verkehr und im Gesundheitswesen gemäß $\$ 300$ StGB bzw. im öffentlichen Kontext gemäß $\$ 335$ Abs. 2 StGB, um an die hierzu entwickelten Auslegungsgrundsätze anknüpfen zu können. ${ }^{62}$

61 SSW-StGB/Satzger $\$ 265 \mathrm{~d}$ Rn. 24; BeckOK-StGB/Bittmann/Nuzinger/Rübenstahl $\$ 265 \mathrm{~d}$ Rn. 58 .

62 Bezüglich der Untergrenze eines zugewendeten Vorteils großen Ausmaßes existiert in der Literatur zu $\$ 300$ StGB allerdings ein uneinheitliches Meinungsbild, das von 10.000 bis 50.000 Euro reicht, s. SK-StGB/Rogall $\$ 300$ Rn. $6(10.000$ Euro); LK-StGB/Tiedemann $₫ 300$ Rn. 4 (über 20.000 Euro). Bei $₫ 335$ Abs. 2 Nr. 1 StGB hingegen wird die Untergrenze überwiegend bei 25.000 Euro eingezogen, s. LK-StGB/Swoboda $₫ 335$ Rn. 6; BeckOK-StGB/Trüg $\$ 335$ Rn. 3.1. Da die Strafdrohung der Grunddelikte in $\$ \$ 265$ c, 265d StGB geringer ist als bei den $\$ \$ 331 \mathrm{ff}$. StGB fordert Rübenstabl JR 2017, 333 (338), die Untergrenze des Vorteils i.S.d. $\$ 265$ e Nr. 1 StGB keinesfalls niedriger als bei $\$ 335$ Abs. 2 Nr. 1 StGB anzusetzen; 
Wird eine Tat nach $\$ 265$ c StGB gewerbsmäßig oder von einem Bandenmitglied begangen, ist sie taugliche Vortat einer Geldwäsche $(\mathbb{} 261$ Abs. 1 Nr. 4a StGB).

In Verbindung mit der Implementierung des $\$ 265$ e StGB steht zudem eine Anpassung der Strafprozessordnung. So wurde der Katalog der Straftaten, hinsichtlich deren Aufklärung bei entsprechenden Verdachtsmomenten eine Telekommunikationsüberwachung angeordnet werden kann, um Sportwettbetrug und Manipulation von berufssportlichen Wettbewerben unter den in $\$ 265$ e $S .2$ genannten Voraussetzungen erweitert, s. $\$ 100 \mathrm{a}$ Abs. 2 Nr. 1 p) StPO. Hierdurch soll typischen Ermittlungsschwierigkeiten bei Korruptionsdelikten sowie dem Gewicht der geschützten Rechtsgüter Rechnung getragen werden. ${ }^{63}$ Taten nach den $\$ \$ 265$ c, 265d StGB werden bei einem entsprechenden Anfangsverdacht von Amts wegen verfolgt.

Um mithilfe der $\$ \$ 265 c$, 265d StGB auch grenzüberschreitenden Manipulationsabsprachen, die aufgrund der Internationalität des Spitzensports erwartet werden, begegnen zu können, wurden sie außerdem in $\$ 5$ Nr. 10a StGB aufgenommen. Denn durch die ausdrückliche Klarstellung in den $\$ \$ 265$ c Abs. 5, 265d StGB Abs. 5 StGB, dass sich die Unrechtsvereinbarung auf Sportwettbewerbe im Inland oder Ausland beziehen kann, wird zunächst nur der tatbestandliche Schutzbereich der Vorschriften um-

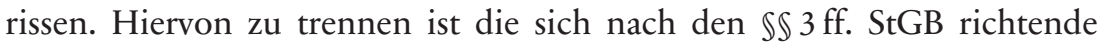
Reichweite deutscher Strafgewalt. Da es zur Annahme eines inländischen Begehungsortes gemäß $₫ 3$ i.V.m. $\$ 9$ StGB ausreicht, wenn die Tathandlung zum Teil auf deutschem Boden begangen wurde, unterfielen grenzüberschreitende Manipulationsabsprachen, bei denen sich ein Beteiligter im Ausland befindet, unabhängig von der Nationalität der Beteiligten und dem Austragungsort des Wettbewerbs zwar bereits nach dem Territorialitätsprinzip des $₫ 3 \mathrm{StGB}$ dem deutschen Strafrecht, sofern die verwirklichte Tathandlungsmodalität der $\$ \mathbb{S} 265 \mathrm{c}$, 265d StGB die Äußerung und Kenntnisnahme einer Willenserklärung verlangt. ${ }^{64}$

so auch Stam NZWiSt 2018, 41 (47), der zur Wahrung des ultima ratio-Grundsatzes gar 50.000 Euro als Mindestwert fordert.

63 BT-Drs. 18/8831, S. 23.

64 Für das Fordern, Anbieten, Versprechen und Sich-Versprechen-Lassen kann Tatort sowohl der Ort sein, an dem die Erklärung abgegeben wird, als auch der Ort, an dem sie zugeht. Auf die Realakte des Annehmens oder Gewährens eines Vorteils wird dies erweitert, so dass der Tatort hier auch der Ort sein kann, an dem die Annahme bzw. Gewährung eintritt, s. MüKo-StGB/Krick $\$ 299$ Rn. 114; Graf/ Jäger/Wittig/Sahan $\$ 299$ StGB Rn. 4. 
Eine Anwendungslücke verbliebe aber für im Ausland getroffene korruptive Abreden zweier Nicht-Deutscher, die sich auf einen in Deutschland stattfindenden Sportwettbewerb beziehen. Denn diesbezüglich führt $\$ 3$ StGB auch in Verbindung mit $\$ 9$ Abs. 1 StGB und dem Abstellen auf den tatbestandlichen Erfolgseintritt (Variante 3) nicht zur Anwendbarkeit deutschen Strafrechts, da die $\$ \$ 265$ c, 265d StGB mit Abschluss der Unrechtsvereinbarung vollendet sind und eine etwaige Wettbewerbsmanipulation in Deutschland keinen inländischen Erfolgsort konstruiert. ${ }^{65}$ Diese Lücke wird durch die Aufnahme der Vorschriften in den Katalog des $\$ 5$ StGB geschlossen, der in Durchbrechung des Territorialitätsprinzips die nationale Strafgewalt auf solche Auslandstaten erstreckt, die sich gegen inländische Interessen richten. Den zur Aufnahme erforderlichen Inlandsbezug sieht der Gesetzgeber in einer sich durch die im Ausland erbrachten Tatbeiträge verdichtenden Gefahr tatsächlicher Manipulationen inländischer Wettbewerbe, die das Vertrauen der hiesigen Bevölkerung in die Integrität des Sports und Vermögensinteressen von Sportakteuren beschädigen könnten. ${ }^{66}$ Die Effektivität des angestrebten Rechtsgüterschutzes verlange daher die Verhinderung denkbarer Umgehungsversuche, die Tathandlung bereits im Ausland vorzunehmen. ${ }^{67}$

65 Zum fehlenden Erfolgsort i.S.d. $\$ 9$ Abs. 1 Var. 3 StGB bei abstrakten Gefährdungsdelikten s. Schönke/Schröder/Eser/Weißer $\$ 9$ Rn. 6a; Lackner/Kühl/Heger/ Heger $\$ 9$ Rn. 2; Satzger Jura 2010, 108 (113).

66 BT-Drs. 18/8831, S. 14.

67 BT-Drs. 18/8831, S. 14; krit. Rehmet HRRS 2017, 518 (519f.); Perron JuS 2020, 809 (814f.). 


\section{Teil 2: Phänomenologische und strafrechtliche Grundlagen von Manipulationen im Sport}

Wie bereits die kurze Zusammenfassung der Gesetzgebungshistorie zeigt, ist die Einführung der $\$ \$ 265 c$, 265d StGB nicht aus der Luft gegriffen. Sie fußt auf der sich im Laufe der Jahre offenbar herausgebildeten und im Gesetzentwurf zumindest angedeuteten Überzeugung des Gesetzgebers, wonach es sich bei Manipulationsabsprachen im Hinblick auf Wettbewerbe des organisierten Sports um ein sozialschädliches Verhalten handele, das sich strafrechtlich nicht ausreichend sanktionieren lasse. ${ }^{68}$ Unabhängig der im Einzelnen noch darzustellenden Kriterien legitimer Strafgesetzgebung wird sich die Prüfung der Legitimation der $\$ \$ 265$ c, 265d StGB jedenfalls mit diesen Annahmen auseinanderzusetzen haben. In Vorbereitung auf im weiteren Untersuchungsverlauf erforderliche Rückgriffe erscheint es deshalb angebracht, die nun gezielt kriminalisierte Verhaltensweise zunächst phänomenologisch zu erfassen (dazu A.) und auf bereits vor Einführung der $\$ \mathbb{S} 265 \mathrm{c}, 265 \mathrm{~d}$ StGB existierende strafrechtliche Reaktionsformen zu überprüfen (dazu B.). Hierbei gewonnene Erkenntnisse werden die für die Legitimationsbewertung zentrale Anwendung eines noch zu beschreibenden Prüfungsmaßstabes auf die untersuchten Tatbestände unterstützen.

\section{A. Phänomenologie der Sportmanipulationen}

Allgemein gesprochen zielen die neu eingeführten Straftatbestände auf den Bereich der Sportmanipulationen. Diese Ausrichtung bekundet bereits die Deliktsüberschrift des $\$ 265 \mathrm{~d}$ StGB und wurde auch durch die deren Einführung begleitende Kommunikation des federführenden Bundesministeriums für Justiz und Verbraucherschutz unterstrichen, dessen damaliger Minister Heiko Maas den Gesetzeszweck öffentlichkeitswirksam und bildhaft damit umschrieb, Spielmanipulationen „die rote Karte zu zeigen “. ${ }^{69}$ Wie gesehen weisen auch die Tatbestandsfassungen eine sportbezogene Manipulation als essenziellen Bezugspunkt der nach den $\$ \mathbb{S} 265 \mathrm{c}$,

68 BT-Drs. 18/8831, S. $10 \mathrm{f}$.

69 Vgl. die Einlassungen und Pressefotos bei der Vorstellung der Gesetzesinitiative, www.dw.com/de/gesetzentwurf-zu-wettbetrug-verabschiedet/a-19166949. 
265d StGB kriminalisierten Absprachen aus, wenngleich deren tatsächliche Ausführung keine Strafbarkeitsvoraussetzung darstellt. Eine kritische Auseinandersetzung mit den Straftatbeständen kommt ohne eine phänomenologische Eingrenzung und Beleuchtung ihres in Bezug genommenen Verhaltensgegenstands nicht aus.

Der Bereich der Sportmanipulationen fällt dabei in einem ersten $\mathrm{Zu}$ gang durch eine begriffliche Unschärfe (dazu I.) und unzählige Erscheinungsformen auf. Um letztere einerseits phänomenologisch annähernd vollständig abzubilden und andererseits im Sinne der strafrechtlich vorgegebenen Fokussierung gegenseitig abzugrenzen, werden im Folgenden entlang der insofern präzisierenden Merkmale des Gesetzestextes der $\$ \$ 265 \mathrm{c}, 265 \mathrm{~d}$ StGB die tatbestandlich adressierten Manipulationsformen in einer systematischen Kategorisierung denkbarer Sportmanipulationen verortet und auf mehreren Ebenen von anderen Fallgruppen unterschieden (dazu II.). Hierdurch sollen die erfassten Manipulationsformen als zentraler Anknüpfungspunkt der neu geschaffenen Strafbarkeit kontextualisiert und eingegrenzt werden. Anschließend lassen sich spezifische Aussagen sowohl zu ihren Bedingungsfaktoren und Erklärungsansätzen (dazu III.) als auch zu ihrer tatsächlichen Verbreitung (dazu IV.) treffen.

\section{Begriffsklärung}

Der Kategorisierung der Sportmanipulationen vorangestellt wird eine Begriffsklärung. Diese erscheint vor allem mit Blick auf die in der einschlägigen öffentlichen Diskussion nicht immer trennscharf gebrauchten Begriffe der Sportmanipulation, der Sportkorruption sowie des Match Fixing notwendig, deren jeweiliger Bedeutungsgehalt präzise darzustellen und auf gegenseitige Übereinstimmungen und Unterschiede zu untersuchen ist.

1. Herleitung der Begriffsbestimmung und offene Definition der Sportmanipulation

Eine Annäherung an den allgemeinen Bedeutungsgehalt des Begriffs der Manipulation trifft zunächst auf wertneutrale, eher technisch orientierte Festlegungen, die ausgehend von der lateinischen Übersetzung unter einer Manipulation lediglich einen Hand- oder Kunstgriff verstehen. ${ }^{70}$ Der hohe

70 Duden Fremdwörterbuch, Eintrag: Manipulation, die. 
Abstraktionsgrad ist dabei den vielen Lebensbereichen geschuldet, in denen eine Manipulation vorkommen kann und kontextbezogen aufgeladen wird. Während sie etwa in der chirurgischen Medizin im Sinne eines Kunstgriffes auch positiv konnotiert ist, beschreibt sie in der Psychologie eine als problematisch, teilweise gar als pathologisch empfundene "Steuerung fremden Denkens, Fühlens und Verhaltens, ohne dass sich die Betroffenen der Steuerung bewusst sind “. ${ }^{71}$ Dieses negativ besetzte Begriffsverständnis dürfte auch die Verwendung im allgemeinen Sprachgebrauch widerspiegeln, in dem als möglicher Gegenstand einer Manipulation über Bestandteile der Psyche hinaus zahlreiche weitere Prozesse aufgefasst werden (z.B. Abgaswerte, Forschungs- und Wahlergebnisse), die infolge einer verdeckten Einflussnahme in ihrem automatisierten oder zumindest regelgeleiteten Ablauf oder Ausgang zu Gunsten des Eingreifenden verändert werden.

Diese Elemente prägen auch das Manipulationsverständnis im Bereich des Sports, wenngleich sich auch hier keine einhellig anerkannte Definition etabliert hat. Die diesbezüglichen Versuche enthalten ebenfalls übereinstimmend ein moralisches Unwerturteil, unterscheiden sich aber über die Ergänzung zusätzlicher Definitionselemente in ihrer Reichweite und Zwecksetzung. So werden in einer im Ansatz offenen Begriffsklärung die instrumentalisierende Steuerung und die damit einhergehende Deformation von Integrität als charakteristische Merkmale einer Sportmanipulation hervorgehoben und über die Bildung von Fallgruppen weiter konkretisiert. ${ }^{72}$ Demgegenüber definiert der Europarat eine Sportmanipulation als eine vorsätzliche Abmachung, Handlung oder Unterlassung, die auf eine unlautere Veränderung des Ergebnisses oder des Verlaufs eines Sportwettbewerbs abzielt, um die Unvorhersehbarkeit des genannten Wettbewerbs ganz oder teilweise in der Absicht aufzuheben, einen ungerechtfertigten Vorteil für sich oder andere zu erlangen. ${ }^{73} \mathrm{Zu}$ dieser in sich weitgehend abgeschlossenen und auf die unmittelbare Wettbewerbsbeeinflussung begrenzten Begriffsbestimmung trägt auch ihr politischer Hintergrund bei. Sie ist einer Konvention vorangestellt, die sich mit staatlichen Abwehrmaßnahmen gegen Sportmanipulationen befasst und dient der internatio-

71 DIE ZEIT (Hrsg.), Lexikon, Band 9 (Eintrag: Manipulation).

72 Grupe/Mieth/Mieth Lexikon der Ethik im Sport, S. 340 (Eintrag: Manipulation).

73 Art. 3 Nr. 4 des Übereinkommens des Europarates über die Manipulation von Sportwettbewerben vom 18.9.2014 (sog. Magglinger Konvention), SEV Nr. 215; hierzu auch Muresan Causa Sport 2016, 3 ff. 
nalen Strafverfolgungsbehörde Interpol als Arbeitsdefinition. ${ }^{74}$ Dies deutet auf eine bereits von Strafwürdigkeitserwägungen durchzogene Begriffsbestimmung hin, die sich für einen phänomenologischen Überblick nicht eignet.

Im Folgenden soll in Anlehnung an den zuerst zitierten Ansatz unter einer Sportmanipulation jede geplante oder spontane Verhaltensweise verstanden werden, die sich durch eine unlautere Einflussnahme auf einen im Zusammenhang mit dem Sport stehenden Vorgang, die angestrebte Erlangung eines irgendwie gearteten Vorteils sowie die Intention eines verdeckten Vorgehens kennzeichnet und in Fallgruppen auszudifferenzieren ist. Eine Eingrenzung auf bestimmte Akteure ist hiermit zunächst nicht verbunden. Die durch das Adjektiv unlauter eingeführte moralische Komponente erfordert dabei weniger die Verletzung eines festgelegten Regelwerkes als vielmehr einer bereichsspezifischen Sportethik, die auf den Prinzipien des Fair Play, der Chancengleichheit sowie des Leistungsprinzips fußt. Umgekehrt unterfällt die einfache Verletzung sportinterner Regeln während des Wettkampfs aus Ungeschick oder übertriebenem Einsatz als Teil desselben nicht dem Begriff der Sportmanipulation. ${ }^{75}$

\section{Verhältnis zur Korruption im Sport}

Die Weite der zugrunde gelegten Definition der Sportmanipulation beeinflusst auch ihr im öffentlichen wie wissenschaftlichen Diskurs nicht immer einheitlich abgestecktes Verhältnis zum Begriff der Korruption im Sport, der häufig zum Zielobjekt einer strafrechtlichen Intervention erklärt wird. Erschwert wird eine Abgrenzung dabei durch den seinerseits von verschiedenen disziplinären Zugängen geprägten, einer einheitlichen Festlegung entbehrenden Korruptionsbegriff. ${ }^{76} \mathrm{Zu}$ dessen unumstrittenem Kern zählt lediglich das Merkmal des Missbrauchs anvertrauter Macht zum privaten Nutzen oder Vorteil. ${ }^{77}$ Aus dessen Anwendung auf den Sport wird bei gleichzeitiger Zugrundelegung einer angereicherten Manipulationsdefinition teilweise der Schluss eines deckungsgleichen Bedeu-

74 Vgl. Interpol/IOC (Hrsg.), Handbook, S. 18.

75 Vgl. Bösing Manipulationen, S. 6.

76 Übersicht bei Heilemann Bestechlichkeit, S. $34 \mathrm{ff}$.

77 S. die Definitionen bei Transparency International (Hrsg.), Jahresbericht 2018, S. 5 bzw. Weinreich, in: ders. (Hrsg.), Korruption, 2006, S. 22 (26). 
tungsgehaltes und einer austauschbaren Verwendung beider Begriffe gezogen. ${ }^{78}$

Dieser begrifflichen Kongruenz ist auf Basis eines offeneren Manipulationsverständnisses entgegenzutreten. Nicht alle manipulativen Einflussnahmen im Sport haben zwangsläufig auch eine korrupte Dimension. ${ }^{79}$ Orientiert man sich hinsichtlich des allgemeinen Korruptionsbegriffs an einer kriminologischen Definition, nach der unter Korruption der Machtmissbrauch von Angehörigen besonderer Macht zu verstehen ist, die sich aufgrund einer Einflussnahme mit an einer manipulierten Leistung Interessierten über sachwidrige Vorteile einig werden, ${ }^{80}$ so ergibt sich daraus zum einen zwar der notwendige Sachzusammenhang zwischen Korruption und einer manipulativen Einflussnahme als ihrem Bezugspunkt. Zum anderen entschwinden aber solche Formen der Sportmanipulation aus dem Begriffsfeld der Korruption, die ein Sportakteur spontan und ohne vorangehende Absprache mit einem Drittbegünstigten alleine ausübt. ${ }^{81}$ Auch eine Zuordnung des Dopings zur Sportkorruption erscheint fragwürdig, wenn das erforderliche Kennzeichen der besonderen Machtposition bei Sportakteuren gerade in deren unmittelbarer Steuerungsherrschaft über ein medial verfolgtes, aber allein ihnen zugängliches Wettkampfgeschehen erkannt wird. ${ }^{82}$ Die Einnahme verbotener Substanzen zur Leistungssteigerung verschafft illegitime Vorteile, hält sich aber im Rahmen der Grundannahme von um den Sieg eifernden Athleten und erweitert kaum die Möglichkeiten eines Missbrauchs der besonderen Macht zur Gestaltung eines sporttypischen Wettkampfs.

78 ICSS/Sorbonne (Hrsg.) Part I, S. 159; blickt man etwa auf die weite Definition von Gorse/Chadwick Prevalence, S. 8, wonach Korruption im Sport jegliche illegale, unmoralische oder unethische Aktivität erfasst, die zu Gunsten des persönlichen materiellen Gewinns einer oder mehrerer in die Aktivität verwickelten Parteien auf die absichtliche Verzerrung des Ausgangs eines sportlichen Wettbewerbs (oder eines Elements davon) abzielt (Übersetzung aus dem Englischen durch den Verf.), so lassen sich tatsächlich kaum wesentliche Unterschiede zur Manipulationsdefinition des Europarats feststellen.

79 So auch Andreff, in: Breuer/Forrest (Hrsg.), Palgrave Handbook, 2018, S. 13 (14).

80 Vgl. Bannenberg Korruption, S. 12 ff. mit Verweis auf das Fehlen eines einheitlichen Korruptionsbegriffs.

81 Vgl. Schild, in: Wagner/Wolf (Hrsg.), Korruption, 2011, S. 158 (163).

82 Ebenso Schild, in: Wagner/Wolf (Hrsg.), Korruption, 2011, S. 158 (162 ff.); den Bereich des Dopings auf Basis ihrer Definition grundsätzlich der Sportkorruption zuordnend hingegen Gorse/Chadwick Prevalence S. 7 f.; so auch Weinreich, in: ders. (Hrsg.), Korruption, 2006, S. 22 (26). 
Diese aus dem allgemeinen Begriffsverständnis abgeleiteten Ausgrenzungen können in eine positive Definition der spezifischen Sportkorruption überführt werden. Demnach bezeichnet Sportkorruption ein Verhalten von Athleten, bei dem diese nicht den sportüblich hohen Einsatz zur Erringung eines sportlichen Sieges oder Ranges erbringen und anderen Athleten diesen vorsätzlich überlassen oder aber von Funktionsträgern bei Ausübung eines Amtes, in dem diese die ihnen übertragenen Aufgaben bewusst nicht entsprechend den Zielsetzungen und moralischen Werten ihres Verbandes oder des Wettkampfsports im Allgemeinen versehen, weil sie jeweils hierdurch pekuniäre und nicht pekuniäre Vorteile für sich von dem Begünstigten erhalten oder erhoffen..$^{83}$ Eine solche Begriffsklärung garantiert ob ihrer Abhängigkeit von wandelbaren Wertanschauungen in einzelnen Sportarten keine zeitlose Einordnung sämtlicher Einzelfälle, steht aber im Einklang mit den zentralen Merkmalen einer kriminologischen Korruptionsdefinition und ermöglicht eine Differenzierung zwischen Manipulationen im Sport und ihrer als Sportkorruption hervorzuhebenden Teilmenge.

\section{Verhältnis zu Match Fixing}

Ebenfalls nur eine Sonderform der Sportmanipulation beschreibt der Begriff des Match Fixing. Hierunter sind Handlungen zu verstehen, die von Mannschaften, Athleten oder Offiziellen innerhalb eines Spiels oder in dessen Vorfeld unternommen werden, um dessen ungewisses Ergebnis entgegen der Sportethik zum Zwecke des privaten Nutzens des Ausführenden oder eines Dritten zu verändern. ${ }^{84}$ Ausgeübt von Spielern oder Mannschaften kann dies bedeuten, den Sport in einer Weise zu betreiben, die den Eintritt eines bestimmten Ereignisses garantiert. Im Falle von Schiedsoder Kampfrichtern drückt sich Match Fixing in der Gewährung einer von den Sportregeln nicht gedeckten begünstigenden oder benachteiligenden Behandlung eines Athleten oder einer Mannschaft aus.

Match Fixing kann auf Absprachen der Sportakteure untereinander oder mit externen Dritten beruhen, die mit Bestechungszahlungen verbunden sind und seine Zuordnung zum soeben definierten Bereich der Sportkorruption ermöglichen. Es kann aber auch von einzelnen Sportlern alleine

83 Maennig Vierteljahreshefte zur Wirtschaftsforschung 73 (2004), 263 (265).

84 Mintas, in: Kainz/Scherrer/Werner (Hrsg.), Sportfinanzierung, 2012, S. 97; Breuer/ Kaiser in: Frawley/Schulenkorf (Hrsg.), Critical Issues, 2017, S. 64 (65). 
ausgeführt werden. Dies veranlasst die Einführung der Unterkategorien des bestechungsbedingten und des von Bestechungsprämien unabhängigen Match Fixing. ${ }^{85}$ Eine gelegentlich vorgenommene Gleichsetzung des Match Fixing mit dem Begriff der Sportmanipulation ist hingegen unpräzise. Nicht nur werden die als Objekt einer Manipulation grundsätzlich in Betracht kommenden Wettbewerbe nicht in jeder Sportart als „Match“ bezeichnet. ${ }^{86}$ Die synonyme Verwendung verengt den Blick auch auf Manipulationen innerhalb eines laufenden Wettbewerbs und scheint unter diesen auch nur solche zu erfassen, die eine Festsetzung des Endergebnisses bewirken sollen. Zur Abdeckung bloßer Verlaufsmanipulationen bedarf es daher der Ergänzung um den Begriff des Spot Fixing. ${ }^{87}$

II. Erscheinungsformen der Sportmanipulationen und am

Anwendungsbereich der $\$ \$ 265 \mathrm{c}, 265 \mathrm{~d}$ StGB orientierte Abgrenzungen

Das begrifflich demnach weit abgesteckte Feld der Sportmanipulationen soll im Folgenden durch die Einziehung von Kategorien und die Benennung entsprechender Beispielsfälle unterteilt und veranschaulicht werden. Im Sinne einer Fokussierung auf die durch die $\$ \$ 265$ c, 265d StGB strafgesetzlich erfassten Manipulationsformen werden die tatbestandlichen Voraussetzungen dabei als Abgrenzungskriterien herangezogen. Deren Einbindung dient der Absteckung des für den weiteren Gang der Untersuchung relevanten phänomenologischen Teilbereichs. So kann auf ihn etwa die für Legitimationsfragen bedeutsame Untersuchung eines bereits durch andere Tatbestände etablierten strafrechtlichen Schutzes präzise ausgerichtet werden (unter B.).

Bezugspunkt der jeweils strafbaren Absprache ist in beiden Tatbeständen übereinstimmend die Beeinflussung eines sportlichen Wettbewerbs zu Gunsten des Wettbewerbsgegners als Gegenleistung eines in Aussicht gestellten Vorteils. In $\ 265 \mathrm{~d}$ StGB muss die Beeinflussung zusätzlich in wettbewerbswidriger Weise erfolgen. Anhand der dieser gesetzlichen Charakterisierung zu entnehmenden Unterscheidungsmerkmale sollen die tatbestandlich erfassten unlauteren Einflussnahmen auf dem Gesamttableau der

85 Spapens/Olfers European Journal of Crime, Criminal Law and Criminal Justice 2015, 333 (338).

86 Interpol/IOC (Hrsg.), Handbook, S. 18.

87 Hierzu Duttig Beweismaß, S. 289. 
Sportmanipulationen verortet und auf mehreren Ebenen von für diese Untersuchung irrelevanten Fallgruppen abgegrenzt werden.

\section{Abb. 1: Erscheinungsformen von Sportmanipulationen (eigene Darstellung)}

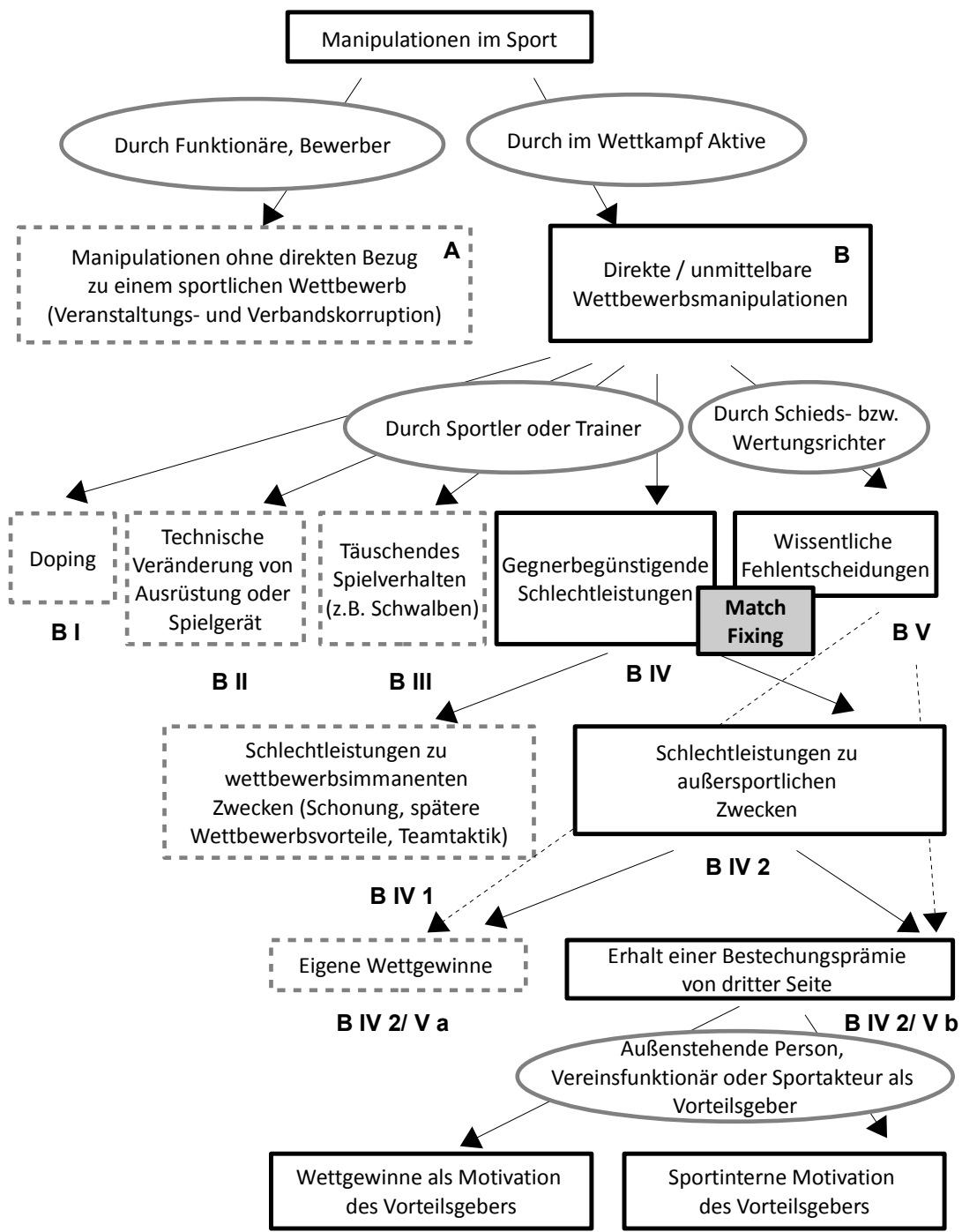

B IV 2/ V b a

B IV 2/ V b $\beta$ 
1. Abgrenzung der erfassten direkten Wettbewerbsmanipulation zur indirekten Sportkorruption

Auf einer übergeordneten Ebene kann eine erste Differenzierung entsprechend dem Bezugspunkt der Manipulation vorgenommen werden. Die $\$ \mathbb{S} 265 \mathrm{c}, 265 \mathrm{~d}$ StGB beschränken die Strafbarkeit auf Beeinflussungen des sportlichen Wettbewerbs. Ungeachtet dessen näherer Qualifizierung muss sich die vereinbarte Manipulation jedenfalls unmittelbar auf ein Wettkampfgeschehen richten. Bereits ausgeschlossen werden können demnach die zumeist von Verbands- oder Vereinsfunktionären begangenen manipulativen Handlungen, die lediglich im erweiterten Zusammenhang mit einem sportlichen Wettbewerb stehen, da sie nicht dessen sportlichen Verlauf oder Ausgang, sondern dessen Austragung oder Vermarktung betreffen (Kennzeichnung A im Schaubild).

Hierunter fällt etwa das Fehlverhalten bestechlicher Spitzenfunktionäre in internationalen Dachverbänden, die bei der Vergabe von Turnieren oder entsprechenden Sponsoring- und Vermarktungsrechten sich hierfür bewerbenden Staaten oder Firmen im Gegenzug zu versprochenen persönlichen Vorteilen eine verdeckte und unsachliche Bevorzugung zusagen. Entsprechende Vorwürfe wurden zuletzt wiederkehrend insbesondere gegen Funktionäre des Weltfußballverbands FIFA erhoben, etwa im Zusammenhang mit der Vergabe der Weltmeisterschaften an Russland 2018 und Katar 2022 sowie der Vergabe von Medien- und Sponsoringrechten bei Fußballturnieren in Südamerika. ${ }^{88}$ Derartige Sachverhalte erfüllen fraglos die zweite Variante der oben eingeführten sportspezifischen Korruptionsdefinition und lassen sich in Abgrenzung zur ersten Variante der unmittelbaren Wettkampfmanipulationen als indirekte Sportkorruption oder Veranstaltungskorruption bezeichnen. ${ }^{89}$

Dieser können auch umgekehrte Konstellationen zugerechnet werden, in denen kleinere Verbände oder Sponsoren aktiv eingeforderte Schmiergelder an Verantwortungsträger von Rundfunkanstalten zahlen, um eine werbewirksame Berichterstattung über die veranstalteten oder geförderten Wettkämpfe zu erhalten..$^{90}$ Auch im Zusammenhang mit Bauaufträgen für

88 Vgl. eindrücklich Kistner Fifa Mafia, S. 245 ff.

89 S. Rössner FS Mehle, 2009, S. 567: „indirekte Sportkorruption“; Maennig Vierteljahreshefte zur Wirtschaftsforschung 73 (2004), 263 (265): „Veranstaltungskorruption".

90 Zur Verurteilung des ehemaligen Leiters der Sportredaktion des Hessischen Rundfunks Jürgen Emig wegen Bestechlichkeit und Untreue s. LG Frankfurt v. 2.10.2008 - 5-12 KLs/2/07/7740 Js 214435/04; zum ähnlichen Fall rund um den 
Sportstätten oder der Abwicklung von Spielertransfers sind korruptive Absprachen und Bestechungszahlungen an Vereinsverantwortliche dokumentiert. ${ }^{91}$ Der sportspezifische Charakter ist in der Kategorie der indirekten Sportkorruption grundsätzlich schwächer ausgeprägt, da der zu manipulierende Vorgang keinen nach Sonderregeln verlaufenden sportlichen Wettkampf, sondern eine gewöhnliche wirtschaftliche Bezugsentscheidung betrifft. Es handelt sich daher um eine Form der allgemeinen Wirtschaftskorruption, die lediglich das wirtschaftliche Umfeld des kommerzialisierten Sports für unlautere Vorteile im Geschäftsleben ausnutzt. ${ }^{92}$ Sie wird vom Anwendungsbereich der $\$ \$ 265 \mathrm{c}, 265 \mathrm{~d}$ StGB nicht erfasst und bleibt daher im weiteren Verlauf der Untersuchung außen vor.

2. Abgrenzung der erfassten gegnerbegünstigenden Schlechtleistung zur Manipulation zum eigenen Wettbewerbsvorteil

Den fortan fokussierten direkten Wettbewerbsmanipulationen gemein ist die Intention der Einschränkung der Unvorhersehbarkeit des Verlaufs eines Sportwettbewerbs durch ein Verhalten, das zum Eintritt eines bestimmten Ereignisses oder Resultates führen soll. Voraussetzung für einen derartigen Eingriff ist ein unmittelbarer Einfluss auf das Wettbewerbsgeschehen, der während oder im Vorfeld dessen ausgeübt werden kann und in erster Linie den am Wettbewerb direkt beteiligten Sportlern, Schiedsrichtern, Trainern oder technischen bzw. medizinischen Betreuern zukommt. ${ }^{93}$ Manipulationen, die von im Wettbewerb mit anderen Teams oder Kontrahenten stehenden Akteuren ausgehen, lassen sich dabei nach ihrer jeweils verfolgten wettbewerbsbezogenen Zielrichtung weiter unterscheiden (Kennzeichnung B I-V im Schaubild).

ehemaligen Sportchef des Mitteldeutschen Rundfunks Winfried Mohren s. Wabnitz/Janovsky/Schmitt/Bannenberg 13. Kapitel Rn. 102.

91 So gab Karl Heinz Wildmoser Jr. als Sohn des damaligen Präsidenten des TSV 1860 München gegen eine Zahlung in Millionenhöhe ausschreibungsrelevante Daten an ein Bauunternehmen weiter, die diesem den Auftrag zum Bau der Allianz Are$n a$ in München sicherten, vgl. Heilemann Bestechlichkeit, S. 112, $117 \mathrm{ff}$.

92 Rössner FS Mehle, 2009, S. 567 f.; zu Problemen der Strafverfolgung Pieth/Zerbes ZIS 2016, $619 \mathrm{ff}$.

93 Die in manchen Sportarten denkbaren direkten Eingriffe durch Zuschauer am Spielfeld- oder Streckenrand blieben bei der hier vorgenommenen Systematisierung außen vor. 
Vor dem Hintergrund der Sportlogik des rivalisierenden Überbietens und Siegstrebens erscheinen zunächst solche unlauteren Einflussnahmen auf das Wettkampfgeschehen plausibel, durch die ein Teilnehmer die eigenen Aussichten auf einen Sieg oder eine gute Platzierung zu verbessern versucht, sei es durch die täuschungsbasierte Erlangung eines spieltaktischen Vorteils, die regelwidrige Aushebelung limitierender Leistungsfaktoren biologischer oder technischer Art oder die zielgerichtete Schwächung des Gegners. Umgekehrt können manipulative Einwirkungen aber auch dem Zweck eines schwachen eigenen Abschneidens im Wettbewerb dienen. In diesen Fällen wird absichtlich durch ein passives Spielverhalten unterhalb des eigentlichen Leistungsvermögens oder durch offensichtliche Regelverstöße eine nachteilige Spielsituation herbeigeführt, die die Siegchancen der konkurrierenden Teilnehmer erhöht. Dabei muss es dem Sportakteur nicht zwingend auf die Herbeiführung eines für ihn negativen Endresultats des Wettbewerbs in Form der eigenen Niederlage ankommen (sog. Ergebnismanipulation). Das bewusst gegnerbegünstigende Spielverhalten kann sich auch lediglich auf einzelne spieltaktisch-nachteilige Ereignisse beschränken, nach deren Eintritt der Manipulator seinen Einsatz wieder erhöht. Bloße Verlaufsmanipulationen (oder auch Spot Fixing) können gänzlich ohne Auswirkung auf das Endergebnis bleiben oder dieses lediglich in der Punkteverteilung verändern, etwa wenn es dem Manipulator vorrangig auf die Gesamtzahl der erzielten Tore oder Punkte in einem Spiel oder auf eine bestimmte Punktedifferenz im Endergebnis ankommt (sog. Point Shaving ${ }^{94}$ ), ohne zugleich den Sieger bestimmen zu wollen.

Die konträre wettbewerbsbezogene Zielrichtung der beiden Manipulationsformen korreliert mit der Verletzung unterschiedlicher sportethischer Grundprinzipien. Einen eigenen unrechtmäßigen Wettbewerbsvorteil bezweckende Manipulationen verstoßen gegen den Grundsatz der Chancengleichheit, der als Voraussetzung des Vergleichs von in Konkurrenzsituationen erbrachten Leistungen allen Athleten oder Teams die gleichen Handlungsbedingungen zur Realisierung ihres Könnens sowie die Beachtung der vorgegebenen Regeln garantiert. ${ }^{95}$ Den Gegner begünstigende Einflussnahmen geraten hingegen mit dem Leistungsprinzip in Konflikt, das Akteure im Sport zum ständigen Streben nach dem Sieg und der Aus-

$94 \mathrm{Zu}$ dieser Manipulationsform Duttig Beweismaß, S. 290.

95 Grupe/Mieth/Schwier Lexikon der Ethik im Sport, S. 80 (Eintrag: Chancengleichheit). 
schöpfung ihres Leistungsvermögens anhält. ${ }^{96}$ Der Anwendungsbereich der $\$ \mathbb{S} 265 \mathrm{c}$, 265d StGB wird durch den Gesetzestext in dieser Frage klar umrissen. Die Einflussnahme auf Verlauf oder Ergebnis des sportlichen Wettbewerbs muss in den einzelnen Tatbeständen zugunsten des Wettbewerbsgegners erfolgen. Die durch den Sportakteur zugesagte Gegenleistung muss also in einer bewussten Schlechtleistung innerhalb des Wettkampfs bestehen, aus der der Konkurrent einen unmittelbaren Nutzen ziehen kann.

Mit den eigennützigen Wettbewerbsmanipulationen hingegen ausgeschlossen werden drei durchaus prominente Fallgruppen. Erstens das Doping (Kennzeichnung B I im Schaubild), worunter vereinfachend die Einnahme unerlaubter Substanzen oder die Nutzung unerlaubter Methoden zur Steigerung oder zum Erhalt der körperlichen Leistungsfähigkeit im Sport verstanden werden kann. ${ }^{97}$ Dessen Verbreitung, die auch populäre Aushängeschilder ihrer Sportarten wie die Radsportler Lance Armstrong und Jan Ullrich, die Sprinter Ben Johnson und Marion Jones oder den Schwimmer Sun Yang umschließt und bisweilen sogar Züge staatlicher Förderung trägt, hat ganze Sportarten (Radsport, Leichtathletik, Langlauf, Gewichtheben) und Nationalverbände in Verruf gebracht. ${ }^{98}$ Eine strafrechtliche Verfolgung des Dopings erfolgt indes gesondert über die Vorschriften des 2015 in Kraft getretenen AntiDopG.

Zweitens der auch als E-Doping oder Techno-Doping bezeichnete Einsatz verbotener technischer Hilfsmittel zur Leistungssteigerung während des sportlichen Wettbewerbs (Kennzeichnung B II im Schaubild). ${ }^{99}$ Hierunter fällt die zuletzt im Schachsport für Aufsehen sorgende verdeckte $\mathrm{Zu}$ hilfenahme leistungsfähiger Analyseprogramme über mitgeführte Smartphones genauso wie die Aktivierung eines im Rahmen eines Renn- oder

96 Grupe/Mieth/Grupe Lexikon der Ethik im Sport, S. 331 ff. (Eintrag: Leistung/Leistungssport).

97 Vgl. Welt Anti-Doping Agentur (Hrsg.), World Anti-Doping Code Art. 1 und 2.

98 So ist etwa der russische Leichtathletikverband Rusaf nach der Aufdeckung staatlich gelenkter Dopingpraktiken seit 2015 für internationale Wettkämpfe gesperrt und droht sogar aus dem Weltverband ausgeschlossen zu werden, s. Sueddeutsche.de vom 29.1.2020, www.sueddeutsche.de/sport/vor-olympia-in-tokio-russlan ds-leichtathleten-droht-ausschluss-aus-weltverband-1.4777607.

99 Zur Definition Krähe SpuRt 2008, 149 f.; zu Fallgruppen Vieweg, in: ders. (Hrsg.), Techno-Doping, 2015, S. 47 (52 f.). 
Mountainbikes verbauten Miniatur-Motors. ${ }^{100}$ Ergänzt wird eine derartige Addition externer Hilfsmittel durch die klassischeren Fälle der regelwidrigen Veränderung der Beschaffenheit von Material und Sportgeräten. ${ }^{101}$ Diese kann im Bob- und Schlittensport sowie im Motorsport auf eine leichtere Steuerbarkeit des Fahrzeugs abzielen oder beim Skispringen und Schwimmen zum Einsatz aero- bzw. aquadynamisch überlegener Anzüge führen.

Aber auch in Ballspielsportarten zeigen sich neuerdings entsprechende Anschauungsbeispiele, die von der Presse die Beinamen „Deflategate“ bzw. „Tampergate“ erhielten. In ersterem geriet der Quarterback des amerikanischen Footballteam New England Patriots Tom Brady im Jahr 2015 unter Verdacht, vor einem Halbfinalspiel die Reduzierung des Luftdrucks der von seinem Team eingesetzten Footballs angeordnet zu haben, damit er diese präziser werfen können würde. ${ }^{102}$ In letzterem bearbeitete der Schlagmann der australischen Cricket-Nationalmannschaft Cameron Bancroft auf Vorschlag zweier Teamkollegen den Ball vor einem eigenen Versuch in einem Länderspiel gegen Südafrika im Frühjahr 2018 unzulässig mit einem mitgeführten Klebeband, um dessen Flugeigenschaften zu verändern. ${ }^{103}$

Drittens bleibt auch ein täuschendes Spielverhalten der Athleten außen vor, das insbesondere in Kontaktsportarten die Fehlwahrnehmung eines Schiedsrichters provozieren und diesen infolgedessen zu einer den Täuschenden begünstigenden Entscheidung verleiten soll (Kennzeichnung B III im Schaubild). Die Täuschungshandlung kann in der theatralischen Vorspiegelung eines tatsächlich nicht stattgefundenen irregulären Kontakts durch einen Gegenspieler (sog. Schwalbe) liegen oder in einer bewusst wahrheitswidrigen Auskunft im Anschluss an eine unübersichtliche Spielsituation gegenüber dem in der Bewertung unsicheren und daher beim Spieler nachfragenden Schiedsrichter. Ziel einer solchen Aktion

100 Die Verwendung eines verdeckten Elektromotors führte etwa zur Disqualifizierung der belgischen Mountainbikerin Femke Van den Driessche von der Radcross-Weltmeisterschaft 2016, s. Römer/Niestedt Unerlaubte Substanz im Fahrrad, Spiegel Online vom 23.5.2016, www.spiegel.de/wissenschaft/technik/e-dopi ng-wie-man-elektromotoren-in-rennraedern-versteckt-a-1091641.html.

101 Hierzu Schattmann Betrug, S. 120 ff.

102 Gustke „Deflategate“ in der NFL: Viel Wind um wenig Luft, Tagesspiegel.de vom 22.1.2015, www.tagesspiegel.de/sport/big-four-die-us-sport-kolumne-deflate gate-in-der-nfl-viel-wind-um-wenig-luft/11266304.html.

103 „Schmeißt sie alle raus!“, Spiegel Online vom 28.3.2018, www.spiegel.de/sport/s onst/australien-skandal-im-cricket-schmeisst-sie-alle-raus-a-1200336.html. 
kann neben der Wertung eines vermeintlichen Tores oder Punktes sowie dem Erhalt eines Straf- oder Freistoßes auch die Dezimierung des gegnerischen Teams sein.

Von dieser binären Abgrenzung direkter Wettbewerbsmanipulationen entlang eines unmittelbar verfolgten Wettbewerbsvorteils oder -nachteils ausgenommen bleibt die Gruppe der Sportrichter. Diese können den ihnen durch die einzelnen Regelwerke eingeräumten erheblichen Einfluss auf das Wettkampfgeschehen ebenfalls zu manipulativen Verzerrungen nutzen, stehen aber in keinem Konkurrenzverhältnis zu einem Wettbewerbsgegner. Ihre manipulative Schlechtleistung bemisst sich an der für sie maßgeblichen Pflicht zur neutralen Spielleitung ${ }^{104}$ und äußert sich in der bewussten Bevorzugung eines Wettbewerbsteilnehmers durch gegen besseres Wissen getroffene Fehlentscheidungen oder unangemessene Leistungsbewertungen (Kennzeichnung B V im Schaubild). Neben den Wettbewerbsgegner begünstigenden Einflussnahmen durch Athleten, Spieler oder Trainer wird durch die spezifisch zugeschnittenen Absätze 3 und 4 auch die absichtliche Schlechtleistung von Schieds-, Wertungs- und Kampfrichtern von den $\$ \$$ 265c, 265d StGB erfasst.

\section{Abgrenzung der erfassten Schlechtleistung zu außersportlichen Zwecken zur sportimmanent motivierten Leistungsreduzierung}

Dem Wettbewerbsgegner durch Schlechtleistung bzw. parteiische Fehlentscheidungen in neuralgischen Spielsituationen absichtlich wettbewerbsbezogene Vorteile zu verschaffen, unterfällt der besonderen Manipulationsform des Match Fixing. Gerade bei Athleten und Trainern können die Gründe für ein solches Verhalten vielfältig sein. Sie lassen sich zwei übergeordneten Motivgruppen zuordnen. Auf der einen Seite kann die Aussicht auf den Erhalt außersportlicher Prämien in Form ergebnis- oder verlaufsabhängiger Wettgewinne oder externer Bestechungsgelder den entscheidenden Anreiz für das Herbeiführen nachteiliger Spielsituationen oder eigener Niederlagen bilden (Kennzeichnung B IV 2 im Schaubild). Auf der anderen Seite verleiten aber auch sportimmanente Faktoren zu Leistungsreduzierungen und der freiwilligen Weggabe einer Siegchance

104 Exemplarisch $₫ 5$ Abs. 1 DHB-Schiedsrichterordnung. 
(Kennzeichnung B IV 1 im Schaublid). ${ }^{105}$ Diese können in der Notwendigkeit eines umsichtigen Umgangs mit den immensen körperlichen Herausforderungen des Wettbewerbsprogramms oder in einem bestimmten Austragungsmodus angelegt sein.

a) Schonung von Kräften als sportimmanenter Zweck der Leistungsreduzierung

In vielen Sportarten verleitet ein dichtes Programm aufeinander folgender Wettkämpfe sowohl Einzelsportler als auch Teams gelegentlich dazu, in einzelnen Wettbewerben oder Spielen, die für sie aus sportlichen Gründen von untergeordneter Bedeutung sind, ihre Kräfte zu schonen. Die hiermit einhergehende Bevorteilung des Wettbewerbsgegners kann in einer allgemeinen oder situativen Reduzierung des Einsatzes liegen, beispielsweise im Schlagen des Balles mit verminderter Kraft, im zurückhaltenden Bestreiten von Zweikämpfen oder im Verzicht auf die Ausführung einer Übung, die zwar eine hohe Wertung verspricht, aber auch Verletzungsrisiken birgt. Sie kann sich auch aus einer vorab durch den Trainer vorgegebenen Aufstellung ergeben, die auf besonders leistungsstarke Spieler verzichtet, damit diese in den kommenden Spielen ausgeruht eingreifen können. Trotz bewusster Leistungsreduzierungen kann in derartigen Fällen hinter dem primären Ziel eines sparsamen Umgangs mit den körperlichen Ressourcen durchaus auch ein gutes eigenes Resultat angestrebt werden.

b) Indirekte Belohnung von Niederlagen durch den Wettbewerbsmodus

Anders verhält sich dies in mehrstufigen Pokalwettbewerben, in denen gerade ein verlorenes oder zumindest zu Punktverlusten führendes abschließendes Vorrundenspiel für einen bereits für die Endrunde qualifizierten Teilnehmer mit sportlichen Vorteilen im weiteren Turnierverlauf verbunden sein kann. Entsprechende Beispiele sind sportartübergreifend zu finden. Sie reichen vom chinesischen Badminton-Doppel Yu Yang und Wang Xialoi, das ein Gruppenspiel bei den Olympischen Spielen 2012 auf groteske Weise verloren gab, um im anschließenden Viertelfinale einem Aufein-

105 Zur Differenzierung zwischen außersportlichen und sportimmanenten Manipulationszwecken auch PHB-SportR/Reinhart, 3. Aufl., 8. Teil 5. Kap. Rn. 152; Duttig Beweismaß, S. 285 ff. 
andertreffen mit einem als stark eingeschätzten Doppel aus dem Weg zu gehen, ${ }^{106}$ bis zum australischen Basketball-Nationalteam, dessen überraschende Niederlage bei der Weltmeisterschaft 2014 gegen Angola offenbar der Verhinderung eines Duells mit dem Topfavoriten USA diente. ${ }^{107}$ Auch das unter dem Titel „Schmach von Cordoba“ in die Fußball-Historie eingegangene Vorrundenspiel zwischen der Bundesrepublik Deutschland und Österreich bei der Weltmeisterschaft 1982, bei der sich die Kontrahenten vor dem Spiel auf ein für beide zur Endrundenqualifizierung führendes Unentschieden einigten, veranschaulicht ein solches durch das Turnierformat motiviertes Match Fixing, bei dem sogar im zuvor hergestellten Einverständnis mit dem unmittelbaren Wettbewerbsgegner vorgegangen wurde.

Mitunter kann der mit einer Niederlage verfolgte sportimmanente Vorteil aber auch in fernerer Zukunft liegen und sich erst auf einen Folgewettbewerb beziehen. Dies kann wiederum in organisatorischen Entscheidungen der Veranstalter begründet sein. So animiert etwa das in nordamerikanischen Profiligen zwischen den einzelnen Spielzeiten angesetzte Verfahren der sog. Lottery Draft unterdurchschnittlich platzierte Teams am Ende einer Saison dazu, durch Niederlagen in der Abschlusstabelle möglichst weit zurückzufallen, um so die an die Endplatzierung gekoppelten Chancen auf ein frühes Zugriffsrecht bei der anstehenden Wahl der neu in die Liga kommenden Jungtalente zu steigern. ${ }^{108}$ Auch unter direkten sportlichen Kontrahenten kann es zu Versprechungen künftiger Wettbewerbsvorteile kommen, die einen kurzfristigen Misserfolg motivieren. Hiervon sind vor allem Einzelsportarten betroffen, deren Modus auf einer individuellen Rangliste basiert, die bestimmte Wettkämpfe für den einzelnen Athleten zu zukunftsweisenden Qualifizierungs- oder Relegationsspielen werden lässt, während sie für den jeweiligen Gegner keine hervorgehobene Bedeutung haben. Im japanischen Sumoringen kam es vor solchen Kämpfen etwa nachweislich zu Absprachen, die einen zum Klassenerhalt benötigten Sieg des vom sportlichen Abstieg bedrohten Kämpfers vorsahen, so-

106 Chinesisches Doppel manipuliert Wettbewerb, Focus Online vom 1.8.2012, www.focus.de/sport/olympia-2012/badminton-skandal-bei-olympia-chinesischesdamendoppel-manipuliert-wettbewerb_aid_791368.html.

107 Australien wehrt sich gegen Vorwürfe, Faz.net vom 5.9.2014, www.faz.net/aktu ell/sport/mehr-sport/basketball-wm-australien-wehrt-sich-gegen-vorwuerfe-1313 6657.html.

$108 \mathrm{Zu}$ dieser als „Tanking“ bezeichneten absichtlichen Anhäufung von Niederlagen Taylor/Trogdon Journal of Labor Economics 20 (1), 23 ff.; Andreff, in: Breuer/ Forrest (Hrsg.), Palgrave Handbook, 2018, S. 13 (18). 
fern dieser seinen Kontrahenten dafür in künftigen Aufeinandertreffen freiwillig gewinnen ließe. ${ }^{109}$ Eine signifikant erhöhte Siegwahrscheinlichkeit für den gemäß der Rangliste schwächer einzuschätzenden Akteur konnte auch im Herrentennis für Matches festgestellt werden, in denen es für diesen noch unmittelbar um die Qualifikation für ein anstehendes Grand Slam Turnier ging. ${ }^{110}$

\section{c) Die sog. „Stallorder“ als Grenzfall}

Auf Grenzfälle der bewussten Schlechtleistung zu wettbewerbsimmanenten Zwecken stößt man in Einzelsportarten, in denen die um den Sieg in einem Rennen konkurrierenden einzelnen Teilnehmer gleichzeitig übergeordneten Teams angehören. Hier lässt sich immer wieder beobachten, dass einzelne Sportler ihre reelle Siegchance durch das Unterlassen eines Schlusssprints oder eine von vornherein unsinnige Kräfteeinteilung zu Gunsten eines Wettbewerbsgegners opfern, der gleichzeitig ihr Teamkollege ist. Beim Großen Preis von Österreich 2002 reduzierte der in Führung liegende Formel 1-Fahrer Rubens Barrichello auf der Zielgeraden seine Geschwindigkeit, damit der zweite Ferrari-Pilot Michael Schumacher ihn gerade noch vor der Ziellinie überholen und den Sieg erzielen konnte. Statt auf der Zielgeraden ihre Titelchance mittels eines beherzten Antritts aus der dreiköpfigen Spitzengruppe heraus zu realisieren, richteten sich die Radfahrer Marcus Burghardt und Andreas Schillinger bei den deutschen Straßenradmeisterschaften 2019 vorzeitig auf und ließen den beim selben Profiteam angestellten Maximilian Schachmann unangefochten als Sieger ins Ziel fahren. ${ }^{111}$ Und bei Langstreckenläufen agieren ihrerseits ambitionierte Läufer bisweilen allein als Tempomacher, die sich in der ersten Rennhälfte bis zur eigenen Rennaufgabe verausgaben, um den in ihrem Windschatten laufenden Favoriten aus dem gleichen Nationalkader eine gute Endzeit und das Abschütteln der Konkurrenz zu ermöglichen. Die beispielhaft genannten Sportler verzichten also nicht zwecks eines eigenen sportlichen Vorteils auf ihre Siegchance, sondern unterwerfen sich der Taktik einer Teamleitung (sog. Stallorder), die aus Gründen des übergeordneten Teamerfolgs in der Gesamtwertung eines mehrstufigen Wettbe-

109 Vgl. die Studie von Duggan/Levitt American Economic Review 92 (5), 1594 ff.

$110 \mathrm{Jetter} /$ Walker Southern Economic Journal 84 (1), $155 \mathrm{ff}$.

111 Schachmann nach Bora-Gala im Meistertrikot zur Tour, Radsport News vom 30.6.2019, www.radsport-news.com/sport/sportnews_115818.htm. 
werbs die Unterstützung eines anderen Wettbewerbsteilnehmers einfordert. Freilich ist im Einzelfall zu überprüfen, ob das der Teamtaktik erbrachte Opfer des eigenen Sieges nicht doch durch vereinbarte Extra-Vergütungen teamintern ausgeglichen wird und somit außersportlichen Zwecken dient.

d) Sportinterner Umgang und Spiegelung der Differenzierung in den $\int \mathbb{S} 265 \mathrm{c}, 265 \mathrm{~d}$ StGB

Der öffentliche und sportinterne Umgang mit Schlechtleistungen zu wettbewerbsimmanenten Zwecken ist uneinheitlich. Teilweise lösen sie verbandsrechtliche Sanktionen und öfentliche Empörung aus, ${ }^{112}$ teilweise werden sie stillschweigend hingenommen. Ausschlaggebend hierfür scheint neben eines sportartabhängigen Akzeptanzniveaus für strategisch provozierte Niederlagen auch die Offenkundigkeit zu sein, mit der ein entsprechender Vorsatz im Wettkampfverhalten der Sportler sichtbar wird. Erschwert wird eine einhellig abschätzige Bewertung auch durch eine gewisse sportethische Widersprüchlichkeit. ${ }^{113}$ Das Leistungsprinzip als Angriffsobjekt der für eine Manipulation konstitutiven Moralwidrigkeit scheint vom Sport selbst nicht konsequent hochgehalten zu werden, wenn bestimmte Wettbewerbsmodi seine punktuelle Verletzung durch absichtliche Niederlagen mit kurz- oder mittelfristigen Vorteilen belohnen, die wiederum perspektivisch den größtmöglichen sportlichen Erfolg versprechen.

Übertragen auf die $\$ \$ 265 c$, 265d StGB findet die dargestellte Differenzierung zwischen Schlechtleistungen zu außersportlichen und wettbewerbsimmanenten Zwecken keine explizite Entsprechung im Normtext. Jedoch ergibt sich bereits aus dem Anknüpfen beider Tatbestände an einer

112 Verbandsrechtlich werden sie dabei häufig der sanktionsbewehrten Generalklausel eines „unsportlichen Verhaltens“ zugeordnet, so etwa auch im Fall der chinesischen Badminton-Spielerinnen, die umgehend durch den Weltverband WBF vom laufenden Turnier disqualifiziert wurden; auch in der NBA können offensichtliche Fälle des „Tanking“ bzw. sich hierzu bekennende Äußerungen von Spielern oder Teamoffiziellen zu Strafen führen, s. Ködel Warum NBATeams absichtlich verlieren, Süddeutsche.de vom 12.4.2018, www.sueddeutsche .de/sport/tanking-im-basketball-warum-nba-teams-absichtlich-verlieren-1.393945 1.

113 In diese Richtung auch Forrest, in: Breuer/Forrest (Hrsg.), Palgrave Handbook, 2018, S. 91 (93 Fn. 4). 
der Manipulation vorangehenden Absprache, die die Beeinflussung mit einer ausdrücklichen Vorteilszusage verbindet, die strafrechtliche Ausgrenzung vieler der beschriebenen Schlechtleistungen zu rein wettbewerbsimmanenten Zwecken. Absichtliche Niederlagen zur Verbesserung der Ausgangsposition im weiteren Turnierverlauf oder bei der anstehenden Talente-Auswahl werden regelmäßig nicht auf derartigen Absprachen beruhen. Da die erstrebten Vorteile im Wettbewerbsmodus selbst liegen, werden sich die betreffenden Sportler oder Teams autonom für eine Schlechtleistung entscheiden, ohne dass es hierzu eines Impulses durch von dritter Seite in Aussicht gestellte Vorteile bedarf.

Anders verhält es sich bei den beispielhaft erwähnten Niederlagen von Sumoringern und Tennisspielern oder der Vereinbarung eines Unentschiedens im letzten Gruppenspiel. Hierbei sind gerade die durch den Wettbewerbsgegner im Vorfeld zugesagten Vorteile künftiger Siege bzw. der sicheren Endrundenqualifikation handlungsleitend. Auch die entscheidende Leistungsreduzierung zugunsten des Teamkollegen kann vor dem jeweiligen Wettbewerb teamintern verabredet und dem Zurückbleibenden durch die Zusage einer künftig auf ihn zugeschnittenen Taktik schmackhaft gemacht worden sein. Wie gezeigt erfasst der den $\$ \$ 265 c$, 265d StGB zugrunde liegende Vorteilsbegriff auch sportimmanente Nützlichkeiten. Einen gezielten Ausschluss solcher Konstellationen bezweckt $\$ 265 \mathrm{~d}$ StGB jedoch durch die qualifizierte Beschreibung der im Gegenzug zugesicherten gegnerbegünstigenden Beeinflussung mit dem Merkmal „in wettbewerbswidriger Weise“. Diese soll ausweislich der Gesetzesbegründung als Korrektiv dienen, das aufgrund des Fehlens der bereits durch einen Wettbezug garantierten außersportlichen Zweckrichtung bei $\$ 265 \mathrm{~d}$ StGB notwendig sei, und Einflussnahmen auszugrenzen, bei denen lediglich wettbewerbsimmanente Vorteile gewährt würden und die zumindest dem mittelbaren Ziel des eigenen sportlichen Erfolgs dienten. ${ }^{114}$ Gegnerbegünstigende Manipulationen, durch die ein Sportakteur mittelbar sportimmanente Vorteile anstrebt, können so allenfalls $\$ 265$ c StGB verwirklichen. Hierzu müsste jedoch über einen Austausch von Zusagen kurzfristiger und mittelbarer sportimmanenter Vorteile hinaus eine Wettplatzierung im Raum stehen. Solche Konstellationen werden die Ausnahme bilden. Der Anwendungsbereich der $\$ \$ 265 \mathrm{c}, 265 \mathrm{~d}$ StGB ist folglich auf gegnerbegünstigende Schlechtleistungen fokussiert, durch die Sportler und Trainer außersportliche Zwecke verfolgen.

114 BT-Drs. 18/8831, S. 21. 
Dies zeigt sich auch bei den tatbestandlich jeweils miterfassten Sportrichtern. Die vorstehende Differenzierung und entsprechende tatbestandliche Anpassung ist für sie aufgrund ihrer Sonderstellung als neutrale Spielleiter ohne eigenes Wettbewerbsinteresse von geringer Relevanz, da ihnen ohnehin keine wettbewerbsimmanenten Vorteile in Aussicht gestellt werden können. Ihre regelwidrige Einflussnahme wird somit nahezu ausnahmslos materiellen außersportlichen Zwecken dienen. ${ }^{115}$ Sollten sie hingegen in Einzelfällen absichtliche Fehlentscheidungen eigenständig aus purer Sympathie für den bevorzugten oder Antipathie gegenüber dem benachteiligten Wettbewerbsteilnehmer treffen, fehlt es für eine Subsumtion unter die $\$ \$ 265$ c, 265d StGB bereits am Anknüpfungspunkt einer die Manipulation vorbereitenden Absprache mit Vorteilszusage.

4. Abgrenzung der erfassten Bestechungsprämien von eigens erstrebten Wettgewinnen und der Weitergabe von Insiderinformationen aus Gefälligkeit

Abgesehen von Einzelfällen, in denen sich Sportakteure durch eine gegnerbegünstigende oder regelwidrige Schlechtleistung einzig einem auf sie von außen ausgeübten Druck entledigen wollen, ${ }^{116}$ wird der durch die Schlechtleistung verfolgte außersportliche Zweck regelmäßig in materiellen Vermögenszuwächsen bestehen. Solche lassen sich für die Sportakteure grundsätzlich auf zwei Arten erzielen, die sich wiederum in der Konstellation der an der Manipulation Beteiligten und somit in einer etwaigen tatbestandlichen Verwirklichung der $\$ \$ 265 \mathrm{c}, 265 \mathrm{~d}$ StGB niederschlagen.

Zunächst können sie durch das Platzieren von Sportwetten auf ein sodann durch Schlechtleistung selbst herbeigeführtes Wettbewerbsereignis oder -ergebnis finanzielle Gewinne einzustreichen versuchen (Kennzeichnung B IV 2/V a im Schaubild). So ging etwa der ehemalige BasketballSchiedsrichter Tim Donaghy vor, der über einen Zeitraum von vier Jahren auf ca. die Hälfte der ihm übertragenen Spiele der nordamerikanischen

115 So auch PHB-SportR/Reinhart, 3. Aufl., 8. Teil 5. Kap. Rn. 154.

116 So führten etwa die Spieler von Gremio Porto Alegre in einem Spiel der brasilianischen Liga die eigene Niederlage absichtlich herbei, da sie mit einem Sieg die Meisterschaft des verhassten Lokalrivalen sichergestellt hätten und in diesem Fall mit massiven körperlichen Übergriffen durch die eigenen Anhänger hätten rechnen müssen, s. Douglas Costa gesteht Spielmanipulation, Spiegel Online vom 21.2.2018, www.spiegel.de/sport/fussball/brasilien-ex-bayern-muenc hen-profi-douglas-costa-gesteht-spielmanipulation-a-1194776.html. 
Profiliga NBA wettete und diese anschließend gemäß seiner sich zumeist auf die Punktdifferenz im Endergebnis beziehenden Wettprognose zu manipulieren versuchte. ${ }^{117}$

Da den Sportakteuren jedoch die Platzierung eigener Sportwetten verbandsrechtlich verboten ist und durch die Rückverfolgung von Geldflüssen nachgewiesen werden kann, verlegen sich einige darauf, ihre Familienangehörigen oder Freunde von der beabsichtigen Schlechtleistung zu unterrichten und ihnen zu einem sicheren Wettgewinn zu verhelfen. Ein solches Verhalten kann von Einzelsportlern ausgehen wie beispielsweise dem Tennisspieler Daniel Köllerer, dem absichtliche Niederlagen vorgeworfen werden, ohne dass er selbst von diesen finanziell profitiert hätte. ${ }^{118}$ Es kann aber auch von mehreren Spielern eines Teams kollusiv vereinbart werden wie im Fall des französischen Handballclubs Montpellier HB, dessen Spieler rund um die prominenten Brüder Luka und Nikola Karabatic im Jahr 2012 mutmaßlich beschlossen, das für sie als bereits feststehenden Meister bedeutungslose Saisonspiel gegen den abstiegsbedrohten Club Cesson-Rennes absichtlich mit verringertem Einsatz anzugehen, woraufhin hiervon in Kenntnis gesetzte Verwandte und Bekannte ungewöhnlich hohe Wetteinsätze auf eine - tatsächlich eingetretene - Halbzeitführung des krassen Außenseiters tätigten. ${ }^{119}$ Beschreibt die Erzielung von Wettgewinnen durch die eigene oder eine nahestehende Person unzweifelhaft ein außersportliches Manipulationsmotiv, erfüllt ein entsprechend vorgehender Sportakteur dennoch nicht zwangsläufig die Voraussetzungen der $\$ \mathbb{S} 265 \mathrm{c}, 265 \mathrm{~d}$ StGB. In den exemplifizierten Fällen eines nach eigenen Wettgewinnen strebenden Sportakteurs bzw. einer aus purer Gefälligkeit an Dritte weitergegebenen Insiderinformation fehlt es am tatbestandlichen Kernstück einer die Schlechtleistung durch eine Vorteilszusage einleitenden Absprache. ${ }^{120}$

Der vom manipulierenden Sportakteur verfolgte außersportliche Zweck kann jedoch auch die Form einer materiellen Bestechungsprämie annehmen (Kennzeichnung B IV 2/V b im Schaubild). Deren Erhalt ist zwingend an das kollusive Zusammenwirken mit einem Vorteilsgeber gebun-

117 Emrich/Pierdzioch, in: Emrich/Pierdzioch/Pitsch (Hrsg.), Falsches Spiel, 2015, S. 15 (22).

118 Zur Sachverhaltsdarstellung auch Duttig Beweismaß, S. 305.

119 Vgl. Forrest, in: Breuer/Forrest (Hrsg.), Palgrave Handbook, 2018, S. 91 (94).

120 S. Valerius Jura 2018, 777 (784 f.); Forrest, in: Breuer/Forrest (Hrsg.), Palgrave Handbook, 2018, S. 91 (94) bezeichnet diese Fallgruppe als „home-made fixes“ und ordnet sie ohne spezifisch strafrechtliche Subsumtion der geringfügigen Korruption zu. 
den. Die Schlechtleistung dient dann der Herbeiführung eines primär im Interesse des Vorteilsgebers liegenden Wettbewerbsereignisses oder -ergebnisses, das im Vorfeld vereinbart und mit der Gewährung eines zumeist in der Zahlung eines fixen Geldbetrags bestehenden Vorteils verknüpft wurde. Mit einer solchen Bestechungsabrede zwecks manipulativer Schlechtleistung sind die Grundzüge des übereinstimmend aufgenommenen tatbestandlichen Verhaltens der $\mathbb{S} \mathbb{2 6 5 c}$, 265d StGB beschrieben. Deren Einschlägigkeit bemisst sich somit zunächst nach der Frage einer finanziellen Außensteuerung des Sportakteurs und erst nachrangig - nämlich bei der konkreten Zuordnung des Verhaltens zu einem der beiden Tatbestände, für die die dem Sportakteur bekannte Motivlage des Vorteilsgebers ausschlaggebend ist - nach einem etwaigen Wettbezug der Manipulation.

\section{Unterscheidung nach Motivlage des Vorteilsgebers}

Bei der Person des Bestechenden lassen sich regelmäßig zwei Motive unterscheiden, die das Gewähren eines materiellen Vorteils für die Zusage einer Wettbewerbsmanipulation antreiben können. Auf der einen Seite ein über Sportwetten realisiertes monetäres Gewinnstreben (Kennzeichnung B IV 2/V b a im Schaubild), auf der anderen Seite ein primär sportinternes Interesse am Ausgang eines einzelnen Spiels oder der Herbeiführung einer bestimmten Tabellensituation (Kennzeichnung B IV 2/V b $\beta$ im Schaubild). ${ }^{121}$ Wie bei der tatsächlichen Manipulation durch den Sportakteur selbst ist also auch hinsichtlich des Anreizes eines ihm von dritter Seite gewährten Vorteils zwischen außersportlichen und sportimmanenten Zwecken zu unterscheiden.

\section{a) Bestechungsprämie zwecks Wettgewinnen}

Im ersten Fall nutzt der zumeist außerhalb des Sportgeschehens stehende Vorteilsgeber einen Kontakt zu einem Sportakteur und „erkauft" sich in Form der von diesem zugesagten Schlechtleistung die Voraussicht auf ein bestimmtes Wettbewerbsereignis oder -ergebnis, auf dessen Eintreten er anschließend bei Wettanbietern Einsätze platziert, die zu einem die Höhe

121 Zur Differenzierung Momsen/Vaudlet, in: Emrich/Pierdzioch/Pitsch (Hrsg.), Falsches Spiel, 2015, S. 219 (228 f.); Forrest, in: Breuer/Forrest (Hrsg.), Palgrave Handbook, 2018, S. 91 ff.; ICSS/Sorbonne (Hrsg.) Part I, S. 169. 
der Bestechungssumme übersteigenden Wettgewinn führen sollen. Die Manipulationsabsprache wird dabei kaum einmal schon während eines Erstkontakts zwischen Sportakteur und Vorteilsgeber durch das direkte Angebot von Manipulation bzw. Prämie getroffen werden. Regelmäßig wird ihr eine Phase des Kennenlernens vorausgehen, die ihren Ursprung in einer zufälligen Begegnung, etwa in der Wettszene, oder der gezielten Vermittlung durch einen gemeinsamen Bekannten, etwa einen gut vernetzten ehemaligen Spieler oder Spielerberater, haben kann und während derer durch Andeutungen behutsam die Bereitschaft für wettbezogenes Match Fixing eruiert wird (sog. ,grooming"). ${ }^{122}$ Mitunter wird eine solche Bereitschaft unter Ausnutzung zuvor in Erfahrung gebrachter persönlicher Schwächen oder Krisensituationen des Sportakteurs (z. B. Spielschulden, eingestellte Gehaltszahlungen, atmosphärische Probleme im Team) durch den Vorteilsgeber stimuliert. ${ }^{123}$

Das in Deutschland prominenteste Beispiel dieser Fallgruppe lieferte der in zwei als „Fußball-Wettskandale“ betitelte Manipulationskomplexe verwickelte Ante Sapina. Dieser gewann zunächst im Jahr 2004 unter anderen den DFB-Schiedsrichter Robert Hoyzer gegen Zahlung von Geldbeträgen zwischen 3.000 und 50.000 Euro dazu, mehrere Spiele der Zweiten und Dritten Liga sowie des DFB-Pokals durch Fehlentscheidungen im Sinne der Wetten Sapinas zu manipulieren. ${ }^{124}$ So verhalf Hoyzer etwa dem damaligen Drittligisten SC Paderborn durch zwei fragwürdige Strafstöße und einen gegnerischen Platzverweis zu einem überraschenden Sieg über den favorisierten Hamburger SV in der ersten Pokalrunde. Auch wenn es nicht immer zu einer Auszahlung von Wettgewinnen kam - teilweise ließ sich die verabredete Einflussnahme im Wettbewerb nicht realisieren oder führte nicht zum erhofften Endergebnis, teilweise misslangen die kombinierten Wetten - , erspielte sich Sapina in mindestens 4 Fällen infolge der Manipulation Geldbeträge zwischen 300.000 und 870.000 Euro. ${ }^{125}$

Nur wenige Jahre später wurde Sapina erneut als Teil eines internationalen Netzwerks enttarnt, das im Zeitraum von 2008 bis 2011 unter Einsatz von Bestechungsgeldern in Höhe von jedenfalls 2 Millionen Euro in drei-

122 S. Interpol/IOC (Hrsg.) Handbook, S. $21 \mathrm{f}$.

123 Mutschke, in: Höfling/Horst/Nolte (Hrsg.), Fußball, 2014, S. 41 (42 f.); ausführlich zur Vorgehensweise bei der Anwerbung von Sportakteuren Hill Sichere Siege, S. $147 \mathrm{ff}$.

124 So die Feststellungen in BGHSt 51, 165 (167); ausführlich zum „Wettskandal“ der Saison 2005 und seiner Aufarbeitung Sengle, in: Württembergischer Fußballverband (Hrsg.), Manipulation, 2008, S. 9 (17 ff.).

125 So die Feststellungen in BGHSt 51, 165 (167). 
zehn Ländern insgesamt mindestens 320 Fußballspiele verschiedener Ligen und Pokalwettbewerbe bis in den Juniorenbereich manipuliert haben soll. ${ }^{126}$ Über vorwiegend bei einem asiatischen Anbieter platzierte Wetten soll in diesem aufgrund der von dort betriebenen Strafverfolgung als „Bochum-Fall“ titulierten Manipulationskomplex ein Gesamtprofit von ca. 31 Millionen Euro erzielt worden sein. ${ }^{127}$ Unter den kooperierenden Sportakteuren befanden sich dabei unter anderem Spieler der damaligen Regionalligisten SC Verl und SSV Ulm 1846 sowie der Zweitligisten FC St. Pauli und VFL Osnabrück, die den Erhalt von Manipulationsprämien in Höhe von bis zu 25.000 Euro einräumten. ${ }^{128}$

Neben diesen beiden Manipulationskomplexen, die aufgrund der Betroffenheit heimischer Wettbewerbe gerade hierzulande Aufsehen erregten, liegt das gleiche Muster von durch die Aussicht auf Wettgewinne motivierten Bestechungsprämien in der jüngeren Vergangenheit auch zahlreichen Manipulationen von Spielen der spanischen, ${ }^{129}$ italienischen ${ }^{130}$ und

126 ICSS/Sorbonne (Hrsg.) Part I, S. 7; Forrest, in: Breuer/Forrest (Hrsg.), Palgrave Handbook, 2018, S.91 (95); Presseerklärung von Europol vom 6.2.2013, www.europol.europa.eu/newsroom/news/update-results-largest-football-match-f ixing-investigation-in-europe; die variierenden Zahlen erklären sich durch die unterschiedlich vorgenommene Einbeziehung weiterer Personen und Manipulationsfälle in dieses Netzwerk.

127 Andreff, in: Breuer/Forrest (Hrsg.), Palgrave Handbook, 2018, S. 13 (24); IRIS (Hrsg.) Preventing, S. 43.

128 Schuon belastet Teamkollegen Cichon, Spiegel Online vom 12.1.2011, www.spi egel.de/sport/fussball/wettskandal-prozess-schuon-belastet-frueheren-teamkolleg en-cichon-a-739143.html.

129 Im Jahr 2019 kam es wegen des Vorwurfs wettbezogener Spielmanipulationen in der ersten und zweiten Liga zu Verhaftungen von Spielern und Managern durch spanische Behörden, s. Spaniens Fußball droht ein großer Wettskandal, Faz.net vom 28.5.2019, www.faz.net/aktuell/sport/fussball/manipulation-spanie ns-fussball-droht-ein-grosser-wettskandal-16210886.html.

130 In der Spielzeit 2010/2011 ereignete sich ein als Calcioscomesse bezeichneter Manipulationskomplex, der sowohl wettbezogenes als auch sportlich motiviertes Match Fixing umfasste und in den insgesamt 20 Clubs und 160 Personen - unter ihnen namhafte Akteure wie der Nationalspieler Stefano Mauri und der spätere Nationaltrainer Antonio Conte - in allen vier professionellen italienischen Fußballligen verwickelt gewesen sein sollen. Allein für das Spiel zwischen US Lecce und Lazio Rom sollen 600.000 Euro an Bestechungsgeldern gezahlt worden sein, damit insgesamt mehr als vier Tore erzielt würden. Tatsächlich endete die Begegnung 2:4, was den Initiatoren einen Wettgewinn von 6 Millionen Euro bescherte, s. IRIS (Hrsg.) Preventing, S. 43 f.; Rebeggiani/Rebeggiani, in: Haberfeld/Sheehan (Hrsg.), Match-fixing, 2013, S. 157 (165). 
griechischen ${ }^{131}$ Fußballliga sowie internationaler Qualifikationsrunden ${ }^{132}$ zugrunde. In der Vorgehensweise der Initiatoren zeigt sich dabei mittlerweile eine bemerkenswerte Bandbreite. Neben der „klassischen“ Kontaktierung einzelner Spieler und Schiedsrichter im beschriebenen Stil, die in Teamsportarten noch immer die Unsicherheit einer nicht erfolgreichen Realisierung der Manipulation birgt, sind Gruppen finanzstarker Manipulatoren dazu übergegangen, durch Investments ganze Clubs in unterklassigen oder weniger populären Ligen unter ihre Kontrolle zu bekommen und sodann kontinuierlich über Transfers mit Trainern und Spielern auszustatten, die in ihre manipulativen Ziele eingeweiht sind. ${ }^{133}$ Mitunter werden so auch eigens Spiele unter dubiosen Rahmenbedingungen arrangiert und nach einem von Sportwetten flankierten Drehbuch ausgetragen. Im Februar 2011 traten etwa am selben Tag die Fußballnationalmannschaften von Bolivien und Lettland bzw. von Bulgarien und Estland zu zwei Freundschaftsspielen gegeneinander an, die von einer britischen Briefkastenfirma organisiert worden waren, ohne Werbung und TV-Übertragung stattfanden, von Schiedsrichtern ohne gültige FIFA-Lizenz vor wenigen anwesenden Zuschauern geleitet wurden, dafür aber beträchtliche

131 Im Zuge von Ermittlungen der UEFA wurde im Jahr 2011 eine Liste mit 27 als verdächtig eingeschätzten Spielen aus den ersten beiden Ligen sowie dem griechischen Pokal veröffentlicht. Häufig involviert in die Bestechung von Spielern und Schiedsrichtern waren demzufolge die Clubs Olympiakos Volos und Kavala, die von der Disziplinarkommission des griechischen Ligaverbands mit Punktabzügen verurteilt wurden; s. Duttig Beweismaß, S. 301; ICSS/Sorbonne (Hrsg.) Part 1, S. 181.

132 Der Weltfußballverband FIFA hielt die Manipulation des Qualifikationsspiels für die Weltmeisterschaft 2018 zwischen Senegal und Südafrika durch den ghanaischen Schiedsrichter Joseph Lampertey in Form eines eklatant unberechtigten Strafstoßes zu Gunsten Südafrikas für erwiesen und sperrte ihn auch aufgrund weiterer Vorfälle lebenslänglich, s. CAS 2017/A/5173.

133 So schleuste ein als Investmendfonds auftretender Kreis italienischer Geschäftsmänner zunächst Trainer und Sportdirektor, später zahlreiche Spieler in den spanischen Drittligist Deportivo Eldense ein. Der Verein verlor in der Folge mehrere Ligaspiele der Saison 2016/2017 außergewöhnlich hoch, s. Kistner „Idiot! 4:1 sollte es sein“, Sueddeutsche.de vom 8.4.2017, www.sueddeutsche.de/spo $\mathrm{rt} /$ schiebung-im-fussball-idiot-4-1-sollte-es-sein-1.3456478. Beim finnischen Fußballverein Rovaniemen Palloseura erhielten über drei Jahre hinweg neun Spieler regelmäßig Bestechungsgelder vom singapurischen Spielmanipulator Wilson Raj Perumal, vgl. Gieselmann Die Betrogenen vom Polarkreis, 11Freunde.de vom 12.1.2016, www.11freunde.de/artikel/der-finnische-klub-rops-im-ban n-der-wettmafia. 
Wetteinsätze auf sich zogen. ${ }^{134}$ Sie endeten 2:2 bzw. 2:1, wobei alle sieben Tore aus Elfmetern hervorgingen. Vergleichbar Merkwürdiges ereignete sich bei einem Qualifikationsspiel zu einem unterklassigen, aber immerhin mit 15000 Dollar dotierten ITF-Tennisturnier in Doha, das der Ukrainer Artjom Babmet gegen Krittin Koaykul aus Thailand mit 0:6 und 0:6 verlor. ${ }^{135} \mathrm{Ihm}$ gelang dabei kein einziger Punktgewinn und Videoaufnahmen des Spiels begründen massive Zweifel daran, dass es sich bei Bahmet überhaupt um einen Tennisprofi handelt.

Schon dieser Fall zeigt, dass es sich bei der wettbezogenen Vorteilsgewährung für Spielmanipulationen keineswegs um ein auf den Fußball beschränktes Phänomen handelt. Sie lässt sich auch immer wieder im amerikanischen College-Basketball beobachten, wo bereits in den 1950er Jahren insgesamt 32 Studierende aus sieben verschiedenen Universitäten des sog. Point Shavings gegen Bestechungssummen von wöchentlich 50 US Dollar bis zu einmalig 2.500 US-Dollar pro Spieler und Spiel überführt wurden. ${ }^{136}$ In nahezu jedem folgenden Jahrzehnt ereigneten sich weitere umfangreiche Bestechungsfälle. ${ }^{137}$ Und der Cricketsport wurde 2010 von dem Bericht britischer Investigativjournalisten erschüttert, demzufolge drei pakistanische Nationalspieler um dem Kapitän Salman Butt in einem Freundschaftsspiel gegen England zwei für das Endergebnis unbedeutende Fußfehler (sog. No-Balls) begingen, für deren Zusage sie im Vorfeld von einem vermeintlichen Wettspieler 150.000 Pfund angenommen hatten. ${ }^{138}$ Auch Tennis, Badminton, Snooker und Rugby tauchen in den Meldungen über entsprechende Spielabsprachen vermehrt auf. ${ }^{139}$ Der in all diesen manipulationsbezogenen Absprachen prägende Wetthintergrund wird strafrechtlich von $\$ 265$ c StGB aufgenommen.

134 Vgl. Ludwig in: Kainz/Scherrer/Werner (Hrsg.), Sportfinanzierung, 2012, S. 181 (191).

135 DPA-Meldung vom 12.12.2019, veröffentlicht bei Sueddeutsche.de, www.suedd eutsche.de/sport/tennis-merkwuerdiges-0-6-0-6-weitere-korruption-im-tennis-dpa .urn-newsml-dpa-com-20090101-191212-99-117751.

136 S. Heilemann Bestechlichkeit, S. 77 f.

137 Übersicht bei Maennig Vierteljahreshefte zur Wirtschaftsforschung 73 (2004), $263(266)$.

138 S. Bender Mannigfaltige Manipulationen, Die Tageszeitung vom 14.9.2010, S. 19, https://taz.de/!384899/; vgl. auch die Darstellung bei Duttig Beweismaß, S. 303.

139 Eine Übersicht einschlägiger Meldungen liefert der von Interpol zweiwöchig herausgegebenen Newsletter, Integrity in Sports Bi-weekly Bulletin, www.interp ol.int/Crimes/Corruption/Corruption-in-sport. 
b) Bestechungsprämie zwecks sportlicher Erfolge

Im Gegensatz zu den beschriebenen Wettspielern, die Verlauf oder Ergebnis eines sportlichen Wettbewerbs für eigene finanzielle Gewinne instrumentalisieren, ohne an diesem selbst emotional sonderlich interessiert zu sein, kann gerade auch das Interesse an den sportinternen Auswirkungen eines bestimmten Wettbewerbsergebnisses Bestechungshandlungen veranlassen. Entsprechend orientierte Vorteilsgeber entstammen dabei häufig dem Kreis an Funktionsträgern eines am Wettbewerb beteiligten Vereins oder dem Betreuerstab eines Einzelsportlers. Leitmotiv der ihrerseits initiierten Wettbewerbsmanipulation ist der maximale sportliche Erfolg des eigenen Vereins bzw. des betreuten Athleten, wobei auch dessen hiermit regelmäßig einhergehende wirtschaftliche Besserstellung die Entschlussfassung fördern kann. Der Umsetzung dienen vor allem zwei Formen der Einwirkung: Ein Sieg in einem konkreten Spiel oder Wettbewerb lässt sich entweder durch die verdeckte Auszahlung von Verlustprämien an den unmittelbaren Wettbewerbsgegner erreichen oder durch die Bestechung des Schieds- oder Wertungsrichters, in deren Folge dieser das eigene Team bzw. den unterstützten Athleten regelwidrig bevorzugt. ${ }^{140}$

Mittels Verlustprämien wurde etwa auf den Abstiegskampf der FußballBundesliga in der Saison 1970/1971 Einfluss genommen. Um den Klassenerhalt ihrer Vereine zu sichern, zahlten die Präsidenten bzw. Manager der in der gefährdeten Tabellenregion platzierten Vereine Kickers Offenbach und Arminia Bielefeld vor den finalen Saisonspielen jeweils Bestechungsprämien an einen oder mehrere kooperationsbereite Spieler des kommenden Gegners, damit diese nicht ihre beste Leistung erbringen und das Spiel verlieren würden. ${ }^{141}$ Auf diese Weise erzielte Arminia Bielefeld unter anderem Siege über die mit 40.000 DM bzw. 220.000 DM nahezu komplett be-

140 Als weitere Form der Bestechung aus sportinternen Motiven kann das Gewähren von Siegprämien an Drittvereine angesehen werden, die zu vollem Einsatz in einem Spiel gegen einen tabellarischen Konkurrenten des Vereins motiviert werden sollen, aus dessen Umfeld die Prämie in Aussicht gestellt wird. Solche vereinsfremden Siegprämien zur Verbesserung der eigenen tabellarischen Situation werden aber schon sportrechtlich nicht einheitlich beurteilt, da sie das sporttypische Leistungsprinzip eher verstärken. In dieser Übersicht bleiben sie aufgrund ihrer Irrelevanz für die $\$ \$ 265 c, 265 d$ StGB außen vor. Ausführlich hierzu Bach JR 2008, 57 ff.

141 Zum Sachverhalt und der verbandsrechtlichen Aufarbeitung des BundesligaSkandals von 1970/1971 s. Sengle, in: Württembergischer Fußballverband (Hrsg.), Manipulation, 2008, S. 9 ff.; ein vergleichbares Vorgehen trat jüngst im belgischen Fußball zutage, wo der Erstligist KV Mechelen erwiesenermaßen 
stochenen Teams von Schalke 04 und Hertha BSC, die zum Klassenerhalt führten, ehe Arminia Bielefeld nach Aufdeckung der Vorgänge durch den DFB die Bundesligalizenz entzogen wurde. Auch im internationalen Fußball finden sich Beispiele von durch Verlustprämien manipulierten Spielen zur Erreichung sportlicher Erfolge. So händigte der Präsident des französischen Clubs Olympique Marseille drei Spielern des FC Valenciennes im Mai 1993 jeweils 40.000 Euro für eine schwache Leistung aus, die es den Spielern von Marseille ermöglichte, das Ligaspiel zwischen beiden Teams unter Schonung der Kräfte für das darauffolgende Finale der Champions League zu gewinnen. ${ }^{142}$ Dass es auch unter Sportlern selbst zur Vereinbarung von mitunter spontanen Verlustprämien kommen kann, belegt der Radsport, wo es einer gängigen Praxis entsprechen soll, einen Kontrahenten in einer Fluchtgruppe durch das Angebot von Geld zur Untätigkeit im Zielsprint und dem Verzicht auf den Etappensieg zu verleiten. ${ }^{143}$

Für das Auffinden von Beispielen sportintern motivierter Einwirkungen auf einen Sportrichter genügt ein Blick in die jüngere Sporthistorie. Vom Wunsch nach dem erstmaligen Gewinn der Handball Champions League getragen sollen Manager und Trainer des THW Kiel im Jahr 2007 versucht haben, die polnischen Schiedsrichter des Finalspiels gegen die SG Flensburg Handewitt mittels einer Prämie von 92.000 Euro zu einer Bevorzugung des THW Kiels zu veranlassen. ${ }^{144}$ Nur ein Jahr zuvor wurden dem italienischen Fußballverein Juventus Turin die zwei in den beiden Vorjahren errungenen Meistertitel aberkannt, nachdem sich Vorwürfe gegen dessen Manager Luciano Moggi erhärteten, die Erfolge durch die systematische Bestechung von Schiedsrichtern vorbereitet zu haben. ${ }^{145}$ Bezüglich der Bestechung von Wertungsrichtern lässt sich auf Vorkommnisse während der

Spiele am Ende der Saison 2017/2018 manipulieren wollte, um den sportlichen Abstieg abzuwenden, s. Grabitz/Stolz Skandal im belgischen Fußball: Lug und Trug, Tagesspiegel.de vom 14.10.2018, www.tagesspiegel.de/sport/fc-bruegge-rsc -anderlecht-und-co-im-fokus-skandal-im-belgischen-fussball-lug-und-trug/231836 52.html.

142 S. Forrest, in: Breuer/Forrest (Hrsg.), Palgrave Handbook, 2018, S. 91 (92 Fn. 2).

143 S. Andreff, in: Breuer/Forrest (Hrsg.), Palgrave Handbook, 2018, S. 13 (18); Vgl. auch die gegen Jan Ullrich und Richard Virenque erhobenen Vorwürfe, Der Stern vom 20.6.2001, www.stern.de/sport/sportwelt/radsport-jan-ullrich---verkaufte--et appensiege--3285492.html.

144 S. Heilemann Bestechlichkeit, S. 86; Schmitt/Wulzinger Spur nach Warschau, Der Spiegel, 5/2010, S. $136 \mathrm{ff}$.

145 Zum sog. Calciopoli-Manipulationsskandal s. Schönau Juventus fürchtet um die Trophäen, Süddeutsche.de vom 13.5.2006, www.sueddeutsche.de/sport/wett-ska ndal-juventus-fuerchtet-um-die-trophaeen-1.886152. 
Olympischen Spiele von Seoul 1988 und Salt Lake City 2002 verweisen. Um einen einheimischen Olympiasieger im Supermittelgewichtsboxen präsentieren zu können, erhielten die Kampfrichter des Finalkampfes Bestechungsgelder und erklärten den Koreaner Park Si-Hun in fragwürdiger Weise zum Sieger nach Punkten über den Amerikaner Roy Jones. ${ }^{146}$ In Salt Lake City wiederum soll es zu einer Abmachung zwischen Mitgliedern des französischen und russischen Eiskunstlaufverbandes gekommen sein, in deren Folge eine französische Wertungsrichterin dem russischen Duo Berezhnaya/Sikharulidze mit einer unangemessen hohen Note zum Olympiasieg im Paarlauf verholfen haben soll, während das französische Paar Ainissina/Peizerat ihren Sieg im Finale des Eiskunstlaufs einer auffällig hohen Bewertung eines russischen Wertungsrichters verdankte. ${ }^{147}$ Mit der Charakteristik solcher, jenseits von Sportwetten motivierten Vorteilsgewährungen für wettbewerbsimmanente Schlechtleistungen korrespondiert die tatbestandliche Gestaltung des $₫ 265 \mathrm{~d}$ StGB.

\section{Zusammenfassung}

Von einem offen gehaltenen Begriff der Sportmanipulation ausgehend, eröffnet sich ein weites Feld an Erscheinungsformen. Diese lassen sich auf verschiedenen Ebenen entlang der Kriterien Bezugsobjekt der Manipulation, begünstigter Wettbewerbsteilnehmer, verfolgter Zweck des Manipulators und Motiv eines involvierten Vorteilsgebers systematisieren. Der dabei beschrittene Weg vom Allgemeinen ins Spezielle wurde vorliegend durch den tatbestandlichen Zuschnitt der im Rahmen dieser Arbeit untersuchten Straftatbestände geleitet, deren Anwendungsbereich durch die Ausgrenzung beispielhaft veranschaulichter Fallgruppen zunehmend konturiert werden sollte.

In den besonderen Fokus gerieten auf diese Weise letztlich gegnerbegünstigende oder regelwidrige Wettbewerbsmanipulationen zur Erreichung eines im Rahmen einer vorangegangenen Absprache hierfür in Aussicht gestellten außersportlichen Vorteils, der seinerseits aus außersportli-

146 S. Maennig Vierteljahreshefte zur Wirtschaftsforschung 73 (2004), 263 (267).

147 S. Heilemann Bestechlichkeit, S. 81; insbesondere der französische Verband bestritt eine Absprache vehement. Spätere Ermittlungen legten nahe, dass die Wertungsrichterin womöglich aus dem Umfeld der russischen Organisierten Kriminalität erpresst worden sei, s. Spiegel Online vom 1.8.2002, www.spiegel.d e/sport/sonst/olympia-skandal-die-spur-fuehrt-zur-russenmafia-a-207706.html. 
chen oder sportimmanenten Motiven heraus gewährt werden kann. Diese von den $\$ \$ 265 c$, 265d StGB adressierte Fallgruppe setzt also zunächst eine finanzielle Außensteuerung des manipulierenden Sportakteurs voraus und ist sodann je nach einem vorhandenen Bezug zu Sportwetten zu differenzieren. Sie kann sportartübergreifend in Erscheinung treten und entspricht zugleich den oben beschriebenen Definitionsmerkmalen des Match Fixing und der unmittelbar wettkampfbezogenen Sportkorruption.

Personell verlangt ihre Struktur mindestens einen mit der Möglichkeit zur unmittelbaren Einflussnahme auf das Wettkampfgeschehen ausgestatteten Sportakteur. Dies trifft jedenfalls auf Sportler, Trainer und Schiedsrichter, in bestimmten Fällen auch auf enge Betreuer oder Vereinsfunktionäre zu. Als ihr Partner im Rahmen der die Manipulation initiierenden korruptiven Abrede kommt grundsätzlich jedermann in Betracht. Über die Motivlage des Vorteilsgebers werden die Manipulationen dabei häufig in den direkten Zusammenhang mit Sportwetten gestellt. Aber auch eine Initiierung aus sportinternen Motiven heraus ist denkbar. Die der Sporthistorie entnommenen Beispielsfälle zeigen, dass der Vorteilsgeber in diesen Fällen häufig dem direkten Umfeld eines Wettbewerbsteilnehmers angehört.

Im weiteren Verlauf der Untersuchung wird - wie auch bereits in der Einleitung - für diese gesetzlich adressierte Fallgruppe der absprachebasierten Sportmanipulationen der Begriff des Match Fixing verwendet. Dies erfolgt in Kenntnis der streng genommen nicht vollständigen inhaltlichen Übereinstimmung und der weiteren bereits angeführten Einwände ${ }^{148}$ aus Gründen der Prägnanz und der international geläufigen Bezeichnung des Phänomens. Soweit im Folgenden der Begriff Match Fixing erkennbar als Oberbegriff der gesetzlich adressierten Manipulationen verwendet wird, schließt er das für Verlaufsmanipulationen präzisierende Spot Fixing ein und soll sich auch auf Sportarten beziehen, deren Wettbewerbe gemeinhin nicht als „Matches“, sondern als „Rennen“, „Läufe“ oder „Kämpfe“ bezeichnet werden.

III. Bedingungsfaktoren von Match Fixing und Erklärungsansätze

Im Rahmen der Differenzierung der Erscheinungsformen wurden die hier fokussierten bestechungsbedingten Schlechtleistungen von Sportakteuren bereits kurz kontextualisiert und die Motive der beteiligten Protagonisten

Vgl. oben Teil 2 A. I. 3. 
angedeutet. Dies soll im Folgenden ausgeführt werden. Anhand der Darstellung äußerer Bedingungsfaktoren und der Bewertung eines hieran angepassten Erklärungsansatzes für diese Art des abweichenden Verhaltens im Sport sollen die Entstehungsprozesse dieser Sportmanipulationen verdeutlicht werden, deren Verständnis für eine nachfolgende Befassung mit geeigneten Reaktionsformen unverzichtbar ist.

\section{Bedingungsfaktoren}

Unter Bedingungsfaktoren werden hier bestimmte Begleiterscheinungen des modernen Sports verstanden, die für das untersuchte Match Fixing in beiden Richtungen von entscheidender Bedeutung sein können, indem sie etwa diesbezügliche Anreize und günstige Tatgelegenheiten schaffen oder aber Anreize nivellieren und die Wahrnehmung einer Tatgelegenheit erschweren. Im Folgenden sollen der Sportwettenmarkt als wichtiges Bezugssystem für wettbezogene Manipulationen, die Kommerzialisierung des Sports als möglicher Katalysator sportintern motivierter Bestechungsprämien sowie vorerst nur andeutungsweise die Selbstregulierung der Verbände hinsichtlich Manipulationsabsprachen in ihrer jeweiligen Ausprägung und deren manipulationsbezogenem Einfluss dargestellt werden.

\section{a) Entwicklung und Zustand des Sportwettenmarkts}

Ein Anteil der hier untersuchten Manipulationen wird durch die Aussicht angetrieben, mit ihrer Hilfe sichere finanzielle Gewinne durch Sportwetten erzielen zu können. Dies bedingt jedoch zunächst die Existenz eines für Manipulatoren zugänglichen Markts für Sportwetten, auf dem Wetten für grundsätzlich manipulierbare Ereignisse innerhalb bestimmter sportlicher Wettbewerbe angeboten werden. Gestalt und Mechanismen des Sportwettenmarkts stellen demnach einen maßgeblichen Bedingungsfaktor für wettbezogenes Match Fixing dar.

aa) Wachstumsexplosion infolge Deregulierung und neuer Technologien

Ausgelöst von einem politischen Kurswechsel, vor allem aber von technologischen Entwicklungen hat der Markt für Sportwetten in den vergangenen zweieinhalb Jahrzehnten national wie international gravierende Ver- 
änderungen erfahren. Historisch gesehen unterlagen Sportwetten als Ausprägung des Glücksspiels nahezu überall aus moralischen, religiösen oder gesundheitsschützenden Gründen einer strengen staatlichen Regulierung, die sich noch heute vielerorts in staatlichen Monopolen in Form der $\mathrm{Zu}$ lassung lediglich eines einzelnen staatlichen Wettanbieters oder gänzlichen Glücksspielverboten ausdrückt. ${ }^{149}$ Gerade innerhalb der Europäischen Union geriet dieser prohibitive Ansatz mit Verweis auf die Wettbewerbsfreiheit durch Gerichte und internationale Organisationen wie die Welthandelsorganisation zunehmend unter Druck. ${ }^{150}$ Versuche einer sanften Marktöffnung führten daraufhin in mehreren EU-Staaten, darunter Deutschland, zum zumindest temporär genehmigten Eintritt privater Wettanbieter. ${ }^{151}$ Der interessierte Wettkunde war fortan nicht mehr an einen Anbieter gebunden, sondern konnte verschiedene Angebote vergleichen.

Den staatlichen Kurswechsel mitbestimmend und für die Erscheinungsform des Sportwettenmarkts von noch drastischerer Auswirkung war indes die Verbreitung des Internets. Die Ersetzung des Gangs zu einem stationären Wettbüro durch den unkomplizierten Zugang zu einem Online-Anbieter, bei dem Wetten anonym, rund um die Uhr per Smartphone und aufgrund geringerer Transaktionskosten auch zu kundenfreundlicheren Quoten platziert werden können, sorgte für einen extremen Anstieg der Nachfrage nach Sportwetten. ${ }^{152}$ Dieser führte nicht nur zu einer regelrechten Explosion der Anzahl von gar nicht oder lediglich in einzelnen sog. Offshore Ländern mit geringer Steuerpflicht und Regulation lizensierten Anbietern, sondern auch zu einer Erweiterung deren Sortiments. ${ }^{153}$ Die lange Zeit dominierende 1 x 2-Siegwette, die den Wettenden drei mögliche Aussagen hinsichtlich des Ausgangs eines Spiels eröffnet $(1=$ Sieg des erstgenannten Akteurs, 2 = Sieg des letztgenannten Akteurs, $\mathrm{x}=$ Unentschieden) und etwa durch das zur Deutschen Klassenlotterie gehörende Angebot ODDSET lange Zeit nur in Kombination mit anderen Spielen angenommen worden war, wurde nun nicht nur als Einzelwette mit konkre-

149 Vgl. die Übersicht bei IRIS (Hrsg.) Preventing, S. 35.

150 Andreff Systems 2017, 5(1), 12, S. 3.

151 Vgl. die amtliche Erläuterung zum Ersten Staatsvertrag zur Änderung des Staatsvertrages zum Glücksspielwesen in Deutschland, Erster GlüÄndStV v. 7.12.2011, S. 7 f.; ausführlich zu Entwicklung und aktuellem Stand der Sportwettenregulierung in Deutschland s. unten Teil 3 C. II. 1. d).

152 Forrest/McHale/McAuley International Journal of Sport Finance 2008, 156 (159).

153 S. dazu Andreff Systems 2017, 5(1), 12, S. 3 f.; ICSS/Sorbonne (Hrsg.) Part I, S. 75; außerdem die Tabelle bei IRIS (Hrsg.) Preventing, S. 28. 
ten Ergebnistipps und zu festen Quoten angeboten, sondern durch mehrere gänzlich neue und dynamische Wettformen ergänzt, die die Gewinnchancen der Wettenden zumindest theoretisch verbessern und insbesondere bei Spielen mit klarer Verteilung der Favoritenrolle Spannung versprechen. ${ }^{154}$

Form- und Qualitätsunterschiede der sportlichen Kontrahenten von vornherein auszugleichen versucht etwa die sog. Asian Handicap-Wette, die dem Außenseiter noch vor Beginn eines Spiels einen fiktiven Vorsprung in Form einer Tor- oder Punktanzahl gewährt, der schließlich auf das reale Endergebnis addiert wird. ${ }^{155}$ Anfänglich werden also beide Teams von den Buchmachern mit annähernd gleichen Siegquoten bedacht. Die Festsetzung des einbezogenen Handicaps mit einer relativen Zahl - z.B. Begünstigung des Außenseiters mit einem Vorsprung von 0,5 oder 1,5 Toren - eliminiert zudem ein Unentschieden und reduziert die Wettform von drei auf zwei mögliche Spielausgänge. In die Kategorie der Zwei-Weg-Wetten fallen auch die von tatsächlichem Sieger und Verlierer eines sportlichen Wettkampfs noch weiter abgelösten sog. Over/UnderWetten. ${ }^{156}$ Hier bezieht sich die Wettaussage des Wettenden darauf, ob ein bestimmter zählbarer Wert im Rahmen des sportlichen Wettbewerbs überoder unterboten wird. Bei der vom Buchmacher festgesetzten Bezugsgröße kann es sich beispielsweise um die Anzahl der in einem Spiel insgesamt erzielten Tore bzw. Punkte oder um die Anzahl der Einzelspiele in einem Tennismatch handeln. Schließlich werden inzwischen auch Wetten auf den Eintritt einzelner, vom Endergebnis gänzlich entkoppelter Spielereignisse wie Eckstöße, Einwürfe, Abseitsstellungen oder gelbe bzw. rote Karten angeboten. ${ }^{157}$

Neben diesen Erweiterungen des inhaltlichen Angebots haben sich im Zuge der Digitalisierung des Sportwettenmarkts auch neue Möglichkeiten für dessen Wahrnehmung in zeitlicher Hinsicht ergeben. Eine Wette muss nicht mehr vor Beginn des entsprechenden Wettbewerbs abgegeben worden sein, sondern lässt sich jetzt auch während eines laufenden Wettbe-

154 S. auch die Tabelle bei IRIS (Hrsg.) Preventing, S. 28.

155 Spöring, in: Kainz/Scherrer/Werner (Hrsg.), Sportfinanzierung, 2012, S. 103 (106); hierzu auch LG Bochum vom 19.5.2011 - 12 KLs 35 Js 141/10 - 16/11 Rz 90.

156 Hierzu Spöring, in: Kainz/Scherrer/Werner (Hrsg.), Sportfinanzierung, 2012, S. 103 (106f.).

157 Spöring, in: Kainz/Scherrer/Werner (Hrsg.), Sportfinanzierung, 2012, S. 103 (106); Übersicht zu den im Fußball angebotenen Ereigniswetten bei Van Rompuy Spielmanipulationen S. 17. 
werbs platzieren. Solche Live-Wetten basieren auf der Annahme eines in der medialen Verfolgung eines Sportevents liegenden Anreizes, durch zeitgleiche eigene Wetten an diesem gewissermaßen aktiv mitzuwirken und Nervenkitzel und Unterhaltungswert der Betrachtung hierdurch zu steigern. Ihre Aufnahme verdanken die Anbieter der Entwicklung leistungsstarker Rechenprogramme, die auf der Basis von Algorithmen die Quoten für die einzelnen im Angebot befindlichen Wettaussagen automatisch und in Echtzeit an den Verlauf eines Spiels anpassen. ${ }^{158}$

Infolge der durch Deregulierung und Digitalisierung begünstigten, sich gegenseitig stimulierenden Angebot und Nachfrage verzeichnet der Markt für Sportwetten ein rasantes Wachstum, das sich statistisch belegen lässt. Global betrachtet stieg der jährliche Wert der Bruttospielerträge (BSE), die die von den Wettanbietern einbehaltene Summe nach Auszahlung aller Wettgewinne beschreibt und als verlässlicher Indikator für die Größe des Sportwettenmarkts gilt, von 6 Milliarden Euro im Jahr 2000 auf 30 Milliarden Euro im Jahr 2016. ${ }^{159}$ Die Gesamtsumme weltweit getätigter Einsätze auf Sportwetten betrug 2016 schätzungsweise 478 Milliarden Euro. ${ }^{160} \mathrm{Da}-$ von entfielen bereits über zwei Drittel auf Live-Wetten. ${ }^{161}$ Deutschland rangiert in der von China und den USA angeführten internationalen Rangliste auf Platz 13. ${ }^{162}$ Der für das Jahr 2018 ausgewiesene landesweite BSE-Wert von knapp über 1,2 Milliarden Euro bedeutet eine Zunahme von ca. $85 \%$ im 5-Jahresvergleich zu 2013. ${ }^{163}$ Damit handelt es sich bei Sportwetten um das am stärksten wachsende Marktsegment innerhalb des deutschen Glücksspielmarkts. Von den geschätzten jährlichen Gesamtwetteinsätzen, die sich im Jahr 2018 laut dem Statistikportal „statista“ auf 8,8 Milliarden Euro addierten, ${ }^{164}$ erfolgen ca. $35 \%$ über den Online-Vertriebsweg. ${ }^{165}$ Von den in Deutschland getätigten Sportwetteinsätzen entfallen knapp drei Viertel auf die Sportarten Fußball (54,5\%) und Tennis

158 Forrest, in: Breuer/Forrest (Hrsg.), Palgrave Handbook, 2018, S. 91 (101).

159 Forrest, in: Breuer/Forrest (Hrsg.), Palgrave Handbook, 2018, S. 91 (100).

160 IRIS (Hrsg.) Preventing, S. 40.

161 Vgl. Forrest, in: Breuer/Forrest (Hrsg.), Palgrave Handbook, 2018, S. 91 (102); ebenso die Schätzung des Deutschen Sportwettenverbands, s. Haucap/Nolte/ Stöver (Hrsg.) Faktenbasierte Evaluierung, S. 111.

162 IRIS (Hrsg.) Preventing, S. $40 \mathrm{f}$.

163 Glücksspielaufsichtsbehörden der Länder (Hrsg.) Jahresreport 2018, S. 6, 12 bzw. Jahresreport 2014, S. 8, 13.

164 Statistikportal „statista“, https://de.statista.com/statistik/daten/studie/557955/um frage/wetteinsaetze-auf-dem-deutschen-sportwettenmarkt/.

165 Glücksspielaufsichtsbehörden der Länder (Hrsg.) Jahresreport 2017, S. 6, 12. 
$(17,1 \%) .{ }^{166}$ Allein während der Fußball-Weltmeisterschaft 2018 wurden hierzulande auf die 64 Turnierspiele 700 Millionen Euro gesetzt. ${ }^{167}$ Auch global betrachtet nimmt Fußball bei der sportartspezifischen Verteilung der Wetteinsätze den Spitzenplatz ein, gefolgt von Tennis, Kricket und Basketball.

Relativierend muss bei der Interpretation dieser Zahlen allerdings beachtet werden, dass sie als Aussagen über Umfang und Entwicklung des Sportwettenmarkts die nur schätzungsweise zu bestimmende Größe der jeweiligen Schwarzmärkte einbeziehen. Als Form des Glücksspiels bleiben Sportwetten genehmigungspflichtig. Trotz der mancherorts beobachtbaren Auflockerung von Wettverboten und staatlichen Wettmonopolen existiert nach wie vor ein nicht-regulierter Sportwettenmarkt von beträchtlichem Ausmaß. Diesem unterfallen Angebote für Sportwetten, für die die Anbieter nicht über die erforderliche Erlaubnis der staatlichen Behörde verfügen, sowie Angebote, die schlechterdings verboten sind.

In Deutschland lässt sich der nicht-regulierte Markt dementsprechend noch einmal in einen Grau- und einen Schwarzmarkt untergliedern. Während dem Graumarkt solche Wettanbieter angehören, die zumindest in anderen EU-Mitgliedsländern über Lizenzen für Sportwettenangebote verfügen und der dortigen regulatorischen Überwachung unterliegen, umfasst der Schwarzmarkt Sportwetten, die in der gesamten EU nicht lizensiert sind und illegal angeboten werden. ${ }^{168} \mathrm{Da}$ die in Deutschland populären privaten Sportwettanbieter bis zum Abschluss eines im Glücksspielstaatsvertrag (GlüStV) geregelten Konzessionsverfahrens gegenwärtig lediglich mit einer temporären Ausnahmeerlaubnis ausgestattet sind, werden sie aufgrund der ihnen zumeist in Malta oder Gibraltar erteilten EU-Lizenzen dem Graumarkt zugeschlagen. ${ }^{169}$ Dies hat zur Folge, dass hierzulande ca. $95 \%$ der benannten Bruttospielerträge im Bereich Sportwetten auf das nicht-regulierte Marktsegment entfallen, wobei sich die Verteilung bereits

166 Bundesministerium für Wirtschaft und Energie (Hrsg.), Wirtschaftsfaktor Sportwetten, S. 6.

167 Wilmroth So viel verwetten die Deutschen bei der WM, Sueddeutsche.de vom 14.7.2018, www.sueddeutsche.de/wirtschaft/gluecksspiel-so-viel-verwetten-die-de utschen-bei-der-wm-1.4052568.

168 Haucap/Nolte/Stöver (Hrsg.) Faktenbasierte Evaluierung, S. 99.

169 Glücksspielaufsichtsbehörden der Länder (Hrsg.) Jahresreport 2018, S. 5. Ausführlich zu Entwicklung und gegenwärtigem Stand der Glücksspiel- und Sportwettenregulierung s. unten Teil 3 C. II. 1. d). 
seit mehreren Jahren stark zu dessen Gunsten verschiebt. ${ }^{170}$ Wenngleich nicht ganz diesen Wert erreichend weist auch die Untersuchung des globalen Sportwettenmarkts dem illegalen Segment beträchtliche Anteile an den erzielten Bruttospielerlösen (50\%) und dem Gesamteinsatzvolumen (82\%) zu. ${ }^{171}$ Unter den vier Ländern mit den weltweit höchsten Bruttospielerlösen auf illegalen Märkten sind mit China, Südkorea und Hongkong drei Länder aus Asien vertreten, wo eine große kulturelle Affinität der Bevölkerung zum Glücksspiel auf das Fehlen attraktiver regulierter Angebote und einen geringen staatlichen Einsatz bei der Bekämpfung illegaler Märkte trifft. ${ }^{172}$

Das Ausmaß an Wetttätigkeit in illegalen Märkten überrascht indes kaum. Noch immer prohibitiv ausgestaltete Regulierungskonzepte lenken die große Nachfrage nach Sportwetten in Schattenmärkte. Selbst in Ländern, in denen private Sportwettanbieter prinzipiell zugelassen sind, wird deren Wettprogramm aufgrund des Schutzes der Bevölkerung vor Spielsucht erheblichen Beschränkungen unterworfen. $\mathrm{Zu}$ diesen zählen etwa Verbote der beliebten Live- und Ereigniswetten sowie die Festsetzung strenger Einsatzlimits für Wettkunden. ${ }^{173}$ Zudem schütten illegale Anbieter mangels Steuerabgaben und unter dem Druck breiter Konkurrenz einen erheblich größeren Anteil der eingenommenen Einsätze wieder an die Wettkunden aus und bieten daher günstigere Quoten an. ${ }^{174}$

Ergänzt wird die hieraus resultierende Attraktivität illegaler Märkte durch deren vergleichsweise einfache Zugänglichkeit. Entsprechende Angebote lassen sich mitunter online über einzig an Offshore-Standorten lizensierte Websites erreichen oder in bestimmten stationären Wettannahmestellen wahrnehmen. Sind diese Zugänge aufgrund von Internetsperren und eines konsequenten staatlichen Vorgehens gegen illegale Wettbüros versperrt, ermöglichen auf die Vermittlung von Wetten spezialisierte Agenturen Umwege insbesondere zu den großen illegalen Wettmärkten in Asien. ${ }^{175}$ Diese sind pyramidal strukturiert und verbinden über mehrere

170 Glücksspielaufsichtsbehörden der Länder (Hrsg.) Jahresreport 2018, S. 6, 12; Haucap/Nolte/Stöver (Hrsg.) Faktenbasierte Evaluierung, S. 105 f. mwN.

171 IRIS (Hrsg.) Preventing, S. 40.

172 S. ICSS/Sorbonne (Hrsg.) Part I, S. 82.

173 Vgl. etwa in Deutschland die Beschränkung in $\$ 21$ GlüStV.

174 Der Unterschied in der Auszahlungsquote soll dabei ca. $14 \%$ betragen, s. IRIS (Hrsg.) Preventing, S. 40.

175 Schätzungen zufolge werden ca. $70 \%$ des Wettumsatzes im Fußball inzwischen bei asiatischen Buchmachern platziert, s. Sportradar (Hrsg.) World Match Fixing, S. 10. 
hierarchische Ebenen von Agenten ein Netzwerk von Straßenhändlern mit einem kooperierenden, nicht lizensierten Online-Wettanbieter, der hierüber in den für ihn gesperrten Markt gelangt. ${ }^{176}$ Die Wetten des Kunden werden dabei häufig durch einen sog. Runner auf Anweisung des Wettagenten platziert. ${ }^{177}$ Auf diese Anonymität zusichernde und kaum zurückzuverfolgende Weise gingen etwa auch die Initiatoren des erwähnten Fußball-Manipulationsskandals von 2011 („Bochum-Fall“) vor, die die Wetten auf die von ihnen manipulierten Spiele über ein in London ansässiges Vermittlerunternehmen in Asien platzieren ließen. ${ }^{178}$ Die ihnen dabei angebotenen Quoten waren selbst zuzüglich des vom Vermittler für seine Dienste addierten Aufpreises erheblich attraktiver als auf dem europäischen Wettmarkt.

\section{bb) Ableitung für die Gefahr des Match Fixing}

Die dargestellte Entwicklung eines rasant anwachsenden, globalisierten und sich in unterschiedliche Segmente aufteilenden Sportwettenmarkts beeinflusst zweifelsohne die Entstehungsbedingungen von wettbezogenem Match Fixing. Es liegt dabei nahe, aus den beschriebenen Veränderungen eine erhöhte Gefährdung der Integrität des Sports abzuleiten, da sie in mehrerer Hinsicht die Anreize für die Initiierung von Wettbewerbsmanipulationen erhöht und deren Umsetzung und Ausnutzung auf dem Wettmarkt erleichtert haben dürften. Zuvörderst ist hierbei der mit dem immens ansteigenden Gesamtvolumen an Wetteinsätzen einhergehende $\mathrm{Zu}$ wachs an Liquidität in den Wettmärkten zu nennen. Ein Wettmarkt mit höherem Transaktionsvolumen ermöglicht die Platzierung hoher Einsätze auf manipulierte Spiele, ohne dass hierdurch die Wettquoten der Buchmacher in eine ungünstige Richtung verschoben oder die Einsätze den das Wettverhalten analysierenden Wettanbietern auffallen würden. ${ }^{179}$ Der

176 Vgl. IRIS (Hrsg.) Preventing, S. 52; Van Rompuy, in: Transparency International (Hrsg.), Corruption Report, 2016, S.236f.; ausführlich zur Beschreibung des Systems und ihrer Beziehung zum Begriff der Organisierten Kriminalität unten Teil 3 C. II. 1. a) bb) (3) ( $\mathrm{y}$.

177 Vgl. IRIS (Hrsg.) Preventing, S. 52.

178 LG Bochum vom 19.5.2011 - 12 KLs 35 Js 141/10 - 16/11 Rz 96; Andreff Systems 2017, 5(1), 12, S. $4 \mathrm{f}$.

179 ICSS/Sorbonne (Hrsg.) Part II, S. 29 ff.; Forrest/McHale/McAuley International Journal of Sport Finance 2008, 156 (158); van Rompuy Spielmanipulationen, S. 15 . 
über ggf. mehrfache Vermittlung internationaler Akteure genutzte $\mathrm{Zu}$ gang zu Märkten, deren komplexe Organisationsstruktur kaum eine effektive Überwachung zulässt, ist der Verschleierung von Geldströmen ebenfalls zuträglich. ${ }^{180}$ Außerdem bieten gerade diese Märkte mit ihrer Identitätsverschleierung, hohen Ausschüttungsquote und der häufig getätigten Umwandlung von eingezahltem Bargeld in elektronisches Guthaben bei einem Online-Wettanbieter günstige Bedingungen für Geldwäsche, die ebenfalls mit Match Fixing verbunden sein kann. ${ }^{181}$

Neben diesen allgemeinen Kennzeichen des entwickelten Wettmarkts wird auch dessen spezifischer Angebotserweiterung ein nicht unerhebliches Gefährdungspotenzial für die Integrität sportlicher Wettbewerbe zugesprochen. Dies wird zunächst auf die zunehmende Aufnahme unterer Ligen und zweitklassiger Wettbewerbe in das verfügbare Wettangebot bezogen. Aus der geringeren öffentlichen Beachtung solcher Wettbewerbe und der regelmäßig niedrigeren Bezahlung der dort aktiven Sportakteure, die sie für Bestechungsprämien empfänglicher werden ließe, resultiere eine erhöhte Anfälligkeit für Manipulationsversuche. ${ }^{182}$ Eine solche würde auch durch die Implementierung neuer Wettformen wie Handicap-, Over/ Under-, Ereignis- und Live-Wette begründet. Schließlich sei gerade in Teamsportarten, deren Verlauf von vielen Faktoren und Personen abhänge, eine Absprache über ein einzelnes Spielereignis oder dessen vorgegebene Häufung leichter zu treffen und durch den Sportakteur umzusetzen als die manipulative Herbeiführung eines bestimmten Endergebnisses. ${ }^{183}$ Die vereinbarte Schlechtleistung könne sich auf einzelne Spielsituationen beschränken und würde nicht automatisch den sportlichen Erfolg des manipulierenden Akteurs verhindern. Live-Wetten beinhalteten dabei die zusätzliche Gefahr, dass Schwankungen der Quoten durch ein mit dem Sportakteur genau abgesprochenes Wechselspiel von vollem und reduziertem Wettkampfeinsatz ausgenutzt würden, um den Gewinn zu maximieren. ${ }^{184}$ Zudem ließen sich verdächtige Wettmuster in der hohen Frequenz getätigter Einsätze schwerer nachvollziehen. ${ }^{185}$

180 Forrest/McHale/McAuley International Journal of Sport Finance 2008, 156 (159).

181 Vgl. IRIS (Hrsg.) Preventing, S. 40, 45, 55; Andreff Systems 2017, 5(1), 12, S. 5 f.

182 Forrest/McHale/McAuley International Journal of Sport Finance 2008, 156 (159).

183 Adams/Rock ZfWG 2010, 381 (384f.); Streinz/Liesching/Hambach/Bolay/Pfütze $\$ 21$ GlüStV Rn. 22.

184 ICSS/Sorbonne (Hrsg.) Part I, S. 106; Forrest/McHale Journal of Management Mathematics 2019, 1 (13f.).

185 Van Rompuy Spielmanipulationen, S. 5 f. 
Wenngleich diese Annahmen zunächst plausibel klingen, ist die Ableitung eines gerade durch die neuen Wettformen geschaffenen Manipulationsrisikos differenziert zu betrachten. Denn die beschriebenen manipulationsbegünstigenden Faktoren des Wettmarkts schließen sich insbesondere im Bereich der Ereigniswetten gegenseitig aus. Da zum einen insgesamt weniger Wettkunden auf einzelne Ereignisse wetten, zum anderen die oberen Einsatzlimits bei Ereigniswetten von den Anbietern im Vergleich zu vor dem Wettbewerb abgeschlossenen Ergebniswetten signifikant gedeckelt werden, fällt das Gesamtaufkommen an Wetteinsätzen im Markt bedeutend geringer aus. ${ }^{186}$ Die Einsatzlimits reduzieren nicht nur die Gewinnaussichten bei einer Ereigniswette und somit die wirtschaftlichen Anreize einer manipulativen Absprache. ${ }^{187}$ Den gleichwohl getätigten Einsätzen wird auch der Deckmantel einer hohen Marktliquidität entzogen. So konnte dem Snooker-Spieler Stephen Lee wettbezogenes Match Fixing nachgewiesen werden, nachdem auf die Wettaussage, er werde bei den UK Championship im Jahr 2008 in seinem Erstrundenspiel den ersten Frame verlieren, insgesamt knapp 3.500 Pfund an Einsätzen platziert wurden, während in keinem der übrigen 15 Erstrundenmatches auf das Ereignis "Gewinn des ersten Frame“ mehr als 100 Pfund gesetzt wurden. ${ }^{188}$

Die technisch wie moralisch leichtere Umsetzbarkeit des bloßen Spot Fixing auf dem Sportfeld wird durch eine reduzierte Profitabilität und ein erhöhtes Entdeckungsrisiko begleitender Einsätze auf dem Wettmarkt ausgeglichen. Bei Handicap- oder Over/Under-Wetten wird der manipulationsbezogene Vorteil einer Trennung von Spielgewinn und Wettgewinn von einer insbesondere auf die Beliebtheit der Wettformen im asiatischen und nordamerikanischen Raum zurückzuführenden hohen Liquidität flankiert. Auf einem Index, der über die Aspekte der Kosten einer Manipulation, deren Erfolgs- und Aufdeckungswahrscheinlichkeit, deren Schweregrad und der Liquidität des Wettmarkts den Grad der von einzelnen Wettformen ausgehenden Gefahren anzugeben versucht, wird ihnen daher ein höherer Gesamtscore zugewiesen als den Ereigniswetten. ${ }^{189}$

In diesem Sinne vorhersehbar konnten Studien bisher auch keinen signifikanten Zusammenhang von wettbezogenem Match Fixing und Ereig-

186 Forrest/McHale/McAuley International Journal of Sport Finance 2008, 156 (162); Spöring, in: Kainz/Scherrer/Werner (Hrsg.), Sportfinanzierung, 2012, S. 103 (106); dies statistisch belegend Van Rompuy Spielmanipulationen, S. $16 \mathrm{ff.}$

187 Haucap/Nolte/Stöver (Hrsg.) Faktenbasierte Evaluierung, S. 206.

188 Forrest/McHale Journal of Management Mathematics 2019, 1 (6).

189 ICSS/Sorbonne (Hrsg.) Part II, S. 66 f. 
niswetten feststellen. Vielmehr zeigte eine Auswertung der von Überwachungssystemen des Sportwettenmarkts aufgrund von Unregelmäßigkeiten als hochverdächtig eingeschätzten Fußballspiele, dass sich die wettbezogene Ausnutzung verabredeter Manipulationen im Fußball weit überwiegend über die Wettformen der herkömmlichen Siegwette, der AsianHandicap Wette sowie vor allem der Wette auf die Gesamttoreanzahl (z.B. Over/Under 2,5 Tore), vollzieht, wohingegen Ereigniswetten von den Manipulatoren überwiegend ignoriert werden. ${ }^{190}$ Verdächtige Live-Wetten wurden zwar bei einem deutlich größeren Anteil der wahrscheinlich manipulierten Spiele registriert, erfolgten aber zumeist in Kombination mit zuvor bereits abgeschlossenen Pre-Match-Wetten, so dass jedenfalls ein spezifisches Integritätsrisiko durch Live-Wetten empirisch nicht belegt ist. ${ }^{191}$

Schließlich ist zu beachten, dass sich die Gefährdungspotenziale nicht allein aus den systemischen Veränderungen des expandierten Wettmarkts ergeben, sondern auch aus den hierdurch stimulierten Motivlagen der für eine wettbezogene Spielmanipulation relevanten Personenkreise. So ist etwa ein neuer Typus an Wettspieler entstanden, der Sportwetten nicht mehr zum Freizeitvergnügen, sondern nahezu professionell betreibt. ${ }^{192}$ Ein großer Anteil der insgesamt registrierten Wetttätigkeit lässt sich auf einen geringen Prozentsatz an Wettkunden zurückführen. Diese Gruppe platziert Wetten in hohem Volumen ohne emotionale Teilnahme an dem bewetteten sportlichen Ereignis und begreift Sportwetten als einen Finanzmarkt, auf dem sich durch vergleichende Analysen und strategisches Vorgehen beträchtliche Gewinne abschöpfen lassen. Eine derart profitorientierte Herangehensweise impliziert zumeist auch eine Befassung mit den Schwachstellen des Systems und kann mittelfristig zur Erwägung von manipulativer Einflussnahme auf das bewettete Ereignis verleiten.

Auf Seiten der Sportakteure können indes verschiedene mittelbare Effekte der veränderten Konstitution des Sportwettenmarkts eine gesteigerte Kooperationsbereitschaft für manipulative Absprachen hervorrufen. Zum einen können ihnen aufgrund der auf dem liquiden Sportwettenmarkt nun erzielbaren Gewinne durch Vorteilsgeber höhere Bestechungsprämien für manipulative Einwirkungen in Aussicht gestellt werden. ${ }^{193}$ Zum anderen ist Untersuchungen und Aussteigerberichten zufolge unter Profisportlern exzessives und problematisches Spielverhalten in Bezug auf Sportwet-

190 Von Rompuy Spielmanipulationen, S. $29 \mathrm{f}$.

191 Von Rompuy Spielmanipulationen, S. $28 \mathrm{ff}$.

192 Andreff Systems 2017, 5, 12, S. 4; ICSS/Sorbonne (Hrsg.) Part II, S. 9 ff.

193 Forrest/McHale/McAuley International Journal of Sport Finance 2008, 156 (158). 
ten überproportional verbreitet. ${ }^{194}$ Dieses kann zu finanziellen Notlagen führen, die die Empfänglichkeit für Manipulationsprämien ausdehnen, wie nicht nur die bereits erwähnten Fälle des NBA-Schiedsrichters Tim Donaghy und des in den Manipulationsskandal von 2011 verwickelten Fußballprofis Rene Schnitzler zeigen, deren Prämien teilweise im Erlass von angehäuften Wettschulden bestanden. ${ }^{195}$ Zudem verfügen die betroffenen Sportakteure infolge ihres Hobbies teilweise über direkte persönliche Kontakte zu den Betreibern von Wettshops und in die Szene professioneller Wettspieler hinein. Diese natürlichen Berührungspunkte zwischen den in eine wettbezogene Spielmanipulation überwiegend involvierten Personengruppen können die Anbahnung einer korruptiven Abrede erleichtern. So kannten sich auch Robert Hoyzer und Ante Sapina bereits seit geraumer Zeit aus einem von Sapinas Bruder betriebenen Wettcafé, ehe sie gemeinsam den Entschluss zu Spielmanipulationen fassten.

\section{b) Kommerzialisierung des Sports}

Obwohl bereits im antiken Sport unlautere Einwirkungen auf Wettbewerbe verzeichnet wurden, ist Match Fixing heutzutage auch stets vor dem Hintergrund der kommerzialisierten Rahmenbedingungen des Sports zu sehen. Ausgelöst durch das Interesse der Medien am Sport wurden sportliche Wettkämpfe zunehmend für kommerzielle, sportfremde Zwecke wie Werbung, Sponsoring und Merchandising vermarktet. Die dem Sport hierdurch zufließenden Einnahmen haben in vielen Bereichen zu einer Professionalisierung geführt, können aber auch Anreize für manipulative Einwirkungen schaffen.

194 Vgl. Spapens/Olfers European Journal of Crime, Criminal Law and Criminal Justice 2015, 333 (352 f.).

195 Zum „Fall Schnitzler“ s. Feltes, in: Haberfeld/Sheehan (Hrsg.), Match-fixing, 2013, S. 15 (23); einer Umfrage der amerikanischen College-Liga NCAA zufolge gaben 2,1\% der befragten Basketballspieler an, aufgrund von persönlichen Wettschulden bereits aufgefordert worden zu sein, das Resultat eines Spiels zu beeinflussen, s. Drape N.C.A.A. survey reveals athletes' gambling habits, NYTimes.com vom 13.5.2004, www.nytimes.com/2004/05/13/sports/colleges-ncaa-sur vey-reveals-athletes-gambling-habits.html. 
aa) Kennzahlen

Der Sport ist zu einem eigenständigen und ernst zu nehmenden Wirtschaftsfaktor geworden, auf den in Deutschland bereits 2,3\% des Bruttoinlandprodukts entfallen. ${ }^{196}$ Das große öffentliche Interesse an den populären Sportarten spült durch Zuschauereinnahmen, Merchandising und Sponsoring, vor allem aber durch den Verkauf von Vermarktungs- und Übertragungsrechten große Summen in die Kassen der entsprechenden Turnierveranstalter und Sportverbände bzw. deren Vermarktungsgesellschaften. Veranschaulichen lässt sich die rasante Entwicklung anhand des Fußballs. Zahlte die ARD für die Fernsehrechte an der Bundesligasaison 1965/1966 noch umgerechnet 0,3 Millionen Euro, erhielt die Deutsche Fußballliga (DFL) in der Saison 2019/2020 von den übertragenden Sendern rund 1,16 Milliarden Euro, was selbst in einem 15-Jahresvergleich noch einen Zuwachs von $287 \%$ bedeutet. ${ }^{197}$ Diese Einnahmen werden auf die Vereine der ersten und zweiten Bundesliga umverteilt, die ihre Lizenzspielerabteilungen mittlerweile zunehmend als Kapitalgesellschaften ausgliedern. Dank zusätzlicher dreistelliger Zuwachsraten in den Bereichen Merchandising und Sponsoring ist etwa der Umsatz der Branchenführerin FC Bayern München AG von 176 Millionen Euro im Jahr 2002 auf 750 Millionen Euro im Geschäftsjahr 2018/2019 gestiegen und ermöglicht so eine stetige Erhöhung des Spieleretats und immer neue Transferrekorde. ${ }^{198}$ Der gesamte Profifußball erzeugt in Deutschland eine jährliche Wertschöpfung von 7,9 Milliarden Euro, Steuereinnahmen von 2,5 Milliarden Euro und steht in direktem Zusammenhang mit 110.000 Arbeitsplätzen. ${ }^{199}$

Auch in anderen Sportarten profitieren Verbände, Ligen und Athleten von wachsenden Einnahmen durch Medienrechte und Sponsoring. Die Kosten für die Übertragung der Olympischen Spiele stiegen in Europa von 1,74 Millionen Dollar bei den Olympischen Spielen 1974 in München auf 442 Millionen Dollar bei den Wettkämpfen 2008 in Peking. Die jährlichen Erlöse der als umsatzstärksten Sportliga der Welt geltenden amerikani-

196 Ablert/an der Heiden/Repenning Sportsatellitenkonto 2016, S. 8; dieser Wert erweist sich in entwickelten Volkswirtschaften weltweit als stabil, s. ICSS/Sorbonne (Hrsg.) Part I, S. 16.

197 Meldung der Deutschen Fußballiga DFL, www.dfl.de/de/hintergrund/vermarkt ung/dfl-ueberspringt-erstmals-milliarden-marke-bei-nationalen-medien-rechten/.

198 FC Bayern erneut mit Rekordumsatz, Sueddeutsche.de vom 15.11.2019, www.sueddeutsche.de/sport/fc-bayern-rekordumsatz-2018-19-jahreshauptversam mlung-1.4684490.

199 McKinsey\&Company (Hrsg.) Wachstumsmotor Bundesliga, S. 4. 
schen Footballliga NFL werden nach einer Steigerung um $50 \%$ in den vergangenen 8 Jahren mittlerweile auf rund 11,2 Milliarden Dollar geschätzt, wovon knapp die Hälfte gemäß einer tarifvertraglichen Einigung an die Spieler auszuzahlen ist. ${ }^{200}$ Beim Tennisturnier in Wimbledon wurden 2019 insgesamt 42,1 Millionen Euro an Preisgeld in der Herren- und Damenkonkurrenz ausgeschüttet. ${ }^{201}$ Allein die jeweilige Prämie für den Turniersieg ist im Vergleich zum Jahr 1990 um das Elffache angestiegen.

\section{bb) Ableitungen für die Gefahr des Match Fixing}

Angesichts des finanziellen Umfangs von Sponsoringaufträgen sowie Austragungs- und Übertragungsrechten für Sportverbände, Vermarktungsgesellschaften, Wirtschafts- und Medienunternehmen werden Manipulationen im Zusammenhang mit den Ausprägungen der Kommerzialisierung des Sports wohl in erster Linie mit deren Vergabeentscheidungen und damit der indirekten Sportkorruption assoziiert. Den Kennzahlen lässt sich aber auch die wirtschaftliche Bedeutung unmittelbar wettkampfbezogener Ergebnisse entnehmen. Diese kann einen starken Anreiz für Sportler oder Entscheidungsträger eines Vereins darstellen, einen bestimmten eigenen sportlichen Erfolg durch das Gewähren von Verlust- bzw. Bevorzugungsprämien an Wettbewerbsgegner bzw. Schiedsrichter sicherzustellen und ist somit zu den Bedingungsfaktoren der hier untersuchten Manipulationsform bestechungsbedingter Schlechtleistungen auf dem Spielfeld zu zählen.

Denn in vielen Sportligen herrscht ein scharfer Wettstreit der teilnehmenden Vereine um die Früchte der Kommerzialisierung. Gerade im Fußball ist durch vom sportlichen Erfolg abhängige Zuschauer- und Sponsoringeinnahmen und eine hauptsächlich am sportlichen Abschneiden der vergangenen Spielzeiten ausgerichtete Verteilung der Fernsehgelder ein wirtschaftliches Gefälle der konkurrierenden Vereine entstanden, das sich auf die sportlichen Rahmenbedingungen überträgt. Ein unerwarteter sportlicher Misserfolg (z.B. ein Abstieg oder das Verfehlen der Qualifikati-

200 Belzer Thanks to Roger Goodell, NFL revenues projected to surpass $\$ 13$ billion in 2016, Forbes Online vom 29.2.2016, www.forbes.com/sites/jasonbelzer/2016/ 02/29/thanks-to-roger-goodell-nfl-revenues-projected-to-surpass-13-billion-in-201 6/\#1beda2f01cb7.

201 Preisgeld Wimbledon 2019: So viel verdienen die Tennisprofis, Tennismagazin.de vom 26.6.2019, www.tennismagazin.de/news/preisgeld-wimbledon-2019tennis-kerber-zverev-federer-nadal-djokovic. 
on für einen internationalen Wettbewerb) kann einschneidende Einnahmeverluste auslösen und dazu führen, dauerhaft ins Hintertreffen zu geraten. Ein Abstieg aus der Bundesliga etwa lässt den Jahresumsatz eines Vereins häufig auf die Hälfte zusammenschrumpfen. ${ }^{202}$ Diese Drohkulisse kann Entscheidungsträger, die die sportliche wie wirtschaftliche Bilanz des Vereins zu verantworten haben, dazu verleiten, einen drohenden Abstieg durch die Initiierung von Spielmanipulationen zu Gunsten des eigenen Vereins abzuwenden. Ins Positive gewendet kann die Qualifikation für einen internationalen Wettbewerb ${ }^{203}$ oder der Gewinn eines renommierten Pokals neben der Siegprämie neue Vermarktungsmöglichkeiten erschließen, die über einen angehobenen Spieleretat wiederum die sportlichen Aussichten für die Zukunft verbessern.

Auf der anderen Seite immunisiert die beschriebene Entwicklung viele Sportakteure gegen die Verlockungen von Bestechungsprämien. Gerade in dem Segment des Sports, in dem es für Vereine um umfangreiche wirtschaftliche Vorteile geht, ist auch ein Anstieg der Spielergehälter zu verzeichnen, der sie finanziell unabhängig stellt. In Einzelsportarten steht der Aussicht auf Bestechungsprämien durch absichtliche Schlechtleistungen die Chance auf angehobene Preisgelder bei erfolgreichem Einsatz gegenüber. Auch wenn gerade Manipulationsabsprachen ohne Wettbezug, von denen sich der Vorteilsgeber einen sportlichen Vorteil erhofft, vereinzelt mit den Folgen der Kommerzialisierung in Verbindung gebracht werden können, sollte deren Einfluss auf die Fallgruppe nicht überschätzt werden.

\section{c) Verbandsinterne Verfolgung und Sanktionierung von Match Fixing}

Als Angriff auf die Integrität ihrer Wettbewerbe und Verletzung sportethischer Grundprinzipien werden durch außersportliche Vorteile motivierte Manipulationen von Sportakteuren durch die einzelnen Sportverbände im Rahmen ihrer autonomen Selbstregulierung verfolgt und sanktioniert. Dies lässt sich ihren unterschiedliche Bezeichnungen tragenden Regelwerken entnehmen, deren Aufbau, Verfahrensfestsetzung und Effektivität im

202 Was der Abstieg in die Zweite Liga kostet, DPA-Bericht bei Faz.net vom 4.5.2016, www.faz.net/aktuell/wirtschaft/fussball-bundesliga-abstieg-kostet-die-v ereine-viel-geld-14215401.html.

203 Allein die Teilnahme an der UEFA-Champions League garantiert den Vereinen eine Startprämie von 15,25 Millionen Euro, die über leistungsabhängige Prämien noch ansteigen kann, s. de.uefa.com/uefachampionsleague/news/newsid=256 2558.html. 
weiteren Verlauf detailliert untersucht werden wird. ${ }^{204}$ Da die verbandsrechtliche Ahndung dieses Verhaltens einen wichtigen Bedingungsfaktor für die untersuchte Manipulationsform darstellt, soll bereits an diese Stelle knapp auf die Tatbestände hingewiesen werden, die von Bestechungsprämien begleitete Manipulationsabsprachen explizit oder in Form einer Generalklausel als sportwidriges und damit sanktionierbares Verhalten kennzeichnen. Bei ihrer Verwirklichung drohen den Sportakteuren Geldbußen und Sperren bis hin zu Ausschlüssen auf Lebenszeit.

Im Gegensatz zum Doping fehlen den Verbänden allerdings institutionalisierte Kontrollsysteme zur Aufdeckung des Fehlverhaltens. Allein ein schwaches Wettkampfverhalten gibt selten Aufschluss über dahinter stehende manipulative Intentionen. Zumindest hinsichtlich wettbezogener Manipulationsabsprachen versuchen die Sportverbände aus einer Überwachung des Wettmarkts Indizien zu gewinnen und auf diese Weise das Entdeckungsrisiko für Sportakteure zu erhöhen. Davon abgesehen sollen Vorkehrungen wie die kurzfristige Ansetzung von Schiedsrichtern oder eine gewisse Abschirmung von Spielern während eines Turniers bereits die Initiierung einer Manipulation erschweren. Auch auf diese Maßnahmen wird im Rahmen der Prüfung der Erforderlichkeit einer strafrechtlichen Verfolgung noch ausführlicher eingegangen werden. ${ }^{205}$

Abgesehen von ihren begrenzten Aufdeckungsmöglichkeiten wird einzelnen Sportverbänden bisweilen auch ein unzureichender Aufklärungswille vorgeworfen. Die Aufdeckung von Fällen des Match Fixing würde aus Sorge vor Imageschäden für die eigene Sportart nicht konsequent betrieben. Darüber hinaus wird ein Zusammenhang von indirekter Sportkorruption innerhalb der Verbände und einem nachlässigen Vorgehen gegen, wenn nicht sogar einer eigenen Verwicklung in Match Fixing hergestellt. ${ }^{206}$ Tatsächlich kann bereits die Kenntnis der Sportler von korrupten Praktiken auf der Ebene der Verbandsoffiziellen eigene moralische Hemmschwellen vor der Beteiligung an Spielmanipulationen abbauen, ${ }^{207}$ was die verbandsinterne Haltung gegenüber Manipulationen durchaus als einen ambivalenten Bedingungsfaktor ausweist.

204 Ausführlich zum Folgenden unter Teil 3 C. II. 1. bb).

205 S. unten Teil 3 C. II. 1. a) aa).

206 S. Hill, in: Transparency International (Hrsg), Corruption Report, 2016, S. 231 (234).

207 ICSS/Sorbonne (Hrsg.) Part II, S. 23. 
2. Erklärungsansätze auf Grundlage der ökonomischen Kriminalitätstheorie

Den beschriebenen Bedingungsfaktoren lassen sich bestimmte Anreize für Match Fixing und diesbezüglich günstige Tatgelegenheiten entnehmen. Ein Erklärungswert für die Wahrnehmung derselben ergibt sich hieraus aber noch nicht. Spezifisch ursachenbezogene Theorien für normwidriges Verhalten in Form der Wettbewerbskorruption im Sport wurden in den vergangenen Jahren nahezu ausnahmslos auf der Grundlage ökonomischer Kriminalitätstheorien entwickelt. Diese um die Einbindung der Bezugssysteme des Wettmarkts, der Kommerzialisierung und der verbandsrechtlichen Regulierung bemühten Ansätze werden im Folgenden überblicksartig dargestellt, auf ableitbare Aussagen hinsichtlich der Manipulationsanfälligkeit konkreter Sportarten und bestimmter Situationen untersucht und schließlich in ihren Grenzen und Potenzialen eingeordnet.

\section{a) Ansätze auf Basis der Annahme der Rational Choice}

Ihre korruptiven Merkmale herausgreifend wurde insbesondere zur Analyse wettbezogener Spielmanipulationen auf im Rahmen der Wirtschaftskriminalität populäre ökonomische Erklärungsmodelle abweichenden Verhaltens zurückgegriffen. Ihrer Grundannahme zufolge richten sämtliche Individuen ihr Verhalten nach rationalen Maßstäben aus und treffen ihre Entscheidungen auch für illegale Aktivitäten auf der Basis einer strengen Kosten-Nutzen-Abwägung. ${ }^{208}$ Delinquentes Verhalten ist demnach das Ergebnis eines rationalen Wahlaktes (Rational Choice), bei dem unter mehreren legalen und illegalen Handlungsalternativen diejenige gewählt wird, die dem Individuum zum Entscheidungszeitpunkt den größten erwarteten Nutzen verspricht, wobei die vorangehende Kalkulation nicht nur von wirtschaftlichen Vor- und Nachteilen, sondern auch von gesellschaftlichen, moralischen und psychologischen Aspekten beeinflusst wird.

In der Absicht, diese Grundannahme auf Sportkorruption anzuwenden und zu erweitern, werden die Entscheidungsprozesse potenzieller Täter in mathematische Gleichungen übertragen, deren Variablen die abwägungserheblichen Faktoren darstellen. Übereinstimmend wird dabei davon ausgegangen, dass es zu korruptem Verhalten im Sport kommt, wenn dessen

208 Becker Journal of Political Economy 76, 169 ff.; Ehrlich Journal of Economic Perspectives 10 (1) 1996, 43 (44); Wittig MSchrKrim 1993, 328 ff. 
kalkulierter Nettonutzen, der sich aus der Differenz zwischen dem Nutzen einer erfolgreichen Korruption, auf die keine Bestrafung folgt, und dem negativen Nutzen bei Entdeckung, Verurteilung und Bestrafung ergibt, eine individuell angesetzte moralische Wertgrenze für beide an der $\mathrm{Ab}$ sprache beteiligten Parteien übersteigt. ${ }^{209}$ Die verschiedenen Ansätze unterscheiden sich im Spezifizierungsgrad ihrer Anpassung an einzelne Korruptionsformen, etwa in ihrer genauen Festlegung von Nutzen als Minuend und negativem Nutzen bzw. Kosten als Subtrahend.

Nach einem Modell soll für den Nutzen neben der Erfolgswahrscheinlichkeit der Korruption und deren pekuniärem Bruttoerfolg bei Gelingen - etwa aus gewonnenen Wetten, Bestechungsprämien, Preisgeldern oder Austragungsrechten - auch ein nichtpekuniärer Nutzen in Form des Imagegewinns des Akteurs entscheidend sein. ${ }^{210}$ Letzterer kann einem Sportakteur bei vereinbarten wettbewerbsinternen Schlechtleistungen aber nicht entstehen und wäre durchgehend mit Null anzusetzen. Das weist den Ansatz als einen auf die allgemeine Sportkorruption ausgerichteten aus, der auch durch Doping erreichte sportliche Erfolge sowie Veranstaltungskorruption zu erfassen versucht. Im Hinblick auf Match Fixing bedarf er auch insoweit der Spezifizierung, als seine Formel für die Entscheidungsfindung beider Korruptionsparteien Anwendung finden soll. Deren Parameter sind mithin an den unterschiedlichen Kontext des Angebots einer Spielmanipulation durch Sportakteure und deren Nachfrage durch wettende Vorteilsgeber anzupassen.

Im Bemühen um eine solche angebotsbezogene Spezifizierung wird andernorts ${ }^{211}$ der vom Sportakteur erwartete Nutzen einer eigens durchgeführten Manipulation lediglich mit dem Produkt aus der Wahrscheinlichkeit einer erfolgreichen und unentdeckten Manipulation und der Summe der hierfür erhaltenen Bestechungsprämie beschrieben (qG). Auf der gegenüberliegenden Kostenseite sei das Produkt aus der Wahrscheinlichkeit einer Aufdeckung der Manipulation und der dann zu erwartenden Strafe (z.B. Bußgeld plus lebenslange Sperre und Verdienstausfall) $(\mathrm{pF})$ mit dem Geldwert eines sportinternen Reputationsverlusts infolge der Schlechtleistung $(\mathrm{V}[\mathrm{R}])$ und dem Geldwert der durch die bloße Teilnahme an einer

209 Vgl. Maennig Vierteljahreshefte zur Wirtschaftsforschung 73 (2004), 263 (274 f.); Andreff Systems 2017, 5(1), 12, S. 6 f.; auch Adams/Rock ZfWG 2010, 381 (384f.).

210 Maennig Vierteljahreshefte zur Wirtschaftsforschung 73 (2004), 263 (275).

211 Forrest/McHale/McAuley International Journal of Sport Finance 2008, 156 (157 f.); ähnlich Rebeggiani/Rebeggiani, in: Haberfeld/Sheehan (Hrsg.), Match-fixing, 2013, S. 157 (164 ff.); grundlegend zu diesem Ansatz auch Ehrlich Journal of Economic Perspectives 10 (1) 1996, 43 (46 ff.). 
betrügerischen Aktion ausgelösten moralischen Schuldgefühle (V[C]) zu addieren. Übersteige der kalkulierte Nutzen die Kosten (qG > pF + V $[R]+$ $\mathrm{V}[\mathrm{C}]$ ), wird ein risikoneutraler Sportakteur die Möglichkeit einer Spielmanipulation wahrnehmen.

Voraussetzung hierfür sei jedoch eine entsprechende Nachfrage, die ihrerseits durch Kosten-Nutzen-Kalkulationen der an einer Manipulation interessierten Vorteilsgeber entstehen soll. Im Fall intendierter Wettplatzierungen habe der mit Sicherheit zu erwartende Gewinn aus den manipulationsbezogenen Wetten (G[f]) die Summe aus aufzuwendenden Bestechungsprämien (B), ${ }^{212}$ den möglichen sonstigen Kosten der Manipulationsorganisation etwa zur Erlangung von Zugang zum Sportakteur $(\mathrm{C}[\mathrm{F}])$, den insgesamt getätigten Wetteinsätzen $(\mathrm{M}[\mathrm{F}])$ sowie den in ihrer Eintrittswahrscheinlichkeit einzuschätzenden Kosten einer Sanktion infolge einer aufgedeckten Manipulationsabsprache (q x C $[S]$ ) zu übertreffen: $\mathrm{G}(\mathrm{f})>(\mathrm{B}$ $+\mathrm{C}[\mathrm{F}]+\mathrm{M}[\mathrm{F}]+\mathrm{q} \times \mathrm{C}[\mathrm{S}]) .{ }^{213}$ Trete dies ein, bildeten sich begegnende Angebot und Nachfrage einen Markt, der beständig eine bestimmte Anzahl an manipulierten Spielen produziere. Im Sinne einer Wechselwirkung beeinflusse dieser Match Fixing-Markt die Funktionsweise des von den Vorteilsgebern anschließend genutzten Sportwettenmarkts genauso wie er umgekehrt selbst von dieser beeinflusst werde. Denn die Einbindung manipulierter Spiele verändere die normale Gewinnverteilung des Sportwettenmarkts zu Gunsten der Vorteilsgeber und animiere und befähige sie zu zunehmenden Investitionen in Manipulationsabsprachen, was wiederum eine Erhöhung des Angebots von Manipulationen durch Sportakteure auslösen könne. ${ }^{214}$ Gerade wettbezogene Manipulationen erklären sich diesem Ansatz zufolge also als Produkt zweier im Ergebnis übereinstimmender rationaler Wahlentscheidungen von Sportakteuren und außenstehenden Vorteilsgebern, deren Determinanten vor dem Hintergrund der Mechanismen zweier interagierender Märkte zu analysieren sind.

Bei Übertragung der Formel auf die Nachfrage eines sportintern motivierten Vorteilsgebers nach Manipulationen wären deren Variablen zu modifizieren. Der etwa von einem bestechenden Vereinsfunktionär erwartete Nettonutzen besteht nicht primär aus persönlichen pekuniären Vorteilen,

212 Diese kann je nach Form der Manipulation und je nach Alter, Spielklasse und Position des bestochenen Sportakteurs sehr unterschiedlich ausfallen, vgl. ICSS/ Sorbonne (Hrsg.) Part II, S. 33.

213 Andreff Systems 2017, 5(1), 12, S. 11.

214 Vgl. Andreff Systems 2017, 5(1), 12, S. 8 ff.; ICSS/Sorbonne (Hrsg.) Part II, S. 44, $54 \mathrm{f}$. 
sondern setzt sich aus dem antizipierten Prestigegewinn des Vereins durch einen bestimmten sportlichen Erfolg und den vielfältigen wirtschaftlichen Vorteilen eines Turniersiegs, einer Qualifikation für den internationalen Wettbewerb oder eines Klassenerhalts für den Verein zusammen. Mitunter kann mit der Erreichung der sportlichen Ziele auch die eigene berufliche Situation verknüpft sein. Abzuwägen ist dieser Nutzen gegen die im Falle der Aufdeckung gezahlter Manipulationsprämien an Schiedsrichter oder gegnerische Spieler drohenden verbandsrechtlichen Sanktionen, die die persönliche Berufslaufbahn des Funktionärs im Sport beenden und den Verein im sportlichen Wettbewerb, aber auch in der Gunst der Anhänger langfristig zurückwerfen können. Tatsächlich konzentrieren sich die ökonomischen Ansätze aber stark auf die Erklärung wettbezogener Manipulationen und blenden sportintern motivierte Bestechungszahlungen überwiegend aus, sei es wegen der Vermutung ihrer geringeren praktischen Relevanz oder einer stärker emotionsgetragenen Entscheidungsfindung.

b) Theoretische Ableitungen für die Manipulationsanfälligkeit bestimmter Sportarten und empirische Belege

Aus den benannten theoretischen Einflussfaktoren eines ökonomischen Modells lassen sich für den Bereich des wettbezogenen Match Fixing in zwei Schritten sportart- und täterspezifische Risikoprofile erstellen. Zunächst sind die beidseitigen Abwägungsvariablen in generell manipulationsbegünstigende Umstände des Sports zu übersetzen, ehe deren Schnittmenge ermittelt und mit den realen Eigenarten konkreter Sportarten abgeglichen werden kann. Wie gesehen hängt die Höhe der Bestechungsprämie von den unentdeckt realisierbaren Wettgewinnen des Vorteilsgebers ab und verlangt daher einen liquiden Wettmarkt gerade hinsichtlich des manipulierten Wettbewerbselements. Die Wahrscheinlichkeit des Erhalts der oftmals an die Herbeiführung des verabredeten Manipulationserfolgs gekoppelten Prämie dürfte in Einzelsportarten höher ausfallen als in komplexen Teamsportarten bzw. von solchen Schieds- und Wertungsrichtern höher angesetzt werden, die über großen Einfluss auf Verlauf und Ausgang eines Wettbewerbs verfügen. ${ }^{215}$

Auf der anderen Seite ist der protektive Faktor des Risikos eines infolge einer langjährigen Sperre erlittenen Einkommenswegfalls bei Akteuren

215 Adams/Rock ZfWG 2010, 381 (384f.); Forrest/McHale/McAuley International Journal of Sport Finance 2008, 156 (162). 
schwächer ausgeprägt, die entweder in weniger populären Sportarten oder unteren Ligen einen geringeren Verdienst vorzuweisen haben oder bereits am Ende ihrer Karriere stehen. ${ }^{216}$ Zudem ist er mit der Wahrscheinlichkeit einer Aufdeckung der Manipulation verbunden, die mangels starker öffentlicher Aufmerksamkeit ebenfalls in unterklassigen Wettbewerben, aber auch im Spitzensport zumindest dort als gering eingeschätzt werden dürfte, wo die Reduzierung des Einsatzes bisweilen auch als akzeptierte sportinterne Taktik eingesetzt wird und nicht zwangsläufig einen Manipulationsverdacht erregt. ${ }^{217}$ Der gefürchtete sportliche Reputationsverlust infolge durch Schlechtleistung provozierter Niederlagen ist etwa in für den Tabellenstand irrelevanten Spielen am Ende einer Saison reduziert. ${ }^{218}$ Für Einzelsportler, deren Schlechtleistung zudem keine Rechtfertigungslast gegenüber enttäuschten Teamkameraden begründet, gilt dies insbesondere für Niederlagen bei kleineren Turnieren. Schließlich ist die moralische Hemmschwelle vor der Verwicklung in eine betrugsnahe Manipulation in solchen sportlichen Wettbewerben herabgesetzt, in denen sich manipulative Einwirkungen zu Wettzwecken ohne Bestimmung des letztlich siegreichen Teilnehmers - durch Spot Fixing oder Point Shaving - umsetzen lassen. In manchen Sportarten kann auch die Orientierung an einer durch Verbandsoffizielle vorgelebten „Korruptionskultur“ grundsätzliche moralische Bedenken zerstreuen. ${ }^{219}$

In der Gesamtschau dieser Ableitungen zeigt sich, dass sich manipulationsbegünstigende Faktoren in gewissem Umfang im Sinne einer systemimmanenten Manipulationsprävention gegenseitig aufheben. Wettmärkte versprechen die höchste Liquidität in weltweit beachteten Turnieren des Spitzensports wie Fußball-Weltmeisterschaften oder Grand-Slam-Turnieren im Tennis, in denen die unter dem Brennglas des öffentlichen Interesses agierenden Protagonisten ihre sportliche Reputation und ihre hervorragenden Verdienstaussichten aber kaum für eine Bestechungsprämie aufs Spiel setzen dürften. ${ }^{220}$ Umgekehrt erschwert es ein geringes Gesamtvolu-

216 Maennig Vierteljahreshefte zur Wirtschaftsforschung 73 (2004), 263 (276); Adams/Rock ZfWG 2010, 381 (385); Spapens/Olfers European Journal of Crime, Criminal Law and criminal Justice 2015, 333 (352).

217 Forrest/McHale/McAuley International Journal of Sport Finance 2008, 156 (162).

218 Interpol/IOC (Hrsg.) Handbook, S. 19.; Rebeggiani/Rebeggiani, in: Haberfeld/ Sheehan (Hrsg.), Match-fixing, 2013, S. 157 (164).

219 ICSS/Sorbonne (Hrsg.) Part II, S. 23, 35.

220 Vgl. Forrest/McHale/McAuley International Journal of Sport Finance 2008, 156 (162); Rebeggiani/Rebeggiani, in: Haberfeld/Sheehan (Hrsg.), Match-fixing, 2013, S. 157 (169f.). 
men an Wetten, in einkommensschwächeren unteren Ligen oder über Ereigniswetten größere Einsätze auf manipulierte Spiele bzw. bloßes Spot Fixing zu platzieren, ohne Aufsehen zu erregen. Auch die in mehrerer Hinsicht manipulationsgeeigneteren Einzelsportarten werden mit Ausnahme des Tennis von kleineren Wettmärkten flankiert. Außerdem sind die Athleten hier häufig wirtschaftlich auf gute Ergebnisse und vordere Ranglistenplätze angewiesen, die durch absichtliche Schlechtleistungen verhindert würden.

Dennoch lassen sich in bestimmten sportlichen Wettbewerben auch Schnittmengen ausmachen, in denen sich nutzensteigernde und kostensenkende Faktoren überlagern und die auf Grundlage des ökonomischen Ansatzes als besonders anfällig für Manipulationen gelten müssen. Eine Kombination aus einem angebotsreichen und umsatzstarken Wettmarkt, gering verdienenden Sportakteuren und vergleichsweise einfach zu bewerkstelligenden Manipulationen des Spielverlaufs ohne die moralisch problematische Beeinflussung des Siegers findet sich etwa im amerikanischen College Basketball. ${ }^{221}$ Das landesweite Finalturnier der Universitäten wird jährlich von Millionen Menschen verfolgt, zieht eine große Anzahl an Wetten an und wird von Studenten bestritten, die über ihr Stipendium hinaus keine wirtschaftlichen Vorteile aus ihrer sportlichen Tätigkeit generieren dürfen. Die Popularität angebotener Wetten auf die Unterbietung einer bestimmten festgesetzten Spanne zwischen den Punktzahlen im Endergebnis ermöglicht es auch klar favorisierten Teams, Bestechungsprämien für den durch absichtliche Nachlässigkeit in der Schlussphase herbeigeführten Manipulationserfolg einzustreichen (Point Shaving), ohne ihre Turnierziele zu opfern. Eine ähnliche Kreuzung manipulationsbegünstigender Parameter wird im Kricket und Rugby identifiziert. ${ }^{222}$

Die Einzelsportarten immanenten Risikofaktoren können sich am ehesten im Tennis ausprägen. Spielern außerhalb der Top 100 der Weltrangliste fällt es schwer, ihre hohen Reisekosten und Personalausgaben für Trainer und Physiotherapeuten durch eingespielte Turnierpreisgelder auszugleichen. ${ }^{223}$ Gerade ältere Spieler mit nur noch geringen Aussichten auf den Sprung in die lukrativen Regionen der Weltrangliste könnten den

221 Maennig Vierteljahreshefte zur Wirtschaftsforschung 73 (2004), 263 (276).

222 Forrest/McHale/McAuley International Journal of Sport Finance 2008, 156 (163f.).

223 S. Lewis/Wilkinson/Henzelin Integrity in Tennis, S. 18; anlässlich der jüngsten Berichte über einen neuen Wettskandal im Tennis Kleffmann Doppelfehler im System, Sueddeutsche.de vom 27.12.2019, www.sueddeutsche.de/sport/tennis-betru g-koepfer-itf-1.4736915. 
Nutzen einer Manipulationsprämie höher einschätzen als den Verlust vereinzelter Preisgelder und Reputation und infolgedessen ihre Spiele bei renommierten und viel bewetteten Turnieren unter Ausnutzung schwankender Quoten bei Live-Wetten absichtlich verlieren.

Im populären Fußball hat das rasante Wachstum von Sportwetten gerade in Europa inzwischen für liquide Wettmärkte selbst in unteren Ligen gesorgt. ${ }^{224}$ Nach Einschätzung asiatischer Wettagenten lassen sich auf ein Spiel der zweiten belgischen Liga Wetten in Höhe von 300.000 Euro platzieren, ohne Aufmerksamkeit zu erregen. ${ }^{225}$ Für dort aktive Spieler ist auf der Kostenseite einer Manipulation lediglich die geringe Wahrscheinlichkeit eines ohnehin schmaleren Verdienstausfalls und gerade in für den Tabellenstand bedeutungslosen Spielen ein minimaler öffentlicher Reputationsverlust infolge der Niederlage zu verbuchen. Von den Top-Ligen erscheinen diejenigen gefährdet, die zum einen ein auch landestypisch hohes Wettaufkommen anziehen, zum anderen manch wirtschaftlich unseriös geführten Verein enthalten, bei dem es immer wieder zu ausstehenden Gehaltszahlungen an die Spieler kommt. Außerdem müssen in sämtlichen Top-Ligen die Schiedsrichter in den Fokus genommen werden, die über großen Einfluss auf Verlauf und Resultat eines Spiels, gleichzeitig aber über ein vergleichsweise geringes Einkommen verfügen.

Empirische Belege dieser abgeleiteten Gefährdungspotenziale lassen sich nur bedingt aus bekannt gewordenen Manipulationsfällen gewinnen, da die wichtige Variable einer geringen Entdeckungswahrscheinlichkeit gerade in den potenziell anfälligen Sportarten auf ein ausgeprägtes Dunkelfeld hindeutet. Dunkelfeldforschung wird bisher aber nur vereinzelt betrieben und lässt sich kaum sportartübergreifend vergleichen. Im Rahmen dieser Einschränkung stützen Hellfeldübersichten und einzelne Studien die abgeleiteten sportart- und situationsgebundenen Integritätsrisiken aber durchaus.

Tatsächlich verzeichnet der amerikanische College-Basketball bereits seit Jahrzehnten eine große Anzahl an Manipulationsfällen. ${ }^{226}$ Eine dominante Rolle spielt dabei offensichtlich die Manipulationsform des Point Shaving durch ein favorisiertes Team, die einer Studie zufolge in immerhin 500 der insgesamt 44.000 analysierten Spielen auftrat. ${ }^{227}$ Im Tennis nähren Anschuldigungen von ehemaligen Spielern seit geraumer Zeit den Verdacht

224 Forrest/McHale/McAuley International Journal of Sport Finance 2008, 156 (163).

225 Forrest/McHale Journal of Management Mathematics 2019, 1 (2).

226 S. bereits oben unter Teil 2 A. II. 5. a).

227 Wolfers American Economy Review 96, $279 \mathrm{ff}$. 
großflächiger Spielmanipulation gerade durch im hinteren Bereich der Weltrangliste platzierte Spieler. ${ }^{228}$ Dieser scheint nun durch eine internationale Ermittlung über wettbezogene Spielmanipulationen im Tennis erhärtet zu werden, über die erstmals im Dezember 2019 berichtet wurde und in die weltweit ca. 135 Tennisspieler involviert sein sollen. ${ }^{229}$ Detaillierte Ergebnisse wurden diesbezüglich jedoch noch nicht verkündet. Von den 1.391 Spielen, die der Tennis Integrity Unit im Zeitraum 2009 bis 2017 von Wettanbietern, Spielern oder anderen Beteiligten als verdächtig gemeldet wurden, betrafen $78 \%$ das mittlere und untere Leistungsniveau der ATP-Challenger- bzw. ITF-Turniere, an denen hauptsächlich Spieler jenseits der Top 100 der Weltrangliste teilnehmen. ${ }^{230}$ Und im Fußball beziehen sich die Meldungen über Spielmanipulationen überwiegend auf untere oder wenig lukrative europäische Ligen, ${ }^{231}$ wobei sich hier - wie auch in anderen Sportarten - eine erhöhte Anfälligkeit solcher Spiele belegen lässt, in denen die Bedeutung eines Erfolges für die Kontrahenten aufgrund einer übergeordneten Tabellen- oder Wettbewerbssituation stark ungleich verteilt ist. ${ }^{232}$ Eine Datenbank, die mit biografischen Informationen über in erwiesene Manipulationsfälle verwickelte Spieler gespeist wird, lässt eine starke Überrepräsentation von mindestens 30 Jahre alten

228 S. die Aussagen des ehemaligen Tennisprofis Daniel Köllerer im Interview mit Die Welt vom 29.1.2016, www.welt.de/sport/tennis/article151317449/Sie-botenmir-50-000-Dollar-fuer-eine-Niederlage.html.

229 Naber Wettskandal im Tennis weitet sich aus, Die Welt Online vom 15.12.2019, www.welt.de/vermischtes/article204340410/Wettskandal-im-Tennis-Ermittlungs verfahren-gegen-deutschen-Spieler.html.

230 S. Lewis/Wilkinson/Henzelin Integrity in Tennis, S. $23 \mathrm{f}$. Diese Verteilung wurde auch in qualitativen Interviews mit Spielern bestätigt, ebd., S. 39. Zu den systemischen Ursachen einer problematischen Preisgeldstruktur und der Schaffung diverser Wettmöglichkeiten bei kleinen Provinzturnieren Kleffmann Doppelfehler im System, Sueddeutsche.de vom 27.12.2019, www.sueddeutsche.de/sport/te nnis-betrug-koepfer-itf-1.4736915.

231 Die nachweisbare Anfälligkeit der zweiten niederländischen Fußballiga auf die Kumulation der beschriebenen Risikofaktoren zurückführend Spapens/Olfers European Journal of Crime, Criminal Law and Criminal Justice 2015, 333 (352).

$232 \mathrm{Zu}$ länderübergreifenden Belegen für das erhöhte Manipulationsrisiko bei am letzten Spieltag einer Saison ausgetragenen Fußballspielen zwischen einem abstiegsbedrohten und einem im gesicherten Tabellenmittelfeld platzierten Team Elaad/Krumer/Kantor Journal of Law, Economics, and Organization 34 (2018), 364 ff.; für vergleichbare Konstellationen im Sumoringen Duggan/Levitt American Economic Review 92 (5), 1594 ff. bzw. im Tennis Jetter/Walker Southern Economic Journal 84 (1), $155 \mathrm{ff}$. 
Spielern erkennen, die dem Ende ihrer Karrieren entgegenblicken. ${ }^{233}$ Und eine Umfrage unter Fußballprofis aus ost- und südosteuropäischen Ligen bestätigt überdies das vermutete überproportionale Zusammenfallen von empfangenen Kontaktaufnahmen zwecks Match Fixing und ausstehenden Gehaltszahlungen. ${ }^{234}$

Lassen sich in den Realitäten des Sports also durchaus Entsprechungen zu den theoretisch abgeleiteten Gefährdungspotenzialen finden, aus denen zumindest empirische Indizien für die Aussagekraft des ökonomischen Erklärungsansatzes gezogen werden können, verbleiben auf der anderen Seite Fallgestaltungen, die sich dessen Modell entziehen. So ist etwa die mehrfach zu konstatierende Verwicklung angesehener und finanziell abgesicherter Nationalspieler (der italienische Fußballnationalspieler Stefano Mauri, der französische Handballstar Nikola Karabatic, der indische Volksheld Salman Butt) in Spielmanipulationen mit der Annahme einer handlungsleitenden rationalen Abwägung auf Basis der beschriebenen Faktoren kaum in Einklang zu bringen.

\section{c) Grenzen und Potenziale}

Bereits eine nur eingeschränkt mögliche empirische Überprüfung offenbart die Grenzen und Potenziale einer auf die Wettbewerbskorruption im Sport angepassten ökonomischen Devianztheorie. Sie eignet sich nicht zur umfassenden Erklärung korruptiver Absprachen von Spielmanipulationen. Ihre Grundannahme, die den Menschen als einen sich beständig durch rationales Wahlhandeln auszeichnenden homo oeconomicus begreift, ist bereits für viele Lebensbereiche in Zweifel gezogen worden ${ }^{235}$ und begegnet auch bei ihrer Anwendung auf Match Fixing Bedenken. Dies gilt zuvörderst für sportintern motivierte Manipulationsabreden, die häufig emotionalen Triebfedern entspringen dürften. Doch auch im Umfeld von Sportwetten wird die Entscheidung zur Initiierung oder Begehung einer Manipulation in einer erheblichen Anzahl von Fällen weniger einer freien Kosten-Nutzen-Abwägung als vielmehr inneren und äußeren Zwängen fol-

233 Hill Trends in Organized Crime 2015, 212 (222 ff.).

234 FIFPro (Hrsg.) Black Book, S. 129 f. In einer Umfrage unter Fußball- und Basketballspielern in Litauen gaben $13 \%$ der in Match Fixing verwickelten Profis ausstehende Gehaltszahlungen als Motiv an, s. Trumpyte, in: Amnesty International (Hrsg.), Corruption Report, 2016, S. 250 (252).

235 Kunz/Singelnstein Kriminologie $\$ 12$ Rn. 31 ff.; zur Kritik am Ansatz des Rational Choice im spezifisch strafrechtlichen Kontext s. unten Teil 3 C. I. 1. a) bb). 
gen. ${ }^{236}$ Diese können in Gestalt pathologischer Belastungen wie Spielsucht $^{237}$ oder Allmachtsfantasien ${ }^{238}$ auftreten oder in Nötigungen von Sportakteuren durch kriminelle Hintermänner bestehen. So gibt unter befragten Fußballprofis aus Osteuropa ein signifikant erhöhter Anteil derjenigen, die von Ansprachen durch Manipulatoren berichten, ebenfalls an, bereits einmal Opfer eines gewalttätigen Akts geworden zu sein. ${ }^{239}$ Wenn Annäherung und Gewaltakt dabei auch nicht zusammengefallen sein müssen, legt dies doch eine gezielte Ausnutzung von Vulnerabilität und den verbreiteten Einsatz von Drohungen durch Manipulatoren nahe.

Selbst wo es hieran fehlt, reduzieren die aufgestellten Formeln komplexe Prozesse der Entscheidungsfindung und behaupten eine nicht einlösbare Klarheit. Die Schlussfolgerung aus der Bewertung von Nutzen und Kosten ist in hohem Maße abhängig von individuellen moralischen Einstellungen, die durch kulturabhängige Korruptionsverständnisse und sportartspezifische Wertvorstellungen zu disparat für die Integration in eine allgemeine Formel ausfallen. ${ }^{240}$ Inwiefern die beständige Manipulationsanfälligkeit einzelner Wettbewerbe einer Sportart nicht auch Ausfluss einer dort über Jahrzehnte etablierten Relativierung des Fair Play- bzw. Leistungsprinzips sein könnte, die durch eine korruptionsbelastete Verbandsebene toleriert und indirekt inspiriert wird, ließe sich etwa eher unter Rückgriff auf Anomie- bzw. Subkulturtheorien beurteilen. ${ }^{241}$ Die Bedeutung äußerer Strukturen und kultureller Normen drückt sich auch in der Beobachtung aus, wonach Fußballspiele zwischen einem Abstiegskandidaten und einem Team aus dem gesicherten Mittelfeld am Ende einer Saison

236 So wohl auch Sinner FS Neumann, 2017, S. 1229 (1240 f.).

237 Die zur Kombination von Risikofaktoren führen kann, indem sie finanzielle Notlagen auslösen und Kontakte in die Wettszene vermitteln kann, vgl. Spapens/Olfers European Journal of Crime, Criminal Law and criminal Justice 2015, 333 (352 f.).

238 Solche lassen sich beispielsweise Ante Sapina attestieren, der sich gegenüber den Wettanbietern für überlegen hielt und sich auch durch eine erste strafgerichtliche Verurteilung nicht von weiteren Manipulationen abhalten ließ.

239 FIFPro (Hrsg.) Black Book, S. 132.

240 Zur grundsätzlichen Bedeutung kultureller Normen als Bestimmungsfaktor für Korruption Fisman/Miguel Journal of Political Economy 115 (2007), $1020 \mathrm{ff}$.

241 Ein Erklärungsansatz auf Basis der Anomietheorie verfolgt Häublein Korruption, S. 187 ff., die Indikatoren zunehmender Anomie im Profifußball in einer abgeschwächten Bedeutung des kollektiven Fair Play und der Überbetonung der Zweckrationalität des Spielcharakters ausmacht; zur Subkulturtheorie grundlegend Sutherland White Collar; diese durchaus überzeugend auf Korruption im italienischen Fußball anwendend Di Ronco/Lavorgna Trends in Organized Crime 2015, 176 (190). 
gerade in solchen Ländern mit einer signifikant erhöhten Wahrscheinlichkeit vom Abstiegskandidaten gewonnen werden, denen auf dem Korruptionsindex von Transparency International höhere Werte zugeordnet werden. ${ }^{242}$ Und angesichts der für die Sportakteure gerade in solchen tabellarisch bedeutungslosen Spielen auf den ersten Blick unklaren Opfer einer Manipulation sowohl unter den sportlichen Konkurrenten als auch auf dem anonymen Wettmarkt erscheint auch eine Analyse des handlungsleitenden Einflusses von Neutralisationstechniken gewinnbringend. ${ }^{243}$

Greift das ökonomische Modell demnach im Hinblick auf den Anspruch einer alleinigen Erklärung von Match Fixing zu kurz, trägt es doch zum Verständnis des Zusammenhangs zwischen individuellen Motivlagen und institutionellen Rahmenbedingungen bei. Sein Wert liegt in der Benennung wirksamer Anreize und Hemmnisse und des Ausweises besonderer Gefahrenlagen infolge des Zusammentreffens manipulationsbegünstigender Faktoren. Der in Angebot und Nachfrage differenzierende, marktbezogene Ansatz erweitert dabei den auf die Sportakteure beschränkten Blick auf Spielmanipulationen um die notwendige Perspektive der Vorteilsgeber und deren Prägung durch die Mechanismen des Sportwettenmarkts. Wenngleich die beschriebenen Unzulänglichkeiten des Ansatzes in der Erklärung manipulativen Verhaltens umgekehrt von auf seiner Basis entwickelten Präventionsmaßnahmen wohl keine breitflächig effektive Verhaltenssteuerung erwarten lassen, können Vorkehrungen von Sportverbänden und Wettanbietern doch zumindest zielgerichteter entwickelt und in bestimmten Sportarten auf bestimmte Risikofaktoren angepasst werden. So kann etwa bei von großem öffentlichen Interesse begleiteten Wettbewerben, die den Protagonisten geringe Verdienstchancen, dafür aber die Möglichkeit zu Verlaufsmanipulationen ohne befürchtete Reputationsoder Preisgeldverluste verschaffen, eine Sensibilisierung der Akteure durch die Sport- oder Ligaverbände und eine enge Kontrolle der Wettbewegungen seitens der Wettanbieter erfolgen.

242 Elaad/Grumer/Kantor Journal of Law, Economics and Organization 34 (2018), 364 ( $367 \mathrm{ff}$. ).

243 Grundlegend zu Neutralisationstechniken in der Kriminologie Sykes/Matza, in: Sack/König (Hrsg.), Kriminalsoziologie, 1979, S. 360 ff. 


\section{Ausmaß des Match Fixing}

Die Vervielfältigung von Anreizen und Tatgelegenheiten infolge der geschilderten Entwicklungen des Sportwettenmarkts und der Kommerzialisierung des Sports lässt einen starken Zuwachs und ein insgesamt beträchtliches Ausmaß bestechungsbedingter Wettkampfmanipulationen im Sport vermuten. Die in den vergangenen Jahren spürbar gesteigerte Frequenz an Medienberichten über bekannt gewordene Manipulationsfälle im Sport scheint diese Vermutung vordergründig zu bestätigen. ${ }^{244}$ Allerdings lässt sich die verstärkte mediale und auch wissenschaftliche Rezeption entsprechender Fälle auch mit einem verbesserten Zugang zu einschlägigen Informationen über neue Kommunikations- und Archivierungstechnologien und einer thematischen Sensibilisierung der Öffentlichkeit erklären. ${ }^{245}$ Demzufolge bezöge sich die öffentliche Wahrnehmung eines grassierenden Problems nur auf ein erweitertes Hellfeld, das keine verlässlichen Aussagen über die tatsächliche Entwicklung und Prävalenz der hier untersuchten Manipulationsformen zulässt.

\section{Methodische Probleme einer Quantifizierung}

Verschiedene Gründe erschweren derartige Aussagen zum Ausmaß des Match Fixing. Schon die Quantifizierung des Hellfeldes, das sich auf von Sportverbänden oder staatlichen Behörden aufgedeckte und sanktionierte Manipulationsfälle erstreckt, erscheint in Ermangelung einer für deren zentrale Erfassung zuständigen Institution und angesichts divergierender Korruptionsverständnisse, die sich in unterschiedlichen Anwendungsbereichen von Verbandsregelwerken und nationalen Strafrechtsordnungen niederschlagen, problematisch. Schwerer wiegt jedoch, dass ein naturbedingtes Merkmal erfolgreicher Korruption darin besteht, unentdeckt zu bleiben. In allen Bereichen ihres Auftretens ist daher von einem imposanten Dunkelfeld auszugehen. In Deutschland wird der Anteil der im Verborge-

244 Vgl. zum Umfang einschlägiger Berichterstattung in den Printmedien und der dort zu beobachtenden extremen Darstellung von Manipulationsfällen ohne Hinweis auf die schwierig zu erfassende tatsächliche Verbreitung s. Kalb/Herrmann/Emrich, in: Emrich/Pierdzioch/Pitsch (Hrsg.), Falsches Spiel, 2015, S. $109 \mathrm{ff}$.

245 Maennig Vierteljahreshefte zur Wirtschaftsforschung 73 (2004), 263 (270); Heilemann Bestechlichkeit, S. 97; Feltes, in: Haberfeld/Sheehan (Hrsg.), Match-fixing, 2013, S. 15 (26). 
nen bleibenden Korruptionsdelikte auf $95 \%$ geschätzt. ${ }^{246}$ Sofern sich das auch nur annähernd auf die hier untersuchten Korruptionsformen im Sport übertragen lässt, stellen deren aufgedeckte und hier teilweise beschriebene Fälle nur die sichtbare Spitze eines Eisbergs dar.

Eine infolgedessen notwendige Untersuchung des spezifischen Dunkelfeldes sieht sich jedoch besonderen methodischen Schwierigkeiten ausgesetzt. Eine teilnehmende Beobachtung etwa erscheint angesichts der äußerlich kaum wahrnehmbaren manipulativen Einwirkungen durch punktuelle Schlechtleistungen im Wettbewerb wenig aufschlussreich. Und in dessen Anschluss geführte Interviews mit potenziell manipulierenden Protagonisten bergen aufgrund der hohen sozialen Kosten die Gefahr von Verzerrungen durch ein angepasstes Aussageverhalten. ${ }^{247} \mathrm{Zu}$ deren Verhinderung können zwar Anonymisierungstechniken in groß angelegten OnlineUmfragen beitragen, bei denen kontaktierte Sportakteure zur Teilnahme unter Verwendung der Randomized Response Technik (RRT) gebeten werden. ${ }^{248}$ Solche Befragungen sind in ihrer Aussagekraft jedoch von einem kaum zu kontrollierenden repräsentativen Rücklauf an Antworten abhängig. Außerdem werden sie zumeist nur innerhalb einer Sportart, häufig sogar noch regional eingegrenzt durchgeführt und nicht detailliert nach Form und Motiv der Manipulation unterschieden. Sie liefern daher nur sektorale und undifferenzierte Werte über die Prävalenz von Match Fixing. Ein weiterer Ansatz könnte in der Identifizierung ungewöhnlicher Spielereignisse und auffälliger Schlechtleistungen mittels der statistischen Auswertung der gerade im Spitzensport vielfältig erhobenen Leistungsdaten liegen. Diese vermerken zwar, wann ein Sportakteur in bestimmten messbaren Kategorien hinter seinen durchschnittlich erzielten Werten und der dementsprechend zu erwartenden Leistung zurückbleibt. Allerdings besteht der Reiz des Sports oftmals gerade im Eintritt des Unerwarteten und der Abhängigkeit des grundsätzlichen individuellen Leistungsvermögens von der Tagesform und der Taktik und Leistung des Gegners, so dass

246 Bannenberg/Schaupensteiner Korruption, S. 40, weiterhin Wabnitz/Janovsky/ Schmitt/Bannenberg 13. Kapitel Rn. 22; Bundeskriminalamt (Hrsg.) Bundeslagebild Korruption 2018, S. 23; Fischer StGB vor $\$ 298$ Rn. 4.

247 Pitsch/Emrich/Pierdzioch, in: Emrich/Pierdzioch/Pitsch (Hrsg.), Falsches Spiel, 2015, S. 157 (159).

248 Wie etwa in der Studie über Match Fixing im deutschen Amateurfußball von Pitsch/Emrich/Pierdzioch, in: Emrich/Pierdzioch/Pitsch (Hrsg.), Falsches Spiel, 2015, S. 157 ff.; für Match Fixing in den Niederlanden Spapens/Olfers European Journal of Crime, Criminal Law and criminal Justice 2015, 333 (344 ff.). 
die isolierte Betrachtung auffälliger Sportdaten keinerlei Rückschlüsse auf manipulative Zwecke erlaubt. ${ }^{249}$

Dies hat zur Folge, dass die empirischen Belege für die vermuteten immensen Zuwachsraten und Ausmaße gerade des wettbedingten Match Fixing selbst in der wissenschaftlichen Literatur überwiegend in Form anekdotischer Evidenz durch die Aneinanderreihung bekannter Manipulationsfälle bzw. die Wiedergabe von Aussagen involvierter Akteure erbracht werden. ${ }^{250}$ Auch die im Rahmen des Gesetzgebungsprozesses zu den $\$ \$ \int 265 \mathrm{c}$, 265d StGB geladenen Experten konnten keine Zahlen zum Ausmaß der erfassten Verhaltensweisen nennen. ${ }^{251}$ Vor dem Hintergrund dieser methodischen Schwierigkeiten und einer nur fragmentarischen Forschung 252 werden im Folgenden verfügbare Hellfelddaten und Studienergebnisse zusammengetragen, um durch die Kombination einzelner Indizien das Ausmaß sowie die sportart- und manipulationsformspezifische Verteilung zumindest fundiert abschätzen zu können.

\section{Hellfeld}

Informationen über die Anzahl aufgeklärter bestechungsbedingter Spielmanipulationen lassen sich verschiedenen Quellen entnehmen. Sofern sie einer nationalen Strafverfolgung unterliegen, geben amtliche Statistiken der Strafverfolgungsbehörden Auskunft über registrierte Verdachtsfälle. In jedem Fall verletzen manipulative Einwirkungen die Regelwerke der einzelnen Sportverbände, weswegen auf Daten über einschlägige Verurteilungen von Sportakteuren durch deren Disziplinarorgane abgestellt werden kann. Diese offenbaren allerdings selten, ob einer manipulativen Einwirkung auch eine korruptive Abrede vorausging. Das gilt schließlich auch für die Alarmmeldungen der von Wettanbietern und Sportverbänden zur Überwachung des Wettmarkts eingesetzten Analyseinstrumente, die darüber hinaus bloße Verdachtsmomente bezüglich wettbezogener Spielma-

249 Forrest/McHale Journal of Management Mathematics 2019, 1 (4 f.).

250 Di Ronco/Lavorgna Trends in Organized Crime 2015, 176 (177); vgl. etwa die Aufzählung von Einzelfällen bei Heilemann Bestechlichkeit, S. 77 ff.; Carpenter International Sports Law Review 12 (2), 13 ff. bzw. die Wiedergabe von Aussagen von Wettbetrügern bei Hill Sichere Siege.

251 Vgl. Bundesministerium des Innern (Hrsg.) Fragenkatalog zum Expertentreffen, S. 71.

252 Krit. insoweit KEA (Hrsg.) Match-Fixing, S. 11; Spapens/Olfers European Journal of Crime, Criminal Law and criminal Justice 2015, 333 (339). 
nipulation liefern. Eine passgenaue Zuordnung von Zahlen zu den hier untersuchten Erscheinungsformen bestechungsbedingter Schlechtleistungen zu Wettzwecken bzw. sportinternen Zwecken erscheint daher schwierig.

Die Polizeiliche Kriminalstatistik weist für den Sportwettbetrug ( $\$ 265$ c StGB) bzw. die Manipulation berufssportlicher Wettbewerbe ( $\$ 265 \mathrm{~d}$ StGB) für das Jahr 2018, in der die Tatbestände erstmals statistisch erfasst wurden, insgesamt drei registrierte Fälle und für das Folgejahr 2019 deren fünf aus. ${ }^{253}$ Ein vergleichender Blick auf das Deliktsfeld Korruption ergibt für das Jahr 2019274 Fälle für Bestechung bzw. Bestechlichkeit im geschäftlichen Verkehr ( $\mathbb{S} 299 \mathrm{f}$. StGB) und insgesamt 913 Fälle für den öffentlichen Sektor ( $\mathbb{S} 331 \mathrm{ff}$. StGB). 254 Ähnlich geringe Fallzahlen finden sich auch in anderen europäischen Ländern, die bereits seit längerem über spezifische Straftatbestände des Sportbetrugs oder der Sportkorruption verfügen, sei es in eigenen sportspezifischen Gesetzen wie etwa in Italien ${ }^{255}$ oder ins allgemeine Strafrecht integriert wie in Frankreich ${ }^{256}$ oder Spanien ${ }^{257}$. Die vor diesem Hintergrund überraschenden Ermittlungsergebnisse von Europol, die sich allein bezüglich des Manipulationskomplexes der Jahre 2009 bis 2012 im europäischen Fußball auf 425 Verdächtige und mehr als 380 manipulierte Spiele erstreckten, ${ }^{258}$ weisen auf zeitweise große Einzelfälle hin, die sich statistisch entsprechend der gerichtlichen Aufarbeitung nach nationaler Zuständigkeit aufteilen und dort aufgrund der eu-

253 Bundeskriminalamt (Hrsg.) Polizeiliche Kriminalstatistik 2019, Jahrbuch Band IV, S. 100.

254 Bundeskriminalamt (Hrsg.) Polizeiliche Kriminalstatistik 2019, Jahrbuch Band IV, S. 143.

255 Gesetz Nr. 401/89 über Interventionen auf dem Gebiet des heimlichen Spiels und der heimlichen Wetten und zum Schutz ordnungsgemäßen Ablaufs sportlicher Wettkämpfe vom 13.9.1989; hierzu im Detail KEA (Hrsg.) Match-Fixing, S. 38 ff.; zu staatlichen Freisprüchen im Calcioscomesse-Komplex (s. Fn. 130) und der seltenen Anwendung generell Wojdyla Causa Sport 2014, 201 (203).

256 Einfügung des Article 445-1-1 in den code pénal durch loi n²012-158 du 1er février 2012 visant à renforcer l'éthique du sport et des droits des sportifs, JORF n ${ }^{\circ} 0028$ du 2 février 2012, page 1906, texte $n^{\circ} 2$.

257 Articulo 286bis 4 Código Penal als im Jahr 2010 durch das Gesetz 5/2010 eingeführte und im Jahr 2015 durch das Gesetz 1/2015 geänderte Ergänzung des allgemeinen Tatbestands der Privatkorruption in Articulo 286bis 1. Zur praktischen Bedeutungslosigkeit Ortiz de Urbina Gimeno, in: Kuhlen/Judlich/Gomez Martin/Ortiz de Urbina Gimeno (Hrsg.), Korruption und Strafrecht, 2018, S. 101 (103); KEA (Hrsg.) Match-Fixing, S. 35.

258 Presseerklärung von Europol vom 6.2.2013, www.europol.europa.eu/newsroom /news/update-results-largest-football-match-fixing-investigation-in-europe. 
ropaweit noch uneinheitlichen strafrechtlichen Erfassung teilweise anderen Tatbeständen zugeordnet werden. ${ }^{259}$

Eine mit Verurteilungen durch staatliche Gerichte oder verbandsinterne Spruchkörper sowie belastbaren Geständnissen von Sportakteuren gefütterte Studie gibt für den Zeitraum von 2000 bis 2010 Aufschluss über die Verteilung bewiesener Korruptionsfälle in internationalen Sportwettbewerben. ${ }^{260}$ Entgegen der hier getroffenen Begriffsbestimmung werden dabei auch Dopingfälle einbezogen, auf die mit 95,6\% der insgesamt 2.089 registrierten Korruptionsfälle ein gewaltiger Anteil entfällt. Von den nur 57 Fällen erwiesener Spielmanipulation lässt sich bei $58 \%$ ein expliziter Wettbezug feststellen. Diese finden wiederum zu $85 \%$ in Europa oder Asien statt und beziehen sich zu $72 \%$ auf den Fußball und innerhalb dessen überwiegend auf Wettbewerbe außerhalb der europäischen Top-Ligen. Zur Erklärung der eher geringen Zahlen des Match Fixing trägt auch die Zähleinheit von einzelnen „cases“ bei, hinter denen durchaus eine Vielzahl manipulierter Spiele stehen kann. In der deutlichen Unterlegenheit gegenüber dem Doping bilden sich wiederum die schwierigere Beweisbarkeit von Match Fixing und dessen uneinheitliche Regulierung ab.

Den genannten Quellen zu erfassten Verdachtsfällen bestechungsbedingter Wettkampfmanipulationen lassen sich nur mit Mühe aussagekräftige Anhaltspunkte und Tendenzen entnehmen. Amtliche Statistiken der Strafverfolgungsbehörden weisen zu entsprechenden Straftatbeständen kaum relevante Fallzahlen auf. Eine Auswertung der nicht erschöpfend dokumentierten Sanktionspraxis der einzelnen Sportverbände liefert für das erste Jahrzehnt des neuen Jahrhunderts überschaubare Zahlen in Bezug auf Match Fixing, wobei sich der Fußball als von wettbezogenen Manipulationen besonders betroffene Sportart herausbildet.

\section{Dunkelfeld}

Erste Erkenntnisse zum Dunkelfeld zumindest wettbezogener Manipulationen können sich aus der von Wettanbietern und Sportverbänden in Kooperation mit spezialisierten Dienstleistern betriebenen Überwachung der

259 So wurden die aus Deutschland heraus operierenden Akteure mangels eines spezifischen Tatbestandes wegen Betrugs bzw. Beihilfe zum Betrug verurteilt. Die amtlichen Kriminal- und Strafverfolgungsstatistiken weisen den Wettbetrug aber nicht als relevanten Sonderfall des $\$ 263$ StGB aus.

260 Gorse/Chadwick Prevalence, S. 5 ff. 
Sportwettenmärkte ergeben. Von Algorithmen erkannte Auffälligkeiten in der Entwicklung der weltweit verfolgten Wettquoten zu einem bestimmten sportlichen Wettbewerb lösen einen Alarm aus, der als erstes Indiz einer möglichen Manipulation von Mitarbeitern der Dienstleister zunächst auf technische Erklärungen überprüft, sodann mit Videomaterial des ausgetragenen Wettbewerbs abgeglichen und entsprechend dem dabei ermittelten Verdachtsgrad klassifiziert wird. ${ }^{261}$ Die Zuordnung derartiger Berichte zum Dunkelfeld erklärt sich daraus, dass die in ihnen festgestellten Verdachtsmomente nicht ausnahmslos zur Kenntnis der Sportverbände gelangen, geschweige denn eine verbandsrechtliche oder gar strafrechtliche Verfolgung auslösen. Hinsichtlich des Ausmaßes des Match Fixing kommt den Daten allenfalls indizielle Bedeutung zu, da das Verfahren einerseits Spielmanipulationen ohne begleitende Auffälligkeiten auf dem Wettmarkt nicht erkennt, andererseits auch solche Spiele als verdächtig meldet, die sich im Anschluss nicht als manipuliert erweisen.

In einem Zeitraum von viereinhalb Jahren zwischen 2009 und 2014 schätzte die Firma Sportradar auf Basis des von ihr zur Überwachung der Wettmärkte eingesetzten Fraud-Detection-System (FDS) insgesamt 1.625 Fußballspiele als äußerst verdächtig ein, was weniger als einem Prozent der in diesem Zeitraum weltweit überwachten Spiele entspricht. ${ }^{262}$ Davon waren knapp $80 \%$ nationale Ligaspiele unterschiedlicher Länder, die sich wiederum zu $78 \%$ auf die jeweiligen Ersten Ligen verteilten, wobei diese auch engmaschiger kontrolliert wurden als untere Ligen. ${ }^{263}$ Viele Alarmmeldungen verzeichnen die Überwachungssysteme auch bei Tennisspielen. ${ }^{264}$ Diese summierten sich im Zeitraum 2009 bis 2017 auf 1.046, wobei ein nahezu kontinuierlicher jährlicher Anstieg von 43 bzw. 69 Meldungen in den Jahren 2009 und 2010 bis hin zu 291 und 256 Meldungen in den

261 Ausführlich zu diesem mehrstufigen Prozess bei der Firma Sportradar Forrest/ McHale Journal of Management Mathematics 2019, 1 (15) sowie später unter Teil 3 C. II. 1. a) aa) (2).

262 Van Rompuy Spielmanipulationen, S. 25; bestätigt auch von Forrest/McHale Journal of Management Mathematics 2019, 1 (15), denen zufolge Sportradar in einem nicht näher benannten Jahr von 45.569 überwachten Fußballspielen am Ende der mehrstufigen Kontrolle 291 Spiele (0,64\%) als höchstverdächtig klassifizierte.

263 Van Rompuy Spielmanipulationen, S. 27.

264 Nach Angaben der International Betting Integrity Association (ESSA), der über 40 lizensierte Wettanbieter angehören, entfielen im Jahr 2018 gar die meisten an die Sportverbände weitergereichten Alarmmeldungen auf Tennis, s. ESSA (Hrsg.) Annual Integrity Report 2018, https://ibia.bet/wp-content/uploads/2019/ 05/ESSA-2018-Annual-Integrity-Report.pdf. 
Jahren 2016 und 2017 zu beobachten ist. ${ }^{265}$ Zusätzlich erhielt die Tennis Integrity Union im gleichen Zeitraum 345 Meldungen von Spielern, Trainern, Journalisten oder anderen Beteiligten mit Informationen aus erster Hand über Spielmanipulationen. Zusammengenommen bezogen sich diese Alarmmeldungen zu $78 \%$ - ein deutlich überrepräsentativer Wert gemessen an ihrem Anteil an allen ausgetragenen Spielen - auf Turniere der mittleren (ATP-Challenger-Turniere) und niedrigen Kategorie (ITF-Turniere) mit einer stärkeren Belastung der Herrenkonkurrenzen. Im Jahr 2017 fiel je eine Alarmmeldung auf 165 bewettbare Herrenspiele und 557 bewettbare Damenspiele, was einem Gesamtanteil manipulationsverdächtiger Spiele von $0,4 \%$ entspricht. ${ }^{266}$ Die Alarmmeldungen trugen im genannten Zeitraum zu insgesamt 58 erfolgreichen Disziplinarverfahren gegen Profispieler bei. ${ }^{267}$

Die Betroffenheit des Fußballs bildet sich demnach auch in den Alarmmeldungen der Wettmarktüberwachung ab, die vergleichbare jährliche Gesamtwerte bei ansteigender Entwicklung mittlerweile aber auch im Tennis ausweisen. Die absoluten Zahlen der auf diese Weise als manipulationsverdächtig ausgewiesenen Spiele wirken in beiden Sportarten beträchtlich, relativieren sich jedoch im Hinblick auf die enorme Gesamtzahl tagtäglich und weltweit ausgetragener Spiele. Mehr als ein Hinweis auf von wettbezogenem Match Fixing besonders belastete Sportarten, eine grobe Schätzung bezüglich des Ausmaßes und ein Indiz für die Vermutung seines Ansteigens lassen sich aus den Alarmmeldungen angesichts ihrer eingeschränkten Aussagekraft nicht ableiten. Für die Prävalenz des nichtwettbezogenen Match Fixing ergeben sich hieraus keine Schlüsse.

Wie erwähnt erscheinen daher anonyme Befragungen von Sportakteuren trotz der Schwierigkeit ihrer sportartübergreifenden Durchführung und eines möglicherweise verzerrten Rücklaufs noch am ehesten geeignet, die tatsächliche Verbreitung von Match Fixing zu erhellen. Im Folgenden werden die Ergebnisse mehrerer, sowohl sportartspezifischer als auch übergreifender Befragungen der jüngeren Vergangenheit zusammengefasst.

So gaben im Jahr 2012 mehr als 3.000 professionelle Fußballspieler aus 15 ost- und südosteuropäischen Ländern in einer von der Spielergewerkschaft FIFPro aufgelegten anonymen Befragung unter anderem Auskunft über persönliche Berührungspunkte mit Match Fixing. Ein knappes Viertel $(24 \%)$ gab an, Kenntnis von erfolgten Spielmanipulationen in der eige-

265 Lewis/Wilkinson/Henzelin Integrity in Tennis, S. 23.

266 Lewis/Wilkinson/Henzelin Integrity in Tennis, S. 25.

267 Lewis/Wilkinson/Henzelin Integrity in Tennis, S. 42. 
nen Liga zu haben und immerhin $12 \%$ berichteten, selbst bereits wegen Spielmanipulationen kontaktiert worden $\mathrm{zu}$ sein. ${ }^{268}$ Länderspezifische Höchstwerte erzielten dabei Russland, wo ein Anteil von $43 \%$ Kenntnis über ausgeführte Manipulationen von Ligaspielen behauptete, sowie Griechenland und Kasachstan mit bis zu $35 \%$ bei den berichteten Kontaktversuchen. ${ }^{269}$

Einen ähnlichen Rücklauf erzielte im Jahr 2017 eine vergleichbar ausgerichtete Online-Umfrage im Rahmen der Erstellung eines Integritätsberichts im Tennis. Von 3.200 teilnehmenden Profispielern aus allen Ländern, die repräsentativ die Größe der verschiedenen Leistungsklassen abbildeten, gaben 14,5\% an, aus persönlicher Beobachtung oder Erfahrung Kenntnis von außersportlich motivierten Spielmanipulationen zu besitzen, wobei sich bei über einem Drittel dieser Gruppe (35\%) die Kenntnis auf mehr als einen Vorfall dieser Art bezog. ${ }^{270}$ Gleichzeitig nahmen nur 5,6\% an, ihre Kollegen würden wahrgenommene Integritätsverstöße „immer“ oder „meistens“ den zuständigen Verbandsstellen melden. ${ }^{271}$ Dies unterstreicht abermals die Vermutung eines großen Dunkelfeldes.

In einer sportartübergreifenden Umfrage des von der Europäischen Union geförderten „Fix the Fixing"-Projekts gingen 34,6\% der über 600 teilnehmenden Athleten aus 13 verschiedenen Sportarten ${ }^{272}$ und sechs europäischen Ländern ${ }^{273}$ davon aus, dass Wettbewerbe in ihrer jeweiligen Leistungsklasse manipuliert würden. ${ }^{274}$ Kenntnis von einer Wettkampfmanipulation innerhalb der vergangenen 12 Monate besaßen $20 \%$, während jeder achte Athlet angab, überwiegend aus finanziellen Gründen selbst bereits einmal an einer Manipulation mitgewirkt zu haben. Etwas geringer $(7,5 \%)$ fiel die Zustimmungsrate auf die Frage nach der eigenen aktiven Beteiligung an einer Wettbewerbsverzerrung bei einer ebenfalls sportartübergreifenden, auf deutsche Kaderathleten in olympischen Sportarten beschränkten Erhebung aus. ${ }^{275}$

268 FIFPro (Hrsg.) Black Book, S. 37.

269 FIFPro (Hrsg.) Black Book, S. 33 f.

270 Lewis/Wilkinson/Henzelin Integrity in Tennis, S. $40 \mathrm{f}$.

271 Lewis/Wilkinson/Henzelin Integrity in Tennis, S. 42.

272 Fußball, Rugby, Handball, Volleyball, Wasserball, Kampfsport, Badminton, Tennis, Leichtathletik, Schwimmen, Turnen, Gewichtheben.

273 Griechenland, Frankreich, Großbritannien, Zypern, Österreich, Irland.

274 Zur Übersicht der Ergebnisse s. theicss.org/2017/07/23/35-athletes-believe-match es-at-their-level-were-fixed-says-forthcoming-study/.

275 Pitsch/Frenger/Emrich/Pierdzioch, in: Emrich/Pierdzioch/Pitsch (Hrsg.), Falsches Spiel, 2015, S. 181 (189). 
Anhaltspunkte für die Verteilung auf die beiden hier untersuchten Formen des Match Fixing zu Wettzwecken bzw. zu sportinternen Zwecken des Vorteilsgebers lassen sich aus den Antworten der Sportakteure auf Fragen nach dem wahrscheinlichsten Initiator einer Spielmanipulation gewinnen. In der erwähnten sportartübergreifenden Umfrage benennt der größte Anteil von 38,1\% einen Offiziellen eines Clubs oder Verbandes, nur 8,9\% hingegen eine Person außerhalb des Sports. Dies könnte auf ein erhebliches Ausmaß nicht wettbezogener Manipulationen hindeuten. $\mathrm{Zu}$ einem anderen Ergebnis gelangt jedoch eine wiederum allein auf den Fußball bezogene Umfrage, in der 32,3\% der ca. 1.500 teilnehmenden Spieler aus acht europäischen Ländern in einer solch außenstehenden Person den wahrscheinlichsten Initiator sehen, während nur 19,3\% diese Rolle Clubfunktionären zuschreiben. ${ }^{276}$ Dabei zeigen sich allerdings beträchtliche länderspezifische Unterschiede. In Griechenland und Rumänien steigt der auf Clubfunktionäre entfallende Anteil der Nennungen auf $48 \%$, in Ungarn wiederum benennt jeder Zweite eine außenstehende Person.

Mit Ausnahme der sportartübergreifenden Umfragen fehlen in den Erhebungen Angaben über selbst begangene Manipulationen, was eine Einschätzung des Ausmaßes von Match Fixing im Dunkelfeld erschwert. Aus einem beträchtlichen Anteil an Kenntnisträgern hinsichtlich erfolgter Manipulationen lässt sich kein unmittelbarer Rückschluss auf deren Anzahl ableiten, da sich theoretisch auch nur wenige Fälle unter den Sportakteuren herumgesprochen haben könnten. Die Umfragen skizzieren im Rahmen eines überraschend schmalen Korridors (12 bis $24 \%)^{277}$ die durchschnittliche Größe der Gruppe von Sportakteuren, die direkt oder indirekt mit Match Fixing in Berührung gekommen ist. Hieraus ergibt sich noch immer eine starke Mehrheit an Sportakteuren ohne derartige Erfahrungen. Die Werte verbieten es aber zweifellos, von Match Fixing als von einer Ausnahmeerscheinung zu sprechen. Vielmehr handelt es sich um ein sportartübergreifend existentes und durchaus verbreitetes Phänomen, das offenbar in einigen Sportarten besondere Häufungen aufweist. In bestimmten Ländern und Ligen können diese gar einen Umfang einnehmen,

276 Errechnet aus den Ergebnissen der von Harvey/Levy im Jahr 2014 im Rahmen der FIFA-Kampagne „Don't Fix it“ konzipierten Befragung, abrufbar unter: fifpro.org/en/rights/match-fixing/match-fixing-don-t-fix-it.

277 Innerhalb dessen liegt auch eine aufgrund ihrer sehr speziellen Zielgruppe nicht ausführlicher beschriebene Umfrage unter litauischen Basketballern, in der von 259 Befragten $21 \%$ angaben, persönlich zwecks Match-Fixing kontaktiert worden zu sein, s. Trumpyte in: Amnesty International (Hrsg.), Corruption Report, 2016, S. 250 (251). 
der über ein Drittel der dort aktiven Sportakteure an der Integrität der von ihnen bestrittenen Wettbewerbe zweifeln lässt. Eine detaillierte Zuordnung zu den Erscheinungsformen bestechungsbedingter Manipulationen fällt angesichts stark divergierender Angaben zu Fragen nach möglichen Initiatoren schwer. Die schwankenden Verhältnisse verdeutlichen jedoch auch diesbezüglich die Notwendigkeit einer sportart- und ligenspezifischen Differenzierung unter Berücksichtigung der dort jeweils unterschiedlich stark ausgeprägten Risikofaktoren wie Wettmarktdaten und korruptionsbelasteten Vereins- und Verbandsstrukturen.

\section{Ergebnis}

Zwecks phänomenologischer Beschreibung der durch die $\$ \$ 265 \mathrm{c}, 265 \mathrm{~d}$ StGB kriminalisierten Verhaltensweisen wurde ausgehend von einer Auseinandersetzung mit den kursierenden Begriffen Sportmanipulation, Sportkorruption und Match Fixing eine kategorisierende Übersicht über die Erscheinungsformen von Manipulationen im Sport erstellt. Entlang der gesetzlich genannten Merkmale der tatbestandlich erfassten Manipulationen erfolgte unter Ausgrenzung verschiedener Fallgruppen eine Hinführung zu bestechungsbedingten Schlechtleistungen innerhalb eines sportlichen Wettbewerbs. Diese können vor allem durch Sportler und Schiedsrichter, aber auch durch sonstige mit unmittelbarem Einfluss auf den Verlauf eines sportlichen Wettbewerbs ausgestattete Personen begangen werden und treten ausweislich der beschriebenen Beispielsfälle in vielen Sportarten auf. Entsprechend dem Motiv des Vorteilsgebers, bei dem es sich um eine sportinterne oder außenstehende Person handeln kann, wurden die Manipulationsabsprachen weiterhin in wettbezogene und sportintern motivierte unterschieden und tatbestandlich zugeordnet.

Ihr Auftreten wird mit der Entstehung einer Sportindustrie und der rasanten Entwicklung der Sportwettenmärkte in Verbindung gebracht, die Verlauf und Ergebnis eines sportlichen Wettbewerbs auf verschiedenen Ebenen mit der Aussicht auf erhebliche wirtschaftliche Vorteile für Teilnehmende und Außenstehende verknüpft und so Anreize für deren manipulative Extraktion geschaffen hätten. Das Zusammentreffen von Anreizen und Ausnutzungsmöglichkeiten begründet besondere Gefährdungsszenarien, die sich zunächst einzelnen Sportarten (insbesondere Fußball, Tennis, Kricket und Basketball), innerhalb derer aber vor allem bestimmten Ländern und Leistungsklassen zuweisen und empirisch durchaus belegen lassen. An der Existenz lukrativer und realisierbarer Tatgelegenheiten an- 
knüpfend, versuchen ökonomische Modelle insbesondere wettbezogene Manipulationen als Resultat eines rationalen Wahlaktes zu erklären, der auch unter dem Einfluss interagierender Marktmechanismen stünde. Wenngleich dieser Ansatz den Blick auf bestimmte manipulationsbegünstigende Zusammenhänge öffnet und Impulse für eine präventive Anpassung bestimmter Rahmenbedingungen geben kann, vermag er wesentliche systemische Einflussfaktoren und individuell variierende moralische Einstellungen nur oberflächlich einzubinden und greift als Erklärungsansatz für bestechungsbedingtes Match Fixing zu kurz.

Bezüglich dessen Ausmaßes lassen sich derweil kaum verlässliche Aussagen treffen. Die Vermutung eines großen, korruptionstypischen Dunkelfeldes und der Mangel an Bemühung zwecks dessen länder- und sportartübergreifender Erforschung können die vielerorts und auch vom Gesetzgeber ${ }^{278}$ behauptete Zunahme und weite Verbreitung von Match Fixing weder zweifelsfrei bestätigen noch widerlegen. ${ }^{279}$ Für wettbezogene Manipulationen ergeben sich aus der Analyse von Wettmarktdaten Indizien für eine vergleichsweise stärkere Belastung von Fußball und Tennis, deren Spiele zu 0,5 bis $1 \%$ betroffen sein könnten. Dass dieser Wert bei Einbeziehung unerkannt wettbezogener sowie nicht-wettbezogener Manipulationen höher ausfällt und sich auf weitere Sportarten erstreckt, legen die Anteile von Sportakteuren nahe, die in anonymen Befragungen von einer eigenen Beteiligung an Spielmanipulationen, empfangenen Kontaktversuchen oder Kenntnissen über von Kollegen begangene Spielmanipulationen berichten. Dabei ist die repräsentative Aussagekraft der herangezogenen Studien jedoch gesondert zu hinterfragen und hinsichtlich der Sportart, des regionalen Bezugspunkts, der Leistungsklasse und des Initiators der Manipulation differenziert auszuwerten.

\section{B. Strafrechtliche Ausgangslage: Reaktionsmöglichkeiten auf die erfassten Sportmanipulationen}

Die Einführung der neuen Tatbestände wurde auch auf eine bis dato unzureichende strafrechtliche Erfassung der nun adressierten und soeben phänomenologisch beschriebenen Manipulationsformen gestützt. Die Gesetzesbegründung weist den diesbezüglich als lückenhaft empfundenen strafrechtlichen Schutz als maßgeblichen Antrieb der vorgenommenen Erwei-

278 BT-Drs. 18/8831, S. 10.

279 So auch Tsambikakis StV 2018, 319 (326). 
terung aus. ${ }^{280}$ Diese Einschätzung der Rechtslage vor Inkrafttreten der neuen Tatbestände wird im Folgenden anhand einer Untersuchung strafrechtlicher Reaktionsformen auf das spezifisch eingegrenzte manipulative Verhalten im Sport jenseits der erlassenen $\$ \mathbb{\$} 265 \mathrm{c}$, 265d StGB überprüft, um im Abgleich mit dem bereits skizzierten Anwendungsbereich der $\$ \$ 265 \mathrm{c}$, 265d StGB das Ausmaß der bewirkten strafrechtlichen Ausdehnung aufzeigen zu können.

Die Darstellung wird der Auseinandersetzung mit allgemeinen Legitimationskriterien und deren Erfüllung durch die $\$ \$ 265$ c, 265d StGB quasi als Vorfrage vorangestellt. Ihrem Ergebnis kann in keine Richtung präjudizielle legitimationsbezogene Relevanz zukommen. Eine in Bezug auf das untersuchte Verhalten tatsächlich feststellbare strafrechtliche Lücke kann ohne nähere Befassung mit Zweck und Umsetzung der Kriminalisierung deren Schließung durch den Gesetzgeber nicht aus sich heraus provozieren. Gleichzeitig vermögen es vorhandene, aber von gewissen Umständen abhängige Möglichkeiten einer strafrechtlichen Ahndung nicht, eine spezifizierte Gesetzgebung von vornherein zu delegitimieren. Im Rahmen der Bewertung übergeordneter Legitimationskriterien strafrechtlicher Tatbestände sind bereits bestehende strafrechtliche Reaktionsformen aber zu berücksichtigen. Deren gesonderte Darstellung dient insofern auch der Vorbereitung eines im weiteren Verlauf erforderlichen Rückgriffs.

Sie unterzieht dabei nur die durch den Anwendungsbereich der $\$ \mathbb{S} 265 \mathrm{c}$, $265 \mathrm{~d}$ StGB spezifizierte Teilmenge an korruptiven Absprachen und hierauf gründenden Manipulationen der Überprüfung einer anderweitigen Strafbarkeit. ${ }^{281}$ Die vorangehende phänomenologische Betrachtung offenbarte auch innerhalb dieser Manipulationsformen Unterschiede in Zeitpunkt der Einwirkung, motivationalem Antrieb und verfolgtem Zweck, die für ihre strafrechtliche Würdigung relevant sein können. Der Überblick trennt die oft mehraktigen Manipulationsvorgänge zeitlich auf und differenziert

280 BT-Drs. 18/8831, S. 1.

281 Ausgeklammert bleibt damit die andernorts untersuchte Strafbarkeit eines Sportlers wegen eines dem eigenen Vorteil dienenden Wettkampfverhaltens in Form einer "Schwalbe“, der mutwilligen Verletzung eines Gegenspielers oder der technischen Veränderungen von Ausrüstung und Sportgeräten. Zur nahezu einstimmig abgelehnten Strafbarkeit wegen Betrugs durch das Begehen einer "Schwalbe“ s. etwa Schattmann Betrug, S. 149 ff.; von Komorowski/Bredemeier SpuRt 2005, 227 ff.; Tenter/Thomas JA 1996, 855 f., die das negative Ergebnis aber jeweils anders begründen. Eingehend zu Fragen der Strafbarkeit gemäß $\$ 223$ StGB bzw. $\$ 303$ StGB durch Wettkampfverhalten PHB-SportR/Reinhart, 3. Aufl., 8. Teil 3. Kap. Rn. 63 ff. bzw. $101 \mathrm{ff}$. 
zwischen manipulativem Verhalten im Wettkampfgeschehen (dazu I.), entsprechenden Absprachen im Vorfeld (dazu II.) und hieran anschließenden Begleithandlungen (dazu III.). Innerhalb dieser für eine strafrechtlich relevante Handlung in Betracht kommenden Anknüpfungspunkte wird im Hinblick auf die geprüften Straftatbestände nach Akteuren und verfolgten Zielen zu unterscheiden sein.

I. Strafbarkeit durch manipulatives Wettkampfverhalten

Eine Fokussierung der Strafbarkeitsprüfung auf das eigentliche Wettkampfgeschehen grenzt zunächst den Kreis potenzieller Täter auf die hieran unmittelbar teilnehmenden Sportler, Trainer und Sportrichter ein. Deliktsbezogen wird es für die hier untersuchte Beeinflussung eines Wettbewerbs zu eigenen Ungunsten bzw. unter Aufgabe der gebotenen Unparteilichkeit kaum einmal der Beeinträchtigung der körperlichen Unversehrtheit eines anderen Teilnehmers oder der Beschaffenheit einer fremden Sache bedürfen, da sie sich auch kontaktlos durch die verdeckte Minimierung des eigenen Leistungsvermögens realisieren lässt. Als charakteristisch für diese Manipulationsform erweist sich insofern ein täuschendes Element - eben in Bezug auf das eigentliche Leistungsvermögen und die tatsächlich verfügbaren Möglichkeiten, eine bestimmte Spielsituation im Sinne des sportlichen Erfolges bzw. Regelwerks besser zu lösen.

In Anbetracht der mit höherklassigen sportlichen Wettbewerben verbundenen Vermögensinteressen steht daher vor allem eine Strafbarkeit der Akteure wegen Betrugs gemäß $\$ 263$ StGB im Raum. Darüber hinaus ließe sich angesichts der vermögensrelevanten Konsequenzen der erbrachten Leistung eines Sportlers oder Schiedsrichters für dessen Verein oder Verband auch an eine Strafbarkeit wegen Untreue gemäß $\$ 266$ StGB denken. Diese scheitert jedoch bereits am Fehlen einer entsprechenden Vermögensbetreuungspflicht. ${ }^{282}$ Somit wird die auf einer manipulativen Abrede beruhende wettkampfimmanente Schlechtleistung von Sportlern und Schiedsrichtern im Folgenden mit den Voraussetzungen des Betrugstatbestandes abgeglichen. Diesen erfüllt, wer in der Absicht, sich oder einem Dritten einen rechtswidrigen Vermögensvorteil zu verschaffen, das Vermögen eines anderen dadurch beschädigt, dass er durch Vorspiegelung falscher oder durch Entstellung oder Unterdrückung wahrer Tatsachen einen Irrtum erregt oder unterhält.

282 Vgl. Heilemann Bestechlichkeit, S. 147 f.; Bösing Manipulationen, S. 67 f., 86 f. 
1. Betrugsstrafbarkeit des Sportlers durch Schlechtleistung im Wettkampf $(\$ 263$ StGB)

Anknüpfungspunkt ist also die Minimierung des eigenen Leistungseinsatzes zum Vorteil des Wettbewerbsgegners, die sich in der aktiven Verursachung eigener spieltaktischer Nachteile (Eigentore, Verursachung von Strafstößen oder Platzverweisen, Schläge ins Aus oder Netz), aber auch im Unterlassen einer zur Verhinderung gegnerischer Tor- oder Punkterzielung gebotenen Verteidigung ausdrücken kann. Als potenziell Getäuschte dieser bewussten Schlechtleistung kommen neben dem eigenen Verein bzw. den Teamkollegen auch der den Wettbewerb ausrichtende Verband sowie die Zuschauer in Betracht. Geschädigt könnte darüber hinaus auch ein dritter Verein sein, der durch einen manipulierten Spielausgang eine möglicherweise vermögenswerte Wettbewerbsposition verliert.

\section{a) Zum Nachteil des eigenen Vereins bzw. der Teamkollegen}

In Teamsportarten könnte ein Betrug zum Nachteil des Vereins als Arbeitgeber vorliegen. Problematisch ist allerdings bereits, inwiefern im leistungsreduzierten Wettkampfverhalten des Sportlers eine Täuschungshandlung liegt. Eine Täuschung ist jede Handlung, die Erklärungswert hinsichtlich Tatsachen besitzt und durch Einwirken auf die Vorstellung einer anderen natürlichen Person bei dieser zu einem Irrtum hierüber führen kann. ${ }^{283}$ Gegenstand einer betrugsrelevanten Täuschung können demnach ausschließlich Tatsachen sein, zu denen als innere Tatsachen auch Absichten zu zählen sind. ${ }^{284}$ Als solche käme auch die Absicht eines Sportlers in Betracht, einen Wettbewerb nicht entgegen dem grundlegenden sportlichen Konkurrenzgebot manipulativ zu den eigenen Ungunsten zu beeinflussen. Allerdings wird er diese gegenüber seinem Verein oder anderen Adressaten nicht explizit zum Ausdruck bringen. Da eine betrugsrelevante Täuschung auch konkludent erfolgen kann, ist entscheidend, ob sie aus seinem Verhalten geschlossen werden kann. So könnte bereits der Teilnahme eines Sportlers an einem Wettbewerb der Erklärungswert innewohnen, er werde diesen nicht manipulativ zu Gunsten des Wettbewerbsgegners beeinflussen.

283 Fischer StGB $\$ 263$ Rn. 14.

284 LK-StGB/Tiedemann $\$ 263$ Rn. 12 ff. 
Zur Ermittlung des Erklärungsgehalts eines bestimmten Verhaltens ist auf die Verkehrsauffassung des betroffenen Rechts- oder Geschäftsbereiches abzustellen. ${ }^{285}$ Den Sport überwölben konstitutive Wertvorstellungen wie das Fair Play- und Leistungsprinzip, aus denen sich eine bestimmte allgemeine Erwartungshaltung von Mitspielern, Funktionären und Zuschauern an eine erbrachte sportliche Leistung zusammensetzt. Gleichwohl fällt es schwer, bereits die bloße Teilnahme am Wettbewerb als Ausdruck einer uneingeschränkten sportethischen Selbstverpflichtung des Sportlers aufzufassen. Zumindest kann die Annahme einer Täuschung kaum auf eine Erwartung des maßgeblichen Empfängerkreises gestützt werden, wonach jeder antretende Sportler durchgehend vollen Einsatz erbringe. ${ }^{286}$ Dafür sind selbst im Spitzensport Fälle des Kräfteschonens zu verbreitet und akzeptiert.

Diese Akzeptanz löst sich jedoch auf, sofern das Leistungsvermögen aufgrund eines vorab gefassten und durch Verlustprämien motivierten Vorsatzes in potenziell spielentscheidenden Situationen zurückgehalten wird. Der Umstand, dass sämtliche Sportverbände bestechungsbedingten Schlechtleistungen in ihren Statuten entgegentreten, weist das Fehlen manipulativer Einwirkungen als zentrale Grundbedingung des sportlichen Wettbewerbs aus. ${ }^{287}$ Eine an den sportspezifischen Anschauungen orientierte Verkehrsauffassung wird dem Wettkampfantritt eines Sportlers zumindest den Erklärungswert zumessen, den Wettkampf in Übereinstimmung mit dessen fundamentalen Regeln anzugehen. ${ }^{288}$ Führt ein insgeheim gegensätzliches Vorhaben zu einem veränderten Wettkampfverhalten, kann darin eine konkludente Täuschung des Sportlers über seine mit der Teilnahme miterklärte Absicht liegen, den Wettkampf nicht infolge Bestechlichkeit zu den eigenen Ungunsten manipulativ beeinflussen zu wollen. ${ }^{289}$ Adressat dieser durch das Wettkampfverhalten übermittelten Täuschung sind unter anderem der eigene Verein und die Mitspieler. Aufgrund der in den vergangenen Jahren sportartübergreifend gewachsenen Sensibilität für Match Fixing lässt sich ein ausgelöster Irrtum auf deren Seite auch nicht mit der Erwägung verneinen, Vereinsoffizielle und Mitspie-

285 MüKo-StGB/Hefendehl $\$ 263$ Rn. 107; Wessels/Hillenkamp/Schuhr Strafrecht BT II Rn. 496.

286 In diese Richtung jedoch Paringer Korruption, S. 212; Triffterer NJW 1975, 612 (615).

287 Konkret zu entsprechenden Tatbeständen im Verbandsrecht s. unten Teil 3 C. II. 1. a) bb) (1).

288 Schattmann Betrug, S. 113.

289 So Schattmann Betrug, S. 113 f.; s. auch Fischer StGB $₫ 263$ Rn. 35 a. 
ler setzten eine unbestechliche Einstellung des einzelnen Sportlers als so selbstverständlich voraus, dass sie sich diesbezüglich gar keine Vorstellung bildeten, die Zielobjekt einer Täuschung sein könnte.

Hinsichtlich einer irrtumsbedingten Vermögensverfügung des Vereins käme allenfalls das Unterlassen der Geltendmachung von Gehaltsrückzahlungsansprüchen gegen den manipulierenden Sportler wegen einer Verletzung des Arbeitsvertrages in Betracht. ${ }^{290}$ Gegen deren Tauglichkeit als Gegenstand einer betrugsrelevanten Vermögensverfügung spricht jedoch, dass sie den getäuschten Vereinsverantwortlichen erst durch die Schlechtleistung des Sportlers selbst entstehen. Das manipulative Wettkampfverhalten gleichzeitig als täuschend und verfügungsbegründend $\mathrm{zu}$ werten, wirkt zirkelschlüssig und würde die herangezogene Fallgruppe des Forderungsbetrugs überstrapazieren, da folglich in jeder vertraglichen Schlechtleistung eine Vermögensverfügung darin gesehen werden könnte, dass sie dem Vertragspartner verborgen bleibt und der aus ihr folgende Anspruch auf Schadensersatz unterlassen wird. ${ }^{291}$ Ohne ein dem Wettkampf nachfolgendes, zweites täuschendes Verhalten mit Bezug auf den Ersatzanspruch etwa auf eine Nachfrage des berechtigten Vereins hin - kann keine vermögensmindernde Verfügung des Vereins angenommen werden. Hieran scheitert eine Betrugsstrafbarkeit des Sportlers zu dessen Nachteil. ${ }^{292}$

Auch bei den getäuschten Teamkollegen lässt sich keine vermögensmindernde Verfügung feststellen. Zu denken wäre zwar an die irrtumsbedingt unterbliebene Geltendmachung von Siegprämien gegenüber dem Verein. Diese sind jedoch strikt an ein bestimmtes, oftmals übergeordnetes sportliches Ziel gekoppelt. Der Nachweis, dieses allein aufgrund der Schlechtleistung eines Spielers verpasst zu haben, wird schwer zu führen sein und den betroffenen Mitspielern kaum zum Erhalt der Prämie durch den Verein verhelfen. ${ }^{293}$

290 Vgl. Triffterer NJW 1975, 612 (615); Paringer Korruption, S. 213. Allgemein zur Möglichkeit eines betrugsrelevanten Schadens durch die Veranlassung des Getäuschten, einen ihm zustehenden Anspruch nicht geltend zu machen LK-StGB/ Tiedemann $\$ 263$ Rn. 245.

291 Schattmann Betrug, S. 134 f.; zust. Heilemann Bestechlichkeit, S. 175; Bösing Manipulationen, S. 76.

292 AA Wabnitz/Janovsky/Schmitt/Bannenberg 13. Kapitel Rn. 104, die eine solche Strafbarkeit annimmt, ohne sich jedoch näher mit den einzelnen Tatbestandsmerkmalen auseinanderzusetzen.

293 Schattmann Betrug, S. 135; Heilemann Bestechlichkeit, S. 175. 


\section{b) Zum Nachteil eines konkurrierenden Drittvereins}

In besonderen Konstellationen wie etwa finalen Spieltagen in einem im Ligasystem ausgetragenen Wettbewerb können durch Schlechtleistung einzelner Spieler herbeigeführte Spielresultate folgenschwere Auswirkungen für dritte Vereine haben, die durch den manipulierten Sieg des Konkurrenten den Klassenerhalt oder die Qualifikation für einen internationalen Wettbewerb verfehlen. Angesprochen sind hiermit etwa die Geschehnisse des Bundesligaskandals von 1971. ${ }^{294}$ Erscheinen diese Vereine als die primär Geschädigten einer solchen Manipulation, lässt sich eine entsprechende Betrugsstrafbarkeit des Sportlers zu ihren Lasten mangels einer eigenen Verfügung des Drittvereins allenfalls über die voraussetzungsreiche Figur eines Dreiecksbetrugs konstruieren.

Als notwendiges Bindeglied lässt sich der jeweilige Verband ausmachen, der übermittelt durch die Person des mit dem manipulativen Wettkampfverhalten konfrontierten Schiedsrichters zunächst einen das regelwidrige Zustandekommen des Resultats nicht beanstandenden Spielbericht erhält, auf dessen Grundlage er sodann im Irrtum über den ordnungsgemäßen Verlauf des Spiels eine Gutschrift der Punkte in der Tabelle vornimmt. ${ }^{295}$ Die Punktvergabe stellt sich in der beschriebenen Sonderkonstellation als eine das Vermögen des Drittvereins unmittelbar mindernde Verfügung dar. Dessen hierdurch beeinträchtigte Aussicht, durch Verbleib in der Liga oder Teilnahme an einem internationalen Wettbewerb höhere Einnahmen zu generieren, erfüllt angesichts der auf absehbare Zeit verhandelten und an Ligazugehörigkeit bzw. Pokalteilnahme gebundenen TV-Einnahmen die Voraussetzungen einer als Vermögensbestandteil anerkannten, konkreten und realisierbaren Exspektanz. ${ }^{296}$

Damit dabei allerdings auch dem Unmittelbarkeitszusammenhang zwischen Verfügung und Vermögensschaden entsprochen wird, müsste der Ausgang des manipulierten Spiels allein über die tabellarische Endplatzierung entscheiden. Dies ist etwa der Fall, wenn der in der Tabelle direkt vor dem begünstigten Verein platzierte Drittverein sein finales Spiel bereits vorgezogen ausgetragen hat und durch einen Sieg noch überholt werden kann. Finden sämtliche Begegnungen eines finalen Spieltages hingegen pa-

294 Hierzu bereits Teil 2 A. II. 5. b).

295 AA Schlösser NStZ 2005, 432 (439), der bereits die Täuschung des Schiedsrichters verneint.

296 In diese Richtung Schattmann Betrug, S. 119 ff.; offen gelassen bei LK-StGB/ Tiedemann $\$ 263$ Rn. 136. 
rallel statt, wie es in vielen Sportligen gerade zur Prävention unlauterer Absprachen üblich ist, führt die durch die Manipulation angestoßene Kausalkette nicht unmittelbar zu einer vermögensmindernden Verfügung des Verbandes. Ist von einer solchen aber auszugehen, begründet die satzungsmäßig fixierte Unterwerfung der Vereine unter die Entscheidungsbefugnis des Verbandes über die Punktvergabe auch das im Rahmen eines Dreiecksbetrugs erforderliche Näheverhältnis zwischen verfügendem Verband und geschädigtem Verein. ${ }^{297}$

Im Rahmen des subjektiven Tatbestandes wäre dann zu differenzieren: Wurde dem Sportler für die Durchführung der Manipulation vom unmittelbaren Wettbewerbsgegner, der mit dem Drittverein tabellarisch konkurriert, eine Verlustprämie in Aussicht gestellt, wird es ihm primär auf deren Erlangung ankommen. Ihre Ausschüttung basiert dann jedoch nicht auf derselben Vermögensverfügung wie der dem Drittverein entstandene Vermögensschaden und stellt sich diesem gegenüber nicht als stoffgleich dar. ${ }^{298}$ Es müsste also auch eine Drittbereicherungsabsicht feststellbar sein, die gerade die mit dem Klassenerhalt bzw. der Teilnahme an einem internationalen Wettbewerb verbundenen Vermögensvorteile des begünstigten Vereins zum Gegenstand hat.

Gemäß einer von Rechtsprechung und Literatur im Grundsatz einhellig getragenen Auslegung der Bereicherungsabsicht kann ein Betrugstäter auch mehrere Ziele nebeneinander anstreben, wobei diese für sich genommen nicht zwingend das treibende Motiv des täuschenden Gesamtverhaltens zu sein brauchen. ${ }^{299}$ Für den BGH reicht als Bestandteil der Bereicherungsabsicht aus, dass ein vorausgesehener Vorteil dem Täter nicht innerlich unerwünscht ist. ${ }^{300}$ Die wohl herrschende Literaturansicht grenzt hingegen danach $\mathrm{ab}$, ob der Vorteil ein notwendiges Zwischenziel oder bloß eine unvermeidliche Nebenfolge darstellt. ${ }^{301}$ Vor diesem Hintergrund lässt sich eine Drittbereicherung wohl zumindest dann annehmen, wenn die Verlustprämie nur für den Fall einer „erfolgreichen“ Spielmanipulation im

297 PHB-SportR/Reinhart, 3. Aufl., 8. Teil 5. Kap. Rn. 170; Schattmann Betrug, S. $124 \mathrm{f}$.

298 Grundlegend zur Voraussetzung der Stoffgleichheit Schönke/Schröder/Perron $\$ 263 \mathrm{Rn} .168 \mathrm{f}$.

299 BGHSt 16, 1 (5 ff.); 21, 384 (386); Lackner/Kühl/Heger/Kühl \$263 Rn. 58; Eisele Strafrecht BT II, Rn. 636; LK-StGB/Tiedemann \$263 Rn. 250; Wittig JA 2013, 401 (402).

300 So bei BGHSt 16, $1 \mathrm{f}$.

301 MüKo-StGB/Hefendehl $₫ 263$ Rn. 913; Schönke/Schröder/Perron $\$ 263$ Rn. 176; LK-StGB/Tiedemann $\$ 263$ Rn. 251; krit. Rengier JZ 1990, 321 (323). 
Sinne des Vorteilsgebers ausgezahlt werden soll. ${ }^{302}$ Denn dann stellt sich ein bestimmter herbeizuführender Spielausgang mit der zwingenden Konsequenz des Klassenerhalts des begünstigten Vereins sowie des Abstiegs des benachteiligten Drittvereins (entsprechend für die Konstellation der Qualifikation für einen internationalen Wettbewerb) für den Sportler als notwendiges Zwischenziel für den primär angestrebten Erhalt der Prämie dar und wirkt mitbestimmend auf seinen Handlungsentschluss ein.

Somit ist eine durch das unmittelbare Wettkampfverhalten verwirklichte Betrugsstrafbarkeit des durch eine Bestechungsprämie zur Manipulation motivierten Sportlers gegenüber dem Verband und zu Lasten eines Drittvereins grundsätzlich zwar denkbar. Sie ist jedoch sowohl von der Ausgestaltung eines mehrstufig organisierten sportlichen Wettbewerbs als auch von der Fassung der konkreten Unrechtsvereinbarung abhängig und dürfte auf Ausnahmekonstellationen beschränkt bleiben.

\section{c) Zum Nachteil der Zuschauer}

Ausgeschlossen ist hingegen eine Strafbarkeit des Sportlers wegen Betrugs zum Nachteil der Zuschauer des Wettbewerbs. Während deren Vermögensverfügung in Form des Erwerbs einer Eintrittskarte zeitlich vor dem täuschenden Wettkampfverhalten liegt und somit nicht kausal durch die Manipulation veranlasst wurde, fehlt es hinsichtlich des Unterlassens der Geltendmachung möglicher Ersatzansprüche gegen den Veranstalter oder den Sportler direkt - deren zivilrechtliche Voraussetzungen zunächst einmal belegt werden müssten ${ }^{303}$ - offensichtlich an der Stoffgleichheit mit der durch den Sportler erstrebten Bereicherung. ${ }^{304}$ Selbst bei Anerkennung einer Inanspruchnahme durch die Zuschauer besteht zwischen einer diesbezüglichen Freistellung und der beabsichtigten Verlustprämie keine Verbindung, so dass es ihm nicht einmal als Zwischenziel um eine solche Freistellung gehen kann.

302 Schattmann Betrug, S. 129; Heilemann Bestechlichkeit, S. 174; wohl auch Triffterer NJW 1975, 612 (615).

303 Einen vertraglichen Rücktrittsgrund in Form eines Mangels bezweifelnd Hartmann/Niehaus JA 2006, 432 f.; Schwab NJW 2005, 938 (940) hingegen erkennt einen Anspruch gegen den manipulierenden Sportler wohl an.

304 Vgl. Valerius SpuRt 2005, 90 (91); Bösing Manipulationen, S. 79 f. 
d) Zum Nachteil des Veranstalters

Auch ein Betrug des Einzelsportlers zum Nachteil eines Turnierveranstalters im Hinblick auf eine Antrittsprämie scheidet aus. Schließt der Sportler bereits einen entsprechenden Antrittsvertrag in der Absicht, den Wettbewerb durch eine Schlechtleistung zu manipulieren, ließe sich eine Täuschung über seinen Erfüllungswillen in Erwägung ziehen. Regelmäßig wird eine Antrittsprämie allerdings für die Teilnahme als solche gezahlt und ist nicht an die Qualität der erbrachten Leistung gebunden, sofern kein völliger Wegfall seiner Leistungsfähigkeit anzunehmen ist, was bei (punktuellen) Leistungsreduzierungen im Gegensatz zum Doping fernliegt. ${ }^{305}$ Dies steht einem Vermögensschaden des Veranstalters entgegen. Ferner würde dem Täter auch eine diesbezügliche Bereicherungsabsicht fehlen. Da ihm bewusst ist, dass ihm die Antrittsprämie bereits für seine Teilnahme als solche ausgezahlt wird, ist ihr Erhalt nicht einmal mitbestimmend für seinen manipulativen Entschluss.

2. Betrugsstrafbarkeit des Schiedsrichters durch Schlechtleistung im Wettkampf ( $\$ 263 \mathrm{StGB})$

Rollenbedingt nimmt das manipulative Wettkampfverhalten eines Schiedsrichters abweichende Formen an. Die unlautere Einflussnahme erfolgt nicht durch Einsatzreduzierung, sondern durch bewusste Fehlentscheidungen unter Verletzung der Pflicht zur neutralen Spielleitung. Die hierdurch bezweckte wettbewerbsinterne Folge ist die absichtliche Bevorzugung eines Wettkampfteilnehmers auf Kosten eines anderen, die sowohl durch die Gewährung unberechtigter Spielvorteile für ersteren (Strafstöße, Freiwürfe) als auch durch die unberechtigte Sanktionierung des letzteren (Zeitstrafen, Platzverweise) erreicht werden kann. Wiederum sind mehrere Betrugskonstellationen denkbar.

a) Zum Nachteil des betroffenen Vereins

Zunächst liegt die Prüfung eines Betrugs zu Lasten des von der Schiedsrichterentscheidung im Wettbewerb unmittelbar benachteiligten Vereins

305 Valerius SpuRt 2005, 90 (91) mit Verweis auf Cherkeb/Momsen NJW 2001, 1745 (1748) bezüglich der Abgrenzung zum Doping. 
bzw. Einzelsportlers nahe, der infolge einer durch die Fehlentscheidung (mit)verursachten Niederlage Preisgelder einbüßt. Ob und mit welchem konkreten Bezugspunkt eine manipulierte Spielleitung dabei als Täuschungshandlung gewertet werden kann, ist umstritten. Ein Abstellen auf die konkrete Fehlentscheidung, mit der der Schiedsrichter wider besseren Wissens erkläre, er habe eine Regelverletzung erkannt, wodurch er eine falsche Tatsache vorspiegele, ${ }^{306}$ verkennt, dass er die einzelne Entscheidung als Ausdruck seiner Situationswahrnehmung kommuniziert. Ihr liegt damit ein Werturteil zugrunde, das sie als Gegenstand einer Täuschung disqualifiziert.

Vergleichbar zur oben festgestellten Täuschung eines manipulierenden Spielers ist auch beim Schiedsrichter der Bezugspunkt vielmehr in der inneren Absicht zu sehen, ein Spiel nicht im Sinne der gebotenen Neutralität zu leiten. Die Unparteilichkeit des Schiedsrichters ist eine von allen Beteiligten vorausgesetzte Grundbedingung eines fairen Wettkampfs. Nach der maßgeblichen Verkehrsanschauung sportartübergreifender Wettkampfkreise kommt der Spielleitung eines Schiedsrichters im Dienste eines Verbandes der Erklärungswert bei, er wolle das Spiel allein gemäß den Verbandsregeln leiten. ${ }^{307}$ Motivieren ihn hingegen von vornherein außersportliche Vorteile zu bewussten Fehlentscheidungen, stellt seine Spielleitung eine konkludente Täuschung über diese Absicht dar, durch die er auf das Vorstellungsbild aller beteiligten Sportakteure und Zuschauer einwirkt.

Eine vermögensmindernde Verfügung des benachteiligten Vereins ist hingegen nicht festzustellen. Zwar dürfte es der Verein infolge des Irrtums über die manipulative Spielleitung unterlassen, in den Verfahrensordnungen der Verbände vorgesehene Möglichkeiten eines Einspruchs gegen die Spielwertung auszuschöpfen. ${ }^{308}$ Der Ausgang eines solchen Verfahrens ist jedoch höchst ungewiss und selbst im Falle eines angesetzten Wiederholungsspiels begründet die Aussicht, dieses zu gewinnen und eventuell Preisgelder zu erzielen, keinen Vermögenswert. ${ }^{309}$ Bemüht man zur Erfassung der wirtschaftlichen Einbußen eines aufgrund von Fehlentscheidun-

306 So Bösing Manipulationen, S. 88.

307 Duyar Sportbeugung, S. 68; in diese Richtung auch Hartmann/Niehaus JA 2006, 432 f.; aA Schlösser NStZ 2005, 421 (429), der gegenüber Vereinen und Zuschauern keinen täuschenden Erklärungswert erkennt.

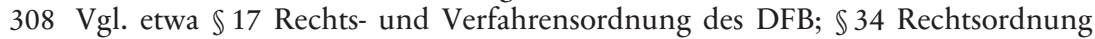
des DHB.

309 Vgl. Bösing Manipulationen, S. 88; von Komorowski/Bredemeier SpuRt 2005, 181 (182). 
gen etwa aus einem Pokalwettbewerb ausgeschiedenen Vereins wiederum die Figur des Dreiecksbetrugs und stellt auf eine Verfügung des ebenfalls getäuschten Verbandes in Form der Spielwertung ab, erlangt erneut das Erfordernis der Absicht stoffgleicher Bereicherung maßgebliche Bedeutung. Dieses wird für einen Großteil der denkbaren Konstellationen abzulehnen sein, da der vom Schiedsrichter erstrebte Vorteil einer externen Prämie mit dem Schaden des Vereins regelmäßig nicht deckungsgleich ist und sich die ihnen zugrunde liegenden Verfügungen unterscheiden. ${ }^{310} \mathrm{Al}-$ lenfalls bei Zahlung einer erfolgsabhängigen Prämie durch Angehörige des begünstigten Vereins ließe sich dessen wirtschaftliche Gewinnaussicht als notwendiges Zwischenziel und Gegenstand einer Drittbereicherungsabsicht des Schiedsrichters begreifen, die dann auch auf der Spielwertung beruht. Im Regelfall wird somit keine Betrugsstrafbarkeit gegenüber oder zum Nachteil des betroffenen Vereins vorliegen.

\section{b) Zum Nachteil des Verbands}

Jedoch könnte die Schiedsrichtern zukommende Vergütung Ansatzpunkt eines Betrugs zum Nachteil des auszahlenden Verbands sein. Gegenstand einer Täuschung des Verbandes könnte dabei nicht nur die manipulative Spielleitung selbst sein, hinsichtlich derer eine direkte Kommunikationsbeziehung ohnehin schwerer zu begründen ist, sondern auch ein dem Wettbewerb vorangehendes bzw. nachfolgendes Verhalten. Je nach Zeitpunkt der Entschlussfassung zur Manipulation eines Wettbewerbs käme eine konkludente Täuschung bereits bei Abschluss des entsprechenden Dienstvertrages mit dem Verband in Betracht. Denn mit Übernahme einer Spielleitung wird zugleich erklärt, diese unparteiisch erbringen zu wollen. ${ }^{311}$ Häufig dürfte eine den konkreten Manipulationsentschluss hervorrufende Abrede mit einem Vorteilsgeber jedoch erst nach Ansetzung und Vertragsschluss erfolgen. In vielen Sportarten kommt mit der im Anschluss an einen Wettkampf obligatorischen Übersendung eines Spielberichts an den Verband dann noch ein weiterer Anknüpfungspunkt eines täuschenden Verhaltens des Schiedsrichters in Betracht. Werden im Spielbericht keine Beanstandungen vermerkt, kommt ihm der objektive Erklä-

310 Duyar Sportbeugung, S. 301; Heilemann Bestechlichkeit, S. 147, PHB-SportR/ Reinhart, 3. Aufl., 8. Teil 5. Kap. Rn. 168.

311 S. PHB-SportR/Reinhart, 3. Aufl., 8. Teil 5. Kap. Rn. 168; Duyar Sportbeugung, S. 290. 
rungswert zu, der Ausgang des Spiels sei unter regulären Bedingungen zustande gekommen. ${ }^{312}$ Aufgrund der parteiischen Spielleitung ist dies falsch.

In der folgenden Entrichtung der vereinbarten Vergütung liegt eine durch die hervorgerufene Fehlvorstellung einer lauteren Spielleitung bedingte Vermögensverfügung des Verbandes. Zwar erlangt der Verband im Gegenzug eine Schiedsrichterleistung. Diese ist allerdings parteiisch erfolgt, bildet keinen adäquaten Gegenwert und begründet daher einen Vermögensschaden. ${ }^{313}$ Fraglich bleibt, ob die Vergütung auch Gegenstand der Bereicherungsabsicht des Schiedsrichters war. Bestritten wird dies mit dem Argument, ihm sei es allein auf die externe Manipulationsprämie angekommen, während die Vergütung der Spielleitung lediglich eine mittelbare Folge und gerade kein absichtsvoll erstrebtes Ziel dargestellt hätte. ${ }^{314}$

Angesichts der angedeuteten erweiterten Auslegung der Bereicherungsabsicht gilt es allerdings zu bedenken, dass der Schiedsrichter gerade auch im Hinblick auf die beabsichtigte Manipulationsprämie alles daran setzen wird, die manipulative Schlechtleistung gegenüber dem Verband zu verdecken. Die Prämie wird regelmäßig an die Bestandskraft des von ihm durch Fehlentscheidungen herbeigeführten Resultats gebunden sein. Die letztlich verbindliche Spielwertung verlangt aber gerade ein vom Verband nach Erhalt des Spielberichts wie gewohnt durchgeführtes Verfahren, zu dem auch die Vergütung des Schiedsrichters zählt. Als gewichtiges Indiz der Anerkennung des Spielausgangs ist sie ein notwendiges Zwischenziel. ${ }^{315}$ Ein Betrug des Schiedsrichters zum Nachteil des Verbandes ist grundsätzlich denkbar. ${ }^{316}$ Sie kann im Einzelnen jedoch von der verbandseigenen Ausgestaltung der Kommunikationsbeziehung zu den Schiedsrichtern und ihrer Vergütung abhängen.

c) Zum Nachteil der Zuschauer

Ein Betrug zum Nachteil der Zuschauer scheidet hingegen aus. Da Sportzuschauer ihre Erwartung an eine neutrale Spielleitung unabhängig vom

312 Triffterer NJW 1975, 612 (614); Schlösser NStZ 2005, 423 (429).

313 PHB-SportR/Reinhart, 3. Aufl., 8. Teil 5. Kap. Rn. 168; Schwab NJW 2005, 938 (940 Fn. 30); Schlösser NStZ 2005, 423 (429); aA Valerius SpuRt 2005, 90 (91).

314 Von Komorowski/Bredemeier SpuRt 2005, 181 (183).

315 Duyar Sportbeugung, S. $297 \mathrm{f}$.

316 So auch Schwab NJW 2005, 938 (940 Fn. 30); Schlösser NStZ 2005, 423 (429); Wabnitz/Janovsky/Schmitt/ Bannenberg 13. Kapitel Rn. 104. 
Verhalten des konkreten Schiedsrichters bereits aus der Institution des Schiedsrichterwesens ableiten, erscheint es bedenkenswert, bereits die Kausalbeziehung zwischen der Täuschungshandlung eines manipulierenden Schiedsrichters und einem Irrtum der Zuschauer in Zweifel zu ziehen. ${ }^{317}$ Doch selbst bei Annahme eines Irrtums könnte eine hiervon ausgelöste Vermögensverfügung allein in der unterlassenen Geltendmachung von Ersatzansprüchen aufgrund des manipulierten Spiels liegen. Solche sind sowohl auf vertraglicher Basis gegen den Veranstalter als auch auf deliktischer Basis gegen den Schiedsrichter fraglich. ${ }^{318}$ Jedenfalls fehlte es diesbezüglich an der stoffgleichen Bereicherung durch den Schiedsrichter, der es nicht einmal nachrangig auf eine Freistellung von der Inanspruchnahme durch Zuschauer abgesehen hat. ${ }^{319}$

\section{Zwischenergebnis}

Eine durch das Wettkampfverhalten verwirklichte Strafbarkeit des zu Gunsten des Wettbewerbsgegners manipulierenden Sportlers reduziert sich nicht nur von vornherein auf den Betrugstatbestand, sondern kann auch innerhalb dessen kaum begründet werden. Selbst wenn er es auf eine ihm in Aussicht gestellte Verlustprämie absieht, kommt ein Betrug lediglich in Teamsportarten gegenüber dem Verband und zum Nachteil eines konkurrierenden Vereins in Betracht, verlangt jedoch eine seltene wettbewerbsimmanente Ausgangslage. Ein Betrug zum Nachteil des eigenen Vereins, von Zuschauern oder Veranstaltern ist abzulehnen. Eine entsprechende Strafbarkeit des aufgrund von Manipulationsprämien parteiischen Schiedsrichters ist gegenüber und zum Nachteil seines Verbands, in seltenen Sonderkonstellationen auch zu Lasten des im Wettkampf unmittelbar benachteiligten Vereins denkbar. Auch sie hängt allerdings stark von den Gegebenheiten des Einzelfalles ab und stellt hohe Anforderungen an den Nachweis nahezu sämtlicher Tatbestandsmerkmale. Neben den ohnehin eng umgrenzten betrugsrelevanten Konstellationen mag dies ein weiterer

317 So Schlösser NStZ 2005, 423 (429).

318 Einen Mangel ablehnend Hirsch FS Szwarc, 2009, S. 559 (578); im Kontext des Dopings gleichsam Kerner/Trüg JuS 2004, 140 (145); Schwab NJW 2005, 938 (940) nimmt hingegen einen direkten Anspruch der Zuschauer gegen den Schiedsrichter aus $₫ 826$ BGB an; ebenso Duyar Sportbeugung, S. $304 \mathrm{f}$.

319 Im Ergebnis auch Hartmann/Niehaus JA 2006, 432; Paringer Korruption, S. 199; von Komorowski/Bredemeier SpuRt 2005, 181 (183); Duyar Sportbeugung, S. $304 \mathrm{f}$. 
Grund dafür sein, dass es in der Praxis noch zu keiner eigenständigen Verurteilung eines Sportakteurs wegen Betrugs durch manipulatives Wettkampfverhalten abseits des Dopings kam. ${ }^{320}$

\section{Strafbarkeit durch vorangehende Manipulationsabsprache}

Lässt sich mit Blick auf das unmittelbar manipulative Wettkampfverhalten somit tatsächlich eine lückenhafte strafrechtliche Abdeckung der untersuchten Sportmanipulationen vermuten, gilt es dies durch eine Vorverlagerung des Anknüpfungspunktes der Strafbarkeit auf die der Manipulation vorangehende Absprache und die damit verbundene Auszahlung und Annahme von Manipulationsprämien zu überprüfen. Hiermit geht zunächst eine Erweiterung des potenziellen Täterkreises einher. Denn als Vorteilsgeber im Rahmen einer vorgelagerten Manipulationsvereinbarung können auch am Wettkampf selbst nicht unmittelbar mitwirkende Vereinsverantwortliche oder externe Personen beteiligt sein. Zudem geht die diesbezügliche Suche nach einem tatbestandlichen Vorwurf über den Betrug hinaus, der mangels interaktiver Kommunikationsbeziehung der an der Abrede Beteiligten zu der Außenwelt bei isolierter Betrachtung der Absprache ausscheidet. ${ }^{321}$ Die Charakteristika einer verdeckten Absprache, der Zusage einer unlauteren Einflussnahme gegen Prämienzahlung sowie des dabei denkbaren Einsatzes von Vereinsvermögen rücken vielmehr die Delikte der Bestechung bzw. Bestechlichkeit $(\mathbb{} 299 \mathrm{StGB})$ und der Untreue $(\$ 266 \mathrm{StGB})$ in den Fokus.

\section{Strafbarkeit wegen Bestechung bzw. Bestechlichkeit ( $\$ 299$ StGB)}

Die Zahlung von Geld oder das Gewähren anderer Vorteile im Austausch gegen die von einem Sportakteur getätigte Zusage einer Spielmanipulation dürfte umgangssprachlich häufig als „Bestechung“ bzw. „Bestechlichkeit“ bezeichnet werden, was die Prüfung der gleichnamigen Tatbestände im

320 Vgl. Adolphsen/Nolte/Lehner/Gerlinger/Rössner Kap. 11 Rn. 1723; Brauneisen, in: Württembergischer Fußballverband (Hrsg.), Sportwette, 2013, S. 43 (61).

321 Auch wenn mit der Manipulation etwa ein Wettgewinn erzielt werden soll, ist in der bloßen Absprache noch kein betrugsrelevantes Verhalten zu Lasten des Anbieters zu sehen. Es bedarf weiterer täuschender Zwischenhandlungen, s. Heilemann Bestechlichkeit, S. 139. 
StGB nahelegt. In ihrem Rahmen erscheint es auch irrelevant, ob die durch zugesagte Vorteile motivierte Manipulation nun einem sportlichen Ziel oder der Erlangung illegitimer Wettgewinne dienen soll. Sie stellen jedoch jeweils besondere Anforderungen an die Person des Vorteilsnehmers, unabhängig davon, ob sie nun als Täter agiert oder als Zielperson einer Bestechung involviert wird.

Von vornherein ausgeschieden werden kann demnach eine Strafbarkeit der an einer Manipulationsabsprache Beteiligten nach den $\$ \$ 331 \mathrm{ff}$. StGB. Weder Sportler noch Trainer, Sportrichter oder Vereinsfunktionäre sind Amtsträger im Sinne des $\$ 11$ Abs. 1 Nr. 2 StGB. Wird in den jeweiligen Absätzen 2 der $\$ \mathbb{S} 331 \mathrm{ff}$. StGB explizit die Tätereigenschaft eines Schiedsrichters genannt, ist damit ausschließlich ein zur Entscheidung von Rechtsstreitigkeiten berufener Schiedsrichter im zivilprozessualen Sinne ( $\$ \$ 1025 \mathrm{ff} . \mathrm{ZPO}$ ) gemeint. ${ }^{322}$ Für die verbleibende Strafbarkeit der Beteiligten wegen Bestechlichkeit und Bestechung im privaten Sektor gemäß $\$ 299$ Abs. 1 Nr. 1 bzw. Abs. 2 Nr. 1 StGB müsste auf der Seite des Vorteilsnehmers ein im geschäftlichen Verkehr handelnder Angestellter oder Beauftragter eines Unternehmens auszumachen sein und sich die mit ihm geschlossene oder intendierte Unrechtsvereinbarung auf eine Bevorzugung beim Bezug von Waren oder Dienstleistungen beziehen.

a) Sportakteure als Angestellte oder Beauftragte eines Unternehmens

Zunächst müssten manipulationsfähige Athleten, Trainer oder Sportrichter Angestellte oder Beauftragte eines Unternehmens sein. Unter einem Unternehmen bzw. einem inhaltlich deckungsgleichen geschäftlichen Betrieb wird dabei jede auf gewisse Dauer betriebene Tätigkeit im Wirtschaftsleben verstanden, die sich durch den Austausch von Leistungen und Gegenleistungen vollzieht. ${ }^{323}$ In Teamsportarten trifft dies unabhängig ihrer exakten gesellschaftsrechtlichen Ausgestaltung zumindest auf die Profi-Sparte eines Sportvereins als Arbeitgeber von Sportlern und Trainern zu. ${ }^{324}$ Demgegenüber erfüllen Einzelsportler, die sich selbst finanzieren

322 MüKo-StGB/Korte $\$ 331$ Rn. 168; Fischer StGB \$331 Rn. 29.

323 BGHSt 2, 396 (402); zur inhaltlichen Übereinstimmung von „Unternehmen“ mit dem vor der tatbestandlichen Neufassung 2015 verwendeten "geschäftlichen Betrieb“ s. BT-Drs. 18/4350, S. 22.

324 Achenbach/Ransiek/Rönnau/Rönnau Teil 3 Kapitel 2 Rn. 66 Fn. 438; Momsen/ Vaudlet, in: Emrich/Pierdzioch/Pitsch (Hrsg.), Falsches Spiel, 2015, S. 219 (232). 
oder in staatlichen Sportförderprogrammen befinden, die erforderliche Eigenschaft nicht, da weder die staatlichen Zuwendungen noch ihre Verbandsmitgliedschaft einen Angestellten- oder Beauftragtenstatus begründen.

Bei Schiedsrichtern fungiert der jeweilige Sportverband (z.B. DFB oder DHB) oder ein organisatorisch angebundener und für die Veranstaltung von Ligaspielen zuständiger Ligaverband (z.B. DFL bzw. HBL) als beauftragender Geschäftsherr. Der Verband bildet die Schiedsrichter aus und setzt sie für die Leitung von Spielen an. Die von Sportverbänden häufig gewählte Rechtsform eines Idealvereins i.S.d. $\$ 21$ BGB steht ihrer Subsumtion unter den Begriff des geschäftlichen Betriebs nicht entgegen, da es hierfür grundsätzlich keiner Gewinnerzielungsabsicht bedarf, die Verbände in Form des Verkaufs von Fernseh- und Sponsorenrechten aber ohnehin zumindest untergeordnet auch Erwerbszwecke wirtschaftlicher Art verfolgen. ${ }^{325}$ Dies gilt erst recht für die zumeist als Kapitalgesellschaften organisierten und vielfältig im Wirtschaftsleben auftretenden Ligaverbände. ${ }^{326}$ Teamsportler, Trainer und Schiedsrichter lassen sich somit als taugliche Vorteilsnehmer einordnen.

b) Bevorzugung beim Bezug von Waren im geschäftlichen Verkehr

Die durch eine Prämie zu einer schlechten Leistung angeregten Akteure müssten ferner auch im geschäftlichen Verkehr ihres Geschäftsherrn tätig werden. Für Spieler und Trainer kann dies noch angenommen werden, da das über ihr spielbezogenes Verhalten bestimmte sportliche Abschneiden ihres Vereins gleichzeitig dessen Positionierung in einem mit anderen Vereinen derselben Liga bestrittenen wirtschaftlichen Konkurrenzkampf beeinflusst. ${ }^{327}$ Im Gegensatz dazu steht die Spielleitung eines Schiedsrichters

325 Zur Irrelevanz der Gewinnerzielungsabsicht Fischer StGB $\$ 299$ Rn. 5; zur wirtschaftlichen Betätigung von DFB und DFL Krack ZIS 2011, 475 (476); aA Schösser NStZ 2005, 423 (424 Fn. 14).

326 Beispielsweise durch die Verhandlung von Vermarktungsverträgen, vgl. Krüger/ Hilbert/Wengenroth Causa Sport 2013, 188 (189).

327 LK-StGB/Tiedemann $\$ 299 \quad$ Rn. 32a; NK-StGB/Dannecker $\$ 299$ Rn. 89; Achenbach/Ransiek/Rönnau/Rönnau Teil 3 Kapitel 2 Rn. 66 Fn. 438; aA Krack ZIS 2011, 475 (479), demzufolge die bloße faktische Möglichkeit der Beeinflussung wirtschaftlicher Entscheidungen des Vereins nicht ausreicht, wenn der Spieler an ihnen letztlich nicht beteiligt ist; so auch Krüger/Hilbert/Wengenroth Causa Sport 2013, 188 (189). 
in keinem Zusammenhang mit der wirtschaftlichen Aktivität seines Verbandes, der durch ihren Einsatz ausschließlich seinen Hauptzweck der Sicherstellung eines regelgeleiteten Sportbetriebes fördern, nicht hingegen am Wirtschaftsverkehr teilnehmen möchte. ${ }^{328}$ Bestochene Schiedsrichter handeln bereits nicht im geschäftlichen Verkehr ihres Auftraggebers.

Darüber hinaus müsste sich die Unrechtsvereinbarung auf die Bevorzugung beim Bezug von Waren oder Dienstleistungen beziehen. Hieran fehlt es aber sowohl bei Sportlern und Trainern als auch bei Schiedsrichtern. Das im Austausch gegen den Vorteil zugesagte Verhalten des Sportakteurs beschränkt sich auf eine Schlechtleistung, die er gegenüber seinem Arbeitoder Auftraggeber erbringt, ohne dass dadurch ein Bezugsvorgang zu Gunsten des Vorteilsgebers oder eines Dritten beeinflusst werden soll. ${ }^{329}$ Der manipulierte Spielverlauf wird weder als Leistung des Vereins oder Verbands vom Vorteilsgeber bezogen, noch als Leistung des Vorteilsgebers vom Geschäftsherrn. ${ }^{330}$ Zwischen Vorteilsgeber bzw. einem Dritten und dem Prinzipal des Sportakteurs kommt es zu keinem Bezug.

\section{c) Zwischenergebnis}

Absprachen zur Manipulation sportlicher Wettbewerbe lösen keine Strafbarkeit gemäß $\$ 299$ StGB aus. Während Einzelsportler schon die tatbestandlichen Anforderungen an einen Vorteilsnehmer nicht erfüllen und Schiedsrichter bei ihrer Spielleitung nicht im Rahmen des geschäftlichen Verkehrs eines Unternehmens tätig werden, mangelt es den Abreden insgesamt an der intendierten Bevorzugung bei einem Bezug von Waren oder Dienstleistungen. Da die verfehlten Tatbestandsmerkmale von den spiegelbildlich gestalteten $₫ 299$ Abs. 1 Nr. 1 StGB bzw. $\$ 299$ Abs. 2 Nr. 1 StGB ebenso vorausgesetzt werden, entfällt eine strafbare Bestechlichkeit oder Bestechung. Die hierzu in Widerspruch tretende Einschätzung des LG Kiel, das den Eröffnungsbeschluss im Strafverfahren gegen Verantwortliche des Handballvereins THW Kiel wegen einer mit der Erwartung einer Bevorzugung in einem Finalspiel verknüpften Geldzahlung an Schieds-

328 Krack ZIS 2011, 475 (477 f.); Brauneisen, in: Württembergischer Fußballverband (Hrsg.), Sportwette, 2013, S. 43 (61 f.).

329 Achenbach/Ransiek/Rönnau/Rönnau Teil 3 Kapitel 2 Rn.66; Krüger/Hilbert/ Wengenroth Causa Sport 2013, 188 (190); Jaleesi Kriminalisierung, S. 43 f.; Schösser NStZ 2005, 423 (424); im Ergebnis auch BT-Drs. 18/8831, S. 11.

330 LK-StGB/Tiedemann \$299 Rn. 32a; Schönke/Schröder/Eisele \$299 Rn. 25. 
richter auf den Tatvorwurf des $₫ 299$ Abs. $1 \mathrm{aF}$ StGB erweiterte, wurde in Form eines diesbezüglichen Freispruchs korrigiert. ${ }^{331}$

\section{Strafbarkeit wegen Untreue ( $\$ 266 \mathrm{StGB})$}

Im selben Verfahren stand auch der Vorwurf der Untreue gemäß $\$ 266$ StGB im Raum. Im Allgemeinen kann dieser auf die bereits den Bundesligaskandal von 1971 erfassende Fallgruppe bezogen werden, in der ein Vereinsverantwortlicher aus sportinternen Motiven - etwa zwecks Verhinderung des Abstiegs der eigenen Mannschaft oder Gewinns eines Finalspiels - die vereinsfremden Spielern oder Schiedsrichtern im Rahmen einer Manipulationsabsprache zugesagten Prämien dem Vereinsvermögen entnimmt. Der potenzielle Täterkreis zieht sich demnach wieder zusammen und umschließt bestimmte Vereinsrepräsentanten. Ihr Verhalten könnte den Tatbestand in Form der spezielleren Missbrauchsvariante i.S.d. $\$ 266$ Abs. 1 Var. 1 StGB verwirklichen. Dazu müsste der Vereinsverantwortliche eine ihm zustehende Verfügungs- oder Verpflichtungsbefugnis über fremdes Vermögen missbrauchen, eine Vermögensbetreuungspflicht verletzen und dem Verein dadurch einen Vermögensnachteil zufügen. 332

a) Missbrauch einer Verfügungs- oder Verpflichtungsbefugnis und Verletzung einer Vermögensbetreuungspflicht

Als Inhaber der erforderlichen Verfügungs- oder Verpflichtungsbefugnis kommen innerhalb eines Sportvereins die Angehörigen des Vorstands, im Falle einer als $\mathrm{GmbH}$ ausgegliederten Abteilung auch der Geschäftsführer in Betracht. Erstere werden von den Vereinsmitgliedern per Wahl bestimmt und sind als rechtliche Vertreter gemäß $\$ 26$ Abs. 1 S. 2 BGB zur rechtswirksamen Verpflichtung des Vereins im Außenverhältnis befugt, während die Verfügungs- und Verpflichtungsbefugnis des Geschäftsfüh-

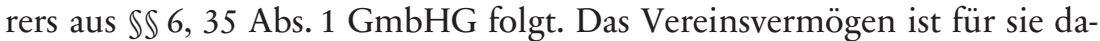
bei auch fremd. An dieser Stelle bereits auszuscheiden sind hingegen Kon-

331 LG Kiel Urteil vom 26.1.2012 - 5 KLs 1/10; zum Sachverhalt s. oben Teil 2 A. II. 5. b).

332 Zur Vermögensbetreuungspflicht als Voraussetzung auch der Missbrauchsvariante BGHSt 24, 386; 33, 244 (250); Fischer StGB \$266 Rn. 6a; MüKo-StGB/Dierlamm $\$ 266$ Rn. 40; Rengier Strafrecht BT I $\$ 18$ Rn. 14. 
stellationen, in denen ein Vorstandsmitglied oder Geschäftsführer allein sein privates Vermögen für Bestechungsprämien einsetzt. Zusätzlich ordnen explizite Vorgaben in den Vereinssatzungen die Wahrung auch der geschäftlichen Vermögensinteressen des Vereins dem Pflichtenkreis der mit der entsprechenden Rechtsmacht ausgestatteten Vorstandsmitglieder und Geschäftsführer zu. ${ }^{333}$

Ein Missbrauch der Befugnis liegt grundsätzlich in einem im Außenverhältnis wirksamen rechtsgeschäftlichen Handeln, durch das zugleich die dem Handelnden im Innenverhältnis gesetzten Grenzen überschritten werden. ${ }^{334}$ Letztere werden maßgeblich durch die konkrete Vereinssatzung ausgeformt, die die Organe eines Sportvereins regelmäßig auch zur Wahrung der Integrität des Sports verpflichtet. Auch wenn ein im Leistungssport aktiver Verein auch wirtschaftliche Interessen verfolgt, müssen die sportlichen und gemeinnützigen Zwecke im Interesse aller Mitglieder gewahrt bleiben. ${ }^{335}$ Ausgezahlte oder verbindlich zugesagte Manipulationsprämien beschreiben demnach einen intern unzulässigen Gebrauch von Vereinsgeldern zu satzungswidrigen Zwecken. ${ }^{336}$ Der hierin liegende Pflichtenverstoß kann anknüpfend an der Absicht der Verantwortlichen, durch einen „erkauften“ Sieg das sportliche Wohlergehen des eigenen Vereins zu fördern, auch nicht durch Heranziehung der mit erweiterten Handlungsspielräumen des Befugnisinhabers verbundenen Fallgruppe eines Risikogeschäfts in Frage gestellt werden. ${ }^{337}$ Dieser Zuordnung widersprechen die bei einer Aufdeckung der Manipulation drohenden Nachteile für den Verein durch Sanktionen und Ansehensverlust. 338

\section{b) Vermögensnachteil}

Der mit der Prämie bezweckte sportliche Erfolg des eigenen Vereins ist jedoch für den nachzuweisenden Vermögensnachteil von Relevanz. Im

333 Heilemann Bestechlichkeit, S. 159; Triffterer NJW 1975, 612 (613).

334 Rengier Strafrecht BT I $₫ 18$ Rn. 6.

335 BGH NJW 1975, $1234 \mathrm{f}$.

336 Heilemann Bestechlichkeit, S. 158 f.; vgl. auch BGH NJW 1975, 1234 f.

337 In Erwägung ziehen dies zumindest beim Versuch der Abwendung eines Abstiegs durch Manipulationsprämien Schreiber/Beulke JuS 1977, 656 ff. Allgemein zu Risikogeschäften im Rahmen der Untreue MüKo-StGB/Dierlamm $\$ 266$ Rn. $228 \mathrm{ff}$.

338 Saliger JA 2007, 326 (332); im Ergebnis auch Schreiber/Beulke JuS 1977, 656 (658). 
kommerzialisierten Leistungssport sind bestimmte sportliche Errungenschaften mit wirtschaftlichen Vorteilen verbunden, die die zur Manipulation von entscheidenden Spielen eingesetzte Bestechungssumme deutlich übertreffen können. In der zur Nachteilsermittlung maßgeblichen Saldierung des Gesamtvermögens des Vereins vor und nach der pflichtwidrigen Handlung seines Repräsentanten stellt sich demnach die Frage, ob der in der Bestechungssumme liegende Nachteil nicht durch einen Vermögenszuwachs kompensiert wird. Grundsätzlich kann eine solche Kompensation angenommen werden, wenn mit der Weggabe eines Vermögenswertes eine äquivalente Erwerbsaussicht eröffnet wird. ${ }^{339}$ Die Kompensationsfähigkeit von Vermögensvorteilen, die durch einen manipulierten Spielausgang erlangt werden, ist allerdings in dreierlei Hinsicht fraglich.

Sie könnte bereits aufgrund des Beruhens des potenziellen Vermögenszuwachses auf einer sittenwidrigen Absprache i.S.d. $\$ 138$ BGB abzulehnen sein, verweigert man rechtlich missbilligten Erwerbsaussichten grundsätzlich den Zugang in die Saldierung. ${ }^{340}$ Dieser Einwand lässt sich nicht durch den Verweis darauf entkräften, die dem Verein zukommenden Vermögensvorteile gingen letztlich gar nicht unmittelbar aus der missbilligten Manipulationsvereinbarung hervor, sondern basierten auf späteren rechtmäßigen Geschäften des Vereins über Ticketverkäufe und Vermarktung. ${ }^{341}$ Denn die fragliche Kompensation kann nur in der vermögenswerten Exspektanz des Vereins liegen, die ihm direkt aus der Unrechtsvereinbarung zufließt. ${ }^{342}$ Jedoch verlangt der Charakter der Untreue als Vermögensschädigungsdelikt eine Differenzierung zwischen Pflichtverletzung und Vermögensnachteil, die durch eine primär aus dem Makel der Sittenwidrigkeit abgeleitete Nachteilsbegründung ungeachtet der tatsächlichen wirtschaftlichen Folgen des Geschäfts eingeebnet würde. ${ }^{343}$ Die Sittenwidrigkeit der zugrunde liegenden Absprache kann im Sinne einer Unbeständigkeit des Vermögensvorteils in dessen bilanzielle Bewertung einfließen, darf aber die gebotene wirtschaftliche Betrachtung nicht blockieren. ${ }^{344}$

Allerdings erfordert der bei einer Kompensation zu beachtende Unmittelbarkeitszusammenhang, dass bei Saldierung auf der Vorteilsseite grundsätzlich nur Vermögensvorteile berücksichtigt werden, die unmittelbar

339 Schönke/Schröder/Perron $\$ 266$ Rn. 41.

340 SK-StGB/Hoyer $\$ 266$ Rn. 96; Schönke/Schröder/Perron $\$ 266$ Rn. 41.

341 So jedoch Schreiber/Beulke JuS 1977, 656 (659); Bösing Manipulationen, S. 61.

342 Vgl. LK-StGB/Schünemann \$266 Rn. 185.

343 SSW-StGB/Saliger $\$ 266$ Rn.77; Rönnau ZStW 119 (2007), 887 (921); Vgl. BVerfG NJW 2010, 3209 (3215).

344 LK-StGB/Schünemann $\$ 266$ Rn. 184 f.; Rieble ZIP 2009, 1593 (1596). 
durch die Pflichtverletzung ausgelöst worden sind. ${ }^{345}$ Hieran könnten je nach Zeitpunkt der gezahlten Manipulationsprämie Zweifel gehegt werden. Wird die Auszahlung als einschlägige Pflichtverletzung erst nach erfolgter Manipulation vorgenommen, könnte sie sich zu diesem Zeitpunkt wegen der Unwirksamkeit der zugrunde liegenden Absprache und der bereits erfolgten manipulativen Herbeiführung des Spielausgangs als nicht mehr erforderlich erweisen und führte isoliert gesehen nicht zu einem (bereits eingetretenen) Vorteil. Eine solche Aufteilung wirkt jedoch formalistisch und widerspricht der bei Saldierung gebotenen wirtschaftlichen Betrachtung, die das Manipulationsgeschäft als einheitlichen, zusammenhängenden Vorgang zu würdigen hat. ${ }^{346}$

Somit kommt es darauf an, ob die mit dem manipulierten Spielausgang verknüpften wirtschaftlichen Vorteile eine hinreichend verdichtete Erwerbsaussicht des Vereins verkörpern. Dies lässt sich zumindest bei solchen Spielen annehmen, die unmittelbar über den Klassenerhalt, die Teilnahme an einem internationalen Wettbewerb oder dessen Gewinn entscheiden. Denn mit diesen Erfolgen gehen nicht nur die eher vage Hoffnung auf künftig steigende Einnahmen aus Ticketverkäufen und Merchandising, sondern in Form von vorab fix verhandelten Erlösen aus Übertragungs- und Vermarktungsrechten auch konkrete und unmittelbar realisierbare Erwerbsaussichten einher. ${ }^{347} \mathrm{Ob}$ diese vermögenswerten Kompensationsfaktoren im Rahmen einer bilanziellen Bewertung die wiederum wertmindernd anzusetzende Uneinklagbarkeit der sittenwidrig erkauften Chance sowie die Gefahr verbandsrechtlicher Sanktionen überwiegen, ist vom Einzelfall abhängig, angesichts der erheblichen ligaabhängigen Unterscheede und des als eher gering einzuschätzenden Aufdeckungsrisikos einer Manipulationsvereinbarung aber durchaus zu vermuten.

\section{c) Zwischenergebnis}

In vielen Fällen der Auszahlung von Manipulationsprämien an vereinsfremde Spieler oder Schiedsrichter durch Vorstandsmitglieder oder Ge-

345 BGH NJW 2015, 1618 (1621); NK-StGB/Kindhäuser $\$ 266$ Rn. 107; Fischer StGB \$266 Rn. 115.

346 BGH NJW 1975, 1234 (1235); zust. SSW-StGB/Saliger \$266 Rn. 76; Schreiber/ Beulke JuS 1977, 656 (658).

347 Vgl. BGH NJW 1975, 1234 (1235); LG Bielefeld JZ 1977, 692; Triffterer NJW 1975, 612 (614); Heilemann Bestechlichkeit, S. 161 Fn. 544; abl. Schreiber/Beulke JuS 1977, 656 (658 ff.). 
schäftsführer eines Sportvereins dürfte die aufgewendete Bestechungssumme durch die konkrete Aussicht auf einen Vermögenszuwachs infolge sportlicher Erfolge kompensiert werden. Mangels Vermögensnachteils des Vereins scheidet eine Strafbarkeit wegen Untreue aus. Sie kommt bei Bejahung eines entsprechenden Schädigungsvorsatzes allenfalls bei der Manipulation unbedeutenderer Spiele in Betracht.

\section{Strafbarkeit durch Folgehandlungen im Zusammenhang mit Sportwetten}

Die einem sportlichen Wettbewerb vorangehende Manipulationsabsprache selbst begründet demnach keine unmittelbare Strafbarkeit für die involvierten Akteure. Dies gilt unabhängig der ihr zugrunde liegenden Motivation. Wird sie von den Beteiligten aber bewusst in einen Zweckzusammenhang gestellt, in dem sie der notwendigen Vorbereitung einer Folgehandlung dient, könnte ihr im Falle deren Strafbarkeit zumindest mittelbar strafrechtliche Relevanz zukommen. Als eine solche Folgehandlung abseits des überwiegend straffreien Wettkampfgeschehens kommt der Abschluss eines Wettvertrags bezüglich des manipulierten Sportereignisses in Betracht. Da der Wettspieler die vorangehende Vereinbarung einer manipulativen Einwirkung auf den Wettgegenstand dem Wettanbieter gegenüber nicht offenlegt, könnte er sich hierdurch wegen Betrugs gemäß $\$ 263$ StGB, je nach tatsächlicher Ausgestaltung der Wettannahme alternativ wegen Computerbetrugs gemäß $\$ 263$ a StGB strafbar machen. Die zu prüfende Strafbarkeit wäre also eine solche der den Wettvertrag abschließenden Person. Aufgrund von verbandsrechtlichen Wettverboten wird es sich hierbei zumeist nicht um einen Sportler oder Schiedsrichter handeln, sondern um einen externen Vorteilsgeber. Dessen mögliche Betrugsstrafbarkeit könnte jedoch Möglichkeiten einer strafbaren Beteiligung des manipulierenden Sportakteurs eröffnen.

\section{Strafbarkeit des Wettspielers wegen Betrugs zum Nachteil des Wettanbieters $(\mathbb{2} 263$ StGB)}

Die Subsumtion des Abschlusses eines Wettvertrages bezüglich eines manipulierten sportlichen Wettbewerbs unter den Tatbestand des $\$ 263$ StGB erfordert bei zwei Merkmalen einen gesteigerten Begründungsaufwand. Zunächst erscheint fraglich, ob im Verhalten des Wettspielers eine be- 
trugsrelevante Täuschungshandlung liegt. Außerdem ist ein beim Wettanbieter eintretender Vermögensschaden in Form und Zeitpunkt näher zu untersuchen.

\section{a) Täuschung}

Der Wettspieler müsste einen Vertreter des Anbieters bei Abschluss des Wettvertrages getäuscht haben. Gegenstand der Täuschung muss eine Tatsache sein. Der Ausgang des bewetteten sportlichen Wettbewerbs kommt als ein vom Tatsachenbegriff ausgeschlossenes künftiges Ereignis nicht in Betracht. ${ }^{348}$ Als Täuschungsgegenstand verbleibt die eigene Beteiligung an einer Manipulationsabsprache. Allerdings wird deren Unterbleiben dem Mitarbeiter der Wettannahmestelle bei Platzierung der Wette nicht ausdrücklich mitgeteilt werden. Zu prüfen ist folglich eine konkludente Täuschung durch schlüssiges Verhalten, die sich grundsätzlich auch auf Negativtatsachen beziehen kann, also die Behauptung transportiert, ein bestimmter tatsächlicher Umstand sei nicht gegeben. ${ }^{349}$ Der bloßen, im Regelfall stillschweigenden Abgabe einer Wette müsste der Erklärungswert innewohnen, die den Gegenstand der Wette bildenden Wahrscheinlichkeiten des Spielausgangs nicht manipulativ beeinflusst zu haben.

Tatsächlich hat der BGH in Fällen der Platzierung von Sportwetten durch Personen, die zuvor Bestechungszahlungen an am wettgegenständlichen Wettbewerb beteiligte Sportakteure geleistet hatten, das fehlende Mitwirken an einer Manipulation als Erklärungsgegenstand einer konkludenten Täuschung anerkannt. ${ }^{350}$ Hierbei führte er zunächst grundlegend aus, bei Ermittlung des Erklärungswerts eines rechtsgeschäftlichen Verhaltens komme es auf den erkennbaren Erwartungshorizont des Vertragspartners an. Dieser müsse nicht für den Einzelfall ermittelt werden, sondern richte sich nach der Verkehrsanschauung, für die auch der konkrete Geschäftstyp und dessen rechtliche Prägung maßgeblich seien. Diese Einbeziehung könne zwar nicht zur Zugrundelegung einer Erwartung der allgemeinen Redlichkeit des Vertragspartners führen. Die Erwartung werde

348 Schlösser NStZ 2005, 423 (424f.); Schäfers ZfWG 2008, 236 (238).

349 Vgl. BGHSt 51, 165 (169); 58, 102 (108).

350 Erstmals im „Pferdewettenfall“ BGHSt 29, 165 (167f.); sodann in den beiden prominenten Entscheidungen zu Spielmanipulationen im Fußball BGHSt 51, 165 (171f.); BGHSt 58, 102 (106). Die im folgenden Absatz nachvollzogene Argumentation ist überwiegend BGHSt 51, 165 (171 f.) entnommen. 
sich aber zumindest darauf richten, dass nicht die zivilrechtlich vorgegebenen, unverzichtbaren Vertragsgrundlagen (essentialia negotii) des konkreten Geschäfts vorsätzlich zum eigenen Vorteil manipuliert wurden. Zur Geschäftsgrundlage des Wettvertrags, der als Unterform des zufallsabhängigen Glücksspiels einzuordnen sei, zähle die ausschließliche Maßgeblichkeit der für eine redliche sportliche Auseinandersetzung typischen Faktoren für den Spielausgang. Der Wettplatzierung wohne demnach der Aussagegehalt inne, das wettgegenständliche Risiko nicht vorab durch die Einwirkung auf Spieler oder Schiedsrichter manipulativ verändert zu haben. ${ }^{351}$ Wurden entsprechende Manipulationsabsprachen getroffen, liege folglich in der auf Abschluss eines Wettvertrags gerichteten Willenserklärung eine konkludente Täuschung des Wettanbieters.

An dieser Bewertung wird kritisiert, es handele sich um eine normative Überdehnung des Täuschungsbegriffs, der zu weit von den tatsächlichen Gegebenheiten gelöst werde und als letztlich willkürliche Konstruktion das bei einer Täuschung durch Unterlassen erforderliche Korrektiv der Aufklärungspflicht entwerte. ${ }^{352}$ Unterstützend wird dabei auf den nicht hinreichend berücksichtigten anonymen und formalisierten Vorgang der Wettabgabe rekurriert, der regelmäßig eine Erklärung über eine Nichtmanipulation seitens des Wettenden nicht nur nicht erwarten lasse, sondern im Falle ihrer ausdrücklichen Mitteilung gar als irritierend und verdächtig ausweise. ${ }^{353}$ Doch dieser Einwand verkennt Charakteristika der konkludenten Täuschung und erlaubt keine sachgerechte Bewertung möglicher Fallgruppen. Denn unbestritten als konkludente Täuschung anerkannte Verhaltensweisen wie etwa die Vorspiegelung der Zahlungsfähigkeit und -bereitschaft beim Bezug von Waren müssten - insbesondere sofern sie formalisierte Geschäfte des Massenverkehrs beträfen - unter dieser Maßgabe ebenfalls in Frage gestellt werden. ${ }^{354}$ Die Ungewöhnlichkeit einer ausdrücklichen Erklärung ist für die Konkludenz genauso konstitutiv wie eine gewisse Normativierung des Täuschungsbegriffs unvermeidlich. Das bei Auslegung des Erklärungswerts zentrale Kriterium der Verkehrsanschauung lässt sich nicht allein durch faktische Aspekte ausfüllen, sondern ver-

351 Freilich müssen die intendierten Manipulationen dann auch geeignet sein, den Spielverlauf mit einer hohen Wahrscheinlichkeit erheblich zu beeinflussen, was auf die Auslobung von Siegprämien oder die Organisation von Schmähgesängen nicht zutrifft, s. MüKo-StGB/Hefendehl \$263 Rn. 151.

352 Jahn/Meier JuS 2007, 215; Schild ZfWG 2007, 10 (11); Schlösser NStZ 2005, 423 (425f.).

$353 \mathrm{Jahn} /$ Meier JuS 2007, 215 (216).

354 Krüger/Hilbert/Wengenroth Causa Sport 2013, 188 (193 f.). 
langt einen Rückgriff auf generalisierte Verhaltensmaßstäbe und spezifische rechtliche Rahmenbedingungen. ${ }^{355}$ Gelingt hierbei für den konkreten Fall eine sachgerechte Trennung von relevanten und irrelevanten Erwartungen, kann die daraus abgeleitete Annahme einer konkludenten Täuschung nicht mit dem dogmatischen Wunsch nach einem breiten Anwendungsbereich der strafrechtlichen Garantenstellung entkräftet werden. ${ }^{356}$

Ist dem BGH in der grundsätzlichen Charakterisierung der konkludenten Täuschung und im konkret gefundenen Ergebnis zuzustimmen, bleibt auch er eine Bestimmung der Grenzen der Normativierung des Täuschungsbegriffs und eine ausführliche Begründung von Differenzierungen auf Basis der Verkehrsanschauung schuldig. Dies zeigt sich etwa in der Behandlung von Fällen, in denen der Wettende nicht selbst an der Manipulation eines Wettbewerbs mitwirkt, von der Planung einer solchen aber Kenntnis erlangt. Wie auch in den sog. Spätwetterfällen, bei denen der Wettende in letzter Minute auf einen ihm im Gegensatz zum Wettanbieter bereits bekannten Ausgang setzt, soll hier eine konkludente Täuschung nach Ansicht des BGH ausscheiden. ${ }^{357} \mathrm{Da}$ aber auch diese Wissensvorsprünge in Form der in den Wettquoten abgebildeten Ungewissheit des Ergebnisses die identitätswesentlichen Merkmale des Vertragstyps betrifft, lässt sich die Ablehnung eines solchen Sonderwissens als Täuschungsgegenstand kaum allein mit der schützenswerten Erwartung einer ausbleibenden Beeinträchtigung der essentialia negotii begründen. ${ }^{358}$ Ergänzt werden sollte das Kriterium der Verkehrserwartung daher durch einen zurechnungsorientierten Ansatz, der die Ablehnung einer konkludenten Täuschung beim bloßen Ausnutzen von Informationsvorsprüngen durch den Wettenden über Erwägungen bezüglich der Zuständigkeit für Informationsdefizite bzw. wettvertragstypische Risiko- und Verantwortungsaufteilung abzusichern vermag. 359

355 Vgl. Kasiske GA 2009, 360 (364); Krack ZIS 2007, 103 (107); Saliger/Rönnau/ Kirch-Heim NStZ 2007, 361 (362).

356 Gaede HRRS 2007, 18.

357 BGHSt 16, 120 (121); zur Verwendung eines Tipps bezüglich einer bevorstehenden Manipulation BGH NStZ 2014, $317 \mathrm{f}$.

358 Vgl. Kubiciel HRRS 2007, 68 (70); Wessels/Hillenkamp/Schubr Strafrecht BT II Rn. 500; hieraus die generelle Einbeziehung von zurückgehaltenem Sonderwissen in die Täuschung ableitend Krack ZIS 2007, 103 (105); NK-StGB/Kindhäuser $\$ 263 \mathrm{Rn} .133$.

359 Vgl. etwa Kubiciel HRRS 2007, 68 (70 f.); so auch Saliger/Rönnau/Kirch-Heim NStZ 2007, 361 (363 f.), wonach erlangte Informationsvorsprünge des Wettenden zum allgemeinen und daher straflosen Geschäftsrisiko bei Wetten gehörten; ähnlich MüKo-StGB/Hefendebl $\$ 263$ Rn. 152, der einschränkend die Rechtmä- 
Dieser Leitlinie einer dem Täter zurechenbaren Täuschung über die selbstverständliche Grundlage eines Geschäftstyps zufolge führt jedenfalls die aktiv vereinbarte Manipulation eines Wettbewerbs im Zeitpunkt der Abgabe einer diesbezüglichen Sportwette durch an der Absprache beteiligte Sportakteure oder Hintermänner zur Annahme einer Täuschung. Diese führt beim Mitarbeiter des Wettanbieters zumindest in Form des sachgedanklichen Mitbewusstseins zu einem Irrtum über die Manipulationsfreiheit des Wettereignisses. ${ }^{360}$

\section{b) Vermögensschaden}

Umstritten ist ferner, ob und in welcher Weise der in Person seines Angestellten getäuschte Wettanbieter infolge einer durch den Irrtum ausgelösten Vermögensverfügung einen Vermögensschaden erleidet. Für eine Vermögensverfügung kommen zwei Anknüpfungspunkte in Betracht. Nahe liegt zunächst die Fokussierung auf die im Anschluss an den entsprechend der vereinbarten Manipulation verlaufenden Wettbewerb erfolgende Auszahlung eines Wettgewinns an den Manipulator, auf den dieser aufgrund der Spielmanipulation keinen Anspruch hat. Als unmittelbar vermögensminderndes Tun führt sie zu einem endgültigen Vermögensverlust auf Seiten des Wettanbieters. Die Strafbarkeit wegen vollendeten Betrugs von einer Gewinnauszahlung abhängig zu machen, hieße jedoch, die in der Realität durchaus häufigen Konstellationen auszuklammern, in denen erwiesene Manipulationsabsprachen im Wettbewerb nicht umgesetzt werden konnten oder zumindest nicht zum Eintritt des wettgegenständlichen Ereignisses führten.

Dogmatisch würde dabei übersehen, dass bereits im täuschungsbedingten Eingehen einer vertraglichen Verpflichtung eine möglicherweise schadensrelevante Vermögensminderung liegen kann (sog. Eingehungsbe-

Bigkeit der Erlangung voraussetzt; andere verlangen in Anknüpfung an BGHSt 16, 120 (121) zusätzlich, dass die Informationen aus allgemein zugänglichen Quellen stammten, vgl. Kasiske GA 2009, 360 (369).

360 BGHSt 51, 165 (174); BGHSt 58, 102 (106); zust. Graf/Jäger/Wittig/Dannecker \$263 StGB Rn. 354; Gaede HRRS 2007, 18 (19); Krack ZIS 2007, 103 (105 ff.); aA Jahn/Maier JuS 2007, 215 (218); Schlösser NStZ 2005, 423 (427 f.), die einen Irrtum ablehnen, da sich der Wettbüroangestellte regelmäßig überhaupt keine Gedanken über eine mögliche Manipulation des Wettbewerbs mache; Schäfers ZfWG 2008, 236 (240 f.); Ostermeier ZfWG 2007, 253 (257), die keine Ursächlichkeit zwischen Täuschung und Irrtum erkennen. 
trug). ${ }^{361}$ Der von $\$ 263$ StGB gewährte Vermögensschutz erfasst bereits die konkrete Gefahr des endgültigen Verlusts eines Vermögensbestandteils, die auch in der Entstehung einer Verbindlichkeit begründet sein kann. ${ }^{362}$ So ist dem Vermögen des Wettanbieters schon infolge des abgeschlossenen Wettvertrages der Wert des dem Wettkunden verschafften und durch den Eintritt des von ihm angegebenen Wettereignisses bedingten Anspruchs auf Auszahlung des Wettgewinns in x-facher Höhe des Wetteinsatzes abzuziehen. Ob hierin nun ein Schaden liegt, ist gemäß dem Prinzip der Gesamtsaldierung danach zu ermitteln, ob der Gesamtwert des Vermögens des Wettanbieters nach der vorgenommenen Verfügung hinter dem Gesamtwert vor der Verfügung zurückbleibt. ${ }^{363}$ Der Wettvertrag müsste also für sich genommen eine nach wirtschaftlicher Betrachtungsweise feststellbare Verschlechterung der Vermögenslage des Anbieters in Form eines Negativsaldos bewirken. ${ }^{364}$

Diese Voraussetzung sieht der BGH in den beiden Entscheidungen zu manipulierten Sportwetten mit festen Gewinnquoten im Ergebnis als gegeben an, wobei sich die jeweilige Begründung unterscheidet. Die im ersten Urteil zum „Fall Hoyzer“ angestrebte Anpassung der zum Eingehungsbetrug entwickelten Grundsätze an die Besonderheiten der Sportwette sieht zunächst die Bewertung der Wettquote als Verkaufspreis der vom Wettenden erkauften Wettchance vor. ${ }^{365}$ Ihre Festsetzung durch die Wettanbieter entspringe einer bestimmten Risikokalkulation, die an die Wahrscheinlichkeiten der denkbaren Spielverläufe anschließe. Durch das Mitwirken bestochener Akteure trete nun aber eine Risikoverschiebung ein, die die mangels Kenntnis aufrechterhaltene Berechnungsgrundlage des Wettanbieters zu seinem Nachteil falsch werden ließe. Der Wettende erlange eine im Verhältnis zum Verkaufspreis zu hohe Gewinnchance bzw. eine Gewinnchance zu einem zu günstigen Verkaufspreis. In der Differenz zwischen der aufgrund der Kalkulation des Buchmachers tatsächlich angebotenen und einer an die unerkannt eingetretene Risikoverschiebung angepassten, hypothetischen Quote liege ein dem Wettanbieter bereits bei Vertragsabschluss entstehender Vermögensschaden, der aufgrund der Unsicherheit der endgültigen Vermögensminderung allerdings keinen Ge-

361 BGHSt 16, 220 (221); BGH NStZ 2008, 96 ff.; Schönke/Schröder/Perron $\$ 263$ Rn. $128 \mathrm{ff}$.

362 Fischer StGB $\$ 263$ Rn.156ff.; Wessels/Hillenkamp/Schuhr Strafrecht BT II Rn. $572 \mathrm{ff}$.

363 BGHSt 16, 220 (221); 34, 201; 45, 1 (4).

364 BGH NStZ 2008, 95 (96); Fischer StGB $\$ 263$ Rn. 176 f.

365 Vgl. zum Folgenden BGHSt 51, 165 (174 ff.). 
fährdungsschaden darstelle. Dessen Bezifferung sei nicht erforderlich, solange die relevanten Risikofaktoren benannt würden. Ob die Manipulation sich überhaupt auswirke, sei für die Vollendung des $\$ 263$ StGB irrelevant. Eine spätere Auszahlung des Wettgewinns stelle lediglich eine Schadensvertiefung dar, die allenfalls die nicht zwingend notwendige Bestimmung der Schadenshöhe (Wettgewinn abzüglich Wetteinsatz) erleichtere.

Die an dieser Schadensbegründung durchaus vielstimmig anknüpfende Kritik richtet sich teilweise gegen die dogmatische Verortung eines solchen Quotenschadens, teilweise gegen dessen konkrete Konzeption. Einer Einordnung als Eingehungsbetrug widerspreche einerseits die gleichzeitige Ablehnung eines Gefährdungsschadens, ${ }^{366}$ andererseits der auch beim BGH anklingende Umstand, dass mit Abschluss des Wettvertrages die beiden Vertragspartner ihre Leistungen bereits erbracht hätten. ${ }^{367}$ Die sich in der Aushändigung des Wettscheins manifestierende Gewähr der Wettchance gegen Entrichtung des Einsatzes beschreibe bereits den Austausch der vertragstypischen Verbindlichkeiten und weise eine hierdurch eintretende Vermögensminderung als Erfüllungsschaden aus, für den eine spätere Auszahlung irrelevant sei. ${ }^{368}$

Neben dieser Uneinigkeit bezüglich der dogmatischen Zuordnung wird auch bestritten, dass es sich bei einem derart konzipierten Quotenschaden überhaupt um einen betrugsrelevanten Vermögensschaden handelt. Gegen die schadensbegründende Heranziehung einer die Manipulation hypothetisch berücksichtigenden Vergleichsquote werden dabei gleich mehrere Einwände vorgebracht. Noch stärker als bei der Annahme einer konkludenten Täuschung werde die Strafbarkeit hier auf Fiktionen gestützt, da die Kenntnis von Manipulationen den Wettanbieter in der Realität nicht etwa zur Anpassung seiner Quote bewegen würde, sondern zur Entnahme des Wettbewerbs aus seinem Angebot. ${ }^{369}$ Doch selbst wenn man sich auf die Überlegung einer solchen Quotendifferenz einlasse, werde eine Ermittlung des Schadens gemäß der Maßgabe des Vergleichs der objektiven wirtschaftlichen Werte der ausgetauschten Leistungen aufgrund der nur unpräzisen Bestimmung der in die Saldierung einzustellenden Vermögenspo-

366 Saliger/Rönnau/Kirch-Heim NStZ 2007, 361 (365); Achenbach/Ransiek/Rönnau/ Kölbel Teil 5 Kapitel 1 Rn. 314 Fn. 855.

367 Krack ZIS 2007, 103 (109f.).

368 Engländer JR 2007, 477 (479); Radtke Jura 2007, 451 f.; Krack ZIS 2007, 103 (109f.).

369 Matt/Renzikowski/Saliger $₫ 263$ Rn. 261; MüKo-StGB/Hefendehl $\$ 263$ Rn. 598; Schönke/Schröder/Perron $\$ 263$ Rn. 114; Reinhart SpuRt 2007, 52 (54). 
sitionen kaum gelingen. ${ }^{370}$ Die Bildung einer Vergleichsquote müsste nicht nur eine mangels Erfahrungswerten kaum mögliche Bewertung der Auswirkung bestimmter Manipulationsformen auf die Wahrscheinlichkeit verschiedener Spielverläufe beinhalten, sondern auch die in Wettquoten stets bereits eingepreiste, undurchsichtige Gewinnspanne des Anbieters berücksichtigen. ${ }^{371}$ Unterstützung erfuhr die Kritik auch vom Bundesverfassungsgericht, das zwar in anderem Zusammenhang, aber mit grundsätzlicher Bedeutung gerade beim Eingehungsbetrug eine genaue und wirtschaftlich nachvollziehbare Bezifferung des Vermögensschadens für verfassungsrechtlich unerlässlich hält und damit indirekt auch die Figur des Quotenschadens in Frage stellt. ${ }^{372}$

Im Kontext dieser verschärften Anforderungen an die Schadensermittlung steht die zweite Entscheidung des BGH zum Sportwettbetrug aus dem Jahr 2012. ${ }^{373}$ Im Ergebnis mit der Entscheidung im „Fall Hoyzer“" übereinstimmend wird ein vollendeter Betrug bereits mit Abschluss des Wettvertrages für denkbar gehalten. Der Versuch des Gerichts, den Anwendungsbereich eines Eingehungsschadens einerseits zu beschränken und diesen andererseits neu zu begründen, kann jedoch als Eingeständnis der problematischen Konzeption des Quotenschadens und notwendige Anpassung an die verfassungsgerichtlichen Vorgaben gewertet werden. So orientiert sich der BGH nun stark an der die Bezifferung der Schadenshöhe seiner Ansicht nach erleichternden Erfüllungsphase. Sobald es zur Auszahlung eines Wettgewinnes komme, seien Erwägungen zu einem vorangehenden Eingehungsschaden überflüssig und der Schaden könne in Höhe der ausgezahlten Gewinnsumme abzüglich des Einsatzes festgestellt werden. Dieser sei auch nicht gebunden an eine nachzuweisende Kausalität der Manipulation für Spielausgang und Wetterfolg, da für die innere Verknüpfung von Täuschung, Irrtum und Vermögensverfügung allein der tatsächliche Verlauf der Willensbildung und damit der Umstand maßgeblich sei, dass der Wettanbieter eine Wette auf ein manipuliertes Spiel gar nicht angenommen hätte.

370 Achenbach/Ransiek/Rönnau/Kölbel Teil 5 Kapitel 1 Rn. 315 f.; Rönnau/Soyka NStZ 2009, 12 (14); Saliger/Rönnau/Kirch-Heim NStZ 2007, 361 (365).

371 Reinhart SpuRt 2007, 52 (54); Saliger FS Samson, 2010, S. 455 (457).

372 Erstmalig zur Untreue BVerfGE 126, 170 (211); die Übertragung auf den Eingehungsbetrug erfolgte dann in BVerfGE 130, 1 (47 f.); zur Auswirkung dieser Rechtsprechung auf den Quotenschaden Steinsiek/Vollmer ZIS 2012, 586 (589 f.); Krüger/Hilbert/Wengenroth Causa Sport 2013, 188 (191); Saliger HRRS 2012, 363 (367).

373 Vgl. zum Folgenden BGHSt 58, 102 (110 ff.). 
Für den bei fehlender Gewinnausschüttung in Betracht kommenden Eingehungsschaden soll es hingegen nicht mehr auf eine Quotendifferenz ankommen. Vielmehr seien die sich infolge des Wettvertrages gegenüber stehenden, von gegensätzlichen Bedingungen abhängigen Ansprüche auf Wettgewinn bzw. auf Behaltendürfen des vorgeleisteten Wetteinsatzes in ihrem Geldwert zu saldieren. Entsprechend dem Charakter des Wettvertrages als Risikogeschäft bemesse sich dieser maßgeblich nach der jeweiligen Verlust- bzw. Realisierungswahrscheinlichkeit, die wiederum an die Wahrscheinlichkeit des Eintritts des zur Bedingung gemachten Spielausgangs anknüpfe. Durch eine vom Wettenden entsprechend seiner Wettvoraussage initiierte Manipulation erhöhe sich also der Geldwert seines Anspruchs gegen den Wettanbieter, während sich dessen Anspruch wertmäßig vermindere. Einen Vermögensschaden erleide Letzterer, wenn die von ihm gegenüber dem Wettenden eingegangene und infolge der Manipulation mit einem erhöhten Realisierungsrisiko behaftete Verpflichtung zur Auszahlung des Wettgewinns nicht mehr durch den Anspruch auf den Wetteinsatz aufgewogen werde. Für dessen notwendige Bezifferung müsse gegebenenfalls mit sachverständiger Hilfe die Beeinflussung der Manipulation auf den Wetterfolg bewertet werden, wobei die anfänglich angebotene Quote als Indiz des ursprünglichen Wettrisikos hierbei genauso zu beachten sei wie das Ausmaß der Manipulation. Bei verbleibenden Unsicherheiten könne unter Berücksichtigung aller bekannten Faktoren ein Mindestschaden geschätzt werden. Sofern dies jedoch nicht tragfähig gelinge, komme nur eine Strafbarkeit wegen versuchten Betrugs in Betracht.

Die sich hierin ausdrückende methodische Neujustierung der Schadensermittlung beim Eingehungsbetrug ist zu begrüßen. $\mathrm{Zu}$ verteidigen ist sie insbesondere gegen den Vorwurf einer unzulänglichen und bloß terminologischen Abwendung vom Quotenschaden, dessen Problematik kaum fassbarer Vermögenspositionen sich bei Ermittlung der Verlustwahrscheinlichkeiten in gleicher Weise stellte. ${ }^{374}$ Nicht nur gewährleistet eine Fokussierung auf den Geldwert der synallagmatischen Ansprüche eine systemgerechte Einbindung der Sportwettverträge in die Grundsätze zum Risikogeschäft. ${ }^{375}$ Sie präzisiert auch den maßgeblichen Gegenstand der Saldierung und löst ihn von den Unwägbarkeiten einer multifaktoriellen und fiktiven Vergleichsquote. ${ }^{376}$ Fraglos bleibt auch die nun erforderliche zweischritti-

374 Hierzu Schiemann NJW 2013, 888.

375 MüKo-StGB/Hefendebl \$263 Rn. 609.

376 Achenbach/Ransiek/Rönnau/Kölbel Teil 5 Kapitel 1 Rn. 317; Funck Betrugsschaden, S. $386 \mathrm{f}$. 
ge Umrechnung einer konkreten manipulativen Einwirkung zunächst auf die Wahrscheinlichkeit des Ausgangs eines mannschaftssportlichen Wettbewerbs und sodann auf den Geldwert des Anspruchs des Wettenden anspruchsvoll, zumal die Manipulationsbereitschaft eines Spielers diesbezüglich nicht mit der durch Buchmacher erfahrungsgemäß berechenbaren Schwächung einer Mannschaft durch eine Verletzung gleichgesetzt werden kann. ${ }^{377}$ Unter sachverständiger Würdigung der Anzahl betroffener Spieler, ihrer Positionen und damit verbundenen Möglichkeiten einer verdeckt unlauteren Einflussnahme sowie der auch von der Stärke der gegnerischen Mannschaft abhängigen Erwartung geeigneter Spielsituationen erscheint die manipulationsbedingte Verschiebung der Wahrscheinlichkeit des Eintritts des Wettereignisses jedoch annäherungsweise quantifizierbar. ${ }^{378}$ Hinsichtlich der anschließenden Ableitung der ermittelten Wahrscheinlichkeit für den Geldwert des Anspruchs lässt sich womöglich auf in den Wirtschaftswissenschaften gängige Erwartungswertberechnungen zurückgreifen.

Keine Zustimmung verdient indes die vom BGH präferierte Schadensbegründung über die Erfüllungsphase und die dabei vorgenommene Bezifferung des Auszahlungsschadens. Dessen theoretisch nachvollziehbare Beschreibung als Vertiefung des mit Vertragsschluss ausgelösten Vermögensnachteils, der vollständig in dem durch die Vertragserfüllung herbeigeführten Schaden enthalten sei, lässt eine Identität von Eingehungs- und Auszahlungsschaden vermuten. Diese löst der BGH jedoch selbst wieder auf, indem er für die Bestimmung der Schadenshöhe allein den Umstand für entscheidend erachtet, dass der Anbieter die Wette bei Kenntnis der Manipulation nicht angenommen hätte und somit der Wettgewinn als ganzer nicht geschuldet sei. ${ }^{379}$ Dies läuft auf eine Gleichsetzung von Schaden und täuschungsbedingter Verfügung hinaus, die den von $\$ 263 \mathrm{StGB}$ gerade nicht gewährten Schutz der Dispositionsfreiheit verkennt und das durch die initiierte Manipulation tatsächlich geschaffene Vermögensrisiko zu Gunsten einer primär normativen Schadensbeschreibung übergeht. ${ }^{380}$ Die vom Ausmaß der tatsächlichen Einwirkung freigestellte Annahme ei-

377 In diese Richtung aber noch MüKo-StGB/Hefendehl 3. Auflage, $\mathbb{2} 263$ Rn. 511; Reinhart SpuRt 2007, 52 (54).

378 So wohl auch Kulhanek NZWiSt 2013, 246 (250 f.); Bittmann ZWH 2013, 137 jeweils mit möglichen Modellen einer Schadensberechnung; skeptisch hingegen Funck Betrugsschaden, S. 387 ff.; Kretschmer FS Rössner, 2015, S. 628 (637); Jäger JA 2013, 868 (870).

379 Vgl. BGHSt 58, 102 (110).

380 Greco NZWiSt 2014, 334 (335); MüKo-StGB/Hefendehl \$ 263 Rn. 601. 
nes Auszahlungsschadens schlicht in Höhe des gesamten Wettgewinns ebnet die notwendige Wertdifferenz zwischen Risiko und Realisierung ein und kann im Einzelfall zu einer erheblichen und kaum begründbaren Diskrepanz zwischen Eingehungs- und Erfüllungsschaden führen. ${ }^{381} \mathrm{Um}$ dies im Sinne einer konsistenten und empirisch orientierten Schadensermittlung abzuwenden, hat auch der Auszahlungsschaden die manipulationsbedingte Risikoverschiebung abzubilden, auch wenn hierdurch künftig auch in Fällen der Gewinnauskehrung komplexe Erwägungen zur Höhe des Eingehungsschadens angestellt werden müssen. ${ }^{382}$

Ohne Auswirkung auf die Schadensfeststellung bleiben letztlich die Einnahmen, die der Wettanbieter infolge eines zu Gunsten des Außenseiters manipulierten Spiels durch die einbehaltenen Einsätze anderer Wettkunden erzielt, die von einem Favoritensieg ausgegangen waren. Grundsätzlich garantiert die Ausrichtung der Quoten an der erwarteten Verteilung der Wetteinsätze dem Wettanbieter einen vom Ausgang des Wettbewerbs unabhängigen Gesamtgewinn. ${ }^{383} \mathrm{Je}$ mehr die tatsächliche Wettverteilung aber von der Prognose abweicht, desto stärker hängt zumindest die Höhe des letztlich erzielten Gewinns vom Ergebnis des Wettbewerbs ab. Entwickelte sich die Wettverteilung bei konstant angebotenen Quoten nun tatsächlich entgegen der Prognose, könnte sich die Gewinnaussicht des Anbieters bei einem Sieg von Team A beispielsweise nur auf $5 \%$ der Gesamteinsätze, bei einem Sieg von Team B hingegen auf $15 \%$ belaufen. Führte nun die massive Wettplatzierung des Manipulators auf einen Sieg von Team B zwar zu einem geringfügigen Absinken der bei einem Sieg von B erreichbaren Gesamtgewinns, aber insgesamt zu einer Annäherung an die gewünschte Wettverteilung und damit zu einer höheren garantierten Gewinnsumme des Anbieters, könnte diese die erhöhte Leistungswahrscheinlichkeit des Anbieters gegenüber dem Manipulator bei einem Sieg von Team B kompensieren. ${ }^{384}$ Hierbei würde jedoch übersehen, dass gerade in der Realität der Online-Wettanbieter die Quote, über die der einzelne Wettvertrag geschlossen wurde, zwar unveränderlich bleibt, im Angebot für weitere interessierte Wettspieler aber fortlaufend dynamisch angepasst wird, um über Anreize die vom Anbieter intendierte Wettverteilung zu er-

381 Vgl. Schlösser NStZ 2013, 629 (631 ff.); ähnlich auch Bittmann ZWH 2013, 137 (140).

382 Greco NZWiSt 2014, 334 (335) mit einem entsprechenden Berechnungsvorschlag zum Auszahlungsschaden.

383 Saliger/Rönnau/Kirch-Heim NStZ 2007, 361 (367).

384 So Funck Betrugsschaden, S.397, der eine Schadenskompensation in der Konstellation einer unveränderlichen Quote annimmt. 
reichen. Dann stellen sich die Vermögensvorteile der Erreichung der gewünschten Wettverteilung aber gerade nicht mehr durch den konkreten Vertragsschluss mit dem Manipulator ein, sondern durch nachträgliche Handlungen des Opfers. ${ }^{385}$ Entsprechend können auch die nach einem manipulationsbetroffenen Wettbewerb konkret einbehaltenen Einsätze der Wettverlierer keinen im Rahmen der Schadenskompensation zu berücksichtigenden Ausgleich darstellen, da der insofern in Betracht kommende Vermögenszuwachs des Anbieters in keinem Unmittelbarkeitszusammenhang mit der irrtumsbedingten Verfügung steht, sondern auf rechtlich selbstständigen Handlungen Dritter beruht. ${ }^{386}$

\section{c) Zwischenergebnis}

Die Betrugsstrafbarkeit bei Wetten auf eigens manipulierte sportliche Wettbewerbe zu Lasten des Wettanbieters wird kontrovers diskutiert. Gerade die Tatbestandsmerkmale der Täuschung sowie des Vermögensschadens lassen sich nicht ohne weiteres annehmen, sondern verlangen nach einer an den Besonderheiten des Wettvertrages ausgerichteten Präzisierung bzw. Anpassung der in ihrem Rahmen entwickelten dogmatischen Fallgruppen. Wenngleich die Rechtsprechung hierbei insbesondere bei Begründung und Bezifferung des Schadens einzelne kritikwürdige Ableitungen vornimmt, ist den von ihr entwickelten grundsätzlichen Leitlinien zuzustimmen. Ihnen zufolge verwirklicht bereits die Abgabe einer Wette den Betrugstatbestand, sofern sie einer Manipulationsabsprache bezüglich des wettgegenständlichen Ereignisses nachfolgt, an der der Wettende beteiligt war. Ob es sich bei der Person des Wettenden dabei um einen am wettgegenständlichen Wettbewerb mitwirkenden Sportakteur oder einen Hintermann handelt, ist für den Eintritt der Strafbarkeit ebenso wenig von Relevanz wie der genaue Umfang der avisierten Manipulation bzw. ihre erfolgreiche Umsetzung und die tatsächliche Erzielung eines Wettgewinns.

385 Funck Betrugsschaden, S. 398.

386 BGH NJW 2013, 883 (886); Graf/Jäger/Wittig/Dannecker $\ 263$ StGB Rn. 358; Kulhanek NZWiSt 2013, 246 (250); zum Unmittelbarkeitserfordernis Rengier Strafrecht BT I $₫ 13$ Rn. 156. 
2. Strafbarkeit des Wettspielers wegen Computerbetrugs zum Nachteil des Wettanbieters ( $\$ 263$ a StGB)

Die festgestellte Strafbarkeit gemäß $\$ 263$ StGB scheidet jedoch in den zunehmend praxisrelevanten Fällen aus, in denen der Manipulator seine Wette nicht im Wettbüro gegenüber einem Mitarbeiter des Anbieters abgibt, sondern an einem Wettautomaten oder über das Internet platziert. Da es hierbei zu keinem Kontakt mit einem Menschen kommt, ist bereits ein in $\$ 263$ StGB vorausgesetzter menschlicher Irrtum nicht möglich. Allerdings verwirklicht eine auf diese Weise vorgenommene Wettplatzierung regelmäßig den Tatbestand des Computerbetrugs ( $\$ 263 \mathrm{a}$ StGB), der zur Schließung von infolge des zunehmenden Einsatzes von Datenverarbeitungssystemen entstandenen Lücken im Vermögensschutz geschaffen wurde. ${ }^{387}$

Die Eingabe von Wettereignis, erwartetem Spielausgang und Einsatz in das elektronische Portal des Anbieters stellt sich als unbefugte Verwendung von Daten i.S.d. $\$ 263 a$ Abs. 1 Var. 3 StGB dar. Nach der aus der gesetzgeberisch intendierten Struktur- und Wertgleichheit zu $\$ 263$ StGB abgeleiteten betrugsspezifischen Auslegung erfolgt eine Verwendung nämlich dann unbefugt, wenn sie gegenüber einer hinzugedachten natürlichen Person Täuschungscharakter hätte. ${ }^{388} \mathrm{Im}$ Detail uneinheitlich wird dabei die Frage nach dem Umfang des Prüfungshorizonts dieser Vergleichsperson beurteilt. Ob nur dann von einer Täuschungsäquivalenz der Datenverwendung ausgegangen werden kann, wenn die in Bezug genommenen Tatsachen Niederschlag in der Programmgestaltung des Computers gefunden haben ${ }^{389}$ oder diese Forderung gerade bei Erschleichen eines Vertragsschlusses zu einer zu technik-fixierten Aushebelung der jeweiligen Verkehrsauffassung über den allgemein anerkannten Inhalt führen würde, ${ }^{390}$ kann dahinstehen. Denn der potenziell relevante Wille des Anbieters, keine Wetten auf manipulierte Spiele zuzulassen, wird sich regelmäßig durch

387 S. Wessels/Hillenkamp/Schubr Strafrecht BT II Rn. 601.

388 BGHSt 47, 160 (162 f.); Fischer StGB \$263a Rn. 11; Wessels/Hillenkamp/Schubr Strafrecht BT II Rn. 613; explizit für Fälle des Wettbetrugs BGH NStZ 2013, 281 (282), NJW 2016, 1336 (1337).

389 In diese Richtung BGHSt 47, 160 (163) zumindest für Fälle des Missbrauchs von Scheckkarten.

390 Schönke/Schröder/Perron $\$ 263$ a Rn. 9. 
die Festsetzung von Höchstgrenzen für Wetteinsätze auch im Datenverarbeitungsprogramm manifestieren. ${ }^{391}$

Hinsichtlich der Qualifizierung der Datenverwendung als unbefugt kann demnach auf den im Rahmen des $\$ 263$ StGB begründeten Täuschungscharakter der auf Vertragsschluss gerichteten Willenserklärung verwiesen werden. Die Benutzung eines Datenverarbeitungssystems unter Verheimlichung der Beteiligung an einer Manipulation des wettgegenständlichen Ereignisses ist täuschungsrelevant. Die unbefugte Dateneingabe in die Software des Anbieters verleitet den Computer zu einer vermögensrelevanten Disposition. Der hierdurch abgeschlossene Wettvertrag kann aufgrund der übereinstimmenden Schadensbegriffe entsprechend den Ausführungen zu $\$ 263$ StGB einen Eingehungsschaden darstellen.

3. Strafbarkeit des Wettspielers wegen Betrugs zum Nachteil der redlichen Wettteilnehmer $(\$ 263$ StGB)

Neben den Wettanbietern könnten durch die Wettplatzierung des Manipulators auch die übrigen Wettteilnehmer in ihrem Vermögen beeinträchtigt sein. Bei den hier untersuchten Wetten mit festen Quoten und variablen Gewinnanteilen ${ }^{392}$ kann das von vornherein nur auf Wettteilnehmer zutreffen, die auf ein anderes als das manipulativ beabsichtigte Ereignis gesetzt haben. Sie haben durch Platzierung einer Wette einen bedingten Anspruch gegen den Anbieter erworben, dessen Wert infolge seiner durch die intendierte Manipulation unerkannt herabgesetzten Realisierungswahrscheinlichkeit nicht mehr dem Wert des dem Anbieter im Gegenzug eingeräumten bedingten Anspruch auf Behaltendürfen des Einsatzes entspricht. Bei gelingender Manipulation werden sie um ihre Gewinnchance

391 S. BGH NStZ 2013, 281 (282), NJW 2016, 1336 (1337); vgl. auch Brauneisen, in: Württembergischer Fußballverband (Hrsg.), Sportwette, 2013, S. 43 (59 f.); Ivanov/Köpferl Jura 2016, 554 (563), denen zufolge die vorprogrammierten Einsatzhöchstgrenzen auch auf Grundlage einer subjektiven Auslegung zur Annahme einer unbefugten Datenverwendung führten; aA MüKo-StGB/Mühlbauer $\$ 263 \mathrm{a}$ Rn. 87 mit Verweis auf die vielfache Zweckbindung der Einsatzhöchstgrenzen (unter anderem Schutz der Wettspieler, Voraussetzung des Erhalts einer Konzession), die demnach keinen spezifisch manipulationsverhindernden Bedeutungsgehalt aufwiesen.

392 Zur Untersuchung einer solchen Strafbarkeit bei Wetten mit starrem Gewinnanteil (Fußball-Toto-System) Funck Betrugsschaden, S. 394 f. 
gebracht. ${ }^{393}$ Für die Annahme des $₫ 263$ StGB auch in diesem Verhältnis fehlt es jedoch an einer Kommunikationsbeziehung zwischen dem Manipulator und den übrigen Wettteilnehmern. Selbst wenn sich über die Figur des Dreieckbetrugs die Vermögensverfügung des Wettanbieters den anderen Wettteilnehmern zurechnen ließe, ist ein Betrug des manipulationsbeteiligten Wettspielers gegenüber dem Anbieter zum Nachteil der auf ein anderes Ereignis setzenden Mitwetter abzulehnen. Denn die Gefährdung ihrer Vermögensinteressen beruht nicht auf der täuschungsbedingten Vermögensverfügung des Wettanbieters, sondern auf der Manipulationsabsprache selbst. ${ }^{394}$

\section{Beteiligung des Sportakteurs}

Trifft die an die Person des Wettenden geknüpfte Betrugsstrafbarkeit zum Nachteil des Wettanbieters einen externen Vorteilsgeber, schließt sich die Frage nach einer möglichen Beteiligung der in die Manipulationsabsprache involvierten Sportakteure an. Ihrer Stellung als Mittäter des Betrugs i.S.d. $\$ 25$ Abs. 2 StGB könnte das Erfordernis einer gemeinsamen Tatausführung entgegenstehen, da ihre Zusage der manipulativen Einwirkung im Vorfeld der Täuschungshandlung liegt und somit im eigentlichen Ausführungsstadium der Tat keine Einflussmöglichkeit besteht. Mit Blick auf die allgemeinen Abgrenzungskriterien führt allerdings ein lediglich im Vorbereitungsstadium erbrachter Beitrag bei gleichzeitiger Tatortabwesenheit selbst für primär auf das Kriterium der Tatherrschaft abstellende Ansichten noch nicht zwingend zum Ausschluss einer Mittäterschaft. ${ }^{395}$ Angesichts dessen, dass erst die zugesagte Manipulation durch einen mitwirkenden Sportakteur die Gewinnwahrscheinlichkeiten verschiebt und eine Wettplatzierung wirtschaftlich lukrativ werden lässt, sprechen indes gute Gründe dafür, in ihr einen in der Tatbestandsverwirklichung fortwirkenden Beitrag von zentraler Bedeutung zu sehen, der eine funktionelle Tat-

393 BGH NJW 2007, 781 (788), Zitatstelle in der Urteilsanmerkung von Feindegen.

394 Funck Betrugsschaden, S. 394 Fn. 1336.

395 Zu der im Schrifttum wohl vorherrschenden sog. „gemäßigten“ Tatherrschaftslehre etwa Rengier Strafrecht AT $\$ 41$ Rn. 19; Kühl Strafrecht AT $\$ 20$ Rn. 110 f.; MüKo-StGB/Joecks/Scheinfeld $\$ 25$ Rn. 195 ff.; speziell für den Betrug hat auch der BGH - auf Grundlage seiner primär subjektiven Abgrenzungstheorie - bereits einen lediglich vorbereitenden Beitrag für Mittäterschaft ausreichen lassen, BGHSt 40, 299 (301); 54, (128). 
herrschaft des Sportakteurs zu begründen vermag. ${ }^{396}$ Ohne Auseinandersetzung mit einer möglichen Mittäterschaft nimmt der BGH in diesen Konstellationen für die Sportakteure hingegen lediglich Beihilfe zum (Computer-)Betrug gemäß $\$ \$ 263$, 263a, 27 StGB an. ${ }^{397}$ Die hierfür erforderliche Förderung des Angriffs auf das Vermögen des Wettanbieters könne sowohl in der Zusage eines unredlichen Verhaltens auf dem Spielfeld gesehen werden als auch in der Manipulation selbst, da die Haupttat erst mit Auszahlung des Wettgewinns beendet sei.

\section{Ergebnis und Abgleich mit dem Anwendungsbereich der $\$ \$ 265 \mathrm{c}$,} $265 \mathrm{~d}$ StGB

Selbst bei Eingrenzung auf korruptiv verabredete, gegnerbegünstigende Sportmanipulationen zeigte die vorangehende phänomenologische Untersuchung unzählige Ausdrucksformen. Eine an Fallgruppenbildung und dem gewöhnlichen zeitlichen Ablauf orientierte Strafbarkeitsprüfung auf Grundlage der vor Inkrafttreten der $\$ \$ 265$ c, 265d StGB gültigen Rechtslage lässt sich folgendermaßen zusammenfassen: allenfalls in Ausnahmefällen kann allein das manipulative Wettkampfverhalten zu einer Strafbarkeit der Sportler und Schiedsrichter führen, wobei ein Blick in die strafgerichtliche Praxis noch keine entsprechende Verurteilung ergibt. Die ihm vorangehende korruptive Absprache bleibt mitsamt der damit verbundenen Auszahlung und Annahme einer Manipulationsprämie für sich genommen für die hieran Beteiligten straffrei und dient so lange auch nicht als Voraussetzung einer strafbaren Folgehandlung, wie die avisierte Manipulation lediglich auf sportinternen Motiven gründet. In der Konsequenz ist eine gänzliche strafrechtliche Freistellung der initiativen Hintermänner sportintern motivierter Manipulationen zu konstatieren. Die demgegenüber verwirklichte Betrugsstrafbarkeit durch eine im Anschluss an die Abrede getätigte Wettplatzierung, die mindestens als Teilnehmer auch den manipulierenden Sportakteur selbst erfasst, zeigt die Abhängigkeit der strafrechtlichen Reaktionsmöglichkeiten von der grundsätzlichen Intention der Manipulation. Es bedarf des Hintergrundes einer Sportwette und

396 So auch Schönke/Schröder/Perron \$263 Rn. 180; Ivanov/Köpferl Jura 2016, 554 (560 f.); aA Schlösser NStZ 2005, 423 (428); Duyar Sportbeugung, S. 332. Freilich kann es je nach für maßgeblich erachteten Abgrenzungskriterien auch auf die Umstände des Einzelfalles ankommen.

397 BGHSt 51, 165 (178). 
der Heranziehung eines am eigentlichen Sportgeschehen gar nicht unmittelbar beteiligten Vermögensträgers in Gestalt des Wettanbieters, um den strafrechtlichen Schutz zu aktivieren. ${ }^{398}$

Im Vergleich dieser Übersicht mit dem zuvor skizzierten Anwendungsbereich der $\$ \$ 265 c, 265 \mathrm{~d}$ StGB zeigen sich gewisse Überschneidungen genauso wie das Ausmaß der durch die neuen Tatbestände geschaffenen strafrechtlichen Ausdehnung. Einer wettbezogenen Manipulationsabsprache folgt regelmäßig eine Wettplatzierung durch den Vorteilsgeber, die dessen Strafbarkeit nach $\$ 263$ StGB unabhängig von der späteren Ausführung der Manipulation oder ihres Erfolges begründet. Die im Hinblick auf den Wettbetrug durch $\$ 265$ c StGB erzielte Erweiterung besteht zum einen in der Loslösung der Strafbarkeit von einer tatsächlichen Wettplatzierung und dem unter Umständen schwierigen Nachweis eines Vermögensschadens, zum anderen in der unbestrittenen täterschaftlichen Erfassung des in die Absprache involvierten Sportakteurs. Dass der Gesetzgeber in einer großen Anzahl von Fällen gleichwohl von einer Verwirklichung beider Delikte durch den Vorteilsgeber ausgeht, belegen seine Überlegungen zum entsprechenden Konkurrenzverhältnis. ${ }^{399}$ Durch die Erfassung von Manipulationsabsprachen ohne Wetthintergrund in $\$ 265 \mathrm{~d}$ StGB wird hingegen ein neues Strafbarkeitsrisiko geschaffen. Abgesehen von der auf Ausnahmekonstellationen beschränkten und gerichtlich bislang nicht bestätigten Betrugsstrafbarkeit einer tatsächlichen Manipulation erfüllen derartige Verhaltensweisen auch in ihrem antizipierten Fortgang keinen anderen Straftatbestand.

Auch wenn in Form der wettbezogenen Sportmanipulationen einige manipulativen Einflussnahmen dem strafrechtlichen Zugriff auch ohne die $\$ \$$ 265c, 265d StGB grundsätzlich offen stehen, ist der einleitend zur Überprüfung gestellten gesetzgeberischen Diagnose eines lückenhaften strafrechtlichen Schutzes des Sports vor Match Fixing letztlich insofern zuzustimmen, als relevante Fallgruppen gar nicht erfasst werden und gerade auf einen in der korruptiven Abrede erblickten sportspezifischen Unrechtsgehalt strafrechtlich nicht angemessen reagiert werden kann. Die bloße Feststellung einer verhaltensbezogenen Lücke entfaltet bezüglich deren strafrechtlicher Schließung aber keinerlei Legitimationspotenzial. Dieses muss vielmehr anhand eines zunächst darzustellenden Maßstabes konkret überprüft werden. Hierbei kann auch die herausgearbeitete Strafbarkeit

398 Vgl. Adolphsen/Nolte/Lehner/Gerlinger/Rössner Kap. 11 Rn. 1722.

399 BT-Drs. 18/8831, S. 15 aufgrund der unterschiedlichen Schutzrichtung von Tatmehrheit ausgehend. 
Teil 2: Phänomenologische und strafrechtliche Grundlagen von Manipulationen im Sport

des Wettbetrugs gemäß $\mathbb{S}$ 263, 263a StGB von argumentativem Gewicht sein. 


\section{Teil 3: Legitimation der $\$ \mathbb{S} 265 \mathrm{c}, 265 \mathrm{~d}$ StGB}

Im Zentrum der hier erfolgenden Auseinandersetzung mit den neu geschaffenen Tatbeständen der $\$ \$ 265 c$, 265d StGB steht die Bewertung ihrer materiellen Legitimation. Diese ist gerade im Strafrecht aufgrund der durch dessen Tatbestände vermittelten Befugnis des Staates zu tiefen Eingriffen in die Rechtspositionen der Bürger von hervorgehobener Bedeutung. Für eine derartige Bewertung unverzichtbar ist eine Befassung mit den allgemeinen und grundlegenden Kennzeichen eines in unserem Rechtssystem als legitim anzusehenden Strafrechts, ohne deren Einbezug als Richtschnur legitimationsbezogene Aussagen über konkrete Strafvorschriften zwangsläufig isoliert und beliebig bleiben. In einem ersten $\mathrm{Ab}$ schnitt wird daher zunächst unter kritischer Würdigung diesbezüglich vertretener Ansätze ein fundiertes und operationalisierbares Prüfungsprogramm entwickelt (hierzu A.). Entlang der herausgestellten Legitimationskriterien lassen sich die $\$ \mathbb{S} 265 \mathrm{c}, 265 \mathrm{~d}$ StGB sodann ausführlich in ihrer Zweckrichtung und Deliktsstruktur analysieren und auf Grundlage der hierbei feststellbaren Übereinstimmung einer belastbaren Legitimationsbewertung zuführen (hierzu B. - D.).

\section{A. Maßstab der Überprüfung}

Trotz seiner evidenten Bedeutung existiert kein unumstrittener Maßstab zur legitimationsbezogenen Überprüfung strafrechtlicher Vorschriften, auf den hier ohne weiteres zurückgegriffen werden könnte. Dieser Mangel resultiert nicht zuletzt aus einer uneinheitlichen Beurteilung der Reichweite der gesetzgeberischen Bestimmungskompetenz. Seine demokratische Legitimation verschafft dem Gesetzgeber grundsätzlich eine generelle verfassungsrechtliche Ermächtigung zum Handeln im Gemeinwohlinteresse. ${ }^{400}$ Hiervon umfasst ist auch die Festlegung des Bereichs des Strafbaren nach eigenem Ermessen. ${ }^{401}$ Einer hieraus abgeleiteten, allenfalls durch wenige verfassungsrechtliche Garantien gebundenen Einschätzungsprärogative des Gesetzgebers sowohl hinsichtlich der durch Strafbewehrung verfolgten

400 Lagodny Schranken, S. 138.

401 S. BVerfGE 80, 244 (255); 120, 224 (240). 
Zwecke als auch hinsichtlich der Eignung und Erforderlichkeit des eingesetzten Mittels lässt sich jedoch die besondere Eingriffstiefe geschaffener strafrechtlicher Sanktionsmöglichkeiten in die Rechtspositionen der Bürger entgegenhalten, die eine erhöhte Rechtfertigungslast nach sich zöge. In diesem Sinne erfordere die Folgenschwere des Rechtsgebiets die Festsetzung überpositiver Legitimationskriterien, die vom Gesetzgeber zu berücksichtigen seien und übergeordnete Wesensmerkmale des Strafrechts vor politischem Missbrauch sicherten.

Noch bevor jedoch diese Streitfrage um Erforderlichkeit und Gestalt allgemeiner Begrenzungsparameter des gesetzgeberischen Ermessens dargestellt wird, wird zunächst die Grundlage des bei den $\$ \$ 265$ c, 265d StGB konkret ausgeübten Ermessens näher beleuchtet. Führten besondere Rahmenbedingungen der Gesetzgebung oder die Natur ihres Gegenstandes im konkreten Fall bereits zu einer anfänglichen Reduzierung des gesetzgeberischen Ermessens, wäre dies im Rahmen der Ermittlung eines anzulegenden Prüfungsmaßstabes und der anschließenden Legitimationsbewertung zu berücksichtigen.

I. Reduzierung des gesetzgeberischen Handlungsermessens im konkreten Fall

Losgelöst von allgemeinen strafrechtlichen Begrenzungsparametern wurden in die den Gesetzgebungsprozess begleitende Diskussion über die Legitimation einer Kriminalisierung des Match Fixing von Vertretern entgegengesetzter Positionen jeweils dem Strafgesetzgeber gerade in diesem konkreten Fall scheinbar übergeordnete Aspekte eingebracht. Auf der einen Seite wurde auf unter Mitwirkung Deutschlands geschlossene internationale Vereinbarungen rekurriert, die die beteiligten Staaten zu stärkeren Bemühungen im Kampf gegen Spielmanipulationen im Sport verpflichteten. Und die Gegenseite verwies auf die verfassungsrechtlich zugesicherte Autonomie des Sports, die diesen dem Strafrecht schlechterdings entziehe.

Hinter beiden Vorbringen steht zumindest die implizite Andeutung einer entsprechenden Bindung des Strafgesetzgebers. Eine durch internationale Vorgaben ausgelöste Kriminalisierungspflicht deformierte den Erlass der $\int \$ 265 c$, 265d StGB zu einem schlichten Umsetzungsakt und bedingte eine Verlagerung der Legitimationsprüfung auf die supranationale Ebene mit einer erforderlichen Anpassung des Maßstabes. Und ein den strafrechtlichen Zugriff blockierender verfassungsrechtlicher Schutzbe- 
reich nähme die Legitimationsbewertung eines sich hierüber hinwegsetzenden gesetzgeberischen Akts bereits vorweg. Jedenfalls disqualifizierten beide Fälle die $\$ \mathbb{S} 265 \mathrm{c}$, 265d StGB als freie Ermessensentscheidung und verschöben den Fokus ihrer legitimationsbezogenen Überprüfung, weswegen eine tatsächliche Reduzierung des gesetzgeberischen Ermessens in beiden Richtungen zu untersuchen ist.

\section{Kriminalisierungspflicht kraft internationaler Vereinbarungen}

Das hier überprüfte Gesetz zur Bekämpfung des Match Fixing blickt nicht nur auf einen Vorlauf nationaler legislativer Bemühungen zurück, sondern ist auch in einen Kontext internationaler Absichtsbekundungen eingebettet, die in verschiedenen Empfehlungen und Übereinkommen ihren Ausdruck finden. Vom Europäischen Parlament ging im Frühjahr 2013 die Aufforderung aus, Spielabsprachen und Korruption im Sport mittels verstärkter Präventionsarbeit, Zusammenarbeit zwischen den Staaten und einer treffgenauen Strafgesetzgebung einzudämmen. ${ }^{402}$ Noch im selben Jahr wurde in der abschließenden Erklärung der 5. UNESCO-Weltkonferenz der Sportminister die Manipulation von Sportwettbewerben aufgrund der Beteiligung der transnationalen Organisierten Kriminalität als Gefahr für die Gesellschaft beschrieben und die Bedeutung eines koordinierten Vorgehens der nationalen und internationalen Behörden und Interessensgruppen bei ihrer Bekämpfung hervorgehoben. ${ }^{403}$ Die Mitgliedstaaten werden dazu aufgerufen, angemessene operative Kapazitäten in den Strafverfolgungs- und Justizbehörden sicherzustellen und auch die Einführung von strafrechtlichen Sanktionen zur unmittelbaren Abschreckung gegen Manipulationen von Sportwettbewerben zu prüfen. ${ }^{404}$ Über einen solchen unverbindlichen und von Deutschland kurz zuvor bereits mit negativem Ergebnis durchgeführten Prüfauftrag ${ }^{405}$ hinaus geht die Formulierung im 2014 folgenden und von Deutschland unterzeichneten Übereinkommen des Europarats über die Manipulation von Sportwettbe-

402 2013/2567 (RSP), Dokument p7_T A(2013)0098.

403 Berliner Erklärung der 5. UNESCO-Weltkonferenz der Sportminister (MINEPS V), S. 2.

404 Berliner Erklärung der 5. UNESCO-Weltkonferenz der Sportminister (MINEPS V), S. 16.

405 S. Reinhart SpuRt 2016, 235 (236 mwN). 
werben. ${ }^{406}$ In dessen Art. 15 wird den Vertragsstaaten vorgegeben, die Manipulation von Sportwettbewerben unter Strafe zu stellen, sofern diese mit Nötigung, Korruption oder Betrug im Sinne ihres innerstaatlichen Rechts einhergehe.

Der deutsche Gesetzgeber ist augenscheinlich darum bemüht, die $\$ \$ 265 c, 265 d$ StGB in Zusammenhang mit diesen staatenübergreifenden Beschlüssen zu stellen und ihre Konformität zu unterstreichen. ${ }^{407} \mathrm{Ob}$ ihm allerdings bezüglich der Manipulation von Sportwettbewerben insbesondere durch das Übereinkommen des Europarates eine Kriminalisierungspflicht auferlegt wurde, die sein diesbezügliches Ermessen reduzierte, erscheint fraglich. Enthielte es eine solche, so wäre der deutsche Gesetzgeber ihr freilich vorsorglich nachgekommen, da die für das Inkrafttreten der Konvention erforderliche Anzahl von fünf Ratifizierungen - darunter drei Mitgliedstaaten des Europarates - bis heute nicht erreicht ist. ${ }^{408}$ Gegen einen internationalen Zwang zur Strafausweitung spricht jedoch die in den Regelungen der Konvention und ihrem begleitenden Explanatory Report erkennbare Intention, den Vertragsparteien keine allzu engen Vorgaben zu machen. So wird kein spezieller Straftatbestand verlangt, der sich ausdrücklich auf die Manipulation sportlicher Wettbewerbe bezieht. Auch die in Art. 26 Abs. 3 aufgenommene Regelung zur Rechtshilfe, wonach die für eine gegenseitige Unterstützung erforderliche beiderseitige Strafbarkeit nicht von der gleichen Straftatkategorie oder gleichen Begriffen abhängig gemacht werden soll, solange das gegenständliche Verhalten nach dem Recht beider Staaten eine Straftat ist, lässt eine Offenheit gegenüber unterschiedlichen Kriminalisierungswegen erkennen. ${ }^{409}$

Zwar statuiert die Konvention bei aller Indifferenz hinsichtlich der genauen Umsetzung die Mindestanforderung einer Bestrafung von Manipulationen von Sportwettbewerben. Sie begrenzt sie aber auf deren Überschneidungen mit den Komplexen der Nötigung, des Betrugs und der Korruption und stellt maßgeblich auf die Reichweite der insoweit bestehenden nationalen Vorschriften ab. ${ }^{410}$ In den $\$ \$ \$ 240,263$ f., 299 StGB verfügt das deutsche Strafrecht über Tatbestände, um willensbeugende und vermögensschädigende Bestandteile einer Manipulation im Sport bzw. kor-

406 Übereinkommen des Europarats über die Manipulation von Sportwettbewerben v. 18.9.2014, SEV Nr. 215.

407 BT-Drs. 18/8831, S. 12.

408 S. die Übersicht zum Ratifikationsstand unter www.coe.int/de/web/conventions /full-list/-/conventions/treaty/215/signatures?p_auth=R9TQpLrJ.

409 Vgl. Kretschmer FS Rössner, 2015, S. 628 (643).

410 Rübenstabl JR 2017, 264 (266). 
ruptives Verhalten im geschäftlichen Verkehr zu ahnden. Ihr Zuschnitt kann im Hinblick auf ein aus der Konvention abgeleitetes, weites Begriffsverständnis der Manipulation eines sportlichen Wettbewerbs für unpassend erachtet werden. ${ }^{411}$ Durch die Konvention unmittelbar indiziert wäre eine hieraus gefolgerte Anpassungsnotwendigkeit des deutschen Strafrechts aber nicht. Es handelt sich bei der Konvention qualitativ nicht um eine unionsrechtliche Richtlinie oder Verordnung, die einen spezifizierten Umsetzungsakt des nationalen Gesetzgebers verlangt. Aus den zur Legitimierung der Neuregelungen herangezogenen internationalen Empfehlungen und Beschlüssen fließt somit keine völkerrechtlich verbindliche Pflicht zur Schaffung eigenständiger Tatbestände in Form der $\$ \$ 265 \mathrm{c}$, 265d StGB. Deren Erlass stellt sich demnach weiterhin als Ausübung eines legislatorischen Ermessens des deutschen Gesetzgebers dar.

2. Kriminalisierungshindernis in Form des grundrechtlichen Schutzbereichs der Autonomie des Sports (Art. 9 GG)

Durch internationale Vorgaben zum Erlass der $\$ \$ 265$ c, 265d StGB nicht verpflichtet, könnte der Gesetzgeber umgekehrt durch die rechtliche Sonderstellung des Sports an der Schaffung von seinen Regelungsbereich betreffenden Strafvorschriften gehindert gewesen sein. Dazu müsste die verfassungsrechtlich begründete Autonomie der Sportverbände einen dem staatlichen Strafrecht prinzipiell entzogenen materiellen Bereich formen oder den Verbänden eine eigenständige formelle Konfliktbewältigung zusichern, die durch einen flankierenden Einsatz des Strafrechts schlechthin entwertet würde.

a) Eingriff in einen materiell strafrechtsfreien Bereich

Anders als in zahlreichen Landesverfassungen ${ }^{412}$ wird der Begriff „Sport“ im Grundgesetz nicht erwähnt. Bestrebungen, ihn als Staatszielbestim-

411 So Kretschmer FS Rössner, 2015, S. 628 (643), der aufgrund des einseitig auf die Schädigung des Wettanbieters ausgerichteten Betrugstatbestands eine mit der Konvention unvereinbare Fokussierung des deutschen Strafrechts auf durch Sportwetten motivierte Manipulationen konstatiert.

412 Exemplarisch Art. 3c LV Baden-Württemberg; Art. 62a LV Hessen; Art. 32 LV Berlin; Art. 140 LV Bayern. 
mung in das Grundgesetz aufzunehmen, blieben bislang erfolglos. ${ }^{413}$ Die verfassungsrechtliche Anknüpfung erfolgt über die Vereinigungsfreiheit aus Art. 9 Abs. 1 GG, die das Recht zur autonomen gesellschaftlichen Selbstorganisation garantiert. ${ }^{414}$ Demnach dürfen sich in einer Organisation zusammengeschlossene Mitglieder einen gruppenspezifischen Zweck setzen und diesen in ihrem Bereich auch selbst durchsetzen. Gerade Leistungssportler sind in Sportvereinen und -verbänden organisiert, welche für die Organisation und Durchführung sportlicher Wettkämpfe zuständig sind und diesbezüglich umfangreiche Regelwerke erschaffen und durchsetzen. 415

Um dem Zweck des organisierten Sports, Wettbewerbe auf regionaler, nationaler und internationaler Ebene auszutragen und die dabei erbrachten Leistungen miteinander zu vergleichen, zur Geltung zu verhelfen, müssen ihre regulativen und organisatorischen Bedingungen einheitlich, autoritär und bestandskräftig ausgestaltet und überwacht werden. Dies erfordert auf der Seite der als Träger der Autonomie operierenden Sportverbände eine besondere, monopolistisch-hierarchische Organisationsstruktur, die durch das sog. Ein-Platz-Prinzip umgesetzt wird. ${ }^{416}$ Danach ist für jede Sportart nur jeweils ein Weltfachverband vorgesehen, der das entsprechende Regelwerk mit weltweiter Verbindlichkeit festlegt und pro Nation wiederum nur einen nationalen Fachverband anerkennt, den er mit der Durchsetzung des Regelwerks bis zu den Mitgliedsvereinen betraut. Außerdem müssen die Abläufe der Wettbewerbe und ihre Resultate von einer staatlichen Regulierung und Überprüfung, die mit Verzögerungen und nationalen Auslegungsdifferenzen einhergingen, weitgehend abgeschirmt werden.

Folgt aus diesem Art. 9 Abs. 1 GG entnommenen Selbstverständnis- und Selbstbestimmungsrecht des organisierten Sports also eine prinzipielle Einschränkung der Normsetzungsbefugnis des Staates, so kann auch ein zum Schutze des Sports aktiv werdender Strafgesetzgeber an verfassungsrechtli-

413 Vgl. dazu Wissenschaftliche Dienste des Deutschen Bundestages (Hrsg.) Sport als Staatsziel im Grundgesetz, WD 10 - 3000 - 069/18.

414 Zur Verbandsautonomie als Teilbereich der Vereinigungsfreiheit und ihrer einfachgesetzlichen Ausgestaltung in den $\mathbb{\$} \$ 21 \mathrm{ff}$. BGB vgl. PHB-SportR/Summerer 3. Kap. Rn. $3 \mathrm{ff}$.

415 PHB-SportR/Pfister/Fritzweiler Einführung Rn. 12 f.; Weinbuch Sportwettmanipulationen, S. 45 ff.; Grunsky SpuRt 2007, 188 (190).

416 Hierzu ausführlich PHB-SportR/Pfister/Fritzweiler Einführung Rn. 14 ff.; Weinbuch Sportwettmanipulationen, S. 7. 
che Grenzen stoßen. ${ }^{417}$ Deren mögliche Verletzung drängt sich umso stärker auf, je weiter sich eine Pönalisierung auf den sporttypischen Kernbereich des Wettkampfgeschehens erstreckt. ${ }^{418}$ Eine derartige Eingriffsqualität könnte den $\$ \$ 265$ c, 265d StGB insofern zu attestieren sein, als die Vorgabe des Schutzgutes der Integrität des Sports eine strafrechtliche Rezeption spezifischer sportethischer Werte erwarten lässt und das in $\$ 265 \mathrm{~d}$ StGB enthaltene Tatbestandsmerkmal der Wettbewerbsbeeinflussung in „wettbewerbswidriger Weise“ offenbar eine gewisse Akzessorietät zu sportinternen Regelverletzungen herstellt. Die staatliche Erklärung einer Kriminalisierung bestimmter intendierter Manipulationsformen als unerlässlich zur Wahrung eines authentischen Leistungssports vermag mit der Primärkompetenz der Sportverbände hinsichtlich der Definition und Bewertung eines leistungsorientierten und fairen Wettkampfverhaltens durchaus in Konflikt zu geraten.

Allerdings kann die Autonomie der Sportverbände ihrerseits nicht grenzenlos sein. Die aus dem vereinsrechtlichen Selbstbestimmungsrecht abgeleitete Annahme einer allgemeinen rechts- oder justizfreien Zone rund um den organisierten Sport herum ${ }^{419}$ widerspricht bereits den implementierten Schranken der verfassungsrechtlichen Gewährleistungsrechte ${ }^{420}$ und kann auch angesichts der inzwischen zahlreichen wirtschaftlichen Interessen der am Leistungssport auch beruflich beteiligten Akteure keinen Bestand haben. Die teilweise existenzielle Bedeutung der Beziehung von Sportlern und Unternehmen zu den Sportverbänden verlangt nach einem gewissen staatlichen Rechtsschutz, der auch im Konfliktfall die Verbandsinteressen mit den durch sie tangierten Persönlichkeits- und Vermögensrechten der Betroffenen austariert. ${ }^{421}$ Verbreitet wird gerade in der durch die Sportverbände in Gang gesetzten Kommerzialisierung des Sports und dem durch ihre Begleiterscheinungen ausgelösten Bedürfnis nach rechtlicher Regulierung ein ihre Autonomie zurückdrängender Faktor erblickt. ${ }^{422}$

417 U. Steiner NJW 1991, 2729 (2733).

418 Hierzu vgl. PHB-SportR/Pfister/Fritzweiler Einführung Rn. 12 f., 25; eine vergleichbare Eingrenzung eines sportautonomen Kernbereichs findet sich bei $U$. Steiner Autonomie, S. 31.

419 Hierzu vgl. Nolte Sport und Recht, S. 18.

420 Weinbuch Sportwettmanipulationen, S. 30.

421 PHB-SportR/Pfister/Fritzweiler Einführung Rn. 19.

422 Kubiciel WiJ 2016, 256 (262); Scherrer/Muresan/Ludwig Sportrecht, S. 51 (Stichwort: Autonomie des Sports). 
Auch für die Bedingungen eines Einsatzes des Strafrechts im organisierten Sport bleibt diese Entwicklung nicht folgenlos. In ökonomisierten und medial abgebildeten Wettbewerben steigt nicht nur die Gefahr von Versuchen, sich durch manipulative Einflussnahme illegitime Vorteile finanzieller oder immaterieller Art zu sichern. ${ }^{423}$ Es verändert sich auch die Dimension ihrer Auswirkung. Zuschauerinteresse, Sponsoring, Erfolgsprämien und der Wettmarkt führen dazu, dass manipulative Verzerrungen über den Bereich der autonom bestimmbaren Sportethik hinausgreifen und fremde Interessenssphären beeinträchtigen können. ${ }^{424}$ Diese werden im Gesetzentwurf auch benannt, wenn die $\$ \$ 265 c$, 265d StGB in den Dienst einer gesamtgesellschaftlich wertvollen Sozialisationsinstanz sowie des Vermögensschutzes von Sportwettanbietern und weiteren Akteuren gestellt werden. ${ }^{425}$ Die Intervention in einem sportethisch geprägten Bereich soll gesamtgesellschaftlich notwendig sein, da durch eine negative Vorbildwirkung des Sports Werte vermittelt werden, die den allgemein anerkannten Prinzipien einer redlichen Leistungsgesellschaft widersprechen. ${ }^{426}$ Trotz der Nähe der Wettbewerbsverzerrung zum Autonomiebereich verbandlicher Selbstbestimmung kann eine gerade auf die Instrumentalisierung der finanziellen und sozialen Begleiterscheinungen des Sports abzielende korruptive Abrede keine prinzipiell verfassungsrechtliche Straffreistellung beanspruchen. Unter der zusätzlichen Voraussetzung der Verhinderung drohender Vermögensschäden bei Dritten erweist sich dann auch die Verknüpfung einer primär von den Verbänden durchzusetzenden Sportregelverletzung mit dem staatlichen Strafrecht als zulässig. ${ }^{427}$

Ein Mandat des Staates zur Pönalisierung rein sportethischer Interessen ist aus verfassungsrechtlicher wie auch aus strafrechtsdogmatischer Perspektive nicht begründbar. ${ }^{428}$ Die von $\$ \$ 265 \mathrm{c}$, 265d StGB erfassten Verhaltensweisen erscheinen aber nicht nur sportethisch missbilligenswert, sondern auch mit Blick auf die durch sie tangierten Interessen allgemeiner Gültigkeit. Die hinter ihnen stehenden Kriminalisierungserwägungen können daher nicht von vornherein aufgrund der zu respektierenden verfassungsrechtlich abgesicherten Sonderstellung des Sports abgelehnt werden.

423 Kubiciel WiJ 2016, 256 (262).

424 Am Beispiel des Dopings aufzeigend Momsen-Pflanz Doping, S. $101 \mathrm{f}$., $67 \mathrm{ff}$.

425 BT-Drs. 18/8831, S. 1.

426 Weinbuch Sportwettmanipulationen, S. $168 \mathrm{f}$.

427 Kubiciel WiJ 2016, 256 (262 f.).

428 Momsen-Pflanz Doping, S. 101; Weinbuch Sportwettmanipulationen, S. $164 \mathrm{f}$. 
Der Gesetzgeber betrat somit keine durch die Autonomie des Sports geformte prinzipiell strafrechtsfreie Verbotszone.

b) Entwertung der zugesicherten Verbandsgerichtsbarkeit und prozessuale Konflikte

Die Verbandsautonomie könnte der vorgenommenen Kriminalisierung jedoch noch auf anderem Wege Hindernisse bereiten. Ausfluss der autonomen Rechtssetzungsfähigkeit der Verbände ist die Einberufung von sportgerichtlichen Gremien, die für die Entscheidung von Streitigkeiten zwischen den Verbänden und ihren Mitgliedern über ihr durch Satzungen und Ordnungen geregeltes Rechtsverhältnis zuständig sind. ${ }^{429}$ Unter anderem verfolgen und sanktionieren die Verbandsgerichte die ihnen unterstehenden Sportler, Trainer, Funktionäre und Schiedsrichter wegen der Beteiligung an korruptiven Absprachen einer Wettbewerbsmanipulation. ${ }^{430}$ Tritt neben das autonom gestaltete verbandsinterne Disziplinarverfahren ein am selben Tatvorwurf anknüpfendes staatliches Strafverfahren, könnte dies prozessuale Widersprüche auslösen, die zur Schwächung der Wirksamkeit der Sportgerichtsbarkeit führen und damit indirekt die verfassungsrechtlich zugesicherte Autonomie beeinträchtigen. Zudem stellt sich mit Blick auf zwei parallel betriebene Verfahren der Sanktionierung die Frage nach der Reichweite des verfassungsrechtlichen Doppelbestrafungsverbots (Art. 103 Abs. 3 GG). Wäre der Anwendungsbereich des Ne bis in idem-Grundsatzes eröffnet, führte die im Regelfall einer verbandsgerichtlichen Entscheidung zeitlich nachgelagerte strafgerichtlich ausgesprochene Strafe zwangsläufig zu einem Verstoß.

aa) Schwächung der Sportgerichtsbarkeit durch prozessuale Konflikte

Eine mögliche Schwächung der Wirksamkeit der Sportgerichtsbarkeit infolge einer strafrechtlichen Ahndung sportbezogener Sachverhalte wird bereits im Kontext des Dopings diskutiert. Befürchtungen richten sich dabei insbesondere auf Konflikte der in verbandsinternen Dopingverfahren zur Geltung kommenden Beweislastregel der strict liability mit den strafprozessual nun durch die Sportler beanspruchbaren und ins Verbandsver-

429 PHB-SportR/Summerer 3. Kap. Rn. 3, 497 ff.

430 Ausführlich zum Ganzen s. Teil 3 C. II. 1. a) bb) (1). 
fahren ausstrahlenden Schutzrechten wie der Unschuldsvermutung und dem Aussageverweigerungsrecht. ${ }^{431}$ Auch wenn das Prinzip der strict liability den Verbandsgerichten gerade bei der Bewertung positiver Dopingproben Erleichterungen verschafft und ihm bei korruptiven Manipulationsabsprachen keine vergleichbare Bedeutung zukommt, könnten auch diesbezüglich gewisse negative Wechselwirkungen aufgrund der unterschiedlichen Zuschnitte der Verfahrensordnungen nicht auszuschließen sein. Das strafprozessuale Schweigerecht des Beschuldigten könnte die zur verbandsinternen Sachverhaltsaufklärung vorgesehene Mitwirkungspflicht des Sportakteurs faktisch aushebeln. Zudem könnten die Verbandsgerichte ihren Vorteil einer schnellen Entscheidungsverkündung einbüßen, wenn sie künftig die entsprechende strafgerichtliche Befassung abwarteten, um von hierbei präsentierten Ermittlungserkenntnissen zu profitieren und das eigene Haftungsrisiko infolge einer divergierenden Entscheidung zu minimieren. ${ }^{432}$

Diese Bedenken lassen sich bisher allerdings nicht auf Beobachtungen der Verbandsgerichtspraxis stützen und erscheinen in ihrer Prognose als unrealistisch. Die verbandsintern betriebene Aufklärung eines manipulationsbezogenen Sachverhalts wurde von parallel durchgeführten Strafverfahren wegen Betrugs und dem hierbei etablierten Informationsaustausch zwischen Verbandsgremien und Ermittlungsbehörden bisher eher gefördert. ${ }^{43}$ So stützte die UEFA die Verhängung langjähriger Sperren in zwei Fällen maßgeblich auf ihr zur Verfügung gestellte polizeiliche Ermittlungserkenntnisse. ${ }^{434}$ Die vor dem Hintergrund der Verbandsautonomie erst einmal überraschende Unterstützung des Gesetzentwurfs durch große

431 S. die Einschätzung des damaligen Vorstandsvorsitzenden des DOSB Michael Vesper, DOSB-Presse vom 17.6.2013, S. 4, https://cdn.dosb.de/alter_Datenbestan d/fm-dosb/downloads/DOSB-Presse/2013/2013-25-DOSB-Presse.pdf; zu den wechselseitigen problematischen Folgen dieses Unterschiedes auch Lutz HRRS 2016, 21 (26f.); Kudlich JA 2007, 90 (95); Jahn SpuRt 2005, 141 (146); Dury SpurRt 2005, 137 (140); die Sorgen hingegen nicht teilend Haug/Martin Causa Sport 2014, 345 (349); Hauptmann/Rübenstahl HRRS 2007, 143 (149).

432 Vgl. Woblers, in: Bundesministerium des Inneren (Hrsg.), Fragenkatalog zum Expertentreffen, S. 69.

433 Dies vermuten Haug/Martin Causa Sport 2014, 345 (351) auch für den Bereich des Dopings.

434 Näher hierzu s. unten Teil 3 C. II. 1. a) bb) (3) ( $\alpha$ ). 
deutsche Sportverbände ${ }^{435}$ erklärt sich zu einem gewissen Teil wohl auch mit erhofften Vorteilen für die eigenen Disziplinarverfahren.

Für eine bewusste Verzögerung der verbandsrechtlichen Verfahren bis zum strafgerichtlichen Urteil lieferten jedenfalls die beiden jüngsten Fußball-Manipulationsskandale keinerlei Anhaltspunkte. Eine solche steht auch nicht zu befürchten, da der hierfür vorgebrachte Verweis auf die intendierte Vermeidung abweichender Entscheidungen haltlos ist. Führt ein manipulationsbezogenes, sportwidriges Verhalten zu einer verbandsinternen Sanktion und einem strafgerichtlichen Freispruch, äußert sich in dieser Divergenz oftmals lediglich die unterschiedliche Fassung der jeweils kompetenzrechtlich legitimen Tatbestände bzw. Verfahrensordnungen. Die von den Verbandsgremien abschließend getroffene Entscheidung unterliegt keiner Bindung und begründet auch keine Haftung des Verbandes, solange sie nach dessen Verfahrensregeln rechtmäßig ergeht. ${ }^{436}$ Diese Trennung führt auch in anderen Bereichen wie zum Beispiel dem Beamtenrecht oder dem anwaltlichen Berufsrecht zu einem zulässigen und funktionierenden Nebeneinander von intern durchgesetzten standesrechtlichen

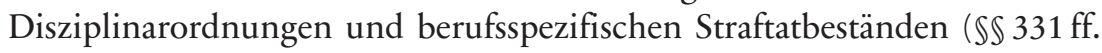
bzw. $\$ 356$ StGB). ${ }^{437}$ Eine Schwächung der Sportgerichtsbarkeit ist demnach schon faktisch kaum zu erwarten. Jedenfalls kann sich aus den vorgetragenen Bedenken kein Hindernis einer Kriminalisierung ergeben.

\section{bb) Zwangsläufiger Verstoß gegen den Grundsatz der Doppelbestrafung}

Nach Art. 103 Abs. 3 GG darf niemand wegen derselben Tat aufgrund der allgemeinen Strafgesetze mehrfach bestraft werden. Das Verbot soll dabei nicht nur eine mehrfache Bestrafung verhindern, sondern in Form des prozessrechtlichen Instituts des Verbrauchs der Strafklage bereits einer wiederholten Verfolgung der Tat im Wege stehen. ${ }^{438}$ Der Grundsatz bean-

435 S. die gemeinsame Stellungnahme von Deutschem Olympischen Sportbund (DOSB), Deutschem Fußballbund (DFB) und Deutscher Fußballliga (DFL) zum Entwurf BT-Drs. 18/8831 vom 15.1.2016, S. 2.

436 Adolphsen Wer die Musik bezahlt, bestimmt die Melodie, Legal Tribune Online vom 22.5.2015, www.lto.de/recht/hintergruende/h/gesetzgebung-regierungsent wurf-anti-doping-gesetz-schiedsgerichte; Mühlbauer, in: Bundesministerium des Inneren (Hrsg.), Fragenkatalog zum Expertentreffen, S. 70.

437 Saliger, in: Bundesministerium des Inneren (Hrsg.), Fragenkatalog zum Expertentreffen, S. 70.

438 Sachs/Degenhart GG Art. 103 Rn. 79. 
sprucht auch innerhalb verbandsinterner Verfahren trotz deren Nähe zum Zivilrecht Geltung und führt zur Unwirksamkeit der Sanktionierung eines Sportlers durch den Weltverband, wenn dessen Verhalten bereits durch den nationalen Verband geahndet wurde. ${ }^{439}$ Sollte er nun auch auf das Verhältnis von Verbandssanktion und Kriminalstrafe Anwendung finden, könnte eine ergangene verbandsrechtliche Sanktionierung einen Strafklageverbrauch nach sich ziehen und bereits die Einleitung eines strafrechtlichen Ermittlungsverfahrens blockieren. Eine Kriminalisierung wäre dem Einwand der prinzipiellen Wirkungslosigkeit ausgesetzt.

Eine solch extensive Auslegung mag sich auf die mitunter durchaus beträchtliche Eingriffsintensität der verbandsinternen Sanktion stützen, die sie in ihrer für den betroffenen Sportakteur spürbaren Wirkung einer strafrechtlichen Verurteilung mitunter gleichsetzt. ${ }^{440}$ Sie stößt allerdings an die Grenze des klaren Wortlauts des Art. 103 Abs. 3 GG, der explizit eine Bestrafung „auf Grund der allgemeinen Strafgesetze“ verlangt. Diese erfassen aber nur das Kriminalstrafrecht und schließen privat- oder berufsrechtlich begründete Disziplinarstrafen aus. ${ }^{441}$ Andernfalls würde auch das vom Verfassungsgeber intendierte Nebeneinander von Kriminalstrafen und Disziplinarrecht ausgehebelt. ${ }^{442}$ Wird nun vereinzelt im Begriff der „allgemeinen Strafgesetze“ eine bloße Tautologie ohne materielle Bedeutung gesehen und auch unter Verweis auf wesentliche Unterschiede zwischen der Sportgerichtsbarkeit und der Disziplinargerichtsbarkeit bzw. der Standesgerichtsbarkeit der freien Berufe eine direkte oder zumindest analoge Anwendung des Doppelbestrafungsverbotes auf das Verhältnis von Sportverbands- und Kriminalsanktion erwogen, ${ }^{443}$ so überzeugt das letztlich nicht. Gegen eine Tautologie spricht die gezielte Ausgrenzung des Disziplinarrechts. Eine analoge Anwendung hingegen würde die unterschiedlichen Intentionen der Sanktionsformen und Regelungsmaterien verkennen. Denn während die sportverbandsrechtliche Sanktion im Dienste des autonom gesetzten Verbandszweckes steht und ein regelkonformes Verhalten der eigenen Mitglieder gewährleisten will, geht es der Kriminalstrafe grundsätzlich um den Schutz eines „sozialethischen Minimums“.

Gerade weil sich der staatliche Strafanspruch aus dem Interesse der Rechtsgemeinschaft ableitet, muss er unabhängig von den lediglich den

439 Hilpert Fußballstrafrecht, S. 87; Reschke SpuRt 2001, 183 (184).

440 Vgl. hierzu unter Teil 3 C. II. 1. a) bb) (2).

441 Sachs/Degenhart GG Art. 103 Rn. 80.

442 Dazu BVerfGE 21, 378 (383 f.).

443 Reinhart SpuRt 2001, 45 (46). 
Partikularinteressen des Sports verpflichteten Verbandsgerichten bestehen. Die Geltung des Doppelbestrafungsverbots und die Annahme eines Prozesshindernisses begründeten aber gerade die Gefahr, die Ahndung von Straftaten faktisch privaten Verbänden zu überlassen. ${ }^{444}$ Aus grammatischen und teleologischen Gründen ist eine Ausdehnung des $\mathrm{Ne}$ bis in idem-Grundsatzes somit abzulehnen. ${ }^{445}$ Kriminalstrafe und verbandsrechtliche Sanktion sind nebeneinander zulässig, wobei die jeweilige Wirkung einer bereits verhängten Sanktion bei der Bestimmung der folgenden im Einzelfall wechselseitig Berücksichtigung finden kann. 446 Auch aus Art. 103 Abs. 3 GG folgt demnach keine den Gesetzgeber beschränkende Ermessensreduzierung.

\section{Zwischenergebnis}

Die vorstehenden Aspekte verdeutlichen das Spannungsfeld, auf dem die legislatorische Entscheidung zu Gunsten der $\$ \mathbb{S} 265 \mathrm{c}$, 265d StGB letztlich getroffen wurde. Einerseits drängte ein internationaler Konsens zu einer einheitlichen Bekämpfung des Match Fixing unter Einschluss gezielter strafrechtlicher Mittel. Andererseits drohte deren Implementierung durch den deutschen Gesetzgeber mit der verfassungsrechtlich verbürgten Autonomie des Sports und ihren prozessualen Ableitungen in Konflikt zu geraten. Mögen sie auch in unterschiedlichem Umfang und bipolarer Weise Einfluss auf den Gesetzgeber genommen haben, vermochten es weder zwischenstaatliche Vorgaben noch die verfassungsrechtlichen Garantien, allein aus sich heraus dessen Entschließungsermessen einseitig zu reduzieren. Aus völkerrechtlicher Verpflichtung erwuchs ebenso wenig ein Kriminalisierungszwang wie aus der verfassungsrechtlichen Sonderstellung des organisierten Sports ein strafrechtliches Interventionsverbot. Die angedeuteten Ausprägungen der Autonomie des Sports sind jedoch an späterer Stelle der Legitimationsprüfung noch einmal ausführlicher aufzugreifen.

444 Fabl SpuRt 2001, 181 f.; Weinbuch Sportwettmanipulationen, S. 57.

445 So auch die hM s. Hilpert Fußballstrafrecht, S. 88; Fabl SpuRt 2001, 181 f.; U. Steiner Autonomie, S. 18; Hauptmann/Rübenstabl HRRS 2007, 143 (151); Lutz HRRS 2016, 21 (27).

446 Etwa über $₫ 46$ Abs. 2 StGB; vgl. hierzu Lutz HRRS 2016, 21 (27); Dury FS Röhricht, 2005, S. 1097 (1110). 
II. Allgemeine strafrechtsbezogene Begrenzungskonzepte

Der Erlass der $\$ \$ 265 c$, 265d StGB ist somit Ausfluss eines grundsätzlich ungebundenen Entschließungsermessens des Gesetzgebers. Die Klärung der Legitimität der gesetzgeberischen Entscheidung wird nicht bereits durch deren Rahmenbedingungen vorweggenommen, sondern kann sich nur nach einem allgemeinen strafrechtlichen Prüfungsmaßstab richten. Wie bereits angedeutet entzweit sich dessen Herausbildung an der Frage nach der Reichweite einer Begrenzung der gesetzgeberischen Einschätzungsprärogative und deren Ableitung. Während eine Gruppe von Begrenzungskonzepten die für maßgeblich erachteten Legitimationskriterien aus dem Strafrecht selbst heraus zu formen versucht, richten andere den Blick diesbezüglich ausschließlich oder zumindest überwiegend auf das Verfassungsrecht. Die unterschiedlichen Ansätze werden im folgenden Kapitel dargestellt. Unter kritischer Würdigung ihrer Konzeptionen werden letztlich fundierte und operationalisierbare Anforderungen an eine legitime Strafnorm benannt, die die Grundlage der im Anschluss erfolgenden Überprüfung der $\$ \$ 265$ c, 265d StGB bilden.

\section{Strafrechtsimmanent fundierte Begrenzungskonzepte}

Strafrechtsimmanente Begrenzungskonzepte eint der Versuch, die Legitimation strafgesetzgeberischer Kriminalisierungsentscheidungen nach der Einhaltung von Vorgaben zu bewerten, die weitgehend autark aus der Aufgabe des Strafrechts bzw. seiner Funktion im Rechtssystem heraus entwickelt werden. Auf eine lange Tradition und vielfältige wissenschaftliche Rezeption blickt dabei insbesondere die Rechtsgutslehre, die in ihrer systemkritischen Ausprägung die Existenz eines schützenswerten Rechtsguts zum ausschlaggebenden Legitimationskriterium eines jeden strafrechtlichen Tatbestands erhebt. Teilweise hierauf aufbauend, teilweise isoliert haben sich daneben weitere Ansätze herausgebildet, deren strafrechtsbegrenzendes Potenzial sich über im wesentlichen strafrechtsimmanent begründete Forderungen nach einem fragmentarischen Einsatz des Strafrechts, nach einer Wahrung dessen Charakters als ultima ratio des staatlichen Instrumentariums sozialer Kontrolle oder nach Strafwürdigkeit und Strafbedürftigkeit einer Verhaltensweise entfalten soll. Inwiefern sich diese Ansätze als allgemeiner Prüfungsmaßstab für die Legitimation von Straftatbeständen eignen, wird durch die jeweilige Darstellung und kritische Würdigung ihrer Annahmen erörtert. 
a) Rechtsgutslehre

aa) Darstellung

Der Begriff des Rechtsguts zählt zu den schillerndsten in der Strafrechtswissenschaft, was nicht zuletzt an seiner uneinheitlichen Verwendung und den verschiedenen ihm zugeschriebenen Funktionen liegt. Noch außerhalb der Kontroverse steht ein Begriffsverständnis, wonach das Rechtsgut zunächst den Schutzgegenstand einer bestehenden Strafnorm bezeichnet und zu deren gesetzessystematischer Einordnung und Auslegung in Zweifelsfällen beitragen kann. ${ }^{447}$ Schon ein solches Rechtsgutsverständnis kommt zwar nicht ohne die Überprüfung von Straftatbeständen auf einen existenten Schutzgegenstand aus. Es bleibt jedoch insofern systemimmanent, als es die Strafnorm als gesetzgeberische Entscheidung hinnimmt und Rechtsgutserwägungen allenfalls bezüglich ihrer formalen Stellung oder einzelfallorientierten Anwendung anstellt. Ein strafrechtskritisches Begrenzungskonzept transportiert ein so verstandener Rechtsgutsbegriff hingegen nicht.

Vertreter des systemkritischen Ansatzes sehen hingegen gerade im Begriff des Rechtsguts das Potenzial, einen externen, den Strafgesetzgeber bindenden Maßstab zu bilden und inhaltliche Anforderungen an die Legitimität von Straftatbeständen zu formulieren. ${ }^{448}$ An eine liberale Strafrechtstradition anknüpfend ${ }^{449}$ ist ihnen zufolge ein strafrechtliches Verbot oder Gebot nur dann gerechtfertigt, wenn es ein menschliches oder gesellschaftliches Interesse schützt, welches die Qualität eines strafrechtlichen Rechtsguts hat. ${ }^{450}$ Die Rechtsgüter sollen dabei nicht durch den Gesetzgeber geschaffen werden können, sondern anhand vorpositiver, dem Gesetzgeber vorgelagerter Güter konstituiert werden.

Unter den Stimmen, die sich grundsätzlich auf die Leistungsfähigkeit des Rechtsguts in einer strafrechtsbegrenzenden Funktion verständigen, lassen sich wiederum zahlreiche, in der konkreten Konzeption voneinander abweichende Ansätze ausmachen. Sie unterscheiden sich im Wesentlichen in der vorgenommenen Begriffsbestimmung, in der Einschätzung

447 Kudlich ZStW 127 (2015), 635 (637 f.); Jescheck/Weigend Strafrecht AT, S. 157 f.

448 Roxin/Greco Strafrecht AT I $\$ 2$ Rn. 7 ff.; SK-StGB/Jäger Vor $\mathbb{~} 1$ Rn. 8 ff.; NK-

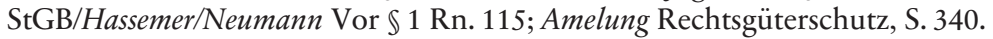

449 Jäger Rechtsgüterschutz, S. 122 f.; Otto, in: Müller-Dietz (Hrsg.), Strafrechtsdogmatik, 1971, S. 1 (14).

450 NK-StGB/Hassemer/Neumann Vor $\$ 1$ Rn. 115. 
der Schutzwürdigkeit verschiedener Rechtsgutsformen sowie in der Bewertung der Verbindlichkeit des Rechtsgutskriteriums. Hinsichtlich des materialen Gehalts des Rechtsgutsbegriffs werden Versuche unternommen, den Kreis strafrechtlich schützenswerter Rechtsgüter mittels einer allgemeingültigen Definition positiv einzugrenzen. Danach sind Rechtsgüter etwa Gegebenheiten oder Zwecksetzungen, die dem Einzelnen in seiner freien Entfaltung im Rahmen eines auf dieser Zielvorstellung aufbauenden sozialen Gesamtsystems oder dem Funktionieren dieses Systems selbst nützlich sind. ${ }^{451}$ Andere stehen solchen begrifflichen Festlegungen skeptisch gegenüber, benennen jedoch Materialisierungskriterien für ein Rechtsgut, anhand derer sich zumindest eine Negativkontrolle durchführen lässt und konkrete Schutzinteressen auf ihre Rechtsgutsqualität hin überprüft werden können. ${ }^{452}$

Differenzen betreffen ferner den Umfang der Einbeziehung kollektiver Rechtsgüter, die Interessen der Allgemeinheit zum Gegenstand haben, in den strafrechtlichen Schutzbereich. Während die sog. dualistischen Rechtsgutslehren ein gleichberechtigtes Nebeneinander individueller und kollektiver Rechtsgüter vertreten, ${ }^{453}$ erblicken die sog. monistischen Ansätze zwischen den beiden Rechtsgutstypen gegenseitige Hierarchie- und Ableitungsverhältnisse. Deren genaue Form ist wiederum umstritten. Einige Stimmen gehen von einem Primat der Universalrechtsgüter aus, aus welchem die Individualgüter abgeleitet bzw. zugeteilt würden. ${ }^{454}$ Sie sehen somit kein erhöhtes Legitimationsbedürfnis des strafrechtlichen Schutzes kollektiver Rechtsgüter. Die sog. personale Rechtsgutslehre setzt ihre Prämissen gestützt auf eine liberale Staatskonzeption gerade umgekehrt. Ihr zufolge sind die Interessen der Allgemeinheit von den Interessen der Person her zu funktionalisieren und kollektive Rechtsgüter nur anzuerkennen, sofern sie wenigstens vermittelt auch Interessen von natürlichen Personen sind. ${ }^{455}$ Dieses Vermittlungsverhältnis zu einem betroffenen Indivi-

451 Roxin/Greco Strafrecht AT I $\ 2$ Rn. 7; eine ähnliche Definition schlägt SK-StGB/ Jäger Vor $\mathbb{1} 1 \mathrm{Rn} .16$ vor, der unter Rechtsgütern für unsere verfassungsgemäße Gesellschaft und damit auch für die verfassungsmäßige Stellung des Einzelnen Bürgers unverzichtbare und deshalb werthafte Funktionseinheiten versteht.

452 NK-StGB/Hassemer/Neumann Vor $\mathbb{~} 1$ Rn. 145; Hefendebl Kollektive Rechtsgüter, S. $23 \mathrm{ff}$; konkret hierzu sogleich Teil 3 A. II. 1. a) cc).

453 Als Vertreter einer dualistischen Rechtsgutskonzeption gilt u.a. Tiedemann Tatbestandsfunktionen, S. 119.

454 Hohmann Umweltdelikte, S. 61; Weigend ZStW 98 (1986), 44 ff.; Maurach/Zipf Strafrecht AT/1 $\$ 19$ Rn 8.

455 Lüderssen ZStW 107 (1995), 877 (899). 
dualinteresse müsse bei jeder auf einem kollektiven Rechtsgut beruhenden Vorschrift sorgfältig dargelegt werden und wirke sich auf deren Legitimität und Deliktsstruktur aus. ${ }^{456}$

Schließlich lassen sich Abstufungen hinsichtlich der propagierten Verbindlichkeit des systemkritischen Rechtsgutsbegriffs konstatieren. Einige sehen in ihm einen verbindlichen Maßstab, der die Kraft besitzt, Straftatbestände gegen den Willen des Gesetzgebers zu delegitimieren. ${ }^{457}$ Andere beschränken seine kritische Wirkmacht auf die Rolle eines kriminalpolitischen Argumentationstopos, das mindestens bei der Bewertung von strafrechtlichen Gesetzesvorhaben Berücksichtigung verdient. ${ }^{458}$

\section{bb) Kritik}

Die spezifischen Einwände gegen die einzelnen Spielarten ausgeklammert, sieht sich bereits der grundsätzliche Anspruch der systemkritischen Rechtsgutslehre mit einer vielstimmigen Kritik konfrontiert. Vielfach setzt diese an der ungenügenden Konturierung des Rechtsgutsbegriffs an. Solange keine Einigkeit über dessen genauen Gehalt bestehe, könne er auch keine limitierende Funktion erfüllen. ${ }^{459}$ Die bisherigen Definitionsversuche ermöglichten gerade in den umstrittenen Grenzfällen keine klare Zuordnung, ${ }^{460}$ changierten zwischen Vagheit und Selektivität ${ }^{461}$ und stünden soweit sie dynamisch Bezug auf Gesellschaftsstrukturen und -modelle zu nehmen versuchten - in Abhängigkeit einer allgemeinen Gesellschaftstheorie, die noch nicht überzeugend begründet worden sei. ${ }^{462}$

456 Vgl. NK-StGB/Hassemer/Neumann Vor $\$ 1$ Rn. 137; krit. Hefendehl Kollektive Rechtsgüter, S. 62 ff., 80 ff., der die Rückbezüglichkeit eines jeden Rechtsguts auf personale Interessen anzweifelt und daher die dualistische Rechtsgutskonzeption im Kern für überzeugend hält, wenngleich er sie durch eine - auch für Legitimitätsfragen beachtliche - Differenzierung kollektiver Rechtsgüter in solche mit unmittelbarem Verwirklichungspotenzial für das Individuum und solche, die lediglich den Schutz kollektiver Rahmenbedingungen bezwecken, präzisiert.

457 Roxin/Greco Strafrecht AT I $\$ 2$ Rn. 92 ff.

458 So wohl NK-StGB/Hassemer/Neumann Vor $\$ 1$ Rn. 146.

459 Stuckenberg GA 2011, 653 (656f.); Woblers GA 2002, 15 (16f.).

460 Frisch, in: Hefendehl/von Hirsch/Wohlers (Hrsg.), Rechtsgutstheorie, 2003, S. 215 (216); Hefendehl GA 2002, 21 (22).

461 Hefendebl Kollektive Rechtsgüter, S. 21; NK-StGB/Hassemer/Neumann Vor $\mathbb{} 1$ Rn. 144.

462 Appel Verfassung und Strafe, S. 345 f., 367 f. 
Die Entwicklung eines verbindlichen Maßstabes aus vorpositiven Gegebenheiten gerate zudem in Konflikt mit den Befugnissen des Gesetzgebers, als demokratisch legitimierte Instanz weitgehend frei und selbstständig darüber zu befinden, welche Verhaltensweisen unter Strafe gestellt gehörten. Sofern die Rechtsgutslehre diese Einschätzungsprärogative des Gesetzgebers nicht anerkenne, ihn gar aus einem grundlegenden Misstrauen heraus über Vorgaben zu bändigen versuche, ${ }^{463}$ trage sie ein Demokratiedefizit mit sich. ${ }^{464}$ Dies wiege umso schwerer, als es an einer verfassungsrechtlichen Fundierung der Vorgaben der Rechtsgutslehre fehle. Sie seien in der Strafrechtswissenschaft weitgehend eigenständig und ohne Anbindung an verfassungsrechtliche Wertungen entwickelt worden. Schon aus diesem Grund könne ihnen keine Verbindlichkeit zukommen. ${ }^{465}$ Der Gesetzgeber sei allein der Verfassung unterworfen, aus der heraus eine systemkritische Rechtsgutslehre bisher nicht überzeugend begründet worden sei und aufgrund systemischer Unvereinbarkeit von materiellem Strafrecht und Verfassungsrecht wohl auch nicht begründet werden könne. ${ }^{466}$

Schließlich wird gerade mit Blick auf jüngere Tendenzen der Strafgesetzgebung auf die Ambivalenz des Rechtsgutsbegriffs hingewiesen. Dieser habe nicht nur limitierende Wirkung, sondern könne im Gegenteil gerade auch zur Rechtfertigung der in den vergangenen Jahren zu konstatierenden Ausdehnung strafrechtlicher Interventionen in das Vorfeld tatsächlicher Beeinträchtigungen herangezogen werden. ${ }^{467}$ Eine Überhöhung des Rechtsguts als zentrale Legitimationsvoraussetzung einer Pönalisierung berge die Gefahr, über die Bildung mediatisierter Rechtsgüter und einen dadurch ausgelösten Schutzreflex Kriminalisierungstendenzen zu begünstigen. ${ }^{468}$ Beispielhaft hierfür stünden die abstrakten Gefährdungsdelikte, die sich zumeist problemlos auf ein schutzwürdiges Rechtsgut zurückfüh-

463 Dieses Misstrauen als Motiv der strafrechtsimmanenten Begrenzungskonzepte diagnostiziert Appel Verfassung und Strafe, S. 48.

464 Stuckenberg GA 2011, 653 (658); s. auch den Diskussionsbeitrag des damaligen Bundesjustizministers Heiko Maas auf der 35. Tagung der Strafrechtslehrerinnen und Strafrechtslehrer 2015 in Augsburg, ZStW 127 (2015), 691.

465 Appel Verfassung und Strafe, S. 48 ff., 354 f.; Lagodny Schranken, S. 163, 425 f.

466 Appel Verfassung und Strafe, S. 357 ff.; Lagodny Schranken, S. 145 ff, 424 ff.

467 Frisch FS Stree/Wessels, 1993, S. 69 (71 ff.); Sternberg-Lieben, in: Hefendehl/von Hirsch/Wohlers (Hrsg.), Rechtsgutstheorie, 2003, S. 65 (72); Jakobs ZStW 97 (1985), 751 (752 ff.).

468 Hassemer ZRP 1992, 378 (380); Jakobs ZStW 97 (1985), 751 (752 f.). 
ren ließen. ${ }^{469}$ Bei einer zu starken Fokussierung auf das Rechtsgut drohten weitere begrenzungstaugliche Kriterien in Vergessenheit zu geraten. ${ }^{470}$

\section{cc) Wertung}

Hinsichtlich der geäußerten Einwände an einer systemkritischen Rechtsgutslehre ist zu differenzieren. Während es manchen an Überzeugungskraft fehlt, erscheinen andere als berechtigt und sind auch von Vertretern der Rechtsgutslehre aufgegriffen worden. Allerdings erzwingen sie keine gänzliche Verwerfung eines gesetzgebungskritischen Ansatzes, sondern veranlassen eher zu dessen Anpassung und Neuausrichtung, die teilweise bereits vielversprechend geleistet wurden.

Die Ablehnung eines gänzlich ungebundenen Strafgesetzgebers, verbunden mit dem Versuch, transparente Kriterien einer Kontrolle gesetzgeberischer Entscheidungen zu entwickeln, begründet nicht automatisch einen Demokratieverstoß. Vielmehr basiert die Rechtsgutslehre gerade auf einer Form des demokratischen Austauschs, indem sie den gesellschaftlichen Diskurs über die Vernünftigkeit und Legitimität staatlicher Maßnahmen integriert und fördert. ${ }^{471}$ Darüber hinaus negiert die Rechtsgutslehre auch keinesfalls jede Form eines Einschätzungs- und Ermessensspielraums des Gesetzgebers. Sie verpflichtet den Gesetzgeber gerade nicht zum Erlass von Strafnormen. Die Entscheidung darüber, ein identifiziertes Rechtsgut durch strafrechtliche Mittel oder andere rechtliche oder sozialpolitische Regelungen zu schützen, verbleibt in seinem Ermessen. ${ }^{472}$

Die vereinzelte Verwendung von Rechtsgutserwägungen zur Unterstützung erweiternder Vorfeldkriminalisierungen kann nicht gegen die grundlegende, systemkritische Intention der Rechtsgutslehre angeführt werden. Gleichwohl enthält sie eine Mahnung in zweifacher Hinsicht. Der Gehalt des Rechtsgutsbegriffs ist über Definitionsmerkmale oder Materialisierungskriterien möglichst präzise freizulegen, um einer leichtfertigen Eti-

469 Vogel StV 1996, 110 (114); Roxin FS Hassemer, 2010, S. 573 (589).

470 Frisch, in: Hefendehl/Hirsch/Wohlers (Hrsg.), Rechtsgutstheorie, 2003, S. 215 (222).

471 NK-StGB/Hassemer/Neumann Vor $\$ 1$ Rn. 119a; s. auch den Diskussionsbeitrag von Neumann auf der 35. Tagung der Strafrechtslehrerinnen und Strafrechtslehrer 2015 in Augsburg, ZStW 127 (2015), 691.

472 Roxin FS Hassemer, 2010, S. 573 (584); ders. StV 2009, 544 (546). 
kettierung sämtlicher Interessen als Rechtsgut vorzubeugen. ${ }^{473}$ Und selbst dann darf die Leistungsfähigkeit der Rechtsgutslehre nicht überschätzt werden. Die straflegislatorischen Tendenzen lassen es sinnvoll erscheinen, das Rechtsgut als notwendige, aber nicht hinreichende Bedingung einer legitimen Strafnorm zu sehen. ${ }^{474}$ Überlegungen zum geschützten Rechtsgut mögen den Ausgangspunkt einer Überprüfung bilden, sind aber durch weitere selbstständige Begrenzungsparameter bzw. Analyse-Topoi zu ergänzen. ${ }^{475}$

Der Einwand der fehlenden rechtlichen Verbindlichkeit eines freischwebend entwickelten, vorpositiven Rechtsgutsbegriffs hat zu verschiedenen Versuchen geführt, die Rechtsgutslehre stärker verfassungsrechtlich anzubinden. Hierbei lassen sich vereinfacht zwei Ansätze unterscheiden: Während der erste an einer positiven Definition festhält und das Rechtsgutskonzept einheitlich als ungeschriebenes Prinzip des Verfassungsrechts in selbiges einbetten möchte, bemüht sich der zweite darum, bereits den Begriff des Rechtsguts über die Verfassung zu konstituieren bzw. zu materialisieren.

Vertreter des ersten Ansatzes verweisen auf die gemeinsame ideengeschichtliche Grundlage von Rechtsgutslehre und Grundgesetz. Der systemkritische Rechtsgutsbegriff sei aus den staatsphilosophischen Gedanken der Aufklärung abzuleiten, die wiederum das Grundgesetz stark geprägt hätten und in dieses inkorporiert worden seien. ${ }^{476}$ Insbesondere die aufklärerischen Überlegungen zum Staatsvertrag werden dabei als wichtige Quelle ausgemacht, da aus ihnen hervorgehe, dass die Bürger dem Staat die Staatsgewalt nur insoweit übertragen, als es zur Sicherung eines friedlichen und freien Zusammenlebens notwendig ist. ${ }^{477} \mathrm{Ob}$ diese historische Bezugnahme allerdings ausreicht, um dem Rechtsgutsbegriff den Status eines ungeschriebenen Prinzips des positiv geltenden Verfassungsrechts zuzuweisen, erscheint zweifelhaft. Die tatsächliche Umsetzung aufklärerischer Prinzipien durch das Grundgesetz müsste konkreter nachgezeichnet

473 Vgl. Stächelin Strafgesetzgebung, S. 44; Puschke Vorbereitungstatbestände, S. 123.

474 NK-StGB/Hassemer/Neumann Vor $\mathbb{~} 1$ Rn. 147; Stächelin Strafgesetzgebung, S. $55 \mathrm{ff}$.

475 Woblers, in: Hefendehl/von Hirsch/Wohlers (Hrsg.), Rechtsgutstheorie, 2003, S. 281 (282); Hefendehl GA 2007, 1 (2).

476 Roxin StV 2009, 544 (545).

477 Schünemann, in: Hefendehl/von Hirsch/Wohlers (Hrsg.), Rechtsgutstheorie, 2003, S. 133 (137 ff.); Roxin FS Hassemer, 2010, S. 573 (578). 
werden. ${ }^{478}$ Auch die aufgezeigte Verbindungslinie zum Sozialkontrakt ist angesichts der Vielfalt der sich rund um das Gedankengebilde eines Gesellschaftsvertrages geformten Konzeptionen zu unspezifisch. 479

Erfolgversprechender erscheint der zweite Ansatz, dem es weniger um die verfassungsrechtliche Anknüpfung einer bereits ausgeformten Rechtsgutslehre geht als vielmehr um eine Konstituierung des Rechtsgutsbegriffs selbst durch der Verfassung entnommene Kriterien. Zwar ließe sich auch der Verfassung und ihrer Konkretisierung durch das Bundesverfassungsgericht kein positiver Rechtsgutsbegriff entnehmen. ${ }^{480}$ Doch enthalte sie Mindestanforderungen an legitime Strafnormen und ermögliche dadurch eine Materialisierung des Rechtsgutsbegriffs „von unten“. ${ }^{481}$ Diese beginne mit dem Charakter des Strafrechts als Schutzrecht in klarer Abgrenzung zu einer verfassungswidrigen Ausrichtung am Pflichtverletzungsgedanken. 482 Aus dieser Aufgabenbestimmung ergebe sich das Erfordernis, das Rechtsgut nicht lediglich als ideellen Wert zu verstehen, der einer kausalen Verletzung entrückt ist. ${ }^{483}$ Hierzu müsse ein als Rechtsgut in Betracht kommender Belang zunächst präzise beschrieben werden und dürfe sich nicht in ungreifbarer Abstraktheit verlieren. ${ }^{484}$ Der zentrale grundrechtliche Schutz von Menschenwürde und Privat- bzw. Intimsphäre erfordere weiterhin eine klare Abgrenzung des strafrechtlich schützenswerten Rechtsguts von reiner Unmoral. ${ }^{485}$ Ferner müsse das Rechtsgut stets vom Handlungsobjekt eines Tatbestandes unterschieden werden. ${ }^{486}$ Die personale Ausgestaltung der Staatsverfassung verlange schließlich zumindest eine Rückführbarkeit strafrechtlich schützenswerter Belange auf die Interessen des einzelnen Menschen. ${ }^{487}$

478 Greco Straftheorie, S. 316 ff.; Engländer ZStW 127 (2015), 616 (629f.).

479 Engländer ZStW 127 (2015), 616 (622 f.).

480 Hefendebl Kollektive Rechtsgüter, S. $42 \mathrm{ff}$.

481 Hefendehl Kollektive Rechtsgüter, S. 22 ff.; NK-StGB/Hassemer/Neumann Vor $₫ 1$ Rn. 145.

482 NK-StGB/Hassemer/Neumann Vor $\$ 1$ Rn. 112; Hefendehl GA 2002, 21 (23).

483 Hefendebl GA 2002, 21 (23).

484 Roxin/Greco Strafrecht AT I $\$ 2$ Rn. 45fff.

485 Amelung Rechtsgüterschutz, S. 320; Hefendehl Kollektive Rechtsgüter, S. 51.

486 Roxin/Greco Strafrecht AT I $\$ 2$ Rn. 65 ff.

487 Inwieweit dies zur Aberkennung bestimmter kollektiver Rechtsgüter führen muss (so NK-StGB/Hassemer/ Neumann Vor $\$ 1$ Rn. $132 \mathrm{ff}$.) oder auch in dualistischen Rechtsgutskonzeptionen hinreichend berücksichtigt werden kann (vgl. Hefendebl GA 2002, 21 [24]; ders., GS Weßlau, 2016, S. 577 [585 ff.], dessen Ansatz einer sozialen Rechtsgutstheorie jedoch nicht uneingeschränkt den dualisti- 
Durch die Aufgabe des Anspruchs, den Kreis schutzwürdiger Rechtsgüter abschließend zu bestimmen, entgeht ein derart konzipierter Ansatz der Kritik an Versuchen allgemeingültiger Rechtsgutsdefinitionen, ohne dabei sein kritisches Potenzial preiszugeben. Wenngleich er bewusst offen gehalten wird, ist er über die Integration verfassungsrechtlicher Prinzipien inhaltlich hinreichend konturiert, um als Maßstab einer nachprüfbaren Kriminalpolitik zu fungieren. Legislatorische Vorhaben oder Entscheidungen lassen sich anhand der operationalisierbaren Materialisierungskriterien auf ihre Legitimität hin überprüfen, ohne dass der Gesetzgeber in positiver Weise zum Tätigwerden verpflichtet würde und auf diese Weise sein anzuerkennender Ermessensspielraum in Abrede gestellt würde. Ein systemkritischer Rechtsgutsbegriff in dieser Ausgestaltung harmonisiert mit einem personalen und liberalen Staatsverständnis.

Zusammenfassend lässt sich sagen, dass die Einwände gegen einen systemkritischen Rechtsgutsbegriff ernst zu nehmen sind. Während sich einige entkräften lassen, zwingen andere dazu, dessen Leistungsfähigkeit als Begrenzungskonzept zurückhaltender zu bewerten. Gleichwohl bietet sich der Rechtsgutsbegriff in einer von unten materialisierten und mit der Verfassung verwobenen Ausgestaltung als Ausgangspunkt bei der Bewertung der Legitimität von Strafnormen an.

b) Sonstige strafrechtsimmanent fundierte Begrenzungskonzepte

Im Versuch, sich unter anderem aufgrund der definitorischen Schwierigkeiten des Rechtsgutsbegriffs von diesem mehr oder weniger zu lösen, an der Notwendigkeit eines aus dem Wesen des Strafrechts ableitbaren Begrenzungsmodells gleichwohl festzuhalten, wurden in der Strafrechtswissenschaft etliche weitere Ansätze entwickelt, um durch die Formulierung verbindlicher Parameter ein rationales und begrenztes Strafrecht sicherzustellen. Sie können an dieser Stelle nur vereinfacht und ohne Vollständigkeitsanspruch zusammengefasst werden.

schen Rechtsgutskonzeptionen zugeordnet werden kann), wird unterschiedlich bewertet. 
aa) Darstellung

Mitunter wird das auch innerhalb der Rechtsgutslehre nachhaltig aufgegriffene ${ }^{488}$ Kriterium der Sozialschädlichkeit einer Verhaltensweise aus deren Kontext gelöst und isoliert als maßgeblicher Auslöser einer strafrechtlichen Erfassung betrachtet. Nur wenn ein Verhalten ein derartiges Maß an Sozialschädlichkeit aufweise, das die Pönalisierung unabweisbar erscheinen lasse, könne es unter Strafe gestellt werden. ${ }^{489}$ Ein weiterer Ansatz versucht eine Beschränkung strafrechtlich zu verfolgender Verhaltensweisen über einen am Wesen der möglichen Sanktion anknüpfenden Rückschluss zu erreichen. Im Ausspruch der Kriminalstrafe äußere sich ein sozialethischer Vorwurf. Dies müsse zurückwirken auf die Qualität des Anlasses der Sanktionierung. Strafrecht dürfe nicht zur reinen Verhaltenssteuerung eingesetzt werden, sondern sei auf sozial unerträgliche Verhaltensweisen zu beschränken, die allein den in der Verhängung der Strafe liegenden sozialethischen Vorwurf verdienten. ${ }^{490}$

Mit Blick auf die Stellung des Strafrechts im gesamten Rechtssystem wird darauf hingewiesen, dass das Strafrecht kein allumfassendes System des Rechtsgüterschutzes darstellen dürfe, sondern fragmentarisch in dem Sinne bleiben müsse, dass es im Sinne des Gesellschaftsschutzes auf gefährliche und verwerfliche Handlungen zu beschränken sei und gegen alternative Mittel der Sozialkontrolle abgewogen werden müsse. ${ }^{491}$ Letzteres kommt insbesondere in der weitergehenden Forderung nach einer Subsidiarität des Strafrechts zum Ausdruck. Sie betont neben der liberalen auch die soziale Seite des Rechtsstaats und zieht gravierende Eingriffe in Gestalt des Strafrechts erst dann in Betracht, soweit keine milderen Möglichkeiten

488 Insbesondere durch Amelung Rechtsgüterschutz, S. 331 ff., der von einem negativ ausgrenzenden Güterschutzgedanken ausgehend diesen über das Kriterium der Sozialschädlichkeit, das er im Rechtsstaatsprinzip verankert sieht und über die soziologische Systemtheorie bestimmen möchte, verfassungsrechtlich anzubinden versucht.

489 Grundlegend Hanack Gutachten für den 47. Deutschen Juristentag, A 31 Rz. $29 \mathrm{f}$.

490 Frisch NStZ 2016, 16 (19 ff.) in expliziter Abgrenzung von der Rechtsgutslehre.

491 Zum fragmentarischen Charakter des Strafrechts erstmalig Binding Lehrbuch des Gemeinen Deutschen Strafrechts, BT I, S. 20, der hierin jedoch noch eine im Grunde bedauerliche Selbstbeschränkung des Gesetzgebers erblickte. Zur Fragmentarität als Postulat eines liberalen Rechtsstaats Vogler ZStW 90 (1978), 132 ff. Zur geschichtlichen Entwicklung des Konzepts ferner Vormbaum ZStW 123 (2011), $660 \mathrm{ff}$. 
der Sozialkontrolle zur Verfügung stehen. ${ }^{492}$ Dies wird auch unter dem Begriff der ultima ratio-Funktion des Strafrechts aufgegriffen und zu präzisieren versucht, wonach unter den im positiven Recht bekannten Mitteln die Kriminalstrafe stets die letzte und äußerste Schutzmaßnahme sein soll und ein Vorrang außerstrafrechtlicher Rechtsinstitute bestünde, soweit diese die Erreichung sozialkonformen Verhaltens verbürgten. ${ }^{493}$

Eine Verbindung von präziser und enger Beschreibung der strafrechtlichen Schutz herausfordernden Verhaltensqualität einerseits und Eingrenzung über einen Vergleich mit alternativen Mitteln der Sozialkontrolle andererseits strebt das Begriffspaar der Strafwürdigkeit und Strafbedürftigkeit an, deren präzise Definition angesichts der verbreiteten Uneinigkeit über ihre jeweiligen inhaltlichen Anforderungen und ihr Verhältnis zueinander ${ }^{494}$ aber nahezu unmöglich geworden zu sein scheint. Ganz grundlegend sollen über diese Kriterien Verhaltensweisen nur dann legitim strafrechtlich erfasst werden können, wenn sie zum einen fundamentale Interessen des Einzelnen oder der Gemeinschaft angreifen und zum anderen keine alternativen Regelungsmaterien zu deren hinreichendem Schutz bereitstehen. ${ }^{495}$

\section{bb) Kritik und Wertung}

Auch diesen Ansätzen wird ihre Entwicklung fernab verfassungsrechtlicher Rückkoppelungen vorgeworfen. ${ }^{496}$ Zudem bleibt stellenweise unklar, in welchem Verhältnis sie zueinander und insbesondere zur Rechtsgutslehre stehen, ob sie den Gehalt des Rechtsgutsbegriffs ersetzen oder ihn voraussetzen und ergänzen wollen. So wird etwa der Begriff der Strafwürdigkeit mitunter als alleinige und übergeordnete Voraussetzung für die Pönalisierung eines Verhaltens verwendet, die den Rechtsgutsbegriff genauso

492 Jescheck/Weigend Strafrecht AT, S. 53 Fn. 10; Hefendehl JA 2011, 401.

493 Zum ultima ratio-Grundsatz in der Literatur vgl. Prittwitz, in: Institut für Kriminalwissenschaften (Hrsg.), Zustand, 1995, S. 387 (391 f.); Rengier Strafrecht AT

$\$ 3$ Rn. 5; zum Zusammenhang von fragmentarischer Natur, Subsidiarität und ultima ratio-Funktion Roxin/Greco Strafrecht AT I $\$ 2$ Rn. 97 ff.

494 Vgl. hierzu Zeiser Trafic, S. 117 f.

495 Vgl. Sax, in: Bettermann/Nipperdey/Scheuner (Hrsg.), Grundrechte III/2, 1972, S. 909 (923 ff.); Müller-Dietz Strafe und Staat, S. 32 ff; Otto GS Schröder, 1978, S. $53 \mathrm{ff}$.

496 Bunzel, in: Hefendehl/von Hirsch/Wohlers (Hrsg.), Rechtsgutstheorie, 2003, S. 96 (97); Appel Verfassung und Strafe, S. 328 f. 
beinhalte wie genuin verfassungsrechtliche Limitierungskriterien. ${ }^{497}$ Die Sozialschädlichkeit wiederum wird teilweise zur Verstärkung des Begrenzungspotenzials des Rechtsgutsbegriffs in der Weise eingesetzt, dass Rechtsgutsverletzungen stets zusätzlich auch sozialschädlich sein müssen, um bestraft werden zu dürfen. ${ }^{498}$ Wird im hier vertretenen Sinne jedoch ein Rechtsgutskonzept verfolgt, das über bestimmte Materialisierungskriterien gerade den Anspruch hegt, die Strafwürdigkeitsbestimmung mit der Verfassung einerseits und der sozialen Wirklichkeit andererseits zu verbinden und bloß bagatellhafte Rechtsgutsberührungen von vornherein auszuschließen, besteht kein Bedarf für das zusätzliche Kriterium der Sozialschädlichkeit ${ }^{499}$ und eine Titulierung des gesamten Begrenzungsansatzes mit dem Begriff der Strafwürdigkeit.

Hinsichtlich der Strafbedürftigkeit, Subsidiarität und ultima ratio-Funktion fällt eine trennscharfe Differenzierung der jeweils enthaltenen Anforderungen ebenfalls schwer, da die Begriffe uneinheitlich, mitunter auch synonym verwendet werden. ${ }^{500}$ Auch bezüglich ihres jeweiligen Aussagegehalts besteht keine Einigkeit. ${ }^{501}$ Das Deutungsmuster zum ultima ratioPrinzip reicht etwa von der Annahme eines kriminalpolitisch bedeutsamen, dogmatisch aber erst einmal unverbindlichen Programmsatzes ${ }^{502}$ bis zu seiner Interpretation als absolute Schranke, die den Einsatz des Strafrechts gestatte, wenn eine bestimmte Schwelle abstrakter Strafwürdigkeit und/oder Strafbedürftigkeit überschritten werde. ${ }^{503}$ In einem rein kriminalpolitischen Verständnis ohne verfassungsrechtliche Begründung erscheint das ultima ratio-Prinzip für sich genommen aber beliebig und lässt sich in Umkehrung seines ursprünglich intendierten Aussagegehalts sogar zur Begründung einer Expansion des Strafrechts heranziehen. ${ }^{504}$ Doch selbst die wohl konsentierte Grundannahme, strafrechtliche Mittel nur dann als legitim zu begreifen, wenn es an alternativen, gleich wirksamen,

497 Etwa bei Zeiser Trafic, S. $121 \mathrm{f}$.

498 Hassemer Einführung, S. 25.

499 So auch Zeiser Trafic, S. 132 f.; ähnlich Frisch FS Stree/Wessels, 1993, S. 69 (76).

500 Vgl. Vormbaum ZStW 123 (2011), 660 (668 Fn. 34); Appel Verfassung und Strafe, S. $391 \mathrm{f}$.

501 Zusammenfassend Jahn/Brodowski JZ 2016, 969 (971 f.).

502 In diese Richtung Landau NStZ 2015, 665 (668), der von einem „Gebot der politischen Klugheit" spricht; wohl auch Roxin GA 2013, 433 (443 f.); ablehnend gegenüber einer verfassungsrechtlichen Verbindlichkeit Gärditz JZ 2016, 641 ff.

503 Vgl. Frisch NStZ 2016, 16 (24).

504 Burchard, in: Asholt/Kuhli (Hrsg.), Strafbegründung, 2017, S. 21 (28 f.); Jahn/ Brodowski JZ 2016, 969 (971 f.). 
aber weniger einschneidenden Steuerungsmitteln fehlt, setzt jedenfalls einen Bezugsgegenstand voraus (Mittel wozu?), vermag also nicht aus sich selbst heraus ein Begrenzungskonzept zu statuieren. Sie beruht ferner auf der zunehmend in Zweifel gezogenen Prämisse, dass es sich beim Strafrecht stets um das eingriffsintensivste staatliche Mittel handele. ${ }^{505}$

Die dargestellten Ansätze verdeutlichen die Intention, dem Strafrecht Grenzen $\mathrm{zu}$ ziehen. Aufgrund der mangelnden verfassungsrechtlichen Fundierung, der unpräzisen terminologischen Abgrenzung und der daraus resultierenden Unklarheit über ihren genauen Gehalt und das Verhältnis untereinander bleiben die Ansätze aber hinter der Rechtsgutslehre im obigen Sinne zurück bzw. lassen sich in diese integrieren. Aus keinem ergibt sich ein geschlossenes und operationalisierbares System der Überprüfung von Strafnormen. Gleichwohl liefern insbesondere Subsidiarität und ultima ratio-Funktion Anhaltspunkte, die sich in verfassungsrechtliche Bezüge einordnen lassen ${ }^{506}$ und im Rahmen eines über den Rechtsgutsbegriff konstituierten Begrenzungskonzepts heranzuziehen sind.

\section{Verfassungsrechtliche Begrenzungskonzepte}

Dem strafrechtsimmanenten Begrenzungsmodellen regelmäßig vorgehaltenen Einwand einer gleichzeitig hermetischen und rechtlich nicht ausreichend verankerten Konzeption lässt sich durch eine Hinwendung zum Verfassungsrecht entgehen. Dieses formuliert in Art. 1 Abs. 1 GG sowie Art. 20 Abs. 3 GG die Bindung des Gesetzgebers an die verfassungsmäßige Ordnung, insbesondere die Grundrechte und grundrechtsgleichen Garantien.

Hiervon umfasst ist etwa der Bestimmtheitsgrundsatz in Art. 103 Abs. 2 GG. Als Teilausprägung des Gesetzlichkeitsprinzips verpflichtet er den

505 Als eine nicht minder einschneidende staatliche Reaktion wird vor allem eine präventive flächendeckende Überwachung angesehen, die in Rechtspositionen aller Bürger eingreife, vgl. Appel Verfassung und Strafe, S. 402 ff., 541 f.; Stächelin Strafgesetzgebung, S. 133 ff.; Frisch NStZ 2015, 16 (23); Gärditz JZ 2016, 641 (646); nach Tiedemann Tatbestandsfunktionen, S. 144 f. Fn. 22; ders. ZStW 87 (1975), 253 (266f.) gewährt die Strafbewehrung gar einen Vertrauensvorschuss und sichert eine Freiheitssphäre $a b$, indem ihretwegen auf engmaschige Überwachung verzichtet wird.

506 Nach Roxin/Greco Strafrecht AT I $\ 2$ Rn. 98 lassen sich Subsidiarität, ultima ratio-Funktion und die fragmentarische Struktur des Strafrechts dem Verhältnismäßigkeitsgrundsatz entnehmen. 
Strafgesetzgeber zu einer möglichst präzisen Beschreibung der Voraussetzungen der Strafbarkeit, die Tragweite und Anwendungsbereich der Strafnorm erkennen lassen. ${ }^{507}$ Indem den Normadressaten allein durch den Gesetzeswortlaut eine verlässliche Voraussicht auf den Bereich des Strafbaren und die Möglichkeit einer entsprechenden Verhaltensanpassung gewährt werden muss, kommt dem Bestimmtheitsgrundsatz durchaus eine freiheitssichernde Funktion zu. ${ }^{508}$ Doch wenngleich er als durch den Gesetzgeber zwingend einzuhaltende Vorgabe allgemein anerkannt ist, trägt er zur Begrenzung des Strafrechts eher in technischer Hinsicht bei. Anders als etwa die Rechtsgutslehre enthält er keine materiellen Kriterien zur Legitimationsbewertung einer inhaltlichen Kriminalisierungsentscheidung, sondern adressiert die Art und Weise ihrer Umsetzung.

Für ein verfassungsrechtlich fundiertes Begrenzungskonzept im hier untersuchten Sinne sind demnach andere verfassungsrechtliche Garantien in den Blick zu nehmen. Da diese jedoch größtenteils auf die Rechtssetzung im Allgemeinen ausgerichtet sind, erscheint fraglich, ob sie sich gerade in Bezug auf die sensible Rechtsmaterie des Strafrechts zu einem Maßstab zusammenführen lassen, der ausreichend kritisches Potenzial entfaltet. Aufschluss hierüber soll zunächst eine Analyse des Umgangs des Bundesverfassungsgerichts mit Vorschriften des materiellen Strafrechts geben. Anschließend wird der Blick auf wissenschaftlich entwickelte verfassungsrechtliche Ansätze der Strafrechtsbegrenzung ausgedehnt.

a) Überprüfung materieller Strafnormen durch das Bundesverfassungsgericht

\section{aa) Darstellung}

Das Bundesverfassungsgericht prüft (explizit im Wege eines Normenkontrollverfahrens oder inzident als Grundlage staatlicher Eingriffe), ob Normen im Einklang mit der Verfassung stehen. Welchen Maßstab es dabei anlegt und ob sich aus diesem ein eigenes strafrechtliches Begrenzungskonzept ergibt, zeigt eine Auslese der bisherigen Entscheidungen zur Verfassungsmäßigkeit strafrechtlicher Normen. Auffällig ist zunächst deren begrenzte Anzahl. ${ }^{509}$ Während sich das Gericht durch seine Entscheidun-

507 BVerfGE 25, 269 ff.; 126, 170 (195).

508 BVerfGE 75, 329 (341).

509 S. Hörnle NJW 2008, 2085. 
gen in die Ausformung vieler Regelungsbereiche aktiv einbrachte und es etwa auch für neuralgische Punkte des Strafverfahrensrechts klare Vorgaben und Leitlinien aufstellte, ${ }^{510}$ ist der Umgang mit Normen des materiellen Strafrechts von Zurückhaltung geprägt. Diesen auf der jahrzehntelangen Spruchpraxis des Gerichts beruhenden Eindruck vermögen auch einzelne kritische Entscheidungen der jüngeren Vergangenheit nicht zu beseitigen, in denen etwa das in $\$ 217$ StGB normierte Verbot der geschäftsmäBigen Förderung der Selbsttötung für verfassungswidrig erklärt wurde ${ }^{511}$ und der Bestimmtheitsgrundsatz das Gericht zu Rügen des Strafgesetzgebers im Falle eines nebenstrafrechtlichen Blanketttatbestands ${ }^{512}$ bzw. der Rechtsprechung bei Auslegung einzelner Tatbestandsmerkmale ${ }^{513}$ veranlasste. Angesichts der Qualifizierung des Strafrechts als intensivste staatliche Eingriffsmaßnahme bleibt die in Bezug auf das materielle Strafrecht überschaubare bundesverfassungsgerichtliche Judikatur ein überraschender Befund.

Legt man die allgemeinen Aussagen des Gerichts zur Rolle des Strafrechts zugrunde, die der konkreten Norm- bzw. Eingriffsprüfung häufig vorangestellt sind, scheinen Übereinstimmungen zu den Grundannahmen der Rechtsgutslehre zu bestehen. Nicht nur wird dort das Strafrecht ebenfalls als Schutzrecht begriffen. ${ }^{514}$ Auch wird zur Bezeichnung des Schutzobjekts auf den Begriff des Rechtsguts zurückgegriffen. ${ }^{515}$ Des Weiteren finden sich Textstellen, die zumindest auf den Versuch hindeuten, Kriterien eines materiellen Verbrechensbegriffs einzuführen. So solle das Strafrecht nur gegen Verhaltensweisen eingesetzt werden, die über ihr Verbotensein hinaus in besonderer Weise sozial schädlich und für das geordnete Zusammenleben der Menschen unerträglich, ihre Verhinderung daher besonders dringlich seien. ${ }^{516}$ Andernorts ist von gewichtigen, elementaren Gemeinschaftsgütern die Rede, deren Schutz Aufgabe des Strafrechts

510 Vgl. etwa die Entscheidungen zum großen Lauschangriff (BVerfGE 109, 279 ff.), zur Telekommunikationsüberwachung (BVerfGE 113, $348 \mathrm{ff}$.), zur OnlineDurchsuchung (BVerfGE 120, $274 \mathrm{ff}$.) sowie zur Vorratsdatenspeicherung (BVerfGE 125, $260 \mathrm{ff}$.).

511 BVerfG NJW 2020, $905 \mathrm{ff}$.

512 Zur festgestellten Verfassungswidrigkeit einer Strafvorschrift im Rindfleischetikettierungsgesetz BVerfGE 143, $38 \mathrm{ff}$.

513 Zur verfassungswidrigen Auslegung des Vermögensschadens im Rahmen der Untreue durch Strafgerichte BVerfGE 126, $170 \mathrm{ff}$.

514 BVerfGE 90, 145 (172); vgl. auch Vogel StV 1996, 110 (111).

515 BVerfGE 120, 224 (240 f.); 126, 170 (197).

516 BVerfGE 88, 203 (258); 120, 224 (239f.). 
sei. ${ }^{517}$ Diese eingrenzenden Kriterien folgten aus der ultima ratio-Funktion des Strafrechts sowie aus der schweren Beeinträchtigung des Persönlichkeitsrechts durch die sittliche Missbilligung einer Strafandrohung. ${ }^{518}$

Darüber hinaus komme dem Grundsatz der Verhältnismäßigkeit eine besondere Bedeutung als Maßstab der verfassungsrechtlichen Kontrolle von Strafnormen zu. ${ }^{519}$ Da das strafrechtliche Verbot einer Verhaltensweise mindestens die allgemeine Handlungsfreiheit gemäß Art. 2 Abs. 1 GG und die Androhung einer Freiheitsstrafe Art. 2 Abs. 2 S. 2 tangiere, müsse die Strafvorschrift den Anforderungen des Verhältnismäßigkeitsgrundsatzes genügen. ${ }^{520}$ Dieser werde aus dem Rechtsstaatsprinzip und den Freiheitsrechten abgeleitet, bezeichne in der allgemeinen verfassungsrechtlichen Dogmatik eine sog. Schranken-Schranke und verlange als solche von sämtlichen staatlichen Eingriffen in die Rechte eines Bürgers, dass sie einen legitimen Zweck verfolgen und im Hinblick auf diesen Zweck ein geeignetes, erforderliches und angemessenes Mittel darstellen. ${ }^{521}$ Übertragen auf die Überprüfung von Strafnormen heiße dies, der Zweck der Norm müsse durch das strafrechtliche Verbot zumindest gefördert werden und dürfte sich nicht durch ein anderes, gleich wirksames, aber das Grundrecht weniger einschränkendes Mittel als die Kriminalisierung des Verhaltens realisieren lassen. ${ }^{522} \mathrm{Im}$ Rahmen der Angemessenheit sei schließlich im Wege einer Abwägung von bezweckten Gemeinwohlbelangen und bewirkten Rechtsgutseinbußen des Betroffenen zu ermitteln, ob die Einschränkung individueller Freiheit eine Belastung des Einzelnen auslöse, die noch in einem vernünftigen Verhältnis zu den der Allgemeinheit erwachsenden Vorteilen stünde. ${ }^{523}$ Strafrechtlich konkretisiert müsse eine Strafbewehrung also mindestens einen Zuwachs an Rechtsgüterschutz vermitteln und die Gefährdung der Gemeinschaftsgüter durch das erfasste Verhalten dürfe kein so geringes Maß erreichen, dass sich die Strafe als übermäßig erweist. ${ }^{524}$

In Widerspruch zu diesen Ausführungen, in denen sich durchaus ein differenziertes und gesetzgebungskritisches Prüfungsprogramm für legitime Strafvorschriften erkennen lässt, stehen freilich die oftmals in den sel-

517 BVerfGE 27, 18 (29); 37, 201 (212); 45, 187 (253).

518 BVerfGE 27, 18 (29); BVerfG NJW 1994, 1577 (1585).

519 BVerfGE 88, 203 (258); 90, 145 (172).

520 BVerfG NJW 1994, 1577 (1578).

521 Kloepfer Verfassungsrecht I, $\$ 10$ Rn. $195 \mathrm{ff}$.

522 BVerfG NJW 1994, 1577 (1579); BVerfGE 120, 224 (239 ff.).

523 BVerfG NJW 2020, 905 (913).

524 BVerfGE 90, 145 (185). 
ben Entscheidungsbegründungen gemachten Aussagen des Gerichts zu einer etwaigen Bindung des Gesetzgebers. Diesbezüglich äußert sich das Gericht ausgesprochen defensiv. Es sei grundsätzlich Sache des Gesetzgebers, den Bereich strafbaren Handelns unter Berücksichtigung der jeweiligen Lage im Einzelnen verbindlich festzulegen. ${ }^{525}$ Bei der Entscheidung, ob er ein bestimmtes Rechtsgut, dessen Schutz ihm wesentlich erscheint, gerade mit den Mitteln des Strafrechts verteidigen und wie er dies gegebenenfalls tun will, sei er grundsätzlich frei. ${ }^{526}$ Das Gericht könne dessen Entscheidung nicht darauf prüfen, ob er die zweckmäßigste, vernünftigste oder gerechteste Lösung gefunden hat. ${ }^{527}$ Auch hinsichtlich der Frage, ob ein pönalisiertes Verhalten das postulierte Schutzgut tatsächlich gefährdet, beschränkt es sich zumeist auf eine eher grobmaschige Evidenz- oder Vertretbarkeitskontrolle der bejahenden gesetzgeberischen Prognose, für die lediglich eine hinreichend gesicherte Grundlage gefordert wird. ${ }^{528}$

\section{bb) Kritik und Wertung}

Daran, dass das Bundesverfassungsgericht einerseits die Aufgabe des Strafrechts im Rechtsgüterschutz verortet, andererseits keine Bindungen des Gesetzgebers bei der Bestimmung schutzwürdiger Rechtsgüter anerkennen möchte, wird deutlich, dass das Gericht den Rechtsgutsbegriff nicht im Sinne der systemkritischen Rechtsgutslehre materiell auflädt, sondern offenbar rein formal begreift. ${ }^{529}$ Dies manifestiert sich in der Entscheidung zur Verfassungsmäßigkeit des strafrechtlichen Inzestverbotes gemäß $\$ 173$ $\mathrm{StGB}$, in deren Rahmen sich der Senat explizit mit der strafrechtlichen Rechtsgutslehre auseinandersetzt und die Annahme einer Bindungswirkung vorpositiver Rechtsgüter entschieden zurückweist. ${ }^{530}$

Sofern das Gericht in seinen Ausführungen dann doch einen Gemeinschafts- und Sozialbezug strafschutzwürdiger Belange fordert, handelt es sich wohl eher um ein bloßes Lippenbekenntnis, das unter dem allgemeinen Eindruck der Eingriffstiefe des Strafrechts abgelegt wird. Der Spiel-

525 BVerfGE 90, 145 (173); in ähnlicher Weise BVerfGE 37, 201 (212); 51, 60 (74); 80,244 (255).

526 BVerfGE 120, 224 (240); BVerfGE 50, 142 (162).

527 BVerfGE 90, 145 (173).

528 BVerfGE 123, 186 (241).

529 Vgl. Appel Verfassung und Strafe, S. 198 f.; Lagodny Schranken, S. 145.

530 BVerfGE 120, 224 (241 f.); s. aber auch das der Entscheidung nachfolgende Minderheitenvotum von Hassemer S. $255 \mathrm{ff}$. 
raum des Gesetzgebers wird offenbar auch auf die Frage ausgedehnt, ob ein Gemeinschaftsbelang derart grundlegend und elementar ist, dass er eine Strafbewehrung legitimiert. ${ }^{531}$ Eine konkrete und sorgfältige Prüfung der kriminalisierten Verhaltensweisen am Maßstab der geforderten qualifizierten Sozialschädlichkeit und Verhinderungsdringlichkeit bleibt jedenfalls regelmäßig aus. In neuartiger Klarheit stellte das Gericht jüngst zumindest fest, dass der Erhalt eines tatsächlich bestehenden oder mutmaßlichen Konsenses über Werte- oder Moralvorstellungen kein unmittelbares Ziel strafgesetzgeberischer Tätigkeit sein könne. ${ }^{532}$

Die verfassungsgerichtliche Prüfung reduziert sich somit auf die Anwendung des Verhältnismäßigkeitsgrundsatzes. Als strafrechtliches Begrenzungsinstrument wird dieser vereinzelt schon für grundsätzlich untauglich erachtet. ${ }^{533}$ Weit umfangreicher stellt sich die Kritik an der konkreten Art der Anwendung durch das Bundesverfassungsgericht dar. Indem es dem Gesetzgeber gestattet, weitgehend ungebunden Ziel und Zweck des strafrechtlichen Verbots zu setzen, ${ }^{534}$ büßt der Verhältnismäßigkeitsgrundsatz beträchtlich an Limitierungspotenzial ein. ${ }^{535}$ So bleibt oftmals offen, ob das Ziel eines strafrechtlichen Verbotes nun in den Strafzwecken, dem Rechtsgüterschutz oder schlicht der Einhaltung vom Gesetzgeber erlassener Verhaltensvorschriften gesehen wird. ${ }^{536}$ Gerät aber bereits der Ausgangspunkt der Prüfung unscharf, ist von den folgenden relationalen Kontrollkriterien nicht viel zu erwarten.

Dies gilt umso mehr, als dem Gesetzgeber auch hinsichtlich dieser weiteren Prüfungsstufen - der Geeignetheit und Erforderlichkeit eines strafrechtlichen Verbotes - große Beurteilungsspielräume zugesprochen wer-

531 Appel Verfassung und Strafe, S. 204; Thurn KJ 2009, 74 (78f.); Vogel StV 1996, 110 (111).

532 BVerfG NJW 2020, 905 (910).

533 Gemäß eines Diskussionsbeitrags von Schünemann bei Brodowski ZStW 127 (2015), 691 (711) ist das Strafrecht von vornherein unverhältnismäßig und daher ein Quantensprung an Legitimation zu verlangen. Greco, in: Brunhöber/ Höffler/Kaspar/Reinbacher/Vormbaum (Hrsg.), Strafrecht und Verfassung, 2013, S. 13 (33) bestreitet die prinzipielle Bedeutung des Verhältnismäßigkeitsgrundsatzes nicht, bezeichnet ihn gleichwohl als Gleich- und Weichmacher jeder Rechtsdogmatik.

534 Bunzel, in: Hefendehl/von Hirsch/Wohlers (Hrsg.), Rechtsgutstheorie, 2003, S. 96 (111) spricht in diesem Zusammenhang von einem Rechtsgutserfindungsrecht des Gesetzgebers.

535 Roxin StV 2009, 544 (545); SK-StGB/Jäger Vor $\$ 1$ Rn. 11; Appel Verfassung und Strafe, S. $181 \mathrm{ff}$.; krit. auch Lagodny Schranken, S. $71 \mathrm{ff}$.

536 Vgl. Appel Verfassung und Strafe, S. 200, 203; Gärditz JZ 2016, 641 (644). 
den, die nur eingeschränkt überprüft werden könnten. ${ }^{537}$ Dies mag dem Umstand geschuldet sein, dass die Fragen nach den Wirkungen des Strafeinsatzes bzw. alternativen und gleich effektiven Regelungsformen in gewissem Maße prognoseabhängig sind. Doch selbst berechtigte empirische Zweifel an der Präventionseffizienz von Strafandrohungen ${ }^{538}$ werden durch das Gericht gesetzgeberfreundlich zugunsten der Annahme einer generalpräventiven Wirkung der Kriminalstrafe zerstreut. ${ }^{539}$ Die Voraussetzungen der Geeignetheit und Erforderlichkeit verkommen dadurch zu geringen Hürden. 540

Die Angemessenheitsprüfung, die als finaler Filter des Verhältnismäßigkeitsgrundsatzes im Gegensatz zu den zweckrationalen Prüfungsstufen der Geeignetheit und Erforderlichkeit stärker normativ geprägt ist, erweist sich letztlich aus Gründen der Gewaltenteilung als weiches Korrektiv. ${ }^{541}$ Denn sofern es um die Abwägung zwischen den durch das strafbewehrte Verbot bewirkten Grundrechtsbeeinträchtigungen und dem dadurch erzielten $\mathrm{Zu}-$ wachs an Rechtsgüterschutz geht, scheut das Gericht häufig davor zurück, eigene Wertungen an die Stelle der Erwägungen des Gesetzgebers zu setzen. So reduziert sich jedoch das Bekenntnis des Gerichts, die Angemessenheit mangels gesetzgeberischer Beurteilungsspielräume in vollem Umfang zu prüfen, ${ }^{542}$ auf die praktische Handhabung, eine Strafdrohung zumeist schon dann für angemessen zu halten, wenn sie nicht „schlechthin unangemessen " ist. ${ }^{543}$ Inwiefern in entgegengesetzter Tendenz hierzu die jüngste Entscheidung zur Verfassungswidrigkeit des $₫ 217$ StGB eine Aktivierung des strafrechtskritischen Potenzials des Angemessenheitskriteriums einläutet, bleibt abzuwarten. Zweifel an dessen über den Einzelfall hinausgehenden Neuausrichtung in Bezug auf materielle Strafnormen könnten sich aus der bei $\$ 217$ StGB im Unterschied zu anderen Straftatbeständen aufdrängenden, spezifischen Grundrechtsverkürzung des pönali-

537 Vgl. etwa BVerfGE 90, 145 (172 ff.).

538 Vgl. hierzu Bachmann/Goeck, in: Brunhöber/Höffler/Kaspar/Reinbacher/Vormbaum (Hrsg.), Strafrecht und Verfassung, 2013, S. 37 (47 ff.).

539 Appel Verfassung und Strafe, S. 183 ff.; vgl. auch Krauß FS Hassemer, 2010, S. 423 (425 f., 431), demzufolge die Vorgehensweise des Bundesverfassungsgerichts dem Strafrecht ein für allemal den Nimbus der Erforderlichkeit sichern würde.

540 Vgl. Vogel StV 1996, 110 (113); Roxin/Greco Strafrecht AT I $\$ 2$ Rn. 87 ff.; Lagodny Schranken, S. 173 ff.; 180.

541 Vgl. Lagodny Schranken, S. 216 f., 367.

542 BVerfGE 88, 203 (262 ff.).

543 BVerfGE 90, 145 (173); krit. dazu Stächelin Strafgesetzgebung, S. 161 f. 
sierten Verhaltens und dem vom Gericht festgestellten Widerstreit zwischen Freiheits- und Schutzdimension des Grundrechts (auf Leben) ergeben, die es zu einer außergewöhnlich hohen Kontrolldichte der strafgesetzgeberischen Entscheidung veranlassten. ${ }^{544}$

Somit bleibt festzuhalten, dass dem Verhältnismäßigkeitsgrundsatz als materiellem Maßstab für die Legitimität von Strafnormen seitens des Bundesverfassungsgerichts besondere Bedeutung zugesprochen wird und er in der Theorie hierfür auch nicht ungeeignet erscheint. In der praktischen Handhabung durch das Bundesverfassungsgericht jedoch läuft er aufgrund großzügig eingeräumter gesetzgeberischer Ermessensspielräume bezüglich sämtlicher Anforderungen zumeist leer. ${ }^{545}$ Alles in allem ergibt sich aus der Judikatur des Bundesverfassungsgerichts keine wirklich feste verfassungsrechtliche Grenze für das materielle Strafrecht jenseits des Bestimmtheitsgrundsatzes. ${ }^{546}$ Die Charakterisierung des Strafrechts als ultima ratio des Rechtsgüterschutzes erweist sich als nicht operative Makulatur. ${ }^{547}$ Der Verhältnismäßigkeitsgrundsatz wird weitgehend entkernt. Es kann insofern nicht überraschen, dass in der Vergangenheit selbst heftig umstrittene Straftatbestände die verfassungsgerichtliche Überprüfung weitgehend ungeschoren passierten. ${ }^{548}$

544 BVerfG NJW 2020, 905 (912 f.).

545 Bunzel, in: Hefendehl/von Hirsch/Wohlers (Hrsg.), Rechtsgutstheorie, 2003, S. 96 (102 ff.); Appel Verfassung und Strafe, S.97; Sternberg-Lieben, in: Hefendehl/von Hirsch/Wohlers (Hrsg.), Rechtsgutstheorie, 2003, S. 65 (76ff.); Hefendehl Kollektive Rechtsgüter, S. 83 ff.; Thurn KJ 2009, 74 (78f.).

546 Vgl. Hörnle Anstößiges Verhalten, S. 25.

547 Landau NStZ 2015, 665 (668); Gärditz JZ 2016, 641 (642f.). Hoffnungen auf eine Stärkung des ultima ratio-Prinzips als Begrenzungsmaßstab keimten anlässlich des bundesverfassungsgerichtlichen Verfahrens zur Verfassungsmäßigkeit des $\mathbb{1} 10$ RindfleischEttikettierungsG auf, nachdem sich der Vorsitzende des Zweiten Senats in einem verfahrensbezogenen Zustellungsvermerk dahingehend äußerte, dass zu prüfen sei, ob das streitige Gesetz unter dem Gesichtspunkt des Strafrechts als ultima ratio des Gesetzgebers verfassungsgemäß sei, vgl. Jahn/Brodowski JZ 2016, 969 (971). Die Entscheidung zur Verfassungswidrigkeit der Norm gründete letztlich jedoch ausschließlich auf der Verletzung des Bestimmtheitsgebots durch die undurchsichtige Verweisungskette, vgl. BVerfGE 143, 38 ff. Eine Auseinandersetzung mit dem ultima ratio-Prinzip erfolgte nicht.

548 Als verfassungsgemäß wurden etwa die Strafvorschriften zu Homosexualität (BVerfGE 6, 389 ff.), Eigenkonsum von Cannabis (BVerfGE 90, 145 ff.) sowie Inzest (BVerfGE 120, $224 \mathrm{ff}$.) erklärt. 
b) Sonstige verfassungsrechtliche Begrenzungskonzepte

aa) Darstellung

Ausgehend von einer Kritik strafrechtsimmanenter Begrenzungskonzepte, deren Verfassungsferne sie zu einem bloßen kriminalpolitischen Diskussionsbeitrag degradiere, aber auch in Distanzierung von der Herangehensweise des Bundesverfassungsgerichts, wurden weitere spezifisch verfassungsrechtliche Ansätze einer Strafrechtsbegrenzung entwickelt. ${ }^{549}$ Diese kommen darin überein, dass sich die Grenzen des Strafrechts allein aus der Verfassung ergeben könnten. Klare Konturen erhielten diese vor allem durch die Grundrechtsdogmatik, die in der Diskussion weitgehend unterschätzt worden sei, wenngleich sie ob ihrer abwehrrechtlichen Dimension und differenzierten Ausprägungen (Eingriffs- und Schrankensystematik) für eine Kontrolle der staatlichen Gewalt geradezu prädestiniert zu sein scheine. 550

Methodisch seien die zu untersuchenden Strafnormen in eine Verhaltensnorm und eine Sanktionsnorm zu zerlegen, wobei die Sanktionsnorm noch einmal in die Primär- (Ausspruch des strafrechtlichen Vorwurfs) bzw. Sekundärsanktion (Übelszufügung) aufgespaltet wird. ${ }^{551}$ Alle drei Bestandteile müssten verfassungsmäßig sein und gesondert an den durch sie tangierten Grundrechten geprüft werden, woraus sich unterschiedliche Anforderungen ergäben. Die Trennung ermögliche eine passgenaue Verortung von Streitfragen. So könnten etwa die problematischen Fallgruppen der Vorverlagerungs- und abstrakten Gefährdungsdelikte im Rahmen der (grundsätzlich strafrechtsneutralen) Verhaltensnorm unter der Frage diskutiert werden, ob der Gesetzgeber hiermit das zulässige Maß der Verhaltenssteuerung überschreite. Die spezifisch strafrechtlichen Verfassungsgarantien (Schuldgrundsatz, Ne bis in idem) ließen sich allgemein als Begrenzungen, die der Staat bei der Einschränkung des Grundrechtsgebrauchs durch strafrechtliche Regelungen zu beachten hat (sog. Schran-

549 Im Folgenden wird insbesondere auf die Konzepte von Appel (Verfassung und Strafe) und Lagodny (Strafrecht vor den Schranken der Grundrechte) eingegangen. Die beiden Ansätze unterscheiden sich in Feinheiten. Im hier interessierenden Kontext soll es aber ausreichen, die verwandten Grundannahmen zu skizzieren.

550 Appel Verfassung und Strafe, S. $311 \mathrm{ff}$.

551 Appel Verfassung und Strafe, S. 574 ff.; Lagodny Schranken, S. 96 ff.; Staechelin Strafgesetzgebung, S. $111 \mathrm{ff}$. 
ken-Schranke), in die Prüfung der Sanktionsnorm am Maßstab der Grundrechte integrieren. 552

Als weitere Schranken-Schranke sei auch hier wiederum der Verhältnismäßigkeitsgrundsatz in allen drei Prüfungen zu beachten. Während der Zweck der Verhaltensnorm im Schutz von Rechtsgütern (freilich auch hier im formellen Sinne verstanden) bestünde, dienten als Zweck der Sanktionsnorm die Strafzwecke, bei der Primärsanktion insbesondere die Normrehabilitierung. ${ }^{553}$ Der Gesetzgeber habe eine weite Definitionsmacht. Ihm obliege es, über die zu schützenden Güter und über Art und Umfang ihres Schutzes zu befinden. ${ }^{554}$ Begrenzt würde seine Zwecksetzungsfreiheit einerseits durch das Verbot der Verfolgung explizit verfassungswidriger Zwecke, andererseits müsse er im Rahmen der Primärsanktion den Zweck der Normrehabilitierung in Relation zur Verhaltensnorm setzen. ${ }^{555}$ Dass sich aus dem Verhältnismäßigkeitsgrundsatz, wenn auch strafrechtsspezifisch angepasst, keine großen Einschränkungen ergeben, wird erkannt und soll durch weitere Limitierungskriterien aufgefangen werden. Hierzu sollen etwa der Gleichheitsgrundsatz, eine zusätzliche rechtsvergleichende Perspektive oder prozessuale Regelungen herangezogen werden. 556

bb) Kritik und Wertung

Wiederum werden dem Gesetzgeber bei der Pönalisierung weite Beurteilungsspielräume eingeräumt. Ein rein formeller Verbrechensbegriff folge daraus aber aufgrund der bestehenden verfassungsrechtlichen Bindungen des Gesetzgebers nicht, die sich insbesondere in der Grundrechtsdogmatik abbildeten. Der Weg, diese Bindungen systematisch offenzulegen, enthält aber methodische Schwachpunkte.

Der Ausgangspunkt einer Auftrennung in Verhaltens- und Sanktionsnorm mag auf die begrüßenswerte Intention zurückzuführen sein, hierdurch ein Mehr an analytischer Präzision zu erreichen. Letztlich geht sie aber auf Kosten einer in diesem Kontext erforderlichen ganzheitlichen Be-

552 Appel Verfassung und Strafe, S. $560 \mathrm{ff}$.

553 Appel Verfassung und Strafe, S. 577.

554 Lagodny Schranken, S. 318 ff.; Appel Verfassung und Strafe, S. 454 f.

555 Appel Verfassung und Strafe, S. $577 \mathrm{f}$.

556 Appel Verfassung und Strafe, S. 583 ff.; zum Gleichheitsgrundsatz auch Lagodny Schranken, S. 453 ff., $491 \mathrm{ff}$. 
trachtungsweise. Gerade die für die Legitimitätsfrage maßgebliche Verschränkung von Verhaltensvorschrift und Strafbewehrung wird durch eine isolierte und unterschiedlich strenge Prüfung aufgegeben. ${ }^{557}$ Hierdurch geht kritisches Potenzial verloren. Dem Versuch einer Schärfung des Verhältnismäßigkeitsgrundsatzes durch die etwas nachgeschoben wirkenden Kriterien des Gleichheitssatzes, der Rechtsvergleichung und der Einbeziehung prozessualer Lösungen ist das Bemühen um eine Begrenzung anzumerken. Ein klar nachvollziehbares und zur konkreten Umsetzung geeignetes Prüfungsprogramm ergibt sich aus diesen Aspekten indes nicht. Schließlich wird die strafrechtliche Rechtsgutslehre zurückgewiesen, ohne dass Möglichkeiten ihrer Einbindung in das zuvor beschriebene System verfassungsrechtlicher Vorgaben ausgelotet worden wären.

\section{Integrative Ansätze einer Strafrechtsbegrenzung}

Die bisherige Darstellung zeigt, dass Konzepte einer Strafrechtsbegrenzung stark von ihrem jeweiligen disziplinären Zugang geprägt sind. Einer Zusammenführung verfassungsrechtlicher und strafrechtstheoretischer Aspekte schien über lange Jahre auch ein gewisser gegenseitiger Argwohn unter Strafrechtswissenschaftlern auf der einen und Staatsrechtlern auf der anderen Seite entgegenzustehen, der sich mitunter in Feststellungen einer generellen dogmatischen Unvereinbarkeit ausdrückte. ${ }^{558}$ Erst seit vergleichsweise kurzer Zeit werden die Fragen nach einem legitimen Strafrecht stärker in einem gemeinsamen Diskurs verhandelt, für den der zunehmend häufiger gebrauchte Begriff des Strafverfassungsrechts sinnbildlich steht. 559

557 Kudlich ZStW 127 (2015), 635 (653); Staechelin Strafgesetzgebung, S. 164.

558 Lagodny Schranken, S. 536 kommt etwa zu dem Ergebnis, das materielle Strafrecht entziehe sich der verfassungsrechtlichen Überprüfung prinzipiell. Zur dogmengeschichtlichen Parallelität Kudlich ZStW 127 (2015), 635 (649 Fn. 48).

559 Exemplarisch Jahn/Brodowski JZ 2016, 969 (970); Burchard, in: Tiedemann/ Sieber/Satzger/Burchard/ Brodowski (Hrsg.), Strafrechtspflege, 2016, S. 27 (28 ff.); zur verstärkten Hinwendung der Rechtsgutslehre zum Verfassungsrecht bereits oben Teil 3 A. II. 1. a) cc). 
a) Schärfung des Verhältnismäßigkeitsgrundsatzes durch den Rechtsgutsbegriff

Vielversprechend wirken dabei insbesondere Ansätze einer Integration des systemkritischen Rechtsgutsbegriffs in das Prüfungsraster des Verhältnismäßigkeitsgrundsatzes. Als verfassungsrechtliche Negativschranke staatlicher Eingriffe ist dessen grundsätzliche Bedeutung auch für das Strafrecht anzuerkennen. ${ }^{560}$ Sein durch die Handhabung des Bundesverfassungsgerichts eingebüßtes kritisches Potenzial lässt sich wiederherstellen, indem die einzelnen Prüfungsstufen nicht gänzlich der Wertung des Gesetzgebers überlassen werden, sondern an geeigneter Stelle eine Aufladung durch die Kriterien eines gesetzgebungskritischen Rechtsgutsbegriffs erfahren.

So wird zum einen gefordert, den Rechtsgutsbegriff in die im Rahmen der Angemessenheit einer Pönalisierung vorzunehmende Güterabwägung einzustellen. Ihre stark normative Ausrichtung berge grundsätzlich die Gefahr, im Ergebnis allein die subjektiven Wertungen des Prüfenden widerzuspiegeln. ${ }^{561}$ Der insoweit bestehende Bedarf an wertender Klassifizierung auf Schutzgutseite könne jedoch gerade durch die Heranziehung der Kriterien des Rechtsgutsbegriffs gedeckt werden und für eine Präzisierung der Prüfung sorgen, ob das durch die Norm geschützte Interesse der Gewalt des Strafrechts proportional ist. ${ }^{562}$

Überzeugender erscheint es indes, die Setzung des legitimen Zwecks der Strafnorm durch den Gesetzgeber und somit bereits den Bezugspunkt der Verhältnismäßigkeitsprüfung anhand des Rechtsgutsbegriffs zu überprüfen. ${ }^{563}$ Nimmt man die einhellig vorgenommene Qualifizierung des Strafrechts als ultima ratio des Rechtsgüterschutzes ernst und sollen straflegislatorische Entscheidungen vor ihrer Umsetzung einer kriminalpolitischen Diskussion zugänglich gemacht werden, muss sich bereits der verfolgte Zweck einer Pönalisierung gewissen einschränkenden Legitimitätskriterien stellen. Nur so gelingt eine Verzahnung maßgeblicher Topoi wie Sozial-

560 Vgl. Hefendebl JA 2011, 401 (404 ff.).

561 Staechelin Strafgesetzgebung, S. 162.

562 Staechelin Strafgesetzgebung, S. 163 f.; selbst Lagodny Schranken, S. 424 ff. erkennt hier eine mögliche Verwendungsart des Rechtsgutsbegriffs, wenngleich er es deutlich zurückhaltender formuliert.

563 In diesem Sinne Hassemer, in: Hefendehl/von Hirsch/Wohlers (Hrsg.), Rechtsgutstheorie, 2003, S. 57 (60); Hefendehl GA 2007, 1 (2); Greco ZIS 2008, 234 (238); SK-StGB/Jäger Vor $\$ 1$ Rn. 11 f.; Thurn KJ 2009, 74 (82); Müller-Dietz Strafe und Staat, S. 16; krit. Engländer ZStW 127 (2015), 616 (627 f.); Stuckenberg GA 2011, 653 (657); Gärditz JZ 2016, 641 (649). 
schädlichkeit und Subsidiarität im Sinne einer konsistenten und operationalisierbaren Begrenzung. Die Prüfungsstufen der Geeignetheit und Erforderlichkeit lassen sich an einem dem Leitbild eines liberalen Strafrechts angepassten Bezugspunkt ausrichten und werden vor ihrer Aufweichung infolge diffuser Zwecksetzungen bewahrt. Stellt man Rechtsgutserwägungen erst in der Angemessenheit an, verzichtet man auf deren präzisierende Wirkung für die Geeignetheits- und Erforderlichkeitsprüfung und akzeptiert das Risiko, dass diese im einigermaßen unkontrolliert ablaufenden Abwägungsvorgang überspielt werden.

Wie bereits ausgeführt wird der Gesetzgeber dadurch nicht gezwungen, strafrechtliche Mittel nur zum Schutz eines vorab definierten Katalogs an Rechtsgütern einzusetzen. Ein solcher kann nicht mit der notwendigen definitorischen Schärfe gebildet werden. Der eigenständig gesetzte Zweck, den der Gesetzgeber mit der Kriminalisierung zu erreichen versucht, ist aber an den Kriterien eines „von unten materialisierten“ Rechtsgutsbegriffs zu messen. Wird er diesen nicht gerecht, ergibt sich daraus jedenfalls ein gravierendes Legitimationsdefizit. ${ }^{564}$

Über dessen konkrete Konsequenz für die Bewertung der betroffenen Tatbestände herrscht indes selbst unter Vertretern einer verfassungsrechtlichen Integration des Rechtsgutsbegriffs Uneinigkeit. Aus der mangelnden Übereinstimmung eines vorgeblichen Schutzgutes mit den entwickelten Komponenten des Rechtsgutsbegriffs unmittelbar den Schluss der Verfassungswidrigkeit der Strafvorschrift zu ziehen, könnte wiederum das dem Gesetzgeber bei der Zweckbestimmung eingeräumte Beurteilungsermessen verkennen. ${ }^{565}$ Aus diesem Grund werden in den konkreten Ableitungen eines gesetzgebungskritischen Rechtsgutskonzepts mitunter zwar verfassungsrechtlich fundierte, letztlich aber nur kriminalpolitisch wirkende Postulate gesehen, die sich an den Gesetzgeber insbesondere im Gesetzgebungsverfahren richteten, während sie nach betätigter Ermessensausübung allenfalls noch eine grobmaschige Kontrolle legislatorischer Entscheidungen ermöglichten. ${ }^{566}$ Eine defensive Auslegung der Rechtsgutserwägungen als unverbindliche Argumentationstopoi bzw. strafrechtswissenschaftliche Hilfestellung für den Gesetzgeber kaschiert jedoch das durch deren verfassungsrechtliche Einbettung und Materialisierung gerade begründete Potenzial, den anzuerkennenden gesetzgeberischen Spielraum im Sinne eines

564 Woblers GA 2002, 15 (17).

565 Vgl. Roxin/Greco Strafrecht AT I $\$ 2$ Rn. 93.

566 Roxin/Greco Strafrecht AT I $₫ 2$ Rn. 94; wohl auch Kudlich ZStW 127 (2015), 625 (651). 
liberalen Strafrechts zulässig einzugrenzen. Die Beschränkung der Aufgabe des Strafrechts auf den Schutz von Rechtsgütern und deren verfassungsrechtliche Materialisierung lassen sich so durchaus als ungeschriebener Verfassungsgrundsatz oder Grundentscheidung des Grundgesetzes auffassen, mit denen jede Entscheidung des Gesetzgebers in Einklang stehen muss. ${ }^{567}$ Die die jeweilige Vorschrift betreffende Konsequenz eines als illegitim zu bewertenden Rechtsguts darf daher nicht nur bei offensichtlicher Unzulänglichkeit im Verdikt der Verfassungswidrigkeit bestehen. ${ }^{568} \mathrm{Nach}$ hier vertretener Ansicht kann eine Strafvorschrift jenseits eines den benannten Legitimitätsanforderungen entsprechenden Rechtsguts vor der Verfassung keinen Bestand haben.

\section{b) Ergänzende Begrenzungskriterien}

Wiederum ist aber zu erwähnen, dass eine Konkretisierung des Zwecks über den Rechtsgutsbegriff eine notwendige, aber keine hinreichende Bedingung legitimer Strafnormen sein kann. Insbesondere abstrakte Gefährdungsdelikte oder Tatbestände im Vorfeld einer tatsächlichen Rechtsgutsbeeinträchtigung erhielten durch einen auf Rechtsgutserwägungen verengten Prüfungsmaßstab einen bedenklichen Freifahrtschein ausgestellt. Auch die Art und Weise eines strafrechtlichen Rechtsgüterschutzes muss daher einer Legitimationskontrolle unterliegen. Hierbei bieten sich wiederum Verknüpfungen zwischen strafrechtsspezifischen Kriterien und den weiteren Stufen des Verhältnismäßigkeitsgrundsatzes an.

Die Geeignetheit einer Pönalisierung ist demnach nicht nur strafzweckbezogen hinsichtlich der präventiven Wirkung der Norm zu überprüfen angesichts der Prognoseabhängigkeit dieser Fragestellung würden sich hier wiederum weite Beurteilungsspielräume des Gesetzgebers auftun -, sondern hat auch eine Analyse der Deliktsstruktur zu umfassen. ${ }^{569}$ Diese soll auf die Beziehung zwischen den tatbestandlich erfassten Verhaltensweisen und der Beeinträchtigung des geschützten Rechtsguts eingehen und die Gefährdungsintensität einzelner Tathandlungen aufzeigen. Die zu über-

567 S. Sondervotum Hassemer zu BVerfGE 120, 224 (256f.).

568 Für einen derartigen Evidenz-Maßstab als „Mittelweg“ indes Jahn Vogel-Symposium, 2016, S. 63 (82 f.); Roxin/Greco Strafrecht AT I $\$ 2$ Rn. 94.

569 Vgl. Hefendehl Kollektive Rechtsgüter, S. 96; Wohlers GA 2002, 15 (17 ff.); Frisch, in: Hefendehl/von Hirsch/Wohlers (Hrsg.), Rechtsgutstheorie, 2003, S. 215 (227 f.); in diese Richtung auch Sondervotum Graßhof zu BVerfGE 90, 145 (199, $201 \mathrm{f}$.$) .$ 
prüfende Strafnorm ist im Hinblick auf ihre Tatbestandsstruktur einer Deliktskategorie zuzuordnen, die ihrerseits spezifische Anforderungen an die Legitimität stellt, wobei die abstrakten Gefährdungsdelikte und ihre Unterteilung im Fokus stehen. ${ }^{570}$ In diesem Sinne lässt sich auch das Begrenzungstopos der Angriffswege integrieren, demzufolge der Benennung eines möglichst konkreten Rechtsguts stets eine Auswahl der für strafwürdig erachteten Beeinträchtigungen nachfolgen muss und in dem insofern der wichtige Gedanke der Fragmentarität zum Ausdruck kommt. ${ }^{571}$

Im Rahmen der Erforderlichkeit sind alternative Regelungssysteme zum Schutz des identifizierten Rechtsguts in den Blick zu nehmen. Existieren in ihnen Sanktionsformen für die Verletzung statuierter Verhaltensvorschriften, sind diese insbesondere bei geplanten Neukriminalisierungen in ihrer Zweckrichtung und Wirkweise den avisierten strafrechtlichen Rechtsfolgen gegenüberzustellen. Inwiefern eine strafrechtliche Absicherung der Verhaltensvorschriften einen vergleichsweise größeren Schutz des Rechtsguts gewährt, ist auch unter Auswertung vorliegender empirischer Erkenntnisse zu beurteilen. Zu einer Präzisierung kann hierbei auch das ultima ratio-Prinzip beitragen. Jedenfalls dann, wenn in ihm nicht nur eine bloße Beschreibung der allgemeinen Verhältnismäßigkeit gesehen wird, sondern ihm ein eigenständiger Mehrwert insofern zugesprochen wird, als er die Erforderlichkeitsprüfung modifiziert. Einem solchen, auf Operationalisierbarkeit ausgelegten Vorschlag zur strafrechtsspezifischen Aufladung des Erforderlichkeitsmaßstabs durch das ultima ratio-Prinzip zufolge sollen etwa Alternativen zur Kriminalsanktion nicht nur bei gleich effektiver Zweckerreichung vorzuziehen sein. Die hinreichende Zielerreichung durch ein alternatives Mittel soll bereits genügen, wenn dies für jeden Sachkundigen ohne längere Prüfung erkennbar ist. ${ }^{572}$

Schließlich bildet die Prüfungsstufe der Angemessenheit ein Korrektiv, in dem die Ableitungen zu Rechtsgut, Deliktsstruktur und Angriffswegen unter normativen Gesichtspunkten zusammengeführt und hinsichtlich der Frage einer bestehenden Proportionalität zwischen angestrebtem Zweck und Beeinträchtigung der Freiheitssphäre der Betroffenen in eine Abwägung eingestellt werden können.

570 Von Hirsch/Wohlers, in: Hefendehl/von Hirsch/Wohlers (Hrsg.), Rechtsgutstheorie, 2003, S. 196 (197 ff.).

571 Stächelin Strafgesetzgebung, S. $56 \mathrm{f}$.

572 Jahn/Brodowski JZ 2016, 969 (976ff.); eine ähnliche Modifikation befürworten Baumann/Weber/Mitsch/Eisele Strafrecht AT $\$ 3$ Rn. 19, denen zufolge die Erforderlichkeit nur bei Unverzichtbarkeit des Einsatzes des Strafrechts anzunehmen sei. 
III. Zusammenfassung und Folgen für den weiteren Verlauf der Untersuchung

Der Ausschluss einer durch internationale Vorgaben etablierten Kriminalisierungspflicht sowie einer bereits durch den Regelungsgegenstand indizierten verfassungsrechtlichen Unzulässigkeit kennzeichnet die \$S 265c, 265d StGB als Produkt eines frei ausgeübten strafgesetzgeberischen Ermessens. Sie eignen sich damit grundsätzlich als Gegenstand einer allgemeinen Legitimationskontrolle von Strafnormen, hinsichtlich deren Dichte und Herleitung jedoch auf keinen allgemein anerkannten Maßstab zurückgegriffen werden kann. Bemühungen um die Entwicklung von Kriterien legitimer Strafnormen lassen sich sowohl in der strafrechtlich bzw. staatsrechtlich geprägten Wissenschaft als auch in der Rechtsprechung des Bundesverfassungsgerichts feststellen.

Eine Würdigung dieser Ansätze hat ergeben, dass der systemkritische Rechtsgutsbegriff zwar schillernd ist, er bei der Überprüfung der Legitimität strafrechtlicher Tatbestände jedoch nicht unbeachtet bleiben darf. Über die Funktion der Strafe als Mittel zu einem bestimmten Zweck herrscht weitgehend Einigkeit. Dann wirkt dieser aber auch notgedrungen auf ihre inhaltliche Ausgestaltung und Begrenzung zurück. ${ }^{573}$ Dies gilt, obschon es bisher nicht gelungen ist, eine präzise Definition dessen zu formulieren, was als Rechtsgut strafrechtlichen Schutz verdient und sonstige Interessen aus dem Bereich des Strafwürdigen ausscheidet.

Den Anforderungen eines einerseits verfassungsrechtlich fundierten, andererseits gesetzgebungskritischen Legitimitätsmaßstabs für Strafnormen entspricht die Integration eines nicht definitorisch festgelegten, aber verfassungsrechtlich materialisierten Rechtsgutsbegriffs als Bezugspunkt des Verhältnismäßigkeitsgrundsatzes. Um dessen übrige Prüfungsstufen nicht zu entwerten, sind sie an den Rechtsgutsüberlegungen anzubinden und unter Berücksichtigung der konkreten Deliktsstruktur der überprüften Tatbestände wenn möglich mit vorhandenen sozialwissenschaftlichen Erkenntnissen über die bereichsspezifische Wirkweise des Strafrechts zu unterlegen.

Übertragen auf die Legitimationsprüfung der $\$ \int$ 265c, 265d StGB erfordert dies zunächst eine Bewertung der den Tatbeständen seitens des Gesetzgebers zugrunde gelegten Rechtsgutsentwürfe anhand der beschriebenen Materialisierungskriterien (dazu B.). Lässt sich ein legitimes Schutzgut ausmachen, stellt sich im Anschluss die Frage nach Geeignetheit, Erforder-

573 Müller-Dietz Strafe und Staat, S. 6. 
lichkeit und Angemessenheit der Strafnormen gerade im Hinblick auf das Rechtsgut, wobei die Struktur der Tatbestände näher zu untersuchen sein wird (dazu C.). Schließlich sind die Normen an der klaren verfassungsrechtlichen Grenze des Bestimmtheitsgrundsatzes in Art. 103 Abs. 2 GG zu messen (dazu D.).

\section{B. Rechtsgut}

Entsprechend der aufgezeigten Erforderlichkeit, das strafrechtlichen Tatbeständen zugrunde liegende Rechtsgut zu identifizieren und zu bewerten, werden im Folgenden die $\$ \$ 265 c$, 265d StGB auf ein schützenwertes Rechtsgut überprüft. Den Ausgangspunkt bildet hierbei der historische Wille des Gesetzgebers. Anhand einer Auswertung von Gesetzentwürfen, vorangehenden Beratungen und publizierten Äußerungen der am Gesetzgebungsverfahren beteiligten Akteure ist die intendierte Schutzrichtung der Tatbestände zu ermitteln. Da das die zu überprüfenden Tatbestände beinhaltende Gesetz im Kontext einer allgemeinen Tendenz der zunehmenden strafrechtlichen Regulierung des Sports steht, 574 werden im Hinblick auf vorgebrachte und sich überschneidende Schutzgutsaspekte verwandte Gesetzentwürfe in den Blick genommen. Ferner erfolgt auch eine Auseinandersetzung mit Vorschlägen, die hinsichtlich der Rechtsgutsfrage in der die einschlägige Gesetzgebung begleitenden wissenschaftlichen Literatur formuliert wurden. Die auf diese Weise gefundenen Rechtsgüter sind jeweils an den aufgezeigten Materialisierungskriterien zu messen. Dabei sind sie insbesondere auf einen hinreichend bestimmten, nicht über bloße Moralvorstellungen konstituierten Gehalt zu überprüfen, dessen reale Verletzbarkeit eine sozialschädliche Dimension aufweist. Hierüber ist ihre Tauglichkeit als legitimer Bezugspunkt einer sich anschließenden Verhältnismäßigkeitsprüfung zu bewerten.

574 Exemplifizierend seien die Referentenentwürfe des bayerischen Justizministeriums für ein Sportschutzgesetz vom 30.11.2009, www.justiz.bayern.de/media/ent wurf_sportschutzgesetz_30112009.pdf bzw. für ein Gesetz zum Schutz der Integrität des Sports vom 12.3.2014, www.justiz.bayern.de/media/pdf/gesetze/sp ort.pdf, sowie das Gesetz zur Bekämpfung von Doping im Sport vom 10.12.2015, BGBl. 2015 I S. 2210, genannt. 


\section{Unzureichende Legitimierungsgründe}

Noch vor einer detaillierten rechtsgutsbezogenen Analyse der konkreten Gesetzentwürfe und ihrer wissenschaftlichen Rezeption wird zunächst auf einige Aspekte eingegangen, die in der politischen und teilweise auch in der wissenschaftlichen Diskussion über einen strafrechtlichen Handlungsbedarf im Sport immer wieder in den Rang eines legitimierenden Schutzgutes gehoben werden, angesichts des hier herangezogenen Maßstabes als ein solches aber von vornherein ausgeschieden werden müssen.

\section{Der Sport als solcher}

Anknüpfend an die Bezeichnung von Gesetzentwürfen als „Sportschutzgesetz" ${ }^{\text {“575 }}$ und Aussagen des damaligen Bundesjustizministers Heiko Maas, mittels strafrechtlicher Tatbestände gegen Doping, Wettbetrug und Spielmanipulationen den Sport schützen zu wollen, 576 stellt sich die Frage, ob nicht der Sport als solcher bereits ein ausreichendes Schutzgut darstellen könnte. Unterstützend wird hierfür bisweilen die ideelle und finanzielle Förderung des Sports durch den Staat angeführt, die diesen berechtige, auch seine Sanktionen zum Einsatz zu bringen, wenn sich der Förderung zuwider laufende Fehlentwicklungen abzeichneten. ${ }^{577}$

Eine solche Schlussfolgerung ist allerdings genauso undifferenziert wie der Oberbegriff des Sports selbst. Die finanzielle Unterstützung eines Bereichs aus Haushaltsmitteln mag ein Indiz dafür sein, dass es sich hierbei aus Sicht des Staates um einen wichtigen Belang des Gemeinwohls handelt. Allein hieraus kann aber keine Rechtfertigung eines wahllosen Einsatzes des Strafrechts in diesem Bereich folgen. Unabhängig seiner finanziellen Zuwendungen bleibt der Staat verpflichtet, strafrechtlichen Handlungsbedarf infolge sozialschädlicher Verhaltensweisen präzise nachzuweisen. Der bloße Verweis auf den Sport als solchen wird den Anforderungen an ein hinreichend bestimmtes Schutzgut dabei nicht gerecht. Denn eine klare und unumstrittene Definition des Sportbegriffs ist bislang weder ge-

575 Referentenentwurf des bayerischen Justizministeriums für ein Sportschutzgesetz vom 30.11.2009, www.justiz.bayern.de/media/entwurf_sportschutzgesetz_3 0112009.pdf.

576 Maas NStZ 2015, 305 (307).

577 Heger NJW-Editorial 4/2016; in diese Richtung auch Ott Selbstdoping, S. 183; Kubiciel KriPoZ 2018, 29 (30). 
setzlich hinterlegt noch sportwissenschaftlich hervorgebracht worden. ${ }^{578}$ Sie kann angesichts des Erfordernisses einer Entwicklungsoffenheit gegenüber neu aufkommenden Trends womöglich auch nicht geleistet werden. ${ }^{579}$ Denn zwangsläufig fiele sie entweder zu eng aus, so dass bestimmte, sportliche Wesensmerkmale eigentlich erfüllende Erscheinungsformen ausgegrenzt würden, oder aber sie verlöre jegliche Konturen, die sie in Streitfragen operationalisierbar werden ließe.

Auch gesellschaftliche Anschauungen zum Sport stellen sich als diversifiziert dar. Abhängig von Altersgruppe, körperlichen Voraussetzungen und Freizeitverhalten wird die sportliche Betätigung als solche aus gesundheitlichen oder sozialen Motiven im Kontext des Breitensports selbst erlebt oder in Form spitzensportlicher Wettkämpfe medial verfolgt. Über die eigene oder fremde Ausübung hinaus wird der Sport aber auch mit der organisatorischen Ausformung durch Verbände und der sozialen Integrationswirkung von Vereinen assoziiert. Anderen wiederum mag der Sport im Zuge seiner Kommerzialisierung gar primär als Wirtschaftsfaktor und Zugpferd der Werbeindustrie erscheinen.

Schon diese unterschiedlichen Zugänge zeigen, dass der Sport als solcher facettenreich ist und nicht zwangsläufig einen durch Regeln ausgeprägten Wettkampfbezug aufweisen muss. Damit ist er aber auch keine normierbare Institution und sein Schutz in dieser allgemeinen Hinsicht kein taugliches strafrechtliches Rechtsgut. ${ }^{580}$ Ein derart vielschichtiges Begriffsfeld, das sich weder sportwissenschaftlich klar definieren noch auf ein hinreichend homogenes gesellschaftliches Verständnis zurückführen lässt, ließe als Rechtsgut strafrechtlicher Tatbestände nicht erkennen, was konkret geschützt werden soll.

578 Holzhäuser/Bagger/Schenk SpuRt 2016, 94; Zuck NJW 2014, 276 (277); prägnant hierzu Röthig/Probl (Hrsg.), Sportwissenschaftliches Lexikon: „Seit Beginn des 20. Jahrhunderts hat sich Sport zu einem umgangssprachlichen, weltweit gebrauchten Begriff entwickelt. Eine präzise oder gar eindeutige begriffliche Abgrenzung lässt sich deshalb nicht vornehmen. Was im Allgemeinen unter Sport verstanden wird, ist weniger eine Frage wissenschaftlicher Dimensionsanalysen, sondern wird weit mehr vom alltagstheoretischen Gebrauch (...) bestimmt."

579 Kubiciel Stellungnahme zu BT-Drs. 18/8831, S. 5.

580 Heger SpuRt 2007, 153 (154). 


\section{Bekämpfung von Korruption}

Als Begründung der $\$ \$ 265$ c, 265d StGB wird auch die Bekämpfung von Korruption vorgebracht: In der Korruption wird ein gesamtgesellschaftliches Problem ausgemacht, das sich einem ansteckenden Virus gleich von gesellschaftlichem Teilbereich zu Teilbereich übertragen werde, sofern nicht innerhalb der jeweiligen Teilbereiche (strafrechtliche) Abwehrmaßnahmen ergriffen würden.581 Eine entsprechende Argumentation klingt auch in der Gesetzesbegründung der zwei Jahre vor Einführung der $\$ \mathbb{S} 265 \mathrm{c}, 265 \mathrm{~d}$ StGB geschaffenen Tatbestände der Bestechlichkeit und Bestechung im Gesundheitswesen gemäß $\$ \$ 299$ a ff. StGB an. ${ }^{582}$

In der Korruptionsbekämpfung als solcher ein zentrales Begründungstopos zu sehen, hieße aber, die elementare Differenzierung von Rechtsgut und Angriffswegen einzuebnen. Bei korruptiven Absprachen handelt es sich um eine Angriffsform, die für sich genommen kein Tatunrecht zu begründen vermag, sondern immer nur in Bezug auf ein eigentliches Rechtsgut auf ihre Strafwürdigkeit hin untersucht werden kann. ${ }^{583}$ Auch im Rahmen der als klassische Korruptionsdelikte bezeichneten Tatbestände des StGB ( $\$ 299$ bzw. $\$ \$ 331 \mathrm{ff}$. StGB) wird demnach um die Benennung eines spezifischen Rechtsguts als Angriffsobjekt der Absprache gerungen. Unabhängig der Bewertung ihrer tatsächlichen Eignung als legitimes Rechtsgut verdeutlichen das „Allgemeininteresse an einem freien, lauteren Wettbewerb" bei den wettbewerbsbezogenen Tatbestandsalternativen in $\$ 299$ Abs. 1 Nr. 1, Abs. 2 Nr. 2 StGB $^{584}$ sowie die „Funktionsfähigkeit der öffentlichen Verwaltung und das Vertrauen der Allgemeinheit in die Sachlichkeit und Unabhängigkeit des Verwaltungshandelns" bei den $\$ \$ 331 \mathrm{ff}$. StGB, ${ }^{885}$ dass allein der pauschale Verweis auf die Notwendigkeit einer Korruptionsbekämpfung einer Strafnorm nicht zur Legitimität verhilft. Dies gilt auch für den Bereich des Sports. Darüber hinaus verkennt eine solche Zielsetzung die grundsätzliche Ausrichtung des Strafrechts. Wenngleich auch der Gesetzgeber bei der Bezeichnung von Strafgesetzen zu

581 Kubiciel jurisPR-StrafR 3/2016, Anm. 1, S. 2.

582 Vgl. BT-Drs. 18/6446, S. 12 f.

583 Krack ZIS 2016, 540 (542 f.); Kindhäuser ZIS 2011, 461; Saliger FS Kargl, 2015, S. 493 (504).

584 So die Rechtsgutsbestimmung der hM, vgl. Lackner/Kühl/Heger/Heger $\mathbb{} 299$ Rn. 1; MüKo-StGB/Krick $\$ 299$ Rn. 15; Schönke/Schröder/Heine/Eisele $\mathbb{} 299$ Rn. 3.

585 Für diesen kombinierten Ansatz BGHSt 30, 46 (48); MüKo-StGB/Korte $₫ 331$ Rn. 8; NK-StGB/Kublen $\$ 331$ Rn. 12 f. 
einer aktivistischen Bekämpfungs-Rhetorik neigt, ${ }^{586}$ handelt es sich beim Strafrecht um ein Schutzrecht, von dem die Bewältigung allerlei gesellschaftlicher Problemlagen nicht erwartet werden sollte.

\section{Erweiterung prozessualer Befugnisse}

Teilweise wird dem nun ermöglichten Einsatz strafprozessualer Aufklärungs- und Ermittlungsbefugnisse legitimierende Wirkung für die materi-

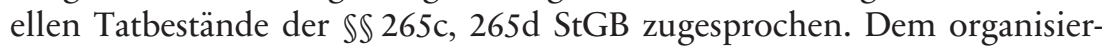
ten Sport und seiner Verbandsgerichtsbarkeit seien Grenzen gezogen, die es nahezu unmöglich machten, das Ausmaß an wettkampfbezogenen Manipulationen aufzudecken und zu ahnden. ${ }^{587}$ Zwangsmittel wie Durchsuchungen und Beschlagnahmen könnten nicht angeordnet werden. Zudem erstrecke sich ihre Disziplinargewalt lediglich auf die einzelnen Sportler. Um die hinter Manipulationsskandalen vermuteten Netzwerke effektiv auszuleuchten und die darin im Hintergrund operierenden Akteure einem ausreichenden Verfolgungs- und Ermittlungsdruck auszusetzen, bedürfe es daher gerade strafprozessualer Zwangsmittel und Interventionsmöglichkeiten..$^{588}$

Auch wenn sich der Versuch, die Einführung neuer Straftatbestände über ihre prozessuale Funktion als den Ermittlungsbehörden dienliche Einstiegsnorm zur Begründung von Zwangsmaßnahmen zu rechtfertigen, immer wieder beobachten lässt, ${ }^{589}$ ist er entschieden zurückzuweisen. Denn die Legitimität der Kriminalisierung von Verhaltensweisen über eine strafprozessuale „Türöffnerfunktion“ begründen zu wollen, kehrt die Legitimationsrichtung der jeweiligen Rechtsgebiete in unzulässiger Weise um. Das Strafprozessrecht hat dem effektiven Rechtsgüterschutz durch das

586 Exemplarisch aus der jüngeren Vergangenheit Gesetz zur Bekämpfung der Korruption vom 20.11.2015, BGBl. 2015 I S. 2025; Gesetz zur Bekämpfung von Doping im Sport vom 10.12.2015, BGBl. 2015 I S. 2210; Gesetz zur Bekämpfung der Korruption im Gesundheitswesen vom 30.5.2016, BGBl. 2016 I S. 1254; Gesetz zur Bekämpfung der Steuerumgehung vom 23.6.2017, BGBl. 2017 I S. 1682; zum Anstieg von „Bekämpfungsgesetzen“ bereits Hefendebl ZStW 119 (2007), 816 (817) mwN.

587 Kubiciel WiJ 2016, 256 (262); Rössner FS Mehle, 2009, S. 567 (570).

588 Bzgl. Doping s. Hauptmann/Rübenstahl HRRS 2007, 143 (147); Rössner FS Mehle, 2009, S. 567 (570).

589 Krit. zu einer entsprechenden Argumentation im Rahmen des \$264a StGB Albrecht KritV 1993, 163 (170); Graf/Jäger/Wittig/Bock \$264a StGB Rn. 12. 
materielle Strafrecht zu dienen, nicht das materielle Strafrecht die Voraussetzungen für ein möglichst breitflächiges und scharfes strafprozessuales Vorgehen zu bilden. ${ }^{590}$ In diesem Verhältnis kann ein vorgeblicher Bedarf nach verbesserten Verfolgungsmöglichkeiten nicht Selbstzweck einer Pönalisierung sein und entbindet daher nicht von der zwingend vorgelagerten Identifizierung eines der materiellen Strafnorm zugrunde liegenden schutzwürdigen Rechtsguts. ${ }^{591}$ Andernfalls würde das materielle Strafrecht instrumentalisiert und von einem Sanktionsrecht für schuldhaft begangenes Unrecht in ein Interventionsrecht umgedeutet. ${ }^{592}$

\section{4. Überwindung von Nachweisschwierigkeiten}

In gleicher Weise wie eine Instrumentalisierung der $\$ \$ \$ 265 c, 265 d$ StGB zu Gunsten des Prozessrechts ausscheidet, muss auch deren Legitimierung über eine reine Auffangfunktion für verwandte, aber schwer nachweisbare Tatbestände auf materiell-rechtlicher Ebene abgelehnt werden. So lässt sich die Strafbarkeit des Sportwettbetrugs nicht einfach mit der Schwierigkeit begründen, in Konstellationen des Abschlusses einer manipulierten Sportwette ohne spätere Auszahlung den Nachweis eines Vermögensschadens i.S.d. $\$ 263$ StGB zu erbringen. ${ }^{593}$ Denn sofern dies nicht gelingt, ist das zunächst einmal Ausdruck des fragmentarischen Charakters des Strafrechts, ${ }^{594}$ nicht aber Aufforderung, den Bereich des Strafbaren legislatorisch durch Absenkung der tatbestandlichen Voraussetzungen auf betrugsähnliche Verhaltensweisen auszuweiten. ${ }^{595}$

Zwar mag es gerade im 22. Abschnitt des StGB in Form des Subventionsbetrugs $(\$ 264$ StGB) und des Kapitalanlagebetrugs ( $\$ 264 a$ StGB) Delikte geben, deren Entstehung vom Impuls, auftretende Anwendungs-

590 Graf/Jäger/Wittig/Eschelbach Vor $\$ \$ \$ 4-5$ AntiDopG Rn. 3; Norouzi/Summerer SpuRt 2015, 63 (65); Kauerhof Causa Sport 2014, 127 (128).

591 Prittwitz FS Schiller, 2014, S. 512 (528); Roxin/Greco Strafrecht AT I $\ 2$ Rn. 49g, 49j f.; Lutz HRRS 2016, 21 (28); Kreuzer ZRP 2013, 181 (183 f.); Zuck NJW 2014, 276 (281).

592 Kauerhof, in: Asmuth (Hrsg.), Entgrenzungen, 2012, S. 291 (330); Kudlich JA 2007, 90 (95).

593 Bohn KriPoZ 2017, 88 (93); in der Überwindung von Anwendungs- und Beweisschwierigkeiten hingegen eine starke Begründungslinie der Tatbestände erblickend Nolte Stellungnahme zu BT-Drs. 18/8831, S. 2; Kubiciel Stellungnahme zu BT-Drs. 18/8831, S. 5 f.; vgl. auch BT-Drs. 18/8831, S. 11.

$594 \mathrm{Zu}$ diesem s. oben Teil 3 A. II. 3. b).

595 Im Allgemeinen s. Roxin/Greco Strafrecht AT I $₫ 2$ Rn. 49g f. 
schwierigkeiten über die Schaffung von Sondertatbeständen zu beseitigen, beeinflusst wurde. ${ }^{596}$ Abgesehen von der auch an ihnen geäußerten Kritik, der zufolge die komplexen Sonderstraftatbestände keinesfalls leichter handhabbar seien und auch deswegen in praktischer Hinsicht ein Schattendasein fristeten, ${ }^{597}$ zielen sie aber zumindest auf den Schutz übergeordneter Allgemeininteressen, die für die Delikte des Sportwettbetrugs und der Manipulation berufssportlicher Wettbewerbe erst einmal vorgebracht werden müssten. ${ }^{598}$

\section{Analyse der vorgebrachten Rechtsgüter}

Während die soeben ausgeführten Aspekte entweder die Ausrichtung des Strafrechts als Schutzrecht ignorieren oder der im Rahmen eines systemkritischen Rechtsgutsbegriffs aufgestellten Anforderung der Bestimmtheit offensichtlich nicht entsprechen und daher vorangestellt wurden, sind in der Diskussion um die strafrechtliche Erfassung von Wettbetrug und anders motiviertem Match Fixing verschiedene Schutzgüter eingebracht worden, die eine eingehende Analyse erfordern. Teilweise wurden sie bereits im Rahmen der vorausgegangenen Anti-Doping-Gesetzgebung entwickelt und geleitet von der Intention einer einheitlichen sportbezogenen Bestimmung auf die von $\$ \$ 265$ c, 265d StGB erfassten Manipulationsformen übertragen. Teilweise werden sie zwar im Ausgangspunkt der Doping-Diskussion entlehnt, mit Blick auf den spezifischen Gehalt der jeweiligen Manipulationsformen aber anders akzentuiert. Und vereinzelt werden sie auch gänzlich ohne Anlehnung an die strafrechtliche Dopingbekämpfung neu formuliert. Die auf diese Weise entstandene Pluralität an Rechtsgutsbestimmungen wird zunächst näher beleuchtet und überblicksartig zusammengefasst, ehe die einzelnen Vorschläge im Detail auf ihre jeweilige Legitimation hin überprüft werden.

596 Kudlich DRiZ 2013, 361; im Einzelnen zu $\$ 264$ StGB s. Schönke/Schröder/Perron $\$ 264$ Rn. 2; MüKo-StGB/Ceffinato $\$ 264$ Rn. 3 ff.; zu $\$ 264$ a StGB s. NKStGB/Hellmann \$264a Rn. 3; Hdb-StR/Kindhäuser/Schumann $\$ 34$ Rn. 98.

597 Vgl. zu $\$ 264$ a StGB Zieschang GA 2012, 607 (615); Fischer StGB $\$ 264 a$ Rn. 2a.

598 Zum Vergleich mit den Tatbeständen der $\$ \$ \$ 265$ cf. StGB vgl. Kretschmer FS Rössner, 2015, S. 628 (644 f.). 
1. Quellen

a) Gesetzgebungsmaterialien

Die Suche nach dem geschützten Rechtsgut der $\$ \$ 265$ c, 265d StGB nimmt am Willen des Gesetzgebers, wie er im entsprechenden Gesetzentwurf zum Ausdruck kommt, ihren Ausgang. Der Gesetzgeber versieht die $\$ \mathbb{S} 265 \mathrm{c}, 265 \mathrm{~d}$ StGB mit einer nahezu einheitlichen Rechtsgutsbestimmung. Geschützt werden die Integrität der erfassten sportlichen Wettbewerbe sowie die Vermögensinteressen bestimmter hierin involvierter Akteure. ${ }^{599}$ Letztere werden tatbestandsspezifisch präzisiert. Im Rahmen des Sportwettbetrugs werden neben den namentlich genannten Anbietern von Sportwetten und den redlichen Wettteilnehmern auch nicht näher bezeichnete sonstige Betroffene in den Kreis der Träger schützenswerter Vermögensinteressen einbezogen. ${ }^{600}$ Durch die von $\$ 265 \mathrm{~d}$ StGB erfassten Manipulationen von berufssportlichen Wettbewerben könnten die am Wettbewerb beteiligten ehrlichen Sportler sowie Sportvereine, Veranstalter und Sponsoren Vermögensschäden erleiden. ${ }^{601} \mathrm{Im}$ Verweis des Gesetzentwurfs auf die Nähe des von $₫ 265 \mathrm{~d}$ StGB geschützten Ausschnitts des hochklassigen Berufssports mit dem strafrechtlich geschützten wirtschaftlichen Wettbewerb $^{602}$ wird teilweise für $\$ 265 \mathrm{~d}$ StGB gar der Rückgriff auf ein zusätzliches, drittes Schutzgut gesehen. ${ }^{603}$

Ein vom Gesetzgeber intendiertes Rangverhältnis zwischen den benannten Schutzgütern der Integrität des Sports und des Vermögens ist dem Gesetzentwurf nicht eindeutig zu entnehmen. In den einschlägigen Abschnitten wird der Integritätsaspekt zwar durchgehend an erster Stelle angeführt. Im unmittelbaren Anschluss und terminologisch durch Gleichrangigkeit indizierende Adverbien angeknüpft („ebenfalls“, „zugleich“) folgt aber stets eine eigenständige Erwähnung der mit dem Sport verbundenen Vermögensinteressen. ${ }^{604}$

Dass gleichwohl der Eindruck entstand, die Integrität des Sports bilde das primäre und vorrangige Schutzgut der Tatbestände, ${ }^{605}$ ist wohl zum

599 BT-Drs. 18/8831, S. 1, $10 \mathrm{ff}$.

600 BT-Drs. 18/8831, S. 15.

601 BT-Drs. 18/8831, S. 10, 20.

602 BT-Drs. 18/8831, S. 11, 20.

603 Rübenstahl JR 2017, 333.

604 BT-Drs. 18/8831, S. 1, 15, 20.

605 In diese Richtung etwa Kubiciel WiJ 2016, 256 (261); ders. SpuRt 2017, 188 (189). 
einen auf die den Gesetzgebungsprozess flankierenden Einlassungen des damaligen Bundesjustizministers Heiko Maas zurückzuführen, die das Gesetz immer wieder dem Schutz des Sports verpflichteten und somit gerade dessen institutionelle Schutzausrichtung betonten. ${ }^{606}$ Zum anderen unterstützt auch der enge zeitliche und sachliche Zusammenhang mit dem Anti-Doping-Gesetz eine solche Deutung. In der öffentlichen Darstellung wurden beide Gesetzeswerke als Ausprägungen einer konzertierten Initiative des Gesetzgebers zur Erhaltung der Integrität des Sports vermittelt. Entsprechend wurde sie neben dem Gesundheitsschutz auch zum zentralen Rechtsgut der Regelungen des Anti-Doping-Gesetzes erklärt. ${ }^{607} \mathrm{Die}$ entsprechende Gesetzesbegründung verweist zwar ebenfalls auf durch dopingbezogene Wettbewerbsverzerrungen potenziell beeinträchtigte finanzielle Interessen. ${ }^{608}$ Diese scheinen allerdings weniger als eigenständige Begründungslinie als vielmehr als ein Bestandteil des übergeordneten und ausfüllungsbedürftigen Schutzguts der Integrität des Sports begriffen zu werden. ${ }^{609}$ Für die $\$ \$ 265$ c, 265d StGB wurde von diesem Verständnis abgewichen. Indem er aus dem Integritätsbegriff herausgelöst und diesem eigenständig an die Seite gestellt wurde, sollte dem Vermögensschutz diesbezüglich offenbar eine hervorgehobene, mindestens gleichrangige legitimatorische Bedeutung zugewiesen werden, die sich auch in der systematischen Verortung der Tatbestände im vermögensschützenden 22. Abschnitt manifestiert. ${ }^{610}$

Die Unterlegung von Straftatbeständen mit einem doppelten Schutzzweck ist im StGB keine Seltenheit. Wie im vorliegenden Fall wird auch andernorts (z.B. beim Kapitalanlagebetrug gemäß $\$ 264 a$ StGB $^{611}$ ) geltend gemacht, eine ein kollektives Rechtsgut beeinträchtigende Verhaltensweise gefährde gleichzeitig ein individuelles Rechtsgut. Eine solche auf die Über-

606 Vgl. Zitatstellen in Rote Karte dem Sportbetrug, Faz.net vom 6.4.2016, www.faz .net/aktuell/sport/sportpolitik/bundesregierung-bringt-gesetz-gegen-wettbetrugauf-den-weg-14163850.html.

$607 \mathrm{Vgl}$. bereits die legaldefinierte Zweckbestimmung in $\$ 1$ AntiDopG; hierzu Erbs/Kohlhaas/Häberle/Wußler $\$ 1$ AntiDopG Rn. 1 ff.; Lehner/Nolte/Putzke/ Nolte AntiDopG $\mathbb{\$} 1$ Rn. 3, 9.

608 BT-Drs. 18/4898, S. 17, 23, 26.

609 Hierzu auch Lehner/Nolte/Putzke/Nolte AntiDopG $₫ 1$ Rn. 44.

610 Vgl. Valerius Jura 2018, 777 (778); ebenfalls von Gleichrangigkeit ausgehend Swoboda/Bohn JuS 2016, 686 (689). Das Vermögen bei $\$ 265$ c StGB hingegen als tendenziell vorrangig geschützt sehen Rübenstabl JR 2017, 264 (269); Schönke/ Schröder/Perron $\$ 265$ c StGB Rn. 2; noch weitergehend (einzig Vermögensschutz) SK-StGB/Hoyer $\$ 265$ c Rn. 5-8.

611 Vgl. LK-StGB/Tiedemann/Vogel \$264a Rn. 22. 
schneidung des Schutzes unterschiedlicher Rechtsgutsarten abstellende Begründung begegnet keinen grundsätzlichen Bedenken. Die Angabe eines die Legitimationsprüfung leitenden Rangverhältnisses ist dabei weder vom Gesetzgeber einzufordern noch aus verschiedenen Rechtsgutskonzeptionen abzuleiten. Vielmehr ist der Schutz beider angeführten Rechtsgüter gleichermaßen als Strafgrund anzusehen und bei der Legitimationsprüfung zu berücksichtigen. ${ }^{612} \mathrm{Ob}$ hieraus folgt, dass eine tatbestandsmäßige Handlung nur im Falle der nachweislichen Gefährdung beider Rechtsgüter bestraft werden darf, ist hingegen eine der Legitimationsprüfung nachgelagerte Frage, die die teleologische Reduktion des Tatbestands im Einzelfall betrifft. ${ }^{613}$

Auf die konkrete gesetzgeberische Begründung der $\$ \$ 265$ c, 265d StGB zurückkommend legt eine auf die Rechtsgutsfrage fokussierte Auswertung der einschlägigen legislatorischen Initiativen der vergangenen zwei Jahrzehnte offen, dass sich insbesondere das nun mit großer Selbstverständlichkeit vorgetragene Schutzgut der Integrität des Sports keineswegs als logische Konsequenz eines Prozesses beschreiben lässt. Die seiner Einführung im Anti-Doping-Gesetz von 2015 vorangehenden zwei Gesetzentwürfe der bayerischen Staatsregierung aus den Jahren 2009 und 2014 stellten zur Rechtfertigung einer Kriminalisierung von Dopingvergehen sowie von Bestechung und Bestechlichkeit im Sport erstmalig auf die Lauterkeit des sportlichen Wettbewerbs, zumindest mittelbar betroffene Vermögensinteressen und letztlich auch explizit auf die Integrität des Sports ab. ${ }^{614}$ Zwar präferierten auch weitere Gesetzentwürfe zu Doping und Sportbetrug eine institutionelle Schutzrichtung. Der dort als Rechtsgut identifizierte sportliche Wettbewerb wurde aber stark am freien wirtschaftlichen Wettbewerb als anerkanntem Schutzgut der $\mathbb{S} 298 \mathrm{ff}$. StGB angelehnt. ${ }^{615}$ Aspekte der

612 Puschke Vorbereitungstatbestände, S. 103.

613 Im konkreten Fall für eine teleologische Reduktion des $\$ 265 \mathrm{c}$ StGB bei Ausschluss einer abstrakten Vermögensgefährdung Rübenstabl JR 2017, 264 (269); aA aufgrund des Vorranges des Integritätsschutzes Kubiciel Wij 2016, 256 (261).

614 Entwurf eines Sportschutzgesetzes vom 30.11.2009, S. 24, 26, www.justiz.bayern .de/media/entwurf_sportschutzgesetz_30112009.pdf; Entwurf eines Gesetzes zum Schutze der Integrität im Sport vom 12.3.2014, S. 43, www.justiz.bayern.de $/ \mathrm{media} / \mathrm{pdf} /$ gesetze/sport.pdf.

615 Entwurf eines Gesetzes zur Verbesserung der strafrechtlichen Dopingbekämpfung der Landesregierung Baden-Württemberg vom 10.4.2013, BR-Drs. 266/13, S. 8, 15 f.; Änderungsantrag der Fraktion Bündnis 90/Die Grünen zum Entwurf eines Gesetzes zur Verbesserung der Bekämpfung des Dopings im Sport vom 4.7.2007, BT-Drs.16/5938, S. 2 f. 
sportlichen Fairness, die nun als prägendes Element der Integrität des Sports angesehen werden, ${ }^{616}$ wurden hingegen ausdrücklich als untaugliches Objekt einer staatlichen Strafgesetzgebung verworfen. ${ }^{617}$ Selbst die für den Erlass von Anti-Doping-Gesetz und der $\$ \$ 265 c$, 265d StGB letztlich verantwortliche Regierungskoalition nahm noch im Jahr 2011 anlässlich einer kleinen Anfrage eine skeptische Haltung gegenüber potenziell schützenswerten Rechtsgütern eines Straftatbestands des Sportbetrugs ein. ${ }^{618}$

\section{b) Wissenschaftliche Rezeption}

Auch in der den Gesetzgebungsprozess begleitenden wissenschaftlichen Literatur hat die Frage nach einem legitimen Rechtsgut eines wettbezogene und sonstige Spielmanipulationen erfassenden Straftatbestandes durchgehend einen besonderen Stellenwert eingenommen. Dabei wurden die vom Gesetzgeber in den zahlreichen Entwürfen vorgegebenen Rechtsgüter nicht nur einer kritischen Bewertung unterzogen, sondern auch durch eigene Vorschläge ergänzt. Überblicksartig soll angeführt werden, welche Belange dabei als eigenständige Rechtsgüter oder zumindest als wesentliche Bestandteile eines übergeordneten Rechtsguts in Betracht gezogen wurden: Fairness bzw. das sportspezifische Fair Play, die Lauterkeit des sportlichen Wettbewerbs, das Vertrauen von Konkurrenten und Zuschauern in die Manipulationsfreiheit spitzensportlicher Wettbewerbe sowie die Glaubwürdigkeit des Sports als Vermittler bedeutender Werte. Über die vom Gesetzgeber festgelegten Rechtsgüter der Integrität des Sports und des Vermögens hinaus stehen somit eine Vielzahl weiterer Interessen und Werte im Raum. Inwiefern sich diese in ihrem jeweiligen Gehalt überschneiden und selbständig oder in kombinierter Form einen Beitrag zur Legitimation der Tatbestände der $\$ \$ 265 \mathrm{c}, 265 \mathrm{~d}$ StGB leisten können, wird im Folgenden eingehend untersucht.

616 BT-Drs 18/4898, S. 26 ff.; BT-Drs. 18/8831, S. 10, 18.

617 Explizit im Achten Gesetz zur Änderung des Arzneimittelgesetzes von 1998, s. BT-Drs. 13/9996, S. 13; dazu Lehner/Nolte/Putzke/Nolte AntiDopG $₫ 1$ Rn. 15; s. ferner Entwurf eines Gesetzes zur Verbesserung der strafrechtlichen Dopingbekämpfung der Landesregierung Baden-Württemberg vom 10.4.2013, BR-Drs. 266/13, S. 7.

618 BT-Drs. 17/6672, S. 5 f.; hierzu auch Reinhart SpuRt 2016, 235 (236); vgl. bereits oben Teil 1 A. 


\section{Integrität des Sports}

Der vom Gesetzgeber vorgenommenen Rechtsgutsbestimmung folgend bildet die Integrität des Sports hierbei den Ausgangspunkt. In einem ersten Schritt wird die allgemeine Bedeutung der Begriffe „Integrität“ und "Sport“ nachvollzogen. Anschließend wird untersucht, inwiefern der Begriff der Integrität als potenzielles Rechtsgut von Tatbeständen bereits an anderen Stellen Einzug ins materielle Strafrecht gehalten hat und sich hierüber ein spezifisch strafrechtliches Begriffsverständnis der Integrität etablieren konnte. Ein solches wäre im Folgenden gerade hinsichtlich des Bezugspunktes Sport zu konkretisieren, wobei der Gesetzentwurf insofern bereits mehrere den Gehalt des Rechtsguts ausfüllende Bestandteile benennt. Diese sind abschließend im Einzelnen und in einer Zusammenschau an den aufgezeigten Anforderungen eines materialisierten Rechtsgutsbegriffs zu messen.

\section{a) Allgemeines Begriffsverständnis}

\section{aa) Integrität}

In Fremdwörterbüchern wird die Begriffsbedeutung von Integrität mit Makellosigkeit, Unbescholtenheit und Unbestechlichkeit angegeben. ${ }^{619}$ Dies entspricht der gängigen Übersetzung des lateinischen Ursprungsworts integritas mit Unversehrtheit, Reinheit. ${ }^{620}$ Darüber hinaus werden als Synonyme Anständigkeit, Ehrlichkeit, Rechtschaffenheit, Redlichkeit, Vertrauenswürdigkeit und Zuverlässigkeit genannt. ${ }^{621}$ Schon die Vielzahl an inhaltlich verwandten Synonymen, die untereinander nur teilweise kongruente Bedeutungsebenen aufweisen, deutet darauf hin, dass es sich bei der Integrität um einen offenen Begriff handelt, der sich kaum auf einen klaren und konsensualen Bedeutungssinn reduzieren lässt. Einerseits lassen die angeführten Synonyme Integrität in erster Linie als persönliche Charaktereigenschaft erscheinen. Auch das dazugehörige Adjektiv „integer" dürfte überwiegend verhaltensbezogen als positives moralisches Werturteil über eine andere Person gebraucht werden, deren Handlungen in Übereinstimmung mit einem allgemein als erstrebenswert erachteten Wer-

619 Duden Fremdwörterbuch, Eintrag: Integrität, die.

620 Pons Online-Wörterbuch, Eintrag: integritas.

621 Duden Online-Wörterbuch, Eintrag: Integrität. 
tekodex stehen (der seinerseits wiederum der näheren Beschreibung bedarf). ${ }^{622}$ Andererseits findet der Begriff offenbar auch als Zustandsbeschreibung eines Gebildes oder Systems Verwendung, etwa wenn im Sinne unverletzlicher Grenzen von der Integrität eines Staates die Rede ist oder im Kontext der Informatik die Vollständigkeit und Fehlerfreiheit von Daten als Datenintegrität bezeichnet wird.

\section{bb) Sport}

Die Schwierigkeit einer juristischen und wissenschaftlichen Definition des Sportbegriffs und ihre in den diversen individuellen Zugängen und daraus resultierenden divergierenden Auffassungen liegenden Ursachen wurden bereits angesprochen. ${ }^{623}$ Selbst wenn man die Organisationsstrukturen sowie die medialen, sozialen und wirtschaftlichen Implikationen ausblendet und den Fokus allein auf das eigentliche Sportgeschehen richtet, verbleibt eine begriffliche Unschärfe. Als einzig unumstrittenes Wesensmerkmal des Sportbegriffs lässt sich der allgemeinen Verkehrsanschauung wohl eine körperliche Ertüchtigung bzw. eigenmotorische Aktivität entnehmen. ${ }^{624}$ Doch auch wenn es nicht mit Kraftentfaltung gleichzusetzen ist, sondern auch körperliche Fähigkeiten wie Ausdauer, Schnelligkeit oder Koordination adressiert, ${ }^{625}$ ruft bereits dieses Erfordernis hinsichtlich des zu fordernden Umfangs umstrittene Grenzfälle hervor, die etwa die Qualifizierung bewegungsarmer Betätigungen wie Schach, Darts, Schießen oder Motorsport betreffen. ${ }^{626}$

Wenngleich sich also bezüglich der Frage nach den Grenzen dessen, was Sport ist, kein allgemeiner Konsens feststellen lässt und in Randbereichen Uneinigkeit verbleibt, eignet sich die Definition des Deutschen Olympischen Sportbundes (DOSB), der sich als Dachverband des deutschen Sports versteht und mit knapp 30 Millionen Mitgliedern einen beträchtlichen Teil der Gesellschaft repräsentiert, noch am ehesten dazu, die diesbezüglich zumindest vorherrschenden gesellschaftlichen Anschauungen abzubilden. ${ }^{627}$ Ihr zufolge hat eine anerkennungsfähige Sportart drei Kriteri-

622 Zur persönlichen Integrität vgl. auch Pollmann Integrität, S. 81, 85.

623 S. oben Teil 3 B. I. 1.

624 Holzhäuser/Bagger/Schenk SpuRt 2016, 94 (97).

625 Wissenschaftliche Dienste des Deutschen Bundestages, WD 10-3000-036/17, Ist E-Sport Sport?, S. 11.

626 PHB-SportR/Reinhart, 3. Aufl., 8. Teil 5. Kap. Rn. 12.

627 Stam NZWiSt 2018, 41 (42); Holzhäuser/Bagger/Schenk SpuRt 2016, 94 (96). 
en zu erfüllen: ${ }^{628}$ Sie muss eine eigene, sportartbestimmende motorische Aktivität eines jeden zum Ziel haben, der sie betreibt. Deren Ausübung muss Selbstzweck der Betätigung sein. Letztlich muss die Sportart die Einhaltung ethischer Werte wie z.B. Fairplay, Chancengleichheit, Unverletzlichkeit der Person und Partnerschaft durch Regeln und/oder ein System von Wettkampf- und Klasseneinteilung gewährleisten. Freilich lässt sich das Abgrenzungspotenzial auch dieser Kriterien in Zweifel ziehen. ${ }^{629}$ Ihre praktische Relevanz, mittelbare Anbindung an den Willen einer großen Mitgliederzahl und fortwährende Erprobung an neu aufkommenden Erscheinungsformen lassen sie dennoch als tauglichste Annäherung an das gesellschaftliche Verständnis des Sportbegriffs erscheinen.

\section{b) Bestehender strafrechtlicher Integritätsschutz}

Insoweit Bedeutungsebenen wie Unbestechlichkeit und Redlichkeit die Integrität nahezu als primäres Angriffsziel von Korruption modellieren, liegt auf der Hand, dass auch das sich zunehmend der Korruptionsbekämpfung widmende Strafrecht den Begriff der Integrität in Rechtsgutsüberlegungen aufgreift. Tatsächlich finden sich im erweiterten Korruptionsstrafrecht Tatbestände, deren Zweck der Gesetzgeber explizit mit Integritätsschutz umschreibt.

So sollen die Bestechlichkeit und Bestechung im Gesundheitswesen gemäß $\int \$ 299 \mathrm{aff}$. StGB den lauteren Wettbewerb im Gesundheitswesen sowie das Vertrauen von Patienten in die Integrität heilberuflicher Entscheidungen schützen. ${ }^{630}$ Der Eindruck eines der Käuflichkeit unverdächtigen Gesundheitssystems und einer finanziell unabhängigen, allein am Wohl des Patienten orientierten ärztlichen Beratung sei Voraussetzung dafür, dass Patienten medizinisch indizierte Behandlungen unbefangen wahrneh-

628 Vgl. $\$ 3$ Aufnahmeordnung des DOSB vom 20. Mai 2006.

629 Neben den erwähnten Bedenken hinsichtlich einer ausreichenden motorischen Aktivität einiger vom DOSB anerkannter Sportarten wie Dart, Billard oder Schach stellt sich auch die Frage, wie sich das ursprünglich der Welt des Amateursports entlehnte Erfordernis der zweckfreien sportlichen Betätigung mit der zunehmenden Professionalisierung und aufkommenden Erscheinungsform von Berufssportlern verträgt, vgl. Ketteler SpuRt 1997, 73 (75); Adolphsen/Nolte/ Lehner/Gerlinger/Rössner/Adolphsen Kap. 1 Rn. $4 \mathrm{f}$.

630 BT-Drs. 18/6446, S. 12; Fischer StGB \$299a Rn. 3; NK-StGB/Dannecker/Schröder $\$ 299$ a Rn. $30 \mathrm{ff}$. 
men. ${ }^{631}$ In dieser Konzeption dient Integrität nicht nur der Absicherung eines regelgeleiteten, von korruptiven Verzerrungen unbeeinträchtigten Leistungswettbewerbs, sondern auch als Objekt eines kollektiven Vertrauens. ${ }^{632}$

In ähnlicher Weise wird bei der Abgeordnetenbestechung gemäß $₫ 108 \mathrm{e}$ StGB argumentiert. Mit der Neufassung des Tatbestands ging auch eine Erweiterung des geschützten Rechtsguts einher, das nicht mehr nur die Sachlichkeit von Abstimmungen umschließt, sondern darüber hinaus im öffentlichen Interesse an der Integrität parlamentarischer Prozesse bestehen soll. ${ }^{633}$ Schon der Anschein, gewählte Mandatsträger würden sich infolge intransparenter Zuwendungen für demokratisch nicht legitimierte Partikularinteressen einsetzen, gefährde den demokratischen Rechtsstaat. ${ }^{634}$ Umstritten ist dabei, ob auch dieser Rechtsgutsbestimmung eine Vertrauensschutzkomponente innewohnt. Dafür spricht, dass eine grundlegende Krise des repräsentativen Systems in erster Linie durch das Sich-Abwenden einer enttäuschten und argwöhnischen Bevölkerung ausgelöst werden kann. In diesem Sinne erachtete der Gesetzgeber noch im Entwurf zu $\$ 108 \mathrm{e}$ StGB aF das öffentliche Vertrauen als Schutzzweck und erfährt hierfür auch nach Neufassung des Tatbestandes Zustimmung. ${ }^{635}$ Entgegen getreten wird dieser Position durch den Hinweis, eine Einzeltat i.S.d. $\$ 108 \mathrm{e}$ StGB sei schon nicht in der Lage, das Allgemeinvertrauen in einem Aus$\mathrm{maß}$ zu erschüttern, das den Staat selbst gefährde. ${ }^{636}$

Im Kernbereich der Korruptionsdelikte ( $\$ 299$ StGB bzw. $\mathbb{S} 331 \mathrm{ff}$. StGB) wird in unterschiedlichem Umfang auf Integritätsschutz rekurriert. Die Diskussion über das von $\$ 299$ StGB geschützte Rechtsgut verläuft selbst bei Beschränkung auf die wettbewerbsbezogene Tatbestandsalternative (Abs. 1 Nr. 1 bzw. Abs. 2 Nr. 2) vielstimmig. Die Vorschläge reichen

631 BT-Drs. 18/6446, S. 12 f.

632 Krit. hierzu Achenbach/Ransiek/Rönnau/Rönnau/Wegner Teil 3 Kapitel 3 Rn. 26; andere erkennen nach dem nachträglichen Verzicht auf eine Pflichtverletzungsvariante in $\$ 299$ a StGB nur den Schutz des Leistungswettbewerbs als Rechtsgut an, während die Vertrauenskomponente allein den Grund für die Schaffung dieses Sondertatbestandes darstelle, vgl. Dann/Scholz NJW 2016, 2077 f.; Lackner/Kühl/Heger/Heger \$299a Rn. 1.

633 BT-Drs. 18/476, S. 6; vgl. Matt/Renzikowski/Sinner $\$ 108$ e Rn. 3; Fischer StGB \$108e Rn. 2.

634 MüKo-StGB/Müller $\$ 108$ e Rn. 1.

635 BT-Drs. 12/5927, S. 4; Lackner/Kühl/Heger/Kühl $₫ 108$ e Rn. 1a; Schönke/Schröder/Eser $₫ 108$ e Rn. 1.

636 NK-StGB/Kargl \$108e Rn. 6; Matt/Renzikowski/Sinner $\$ 108$ e StGB Rn. 2. 
vom Vermögen der Mitbewerber des Bestechenden ${ }^{637}$ über die gegenüber dem Geschäftsherrn bestehenden schuldrechtlichen Pflichten ${ }^{638}$ und das Vertrauen der Allgemeinheit in die Nichtkäuflichkeit übertragener Entscheidungen ${ }^{639}$ bis hin zum lauteren, freien Wettbewerb ${ }^{640}$. Letzterer soll sowohl die Geschäftsinteressen der Mitbewerber als auch das Interesse des Geschäftsherrn als auch das Interesse der Allgemeinheit an der Sicherung des freien Wettbewerbs für die Gesellschaft als Ganzes in sich vereinen. ${ }^{641}$ Eine explizite Erwähnung der Integrität findet sich dabei jedoch weder in Gesetzgebungsmaterialien noch in einschlägigen Publikationen. Anders verhält sich dies im Rahmen der $\$ \$ 331 \mathrm{ff}$. StGB. Wenngleich sich auch bei den Korruptionsdelikten im öffentlichen Sektor noch keine unumstrittene Rechtsgutsbestimmung herausgebildet hat, wird sich überwiegend für einen institutionellen Schutz im Sinne der Integrität der öffentlichen Verwaltung ausgesprochen. ${ }^{642}$ Dass der Tatbestand des $₫ 331$ StGB dabei auch Belohnungen unter Strafe stellt, die die Amtsausübung gar nicht tatsächlich beeinflussen, wird wiederum mit dem mitgeschützten Vertrauen der Bevölkerung in die Reinheit des öffentlichen Dienstes begründet, die schon die Unterbindung des bloßen Anscheins verlange. ${ }^{643}$

Die von Korruptionsdelikten losgelöste strafrechtliche Verankerung des Integritätsschutzes belegen einzelne Tatbestände des Nebenstrafrechts. Die strafbewehrten Verbote des Insiderhandels und der Marktmanipulation in $\$ 119$ WpHG sollen einheitlich die Integrität der Finanzmärkte sicherstellen und das Vertrauen der Anleger in diese Märkte stärken. ${ }^{644}$ Marktintegrität setze dabei allein vom unbeeinflussten Verhältnis von Angebot und Nachfrage gebildete Preise voraus und vermittle die relative Vorteilhaftig-

637 Maurach/Schroeder/Maiwald Strafrecht BT II, $\$ 68$ Rn. 2; Pieth ZStW 109, 756 (773).

638 Szebrowski Kick-Back, S. 170; Jacques Bestechungstatbestände, S. 116.

639 Pragal Privater Sektor, S. 112 ff., 164, 230.

640 HM, vgl. LK-StGB/Tiedemann vor $\$ 298$ Rn. 5; Lackner/Kühl/Heger/Heger $\$ 299$ Rn. 1; MüKo-StGB/Krick $\$ 299$ Rn. 15; Schönke/Schröder/Heine/Eisele $\$ 299$ Rn. 3.

641 MüKo-StGB/Krick $\$ 299$ Rn. 15; Tiedemann Wirtschaftsstrafrecht Rn. 822; abl. Szebrowski Kick-Back, S. 163, 170; Pragal ZIS 2006, 63 (69 f.).

642 BGHSt 47, 295 (303); 49, 275 (283); Fischer StGB $₫ 331$ Rn. 2; LK-StGB/Sowada Vor $₫ 331$ Rn. 37 .

643 NK-StGB/Kublen $\$ 331$ Rn. 13.

644 Erwägungsgrund 12 der Marktmissbrauchsrichtlinie 2003/6/EG, ABl. EG Nr. L 96 vom 12.4.2003, S. 16; vgl. Tiedemann Wirtschaftsstrafrecht Rn. 1041; Schröder Kapitalmarktstrafrecht Rn. 109; krit. zum Gesichtspunkt des Systemvertrauens Beckemper ZIS 2011, 318; Graf/Jäger/Wittig/Diversy/Köpferl \$38 WpHG Rn. 6. 
keit einer Kapitalanlage. ${ }^{645}$ Sie verbürge die Chancengleichheit der Marktteilnehmer, die einen funktionsfähigen Wertpapiermarkt konstituiert und durch die unrechtmäßige Verwendung von Insiderinformationen bzw. eine manipulierte Preisbildung torpediert würde. ${ }^{646}$ Insoweit wird aber nicht der Anspruch des Einzelnen auf Chancengleichheit geschützt, ebenso wenig wie - noch konkreter - dessen Vermögen, sondern die Chancengleichheit als idealtypische Voraussetzung im Sinne des Markts. ${ }^{647}$

Der Überblick zeigt, dass der Begriff der Integrität strafrechtsdogmatisch aufgegriffen und insbesondere im Zusammenhang mit Korruptionsdelikten Eingang in die Rechtsgutsdiskussion gefunden hat. Die oben aufgezeigte Bedeutungsvielfalt aufnehmend lassen sich aus den dargestellten Deliktsbereichen einige strukturelle Merkmale des strafrechtlichen Integritätsverständnisses ableiten: Integrität wird offenbar nicht primär als individuelle Unbestechlichkeit oder persönliche Redlichkeit verstanden, sondern auf größere gesellschaftliche Teilsysteme bezogen (Gesundheitswesen, Volksvertretung, Kapitalmarkt). Die hierin agierenden Akteure haben sich konform mit den das Teilsystem prägenden Regeln zu verhalten und diesen widersprechende Vorteile auszuschlagen. Für den Einsatz des Strafrechts maßgeblich sollen aber weniger die individuelle moralische Nachlässigkeit oder hierdurch ausgelöste konkrete Schädigungen von Konkurrenten sein als vielmehr der durch kumuliertes Fehlverhalten befürchtete Ansehensverlust der Institution als solcher. Denn er könne ihre als gesamtgesellschaftlich wertvoll erachtete Funktionsfähigkeit gefährden. In der Dichotomie der Rechtsgutsklassifizierung ist eine so verstandene Institutionen-Integrität den kollektiven Rechtsgütern zuzuweisen.

Es fällt auf, dass die Integrität als Rechtsgut offenbar zunehmend an Bedeutung gewinnt. Jüngst neu geschaffene Tatbestände wie die $\mathbb{S}$ 299a ff. StGB, die $\$ 1 \mathrm{ff}$. AntiDopG oder eben die $\$ \$ 265 \mathrm{c}$, 265d StGB werden direkt auf den Integritätsschutz gestützt. In der reformierten Neufassung des $\$ 108$ e StGB wird dieser nun in den Vordergrund gerückt, während vormals andere Schutzgüter akzentuiert wurden. Auch der Referentenentwurf zur Neufassung des $\$ 261$ StGB rekurriert in Übereinstimmung mit der umzusetzenden EU-Richtlinie 2018/1673 zur Begründung der Strafbarkeit von Geldwäsche nun nicht mehr auf die Rechtspflege, sondern auf die In-

645 Graf/Jäger/Wittig/Diversy/Köpferl $\$ 38$ WpHG Rn. 5.

646 MüKo-StGB/Pananis $\$ 119$ WpHG Rn. 5 f.

647 MüKo-StGB/Pananis $\$ 119$ WpHG Rn. 6 f. Die Chancengleichheit wird dabei gerade als wichtiges Element der Vertrauenswürdigkeit ausgemacht, s. Schröder Kapitalmarktstrafrecht Rn. 109. 
tegrität des Finanzsektors. ${ }^{648}$ Bemerkenswerterweise zeigt sich der praxisrelevanteste Korruptionstatbestand des $\$ 299$ StGB von dieser Tendenz noch unbeeindruckt. Weder in Einlassungen des Gesetzgebers noch in der Kommentarliteratur finden sich rechtsgutsbezogene Rückgriffe auf den Begriff der Integrität. Stattdessen rückt die herrschende Meinung insbesondere bei der Wettbewerbsvariante des $\$ 299$ Abs. 1 Nr. 1, Abs. 2 Nr. 1 StGB die Lauterkeit des Wettbewerbs in den Fokus der Rechtsgutsdiskussion. ${ }^{649}$

Aus dieser begrifflichen Abgrenzung lassen sich Rückschlüsse auf das strafrechtliche Integritätsverständnis ziehen. So beschränkt sich der Begriff der Lauterkeit eher auf die Absicherung eines regelgeleiteten Wettbewerbs, in dem den Konkurrenten zunächst einmal die gleichen Ausgangschancen zuzugestehen sind und lediglich systemimmanente Vorteile gezogen werden sollen. Integrität hingegen enthält zusätzlich eine ethische Konnotation, eine moralische Erwartungshaltung an die adressierten Akteure. Dies spiegelt sich auch darin wieder, dass sie als Rechtsgut mit dem Gesundheitswesen, dem parlamentarischen Meinungsbildungsprozess und der öffentlichen Verwaltung gerade solche Teilbereiche überdachen soll, deren Vertreter sich einem spezifischen Berufsethos ausgesetzt sehen, das sie in Form von Eidesleistungen auch für sich persönlich anerkennen. Während die öffentliche Meinung im allgemeinen wirtschaftlichen Wettbewerb bis zu einem gewissen Grad auch eigennützige Praktiken hinnimmt, formuliert sie an die besagten Berufsgruppen strengere Verhaltensanforderungen, die sich teilweise durch ein Verhältnis des Anvertraut-Seins, teilweise durch eine ausgeübte Repräsentantenfunktion erklären. Hierzu passt, dass auch im Rahmen der Sonderdelikte der Verletzung von Privatgeheimnis-

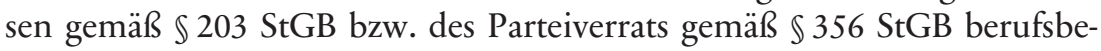
zogen auf Integritätsaspekte abgestellt wird. ${ }^{650}$ Kaum verwunderlich wird dem institutionellen Integritätsverständnis nahezu ausnahmslos eine Vertrauenskomponente an die Seite gestellt, die in Form eines Systemvertrauens teilweise als eigenständiges Rechtsgut begriffen wird. ${ }^{651}$

648 Referentenentwurf des Bundesministeriums für Justiz und Verbraucherschutz zur Verbesserung der strafrechtlichen Bekämpfung von Geldwäsche vom 11.8.2020, S. 10, www.bmjv.de/SharedDocs/Gesetzgebungsverfahren/Dokument e/RefE_Geldwaesche_Bekaempfung.pdf?_blob=publicationFile\&v=1.

649 Lackner/Kühl/Heger/Heger \$299 Rn. 1; MüKo-StGB/Krick $\$ 299$ Rn. 15; Schönke/Schröder/Eisele \$299 StGB Rn. 3; NK-StGB/Dannecker \$299 Rn. 9.

650 Jansen GA 2017, 600 (609); zu $\$ 356$ StGB LK-StGB/Gillmeister 3356 Rn. 9; Lackner/Kühl/Heger/Heger $\$ 356$ Rn. 1.

651 Näher zu dieser s. unten Teil 3 B. II. 2. d) cc) (1). 
c) Die spezifische Konkretisierung der Integrität des Sports als strafrechtlich zu schützendes Rechtsgut durch den Gesetzgeber

Dieses zur Kriminalisierung bereichsspezifischer Korruptionserscheinungen geformte Integritätsstrafrecht wird durch die Strafvorschriften des AntiDopG sowie die $\$ \$ 265$ c, 265d StGB auf den Sport ausgedehnt. Soweit die kursorische Analyse der Integritätsschutz bezweckenden Strafnormen die Integrität als ein ausfüllungsbedürftiges Rechtsgut ausgewiesen hat, verpflichtet dies den Gesetzgeber zur Konkretisierung für den jeweils als schützenswert erklärten gesellschaftlichen Teilbereich. Für den Sport rekurriert er dabei auf die Unverfälschtheit und Authentizität des sportlichen Kräftemessens, die von großer Bedeutung für die immense gesellschaftliche und wirtschaftliche Wirkkraft des Sports seien. ${ }^{652}$ Nur wenn Sportler unter Einhaltung der sportartspezifischen Regeln und unter Beachtung des Gebotes der Fairness aufrichtig nach dem Sieg strebten, blieben die Wettbewerbe glaubwürdig und unvorhersehbar und bewahrten ihre Attraktivität und Faszination, die den Sport zu einem herausragenden Wirtschaftsfaktor werden ließen und ihn befähigten, seine vorbildhaften Werte wie Fairness, Leistungsbereitschaft, Toleranz und Teamgeist tief in die Gesellschaft hineinzutragen. ${ }^{653}$

Diese Beschreibung fügt sich nahtlos in das gesetzgeberische Verständnis einer strafrechtlich schützenswerten Bereichsintegrität ein. Deren allgemeines Kennzeichen eines unmittelbar zunächst nur bestimmte Akteure bindenden ethischen Verhaltensmaßstabs, dessen Einhaltung aufgrund einer breiten Anteilnahme oder Betroffenheit der Bevölkerung jedoch auch gesamtgesellschaftlich wertvolle Funktionseinheiten des Teilbereichs begründet, soll im Sport in besonderer Weise seine Ausprägung finden. Der die Integrität des Sports nach Ansicht des Gesetzgebers charakterisierende Wirkungszusammenhang von authentischen sportlichen Wettbewerben und ihrer sozialen Relevanz ist näher zu betrachten, bevor er an den Kriterien eines Rechtsgutsbegriffs gemessen werden kann. Dabei ist angesichts der insoweit konstatierten begrifflichen Unschärfe zunächst zu ermitteln, von welchen konkreten Umrissen des zu schützenden Bereichs der Gesetzgeber ausgeht, wenn er ohne nähere Eingrenzungen schlicht den Sport als Träger einer systemimmanenten Integrität benennt. Eine Frage, die natürlich auch die tatbestandliche Reichweite der $\$ \mathbb{S} 265 \mathrm{c}, 265 \mathrm{~d}$ StGB bestimmt. Innerhalb dieser Umrisse sind sodann in ausführlicher

652 BT-Drs. 18/8831, S. 10.

653 BT-Drs. 18/8831, S. 10. 
Auswertung und Ergänzung des Gesetzentwurfs der sportethische Wertekodex sowie die gesamtgesellschaftliche Bedeutung des Sports als die gesetzgeberischen Prämissen einer strafrechtlich schützenswerten Integrität zu charakterisieren.

\section{aa) Der zugrunde gelegte Sportbegriff}

Der Vielzahl an vertretenen Sportdefinitionen fügt der Gesetzentwurf zu den $\$ \$ 265 c$, 265d StGB keine eigene hinzu. Er greift aber auch auf keine existente zurück, was sich im Falle wissenschaftlich entwickelter Begriffsklärungen wohl mit der sie umgebenden Uneinigkeit, im Falle vereinzelt auch gerichtlich entwickelter Begriffsklärungen mit ihrer Ausformung auBerhalb des strafrechtlichen Kontextes erklärt. ${ }^{654}$ Vielmehr bemüht er sich um eine möglichst enge Ausrichtung am oben skizzierten allgemeinen gesellschaftlichen Sportverständnis, indem er darauf verweist, dass „es sich bei dem Begriff Sport um einen umgangssprachlichen, weltweit gebrauchten Begriff [handelt], der keine eindeutige begriffliche Abgrenzung zulässt“655 und Zuordnungen daher gemäß den ,jeweils herrschenden Anschauungen innerhalb der Gesellschaft" ${ }^{\star 656}$ vornehmen will. Die hiermit einhergehende Unbestimmtheit versucht er mittels eines Rückgriffs auf die Sportdefinitionen und hierauf basierende Anerkennungsentscheidungen nationaler und internationaler Sportverbände einzugrenzen, in denen er einen gewichtigen Indikator für die Reichweite des aktuellen Sportverständnisses erblickt. Ob er den Tatbeständen hiermit allerdings ein rein formales Sportverständnis unterlegt und die Definitionskompetenz dem DOSB bzw. IOC überträgt, was angesichts des Gesetzesvorbehalts problematisch wäre, ${ }^{657}$ bleibt unklar. Einem derartigen Vorwurf entzieht er sich

654 So gilt die Förderung des Sports gemäß $₫ 52$ Abs. 2 AO als gemeinnütziger und steuerbegünstigter Vereinszweck. Nach dem sich daher regelmäßig mit dem Sportbegriff beschäftigenden Bundesfinanzhof (BFH) umfasst er nur Betätigungen, die der körperlichen Ertüchtigung dienen, wobei eine körperliche, über das ansonsten übliche Maß hinausgehende Aktivität vorauszusetzen ist, die durch äußerlich zu beobachtende Anstrengungen oder durch die einem persönlichen Können zurechenbare Kunstbewegung gekennzeichnet ist, BFH, Urteil v. 9.2.2017, V R 69/14, Nr. 28; explizit zur Abgrenzung von Sport und Spiel auch BVerwG NVwZ 2005, 961.

655 BT-Drs. 18/8831, S. 19.

656 BT-Drs. 18/8831, S. 19.

657 Krit. gegenüber der Entscheidungsmacht eines privaten Dachverbandes über den Anwendungsbereich einer Strafvorschrift Valerius Jura 2018, 777 (783). 
zwar durch die Bezeichnung der sportverbandlichen Entscheidungen als bloßem Anhaltspunkt. Die hierdurch nahegelegte Existenz weiterer Kriterien, deren Vorliegen auch von Spitzenverbänden bisher nicht anerkannte Betätigungen in den strafrechtlichen Schutzbereich befördern könnten, wird allerdings nicht näher ausgeführt. 658

Die mit der Intention eines möglichst entwicklungsoffenen Begriffsverständnisses einhergehende Unsicherheit bezüglich der Weite des Anwendungsbereiches zeigt sich am Beispiel der umstrittenen Frage, ob der Gesetzgeber etwa auch die Integrität des sog. eSports (elektronischer Sport) für schützenswert hält. Das rasante Wachstum dieser Branche, die alle Formen des Wettkampfs zwischen Menschen unter virtueller Hinzunahme von Computerspielen erfasst, und die Meldungen über Manipulationen von mit hohen Preisgeldern dotierten Turnieren verleihen ihr durchaus praktische Relevanz. ${ }^{659}$ Von Seiten der Sportverbände bleibt dem eSport die Anerkennung gegenwärtig noch versagt. ${ }^{660}$ Die Definitionsmerkmale einer gewissen motorischen Aktivität und der Gewährleistung universeller Werte wie Respekt und Unverletzlichkeit der Person werden angesichts der durch bloße Fingerbewegung und ausschließlich im Sitzen verübten Tätigkeit sowie der mitunter expliziten Gewaltdarstellungen in den eSportSpielen in Abrede gestellt. ${ }^{661}$ Gleichzeitig beschreibt eSport ein nach wie vor junges Phänomen, das den sich professionalisierenden Spielern zunehmend körperliche Anstrengungen abverlangt, die kaum hinter denjenigen gewisser anerkannter Sportarten zurückbleiben. So bereiten sich professionelle Spieler etwa mit täglichem Krafttraining für den Rücken auf die stundenlangen Matches vor, die neben langen Konzentrationsphasen und strategischem Geschick auch eine Auge-Hand-Koordination erfordern, die aufgrund der über 400 pro Minute in das Gamepad einzugebenden Befehle komplexer ausfällt als bei einem hochklassigen Tischtennisspiel und zur Ausschüttung von Stresshormonen führt, deren Umfang demjenigen von

658 Krit. auch Stam NZWiSt 2018, 41 (42); Valerius Jura 2018, 777 (783); Rübenstabl JR 2017, 264 (275); Satzger Jura 2016, 1142 (1148); Pfister StraFo 2016, 441 (443 f.).

659 Perron JuS 2020, 809 (811); Kubiciel ZRP 2019, 200 ff.; Schörner HRRS 2017, 407 (408); Satzger Jura 2016, 1142 (1148).

660 Das entsprechende Positionspapier des DOSB zusammenfassend PHB-SportR/ Summerer 5. Kap. Rn. 293.

661 Wissenschaftlicher Parlamentsdienst des Abgeordnetenhauses von Berlin, Gutachten über die Voraussetzungen und Auswirkungen der Anerkennung von eSport als Sportart vom 18.3.2016, S. 14 f. 
Rennfahrern entspricht. ${ }^{662}$ Misst man der Anerkennung durch den DOSB lediglich eine widerlegbare Indizwirkung für den $\$ \$ 265$ c, 265d StGB zugrunde gelegten Sportbegriff bei, ist die Einbeziehung des eSports unter Verweis auf dessen physische und mentale Anforderungen, der Ausgestaltung des Leistungsvergleichs in einem Ligensystem und dessen zunehmender Präsenz gerade in Online-Medien künftig nicht ausgeschlossen. ${ }^{663}$

Fehlt es demnach an einer trennscharfen materiellen Begriffsbestimmung, ergeben sich Einschränkungen des Schutzbereiches aus formal eingezogenen Grenzen. Gegenstand der Manipulationsabsprache in $\$ 265 \mathrm{c}$ StGB hat ein Wettbewerb des organisierten Sports zu sein, der den Bezugspunkt einer angebotenen Sportwette darstellt. In $\$ 265 \mathrm{~d}$ StGB wird gar ein berufssportlicher Wettbewerb verlangt, an dem überwiegend Sportler teilnehmen, die durch ihre sportliche Betätigung unmittelbar oder mittelbar Einnahmen von erheblichem Umfang erzielen. Um eine Überkriminalisierung zu vermeiden, wird also unter Ausschluss des Breitensports ein Ausschnitt des Sports in den Blick genommen, der sich durch einen gewissen Organisierungs- und Professionalisierungsgrad kennzeichnet. ${ }^{664} \mathrm{Ob}$ die gesetzliche Integration des Sportbegriffs insgesamt mit den Anforderungen des Bestimmtheitsgrundsatzes zu vereinbaren ist, wird an späterer Stelle zu untersuchen sein. ${ }^{665}$ Die Beschreibung einer systemimmanenten Integrität hat jedenfalls gerade an den Merkmalen und Besonderheiten eines stärker formal als materiell eingegrenzten Sportbegriffs anzuknüpfen.

662 Holzhäuser/Bagger/Schenk SpuRt 2016, 94 (96f.), die in der Folge auch für eine Anerkennung des E-Sports als Sport streiten; für eine differenzierte Betrachtung PHB-SportR/Summerer 5. Kap. Rn. 297 f.

663 Die Einbeziehung befürwortend Schörner HRRS 2017, 407 (413); auch Kubiciel ZRP 2019, 200 (202), der jedoch zutreffend darauf hinweist, dass angesichts der überwiegenden Organisation von eSport-Turnieren durch Spielehersteller oder andere Unternehmen und eben nicht durch Bundesverbände oder internationale Sportorganisationen mit Blick auf die Voraussetzungen eines berufssportlichen Wettbewebrs nach $\$ 265$ d Abs. 5 StGB Folgefragen zu klären wären; ausführlich zum Abgleich des eSports mit den organisatorischen Anforderungen der Tatbestände ferner Jaleesi Kriminalisierung, S. $170 \mathrm{ff}$.

664 Wenngleich bei $\$ 265 \mathrm{c}$ StGB angesichts des ausgedehnten Markts für Sportwetten auch regionale und Jugendligen sowie gewisse Amateurwettbewerbe zu diesem zu rechnen sind, vgl. BT-Drs. 18/8831, S. 19.

665 S. unten Teil 3 D. I. 1. 
bb) Anknüpfungspunkt und Wirkungszusammenhang der sportspezifischen Integrität

Die in Gesetzentwurf und begleitender Literatur vorgenommene Konstruktion der sportspezifischen Integrität erfolgt im Einklang mit den auf einer abstrakten Ebene identifizierten Wesensmerkmalen strafrechtlicher Integritätsbestimmung. Als ein das Wettbewerbsverhalten der Akteure einrahmender und prägender Kodex positiver Werte wird das Sportethos als Kern des Schutzgegenstandes ausgemacht. Dessen die Grenzen des Teilbereichs übertretende, gesamtgesellschaftliche Wirkmacht wird mit einer breiten ideellen Strahlkraft und einer zunehmenden wirtschaftlichen Bedeutung des hochklassigen Leistungssports begründet. Basiert die Rechtsgutskonzeption der Integrität des Sports demnach auf den gesamtgesellschaftlichen Auswirkungen eines bereichsspezifischen Verhaltensmaßstabs, sind der Gehalt des Sportethos und der Umfang der gesellschaftlichen und wirtschaftlichen Relevanz des Sports näher zu beleuchten.

\section{(1) Das Sportethos als spezifischer Wertekodex}

Über die sportartspezifischen und von Verbänden autonom gesetzten Regelwerke hinausgehend wird ein den Sport insgesamt überwölbendes Ethos identifiziert, das universell gültige Werte umfasst und entsprechende Verhaltenserwartungen an die Sportler richtet. Dieses Ethos des Sports knüpft zunächst an der seit seinen Anfängen im antiken Griechenland tradierten Idealvorstellung eines regelgeleiteten und authentischen Wettkampfes an. Sie beruht auf der Unverfälschtheit und Authentizität sportlicher Wettbewerbe, bei denen sich die Teilnehmer unter Einhaltung der sportartspezifischen Regeln untereinander messen und bei denen derjenige gewinnt, der die beste Leistung erbringt. ${ }^{666}$ Sinnstiftende Wesensmerkmale des sportlichen Wettkampfes sind somit die Chancengleichheit und Leistungsbereitschaft der Teilnehmer, die situationsbedingte und authentische Spontanität ihrer Handlungen und die Ungewissheit hinsichtlich des Ausgangs ihres Kräftemessens. ${ }^{667}$

Die Realisierung eines integren Wettbewerbs verlangt eine bestimmte sittliche Geisteshaltung der teilnehmenden Sportler. Bei aller gebotenen

666 BT-Drs. 18/8831, S. 10.

667 Hutz/Kaiser NZWiSt 2013, 379 (383); Schürmann, in: Asmuth (Hrsg.), Entgrenzungen, 2012, S. 75 (84); Rössner FS Mehle, 2009, 567 (569). 
Einsatzbereitschaft haben sie die Grundbedingungen und Regeln des Wettkampfes zu respektieren und sich gegenüber ihren Konkurrenten aber auch gegenüber der Sportart als solcher tolerant und im Sinne des Gebots der Fairness zu verhalten. ${ }^{668}$ Die erwartete charakterliche Einstellung wird dabei häufig auch mit Sportsgeist oder Ritterlichkeit umschrieben ${ }^{669}$ und findet ihren Ausdruck etwa in Präambeln sportinterner Regelwerke ${ }^{670}$ bzw. der Olympic Charta des IOC, die als eine Ausprägung der Menschenrechtserklärung im Bereich des Sports verstanden wird und Fairness zum intrinsischen Maß des olympischen Sports erklärt. ${ }^{671}$

Bei einem Vergleich der beiden jüngst erlassenen sportbezogenen Strafgesetze fällt auf, dass der Gesetzgeber je nach der konkret pönalisierten Verhaltensweise und ihrer potenziellen Angriffsrichtung auf die Integrität des Sports unterschiedliche Elemente des Sportethos akzentuiert. So wurde bei der Rechtfertigung des Verbots des Selbstdopings maßgeblich auf die Chancengleichheit als Grundlage des Sports abgestellt, die durch den Versuch, die Konkurrenten durch die Einnahme verbotener leistungssteigernder Präparate zu übervorteilen, torpediert werde. ${ }^{672}$ Als ethisch-moralischer Wert des sportlichen Kräftemessens und gleichsam interessensausgleichendes Strukturmerkmal eines wirtschaftlichen Wettbewerbs wurde ihr eine wichtige Doppelfunktion zugewiesen. ${ }^{673}$

In der Gesetzesbegründung der $\$ \mathbb{S} 265 \mathrm{c}$, 265d StGB spielt dieser Aspekt hingegen eine untergeordnete Rolle. Die tatbestandsmäßigen Wettbewerbsverzerrungen erfolgen hier zugunsten des Wettbewerbsgegners. Die Reduzierung der Siegchancen trifft also den Manipulierenden selbst, der sich damit abfindet. In Teamsportarten werden natürlich auch nicht eingeweihte Teamkollegen in ihren Ambitionen beeinträchtigt. Dennoch findet die Chancengleichheit im Gesetzentwurf lediglich im Zusammenhang mit dem Pflichtenprogramm der gemäß $₫ 265$ c Abs. 3 StGB als Täter infrage

668 Vgl. Gienger DRiZ 2016, 16; Jansen GA 2017, 600 (603); Kargl NStZ 2007, 489 (494).

669 Schlöter Doping S. 253; Lenk, in: Maring (Hrsg.), Bereichsethiken, 2014, S. 301 (302); Jahn ZIS 2006, 57 (58).

670 Z.B. Präambel zum Welt-Anti-Doping-Code (WADC), S. 3, www.wada-ama.org /sites/default/files/resources/files/2015-wadc-final-de.pdf.

671 Vgl. $\$ 4$ Fundamental Principles, Olympic Charter; s. dazu auch Schürmann, in: Asmuth (Hrsg.), Entgrenzungen, 2012, S. 75 (83 ff.); Vieweg/Staschik SpuRt 2013, 227.

672 Vgl. $\$ 1$ AntiDopG; BT-Drs. 18/4898, S. 1, 17, 22.

673 BT-Drs. 18/4898, S. 17. 
kommenden Schieds- und Wertungsrichter Erwähnung. ${ }^{674}$ An ihrer statt werden die sportethischen Werte Fairness, Leistungsbereitschaft und sportliches Gewinnstreben besonders hervorgehoben. ${ }^{675}$

(2) Die gesamtgesellschaftliche Bedeutung des Sports als Wertevermittler

Entscheidend für den durch die Rechtsgutsbestimmung bezweckten Institutionenschutz ist jedoch nicht der sportethische Verhaltenskodex als solcher, sondern dessen Einbettung. Denn er wirkt nicht nur im abgeschlossenen System des sportlichen Wettbewerbs und soll dort die sportbezogenen Chancen der Teilnehmer und die finanziellen Interessen der investierenden Sponsoren und Förderer absichern, sondern strahlt auf vielfältige Weise in die Gesellschaft aus. Grund dafür ist die immense und schichtübergreifende Bedeutung des Sports, der sowohl als eigenes Betätigungsfeld als auch als konsumierter Medieninhalt verschiedene soziale Funktionen ausübt.

Der gesellschaftliche Stellenwert des Sports wird von den folgenden Kennzahlen eindrucksvoll verdeutlicht: Im Jahr 2020 waren deutschlandweit 27.838.830 Mitglieder in knapp 90.000 Sportvereinen organisiert. ${ }^{676}$ Damit sind rund $33 \%$ der Bevölkerung Deutschlands Mitglied in Sportvereinen. Unter den übrigen zwei Dritteln wird sich wiederum ein beträchtlicher Teil in Fitnessstudios, im (Hoch)Schul- oder Firmensport, in privaten Gruppen oder alleine sportlich betätigen. Für das Jahr 2015 gab mehr als die Hälfte der Bevölkerung in Deutschland an, mindestens einmal pro Woche Sport zu treiben; der Anteil der zumindest gelegentlich sportlich Aktiven betrug 81,6\%. ${ }^{677}$ Hinzu kommt das ehrenamtliche Engagement in den Sportvereinen, das 2014 einen Umfang von 1,7 Millionen Positionen bei einer durchschnittlichen Arbeitszeit von 13,4 Stunden pro Monat erreichte. ${ }^{678}$ Es kann also davon ausgegangen werden, dass der aktive Sport die Lebenswelt einer breiten Mehrheit der Bevölkerung prägt. Hierbei gerät diese zwangsläufig in Kontakt mit dem sportethischen Verhaltenskodex, auch wenn das konkrete Ausmaß von den persönlichen Gründen der

674 BT-Drs. 18/8831, S. 18.

675 BT-Drs. 18/8831, S. 10.

676 Deutscher Olympischer Sportbund (Hrsg.) Bestandserhebung 2020, S. 1, 11.

677 Bundesministerium für Wirtschaft und Energie (Hrsg.) Zahlen und Fakten zur Sportwirtschaft 2018, S. 13.

678 Breuer/Feiler Sportentwicklungsbericht 2017/2018 - Teil 1, S. 22. 
sportlichen Betätigung, der betriebenen Sportart als solcher sowie dem Wettbewerbsbezug abhängen mag.

Gerade bei Kindern und Jugendlichen wird der Auseinandersetzung mit den sportinhärenten Werten eine positive erzieherische Wirkung zugesprochen. Sie erfahren, dass sich durch Anstrengungen und beharrlichen Einsatz Erfolge erzielen lassen, die aber nur bei Befolgen der Regeln Gültigkeit besitzen und Anerkennung einbringen. Gleichzeitig stärken sie durch den unweigerlichen Umgang mit Niederlagen ihre Frustrationstoleranz. Teamsportarten fördern zudem eine Vielzahl sozialer Kompetenzen. Die Eingliederung in eine Gruppe verlangt Zuverlässigkeit und die Zurückstellung der eigenen Interessen zu Gunsten eines gemeinschaftlichen Ziels, erfordert einen respekt- und rücksichtsvollen Umgang mit den Stärken und Schwächen der Mitspieler auch über kulturelle oder milieuspezifische Unterschiede hinweg und vermittelt damit Empathie und Solidarität. ${ }^{679}$ Somit baut der Sport auf einem Gefüge sozialer Normen auf und lehrt spezifisches sozial-normatives Handeln. ${ }^{680}$ Seine Wertschätzung als Sozialisationsinstanz spiegelt sich darin wider, dass etwa $65 \%$ der 7 bis 18 jährigen in Sportvereinen aktiv sind. ${ }^{681}$ Auch im Zusammenhang mit der Herausforderung der Integration geflüchteter Menschen kommt dem Sport eine Schlüsselrolle zu. Vom Arbeitsmarkt und kulturellen Veranstaltungen weitgehend abgeschirmt, schaffen insbesondere die Sportvereine niedrigschwellige Gelegenheiten für gesellschaftliche Teilhabe und einen interkulturellen Austausch, der Kontakte initiiert und wechselseitige Ressentiments abbaut. ${ }^{682}$ Insgesamt fungiert der aktiv betriebene Sport also als Katalysator bei der Internalisierung von Werten, die in unzähligen gesellschaftlichen Bereichen als bedeutend angesehen werden.

Allerdings erstreckt sich der durch die $\mathbb{S} \$ 265 \mathrm{c}$, 265d StGB verfolgte strafrechtliche Institutionenschutz gerade nicht auf den Breitensport. Für schützenswert erachtet der Gesetzgeber die Integrität des Sports nur bei höherklassigen, auf dem Sportwettenmarkt angebotenen Wettbewerben

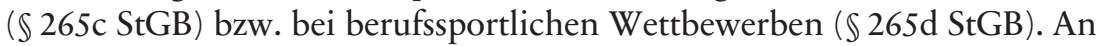

679 Vgl. Kubiciel KriPoZ 2018, 29 (30); Stellungnahme des Deutschen Anwaltsvereins Nr. 12/2016, S. 9.

680 Hutz/Kaiser NZWiSt 2013, 379 (384).

681 Deutscher Olympischer Sportbund (Hrsg.) Bestandserhebung 2020, S. 12.

682 Vgl. Breuer/Feiler Sportentwicklungsbericht 2017/2018 - Teil 1, S. 15, wonach in einer Befragung $25 \%$ der deutschen Sportvereine der Aussage völlig oder eher zustimmten, dass sie sich für Flüchtlinge engagieren; allgemein zur integrationsfördernden Wirkung des Sports bei Menschen mit Migrationshintergrund Meier/Riedl/Kukuk, in: Meier/Riedl/Kukuk (Hrsg.), Migration, 2016, S. 1 ff. 
diesen nimmt aber nur ein winziger Bruchteil der Bevölkerung teil. Im Sinne einer gesamtgesellschaftlichen Relevanz dieser Form der Integrität des Sports müsste also nachgewiesen werden, dass sich der durch die Auseinandersetzung mit dem Sportethos angestoßene Prozess der Wertevermittlung nicht nur durch Selbsterfahrung im Breitensport vollzieht, sondern in vergleichbarem Umfang auch von Wettbewerben des Leistungssports angestoßen werden kann, an denen der Großteil der Bevölkerung allenfalls als Zuschauer beteiligt ist.

Maßgeblich soll hierbei die Vorbildwirkung der Spitzensportler sein. ${ }^{683}$ Unbestritten verfügt der Spitzensport über eine immense mediale Reichweite. Sportliche Großereignisse wie Fußball-Weltmeisterschaften oder Olympische Spiele erzielen hierzulande regelmäßig, Finalspiele von Grand-Slam Turnieren im Tennis oder Handballturnieren zumindest gelegentlich TV-Einschaltquoten von über 10 Millionen Zuschauern. In den Printmedien enthalten sämtliche großen Tageszeitungen ein eigenes Ressort zum Sport und versuchen nicht selten, über sportbezogene Aufmacher auf der Titelseite ihre Auflage zu steigern. Allein die auflagenstärkste Sportzeitschrift Sport BILD kam im Jahr 2017 auf 4,18 Millionen Leser pro Ausgabe. ${ }^{684}$ Gemeinsam mit dem auf dem zweiten Platz folgenden Fachmagazin Kicker generiert es einen Bruttoanzeigenumsatz von über 50 Millionen Euro jährlich. ${ }^{65}$ Unter den Top 20 der mobilen Internetangebote mit der höchsten Reichweite lag im September 2019 der allein auf Sport ausgerichtete Dienst kicker.de auf Rang 6.686 In den sozialen Netzwerken wird den Profilen von Fußball-Nationalspielern, Fußball-Clubs und dem DFB millionenfach gefolgt, was sie wiederum zu begehrten Werbeträgern macht und ihre mediale Präsenz noch einmal erhöht.

Das sich in diesen Kennzahlen widerspiegelnde öffentliche Interesse am Spitzensport ist dabei kein distanziert-nüchternes, sondern geht überwiegend mit emotionaler Anteilnahme einher. Häufig entstehen zu bestimm-

683 BT-Drs. 18/8831, S. 10, 11; Pfister StraFo 2016, 441 (442); Haug/Martin Causa Sport 2014, 345 (346).

684 Axel Springer, Reichweite der Sport Bild in den Jahren 2004 bis 2017 in Millionen Lesern, de.statista.com/statistik/daten/studie/3590/umfrage/reichweite-der-s port-bild-seit-2004/.

685 PZ-online, Ranking der Sportzeitschriften mit den höchsten Anzeigenumsätzen in Deutschland 2019, de.statista.com/statistik/daten/studie/378341/umfrage/anze igenumsaetze-der-sportzeitschriften-in-deutschland/.

686 IVW, Ranking der Top 20 mobilen Internetangebote nach der Anzahl der Visits im Juli 2018 in Millionen, de.statista.com/statistik/daten/studie/264707/umfrage /reichweiten-von-mobilen-internetangeboten. 
ten Sportlern oder Vereinen emotionale Bindungen, die sich in einem gespannten Verfolgen der betreffenden Wettkämpfe äußern und je nach ihrem Ausgang in starke Gefühle von Freude oder Enttäuschung ausschlagen. Gerade die gemeinsame Unterstützung eines Akteurs in einer Gruppe von Freunden, Arbeitskollegen oder zunächst unbekannten Fans kann ein Zusammengehörigkeitsgefühl auslösen und integrativ wirken. ${ }^{687}$ Bisweilen werden Sportler gar zur Projektionsfläche eigener Sehnsüchte. Im zumeist wechselhaften, von Triumphen und Rückschlägen geprägten Verlauf ihrer Saisonleistungen oder gar Karrieren wird eine Vorlage des eigenen Lebens erkannt.

Solche Identifikationsprozesse, die sich insbesondere bei Kindern und Jugendlichen beobachten lassen, werden als Garant für die Vermittlung sportethischer Werte auch über den medialen Konsum angesehen. Erfolgreiche Sportler verkörpern in anschaulicher Weise das Leistungsprinzip. Indem sie ehrgeiziges Gewinnstreben mit einem fairen Umgang mit Konkurrenten und Akzeptanz im Falle einer Niederlage verbänden, lieferten sie für Zuschauer wertvolle Handlungsmodelle, deren Übernahme die eigene charakterliche Formung begünstige. ${ }^{688}$ Zumal das faszinierte Verfolgen ihrer Wettkämpfe den Impuls auslösen könne, eigene sportliche Aktivitäten zu starten oder zu intensivieren, womit wiederum bestärkende Rückkoppelungen mit den damit verbundenen Sozialisationseffekten in Aussicht stünden.

Zwischen der Gesellschaft und dem Phänomen Sport bestünden demnach sozio-kulturelle Interdependenzen: So wie sich das einer Gesellschaft zugrunde liegende Werte- und Normensystem in ihrem Sport widerspiegele, so würden umgekehrt Werte und Einstellungen, die im Sport manifest sind, von einer sportbegeisterten Gesellschaft aufgenommen und in die allgemeinen Verhaltenstraditionen integriert. ${ }^{689}$ Als positives Beispiel wird etwa auf die besonders im öffentlichen Fokus stehenden Nationalteams verwiesen, die sich in ihrer personellen Zusammensetzung zunehmend als Spiegel einer multikulturellen Gesellschaft darstellen. Ihre Erfolge trügen die Bedeutung eines vorurteilsfreien Zusammenhalts in weite Teile des gesellschaftlichen Bewusstseins hinein. Nicht zuletzt die entsprechenden Verbände reklamieren die Rolle des Spitzensports als Botschafter sozial ge-

687 Vgl. Kubiciel WiJ 2016, 256.

688 Pfister StraFo 2016, 441 (442).

689 Wilke Fairness, S. 25. 
wichtiger Werte für sich und akzentuieren diese mittels Kampagnen zu Integration, der Bekämpfung von Rassismus und Fair Play. ${ }^{690}$

Als unabdingbare Voraussetzung der positiven ideellen Beeinflussung einer breiten Öffentlichkeit durch Wettbewerbe des Spitzensports wird dessen Glaubwürdigkeit erachtet. ${ }^{691}$ Sie könne nur solange gelingen, wie die sportethischen Werte im Verhalten der Akteure sichtbar würden und allgemein von deren Redlichkeit und der Authentizität der Wettbewerbe ausgegangen werde. Würden diese hingegen von Berichten über Spielabsprachen und anderen Manipulationen zunehmend in Zweifel gezogen, bestünde die Gefahr, dass der Sport das Interesse der Allgemeinheit verspiele und damit seine gesellschaftliche und wirtschaftliche Bedeutung einbüße. ${ }^{692}$ Die Vorbildwirkung könne sich dann rasch in ihr Gegenteil umkehren und das für das öffentliche Rechtsbewusstsein fatale Signal aussenden, Ehrlichkeit verringere die eigenen Chancen und materielle Gewinne ließen sich am ehesten durch den Einsatz illegitimer Mittel erzielen. ${ }^{693}$ Entscheidendes Bindeglied zwischen dem sich herausgebildeten Sportethos und der Übernahme seiner Werte durch Teile der Bevölkerung sei das Ausmaß des dort aufgebrachten Vertrauens in die Unverfälschtheit leistungssportlicher Wettbewerbe, das daher auch als wesentliches Element der Integrität des Sports ausgemacht wird. ${ }^{694}$

(3) Die gesamtgesellschaftliche Bedeutung des Sports als Wirtschaftsfaktor

Zur gesamtgesellschaftlichen Relevanz des Sports trägt neben seinen erzieherischen und integrativen Funktionen auch seine ökonomische Bedeutung bei. Im Zuge der voranschreitenden Mediatisierung und Kommerzialisierung hat er sich zu einem bedeutsamen wirtschaftlichen Faktor ent-

690 So fördert der Deutsche Fußballbund (DFB) den Fair Play-Gedanken mittels der Ausrichtung von Fair Play-Tagen, der Vergabe einer Fair Play-Medaille sowie der Einberufung einer eigenen Fair Play-Liga im Jugendbereich, www.dfb.de/fai r-playgewaltpraevention/fair-play/. Die integrative Rolle des Fußballs soll unter anderem durch einen Aktionstag, einen Integrationsbeauftragten und einen TVSpot unterstützt werden, www.dfb.de/vielfaltanti-diskriminierung/integration/. Unter der Botschaft "No to Racism" schaltet auch die UEFA mit populären Spielern besetzte TV-Spots.

691 Hurth/Kaiser NZWiSt 2013, 379 (383); Gienger DRiZ 2016, 16; König SpuRt 2010, 106 (107); Cherkeh/Momsen NJW 2001, 1745 (1748).

692 BT-Drs. 18/8831, S. 10.

693 Vgl. Maas NStZ 2015, 305 (307).

694 Beuckelmann NJW-Spezial 2010, 56. 
wickelt. ${ }^{695}$ In den populären und professionell vermarkteten Sportarten profitieren hiervon unmittelbar zunächst die Sportler, deren Verdienstmöglichkeiten sich infolge exponentiell anwachsender Preisgelder, Grundgehälter und Werbegagen erheblich verbessert haben. Auch die großen Sportverbände und Fußballclubs vermelden regelmäßig neue Umsatzrekorde. ${ }^{696}$

Mittlerweile besitzt der Sport aber auch eine beachtliche volkswirtschaftliche Dimension. Im Jahr 2015 beliefen sich die an Organisationen des Spitzensports geleisteten Sponsoring-Ausgaben deutscher Unternehmen auf 900 Millionen Euro. ${ }^{697}$ Die Vergabe von Medienrechten an sportlichen Wettbewerben generierte zusätzlich Gelder in Höhe von 1,1 Milliarden Euro. ${ }^{698}$ Immerhin ein Drittel der breiten Unternehmensbasis gibt an, einen direkten Sportbezug zu haben, sei es durch die Herstellung von Sportwaren und -dienstleistungen, Sponsoring oder sportbezogene Werbung. ${ }^{699}$ Auch im Konsumverhalten der privaten Haushalte nimmt der Sport einen beträchtlichen Posten ein. Zur Befriedigung des Interesses am Spitzensport wurden 2015 größtenteils für Pay-TV, Eintritte zu Sportveranstaltungen und Fanartikel insgesamt 8,8 Milliarden Euro aufgewendet. ${ }^{700}$ Der Umfang der zumindest teilweise durch das mediale Verfolgen des Spitzensports motivierten Ausgaben für die eigenen sportlichen Aktivitäten betrug gar 56 Milliarden Euro. ${ }^{701} \mathrm{Im}$ Wesentlichen von diesem privaten Konsum getragen belief sich der sportbezogene Beitrag zum Bruttoinlandsprodukt (BIP) auf knapp 70 Milliarden Euro und erreichte damit einen Anteil von 2,3\% am gesamten BIP. ${ }^{702}$ In der sog. Sportwirtschaft,

695 BT-Drs. 18/8831, S. 10; dazu bereits oben Teil 2 A. III. 1. b) aa).

696 So verbuchte etwa das IOC in der üblichen Vier-Jahres-Periode zwischen 2013 und 2016 Erlöse in Höhe von 5,5 Milliarden Euro, vgl. Ashelm Olympia ist am Boden, Faz.net vom 30.7.2016, www.faz.net/aktuell/wirtschaft/das-ioc-in-der-kri se-olympia-ist-am-boden-14363340.html; die kumulierte Bilanzsumme der 18 Clubs der Fußball-Bundesliga überschritt in der Saison 2016/2017 erstmals die Drei-Milliarden-Euro-Marke, Deutsche Fußballiga (DFL) Report 2018, S. 29.

697 Bundesministerium für Wirtschaft und Energie (Hrsg.) Zahlen und Fakten zur Sportwirtschaft 2018, S. 23.

698 Wobei 92,5\% auf den Fußball entfielen, vgl. Bundesministerium für Wirtschaft und Energie (Hrsg.) Zahlen und Fakten zur Sportwirtschaft 2018, S. 22, 24.

699 An der Heiden/Meyrahn/Ablert Bedeutung des Spitzen- und Breitensports, 2012, S. 71.

700 Bundesministerium für Wirtschaft und Energie (Hrsg.) Zahlen und Fakten zur Sportwirtschaft 2018, S. 17.

701 Bundesministerium für Wirtschaft und Energie (Hrsg.) Zahlen und Fakten zur Sportwirtschaft 2018, S. 15.

702 Ahlert/an der Heiden/Repenning Sportsatellitenkonto 2016, S. 7 f. 
die sich als Querschnittsbranche aus einer Vielzahl von Wirtschaftszweigen zusammensetzt, waren im Jahr 2016 1,3 Millionen Erwerbstätige beschäftigt, überwiegend im Bereich der öffentlichen und personenbezogenen Dienstleister sowie im Verkehrs- und Gastgewerbe. ${ }^{703}$

Diese Kennzahlen weisen den Sport als relevanten unternehmensseitigen Bezugspunkt, als Produkt und Stimulator des privaten Konsums sowie als großvolumigen Arbeitgeber aus. Auch hierbei steht er aber in Abhängigkeit vom öffentlichen Ansehen des Sports, dessen Beschädigung sich negativ auf seine ökonomischen Funktionen auswirken dürfte.

\section{cc) Zusammenfassung und Einordnung in das „Integritätsstrafrecht“}

Auch die Integrität des Sports erweist sich somit als ein zunächst schwer fassbares Konstrukt, dem über die Addition verschiedener Aspekte Konturen verliehen werden soll. Der vom Gesetzgeber unternommene Konkretisierungsversuch ähnelt dabei grundsätzlich der Begriffsbestimmung in den anderen Bereichen strafrechtlichen Integritätsschutzes. In Form des Sportethos wird zunächst ein bereichsspezifischer Verhaltensmaßstab beschrieben, dessen Einhaltung den unverfälschten und authentischen Ablauf eines Wettbewerbs gewährleisten soll. Diesen gelte es weniger um seiner selbst willen als vielmehr aufgrund seiner gesamtgesellschaftlichen Wirkkraft, die auch von der Unvorhersehbarkeit von Wettbewerbsverlauf und -ausgang abhänge, mittels des Strafrechts zu bewahren.

Der gesetzgeberischen Rechtsgutskonzeption der Integrität des Sports liegt somit eine auf Wechselwirkungen beruhende Bedingungskette zugrunde: Sportethische Gebote wie Fairness und Leistungsbereitschaft sichern die Unvorhersehbarkeit und Spannung sportlicher Wettbewerbe, die für eine breite Faszination in der Bevölkerung sorgen, die wiederum auf verschiedenen Wegen die gesellschaftliche Internalisierung gerade jener auch für das soziale Zusammenleben förderlichen sportethischen Werte anregt und zeitgleich wirtschaftlich nutzbare Potenziale eröffnet. Als entscheidendes Verbindungsstück in dieser gezeichneten Abfolge von der Austragung sportlicher Wettbewerbe bis zum Eintritt der gesellschaftlich erwünschten Wirkungen tritt dabei die Glaubwürdigkeit des (Leistungs-)Sports hervor, so dass das Vertrauen der Allgemeinheit in die Integrität und Authentizität des Sports - wenngleich im Gesetzentwurf nicht

703 Ablert/an der Heiden/Repenning Sportsatellitenkonto 2016, S. 17. 
explizit erwähnt - neben dem Sportethos als ein zentraler Bestandteil der gesetzgeberischen Rechtsgutskonzeption verstanden werden muss.

Bei der Gewichtung der einzelnen Bestandteile lassen sich aber auch Unterschiede zu den weiteren integritätsschützenden Strafnormen konstatieren. Wird dort die Integrität eines Bereiches mitunter stärker mit dem Schutz des wirtschaftlichen Wettbewerbs aufgeladen und die vermögensbezogene Chancengleichheit der in ihm konkurrierenden Bewerber zum tragenden Element erklärt, klingt dieser Aspekt in der Begründung der $\$ \mathbb{S} 265 \mathrm{c}, 265 \mathrm{~d}$ StGB zwar an, wird letztlich aber aus der Integritätsbestimmung ausgelagert und den Vermögens- oder eben (wirtschaftlichen) Wettbewerbsinteressen zugeordnet, die eine zweite oder gar dritte Rechtfertigungslinie bilden sollen. ${ }^{704}$ Diese leicht abweichende Materialisierung setzt sich auch innerhalb der geformten Integrität des Sports fort, die angesichts des wettbezogenen und sonstigen Match Fixing im Vergleich zum Doping klarer auf die ethischen Grundlagen des Sports und ihre gesellschaftlichen Implikationen zugeschnitten wird.

d) Prüfung der Integrität des Sports und ihrer Bestandteile an den Kriterien eines materialisierten Rechtsgutsbegriffs

Vom Standpunkt einer allenfalls auf den Ausschluss willkürlicher und evident verfassungswidriger Rechtsgutsbestimmungen zu beschränkenden Kontrolle strafgesetzgeberischer Zwecksetzungsentscheidungen wird die beschriebene Konkretisierung der Integrität des Sports offenbar schon aufgrund ihres durch die Popularität des Sports vermittelten Gesellschaftsbezugs kaum beanstandet. Da manipulierte Wettbewerbe die Erwartungen des Publikums an einen fairen, allein durch Leistung entschiedenen Wettbewerb enttäuschten und die Attraktivität eines die Menschen zu allen Zeiten faszinierenden Phänomens schmälerten, liege die Kreation eines solchen Rechtsguts im Rahmen des gesetzgeberischen Ermessensspielraums. ${ }^{705}$ Erklärt man hingegen wie hier ein gewissen Kriterien entsprechendes Rechtsgut zur Grundvoraussetzung einer verhältnismäßigen Strafnorm, lässt sich allein aus der nachgewiesenen gesellschaftlichen Bedeutung des Sports noch keine positive Bewertung der Legitimität des strafrechtlichen Schutzes seiner Integrität ableiten.

704 BT-Drs. 18/8831, S. 10; s. auch Jaleesi Kriminalisierung, S. 92.

705 Schönke/Schröder/Perron \$265c Rn. 2. 
Da sich die Integrität des Sports in der Auslegung des Gesetzgebers als Konzept erwiesen hat, das sein Gepräge aus dem Gehalt verschiedener Bestandteile ableitet, sind gerade diese Bestandteile in den Fokus einer kritischen Bewertung zu nehmen. Im Folgenden werden demnach die sportethischen Werte der Fairness und Leistungsbereitschaft sowie das Vertrauen der Allgemeinheit in die Integrität und Authentizität des Leistungssports anhand der dargestellten Materialisierungskriterien des Rechtsgutsbegriffs untersucht. Sollten diese die Anforderungen an ein legitimes Rechtsgut jeweils verfehlen, stellt sich die Frage, inwiefern sich ein solches aus ihrem bloßen Zusammenschluss ergeben kann.

\section{aa) Fairness}

Mit allein vier expliziten Nennungen in der Gesetzesbegründung wird die Fairness vom Gesetzgeber zu einem zentralen Baustein der Integrität des Sports erklärt. Dabei wird sie wahlweise als positiver sportlicher $\mathrm{Wert}^{706}$ oder als Gebot ${ }^{707}$ bezeichnet. Eine nähere Umschreibung des Begriffsgehalts oder erläuternde Beispiele finden sich jedoch nicht. Wird ein authentischer sportlicher Wettbewerb als ein solcher gekennzeichnet, bei dem der Leistungsvergleich der Teilnehmer „unter Einhaltung der sportartspezifischen Regeln und unter Beachtung des Gebotes der Fairness" erfolge, ${ }^{708}$ ergibt sich aus dieser gleichgeordneten Aufzählung zumindest noch, dass Fairness offenbar mehr als die bloße Befolgung der Regeln verlange. Dennoch bleibt zunächst unklar, in welcher der denkbaren Erscheinungsformen die Fairness in Bezug genommen werden soll. Als Fair Play besitzt der Begriff nämlich eine Ausprägung als sportspezifischer Verhaltensmaßstab, beschreibt darüber hinausgehend aber auch ein allgemein-ethisches Prinzip, das in verschiedenen Zusammenhängen als Rechtsbegriff ausgestaltet wurde und auch bereits Einzug in die strafrechtliche Rechtsgutsdiskussion gefunden hat.

706 BT-Drs. 18/8831, S. 10, 18.

707 BT-Drs. 18/8831, S. 10.

708 BT-Drs. 18/8831, S. 10. 


\section{(1) Fair Play im Sport}

Das Gebot des Fair Play wird in der Olympic Charta des IOC in Bezug auf die Ausübung des Sports als Menschenrecht gesetzt und zu den „fundamental principles“ des Sports gezählt. ${ }^{709}$ Mehrere internationale Übereinkommen und Deklarationen verpflichten sich seinem Schutz. ${ }^{710}$ Außerdem genießt es Anerkennung in der Rechtsprechung des Court of Arbitration in Sports (CAS). Fair Play soll nicht nur als oberster Grundsatz jede Sportausübung durchdringen, sondern erweist sich gemäß $\mathbb{3}$ der Aufnahmeordnung des DOSB bereits als konstitutives Wesensmerkmal des Sportbegriffs selbst. ${ }^{711}$

Seine Wurzeln werden dabei im Großbritannien des 18. Jahrhunderts verortet, wo sich in der viktorianischen Oberschicht die Ästhetik der körperlichen Bewegung mit der kaufmännisch geprägten Vorstellung eines vertrauensvollen Wettbewerbs verband, in dem sich die Geschäftspartner auf die gegenseitige Einhaltung der Regeln verlassen konnten. ${ }^{712}$ Angesichts dieser langen Tradition des Fair Play, seines immensen Stellenwertes und der Vielzahl an Bezugnahmen und Erwähnungen erstaunt es, dass es sich um einen sportwissenschaftlich weitgehend unbestimmten Begriff handelt. ${ }^{713}$ Auch ein Blick in die konkreten Regelwerke der nationalen Sportverbände zeigt nicht das erwartet einheitliche Bild. In den einzelnen Vorschriften der Satzungen und Spiel- bzw. Rechtsordnungen der in Deutschland populärsten Sportarten Fußball, Handball, Eishockey, Leichtathletik, Schwimmen und Tennis sucht man den Begriff des Fair Play nahezu vergeblich. Zwar wird er teilweise in Präambeln, gesonderten EthikCodes und in die Satzung einleitenden Vorschriften zum Verbandszweck als Leitmotiv hervorgehoben. ${ }^{714} \mathrm{Zu}$ seiner inhaltlichen Präzisierung tragen

709 IOC, Fundamental Principles of Olympism, Nr. 4.

710 Vgl. Präambel der Anti-Doping-Konvention des Europarates vom 16.11.1989, ETS Nr. 135; Internationales Übereinkommen gegen Doping im Sport der UNESCO vom 19.10.2005; UNESCO-Declaration on Fair Play aus dem Jahr 1976.

711 Aufnahmeordnung des DOSB vom 20.5.2006, https://cdn.dosb.de/user_upload/ www.dosb.de/uber_uns/Satzungen_und_Ordnungen/aktuell_Aufnahmeordnun g_2018_.pdf.

712 Grupe/Mieth/Gabler Lexikon der Ethik im Sport, S. 150 (Eintrag: Fair); MomsenPflanz Doping, S. 52; Wilke Fairness, S. $76 \mathrm{ff}$.

713 Diesen Befund teilend PHB-SportR/Pfister/Fritzweiler Einführung Rn. 36.

714 Vgl. Präambel der Satzung des Deutschen Fußballbundes (DFB) sowie $\$ 4$ Nr. 1 k), Nr. 2 a) zu Zweck und Aufgabe des DFB; $\$ 2$ o) der Satzung des Deutschen Handballbundes (DHB) allerdings allein in Bezug auf Doping; $\mathbb{2} \mathrm{Nr} .2 \mathrm{~d}$ ) der 
diese eher plakativen Bekenntnisse aber wenig bei. Die Zurückhaltung der Verbände bei der Inkorporierung des Fair Play-Begriffs in die konkreten Regelwerke wird dabei ebenfalls auf die Schwierigkeit einer hinreichend klaren Umschreibung der Fairnessanforderungen zurückgeführt, die die Basis einer in jedem Einzelfall zu ziehenden Grenze zur regelwidrigen Unsportlichkeit zu bilden hätten. ${ }^{715}$

Dabei erscheint gerade das Verhältnis des Fair Play-Gebotes zu den sportartspezifisch festgelegten Regeln klärungsbedürftig. Einerseits konkretisiert sich Fair Play gerade in den Regeln, legen diese doch einen transparenten Ablauf des Wettbewerbs fest, verbürgen die grundsätzliche Chancengleichheit der Teilnehmer und verpflichten die Sportler zur Achtung der körperlichen Integrität von Mitspielern und Konkurrenten. Auf der anderen Seite wird Fair Play häufig auch von den zugrunde liegenden Sportregeln entkoppelt. So werden mitunter auch überwiegend als unfair empfundene Verhaltensweisen wie beispielsweise die sog. Matchrace-Taktik im Segelsport, die vornehmlich auf die Blockade eines gegnerischen Bootes und die Erzwingung unzulässiger und mit Strafen zu belegender Manöver ausgerichtet ist, von den Regeln toleriert. ${ }^{716}$ Mehr als das reine playing by the rules zeichnet einen fairen Sportler also offenbar eine bestimmte übergeordnete Haltung und Einstellung aus. ${ }^{717}$ Dies klingt auch in dem vom Europarat vorgelegten Ethikkodex für den Sport an, in dessen Nr. 6 es heißt: „Fair Play umfasst mehr als die Ausübung von Sport unter Einhaltung der Regeln. Es beinhaltet auch den Grundgedanken der Freundschaft, der Achtung des anderen und des Mitmachens im Sinne des Spiels. Fair Play ist definiert als eine Denkweise, nicht nur als Verhaltensweise. "718 Exemplarisch für dieses mehrdimensionale Fair Play-Verständnis steht die sog. Fair Play-Wertung des europäischen Fußballverbandes UEFA, über die Vereine der nationalen Verbände Preisgelder, bis vor drei Jahren gar noch Startplätze in internationalen Turnieren erreichen konnten. ${ }^{719}$ Diese richtet sich zunächst nach dem Umfang der von den einzel-

Satzung des Deutschen Eishockey-Bundes; Ziffer 1 und 3 des Ethik-Codes des Deutschen Leichtathletik Verbandes.

715 Vgl. Tettinger Der Staat 36, 575 (593).

716 PHB-SportR/Summerer 3. Kap. Rn. 32.

717 Schild Sportstrafrecht, S. 31; Wilke Fairness, S. 29 ff.; Momsen, in: Asmuth (Hrsg.), Entgrenzungen, 2012, S. $251 \mathrm{f}$.

718 Vgl. Kodex für Sportethik des Europarates, 1992.

719 Pressemitteilung des europäischen Fußballverbandes UEFA vom 16.2.2015, de.uefa.com/insideuefa/social-responsibility/news/newsid=2210104.html?redirec tFromOrg=true. 
nen Teams in Ligaspielen begangenen und in Form von gelben und roten Karten sanktionierten Regelverstöße. Daneben fließen aber auch von den Regeln unabhängige und durch neutrale Beobachter der Verbände zu bewertende Faktoren wie ein unterhaltsamer Spielstil, ein respektvoller Umgang der Spieler und Teamfunktionäre mit Gegnern und Schiedsrichtern sowie ein stimmungsvolles, aber friedliches Verhalten der Fans in die Wertung mit ein.

Auf einer allgemeinen Ebene lassen sich die verschiedenen Facetten des Fair Play zunächst in der Unterscheidung einer formellen und einer informellen Fairness abbilden. ${ }^{720}$ Während erstere als Verfahrensvorgabe die Gleichheit der Wettkampfbedingungen insbesondere durch Regeln sicherstellen soll, beschreibt letztere einen Verhaltensmaßstab und bindet die Sportler an eine Sondermoral im Sport. ${ }^{721}$ Welche konkreten Anforderungen dieser Verhaltensmaßstab enthält, ist wiederum umstritten. Es existieren hierzu mehrere Definitionsversuche. ${ }^{722}$

In einer engen Auslegung wird Fair Play in seiner informellen Ausprägung als die moralische Konstanz bewusster Regeleinhaltung verstanden. ${ }^{723}$ Objektiv regelkonformes Verhalten müsse demnach Ausfluss des Bemühens der Sportler sein, die einschränkenden Regeln konsequent und bewusst auch unter erschwerten Bedingungen zu befolgen. Hierdurch kann der Kern des informellen Fair Play Gebotes aber noch nicht umfassend charakterisiert sein, soll doch nach allgemeiner Auffassung auch gerade der nicht von den Regeln verlangte Verzicht auf Vorteile im Wettbewerb bzw. die Inkaufnahme von Nachteilen, um der Spielidee Geltung zu verschaffen, als fair gelten. ${ }^{724}$ So honorieren es im Fußball die Anhänger beider Teams regelmäßig mit Beifall, wenn die Verletzung eines Spielers des gegnerischen Teams nicht zu einem Angriff in Überzahl ausgenutzt wird, sondern stattdessen zur Ermöglichung einer raschen Behandlungspause der Ball ins Seitenaus gespielt und damit ein Ballverlust in Kauf genommen wird, den in dieser Situation keine Fußballregel vorschreibt. Unter den Preisträgern der vom DFB jährlich vergebenen Fair Play-Medaille befanden sich zuletzt regelmäßig Spieler, die eine zu ihren Gunsten getrof-

720 Grundlegend hierzu Lenk, in: Maring (Hrsg.), Bereichsethiken, 2014, S. 301 (302 ff.); die Unterscheidung aufgreifend Lehner/Nolte/Putzke/Nolte AntiDopG $\$ 1$ Rn. 42; Vieweg/Staschik SpuRt 2013, 227 (229 f.); PHB-SportR/Summerer 3. Kap. Rn. 30.

721 Vieweg/Staschik SpuRt 2013, 227 (229).

722 Vgl. die Übersicht bei Schild Sportstrafrecht, S. 31.

723 Vgl. hierzu Momsen-Pflanz Doping, S. 53.

724 Vieweg/Staschik SpuRt 2013, 227 (230). 
fene Fehlentscheidung des Schiedsrichters korrigierten bzw. es unterließen, ein tatsächlich gegen sie verübtes Foulspiel dem Schiedsrichter durch die Wirkung unterstreichende, theatralische Gesten anzuzeigen. ${ }^{725}$ Auch der deutsche Tischtennisspieler Timo Boll wurde 2004 mit einem Fair PlayPreis dafür ausgezeichnet, im entscheidenden Satz seines Achtelfinales eine ihn bevorteilende Fehlentscheidung des Schiedsrichters korrigiert zu haben, indem er einen Kantenball seines Gegners anzeigte und den Schiedsrichter damit überstimmte. ${ }^{726}$ Unter Handballspielern ist es gängige Praxis, den Ball bei sog. 7-Meterwürfen wegen des Verletzungsrisikos nicht in Kopfhöhe des Torwarts zu platzieren, obwohl gerade solche Würfe aufgrund der auf dieser Höhe eingeschränkten Reaktionsmöglichkeit des Torwarts die erhöhte Wahrscheinlichkeit eines Torerfolges versprechen. In diesen Fällen verzichten die Akteure also jeweils auf möglicherweise spielentscheidende Vorteile, die ihnen die Regeln eigentlich gewähren.

Die Beispiele zeigen, dass sportintern die bewusste Regeleinhaltung allenfalls als Mindestbedingung des Fair Play erfasst und die erforderliche innere Einstellung mit weitergehenden Kriterien versehen wird. Nach der vom Arbeitskreis für Sportrecht verfassten Karlsruher Erklärung bezeichnet Fair Play eine übergreifende, ethischen Prinzipien verpflichtete Geisteshaltung, die die sportartspezifischen Regeln auch innerlich bejaht, den selbstverständlich mit aller Kraft angestrebten Erfolg nicht um jeden Preis erzielen will, im Gegner nicht den Feind sieht, den es mit allen Mitteln zu besiegen gilt, ihn vielmehr als Partner im sportlichen Wettkampf achtet und ihm deshalb das Recht auf Chancengleichheit, auf Respektierung seiner körperlichen Integrität und seiner menschlichen Würde unabhängig von Nationalität, Rasse und Herkunft zubilligt. ${ }^{727}$ Ein derart umrissenes Fair Play schlösse absichtliche Regelverstöße wie auch den Einsatz zwar nicht explizit verbotener, aber doch dem Geist und Sinn der Regeln widersprechender Mittel sowie jede Form der Korruption aus und beanspruche nicht nur unter den unmittelbar wetteifernden Sportlern Geltung, sondern verpflichte auch Sportverbände, Medien, Sponsoren und Zuschauer

725 Vergabe des Fair Play-Preises des DFB in der Saison 2014/2015 an Carlo Catalano und Reinhold Yabo, www.dfb.de/news/detail/goetze-lobt-fairplay-preistraege r-yabo-ueberragender-sportsmann-135202.

726 Schüßler Timo Boll gibt 2005 Matchpunkt fair zurück, Allgemeine Zeitung vom 5.5.2015, www.allgemeine-zeitung.de/lokales/blogs/zeit-lupe/timo-boll-gibt-200 5-matchpunkt-fair-zuruck-und-verliert_15216019.

727 Karlsruher-Erklärung zum Fair Play, SpuRt 1998, 261 (262); zust. Vieweg/ Staschik SpuRt 2013, 227 (230). 
zur Berücksichtigung des Grundsatzes in ihrem jeweiligen Wirkungskreis. $^{728}$

Tatsächlich erscheint ein solches Verständnis des sportspezifischen Fair Play als offene und rücksichtsvolle Geisteshaltung gegenüber den vorgegebenen Bedingungen der Sportart und den Befindlichkeiten der Mitspieler als vorherrschend. Die von der Karlsruher Erklärung für konstitutiv erklärten Haltungen und Werteinstellungen klingen auch in zahlreichen anderen Begriffsbestimmungen an, in denen Fair Play als - im Detail jeweils leicht unterschiedlich zusammengesetzte - Symbiose der Attribute Anständigkeit, Ehrlichkeit, Respekt, Gentlemanlike, Rücksichtnahme, Chancengleichheit, Vorhersehbarkeit, Richtigkeit und Gerechtigkeit umschrieben wird. ${ }^{729}$ Teilweise erreichen sie dabei ein beträchtliches Abstraktionsniveau, wenn etwa das Ideal des Fair Play als Verpflichtung der Akteure angesehen wird, ihre interpersonalen Beziehungen auf der Grundlage universeller Prinzipien der Freiheit, der Gerechtigkeit und der Reziprozität zu organisieren ${ }^{730}$ oder die vorauszusetzende Haltung sich durch Friedfertigkeit, Mitmenschlichkeit, Ehrlichkeit, Toleranz, Solidarität und Selbstzucht auszeichne. ${ }^{731}$

Allerdings erfährt ein derart voraussetzungsreicher und ethisch aufgeladener Fair Play-Begriff auch Kritik. Seine Anforderungen gerieten schon zum Grundverständnis des Sports als Spiel in Widerspruch. ${ }^{732}$ Denn dieses verlange zunächst einmal Mut, Tapferkeit und den durchsetzungsstarken Willen, den Konkurrenten in Schnelligkeit, Ausdauer oder Kraft zu übertreffen und zu besiegen. Der agonale Charakter des Spiels sei also gerade nicht auf die Herstellung gerechter Verhältnisse, sondern auf Ungleichheit ausgerichtet, die sich im Übrigen schon in einer durch unterschiedliche körperliche Voraussetzungen und Trainingsbedingungen verzerrten Ausgangsbasis abbilde. Das Unterlassen einer spielentscheidenden Handlung aus moralischen Gründen mag im Sinne des Fair Play begrüßt werden, stellt in der Logik des Spiels aber zunächst einmal eine Störung dar. Sofern Fair Play also als intrinsisches Maß des Sports bezeichnet wird, ${ }^{733}$ so ist dem entgegenzuhalten, dass es kein dem Sport in seiner ursprünglichen

728 Karlsruher-Erklärung zum Fair Play, SpuRt 1998, 261 (262 ff.).

729 Zusammenfassend PHB-SportR/Summerer 3. Kap. Rn. 30; Lehner/Nolte/Putzke/ Nolte AntiDopG $₫ 1$ Rn. 42.

730 Schwier Sportwissenschaft 1990, 390 (396).

731 Grupe/Mieth/Gabler Lexikon der Ethik im Sport, S. 150 (Eintrag: Fair).

732 Schild Sportstrafrecht, S. $56 \mathrm{f}$.

733 Vgl. Schürmann, in: Asmuth (Hrsg.), Entgrenzungen, 2012, S. 75 (85) in Bezugnahme auf die Olympic Charta. 
Idee als Spiel innewohnendes Gebot darstellt, sondern bewusst als Kontrapunkt gesetzt wurde, um ein rücksichtsloses Leistungsstreben zu begrenzen. ${ }^{734}$ Diese gegenseitige Begrenzung gerate durch die Entwicklungen des modernen Sports aber zunehmend aus dem intendierten Zustand des Gleichgewichts. Die rasante Kommerzialisierung des Sports und eine Fokussierung der medialen Berichterstattung auf die Sieger bewirkten, dass Fair Play zwar noch von Seiten der Verbände aus Imagegründen beansprucht und vermarktet werde, ${ }^{735}$ in der erfolgsorientierten Realität des Leistungssports aber keine Entsprechung mehr finde. ${ }^{736}$

Anzeichen hierfür lassen sich im Verhalten von Sportlern insbesondere in entscheidenden und emotionalen Wettkampfsituationen finden, in denen der Respekt vor Konkurrenten erkennbar nachlässt und deren Schwächephasen unnachsichtig ausgenutzt werden. Durch aufreizende Körpersprache, psychologischer Tricks und teilweise auch bewusste Regelübertretungen wird versucht, den Kontrahenten zu verunsichern oder in seiner Konzentration zu stören. In gleicher Weise nimmt auch bei den zuschauenden Sportfans die Bereitschaft zum Fair Play situationsabhängig ab, was sich in kollektiven Pfiffen zur Demoralisierung eines Sportlers der Gegenseite äußern kann, sich aber auch in den zunehmend ungehaltenen Reaktionen auf Fair Play-Gesten des eigenen Teams beobachten lässt, sofern dadurch das Aufholen eines Rückstandes bei zerrinnender Spielzeit unwahrscheinlicher wird. Im Fußball wurden in der jüngeren Vergangenheit auch mehrmals Spieler gefeiert, die gegen Ende eines engen Spiels durch ein grobes Foul oder eine Unsportlichkeit einen entscheidenden Gegentreffer verhinderten. ${ }^{737}$

734 Momsen, in: Asmuth (Hrsg.), Entgrenzungen, 2012, S. 251.

735 Im Fußball schalten etwa die UEFA als Kontinental- sowie die FIFA als Weltverband regelmäßig mit populären Stars besetzte Werbespots, die zum Fair Play aufrufen. Mitunter werden vor bedeutenden Spielen von den Kapitänen der Teams Erklärungen zum Fair Play verlesen.

736 In diese Richtung auch Schürmann, in: Asmuth (Hrsg.), Entgrenzungen, 2012, S. 75 (84 ff.); Zurawski/Scharf NK 2015, 399 (410); Lenk, in: Maring (Hrsg.), Bereichsethiken, 2014, S. 301 (311); Kreuzer ZRP 2013, 181 (182).

737 Etwa Federico Valverde, der als Spieler von Real Madrid durch eine mit einem Platzverweis geahndete sog. Notbremse in der Verlängerung des Pokalfinales einen aussichtsreichen Angriff der gegnerischen Mannschaft stoppte, s. Caceres "Jeder hätte an deiner Stelle das Gleiche getan“, Sueddeutsche.de vom 13.1.2020, www.sueddeutsche.de/sport/real-madrid-supercopa-foul-notbremsevalverde-1.4755141. In ähnlicher Weise der uruguayische Nationalspieler Luiz Suarez, der in der Verlängerung des WM-Viertelfinales 2010 gegen Ghana als Feldspieler einen gegnerischen Kopfball mit der Hand neben das eigene Tor 
Solche Verhaltensweisen und die dahinter sichtbar werdende Triebfeder des Erfolgsdrucks nähren seit geraumer Zeit Forderungen nach einer Pragmatisierung und moralischen Abrüstung der Sportethik. ${ }^{738}$ Die Zurückstellung des eigenen Erfolges hinter Regeltreue und Tugendhaftigkeit trotz einer erfolgsfixierten externen Erwartungshaltung würde in keinem anderen Lebensbereich erwartet. ${ }^{739}$ Da sich in der modernen Leistungsgesellschaft im Gegenteil vielmehr die rücksichtslose Durchsetzung von Eigeninteressen und Eigensucht ausbreiteten, trüge die strenge Forderung nach Fairness im Sport illusorische Züge und gleiche der Schaffung einer Insel, die einem eingebüßten und anachronistischen moralischen Prinzip das Überleben sichern solle. ${ }^{740}$

Tatsächlich fällt es auch hinsichtlich der Chancengleichheit, die als integrale Teilmenge des Fair Play Gebotes betrachtet wird, ${ }^{741}$ nicht immer leicht, ihr reales Abbild in der Sportwelt festzustellen. Durch sich stark unterscheidende Vermarktungspotenziale, Investorenengagement und Sponsorenattraktivität hat sich etwa in der Fußball-Bundesliga ein Gefälle an finanziellen Möglichkeiten der Vereine herausgebildet, das sich über die Zusammensetzung des Spielerkaders und die Ausstattung von Trainingsanlagen und medizinischen Abteilungen erheblich auf die Aussicht auswirkt, die Meisterschaft zu erringen. Dies wurde zwar von der UEFA selbst erkannt. Das eingeführte Lizensierungsinstrument Financial Fair Play vermag jedoch allenfalls die gröbsten Auswüchse zu unterbinden, nicht jedoch das bestehende Ungleichgewicht zu reduzieren. ${ }^{742}$ Auch das in den nordamerikanischen Profiligen eingesetzte Instrument des Salary Caps, das durch eine für alle Teams verbindlich festgelegte Gehaltsobergrenze eine gleiche Ausgangslage und eine möglichst breitflächige Verteilung guter Spieler auf die verschiedenen Teams bezweckt, ist durch finanzstarke Teambesitzer bevorzugende Ausnahmeregelungen (z.b. die sog. Signing Boni bzw. Luxury Tax) aufgeweicht worden.

lenkte und seiner Mannschaft hierdurch das Weiterkommen sicherte, s. Weinreich Ghana in der Hölle, Uruguay im Paradies, Spiegel Online vom 3.7.2010, www.spiegel.de/sport/fussball/elfmeterdrama-im-wm-viertelfinale-ghana-in-derhoelle-uruguay-im-paradies-a-704428.html.

738 Lenk, in: Cachay/Digel/Drexel (Hrsg.), Pragmatisierung, S. $1 \mathrm{ff}$.

739 Siep, in: Gerhardt/Lämmer (Hrsg.), Fairneß, 1995, S. 87 (92).

740 Volkwein Olympische Jugend 1995, Heft 2, S. 5.

741 Vgl. Guttmann Rekord, S. 25.

742 Hürner Neymar und das Financial Foul Play, Faz.net vom 8.8.2017, www.faz.net /aktuell/sport/fussball/neymars-rekord-transfer-financial-fair-play-gescheitert-151 38608.html; Norouzi/Summerer SpuRt 2015, 63 (64). 
Doch auch abgesehen von der durch die ökonomische Dynamik entstandenen Verzerrungen der finanziellen Ausgangsbedingungen, erweist sich Chancengleichheit als ein relativer Wert. Was als gefährlich für die gleiche Verteilung von Chancen und die Offenheit des Ausgangs des Wettkampfes gilt, stellt sich als Ergebnis von sportinternen Festlegungen und Aushandlungsprozessen dar. $^{743}$ Während die Leistungssteigerung durch unnatürliche Dopingsubstanzen verboten ist, werden naturgegebene Differenzen in der Sauerstoffsättigung des Blutes ebenso toleriert wie die Nutzung vorteilhafter, in ihrem Zugang aber beschränkter Trainingsmethoden und Ausrüstungsgegenstände. ${ }^{74}$ Die Einteilung von Gewichtsklassen im Boxen und Ringen folgt etwa der Annahme, dass nur die Auseinandersetzungen von in ihren körperlichen Voraussetzungen vergleichbaren Kämpfern fair sein können. Die Ziehung der konkreten Gewichtsgrenzen erfolgt letztlich aber willkürlich und unter Hinnahme der bestehenden Unterschiede zwischen einem $75 \mathrm{~kg}$ und einem $83 \mathrm{~kg}$ schweren Ringer.

Letztlich erweist sich das Gebot des Fair Play im Sport als ein zumindest in der Theorie wirkmächtiges Konzept mit mehreren Adressaten. Sportverbände haben ihm durch die Ausgestaltung eines Chancengleichheit garantierenden Regelwerks zur Geltung zu verhelfen. Von den Sportlern verlangt es neben der Akzeptanz dieser Regeln eine verschiedene ungeschriebene Gebote vereinigende Einstellung und Charakterstärke, die sich in einem respektvollen und trotz Ehrgeizes nicht von Eigensucht bestimmten Verhalten auszudrücken hat. Nur der im Sinne des Fair Play errungene Sieg wird als wertvoll betrachtet. Die Kritik an einem unbestimmten und nicht mehr zeitgemäßen Fair Play-Begriff hat bisher nicht zu dessen Relativierung oder gar Aufgabe geführt. Sie wirft allerdings die berechtigte Frage auf, inwieweit es sich bei Fair Play und Chancengleichheit eher um gesellschaftliche Projektionen und vom organisierten Sport beanspruchte Erziehungsideale handelt als um reale, in dessen Wettbewerben vorgelebte Grundprinzipien.

743 Schürmann, in: Asmuth (Hrsg.), Entgrenzungen, 2012, S. 75 (80 f.); Zuck NJW 1999, 831 (832).

744 Gebauer, in: Wagner/Wolf (Hrsg.), Korruption, 2011, S. 136 (143); Schild Sportstrafrecht, S. 135; Lenk, in: Maring (Hrsg.), Bereichsethiken, 2014, S. 301 (320); Wilke Fairness, S. $115 \mathrm{ff}$. 


\section{(2) Fairness als (Straf-)Rechtsbegriff}

Wenngleich es sich beim Fair Play um eine sportspezifische Ausprägung mit eigenständiger Tradition handelt, steht es doch im Kontext einer allgemeineren Auseinandersetzung mit dem Gebot der Fairness. Angestoßen wurde diese maßgeblich in der modernen Moralphilosophie des 20. Jahrhunderts. So erkennt John Rawls in der Fairness eine Grundbedingung einer gerechten Gesellschaft, die er als ein faires System der Kooperation zwischen freien und gleichen Personen definiert. ${ }^{75}$ Die grundlegende Frage, anhand welcher Prinzipien über die Zuweisung von Rechten und Pflichten und die Verteilung von Gütern innerhalb einer Gesellschaft entschieden würde, ließe sich nur in der Übereinkunft freier und gleicher Menschen in einer fairen Verhandlungssituation beantworten. ${ }^{76}$ Ungleichheiten seien nur zu akzeptieren, sofern sie mit Positionen verbunden seien, die allen unter Bedingungen fairer Chancengleichheit offen stünden, und zum Vorteil der am wenigsten begünstigten Mitglieder der Gesellschaft ausfielen. ${ }^{77}$ Hierbei fällt zum einen auf, dass wiederum ein enger Zusammenhang von Fairness und Chancengleichheit hergestellt wird, wobei letztere nicht in einem formalen Sinne als gleiches Recht eines jeden auf vorteilhafte Positionen verstanden wird, sondern sich gruppenbezogen für Personen mit ähnlichen Fähigkeiten realisieren soll. Zum anderen erweist sich Gerechtigkeit in dieser Konzeption nicht als metaphysische Gegebenheit, sondern zuvörderst als Produkt eines fairen Verfahrens.

Gerade an diesem Bedingungszusammenhang zwischen Gerechtigkeit und Verfahren anknüpfend, hat der Begriff der Fairness vielfältig Eingang in den modernen Rechtsstaat gefunden. Erstmalig 1969 im Zusammenhang mit der Zulassung einer Nebenklage vom Bundesverfassungsgericht erwähnt, ${ }^{748}$ gilt das Recht auf ein faires Verfahren mittlerweile als allgemeines Prozessgrundrecht und wird aus dem Rechtsstaatsprinzip i.V.m. Art. 2 Abs. 1 GG abgeleitet. ${ }^{749}$ Insbesondere für den Strafprozess wird das Fairnessprinzip zum obersten Gebot erklärt. ${ }^{750}$ Positiviert wird es dabei durch Art. 6 Abs. 1 S. 1 EMRK, der dem Angeklagten ein umfassendes Recht auf ein faires Verfahren gewährleistet. Durch diesen Grundsatz sol-

745 Rawls Gerechtigkeit als Fairneß, S. 23.

746 Rawls Theorie der Gerechtigkeit, S. 28 f.

747 Rawls Theorie der Gerechtigkeit, S. $336 \mathrm{f}$.

748 BVerfGE 26, 66 (71).

749 BVerfGE 110, 339 (342); Von Mangoldt/Klein/Stark/Nolte/Aust Art. 103 GG Rn. $89 \mathrm{ff}$.

750 Roxin/Schünemann Strafverfahrensrecht $\$ 11$ Rn. 4. 
len verfassungsmäßige Werte wie beispielsweise die Menschenwürde im Strafverfahren ihre größtmögliche Optimierung erfahren. ${ }^{751}$ Hierzu verlangt er eine möglichst ausgeglichene Stellung der Verfahrensbeteiligten, die etwa eine Mitwirkungsmöglichkeit des Angeklagten an der Erarbeitung der Entscheidungsgrundlage vorzusehen hat. ${ }^{752}$ Dadurch prägt die Fairnessgarantie die Auslegung zahlreicher Prozessrechte wie des strafprozessualen Verteidigungs- und Anwesenheitsrechts sowie des Rechts auf Gehör. Der genaue Gehalt ihrer Vorgaben wird jedoch häufig kasuistisch dargestellt und bedarf der Konkretisierung, was ihr mitunter den Vorwurf einer freischwebenden Generalklausel einbringt, die die detaillierten und differenzierten Wertungen des einfachen Prozessrechts überspiele und zur Unübersichtlichkeit des Strafprozesses beitrage. ${ }^{753}$ Insgesamt ist in dem Grundsatz wohl in erster Linie ein Richtwert für gesetzgeberische Entscheidungen und ein Korrektiv für Ermessensentscheidungen der Strafverfolgungsorgane zu sehen, als dass aus einem abstrakten Fairnessprinzip unmittelbar konkrete Rechtsfolgen abgeleitet werden könnten. ${ }^{754}$

Auch in der Auslegung der zivilrechtlichen Vorschrift des $\$ 242$ BGB wird von Fairness im Zusammenhang mit grundrechtlichen Positionen gesprochen. Über derlei Generalklauseln und unbestimmte Rechtsbegriffe können die Grundrechte als verfassungsrechtliche Wertentscheidungen auch in einer privatrechtlichen Streitigkeit im Wege der mittelbaren Drittwirkung Wirksamkeit entfalten, sind dann allerdings von den Fachgerichten in einen fairen Ausgleich zu bringen. ${ }^{755}$ Dieser ist im Wege der sog. praktischen Konkordanz herzustellen, durch die die einschlägigen Grundrechtspositionen in ihrer Wechselwirkung erfasst und für alle Beteiligten zur möglichst weitreichenden Geltung gebracht werden..$^{756}$

Diese Beispiele unterstreichen die rechtliche Bedeutung des Begriffs der Fairness als Verfahrensvorgabe. Er fungiert dabei als ein die jeweiligen Prozessrechte überwölbender Maßstab, der das Prozedere rechtlicher Entscheidungsfindung im Sinne der Rechtsstaatlichkeit vorhersehbar ausgestalten soll, allen tangierten Interessen Gehör und Berücksichtigung zusichert und im Falle ihrer Kollision zur Vornahme eines Ausgleichs gemahnt. Anhaltspunkte für eine rechtliche Rezeption der Fairness auch in ihrer Dimension

751 D. Steiner Fairnessprinzip, S. $140 \mathrm{ff}$.

752 Roxin/Schünemann Strafverfahrensrecht $\$ 11$ Rn. 7; MüKo-StPO/Gaede Art. 6 EMRK Rn. 2.

753 Frisch FS Bruns, 1978, S. 385 (391); Hettinger Der Staat 36, 575 (589).

754 Kindhäuser/Schumann Strafprozessrecht, $\mathbb{1} 18$ Rn. 11.

755 BVerfGE 73, 261 (269); 81, 242 (254); Vieweg/Staschik SpuRt 2013, 227 (230).

756 BVerfGE 129, 78 (101 f.); 134, 204 (223); 142, 74 (101). 
als materieller Wert und Verhaltensanforderung finden sich demgegenüber im Wettbewerbs-, Bilanz- sowie Medienrecht.

Das Gesetz gegen den unlauteren Wettbewerb (UWG) soll gemäß seiner Schutzzweckbestimmung in $\$ 1$ UWG die regelgebundene Lauterkeit des wirtschaftlichen Wettbewerbs schützen und unfaire Verhaltensweisen der Mitbewerber unterbinden. Die Freiheit der wirtschaftlichen Betätigung dürfe nicht dazu führen, dass Einzelne sich durch unzulässige Praktiken Vorteile im Wettbewerb verschaffen. ${ }^{757}$ Der Begriff der Fairness ist dabei zwar kein explizit verwendetes Tatbestandsmerkmal, beeinflusst als Zwecksetzung aber Auslegung und Anwendung der ausfüllungsbedürftigen Generalklausel der „Unlauterkeit“ und ihrer konkretisierenden Einzeltatbestände. ${ }^{758} \mathrm{Im}$ Bilanzrecht verpflichtet $\$ 264$ Abs. 2 S. 1 HGB Kapitalgesellschaften dazu, im Rahmen ihres Jahresabschlusses unter Beachtung der Grundsätze ordnungsgemäßer Buchführung ein den tatsächlichen Verhältnissen entsprechendes Bild der Vermögens-, Finanz- und Ertragslage zu vermitteln. Beeinflusst wurde die nunmehr maßgebliche Orientierung an den tatsächlichen Verhältnissen vom angloamerikanischen Grundsatz des „true and fair view“. ${ }^{759} \mathrm{Ob}$ sich hieraus allerdings für deutsche Unternehmen wirklich neue Anforderungen an die Bilanzierung ergeben haben, die über die Gewährleistung einer realistischen Einschätzung der Gewinnchancen und Verlustrisiken für Aktionäre bzw. des Aktivvermögens für Gläubiger der Gesellschaft hinausgehen, wird bezweifelt. ${ }^{760} \mathrm{Im}$ Medienrecht verpflichten die Rundfunkgesetze der Länder die Angestellten der öffentlich-rechtlichen Sendeanstalten bei wertenden Einzelbeiträgen, Kommentaren und teilweise auch der gesamten Programmgestaltung zu journalistischer Fairness, die eine ausgewogene Berichterstattung unter Berücksichtigung der Auffassungen der wesentlich betroffenen Personen erfordere. ${ }^{761}$ Auch der Pressekodex des Deutschen Presserates enthält das Gebot der fairen Berichterstattung. ${ }^{762}$

757 BVerfGE 32, 311.

758 Vgl. Henning-Bodewig GRUR Int 2002, 389 f.; als Beispiel einer Konkretisierung der Unlauterkeit durch einen weiteren unbestimmten Rechtsbegriff dient die "unternehmerische Sorgfalt" i.S.d. $\$ 3$ Abs. 2 UWG, s. Obly/Sosnitza UWG, $\$ 3$ Rn. 15 f.

759 Tettinger Der Staat 36, 575 (579f.).

760 Westermann, in: Württembergischer Fußballverband (Hrsg.), Fairness-Gebot, 2004, S. 79 ( 88 f.).

761 S. exemplarisch $₫ 8$ Abs. 1 S. 2 Nr. 3 Gesetz zum Staatsvertrag über den Norddeutschen Rundfunk vom 17./18.12.1991.

762 Vgl. Präambel sowie Ziff. 16 des Pressekodex des Deutschen Presserates. 
Diesen Beispielen lässt sich ein allgemeines Kennzeichen der Verwendung des Fairness-Prinzips als Verhaltensmaßstab entnehmen: methodisch wird es mit unbestimmten Rechtsbegriffen verbunden, durch die sein Gehalt im jeweiligen Einzelfall seine Ausprägung finden soll. Mehr als dass es den greifbaren und gegebenenfalls auch mit Zwang durchsetzbaren Kern einer Rechtsvorschrift bildet, fungiert es als interpretationsleitendes Gebot selbiger. ${ }^{763}$ Indem es dabei zur umfassenden und objektiven Bewertung verschiedener Standpunkte verpflichtet und sich gegen Verzerrungen rechtlich gewährter Chancengleichheit richtet, wird es inhaltlich in besonderer Weise mit dem Gleichheitssatz und der bei Anwendung des Verhältnismäßigkeitsprinzips erforderlichen Interessensabwägung verknüpft. ${ }^{764}$

Konkret in der strafrechtlichen Rechtsgutsdiskussion ist Fairness bisher am ehesten als Bestandteil übergeordneter Kollektivrechtsgüter in Erscheinung getreten, wobei sich Schnittpunkte zu den bereits dargestellten integritätsschützenden Delikten zeigen. Explizite Verwendung findet das Adjektiv "fair" etwa in der Kennzeichnung des Wettbewerbs in Wirtschaft und Gesundheitswesen, wie er von $\$ 299$ Abs. 1 Nr. 1, Abs. 2 Nr. 1 StGB bzw. den $\mathbb{S}$ 299a ff. StGB geschützt werden soll. ${ }^{765}$ Auch über den Begriff der Lauterkeit sollen hierbei wirtschaftsethische Verhaltensstandards in die Rechtsgutskonzeption integriert werden. ${ }^{766}$ Wiederum wird dabei stark auf die Chancengleichheit der konkurrierenden Akteure abgestellt, ${ }^{767}$ die über die Einhaltung der bereichsspezifischen Regelwerke gewährleistet werden soll. Ob es allerdings davon abgesehen ein Verhalten geben kann, das sich als materiell unfair und gerade deswegen strafwürdig darstellt, bleibt unklar.

Eine Ausgestaltung des Fairnessprinzips als eigenständiges Rechtsgut wurde jüngst vor allem im Hinblick auf die Legitimation von Delikten im Kapitalmarktstrafrecht wie z.B. dem Verbot des Insiderhandels gemäß $\$ 119$ Abs. 3 WpHG i.V.m. Art. 14 der Marktmissbrauchsverordnung diskutiert. Der Missbrauch von Insiderinformationen verletzt Primärrechtsnormen, übervorteilt andere Anleger und erschüttert damit die für den Kapitalmarkt elementare Zusicherung einer Gleichbehandlung aller Marktteilnehmer. Hieraus leitet der Gesetzgeber das Schutzgut der Funktionsfä-

763 Vgl. Westermann, in: Württembergischer Fußballverband (Hrsg.), Fairness-Gebot, 2004, S. 79 (90).

764 Vieweg/Staschik SpuRt 2013, 227 (230).

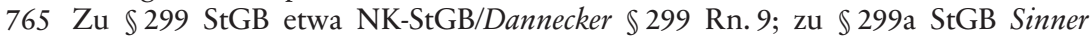
HRRS 2016, 196 (200).

766 Schönke/Schröder/Heine/Eisele Vor $\$ \$ 298$ ff. Rn. 4.

767 LK-StGB/Tiedemann \$299 Rn. 5; NK-StGB/Dannecker \$299 Rn. 12. 
higkeit der organisierten Finanzmärkte $a b,{ }^{768}$ das sich jedoch aufgrund seiner kaum nachweisbaren Prämisse eines ohne Pönalisierung des Insiderhandels massenweise drohenden Rückzugs von Anlegern prononcierter Kritik ausgesetzt sieht. ${ }^{769}$ Als Konsequenz wird mitunter auf die Fairness rekurriert, die als fundamentales Gerechtigkeitsprinzip den Tatbestand eher legitimieren könne als „kollektive Scheinrechtsgüter““770 Dagegen wird allerdings eingewendet, dass einem bloßen Ideal nachgesetzt würde, da es angesichts auf dem Aktienmarkt zwangsläufig existenter Informationsungleichgewichte von vornherein unmöglich sei, einen umfassend fairen Handel herzustellen. ${ }^{771}$ Solange der Gedanke der Unfairness begrifflich nicht präzisiert werden kann, überwiegt wohl noch die Skepsis an einem strafrechtlichen Schutz der Fairness um ihrer selbst willen. ${ }^{772}$ Auch im Zuge der Dopinggesetzgebung wurde allein ein Abstellen auf das Schutzgut der Fairness für unzureichend erachtet, da ein unfaires Verhalten zunächst einmal eine bloße Ausführungsmodalität des unter Umständen mittelbaren Angriffs auf ein tradiertes Individualrechtsgut darstelle, das zu benennen sei. ${ }^{773}$

\section{(3) Vergleich und Einordnung des Gesetzentwurfs}

Es lässt sich somit feststellen, dass es sich bei Fairness um einen vielschichtigen Begriff handelt, der sowohl im Sport als auch im rechtlichen Kontext eine bedeutende Rolle einnimmt. In beiden Bereichen wirkt er zunächst einmal als funktionale Idee für eine Austragung von Konkurrenzbeziehungen. ${ }^{774}$ Der Gestaltung von Regelwerken und Verfahren dient er als formeller Orientierungswert, der nach einer Beteiligung aller tangierten In-

768 BT-Drs. 17/9770, S. 3.

769 Woblers ZStW 125 (2013), 443 (461 ff.).

770 S. den Diskussionsbeitrag von Schünemann auf der Strafrechtslehrertagung 2013 in Zürich, ZStW 125 (2013), 659 (660); in diese Richtung zuvor schon Volk FS Hassemer, 2010, S. 915 (920 ff.), der im Insiderhandel eine Form des strafbaren Eigennutzes und eine primär unmoralische Verhaltensweise erkennt.

771 Wohlers ZStW 125 (2013), 443 (474f.).

772 Klar ablehnend unter Kennzeichnung der Unfairness als Instanz fragwürdigen Pflichtverletzungsdenkens Roxin/Greco Strafrecht AT I $\$ 2$ Rn. 49cf.; vgl. auch die Diskussionsbeiträge von Kablo und Fuchs auf der Strafrechtslehrertagung 2013 in Zürich, ZStW 125 (2013), 659 (662).

773 Momsen, in: Asmuth (Hrsg.), Entgrenzungen, 2012, S. 251 (265).

774 Ott, in: Pawlenka (Hrsg.), Sportethik, 2004, S. 133 (135); Lenk, in: Maring (Hrsg.), Bereichsethiken, 2014, S. 301 (308). 
teressen und der im Ursprung gleichen Verteilung von Möglichkeiten der Einflussnahme verlangt. In der Achtung der Chancengleichheit und der erforderlichen Rücksichtnahme auf die Interessen der Mitbewerber zeigen sich demnach klare Übereinstimmungen. Hierbei lassen sich jeweils auch Bezüge zur grundlegenden moralphilosophischen Bestimmung des Begriffs durch John Rawls erkennen.

Während sich allerdings die Verwendung als Rechtsbegriff weitgehend auf diese regulative Dimension der Fairness beschränkt und auch sein Gebrauch in verhaltenssteuernden Vorschriften primär die Einhaltung von bereichsspezifischen Rahmenbedingungen intendiert, hat das sportspezifische Fair Play in seiner Ausprägung als informelle Leitidee eine umfangreichere Materialisierung erfahren, die vor allem auch ungeschriebene zwischenmenschliche Anstandsregeln umfasst. Der Unterschied lässt sich dabei am Beispiel des freiwilligen Verzichts auf solche Vorteile veranschaulichen, die auf dem Missgeschick oder Pech des Mitbewerbers beruhen. Im Sport wird gerade hierin ein konstitutives Element des Fair Play gesehen, wohingegen ein solcher Verzicht in rechtlichen Beziehungen als überobligatorische Leistung gilt und damit aus dem rechtlichen Fairnessverständnis ausgeklammert wird. ${ }^{775}$

Eine sich dergestalt zusammensetzende sportspezifische Wettkampffairness lässt sich allerdings wiederum nicht ohne weiteres unter Rawls Konzept einer Güterverteilungs- und Anteiligkeitsfairness subsumieren, das zum einen den Genuss von allgemeinen Vorteilen an erbrachte Eigenleistungen bindet und zum anderen die aktive Besserstellung der ohne eigenes Verschulden Benachteiligten durch strukturelle Gegenmaßnahmen anstrebt. ${ }^{776}$ Eine aktive Kompensation naturgegebener oder infrastruktureller Handicaps durch eine übergeordnete Instanz ist im Leistungssport gerade nicht vorgesehen. Im westeuropäischen Flachland aufgewachsenen und trainierenden Langstreckenläufern wird gegenüber ihren physiologisch begünstigten Konkurrenten aus dem ostafrikanischen Hochland kein Vorsprung eingeräumt. Der Skisport-Weltverband FIS wird in Australien keine mit Landematten und einer Anlaufspur aus Keramik ausgestatten Sprungschanzen finanzieren. Im Ergebnis stellt sich das sportspezifische Fair Play somit trotz gewisser Überschneidungen mit dem philosophi-

775 Vieweg/Staschik SpuRt 2013, 227 (230).

776 Lenk, in: Maring (Hrsg.), Bereichsethiken, 2014, S. 301 (305). 
schen und rechtlichen Fairnessverständnis als eigenständige Sondermoral dar. ${ }^{777}$

Auch wenn der Gesetzentwurf zu den $\$ \mathbb{S} 265 \mathrm{c}$, 265d StGB die Fairness nur prominent als schützenswertes Gut benennt, ohne sich durch Präzisierungen klar erkennbar auf die Seite einer der soeben dargestellten Begriffsbedeutungen zu schlagen, ist davon auszugehen, dass er nicht auf ein allgemeines Prinzip rekurriert, sondern gezielt auf die sportspezifische Ausprägung des Fairnessgedankens. Hierfür sprechen die vorgenommene Zuordnung der Fairness zur Integrität des Sports und ihre unmittelbare Ergänzung durch Leistungsbereitschaft und Teamgeist in einer Aufzählung sportethischer Werte. Die Verknüpfung der Fairness mit der Vorbildwirkung der Sportler verdeutlicht, dass es dem Gesetzgeber nicht um eine formelle Wettkampfregel oder Verfahrensvorgabe geht, sondern ein materieller Wert und gesellschaftlich anschlussfähiger Verhaltensmaßstab geschützt werden soll. Nur durch eine solche Auslegung gelingt die intendierte Breitenwirkung, wonach die Inhalte des Fairnessbegriffs eine nachahmenswerte Bedeutung für die Lebensführung insgesamt erlangen und exemplarisch verdeutlichen sollen, wie der Einzelne in einer leistungsorientierten Gesellschaft unter Beachtung der Regeln und im objektiven Vergleich zu Mitbewerbern Erfolge verzeichnen kann. ${ }^{778}$

Untermauert wird diese Auffassung des Fairnessbegriffs auch durch den Einbezug des pönalisierten Angriffswegs in Abgrenzung zum Doping. Die Einnahme verbotener leistungssteigernder Substanzen übervorteilt die Konkurrenten und verschiebt damit den Ausgangspunkt der durch die Sportregeln intendierten Chancengleichheit zu ihren Ungunsten. Die Fairness ist somit vor allem in ihrer formellen Dimension betroffen. ${ }^{779}$ Durch die von $\$ \mathbb{S} 265 \mathrm{c}$, 265d StGB in Bezug genommenen Manipulationen fallen den Konkurrenten hingegen Vorteile zu. Die formelle Chancengleichheit als regulativer Schutz vor verdeckter Benachteiligung wird hierdurch weniger stark beeinträchtigt, weil zumindest in Einzelsportarten der manipulierende Sportler seine Aussichten auf ein gutes Resultat eigenverantwortlich reduziert, ohne dass das Siegstreben redlicher Mitbewerber oder Teamkameraden in Mitleidenschaft gezogen würde. Der vor dem Hintergrund des Fair Play-Verständnisses vorwerfbare Angriff liegt bei solchen Manipulationen eher in der Vernachlässigung einer inneren Einstellung, die in Über-

777 Schild Sportstrafrecht, S. 55 ff.; Vieweg/Staschik SpuRt 2013, 227 (229f.); Pawlen$k a$, in: Maring (Hrsg.), Bereichsethiken, 2014, S. 277 (278 ff.).

778 Momsen, in: Ghosh-Schellhorn/Marti (Hrsg.), Spielregeln, 2008, S. 73 (79 ff.).

779 Lehner/Nolte/Putzke/Nolte AntiDopG $\$ 1$ Rn. 42. 
einstimmung mit der ursprünglichen Grundidee des sportlichen Wettstreitens und aus Respekt vor der diesbezüglichen Erwartungshaltung der $\mathrm{Zu}$ schauer zur Erbringung der bestmöglichen Leistung verpflichtet. Dies weist eine Auslegung somit als Kern des im Gesetzentwurf allgemein gehaltenen Schutzanspruchs der Fairness aus.

\section{(4) Kritik}

Doch kommt ein derartiges Fairnessverständnis als legitimes Strafrechtsgut infrage? Entscheidend hierfür ist seine Überprüfung anhand der dargestellten Materialisierungskriterien eines kritischen Rechtsgutsbegriffs. Zu diesen gehört zunächst die hinreichende Bestimmtheit des geschützten Rechtsguts. Bei der Fairness dürfte es sich also nicht um ein unscharfes Ideal handeln, dessen Abstraktheit es gegen reale Beeinträchtigungen immun stellt. ${ }^{780}$ Dieser Sorge entgegentretend wird angeführt, dass mittels der Tatbestände der $\$ \$ 265$ c, 265d StGB gerade nicht die Fairness als allgemeines Prinzip geschützt werden soll, sondern eine konkrete sportspezifische Ausprägung. Im Rahmen der Dopinggesetzgebung wurde auf deren Konturierung durch die Sportregeln hingewiesen und die bereits erfolgte Rezeption des Fair Play-Gedanken in anderen Rechtsbereichen betont. ${ }^{781}$ Der Strafgesetzgeber könne also an ein sportintern wie auch rechtlich ausgeformtes Konzept anknüpfen.

Auf die unter $\$ \mathbb{S} 265 \mathrm{c}$, 265d StGB fallenden Manipulationsformen lassen sich diese Argumente allerdings nicht übertragen. Denn während sich die Unfairness des Dopings tatsächlich einigermaßen mühelos aus den WADA-Verbotslisten ableiten lässt, hat sich der von Manipulationen zugunsten des Gegners bedrohte Fairnessbereich als diffuser und gerade kaum von Sportregeln eingegrenzt erwiesen. Indem er sich jedenfalls als eine anforderungsreiche innere Einstellung und als ein unter anderem von Verzichtsbereitschaft geprägter materieller Verhaltensmaßstab versteht, übersteigt er die dem Rechtsbegriff der Fairness immanente Zwecksetzung, die sich auf die Herstellung von Verfahrensgerechtigkeit und formeller Chancengleichheit beschränkt. Eine wirklich anschlussfähige und über die verstreute Benennung vereinzelter Elemente hinausgehende Definition der materiellen Sportfairness findet sich aber selbst in der Sportwissenschaft

780 Diedrich, in: Asmuth (Hrsg.), Entgrenzungen, 2012, S. 271 (286f.); s. oben Teil 3 A. II. 1. a) cc).

781 Schlöter Doping, S. 254; Cherkeh/Momsen NJW 2001, 1745 (1750). 
nicht. Am ehesten stellt sie sich als Produkt bestimmter nicht nur sportinterner, sondern sogar sportartspezifischer Aushandlungsprozesse dar, deren Rahmenbedingungen durch die Tendenzen einer Kommerzialisierung des Sports einem stetigen Wandel unterzogen sind. Dies erschwert eine übergreifende Festlegung dessen, was als sportlich fair gilt, und in strafrechtlicher Hinsicht die Bestimmung von Tathandlungen, die eine unmittelbare Nähe zum Rechtsgut aufweisen. ${ }^{782}$ Als bloße Hülle einer Leitidee, die unterschiedlichsten Materialisierungen offen steht und deren reales Substrat in den leistungssportlichen Wettkämpfen zunehmend schwierig $\mathrm{zu}$ identifizieren ist, ${ }^{783}$ kann die sportspezifische Fairness den Bestimmtheitsanforderungen an ein legitimes Rechtsgut nicht genügen. ${ }^{784}$

Als problematisch erweist sich ferner die von legitimen Strafrechtsgütern zu verlangende Abgrenzbarkeit von reinen Moralvorstellungen. Mit der Herauslösung der konkreteren, im Laufe eines langen philosophischen Diskurses konturierten und als Rechtsbegriff rezipierten Fairness aus dem Konstrukt des Sportethos ${ }^{785}$ ist zunächst allenfalls eine terminologische Distanzierung vom Bereich der Moralität verbunden. ${ }^{786}$ Denn auf die Verwendung als Rechtsbegriff kann wegen des aufgezeigten unterschiedlichen Begriffsverständnisses nicht verwiesen werden. Der in Bezug genommene sportspezifisch geprägte Wert der Fairness materialisiert sich derweil über Elemente, die sich zu einem erwünschten Verhaltenskodex in der besonderen Konstellation eines sportlichen Wettkampfs zusammensetzen, deren Verletzung aber nicht zwangsläufig und nicht einmal überwiegend mit der Beeinträchtigung von für den Bestand der Gesellschaft erforderlichen sozialen Funktionen einhergeht. ${ }^{787}$ Respekt, Ritterlichkeit und Vorteilsverzicht beschreiben eine sich innerhalb des von Art.9 GG geschützten Raums der Vereinigungsfreiheit herausgebildete Eigengesetzlichkeit und Sondermoral der Sportwelt, die sich nicht in ein rationales, auf den Schutz

782 Jahn ZIS 2006, 57 (58); Kargl NStZ 2007, 489 (490).

783 Vgl.Jansen GA 2017, 600 (603); Zurawski/Scharf NK 2015, 399 (409).

784 Im Ergebnis so auch Reuther SpuRt 2008, 145 (148); Bohn KriPoz 2017, 88 (92); Jabn ZIS 2006, 57 (58); Bannenberg/Rössner FS Schild, 2007, S. 59 (62); Graf/ Jäger/Wittig/Eschelbach Vor $\$ \$$ 4, 5 AntiDopG Rn. 3; Stellungnahme der Bundesrechtsanwaltskammer Nr. 8/2016, S. 4; Krack ZIS 2016, 540 (545).

785 Hierzu Momsen, in: Asmuth (Hrsg.), Entgrenzungen, 2012, S. 251 (260).

786 Zum Verhältnis von Sportethos als „Ethik des Sports“ und der moralischen Haltung der Fairness als „Ethik der Sportler“ vgl. Schild FS Kargl, 2015, S. 507 (508 f. mwN).

787 Vgl. Heger SpuRt 2007, 153 (154). 
von Rechtsgütern ausgerichtetes Strafrecht importieren lässt. ${ }^{788}$ Denn die Pönalisierung einer hieraus abgeleiteten Unfairness könnte allein an einer Verhaltenseigenschaft, nicht aber an einer durch sie bewirkten Folge anknüpfen und ließe sich somit allein über den abzulehnenden Pflichtverletzungsgedanken rechtfertigen. ${ }^{789}$

Dies gilt auch für den dem sportspezifischen Fairnessbegriff zugerechneten Grundsatz der Chancengleichheit, wenngleich diesem aufgrund seiner vermeintlich von ethischen Prinzipien stärker befreiten Objektivität teilweise Rechtsgutsqualität zugestanden wird. ${ }^{790}$ Tatsächlich hat auch er sich als eine von sportethischen Wertungen durchzogene Festlegung der einzelnen Sportverbände herausgestellt, die sich zwar im Ausgangspunkt einer Idealvorstellung des gerechten Kräftemessens verpflichtet fühlt, andererseits aber auch gewisse Verzerrungen akzeptiert und als einheitlicher Grundsatz und strafrechtlicher Anknüpfungspunkt nicht in Betracht kommt. Die Bestimmung dessen, was in sportlichen Wettbewerben unter gleichen Bedingungen und Chancen zu verstehen ist und welche Verzerrungen man hinzunehmen bereit ist, obliegt einem sportinternen Diskurs, ist Wandlungen unterworfen und verwehrt sich somit einem Schutz durch das Strafrecht. Zudem betrifft das Prinzip der Chancengleichheit die formelle Dimension der Fairness und ist somit nicht in unmittelbaren $\mathrm{Zu}-$ sammenhang mit der Angriffsmodalität der Manipulationshandlung zugunsten des Gegners zu bringen.

Ein Sozialschaden tritt durch den Verstoß gegen diese Gebote schon deswegen nicht ein, weil ihr Geltungsanspruch auf den kleinen und abgegrenzten Bereich des hochklassigen Leistungssports beschränkt bleibt und sich ein solch spezifisches Fairnessverständnis zunächst einmal in keinem anderen Lebensbereich konstatieren lässt. Sofern ein solcher Sozialschaden aber über die immense gesellschaftliche Relevanz des Leistungssports in Verbindung mit seiner wertbildenden Vorbildfunktion konstruiert wer-

788 Jahn ZIS 2006, 57 (58); Reinhart SpuRt 2016, 235 (237); Schlöter Doping, S. 253 ff.; Zurawski/Scharf NK 2015, 399 (410 f.); Kreuzer ZRP 2013, 181 (183); Schild Sportstrafrecht, S. 137 f.; Künast DRiZ 2015, 301.

789 Roxin/Greco Strafrecht AT I $\$ 2$ Rn. 49c.

790 Vgl. Rössner FS Mehle, 2009, S. 567 (573); Momsen-Pflanz Doping, S. 69; Jansen GA 2017, 600 (613 f.), die die Rechtsgutseignung der Chancengleichheit jedoch nicht isoliert, sondern in Verbindung mit der Positionierung innerhalb eines wirtschaftlichen Wettbewerbs diskutieren. 
den soll, ${ }^{791}$ ist dem Folgendes entgegenzuhalten: Den strafrechtlichen Handlungsbedarf mit der kulturellen Bedeutung des Sports zu begründen, hieße, den sich in der Strafrechtsgeschichte vollzogenen Gewinn an Rationalität zu negieren, der gerade durch die Rückführung von Kulturgütern auf konkrete Rechtsgüter als strafrechtliche Schutzobjekte erzielt wurde. ${ }^{792}$ Selbst wenn man hiervon begrenzte Ausnahmen für gesellschaftlich tief institutionalisierte und den sozialen Frieden sichernde Kulturnormen zulassen wollte, ${ }^{793}$ träfen diese Eigenschaften auf die sportspezifische Fairness nicht zu.

In ihren Geboten lässt sich zweifelsohne eine Leitlinie für sozialverträgliches Handeln erblicken und es steht dem Staat frei, für wertvoll erachtete Integrations- und Norminternalisierungsprozesse durch eine finanzielle Subventionierung des Leistungssports zu befördern. Doch zum einen mangelt es an klaren empirischen Belegen für die sozialpsychologischen Auswirkungen von Manipulationen im Leistungssport auf die Wert- und Moralbildung der Gemeinschaft. ${ }^{794}$ Die Wirkkraft des Leistungssports als ein zur Imitation anstiftendes Muster eines kompetitiven, aber fairen Miteinanders bleibt eine Behauptung. Zum anderen ist es schlicht unzulässig, das dem Rechtsgüterschutz verpflichtete Strafrecht in den Dienst der moralischen Volkserziehung zu stellen, indem ihm öffentlichkeitswirksame Verstöße gegen eine bereichsspezifische Ethik untergeordnet werden. ${ }^{795}$ Der potenzielle Verlust an gesellschaftlichen Orientierungswerten rechtfertigt kein strafrechtliches Verbot. Einer befürchteten Einbuße der Geltungskraft des Prinzips der Chancengleichheit etwa stehen schon verfassungsrechtliche Wertungen entgegen, die grundsätzlich jedem dieselben Chancen auf Teilnahme am öffentlichen Leben einräumen. Kommt es bereichsspezifisch zu strukturellen Benachteiligungen müssen die Ursachen in den konkreten Bereichen ausgemacht und behoben werden, ohne dass hierbei eine

791 In diese Richtung Kubiciel jurisPR-StrafR 3/2016 Anm. 1, der von einem historisch tief verwurzelten Bedürfnis mit gemeinschaftsstiftender Bedeutung spricht, so dass dort auftretende Regelumgehungen gesellschaftliche Normerosionen verfestigen könnten; so wohl auch Waßmer ZWH 2019, 6 (7).

792 Vgl. Kudlich SpuRt 2010, 108 f.; Reuther SpuRt 2008, 145 (148).

793 Hierzu Amelung Rechtsgüterschutz, S. 346.

794 Stellungnahme des deutschen Anwaltsvereins Nr. 12/2016, S. 7; Jansen GA 2017, 600 (604).

795 Vgl. Satzger Jura 2016, 1142 (1152); Timm GA 2012, 732 (734 f.); Tsambikakis StV 2018, 319 (320); Momsen KriPoZ 2018, 21 (27); aA wohl Wabnitz/Janovsky/Bannenberg, 4. Auflage, 12. Kapitel Rn. 109, die in den „verheerenden“ Auswirkungen von Manipulationen auf die Sportkultur und die Erziehung der Bevölkerung zum Fair Play einen rechtsgutsrelevanten Aspekt sieht. 
strafrechtliche Bekräftigung der Chancengleichheit im Teilbereich des Leistungssports behilflich sein könnte. ${ }^{796}$ Der Befund der Unbestimmtheit der sportspezifischen Fairness wird demnach durch die Feststellung ergänzt und unterstrichen, dass sie sich aus disparaten Moralvorstellungen zusammensetzt, deren strafrechtlicher Schutz zu einer bedenklichen Ethisierung des Rechtsgüterschutzes ohne Nachweis einer Sozialschädlichkeit führen würde. ${ }^{797}$

Die sportinterne Ausstattung des Fair Play mit einem unterschiedliche Akteure umfassenden Adressatenkreis und die entsprechende gesetzgeberische Schutzintention eines über Vorbilder in die Gesellschaft ausstrahlenden Grundprinzips charakterisieren die sportspezifische Fairness als ein überindividuelles Interesse, das sich nicht nur im bilateralen Verhältnis zweier konkurrierender Sportler entfaltet. Als solches müsste sie mit den für kollektive Rechtsgüter erweiterten Legitimationsbedingungen vereinbar sein. Sie müsste also selbst verletzbar sein und diese Verletzung zumindest das Potenzial in sich tragen, auch die Beeinträchtigung individueller Rechtssphären bewirken zu können. ${ }^{798}$ Schon hinsichtlich einer realen Verletzbarkeit lassen sich aufgrund des unbestimmten und mittels ebenso abstrakter wie disparater Moralvorstellungen aufgeladenen Begriffsverständnisses Zweifel äußern. Jedenfalls kann ein Durchschlagen festgestellter Fairnessverstöße auf die individuelle Rechtssphäre nicht über die Relevanz eines fairen Wettbewerbs für die Autonomie des einzelnen Sportlers begründet werden, wie dies teilweise unter Verweis auf die Mechanismen einer sog. „Dopingfalle“ für die Straftatbestände des AntiDopG versucht wird. ${ }^{799}$ Denn die Autonomie des redlichen Sportlers wird von den unter die $\$ \$ 265$ c, 265d StGB fallenden Manipulationsformen weit weniger stark betroffen, weil ihnen mangels Verbesserung der eigenen Siegchancen kein vergleichbarer Druck innewohnt, sich in gleicher Weise manipulativ zu verhalten.

796 Timm GA 2012, 732 (735).

797 Vgl. Feltes/Kabuth NK 2017, 91 (92 f.); Norouzi/Summerer SpuRt 2015, 63 (64); Kauerhof, in: Asmuth (Hrsg.), Entgrenzungen, 2012, S. 291 (327); die sportspezifische Fairness aufgrund ihrer primär moralischen Konstitution in gleicher Weise als Rechtsgut ablehnend Stellungnahme der Bundesrechtsanwaltskammer Nr. 8/2016, S. 4 f.; Heger SpuRt 2007, 153 (154); PHB-SportR/Reinhart, 3. Aufl., 8. Teil 4. Kap. Rn. 149; Prittwitz FS Schiller, 2014, S. 512 (534 ff.); Diedrich, in: Asmuth (Hrsg.), Entgrenzungen, 2012, S. 271 (287).

798 Momsen, in: Asmuth (Hrsg.), Entgrenzungen, 2012, S. 251 (261).

799 S. Wabnitz/Janovsky/Bannenberg, 4. Auflage, 12. Kapitel Rn. 109. 
Gelegentlich mag ein unfaires Verhalten im Wettbewerb den Ausgangspunkt einer anschließend eintretenden finanziellen Schädigung eines vom Schutzbereich des Fairnessgebots erfassten Akteurs darstellen. So können beispielsweise mutwillige Fehlentscheidungen eines bestochenen Schiedsrichters zum Nachteil eines Teams deren Angehörige um eine Siegprämie bringen. Hierfür haben sich an das unfaire Verhalten jedoch regelmäßig eine Reihe von dem Einfluss des unfair Handelnden entzogenen Ereignissen anzuschließen. So muss eine solche Prämie zunächst einmal clubintern vereinbart worden sein. Ferner darf sich die spielerische Überlegenheit des Teams nicht als so groß erweisen, dass sie die Benachteiligung durch den Schiedsrichter wettmacht und der Sieg gleichwohl errungen wird. Im Fairnessverstoß an sich ist eine solche Vermögensschädigung also keineswegs bereits angelegt. ${ }^{800}$ Der lose Zusammenhang entsteht überhaupt erst aufgrund der Kommerzialisierung des Sports, die aber gerade den Konterpart zum ursprünglichen Fair Play-Verständnis als Leitidee eines zweckfreien Sports verkörpert.

\section{(5) Zwischenergebnis}

Im Rahmen des vom Gesetzgeber zur Legitimation der $\$ \$ 265$ c, 265d StGB vorgebrachten Schutzgutes der Integrität des Sports wird die Fairness als wesentlicher Bestandteil begriffen. Tatsächlich stellt das Gebot des Fair Play Leitidee und Richtschnur des Sports dar und soll in der Ausgestaltung von Regelwerken genauso seinen Ausdruck finden wie im Verhalten der Sportler während eines Wettkampfes. Dass gerade sein materieller Gehalt nicht klar definiert, sondern uneinheitlich aus bejahenden Einstellungen gegenüber den Werten des Sports und allgemeinen, positiven Charaktereigenschaften zusammengesetzt wird, ist dabei ebenso kritisch zu hinterfragen wie die Vereinbarkeit des Prinzips mit der gleichzeitig vorangetriebenen Kommerzialisierung des Sports. Im Vergleich zur rechtlichen Rezeption des Fairnessbegriffs, die sich hauptsächlich in Verfahrensvorgaben zu Gleichbehandlung und Interessensausgleich niederschlägt, erweist sich das sportspezifische Fair Play als voraussetzungsreicher.

800 Vgl. auch Krack ZIS 2016, 540 (545); hinsichtlich eines hinreichenden Vermögensbezugs der Fairnessverletzung zwischen Doping und Schiedsrichterbestechung differenzierend Momsen, in: Ghosh-Schellhorn/Marti (Hrsg.), Spielregeln, 2008, S. 73 (79 ff.). 
Womöglich auch in Reaktion auf die in der Strafrechtswissenschaft anklingenden Zweifel an der Rechtsgutsqualität eines allgemeinen FairnessPrinzips, stellt die Gesetzesbegründung gerade auf die sportspezifische Erscheinungsform ab. Ihrer Eignung als legitimes Strafrechtsgut stehen jedoch gewichtige Bedenken entgegen. Das Fehlen greifbarer Begriffselemente und die Flucht in einen hohen Abstraktionsgrad unterwandern die Forderung nach der Bestimmtheit eines Rechtsguts, die für die Qualifikation einer konkreten Handlung als verletzend unerlässlich ist. In den bislang untauglichen Versuchen einer klareren Konturierung werden vor allem ethische Werte herangezogen, die in spezifischen Aushandlungsprozessen des autonomen Sports ihre Prägung erhielten. Der Unwertgehalt von Verstößen gegen die sportspezifische Fairness erschöpft sich somit in Herabsetzungen einer sportinternen Sondermoral. Die gesellschaftliche Anteilnahme am Fair Play-Prinzip erschöpft sich in Projektionen und moralischen Wunschvorstellungen, die ihm keinen realen bzw. verletzbaren Gehalt verleihen. Eine erforderliche Sozialschädlichkeit lässt sich auch über eine empirisch kaum nachgewiesene und der Aufgabe eines liberalen Strafrechts widersprechende erzieherische Funktion des Leistungssports nicht überzeugend begründen. Zudem fehlt es an der Rückführbarkeit des allgemeinen Interesses an sportspezifischer Fairness auf rechtlich relevante Individualinteressen. Die Fairness ist als legitimes Rechtsgut demnach abzulehnen.

bb) Leistungsbereitschaft

Inwiefern das sportspezifische Fair Play Gebot auch die Leistungsbereitschaft des Sportlers umfasst, kann gegensätzlich beurteilt werden. Auf der einen Seite zählt die Zusage von Anstrengungen zur Respekterbietung gegenüber der Grundidee des Sports. So war bereits der sich auf der Grundlage einer kaufmännischen Geschäftsethik bildende Fair Play Gedanke des 19. Jahrhunderts von der Absicht geprägt, sich an die Spielregeln zu halten und sein Bestes gegen den herausgeforderten Gegner zu geben, um das Spiel innerhalb der Regeln zu gewinnen. ${ }^{801}$ Andererseits lässt sich im Leistungsstreben auch eine primär selbstbezügliche Erwartungshaltung sehen, die mit der Forderung des Fair Play-Prinzips nach Rücksichtnahme auf den Gegner durchaus gelegentlich in Konflikt geraten kann. Jedenfalls wird auch die im Sport zu erbringende Leistungs- und Einsatzbereitschaft

801 Momsen-Pflanz Doping, S. 52. 
als ein vorbildhaft zur charakterlichen Formung beitragender Wert und somit als schützenswerter Bestandteil der Integrität des Sports aufgefasst. ${ }^{802}$ Erst die stillschweigende Übereinkunft der Teilnehmer, das eigene Leistungsvermögen vollumfänglich einzusetzen und sich nach Kräften um ein möglichst gutes Ergebnis zu bemühen, verleiht der ursprünglichen Idee des Miteinander-Wetteiferns ihren Sinn und Reiz. Im Umkehrschluss bedeutet eine mutwillige Leistungsverweigerung einen Angriff auf die Grundfesten des Sports. Insofern tritt die spezifische Angriffswirkung der tatbestandlichen Manipulation eines sportlichen Wettbewerbs zugunsten des Wettbewerbsgegners auf das Schutzgut der Leistungsbereitschaft deutlicher zu Tage als dies mit Blick auf die Kernelemente der Fairness festgestellt werden konnte.

Trotz der grundsätzlich integralen Bedeutung der Leistungsbereitschaft sucht man die Verankerung einer entsprechenden Verpflichtung der Sportler in den Regelwerken vergeblich. Und tatsächlich lassen sich selbst in der Realität des Spitzensports mannigfaltige Abweichungen von ihr beobachten. Einige erklären sich damit, dass die körperlichen Anforderungen bestimmter Wettbewerbe ein durchgängiges Abrufen der maximalen Leistung schlicht nicht zulassen. So geben Tennisspieler insbesondere in auf drei Gewinnsätze ausgerichteten Partien einzelne Sätze nach frühem Rückstand bewusst durch eingeschränkten Bewegungseinsatz ab, um sich für den womöglich entscheidenden folgenden Satz zu schonen. Und Straßenradfahrer verzichten in bestimmten Rennsituationen freiwillig auf einen errungenen Vorsprung, um sich im Windschatten einer größeren Gruppe „auszuruhen“.

Die Beispiele eines bewussten Leistungsverzichts lassen sich auf Fälle erweitern, in denen dieser nicht nur situativ zum Zwecke der strategischen Kräfteeinteilung erfolgt, während am Ziel der Erreichung des bestmöglichen Resultats festgehalten wird. Mitunter bleiben einzelne Sportler oder ganze Teams systematisch hinter ihrem Leistungsvermögen zurück und nehmen hierbei nachteilige Wettkampfergebnisse in Kauf, weil sie sich hiervon langfristig wettbewerbsimmanente Vorteile versprechen. Diese können in der Aussicht auf vermeintlich schwächere Gegner im weiteren Turnierverlauf bestehen, die bereits für die Endrunde qualifizierte Teams zu Niederlagen im letzten Vorrundenspiel animiert. Auch die Aussicht, das eigene Team zur neuen Spielzeit mit dem talentiertesten Nachwuchs-

802 BT-Drs. 18/8831, S. 10; Gienger DRiZ 2016, 16; Momsen, in: Asmuth (Hrsg.), Entgrenzungen, 2012, S. 251 (264). 
spieler verstärken zu können, mag ausschlaggebend für einen bewussten Leistungsverzicht sein. ${ }^{803}$

Die Statuierung einer nachahmenswerten Pflicht, für den eigenen Erfolg vollen Leistungseinsatz zu zeigen, zielt demnach an den Realitäten des Sports vorbei. Sie existiert weder uneingeschränkt im Leistungssport, wo der bewusste Verzicht auf ein Ausschöpfen des Leistungsvermögens nicht nur situativ, sondern bereichsweise auch systematisch erfolgt, noch im Breitensport, dessen Aufgabe gerade darin besteht, Muster für eine lebenslange körperliche Betätigung und eine gesunde Lebensweise zu entwickeln. ${ }^{804}$ Ähnlich wie im Fall des Fair Play handelt es sich auch bei der Leistungsbereitschaft um ein vielfach idealisiertes sportethisches Prinzip, das sich bei näherer Betrachtung als ambivalent erweist und dessen tatsächlich diffuser Gehalt es als strafrechtliches Rechtsgut disqualifiziert. ${ }^{805}$ Verstöße gegen eine idealisierte Vorstellung von Disziplin und Leistungswillen im Teilbereich des Leistungssports zu pönalisieren, um diese Tugenden hierüber in der nicht belegten Erwartung einer breitflächigen Werteübertragung in das gesamtgesellschaftliche Bewusstsein einzuschreiben, weist den Staat als reinen Moralunternehmer aus. Grundsätzlich können die Mitglieder einer liberalen Gesellschaft frei darüber entscheiden, worauf sie wieviel ihrer persönlichen Ressourcen verwenden. Zwar mag es für den Staat erstrebenswert sein, sie in ihren jeweiligen Arbeitsbereichen zu Anstrengungen und Höchstleistungen zu animieren. Einen Anspruch auf individuelle Leistungsstärke besitzt er jedoch nicht. ${ }^{806}$ Demnach kann auch ein bereichsspezifisches strafrechtliches Verbot unzureichenden Einsatzwillens nicht symbolisch mit einer andernfalls drohenden sozialen Entwertung des Leistungsprinzips begründet werden ${ }^{807}$ Ohne diese Argumentationslinie verbleibt jedoch eine Verhaltensweise, die schon sportintern zwar unerwünscht, aber nicht untypisch ist, keine konsequente Sanktionierung nach sich zieht und erst recht keine über die Grenzen des Leistungssports

803 Zur Förderung des absichtlichen Verlierens (sog. Tanking) durch das Draft-System in nordamerikanischen Profiligen bereits oben Teil 2 A. II. 3. b).

804 Stellungnahme der Bundesrechtsanwaltskammer Nr.8/2016, S. 6 f.; Stellungnahme des Deutschen Richterbundes Nr. 2/2016, S. 3.

805 Vgl. Satzger Jura 2016, S. 1142 (1152).

806 Reinhart SpuRt 2016, 235 (238); Timm GA 2012, 732 (736 Fn. 14). Zwar kann sich ein solcher Anspruch arbeitsvertraglich gegen Spitzensportler richten. Eine hieran anknüpfende Strafbarkeit liefe dann aber auf die abzulehnende Kriminalisierung bloßer Vertragsverletzungen hinaus, vgl. Stellungnahme der Bundesrechtsanwaltskammer Nr. 8/2016, S. 7.

807 Timm GA 2012, 732 (736). 
hinausgehende soziale Unerträglichkeit kennzeichnet. ${ }^{808}$ Die Heranziehung des sportethischen Werts der Leistungsbereitschaft als Rechtsgutsbestandteil hält einer kritischen Überprüfung folglich nicht stand.

\section{cc) Vertrauen der Allgemeinheit in die Integrität des Sports}

Es hat sich bereits gezeigt, dass der strafrechtliche Integritätsschutz auch über eine allgemeine Vertrauenskomponente begründet wird. Gerade sie soll die Sozialrelevanz des geschützten Teilsystems verdeutlichen. Dessen bereichsspezifisches Ethos soll nicht in einem Vakuum und nicht allein um seiner selbst willen geschützt werden, sondern auch aufgrund einer Erwartungshaltung der von seiner Beachtung profitierenden Allgemeinheit. Die Einbeziehung einer Vertrauenskomponente erweitert eine zunächst nach innen gerichtete Schutzwirkung also um eine Außenwirkung. ${ }^{809}$

Diese Argumentationslinie wird auf den Leistungssport übertragen. Die Übernahme der positiven ideellen Werte des Sports wie Fairness, Leistungsbereitschaft, Teamgeist und Toleranz erfolge aufgrund einer dem Sport gegenüber eingenommenen Haltung, die über bloßes Interesse hinausgeht. Das Wort Vertrauen wird im Gesetzentwurf zwar nicht ausdrücklich genannt. Es ist aber in der explizit als Schutzobjekt herangezogenen Vorbildwirkung des hochklassigen Leistungssports ${ }^{810}$ inbegriffen, da die behaupteten Identifikationsprozesse mindestens die allgemeine Vorstellung voraussetzen, dass sich dessen Akteure den sportethischen Werten verpflichtet fühlen. Im Gesetzentwurf zum Anti-Doping Gesetz wurde das kollektive Vertrauen darauf, dass sportliche Wettbewerbe fair durchgeführt werden und die Teilnehmer die gleichen Chancen haben, zur Grundvoraussetzung für die Anerkennung und Zukunft des organisierten Sports erklärt. ${ }^{811}$ Denn aufgedeckte Manipulationen erschütterten diese Vorstellung und provozierten eine grundlegende Enttäuschung, die nicht nur eine kollektive Abwendung von der Beschäftigung mit dem Leistungssport zur Folge habe, sondern auch einen Rückzug aus dem Breitensport anstoßen könnte. Hinsichtlich sämtlicher wertvoller Funktionen des Sports wird demnach die Notwendigkeit einer erhöhten Glaubwürdigkeit ausgemacht, die bereits durch den bösen Schein einer Manipulationsbe-

808 Stellungnahme der Bundesrechtsanwaltskammer Nr. 8/2016, S. 7.

809 Vgl. Kargl ZStW 114 (2002), 763 (782).

810 BT-Drs. 18/8831, S. 10, 11.

811 BT-Drs. 18/4898, S. $26 \mathrm{f}$. 
reitschaft in Gefahr gerate. ${ }^{812}$ Als Bindeglied zwischen dem zunächst nur intern gültigen Sportethos und der moralischen Einstellung und Verhaltensausrichtung der Gesellschaft wird das Vertrauen der Allgemeinheit in die Integrität des Sports in die Rechtsgutsbestimmung einbezogen. ${ }^{813}$

\section{(1) Voraussetzungen eines legitimen strafrechtlichen Vertrauensschutzes}

Auf der Grundlage einer rechtsgutsorientierten Strafrechtsbegründung fordern Versuche, Strafnormen über Gesichtspunkte des Vertrauensschutzes zu legitimieren, zunächst einmal Einwände heraus. Durch die Qualifizierung einer subjektiven Befindlichkeit als Rechtsgut gebe man dessen strafrechtsbegrenzendes Potenzial auf, da Vertrauen in alles und jeden gefasst werden könne und sich auch nahezu sämtliche der bereits geregelten Delikte des StGB um ein „Vertrauen in etwas“ erweitern ließen. ${ }^{814}$ Eine solche Tendenz lässt sich etwa beobachten, wenn Vertrauen zum Bestandteil eines individuellen Rechtsguts erklärt wird, indem es gerade auf die Geltung einer Norm bezogen wird. Im Wege eines Reflexes enttäuscht normwidriges Verhalten die individuelle Erwartung der generellen Anerkennung der Norm. Hierin kann allerdings kein rechtsgutsrelevanter Primärschaden gesehen werden, da der eintretende Vertrauensverlust zwingend an das Bestehen einer Norm gebunden ist, die aber zunächst einmal für sich genommen begründet werden muss. ${ }^{815}$ Die Stärkung des Vertrauens in die Geltungskraft und Unverbrüchlichkeit einer Norm mag unter dem Schlagwort der positiven Generalprävention einen möglichen Zweck der Strafe darstellen, liefert aber keinen eigenständigen Begründungstopos für die Schaffung eines strafrechtlichen Verbotes.

Anders wird dies bewertet, sofern als Gegenstand des Vertrauens nicht die bloße Normgeltung, sondern bestimmte Systeme oder Institutionen ausgewiesen werden. Die Bereitschaft, die Rechtsgutsrelevanz eines solchen Systemvertrauens der Allgemeinheit anzuerkennen, zeigt sich insbesondere bei den Bestechungsdelikten im Amt sowie ausgewählten Wirtschaftsdelikten und wird vom Bundesverfassungsgericht auch nicht als

812 Hutz/Kaiser NZWiSt 2013, 379 (384); Momsen-Pflanz Doping, S. 53 f.; Schild Sportstrafrecht, S. $134 \mathrm{ff}$.

813 Explizit im Rahmen der Anti-Doping-Gesetzgebung, s. BT-Drs. 18/4898, S. 26 f.

814 Kargl ZStW 114 (2002), 763 (784).

815 Hefendehl Kollektive Rechtsgüter, S. 35; Kargl, in: Neumann/Prittwitz (Hrsg.), Personale Rechtsgutslehre, 2007, S. 41 (60 f.). 
grundsätzlich verfassungswidrig verworfen. ${ }^{816}$ So erkennt die herrschende Meinung den Schutzzweck der $\$ \$ 331 \mathrm{ff}$. StGB im Vertrauen der Allgemeinheit in die Gesetzmäßigkeit und Sachlichkeit der staatlichen Verwaltung. ${ }^{817}$ Vom Tatbestand der Abgeordnetenbestechung ( $(108 \mathrm{e}$ StGB) werde das öffentliche Vertrauen in die Nichtkäuflichkeit der Mandatsausübung geschützt. ${ }^{818}$ Die Straftatbestände des Kapitalanlagebetrugs ( $\$ 264 a$ StGB), des Insiderhandels sowie der Marktmanipulation werden mit dem Vertrauen der Allgemeinheit in einen funktionierenden und integren Kapitalmarkt begründet. ${ }^{819}$ Und auch bei den wettbewerbsbeschränkenden Absprachen bei Ausschreibungen ( $\$ 298$ StGB) bzw. der Bestechlichkeit und Bestechung im geschäftlichen Verkehr $(\mathbb{2} 299$ StGB) wird im Rahmen der Rechtsgutsdiskussion teilweise auf ein Vertrauen der Allgemeinheit in den freien und redlichen wirtschaftlichen Wettbewerb abgestellt. ${ }^{820}$

Ein Vergleich der hier als Vertrauensgegenstand angeführten Systeme weist zwei verbindende Kennzeichen auf. Zum einen ist ihnen eine hohe Sozialrelevanz zu attestieren. Ihre Existenz und ihr ordnungsgemäßes Funktionieren prägen die Möglichkeitsbedingungen der durch das Grundgesetz garantierten Rechte des Einzelnen. Indem er verspricht, im Austausch gegen das Gewaltmonopol die Freiheit des einzelnen zu sichern, zählt der Staat mitsamt seiner Verwaltung zu den wichtigen Rahmenbedingungen individueller Freiheit. ${ }^{821}$ Ein regulierter wirtschaftlicher Wettbewerb soll übermäßige wirtschaftliche Macht binden und einen Rahmen für die Entfaltung individueller Leistungsfähigkeit schaffen, auf dass letztlich eine gesamtgesellschaftlich optimale Verteilung von Gütern gewähr-

816 So führt BVerfG NStZ 1985, 173 aus: „Das Grundgesetz verbietet es nicht, in dem solchermaßen enttäuschten Vertrauen ein Rechtsgut zu erblicken, welches des strafrechtlichen Schutzes bedürftig ist."

817 BGHSt 15, 354; 47, 22 (25); BT-Drs. 18/4350, 24; LK-StGB/Sowada Vor $₫ 331$ Rn. $34 \mathrm{ff}$.

818 BT-Drs. 12/5927, S. 4; Lackner/Kühl/Heger/Heger $\$ 108$ e Rn. 1; krit. NK-StGB/ Kargl $₫ 108$ e Rn. 6.

$819 \mathrm{Zu} \ 264$ a StGB s. BGHZ 116, 7 (13); Wessels/Hillenkamp/Schuhr Strafrecht BT II Rn. 696; krit. MüKo-StGB/Ceffinato \$264a Rn. 6; Fischer StGB \$264a Rn. 2; zu den Börsendelikten s. BT-Drs. 17/9770, S. 3; Achenbach/Ransiek/Rönnau/Trüg Teil 10 Kapitel 2 Rn. 15; Tiedemann Wirtschaftsstrafrecht Rn. 1041; krit. Woblers ZStW 125 (2013), 443 (460 ff.).

$820 \mathrm{Zu} \ 298$ StGB: Hefendehl Kollektive Rechtsgüter, S. 279 f., 388; krit: MüKo-

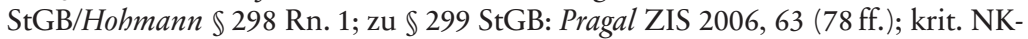
StGB/Dannecker $\$ 299$ Rn. 10.

$821 \mathrm{Kargl} \mathrm{ZStW} 114$ (2002), 763 (789 f). 
leistet wird. ${ }^{822}$ Gleichzeitig wird ein marktwirtschaftliches System ohne funktionierenden Kapitalmarkt als undenkbar angesehen. ${ }^{823}$

Zum anderen fällt die jeweilige Abhängigkeit der Systeme von einer Interaktion mit der Allgemeinheit ins Auge. Die staatliche Verwaltung bedarf in einem demokratischen Rechtsstaat des Glaubens der Bevölkerung an die Rechtmäßigkeit ihrer Entscheidungen. ${ }^{824}$ Und wirtschaftliche Märkte entstehen überhaupt erst durch die Partizipation von Akteuren, die sich von einem gegenseitigen Austausch unter geregelten Bedingungen einen Nutzen versprechen. Demzufolge stellt Vertrauen also eine unverzichtbare Voraussetzung der Funktionsfähigkeit dieser Systeme dar. ${ }^{825}$ Nicht zuletzt die im Jahr 2008 ihren Ausgang nehmende Finanzkrise verdeutlichte eindrucksvoll, wie zunächst trügerisches und später massenhaft entzogenes Vertrauen den Kapitalmarkt in seinen Grundfesten erschütterte. ${ }^{826}$

Werden die Systeme demnach aufgrund ihrer freiheitssichernden Garantien als strafrechtlich schützenswert erachtet, ist das in sie gesetzte Kollektivvertrauen als konstituierendes Element in die Rechtsgutsbestimmung einzuschließen. Denn potenzielle Vertrauensverletzungen ereignen sich nicht mehr nur auf der nachrangigen Ebene der Normstabilisierung, sondern greifen eine Säule der Norm selbst an und stellen den erforderlichen Primärschaden dar. ${ }^{827}$ Dem Einwand, die Anbindung des Vertrauens an ein Kollektiv lasse den Bezug auf die Entfaltungsbedingungen des Einzelnen vermissen, ${ }^{828}$ ist entgegenzuhalten, dass gerade durch die Akzentverschiebung auf das Vertrauen der Allgemeinheit staatliche Institutionen und Systeme nicht mehr um ihrer selbst willen geschützt werden und sich ein solches Systemvertrauen gerade auf die individuellen Handlungsspielräume im Hinblick auf die Betätigung grundrechtlich zugesicherter Freiheiten auswirkt. ${ }^{829}$

Aus diesen Erwägungen ergibt sich kein Freibrief, das Strafrecht durch Schaffung kollektiver Vertrauensrechtsgüter ins Grenzenlose zu erweitern.

822 Satzger Submissionsbetrug, S. 52; Kubiciel, in: Kempf/Lüderssen/Volk (Hrsg.), Prototyp, 2015, S. 158 (168).

823 Otto, in: Schünemann/Tiedemann (Hrsg.), Madrid-Symposium, 1992, S. 447 (456).

824 Haft NJW 1995, 1113 (1116); Schramm JuS 1999, 333, (336).

$825 \mathrm{Vgl}$. Lackner/Kühl/Heger/Heger $\$ 331$ Rn. 1.

826 Hefendehl GS Weßlau, 2015, S. 576 (589f.).

827 Hefendehl Kollektive Rechtsgüter, S. 125 f.

828 Vgl. MüKo-StGB/Hohmann $\$ 298$ Rn. 1; Kargl, in: Neumann/Prittwitz (Hrsg.), Personale Rechtgutslehre, 2007, S. 41 (74f.).

829 Trüg FS Rössner, 2015, S. 686 (694); Hefendehl Kollektive Rechtsgüter, S. 124. 
Vielmehr ist ihnen ein klares Programm an Mindestbedingungen für einen legitimen strafrechtlichen Vertrauensschutz zu entnehmen. Ein strafrechtlich schützenswertes Kollektivvertrauen hat sich stets auf einen hinreichend bestimmten Vertrauensgegenstand zu richten. Hierbei muss es sich um eine gesamtgesellschaftlich wertvolle Funktionseinheit handeln, deren Funktionsfähigkeit sich aus der vertrauensbasierten Interaktion ergibt und je nach ihrer kollektiven Einschätzung konkrete Handlungsanreize für den Einzelnen setzt. Von Bedeutung ist weiterhin, dass ein gegenstandsbezogenes Vertrauen in hinreichend großem Umfang in der Gesellschaft tatsächlich ausgebildet ist. Das Strafrecht vermag nur bestehendes Vertrauen zu schützen, nicht hingegen fehlendes Vertrauen zu erzeugen. ${ }^{830}$ Lässt sich ein real existierendes Vertrauen nicht nachweisen, basiert ein sich über Vertrauen konstituierendes Rechtsgut auf einer bloßen Fiktion und immunisiert sich gegen Verletzungen. Diese Legitimationsbedingungen sind für jeden Einzelfall des geltend gemachten strafrechtlichen Vertrauensschutzes zu überprüfen. Sie erweisen sich als operationalisierbar und bergen begrenzendes Potenzial, mithilfe dessen sich an den sozialen Gegebenheiten vorbeizielende Annahmen aufspüren lassen ${ }^{831}$ und illegitime Vertrauensrechtsgüter, die über die Bezugnahme des Vertrauens lediglich eine mitunter unverhältnismäßige Vorverlagerung des Individualschutzes bezwecken, dekonstruiert werden können. ${ }^{832}$

\section{(2) Konkrete Einordnung und Kritik}

Nach alldem kann ein kollektives Vertrauen unter bestimmten Voraussetzungen zur Legitimation eines strafrechtlichen Tatbestandes beitragen. $\mathrm{Ob}$ dies für das geltend gemachte Vertrauen der Allgemeinheit in die Integrität des Leistungssports gilt, muss eingehend anhand der dargestellten maßgeblichen Kriterien überprüft werden. Zweifel ergeben sich bereits hinsichtlich der Frage, ob ein solches Vertrauen einen hinreichend bestimm-

830 Lampe FS Welzel, 1974, S. 151 (162); Hefendebl Kollektive Rechtsgüter, S. 259.

831 Exemplifiziert wird das von Woblers ZStW 125 (2013), 441 (460 ff.) anhand der Hinterfragung der zur Rechtfertigung der Börsendelikte angeführten These, laut der gerade die Kenntnis von Insidergeschäften die Anleger in ihrem Vertrauen in den Kapitalmarkt beeinträchtigten und einen massenhaften Rückzug provoziere.

832 Hierzu Hefendehl Kollektive Rechtsgüter, S. 262, 266, 274 am Beispiel des Kredit- und Versicherungsbetrugs ( $\$ 265$ b bzw. $\$ 265$ StGB) sowie der Insolvenzdelikte gemäß $\$ \$ 283$ ff. StGB. 
ten Bezugspunkt erkennen lässt. Dies ließe sich noch für den Fall annehmen, dass sich das Vertrauen allein auf die Nichtkäuflichkeit von Sportlern richtet. Die Erwartung, Leistungssportler würden sich dem Angebot externer Vorteile für die Zusage einer Wettbewerbsmanipulation kategorisch verweigern, lässt sich klar umreißen und der Allgemeinheit unproblematisch zuordnen. Durch den Rekurs auf die allgemeine Vorbildwirkung und die Rolle des Sports als Vermittler positiver Werte wird der Bezugspunkt des zum Schutzgegenstand erklärten Vertrauens jedoch dergestalt erweitert, dass sich Leistungssportler in hochklassigen Wettbewerben in einem umfassenden Sinne fair, leistungsbereit und teamorientiert verhalten.

Wie gezeigt erhalten diese Werte aber schon sportintern keine einheitlichen definitorischen Konturen und ihre Ausprägungen im tatsächlichen Sportgeschehen lassen sich aufgrund einiger tolerierter Durchbrechungen nicht immer eindeutig erkennen. Ihre Unbestimmtheit und weitgehend moralische Komposition korrespondieren mit einer Diversität an sportbezogenen Fairness-Vorstellungen in der Gesellschaft, die von den unterschiedlichen emotionalen Bindungen zu den Akteuren noch verstärkt wird. Während der emotional unbeteiligte Zuschauer eines Fußballspiels zu höheren Ansprüchen an einen fairen Leistungsvergleich neigen dürfte, die etwa einen respektvollen Umgang und die Rücksichtnahme auf den Gegner einschließen, kann ein Partei ergreifender Fan wohl auch die verbale Einschüchterung des gegnerischen Teams, ein spieltaktisches Foul oder die Zeitverzögerung der eigenen Spieler zur Bewahrung eines Vorsprungs mit seinem Verständnis von Fair Play vereinbaren. Hinsichtlich des Ausmaßes der Selbstbindung von Leistungssportlern an einen sportethischen Verhaltenskodex wird sich eine einheitliche Erwartungshaltung der Zuschauer schwerlich feststellen lassen. Die Integrität des Sports kann demnach kaum als hinreichend bestimmter Gegenstand eines kollektiven Vertrauens bezeichnet werden.

Doch selbst wenn die Identifizierung eines bestimmbaren Vertrauensgegenstands gelänge, müsste sich der Leistungssport grundsätzlich als ein System erweisen, das sich über Kollektivvertrauen konstituiert und grundrechtliche Handlungsoptionen absichert. In seinem Kernbereich stellt sich der hochklassige Leistungssport zunächst einmal als abgeschlossenes System dar. Die Teilnahme an seinen Wettbewerben setzt außergewöhnliche körperliche Fertigkeiten und einen extrem hohen Professionalisierungsgrad voraus und ist daher einem winzigen Bruchteil der Gesellschaft vorbehalten. Die überwältigende Mehrheit wird auf die Rolle des Zuschauers verwiesen. Und auch wenn die psychologische Unterstützung eines Teil- 
nehmers von den Zuschauerrängen aus möglicherweise den Verlauf eines leistungssportlichen Wettbewerbs beeinflussen mag, handelt es sich hierbei nicht um eine für die Grundfunktion des Leistungssports unverzichtbare Interaktion. ${ }^{833}$ Denn diese besteht darin, in einer regulativ ausgeformten Disziplin einen Sieger zu ermitteln, und ist hierbei weder auf unterstützende Zuschauer noch überhaupt auf die Kenntnisnahme der Öffentlichkeit angewiesen. Eine vergleichbare funktionale Abhängigkeit von der Interaktion mit der Allgemeinheit, wie sie soeben für den marktwirtschaftlichen Wettbewerb und den Kapitalmarkt ausgemacht wurde, besteht im Falle des Leistungssports nicht.

Nun ließe sich anführen, eine solche auf die bloße Durchführung der Wettbewerbe reduzierte Betrachtung lasse die vielschichtige Wechselwirkung zwischen dem hochklassigen Leistungssport und der Gesellschaft außer Acht. Das immense öffentliche Interesse am Spitzensport habe vielfache Interaktionsprozesse in Gang gesetzt, die sich auf dessen Rahmenbedingungen, aber eben auch auf dessen grundsätzlich autonom und verbandsintern vorgenommene regulative Ausformung auswirkten. Durch Sponsorengelder und Rechtevermarktung können Sportverbände und -vereine sowohl die infrastrukturellen Trainingsbedingungen ihrer Athleten verbessern als auch deren umfassende medizinische Versorgung gewährleisten. In bestimmten Sportarten wurden zum Zwecke einer höheren TVAttraktivität Spielgeräte verändert oder den Spielfluss hemmende Pausen verkürzt. ${ }^{834}$ Und dank ihrer Popularität können Sportler als Werbeträger Kaufentscheidungen beeinflussen und als Botschafter gemeinnütziger Zwecke ein Bewusstsein für soziale Probleme schaffen. Kurzum: der Leistungssport sei kein abgeschlossenes System, sondern in ein Geflecht sozialer Interaktionen eingebunden, aus dem seine soziale und wirtschaftliche Funktion hervorgehe.

Obschon die beschriebenen Interaktionsprozesse nicht in Abrede gestellt werden sollen, überzeugt diese Argumentation hinsichtlich der hier interessierenden Frage nicht. Denn sie läuft auf eine Umkehrung der als maßgeblich erkannten Bedingungszusammenhänge hinaus. Die gesellschaftliche Interaktion bedingt nicht die originäre Funktion des Leistungs-

833 AA wohl Trüg FS Rössner, 2015, S. 686 (694f.).

834 Im Tischtennis wird seit 2001 mit im Querschnitt um 2 Millimeter vergrößerten Bällen gespielt, damit das Tempo der Ballwechsel verringert und ihr Nachvollziehen für Zuschauer erleichtert wird. Tennisspieler dürfen sich nach Beendigung eines Ballwechsels neuerdings nur noch 25 Sekunden Zeit lassen, bevor sie den nächsten Aufschlag ausführen. 
sports, sondern es werden soziale und wirtschaftliche Funktionen von außen gesetzt und hinzu addiert, die Interaktion bedingen. Erst infolge der massenhaften medialen Anteilnahme wurde dem Leistungssport eine Vorbildwirkung zugesprochen. Dass eine solche allgemein ein Mindestmaß an kollektivem Vertrauen in die Authentizität der bereichsspezifisch repräsentierten Werte voraussetzt, ist genauso selbstverständlich wie es hinsichtlich des erforderlichen Zusammenhangs von Interkation und Funktion zirkelschlüssig ist. Diesbezüglich entscheidend ist hingegen die Folgenlosigkeit der Subtraktion der öffentlichen Anteilnahme für die Kernfunktion des Leistungssports. Wendet sich das Interesse der Allgemeinheit einem anderen Gegenstand zu, zerfällt auch die Vorbildwirkung des Leistungssports, ohne dass er hierdurch seiner grundlegenden Daseinsberechtigung entledigt oder in der Ausführung seiner verbandsintern festgelegten Aufgaben sonderlich beeinträchtigt würde. Wenn das Kollektivvertrauen enttäuschende Taten aber nicht zugleich den Sport selbst erschüttern, kann das Kollektivvertrauen in die sportethischen Prinzipien auch nicht als Konstitutionsbestimmung des Leistungssports gelten. ${ }^{835}$

Daran ändert auch die ökonomische Dimension nichts. Die Annahme, wonach die wirtschaftliche Bedeutung des hochklassigen Leistungssports stark vom Vertrauen in dessen Integrität abhängig sei, da eine Abwendung der enttäuschten Öffentlichkeit von unglaubwürdigen Wettbewerben mit einem Rückzug von Sponsoren, sinkenden Einnahmen aus Übertragungsrechten, der Abnahme sportbezogenen Konsums und letztlich dem Verlust von Arbeitsplätzen einherginge, ${ }^{836}$ mag zwar zunächst plausibel anmuten. Sie verkennt aber die Gesetzmäßigkeiten eines Markts, auf dem der Faktor Glaubwürdigkeit allenfalls untergeordnet zur allein maßgeblichen Attraktivität eines Produkts beiträgt. Als Produkt, das sich unmittelbar vor Ort oder medial wahrnehmen lässt, konkurriert der Leistungssport mit anderen Freizeitangeboten und Medieninhalten um die Aufmerksamkeit der Öffentlichkeit. Dass Berichte über systematische Wettbewerbsmanipulationen und eine hieraus konstruierte Vertrauenskrise ihn hierbei signifikant zurückwerfen, ist bisher allenfalls vereinzelt im asiatischen Raum zu er-

835 Vgl. Kargl NStZ 2007, 489 (495 Fn. 78); aA wohl Trüg FS Rössner, 2015, S. 686 (694 f.); Schild Sportstrafrecht, S. 134, der Sport als ein performatives Sprachspiel bezeichnet, das eine Realität konstruiere, an die geglaubt werden müsse.

$836 \mathrm{Zu}$ einer möglichen wirtschaftlichen Abwärtsspirale infolge bekannt gewordener Spielmanipulationen s. ICSS/Sorbonne (Hrsg.) Part II, S. 22. Von einer solchen geht auch Jaleesi Kriminalisierung, S. 93 f. aus, ohne jedoch diese Annahme mit dem auch von ihm festgestellten gegenläufigen Indiz einer stetig steigenden Wirtschaftskraft des Sports verbinden zu können. 
kennen gewesen. Der dortige Einbruch des Interesses der Bevölkerung an den von Manipulationsfällen gebeutelten Fußballligen in China und Malaysia und deren dadurch ausgelöster wirtschaftlicher Kollaps zu Anfang der 2000er Jahre stand jedoch auch in enger Verbindung mit der zeitgleich dort eingeführten medialen Verfügbarkeit der sportlich attraktiveren englischen Premier League. ${ }^{837}$ Davon abgesehen erweisen sich etwa die TV-Einschaltquoten des olympischen Finallaufes über 100 Meter in den vergangenen zwei Jahrzehnten als konstant, obwohl immer wieder zahlreichen Spitzenathleten dieser Disziplin Dopingvergehen nachgewiesen werden konnten. Die Fußballbundesliga verzeichnete in drei der auf den „Wettskandal Hoyzer" im Jahre 2005 folgenden Spielzeiten neue Zuschauerrekorde in den Stadien. ${ }^{838}$

Dem Einwand, der sich nicht auf Spiele der Bundesliga erstreckende „Einzelfall Hoyzer“ hätte eben nicht den Grenzwert eines kollektiven Vertrauensentzuges erreicht, wohingegen auf den Match Fixing-Komplex in Italien aus dem Jahr 2005 messbare Zuschauerrückgänge der involvierten Vereine folgten, ${ }^{839}$ ist folgendes entgegenzuhalten: Es kommen auch andere Ursachen - etwa die gesunkenen Erfolgsaussichten der sanktionierten Teams oder die zunehmenden Gewaltprobleme in italienischen Stadien zur Erklärung dieses Trends in Frage, der darüber hinaus mit Blick auf die gegenwärtig wieder attraktive und wettbewerbsfähige Serie A nicht lange anhielt. In ähnlicher Weise darf zumindest hinterfragt werden, ob der Rückzug der öffentlich-rechtlichen Fernsehsender aus der Live-Berichterstattung der Tour de France tatsächlich allein auf die im Jahre 2006 erfolgte Aufdeckung des Dopingnetzwerkes um den spanischen Arzt Eufemiano Fuentes zurückging oder auch die absehbare Erfolglosigkeit deutscher Fahrer hierzu beitrug. ${ }^{840}$ Das internationale Interesse an der Tour de France

837 S. Hill International Journal of Sports Marketing and Sponsorship 11 (2010), $221 \mathrm{ff}$.

838 Vgl. die Tabelle des Deutschen Fußballbunds (DFB), www.dfb.de/bundesliga/st atistik/zuschauerzahlen/.

839 ICSS/Sorbonne (Hrsg.) Part II, S. 25.

840 Die öffentlich-rechtlichen Fernsehsender selbst begründeten den Einbruch der Einschaltquoten auf ein Drittel des zwischen 1998 und 2003 erreichten Niveaus eher mit dem Fehlen deutscher Stars als mit einer abschreckenden Dopingproblematik, vgl. Boubs, Das böse D-Wort, TAZ vom 3.2.2011, www.taz.de/!512741 $7 /$. 
blieb jedenfalls weitgehend stabil. ${ }^{841}$ Mittlerweile überträgt auch die ARD die Etappen wieder live, wenngleich der Radsport nach wie vor zu den am stärksten mit Doping belasteten Sportarten zählt.

Wie diese Beispiele zeigen, wenden sich die Zuschauer offenbar nicht automatisch von solchen Sportarten ab, an deren Integrität zu zweifeln sie vernünftigen Grund hätten. Gerade weil der Umstand eines integren Ausgangs für ihren persönlichen Lebensbereich keine unmittelbare Bewandtnis hat, verfolgen sie diese Wettbewerbe primär als Unterhaltungsprogramm. ${ }^{842}$ In diesem Zugang bestärkt werden sie von einer medialen Vermarktung des Spitzensports, die weniger an der ursprünglichen Idee eines fairen Vergleichs des natürlichen Leistungsvermögens andockt, als vielmehr über die Jagd nach neuen Rekorden, stilisierte Rivalitäten und Underdog-Biographien ein reizvolles Narrativ zu schaffen versucht, zu dem durchaus auch schillernde Protagonisten gehören. ${ }^{843}$ Die Fähigkeit zur Fortschreibung und Erneuerung dieses Narrativs bestimmen die Attraktivität des Produkts Sport und die hieran anknüpfenden wirtschaftlichen Möglichkeiten. Auch in seiner Bedeutung als Wirtschaftsfaktor ist der hochklassige Leistungssport demnach von einem Kollektivvertrauen in seine Integrität weitgehend losgelöst. Ob ein solches Kollektivvertrauen überhaupt existiert, ist schwer festzustellen, weil es für einen kommerzialisierten Spitzensport schlicht nicht darauf ankommt. ${ }^{844}$

Im Vergleich des Leistungssports mit den als legitimen Objekten eines strafrechtlich schützenswerten Kollektivvertrauens eingestuften Institutionen lassen sich demnach zentrale Unterschiede ausmachen: Zum einen ist ein in die Integrität der Wettbewerbe gelegtes Vertrauen der Allgemeinheit für den Leistungssport eine wünschenswerte Begleiterscheinung, aber nicht konstituierend. Seine zunehmend auch wirtschaftliche Funktion hat

$841 \mathrm{Zu}$ einer allerdings auf die belgische Region Flandern beschränkten Untersuchung der Kurzzeit- und Langzeiteffekte von medialen Berichten über Doping im Radsport auf die Einschaltquoten bei Radsportübertragungen Van Reeth International Journal of Sport Finance 2013, Vol. 8, Issue 1, S. 39 ff.

842 Vgl. Pfister StraFo 2016, 441 (442); Tsambikakis StV 2018, 319 (322); Roxin FS Samson, 2010, S. 445 (447); Stellungnahme der Bundesrechtsanwaltskammer Nr. 8/2016, S. 4 f.; vgl. auch das Interview mit dem Sportwissenschaftler Jörg-Uwe Nieland, Sueddeutsche.de vom 7.2.2018, www.sueddeutsche.de/sport/ interviewam-morgen-olympia-ist-ein-wahnsinnig-attraktives-produkt-1.3857515.

843 Hierzu auch Gebauer, in: Wagner/Wolf (Hrsg.), Korruption, 2011, S. 136 (140).

844 In diesem Sinne führt Schürmann, in: Asmuth (Hrsg.), Entgrenzungen, 2012, S. 75 (86) aus, nur der Sportbegriff, der einer prä-professionalisierten Sportwelt gemäß gedacht wird, könne ein Glaubwürdigkeitsproblem haben. Nach der Professionalisierung gebe es nur noch das Imageproblem eines Produkts. 
sich zwar über vielfältige Interaktionen mit der Gesellschaft herausgebildet, einer realen Vertrauensbasis hinsichtlich der sportethischen Werte bedurfte es hierfür aber nicht. Zum anderen bleibt der Leistungssport auch in seiner Verantwortung für das gesamtgesellschaftliche Wohl hinter den strafrechtlich abgedeckten Funktionseinheiten zurück. Ungeachtet der Einwände gegen die entsprechenden Rechtsgüter im Einzelfall, beziehen sich etwa die $\$ \$ \$ 298,299$, 299a ff., 331 ff. StGB sowie die kapitalmarktstrafrechtlichen Vorschriften zumindest mittelbar auf den essentiellen Beitrag des freien wirtschaftlichen Wettbewerbs für die soziale Marktwirtschaft, die Stabilität und Funktionsfähigkeit des Gesundheitswesens und Staatsapparates sowie die Kapitalaufbringungsfunktion des Kapitalmarkts, wohingegen es sich beim hochklassigen Leistungssport nur um einen wirtschaftlichen Teilbereich handelt, dessen Störung das Leben des Einzelnen nicht zwangsläufig beeinträchtigt. ${ }^{845}$

Hinzu kommt, dass gemäß den oben ausgeführten Legitimationsbedingungen nur ein Vertrauen strafrechtlich geschützt werden kann, das sich als handlungsleitend in einem grundrechtlich flankierten Freiheitsbereich erweist. Ein Vertrauensverlust müsste sich demnach etwa in einer durch starke innere Vorbehalte erschwerten Partizipation an einem gesellschaftsrelevanten System niederschlagen. In diesem Zusammenhang allein auf die integren Leistungssportler abzustellen, die in Sorge um ihre Erfolgsaussichten in einem systematisch manipulierten Umfeld womöglich von ihrer Berufsausübung Abstand nehmen könnten, liefe auf eine unzulässige Fragmentierung des Kollektivvertrauens hinaus. Dem großen Rest der Gesellschaft ist eine unmittelbare Teilnahme an leistungssportlichen Wettbewerben verwehrt. Selbst wenn man sowohl die Existenz eines breiten Vertrauens in die Integrität des Leistungssports unterstellt als auch entgegen den hier aufgezeigten Argumenten bereit ist, diesem ausschlaggebende Wirkung für das Ausmaß des Interesses am Leistungssport zuzusprechen, würden erlittene Vertrauenseinbußen den Einzelnen zunächst einmal lediglich in seiner Mediennutzung betreffen und sein Interesse auf andere Inhalte umlenken. Eine relevante Einschränkung von Handlungsmöglichkeiten ist hiermit nicht verbunden.

845 Rübenstahl JR 2017, 264 (268); Jansen GA 2017, 600 (606 ff.); Satzger Jura 2016, 1142 (1154); Stellungnahme des Deutschen Anwaltsvereins Nr. 12/2016, S. 6 f.; Kauerhof Causa Sport 2014, 127 (134); eine gleichrangige gesellschaftliche Bedeutung hochklassiger Sportwettbewerbe erkennt aber Waßmer ZWH 2019, 6 (7). 
Anderes könnte für den Fall gelten, dass ein tief empfundenes Misstrauen gegenüber dem Leistungssport auch die Bereitschaft des Einzelnen reduziert, sich allein oder in Vereinen sportlich zu betätigen. ${ }^{846}$ Infolge eines auf den Sport insgesamt übertragenen Unmuts blieben fortan große Gruppen für die gesundheitlich förderliche und sozialisierende Wirkung der eigenen sportlichen Aktivität unerreichbar. Für ein solch mittelbar misstrauensindiziertes Partizipationshemmnis finden sich allerdings keinerlei Anzeichen. ${ }^{847}$ Die Mitgliederzahlen in den deutschen Sportvereinen haben die in den vergangenen beiden Jahrzehnten gehäuften Berichte von Doping- und wettbasierten Manipulationen im Spitzensport nicht nur unbeschadet überstanden, sondern wuchsen leicht an. ${ }^{848}$ Dieser Trend lässt sich auch für die durch Dopingskandale vermeintlich besonders in Verruf geratenen Sportarten wie etwa den Radsport feststellen. ${ }^{849}$ Ganz offenbar wird in der Wahrnehmung der Bevölkerung zwischen den kommerzialisierungsbedingten Fehlentwicklungen im abgeschlossenen System des Leistungssports und dem hiervon unbelasteten, zugänglichen und ungeschmälert attraktiven Breitensport getrennt. Ein wegen des schwindenden Vertrauens in die Integrität des Leistungssports drohender Rückzug aus dem Breitensport ist nicht zu besorgen. Damit erweist sich die kollektive Vertrauenskomponente aber auch diesbezüglich nicht als handlungsleitend im Sinne der Legitimationsbedingungen.

\section{(3) Zwischenergebnis}

Gemessen an den dargestellten Voraussetzungen eines legitimen strafrechtlichen Vertrauensschutzes ist dem Vertrauen in die Integrität des Sports die Eignung als Rechtsgutsbestandteil abzusprechen. Das Fehlen einer einigermaßen einheitlichen Auffassung der sportethischen Werte erschwert schon die Bestimmung eines hinreichend umgrenzten Vertrauensgegenstandes. Ferner sind die Annahmen, auf die die Eingliederung vertrauensschützender Gesichtspunkte in die Rechtsgutskonzeption der Integrität des Sports gestützt wird, nicht tragfähig. Für ihren Ausgangspunkt, wonach

846 In diese Richtung bezüglich des Dopings BT-Drs. 18/4898, S. $26 \mathrm{f}$.

847 Vgl. auch Jansen GA 2017, 600 (604 f.).

848 Deutscher Olympischer Sportbund (Hrsg.) Bestandserhebung 2020, S. $10 \mathrm{f}$.

849 Die Mitgliederzahlen des BDR stiegen seit 2000 trotz der Dopingskandale gerade am Anfang des Jahrtausends ununterbrochen von 122.807 auf 140.977 im Jahr 2017 an; vgl. BDR (Hrsg.) Jahresberichte 2017, S. 13. 
sich Manipulationen im hochklassigen Leistungssport sozialpsychologisch auf das Interesse der Öffentlichkeit am Sport insgesamt und das allgemeine soziale Verantwortungsbewusstsein auswirkten, fehlen nicht nur empirische Belege. ${ }^{850}$ Verschiedene Anzeichen weisen gar in die entgegengesetzte Richtung einer weitgehenden Entkopplung der Attraktivität des medial verfolgten und selbst betriebenen Sports von einem etwaigen Vertrauen in die Integrität des Leistungssports. Die Interaktion ist gerade nicht vertrauensabhängig. Daher besetzt eine integritätsbezogene Glaubwürdigkeit auch keine konstituierende Rolle für die Funktionsfähigkeit des Leistungssports, die zudem das erforderliche Maß an Sozialrelevanz nicht erreicht. Denn die eröffneten Partizipationsmöglichkeiten sind passiver Natur und durch Manipulationen ausgelöste Störungen der Institution schlagen nicht in Form reduzierter Handlungsmöglichkeiten auf den persönlichen Wirkbereich durch.

\section{e) Zusammenfassung}

In der Benennung der Integrität des Sports als zentrales Schutzgut der $\mathbb{S} \mathbb{S} 265 \mathrm{c}, 265 \mathrm{~d}$ StGB manifestiert sich eine allgemeine legislative Entwicklung hin zum Ausbau eines institutionsbezogenen Integritätsstrafrechts, das im Angesicht von Doping und Match Fixing auf den Sport erweitert wird. Durchaus in Übereinstimmung mit den Wesensmerkmalen des bisherigen strafrechtlichen Integritätsschutzes bezieht sich die Schutzrichtung des neu geschaffenen Rechtsguts dabei sowohl intern auf die Durchführung von unbeeinflussten und einem spezifischen Sportethos verpflichteten Wettbewerben als auch auf deren Außenwirkung. Bei einer vom Gesetzentwurf ausgehenden Analyse haben sich insoweit die sportethischen Werte der Fairness, Chancengleichheit und Leistungsbereitschaft sowie die gesellschaftliche Bedeutung des Leistungssports als Wirtschaftsfaktor und wertbildende, da vertrauenswürdige Sozialisationsinstanz als die wesentlichen Bestandteile des Begriffs herauskristallisiert.

Der anschließende Abgleich mit den Materialisierungskriterien eines die Verhältnismäßigkeitsprüfung begründenden Rechtsgutsbegriffs führte jedoch zu jeweils ungenügenden Ergebnissen. Hinsichtlich der sportethischen Werte fehlt es an einem fernab von disparaten Moralvorstellungen bestimmbaren Kern und damit zusammenhängend an einem in der Reali-

850 S. Stellungnahme des Deutschen Anwaltvereins Nr.12/2016, S. 7; Sinner FS Neumann, 2017, S. 1229 (1234). 
tät des Leistungssports vorfindlichen Substrat, auf das sich der strafrechtliche Schutz unzweifelhaft beziehen ließe. Wenngleich diese Werte in einem erweiterten und übertragenen Sinne für ein gesellschaftliches Miteinander förderlich sein mögen, ist ihr Rückbezug auf die Interessen des Einzelnen unzureichend hergestellt. Der Argumentationslinie über die wertbildende Vorbildfunktion des hochklassigen Leistungssports ist in zweifacher Hinsicht zu widersprechen. Denn weder lässt sich eine entsprechende Wirkkraft des Leistungssports auf die Wertbildung der einzelnen Gesellschaftsmitglieder nachweisen noch sollte das Strafrecht überhaupt zur Bewahrung gesellschaftlicher Orientierungswerte eingesetzt werden.

Einem Kollektivvertrauen in die Integrität des Sports mangelt es an einem hinreichend bestimmten Vertrauensgegenstand, an konstituierender Wirkung für ein gesellschaftlich unabdingbares System und an handlungsleitenden Effekten für den Einzelnen. Ein von Manipulationen unbefleckter Leistungssport stellt keine wesentliche normative Erwartung dar, die im Hinblick auf den freiheitlichen Bestand unserer Gesellschaft nicht aufgegeben werden kann und demnach normativ enttäuschungsfest sein muss. ${ }^{851}$ Die stabile Entwicklung von sportbezogenen Einschaltquoten und der Mitgliedschaften in Sportvereinen legen vielmehr nahe, dass Manipulationen spitzensportlicher Wettbewerbe von der Allgemeinheit geradezu gleichgültig als gelegentlich unvermeidbare Pointe eines Unterhaltungsformats wahrgenommen werden, die sie aber weder zu einer Abwendung vom Leistungssport noch zu einem Rückzug aus dem Breitensport veranlasst.

Stellen die einzelnen Bestandteile der Integrität des Sports für sich genommen kein legitimes Rechtsgut dar, so ergibt sich ein solches auch nicht aus ihrer Addition. Der Leistungssport ist aufgrund seines spezifischen und bisweilen widersprüchlichen Ethos und mangels der Eigenschaft einer für das gedeihliche Zusammenleben der Bürger unverzichtbaren sozialen Funktionseinheit kein tauglicher Bezugspunkt eines strafrechtlichen Integritätsschutzes. Selbst wenn man dessen wertbildende Funktionen unterstellt, ließen sich diese gesellschaftlich ohne weiteres durch andere Formen sozialer Interaktion substituieren. ${ }^{852}$ Selbst bei einem Hinwegdenken des Sports kann sich die Sozialisation und Wertbildung innerhalb der Gesellschaft in der vom Gesetzgeber offenbar für wünschenswert erachteten Richtung entwickeln. Bei der Integrität des Sports handelt es sich letztlich um ein vages Allgemeinrechtsgut ohne hinreichen-

851 Kauerhof Causa Sport 2014, 127 (132 ff.).

852 Jansen GA 2017, 600 (607 f.); Tsambikakis StV 2018, 319 (322). 
den Sozialbezug, das weder die tatbestandsbeschreibende und im Einzelfall auslegungsleitende noch die strafrechtsbegrenzende Funktion eines Rechtsguts zu erfüllen vermag. Entsprechend der hier allgemein befürworteten Konsequenz eines die Legitimitätsanforderungen verfehlenden Rechtsguts sind ausschließlich dem Schutz der Integrität des Sports verschriebene Straftatbestände demnach als verfassungswidrig abzulehnen. ${ }^{853}$

\section{Vermögen}

Oftmals noch im gleichen Atemzug ergänzt die Gesetzesbegründung das Schutzgut der Integrität des Sports um gleichfalls strafrechtlich zu schützende, mit dem Sport verbundene Vermögensinteressen. Gegen deren Eingliederung in einen noch weiter gefassten Integritätsbegriff und für eine eigenständige und hervorgehobene Stellung des Vermögensschutzes spricht zum einen die systematische Verortung der $\$ \$ 265 c$, 265d StGB im aus Vermögensdelikten bestehenden 22. Abschnitt des StGB, zum anderen die Begrenzung der Strafbarkeit auf den vom Wettmarkt begleiteten organisierten Sport bzw. den Berufssport. Letzterer wird über die Einkommensverhältnisse der Protagonisten bestimmt und verdeutlicht dabei die offenbar als höher eingeschätzte Strafwürdigkeit solcher Wettbewerbsmanipulationen, die zu wirtschaftlichen Einbußen bei den Beteiligten führen können.

Das gleichrangige Nebeneinander eines kollektiv-institutionellen und eines individuell-vermögensschützenden Rechtsguts ist insbesondere im systematischen Kontext der neuen Tatbestände kein Novum. Im Kapitalanlagebetrug gemäß $₫ 264$ a StGB findet sich im direkten Umfeld eine Norm, die nach herrschender Meinung die Funktionsfähigkeit des Kapitalmarkts sowie das Vermögen des einzelnen Kapitalanlegers in gleicher Weise schützt. ${ }^{854}$ Eine ähnliche Doppelung des Rechtsguts wird teilweise auch für weitere Kranzdelikte des Betrugs - etwa den Versicherungsmissbrauch $\left(\$ 265\right.$ StGB) und den Kreditbetrug ( $\$ 265$ b StGB) - angenommen, ${ }^{855}$ wobei die Ergänzung des Vermögensschutzes um nicht nur reflexhaft und

853 Zum selben Ergebnis gelangt selbst unter Heranziehung seines strengeren „Offensichtlichkeitsmaßstabes“ Jahn Vogel-Symposium, 2016, S. 63 (83).

854 LK-StGB/Tiedemann/Vogel \$264a Rn. 22 ff.; Lackner/Kühl/Heger/Heger $\$ 264 a$ Rn. 1; Hefendehl Kollektive Rechtsgüter, S. 267 ff.

855 LK-StGB/Tiedemann/Vogel $\$ 264$ a Rn. 25; Schönke/Schröder/Perron $\$ 265$ Rn. 2; Graf/Jäger/Wittig/Bock $\$ 264 a$ StGB Rn. 5; Matt/Renzikowski/Schröder/Bergmann $₫ 265$ b StGB Rn. 1 . 
mittelbar betroffene, sondern als eigenständige Rechtsgüter eingestufte Kollektivinteressen jeweils sehr umstritten ist. 856

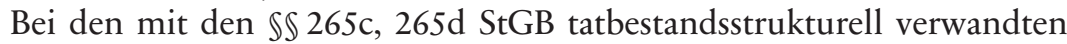
Korruptionsdelikten ist eine doppelte Rechtsgutskonzeption (noch) nicht festzustellen. Gleichwohl lässt sich auch hier zumindest die Tendenz beobachten, das primär auf institutionelle Interessen abzielende Schutzgut über den Einbezug von Vermögensinteressen legitimatorisch auf festere Füße zu stellen. Sind die Ausgangstatbestände der $\$ \$ 331 \mathrm{ff}$. StGB noch allein auf ein überindividuelles Interesse beschränkt, werden individuellen Vermögensinteressen im Rahmen der wettbewerbsorientierten Antikorruptionsvorschriften ein größeres Gewicht zugesprochen. Nachdem im Rahmen des $\mathbb{2} 299$ StGB schon vor der tatbestandlichen Neufassung im Jahr 2015 zumindest teilweise vertreten wurde, die Vorschrift bezwecke neben oder gar anstelle des freien Wettbewerbs den Schutz von Vermögensinteressen der Mitbewerber und des Geschäftsherrn, ${ }^{857}$ hat die Aufnahme des sog. Geschäftsherrenmodells durch Einfügung der Ziffern 2 in den Absätzen 1 und 2 nun zu einer Erweiterung des Rechtsguts und dem Schutz der Vermögensinteressen des Dienstherren geführt. ${ }^{858}$ Bei der Bestechlichkeit im Gesundheitswesen gemäß $\ 299$ a StGB werden die Vermögensinteressen der Wettbewerber im Gesundheitswesen sowie der Patienten und der gesetzlichen Krankenversicherungen zwar nicht als interpretationsleitend, aber zumindest als mittelbar geschützt angesehen. ${ }^{859}$ Mit der Einbeziehung individueller Vermögensinteressen in eine doppelte Schutzrichtung fügen sich die untersuchten Tatbestände der $\$ \$ 265 \mathrm{c}, 265 \mathrm{~d}$ StGB in das Umfeld des 22. Abschnitts ein, können aber auch als Beispiel für die Entwicklung eines zunehmend um vermögensschützende Aspekte angereicherten Korruptionsstrafrechts dienen.

In jedem Fall bedarf es einer Auseinandersetzung mit der Frage, ob die geltend gemachte vermögensschützende Komponente zur Legitimität der Tatbestände beitragen kann. Trotz der im Einzelnen umstrittenen Bestimmung seines Begriffs besteht an der grundsätzlichen Eignung des Vermö-

856 Gegen die Konstruktion eines überindividuellen Rechtsguts bei $₫ 265$ StGB etwa SK-StGB/Hoyer $\$ 265$ Rn. 6; NK-StGB/Hellmann $\$ 265$ Rn. 15; Hefendehl Kollektive Rechtsgüter, S. 264 ff. Für den allein vermögensschützenden Charakter

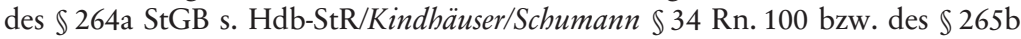
StGB s. MüKo-StGB/Kasiske \265b Rn. 1

857 Maurach/Schröder/Maiwald Strafrecht BT II $\$ 68$ Rn. 2; Walter wistra 2001, 321 (323).

858 Fischer StGB $\$ 299$ Rn. 2a.

859 BT-Drs. 18/6446, S. 12 f. 
gens als strafrechtliches Rechtsgut kein Zweifel. Es beschreibt einen Sachwert, der dem Inhaber in seiner freien Entfaltung im Rahmen eines hierauf ausgerichteten sozialen Gesamtsystems nützlich ist und demnach als "geronnene Freiheit“ bezeichnet werden kann. ${ }^{860}$ Als zentrales Individualrechtsgut kann es auf eine Tradition als strafrechtliches Schutzgut verweisen, die bis zum Entwurf des RStGB von 1871 zurückreicht. ${ }^{861}$ Unter den zahlreichen vermögensschützenden Vorschriften des heutigen StGB gibt es solche wie beispielsweise die $\$ \$ 263$ und 266 StGB, die das Vermögen im Allgemeinen ohne Ansehung ihres Inhabers schützen und weder zwischen natürlichen und juristischen Personen noch zwischen privaten und staatlichen Vermögensträgern unterscheiden, und solche wie etwa $\mathbb{S} 264,265$ $\mathrm{StGB}$, die allein ein näher beschriebenes Sondervermögen schützen, in den genannten Beispielsfällen etwa dasjenige der öffentlichen Hand bzw. der Sachversicherer. ${ }^{862}$ Rückschlüsse auf die Legitimität dieser Strafvorschriften lassen sich aus einem allgemeinen oder sektoralen Vermögensschutz allein aus einer Rechtsgutsperspektive nicht ableiten. Denn er korrespondiert mit einer unterschiedlichen Deliktsstruktur. Hieraus geht hervor, dass das Vermögen zwar ein unumstrittenes Rechtsgut darstellt, sein strafrechtlicher Schutz aber nicht umfassend und lückenlos, sondern nur im Hinblick auf bestimmte Angriffsformen gewährt wird.

Wessen Vermögensinteressen nun von den $\mathbb{S}$ 265c, 265d StGB adressiert werden, wird in der Gesetzesbegründung zunächst offen gelassen. Einführend wird lediglich allgemein festgestellt, Sportwettbetrug und die Manipulationen berufssportlicher Wettbewerbe beeinträchtigten das „Vermögen anderer" ${ }^{863} \mathrm{Um}$ wen es sich dabei handeln kann, wird im weiteren Verlauf deliktsspezifisch zumindest annähernd konkretisiert. Beim Sportwettbetrug gemäß $\$ 265$ c StGB nennt der Gesetzgeber zuvörderst das Vermögen von Sportwettanbietern, ${ }^{864}$ weswegen vorgebracht wird, auch diese Vorschrift etabliere einen Sondervermögensschutz. ${ }^{865}$ Anschließend ergänzt er es um das Vermögen von redlichen Wettteilnehmern und löst den Vermögensschutz letztlich gänzlich von einem bestehenden Wettverhält-

860 Arzt/Weber/Heinrich/Hilgendorf Strafrecht BT $\$ 11$ Rn. 1.

861 RGBl. 1871, S. 176.

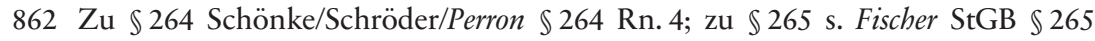
Rn. 2; NK-StGB/Hellmann $\$ 265$ Rn. 15.

863 BT-Drs. 18/8831, S. 1.

864 BT-Drs. 18/8831, S. 15.

865 Vgl. Krack ZIS 2016, 540 (545); Stellungnahme der Bundesrechtsanwaltskammer Nr. 8/2016, S. 5 f.; Kretschmer FS Rössner, 2015, S. 628 (644 f.); zur Berechtigung des Einwandes s. unten Teil 3 C. II. 2. a). 
nis durch den Hinweis auf das ebenfalls geschützte Vermögen von in sonstiger Weise durch Wettbewerbsmanipulationen Betroffenen, ${ }^{866}$ ohne jedoch Beispiele zur Veranschaulichung dieses Kreises zu liefern. Führte man als an einem Wettverhältnis nicht beteiligte Betroffene etwa in die Austragung von Sportveranstaltungen eingebundene Unternehmen an (Logistiker, Busunternehmen, Caterer etc.), so kann der ihnen durch $\$ 265$ c StGB gewährte Schutz allenfalls mittelbare Vermögensnachteile bzw. -gefährdungen betreffen und reflexartig erfolgen. ${ }^{867}$

Im Rahmen des $\$ 265 \mathrm{~d}$ StGB wird dann allein auf mit berufssportlichen Wettbewerben verbundene Vermögensinteressen abgestellt. ${ }^{868}$ Als Regelbeispiele für die Gruppe der Betroffenen, für die Match Fixing in Wettbewerben mit berufssportlichem Charakter zu nachteiligen finanziellen Folgen führen könne, benennt der Gesetzentwurf neben Sportlern und Sportvereinen auch Veranstalter und Sponsoren. ${ }^{869}$ Die insoweit offene Formulierung ermöglicht aber erweiternde Auslegungen, wonach sich der Schutzbereich auch auf Sportverbände und Zuschauer, ${ }^{870}$ mitunter gar auf sämtliche am Sport als Wirtschaftsfaktor beteiligte Akteure erstrecken lässt, deren Vermögensinteressen durch das Wegbrechen von Sponsoren, Vermarktungs- und Werbeeinnahmen oder Eintrittsgelder mittelbar gefährdet wären. ${ }^{871}$

Der intendierte Vermögensschutz ist den Tatbeständen im Falle des $\$ 265$ c StGB allenfalls indirekt, im Falle des $\$ 265 \mathrm{~d}$ StGB gar nicht anzusehen. Beide verzichten auf die tatbestandliche Voraussetzung des Eintritts oder der konkreten Gefahr eines Vermögensschadens. Verlangt $\$ 265 \mathrm{c}$ StGB noch eine Verbindung der Unrechtsvereinbarung zu einer Wettsetzung und einem hierdurch erlangten rechtswidrigen Vermögensvorteil, ist $\$ 265 \mathrm{~d}$ StGB auch von diesem Vermögensbezug getrennt. ${ }^{872}$ Die Vermögensinteressen sollen also offenbar bereits vor abstrakten Gefährdungen bewahrt werden. Im Einzelnen betrifft dies jedoch die Frage nach der Beschaffenheit des Zusammenhangs zwischen Tathandlung und geschütztem Rechtsgut und damit nach der im Bereich des Vermögensstrafrechts neu-

866 BT-Drs. 18/8831, S. 15.

867 BeckOK-StGB/Bittmann/Nuzinger/Rübenstabl \$265c Rn. 9.

868 BT-Drs. 18/8831, S. 20.

869 BT-Drs. 18/8831, S. 10.

870 Vgl. Satzger Jura 2016, 1142 (1153).

871 In diese Richtung Rübenstahl JR 2017, 333.

872 Aus diesem Grund wird das Vermögen mitunter schon nicht als geschütztes Rechtsgut des $\$ 265$ d StGB anerkannt, s. Schönke/Schröder/Perron $\$ 265$ d Rn. 1; Fischer StGB $₫ 265$ d Rn. 2 f. 
ralgischen Angriffsform. Sie verlangt eine intensive Auseinandersetzung mit der Deliktsstruktur der $\$ \$ 265$ c, 265d StGB, die im Rahmen der Identifizierung eines legitimen Rechtsguts als Bezugspunkt der Verhältnismäßigkeit verfrüht wäre. ${ }^{873}$ An dieser Stelle bleibt allein festzuhalten, dass das Vermögen grundsätzlich und ohne die Notwendigkeit einer vom Gesetzgeber geleisteten Bestimmung sämtlicher geschützter Träger als legitimes Rechtsgut der $\$ \$ 265 c$, 265d StGB anzuerkennen ist.

\section{Wettbewerb}

Das vorrangige Ziel einer in Verlauf und Ergebnis gewährleisteten Authentizität sportlicher Wettbewerbe legt es schon terminologisch nahe, den Wettbewerb auch als geschütztes Rechtsgut der $\$ \$ 265$ c, 265d StGB aufzufassen. Zumal eine solche Rechtsgutsbestimmung an den sog. Wettbe-

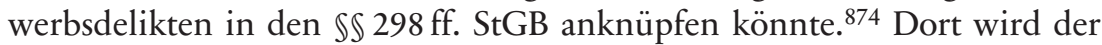
freie wirtschaftliche Wettbewerb aufgrund seiner wichtigen Steuerungsund Verteilungsfunktion, die gleichzeitig individuelle Freiheit garantiert, als ein zwischen Individual- und Kollektivinteressen changierendes Rechtsgut geschützt. ${ }^{875}$ Gegenüber der Integrität des Sports besitzt ein wettbewerbsorientierter Ansatz den Vorteil einer weitgehenden Unabhängigkeit von den moralisch aufgeladenen und in Zusammensetzung und Wirkkraft ungeklärten Wertvorstellungen des Sportethos. ${ }^{876}$ Zwar wird gerade in $\$ 299$ StGB die Fairness als schützenswerte Eigenschaft des wirtschaftlichen Wettbewerbs hervorgehoben, dabei jedoch im Sinne gleicher Ausgangsbedingungen und eines regelgeleiteten Verfahrens auf einen formellen Fairnessbegriff rekurriert. ${ }^{877}$ Die als Rechtsgutsbestandteil problematische, inspirierende und erzieherische Wirkung des Verhaltens der Akteure bleibt aus der Rechtsgutsbestimmung ausgeklammert.

Gleichzeitig ist eine um den Einbezug eines informellen Verhaltenskodex erleichterte und auf die Rahmenbedingungen des Wettbewerbs reduzierte Rechtsgutsbestimmung aufgefordert, die Sozialrelevanz der spezifi-

873 Ausführlich hierzu dann unten Teil 3 C. I. 1. b) bb).

874 Greco GA 2010, 622 (629 f.); Hutz/Kaiser NZWiSt 2013, 379 (383).

875 LK-StGB/Tiedemann $\$ 298$ Rn. 6; NK-StGB/Dannecker $\$ 298$ Rn. 11; Satzger Submissionsbetrug, S. 52; krit. gegenüber dem wirtschaftlichen Wettbewerb als Rechtsgut MüKo-StGB/Hohmann \$298 Rn. 3; Lüderssen StV 1997, 318, 320.

876 Vgl. Ott Selbstdoping, S. 169; in diese Richtung wohl auch Momsen KriPoZ 2018, 21 (26).

877 S. oben Teil 3 B. II. 2. d) aa) (2). 
schen Wettbewerbsform nachzuweisen und die Elemente zu benennen, die einen strafrechtlichen Schutz erfordern. Denn die umfassende strafrechtliche Erfassung jedweden Wettbewerbs wäre mit dem ultima ratioGrundsatz nicht vereinbar. Mit Blick auf den Sport lassen sich insofern zwei Ansätze unterscheiden, die auf ihr Legitimationspotenzial zu untersuchen sind.

a) Schutz des Sports als durch Wettkampfregeln konstituierte Institution

Angesichts der genannten Anforderungen zu kurz greift der Versuch, den sportlichen Wettbewerb bereits als eine durch die Wettkampfregeln konstituierte Institution zu schützen. Er gründet auf der Überlegung, dass erst die Regelhaftigkeit der Leistungserbringung den für den sportlichen Vergleich erforderlichen Maßstab setzt, die konkretisierten und nicht nur moralisch verbindlichen Wettkampfregeln mithin den Kern des mit sozialen Funktionen versehenen Sports ausmachten. ${ }^{878}$ Die Erklärung dieses Kerns zum legitimen Rechtsgut bei gleichzeitiger Ausblendung der Vermögensinteressen der am Wettkampf Beteiligten entspricht einem rein institutionellen Ansatz. In ihm liegt allerdings die Gefahr einer auch vor dem Hintergrund der Autonomie des Sports unzulässigen Gleichsetzung von Sportunrecht und Strafunrecht.

Die Überwachung der Regeltreue und Sanktionierung ihrer Missachtung obliegen in erster Linie dem Schiedsrichter. ${ }^{879}$ Eine parallele Flankierung durch das Strafrecht führte zur Strafbarkeit der Verletzung bloßer Vertragspflichten, die die Sportler zunächst allein im Verhältnis zu ihren Sportverbänden oder den Veranstaltern treffen. ${ }^{880}$ Die Akzessorietät würde zwar insofern aufgelöst, als nicht sämtlichen Regeln eine für den Kern des Wettkampfs konstitutive Bedeutung zugemessen werden kann. Die dann erforderliche Qualifizierung der Regeln dürfte sich jedoch als schwierig herausstellen. So mag eine Differenzierung zwischen regulativen Regeln, deren Verletzung noch innerhalb der Tätigkeit erfolgt, und konstitutiven Regeln, deren Bruch gleichsam als Verlassen des Spiels gedeutet werden

878 Heger SpuRt 2007, 153 (154f.); ähnlich Kubiciel KriPoZ 2018, 29 (31); krit. Schild, in: Wagner/Wolf (Hrsg.), Korruption, 2011, S. 158 (183); Schlöter Doping, S. 256.

879 Reinhart SpuRt 2016, 235 (237).

880 Diesen Einwand erkennt Heger SpuRt 2007, 153 (154 f.) selbst. Eine überzeugende Entkräftung gelingt ihm aber nicht. 
kann, ${ }^{881}$ für den umfangreich normierten Bereich des Dopings eine zweifelsfreie Zuordnung erlauben. Im hier interessierenden Manipulationskontext der punktuellen Leistungsverweigerung und Übervorteilung des Gegners führt sie nicht weiter, da eine Verpflichtung zur durchgehenden Erbringung des maximalen Leistungsvermögens weder in den Regelwerken statuiert ist noch als ungeschriebenes Gesetz existiert. Letztlich fehlt einer auf die Regelhaftigkeit fokussierten Rechtsgutsbestimmung auch der Rückbezug auf gesamtgesellschaftliche Interessen. Der Bedingungszusammenhang zwischen der Einhaltung zentraler Wettkampfregeln und den sozialen Funktionen ebenjenes Wettkampfs wird weder ausreichend beschrieben noch belegt.

\section{b) Schutz des Sports als wirtschaftlicher Wettbewerb}

Breitere Unterstützung erfährt hingegen ein auf die wirtschaftliche Dimension des sportlichen Wettbewerbs abstellender Rechtsgutsentwurf. Schon seit Beginn der Diskussion um einen Straftatbestand des Sportbetrugs wurde ein solcher aufgrund der Kommerzialisierung des Leistungssports tatbestandsstrukturell und hinsichtlich des geschützten Rechtsguts überwiegend in den Zusammenhang mit $\$ 299$ StGB gestellt. ${ }^{882}$ Trotz der Einfügung der Tatbestände in den 22. Abschnitt knüpft auch die Gesetzesbegründung zumindest für $\$ 265 \mathrm{~d}$ StGB hieran an, wenn sie hochklassige Wettbewerbe mit berufssportlichem Charakter in die Nähe des von $\$ 299$ StGB geschützten wirtschaftlichen Wettbewerbs rückt und die Erforderlichkeit deren strafrechtlichen Schutzes damit zu untermauern versucht. ${ }^{883}$ In dieser Bezugnahme wird teilweise die Etablierung des wirtschaftlichen Wettbewerbs als drittes Rechtsgut des $\$ 265 \mathrm{~d}$ StGB neben der Integrität des Sports und des Vermögens gesehen. ${ }^{884}$

$\mathrm{Zu}$ beachten bleibt jedoch, dass eine Anlehnung an den $\$ \$ 298 \mathrm{f}$. StGB nicht nur den Grund, sondern auch die Grenzen des strafrechtlichen Schutzes des freien wirtschaftlichen Wettbewerbs beinhaltet. Seine Legitimation bezieht das institutionelle Rechtsgut aus der Charakterisierung des

881 So etwa Greco GA 2010, 622 (630 ff.).

882 Wabnitz/Janovsky/Bannenberg, 4. Auflage, 12. Kapitel Rn. 109; Rössner FS Mehle, 2009, S. 567 (573, 576 f.).

883 BT-Drs. 18/8831, S. 11; unterstützend Waßmer ZWH 2019, 6 (8); wohl auch Hdb-StR/Kindhäuser/Schumann $\$ 34$ Rn. 203.

884 BeckOK-StGB/Bittmann/Nuzinger/Rübenstabl $\$ 265 d$ Rn. 9; Fischer StGB $₫ 265 d$ Rn. 2, 3. 
wirtschaftlichen Wettbewerbs als ein sozialer Ordnungsrahmen, in dem sich individuelle Handlungsfreiheiten entfalten können. ${ }^{885}$ Allein die Verletzung von Wettbewerbsregeln kann demnach keine Strafbarkeit begründen, solange hierdurch keine konkreten sozialen Folgen eintreten. ${ }^{886} \mathrm{Um}$ gekehrt begründet die bloße Benennung und Addition von potenziell betroffenen Vermögensinteressen keinen wettbewerbsorientierten Schutzanspruch, wenn hierüber der institutionelle Eigenwert des wirtschaftlichen Wettbewerbs ausgeblendet wird. ${ }^{887}$ Gemäß diesen Legitimationsbedingungen müssten im Bereich des organisierten Sports den wirtschaftlichen Wettbewerb kennzeichnende Strukturmerkmale mit vergleichbaren gesamtgesellschaftlichen Auswirkungen feststellbar sein.

aa) Kommerzialisierung als Anknüpfungspunkt

Befürworter einer derartigen Rechtsgutsbestimmung verweisen zunächst häufig auf die durch die Kommerzialisierung angetriebene Entwicklung des Spitzensports zu einem abgrenzbaren und umsatzstarken Wirtschaftssektor. Die Störung eines ursprünglich ideell ausgerichteten Wettbewerbs in Form von Manipulationen habe im Zuge des Sponsorings und des durch Vermarktung gesteigerten und sodann verwerteten Zuschauerinteresses mittlerweile zahlreiche wirtschaftliche Implikationen. ${ }^{888}$ Potenziell betroffen seien dabei nicht nur die das Sportgeschehen selbst tragenden Akteure (Spieler, Trainer) und die unmittelbar und mittelbar an der Durchführung eines konkreten Wettkampfs Beteiligten (Veranstalter, aber auch Gewerbetreibende wie Fan Shop- oder Würstchenbudenbesitzer am Austragungsort), sondern sämtliche Personen, deren wirtschaftliche Betätigung in einer mit dem Spitzensport verbundenen Branche erfolge. ${ }^{889}$ Ein durch Manipulationen ausgelöster Attraktivitätsverlust zöge in verschiedenen Bereichen Umsatzeinbußen nach sich.

Das erwähnte Erfordernis des Nachweises eines über die Aufzählung einzelner Vermögensinteressen hinausgehenden Eigenwerts des Wettbe-

885 Vgl. Trüg FS Rössner, 2015, S. 686 (694f.); Schönke/Schröder/Heine/Eisele Vor. $\$ \$ 298 \mathrm{ff}$. Rn. 4.

886 Momsen, in: Asmuth (Hrsg.), Entgrenzungen, 2012, S. 251 (262); Momsen-Pflanz Doping, S. 178 f.; am Beispiel des $\$ 298$ StGB Otto wistra 1999, 41 (42).

887 Vgl. Ott Selbstdoping, S. $171 \mathrm{ff}$.

888 Waßmer ZWH 2019, 6 (8); Wabnitz/Janovsky/Bannenberg, 4. Auflage, 12. Kapitel Rn. 109.

889 BeckOK-StGB/Bittmann/Nuzinger/Rübenstahl $\$ 265$ d Rn. 9. 
werbs aufgreifend wird vielfach auf die strukturelle Ähnlichkeit zwischen dem sportlichen Wettbewerb und dem über die Vorschriften des UWG sowie $\$ 299$ StGB einen besonderen Lauterkeitsschutz erfahrenden wirtschaftlichen Wettbewerb verwiesen. Parallelen zeigten sich sowohl in den weithin spürbaren Folgen von Verstößen gegen eine interne Wettbewerbsordnung als auch bereits in deren Ausgestaltung und Zwecksetzung. In beiden Ausprägungen des Wettbewerbs gehe es darum, eine verfügbare Prämie dem besten Angebot zuzuordnen. Dieses müsse in Einklang mit hierfür spezifisch gesetzten objektiven Verhaltensnormen entstanden sein, die der Verhinderung unlauteren Konkurrenzverhaltens dienten. ${ }^{890}$ Wenn im Kontext des wirtschaftlichen Wettbewerbs die Vereinbarung eines solchen verbindlichen regulativen Rahmens zum einen dem Leistungsprinzip bestmöglich zum Ausdruck verhelfen und zum anderen das allgemeine Vertrauen in die Rationalität der Prämienvergabe und die Öffentlichkeit des Wettbewerbs sicherstellen soll, ${ }^{891}$ so gelte identisches für den kommerzialisierten Sport. Dort hätten die Regeln, um deren Einhaltung es gehe, sogar noch größere Bedeutung als im Wirtschaftsleben. ${ }^{892}$ Der Zusammenhang von Leistungsfähigkeit und Prämienvergabe sei evident. Der Unrechtsgehalt von sich auf die Leistungsfähigkeit auswirkenden Manipulationen bestünde gerade in der Verzerrung der Wettbewerbschancen der Athleten auf wirtschaftliche Gewinne. ${ }^{893}$ Außerdem bestärkten die Regelwerke und deren Durchsetzung das Vertrauen der Sportler sowie der Allgemeinheit in die Verlässlichkeit und Transparenz des Verteilungsmodus, was wiederum den Sport als Wirtschaftsfaktor konsolidiere.

Vor diesem Hintergrund erklärt sich auch, wieso eine Einordnung als Wettbewerbsdelikt gerade $\$ 265 \mathrm{~d}$ StGB zusätzliche Legitimation verschaffen soll. Die Voraussetzung des Berufssports verengt den Ausschnitt der tatbestandlich erfassten sportlichen Wettbewerbe auf solche des Spitzensports, bei denen Kommerzialisierungserscheinungen deutlich stärker ausgeprägt sein dürften als bei den aufgrund der Ausdehnung des Markts für Sportwetten unter $\$ 265$ c StGB subsumierbaren Wettbewerben unterer Ligen. ${ }^{894}$ In hochklassigen Wettbewerben potenzieren Erfolgsprämien,

890 Cherkeh/Momsen NJW 2001, 1745 (1751).

891 Vgl. Wabnitz/Janovsky/Bannenberg, 4. Auflage, 12. Kapitel Rn. 109.

892 Cherkeh/Momsen NJW 2001, 1745 (1752). Hierin wird teilweise aber auch ein Unterschied zu $\$ 299$ StGB gesehen, da im Bereich des organisierten Sports kein freier, sondern ein umfassend reglementierter Wettbewerb geschützt werde, s. Löffelmann recht + politik 2/2016, 1 (3).

893 Lehner/Nolte/Putzke/Rössner AntiDopG Vor $\$ \mathbb{S} 1 \mathrm{ff}$. Rn. 27.

894 Vgl. Waßmer ZWH 2019, 6 (8). 
Sponsoring, Rechtevermarktung und Merchandising die zu verteilenden Vorteile für sämtliche Beteiligten. Gleichzeitig ist ihre Vergabe von entscheidender Bedeutung für berufliche Existenzen. Zusätzlich verstärkt durch die Subtraktion eines Wettbezuges steht der für Wettbewerbsdelikte konstitutive Verteilungsmodus bei $\$ 265 \mathrm{~d}$ StGB demnach noch stärker im Vordergrund.

\section{bb) Kritik}

Trotz der nicht in Abrede zu stellenden Entwicklung des Spitzensports zu einem wirtschaftlichen Faktor lassen sich infolge eines eingehenden Abgleichs mit den Strukturmerkmalen eines legitimen Wettbewerbsdelikts erhebliche Bedenken an einer so konzipierten Rechtsgutsbestimmung formulieren. Die aufgezeigten Parallelen, die eine nahtlose Einpassung der $\$ \$ \$ 265$ c, 265d StGB in die Riege der strafrechtlichen Wettbewerbsdelikte suggerieren sollen, gründen auf empirisch nicht belegten Annahmen bzw. greifen zu kurz. Denn zum einen erscheinen die mit einem durch Manipulationen gestörten Verteilungsmodus einhergehenden tatsächlichen wirtschaftlichen Einbußen unklar. Zum anderen wird die Vergleichbarkeit der Wettbewerbsformen stark formal begründet und blendet die zentrale Frage nach der jeweiligen Sozialrelevanz weitgehend aus.

Wie bereits erwähnt unterschätzt die Annahme eines linearen Zusammenhangs zwischen Manipulationen im organisierten Sport und dessen wirtschaftlich spürbarem Attraktivitätsverlust die ebenfalls im Zuge der Kommerzialisierung voranschreitende Wandlung des Spitzensports zu einem Teil der Unterhaltungsindustrie, dessen Profitabilität sich bisher gegen Berichte über Manipulationsfälle immun gezeigt hat. ${ }^{895}$ Stellt man zum Beleg mittelbarer Beeinträchtigungen durch wettbewerbsbezogene Verzerrungen auch auf die angeschlossenen Wirtschaftsbranchen ab, so kann zumindest nicht ohne weiteres von dort zu erwartenden Umsatzeinbußen oder reduzierten wirtschaftlichen Teilhabemöglichkeiten ausgegangen werden. Fokussiert man den Blick aber auf die Berufssportler, die um unmittelbar an den Ausgang des Wettkampfs gekoppelte Vorteile konkurrieren (Preisgelder, Siegprämien), so nehmen sie im Falle der tatbestandlich erfassten Manipulationsart der bewussten Leistungsverweigerung die damit verbundenen sportlichen und wirtschaftlichen Wettbewerbsnachteile eigenverantwortlich in Kauf. Anders etwa als bei Submissionsabspra-

895 S. oben Teil 3 B. II. 2. d) cc) (2). 
chen sind zumindest in Einzelsportarten die durch Match Fixing in ihren wirtschaftlichen Aussichten Benachteiligten nicht ohne weiteres auszumachen.

Doch selbst bei Annahme der empirisch bislang nicht nachgewiesenen negativen wirtschaftlichen Folgen von Spielmanipulationen und einer ausgedehnten Schutzbereichsbestimmung, die sämtliche an der wirtschaftlichen Verwertungskette von Sportveranstaltungen beteiligte Akteure umschließt, stellt sich die Frage nach einer ausreichenden gesamtgesellschaftlichen Relevanz des Sports als wirtschaftlichem Wettbewerb. Denn strafrechtlich schützenswert erscheint ein wirtschaftlicher Wettbewerb dort, wo ein regulierter und am Leistungsprinzip ausgerichteter Verteilungsmodus gerade zum Wohle aller beiträgt. Wenn er etwa auf eine ausgewogene Kalkulation von Ressourcen abzielt oder der optimalen Zuordnung von Gütern dient, erweisen sich dessen Beschränkungen und Verzerrungen nicht nur als Störung eines abstrakten Ideals mit Auswirkungen lediglich für den engen Kreis der unmittelbar Involvierten, sondern wirken sich nachteilig auf die Interessen der Gemeinschaft aus. Der aus Rechtsgutsperspektive erforderliche Personalbezug ist dann herstellbar.

Die von der öffentlichen Hand vorgenommenen Ausschreibungen von Waren oder gewerblichen Leistungen dienen etwa nicht nur im konkreten Fall der Erzielung eines möglichst günstigen Preises auf dem Markt, wodurch die Verwaltung ihrer Pflicht zu wirtschaftlichem und sparsamem Handeln nachkommt, sondern beeinflussen durch gewisse Sog- und Spiraleffekte die gesamte Preisbildung und -regulierung in der betreffenden Branche. ${ }^{896}$ Diese weitreichende Konsequenz trägt die Kriminalisierung von wettbewerbsbeschränkenden Absprachen bei Ausschreibungen in $\$ 298$ StGB. Denn nehmen Submissionskartelle durch Absprachen unlauter Einfluss auf diesen Preisbildungsprozess und zwingen den Ausschreibenden zur Annahme eines überhöhten Angebots, entstehen hierdurch gravierende volkswirtschaftliche Nachteile. ${ }^{897}$ Der Ausschreibende selbst zahlt einen deutlich überhöhten Preis und befördert damit mittelbar eine Anhebung des gesamten Preisniveaus auf dem betroffenen Markt, dem sich letztlich auch die Endverbraucher ausgesetzt sehen. ${ }^{898}$ Der einzelne Bürger hat demnach nicht nur die durch Submissionsabsprachen verursachten Defizite der öffentlichen Hand durch Steuern und Abgaben auszu-

896 Satzger Submissionsbetrug, S. 54.

897 LK-StGB/Tiedemann $\$ 298$ Rn. 4; NK-StGB/Dannecker $\$ 298$ Rn. 7 f.

898 NK-StGB/Dannecker $\$ 298$ Rn. 7. 
gleichen, ${ }^{899}$ sondern wird beispielsweise auch mit höheren Mieten als Folge der künstlich überhöhten Baupreise in der traditionell von Kartellbildung geprägten Baubranche belastet. ${ }^{900}$

Bei der von den $\$ \mathbb{S} 299 \mathrm{ff}$. StGB erfassten Bestechlichkeit bzw. Bestechung im geschäftlichen Verkehr bzw. im Gesundheitswesen besteht in ähnlicher Weise die Gefahr, dass Endverbraucher die durch die Wettbewerbsverzerrer eingespeisten Gewinne mitzutragen haben. Wird beim Bezug von Waren oder gewerblichen Leistungen der Preisstabilität und Qualitätssicherung garantierende Konkurrenzkampf der Anbieter durch unsachliche Entscheidungen ausgehebelt, könnte sich dies letztlich in qualitativ minderwertigen oder durch die Notwendigkeit der Refinanzierung zu zahlender Schmiergelder verteuerten Konsumgütern ausdrücken. ${ }^{901}$ Zwar verbleibt den Kunden und Verbrauchern eine Wahlmöglichkeit. Diese kann durch Preiskartelle aber erheblich beeinträchtigt werden, was sie in den Rang der von $\$ 299$ StGB zumindest mittelbar Geschützten erhebt. ${ }^{902}$ Im Bereich heilberuflicher Entscheidungen ist die Wahlfreiheit der beziehenden Patienten von vornherein eingeschränkter, da sie regelmäßig im Vertrauen auf die Expertise des Arztes die von ihm angeratenen medizinischen Leistungen in Anspruch nehmen werden. Aufgrund dieses Abhängigkeitsverhältnisses schlagen durch korruptive Absprachen entstandene Verteuerungen von Medikamenten oder Behandlungsformen unmittelbar zu Buche, während eine qualitativ defizitäre medizinische Versorgung das Risiko gesundheitlicher Nachteile für sämtliche Bürger erhöht. ${ }^{903}$

Durch die $\$ \mathbb{S} 298 \mathrm{ff}$. StGB werden demnach Wettbewerbsformen geschützt, deren Funktionieren die Stabilität der marktwirtschaftlichen Ordnung bzw. des Gesundheitswesens maßgeblich beeinflusst und somit Teilbereiche konstituiert, die durch den Staat in besonderer Weise im Sinne des Allgemeinwohls zu steuern sind. ${ }^{904}$ Denn ihr Bezug zu den Interessen eines jeden Einzelnen äußert sich darin, dass sich korruptive Störungen in für die gesamte Steuerzahler- und Verbraucherschaft spürbaren Belastungen niederschlagen. Dem wirtschaftlichen Wettbewerb im Spitzensport

899 Kube/Vablenkamp VerwArch 85 (1994), 432 (436).

900 Oldigs Submissionsabsprachen, S. 16.

901 Vgl. BGHZ NJW 1968, 1572 (1574); Jansen GA 2017, 600 (607); Schild, in: Wagner/Wolf (Hrsg.), Korruption, S. 158 (183).

902 Bannenberg Korruption, S. 25; LK-StGB/Tiedemann $\$ 299$ Rn. 4; NK-StGB/Dannecker $\$ 299$ Rn. 14; Lackner/Kühl/Heger/Heger $\$ 299$ Rn. 1 präferiert gar einen weitergehenden, unmittelbaren Schutz der Allgemeinheit vor Verteuerungen.

903 BT-Drs. 18/6446, S. 12.

904 Vgl. Satzger Jura 2016, 1142 (1154); Jansen GA 2017, 600 (606ff.). 
hingegen lässt sich weder in der Theorie eine derart neuralgische Funktion für die Verteilung gesamtgesellschaftlich wertvoller Ressourcen bescheinigen, noch führen regelwidrige Eingriffe in ihn $\mathrm{zu}$ vergleichbar weitreichenden negativen Effekten. ${ }^{905}$ Selbst in einer extensiven Bewertung seiner wirtschaftlichen Bedeutung unter Einschluss sämtlicher Branchen, deren Marktchancen vom Verlauf spitzensportlicher Wettbewerbe beeinflusst werden könnten, beschreibt er einen eng umrissenen Wirtschaftssektor mit einer vergleichsweise kleinen Zahl potenziell betroffener Akteure. Eine diese sektoralen Grenzen überwindende Relevanz für die wirtschaftlichen Interessen einer breiten Bevölkerungsschicht hätte er allenfalls, wenn sich gerade infolge wettbewerbsbezogener Manipulationen zu Lasten der Millionen am Spitzensport interessierter Bürger die Preise für Eintrittskarten oder Pay TV-Abonnements erhöhten. Doch für einen solchen Zusammenhang, der noch am ehesten als Äquivalent zu den im Rahmen der SS $298 \mathrm{ff}$. StGB drohenden Verteuerungen in Betracht käme, wenngleich natürlich bereits das Kriterium eines profunden Interesses am Spitzensport den Kreis der potenziell Belasteten verkleinerte, fehlt es an Anhaltspunkten. ${ }^{906}$ Der naheliegenden Annahme folgend, dass gerade sich in Leistungsverweigerung ausdrückende Manipulationen der Qualität und Attraktivität des Spitzensports abträglich sind, wäre mittelfristig eher mit sinkenden Preisen für Zuschauer zu rechnen. Die gesamtgesellschaftlich durchschlagenden Einbußen sind demnach allenfalls emotionaler Natur, als solche jedoch zu diffus, um eine Sozialschädlichkeit von Verzerrungen des wirtschaftlichen Wettbewerbs im Spitzensport zu begründen.

Ohne Berührungspunkte mit den allgemeinen Lebensgrundlagen und individuellen Entfaltungsbedingungen bezeichnet der kommerzialisierte Leistungssport in einer gesellschaftlichen Makro-Perspektive letztlich ein verzichtbares Teilsystem. ${ }^{907}$ Abgesehen von der medialen Präsenz und den hieraus resultierenden emotionalen Verstrickungen unterscheidet ihn strukturell nichts von anderen Subsystemen, deren Lauterkeit aus guten

905 So im Ergebnis auch Schönke/Schröder/Perron $\$ 265$ d Rn. 1; Beuckelmann NJWSpezial 2010, 56 (57); Kudlich SpuRt 2010, 108 (109); Jahn GA 2007, 579 (588); Krack ZIS 2011, 475 (480); Jansen GA 2017, 600 (606 ff.); Diedrich, in: Asmuth (Hrsg.), Entgrenzungen, 2012, S. 271 (288); aA Waßmer ZWH 2019, 6 (8); König SpuRt 2010, 106 (107).

906 Ott Selbstdoping, S. 219.

907 Vgl. Rübenstahl JR 2017, 264 (268); Schild, in: Wagner/Wolf (Hrsg.), Korruption, 2011, S. 158 (183). 
Gründen keinen strafrechtlichen Sonderschutz erfahren. ${ }^{908}$ So hat sich etwa auch im Bereich des Kunsthandels infolge des Versprechens lukrativer Rendite eine kompetitive Wettbewerbssituation unter Sammlern, Anlegern und öffentlichen Institutionen eingestellt, die durch spezifische Vorgaben etwa für das Platzieren der Kunstwerke auf dem Markt oder den Ablauf von Versteigerungen regulativ flankiert wird. Brächten nun Verstöße gegen diese Wettbewerbsordnung den Kunstmarkt in Verruf, wirkte sich das für Künstler, aber auch für Galerien und Auktionshäuser wirtschaftlich nachteilig aus. Außerdem könnten sie auch hier zu Enttäuschungen bei der Bevölkerung führen, wenn etwa unzulässige Preisabsprachen den Ankauf beliebter Werke durch öffentliche Museen erschweren und diese in der Folge nicht mehr allgemein zugänglich sind. Gleichwohl mangelt es den spezifischen Wettbewerbsbedingungen des Kunstmarkts an hinreichender Sozialrelevanz, so dass ein zugeschnittener strafrechtlicher Sonderschutz dieses wirtschaftlichen Bereichs nicht diskutiert wird.

Wird also die Notwendigkeit eines strafrechtlichen Schutzes des sportwirtschaftlichen Wettbewerbs hauptsächlich auf die Behauptung eines Näheverhältnisses zum von $\$ 299$ StGB geschützten gewerblichen Wettbewerb gestützt, so lässt sich nach dem Gesagten festhalten, dass ersterer auch in der pointierten Form des $\$ 265 \mathrm{~d}$ StGB eindeutig hinter der selbst gesetzten Referenz zurückbleibt und maßgeblicher Merkmale entbehrt, die den wirtschaftlichen Wettbewerb als anerkennungsfähiges Strafrechtsgut auszeichnen.

\section{c) Zwischenergebnis}

Beide Ansätze, den $\$ \$ 265$ c, 265d StGB den institutionellen Schutz eines Wettbewerbsdelikts angedeihen zu lassen, erweisen sich als nicht überzeugend. Die Fokussierung auf den Kern der die Wettkämpfe konstituierenden Regeln begibt sich in eine problematische rechtsgutsbezogene Akzessorietät von den Festsetzungen der Sportverbände und bleibt dabei zu abstrakt und ohne Sozialbezug. Eine an die $\$ \mathbb{S} 298 \mathrm{ff}$. StGB angelehnte Rechtsgutsbestimmung hingegen reflektiert zwar die anwachsende und durchaus vielfältige Dimension des Sports als Wirtschaftsfaktor, vermag dessen Mechanismen aber keine besondere gesamtgesellschaftliche Bedeutung abzugewinnen. Denn wenngleich die voranschreitende Kommerziali-

908 Kauerhof Causa Sport 2014, 127 (134); Satzger Jura 2016, 1142 (1154); Dury SpuRt 2005, 137 (138). 
sierung des Leistungssports nicht in Abrede zu stellen ist, geht eine primär hieraus abgeleitete Annahme einer Strafwürdigkeit an den Legitimationsansprüchen eines Wettbewerbsdelikts vorbei.

\section{Ergebnis}

Der Gesetzgeber verfolgt bei der Begründung der $\$ \$$ 265c, 265d StGB einen in mehrfacher Hinsicht pluralistischen Ansatz. Er versucht, die Straftatbestände mit mehreren Schutzgütern abzusichern. Gegen die erfolgende Heranziehung gleichrangiger Individual- und Kollektivinteressen ist grundsätzlich nichts einzuwenden. Gerade in der ihnen konkret zugewiesenen Kombination des individuellen Vermögensschutzes mit einem bereichsspezifischen, institutionellen Schutzzweck fügen sich die $\$ \$ 265 \mathrm{c}$, 265d StGB in ihr gesetzessystematisches Umfeld ein.

Bei näherer Betrachtung entpuppt sich die Integrität des Sports jedoch als ein Scheinrechtsgut. Ihr ihrerseits durch verschiedene vorgebliche Kennzeichen und Funktionen des Sports pluralistisch aufgeladener Gehalt leidet an einer undifferenzierten Bewertung realer Gegebenheiten des Leistungssports und einem unzureichenden Nachweis zentraler Annahmen. In ihrer gesetzgeberisch konturierten Fassung erweist sich die Integrität des Sports als ein zusammengewürfeltes Postulat, das sich über moralische Projektionen und bloß vermutete sozialerhebliche Wirkungszusammenhänge zu materialisieren versucht, den Materialisierungskriterien eines strafrechtlich schützenswerten Rechtsguts jedoch nicht entspricht und nach der hier vertretenen Auffassung als verfassungslegitimer Zweck einer Strafvorschrift somit nicht in Frage kommt. Auch aus dem Rückgriff auf den (wirtschaftlichen) Wettbewerb als Rechtsgut, der die Integrität des Sports nach Ansicht des Gesetzgebers gerade bei hochklassigen Sportwettbewerben des $\$ 265 \mathrm{~d}$ StGB ergänzen, nach teilweise vertretener Ansicht im Schrifttum gar ersetzen soll, ergibt sich kein legitimierendes Potenzial.

Demnach schießt die gesetzgeberische Rechtsgutskonzeption, getragen vom Vorsatz einer möglichst breitflächigen Begründung der $\$ \$ 265 \mathrm{c}, 265 \mathrm{~d}$ $\mathrm{StGB}$, über die Grenzen eines über bestimmte Materialisierungskriterien umrissenen Rechtsgutsbegriffs hinaus. Die intendierte Absicherung eines möglicherweise nur schwach ausgeprägten Individualrechtsgutsschutzes durch die Behauptung zusätzlich verletzter Allgemeininteressen, die sich als vage, nahezu beliebig angereichert bzw. unpassend erweisen, beschreibt die $\$ \$ 265$ c, 265d StGB als Ausdrucksform einer pluralistischen und entgrenzenden Tendenz, die jüngst auch beim Erlass anderer Strafnormen kri- 
tisiert wurde. ${ }^{909}$ Denn reicht es für ein Eingreifen der Tatbestände schon aus, dass die tatbestandsmäßige Unrechtsvereinbarung eines der drei benannten Schutzgüter in irgendeiner Form tangiert, lassen sich aus der Schutzgutskonzeption insgesamt keine klaren Strafbarkeitsgrenzen mehr ableiten. ${ }^{910}$ Für die Praxis können hieraus Schwierigkeiten bei Auslegung und Anwendung der Normen resultieren. ${ }^{911}$ Nach dem hier zugrunde gelegten Maßstab kann der Strafgrund der $\$ \$ 265 c$, 265d StGB allein im Vermögensschutz gesehen werden, dessen Ausgestaltung in den folgenden Prüfungsschritten besonderer Beachtung bedarf.

\section{Verhältnismäßigkeit}

Entsprechend dem hier verfolgten Ansatz kommt dem Begriff des Rechtsguts zwar eine in negativer Hinsicht ausschließende Funktion in dem Sinne zu, als die Konzepte, die dessen verfassungsrechtlich rückgekoppelten Kriterien nicht entsprechen, schon keinen verfassungslegitimen Zweck bilden. Andererseits kann allein ein nach diesem Maßstab anzuerkennendes Rechtsgut Strafnormen nicht in positiver Hinsicht legitimieren. In Form des Verhältnismäßigkeitsgrundsatzes schreibt die Verfassung für die Zulässigkeit sämtlicher staatlicher Eingriffe in Freiheitsrechte vor, das angestrebte gemeinwohlorientierte Ziel gerade in Abhängigkeit zu Tauglichkeit und potenziellen Nebenwirkungen des konkret gewählten Mittels zu bewerten.

Eine legitime Strafnorm kann sich daher nicht auf die Formulierung eines schützenswerten Etwas zurückziehen, wenn gleichzeitig offen bleibt, ob dieses Etwas auf dem vom Gesetzgeber gewählten Weg auch tatsächlich geschützt werden kann, geschützt werden muss und geschützt werden sollte. $\mathrm{Zu}$ prüfen ist demnach, ob eine Strafnorm geeignet und erforderlich ist, den gesteckten Zweck zu erreichen und ob die Schwere des Eingriffs in die Freiheitsrechte des Bürgers im Verhältnis zur Dringlichkeit des angestrebten Rechtsgüterschutzes angemessen ist. ${ }^{912}$ Die Beantwortung dieser

909 So etwa bei $\$ 299$ a StGB, vgl. BeckOK-StGB/Momsen/Laudien $\$ 299$ a Rn. 7.

910 Swoboda/Bohn Jus 2016, 686 (689).

911 Bohn KriPoz 2017, 88 (92); Nuzinger/Rübenstabl/Bittmann WiJ 2016, 34 (35); ein exemplifizierendes Beispiel liefert Fiedler DRiZ 2016, 17.

912 BVerfGE 120, 224 (240 f.). Dass die Gesetzesbegründung zu den $\$ \$ 265$ c, 265d StGB selbst kein Wort zu den Stufen der Eignung, Erforderlichkeit und Angemessenheit verliert, ist ein betrüblicher Anhaltspunkt für die ungenügende Auseinandersetzung des Gesetzgebers mit den verfassungsrechtlichen Grenzen des Strafrechts, vgl. Pfister StraFo 2016, 441 (442). 
Fragen verlangt eine eingehende Auseinandersetzung sowohl mit der Wirkweise des Strafrechts im Allgemeinen als auch mit den konkret in den $\$ \mathbb{S} 265 \mathrm{c}, 265 \mathrm{~d}$ StGB umschriebenen Modalitäten der Verletzung des für wertvoll erachteten Guts. ${ }^{913}$ Durch den Blick auf deliktsstrukturelle Merkmale und einen Vergleich mit alternativen Formen der Sozialkontrolle wird die Legitimationsprüfung einer Strafnorm verfassungsrechtlich eingebunden und angereichert, ohne sich hierdurch vom Rechtsgut zu emanzipieren, dessen sie als Zwecksetzung, Ausgangs- und fortwährender Bezugspunkt zwingend bedarf. Und da dessen bloß diffuse Umschreibung das kritische Potenzial einer substantiierten Prüfung von Geeignetheit, Erforderlichkeit und Angemessenheit weitgehend leerlaufen ließe, ergeben sich im Sinne einer Wechselwirkung aus den Stufen der Verhältnismäßigkeit wiederum Anforderungen an eine möglichst präzise Bestimmung des Rechtsguts.

Wenngleich gravierende Einwände gegen die Rechtsgutstauglichkeit der Integrität des Sports sowie des wirtschaftlichen Wettbewerbs im Sport geltend gemacht wurden, die nach hier vertretener Ansicht schon keinen verfassungslegitimen Zweck darstellen, werden die $\$ \$ 265$ c, 265d StGB im Folgenden gleichwohl auch hinsichtlich der Integrität des Sports auf ihre Verhältnismäßigkeit überprüft. Hierdurch wird die Aussagekraft des rechtsgutsbezogenen Legitimationsdefizites keinesfalls abgeschwächt. Der Schutz eines Gutes, das schon den Anforderungen an einen verfassungslegitimen Zweck nicht entspricht, kann nicht verhältnismäßig ausfallen. Im Hinblick auf die Zielsetzung einer umfassenden Bewertung der Ausweitung des Integritätsstrafrechts auf den Sport erscheint eine Überprüfung des konkret umgesetzten Integritätsschutzes an den Stufen des Verhältnismäßigkeitsgrundsatzes gleichwohl gewinnbringend. Zum einen lässt sich die rechtsgutsbezogene Kritik eines unbestimmten, idealisierten und auf bloß vermuteten Wirkungszusammenhängen beruhenden gesetzgeberischen Integritätsverständnisses anhand der nachzuweisenden Schädigungsoder Gefahreneffekte der tatbestandlich erfassten Verhaltensweisen in Form eines Rückschlusses veranschaulichen. Zum anderen erweitert eine differenzierte Auseinandersetzung mit der Deliktsstruktur der $\$ \$ 265 \mathrm{c}$, 265d StGB und alternativen Maßnahmen des Integritätsschutzes die Basis der abschließenden Legitimationsbewertung und weist sie auch für diejenigen als anschlussfähig aus, die auf der Ebene des verfassungslegitimen Zwecks die von einem materiell aufgeladenen Rechtsgutsbegriff gänzlich

913 Letztere bezeichnet Stächelin Strafgesetzgebung, S. 55 ff., 90 ff. prägnant als Angriffswege. 
uneingeschränkte Setzungskompetenz des Gesetzgebers befürworten. Die auf $\$ 265 \mathrm{~d}$ StGB beschränkte und auch dort nur ergänzende Heranziehung des wirtschaftlichen Wettbewerbs durch den Gesetzgeber drängt dieses Rechtsgut indes aus der primär verfolgten, einheitlich dualistischen Begründung der Tatbestände heraus und rechtfertigt dessen Nicht-Berücksichtigung als Ausgangs- und Bezugspunkt der folgenden Prüfung.

\section{Geeignetheit}

Im Rahmen der Geeignetheit ist allgemein zu prüfen, ob das eingesetzte Mittel zur Erreichung des Zwecks dienlich sein kann. Der gewünschte Erfolg muss also mithilfe des Mittels gefördert werden, wobei bereits die Möglichkeit der Zweckerreichung ausreichen soll. ${ }^{914}$ Besteht das eingesetzte Mittel im Erlass einer Strafnorm ist von ihr zu verlangen, dass der Rechtsgüterschutz durch sie besser gewährleistet werden kann als ohne sie. ${ }^{915}$

Dies erfordert zweierlei: Zum einen müssen der Strafandrohung gewisse generalpräventive Effekte zugetraut werden. Denn entfaltet gerade der Umstand der Kriminalisierung eines bestimmten Verhaltens weder im Sinne einer psychologischen Zwangswirkung noch im Sinne einer positiven Normbestärkung verhaltenssteuernde Wirkung, wird die Wahrscheinlichkeit von Angriffen auf das Rechtsgut durch die Strafnorm nicht reduziert. Die generalpräventiven Potenziale dürfen dabei nicht abstrakt aus allgemeinen Strafzwecküberlegungen abgeleitet werden, sondern müssen sich tatbestandsbezogen gerade hinsichtlich der Normadressaten und des konkret geschützten Rechtsguts der Strafnorm aufzeigen lassen. ${ }^{916}$ Eine detaillierte Nachweispflicht trifft den Gesetzgeber diesbezüglich jedoch nicht. Ihr stehen die ihm bei prognostischen Einschätzungen zustehenden Ermessensspielräume und die vergleichsweise niedrigen Anforderungen der Eignungsprüfung entgegen. Reicht bereits die Möglichkeit der Zweckerreichung aus, entfiele die Geeignetheit erst, wenn generalpräventive Wirkungen einer Strafandrohung gänzlich ausgeschlossen werden könnten. Hiervon kann trotz der in der Kriminologie vorgebrachten profunden Be-

914 BVerfGE 120, 224 (240).

915 Hefendebl JA 2011, 401 (404).

916 Zu dieser „konkretisierten Präventionswirkung“ s. Hefendebl Kollektive Rechtsgüter, S. 96. 
denken gegen die psychologische Zwangswirkung des Strafrechts ${ }^{917}$ nicht ausgegangen werden. Wenngleich die Strafnorm demnach die Beweislast ihrer generalpräventiven Wirksamkeit nicht zu tragen hat, haben entsprechende Überlegungen in der Eignungsprüfung ihren Platz und sollten nicht im Wege einer kategorischen Unterstellung der Geeignetheit des Strafrechts zum Rechtsgüterschutz übergangen werden. ${ }^{918}$

Bezeichnet die zumindest nicht auszuschließende präventive Wirkung ein notwendiges interaktives Element zwischen der Strafnorm und der adressierten Allgemeinheit, bedarf es im Hinblick auf das Erfordernis einer Förderung des Rechtsgüterschutzes in gleicher Weise und noch vorgelagert einer norminternen Verbindungslinie. Diese hat zwischen der tatbestandsmäßigen Handlung und dem geschützten Rechtsgut zu verlaufen. Zielen die im Tatbestand der Norm vertypten Angriffsarten nämlich allesamt am Rechtsgut vorbei, vermag ihr strafrechtliches Verbot nichts zu seinem Schutz beizutragen. Selbst eine reale Abschreckungswirkung der Strafe hinge dann im luftleeren Raum, weil sie lediglich das Unterlassen eines Verhaltens veranlasste, das sich ohnehin nicht auf das Rechtsgut ausgewirkt hätte. Dies käme aber der problematischen Kriminalisierung bloßer Pflichtverletzungen gleich. Ins Positive gewendet verlangt die Geeignetheit einen Tatbestand, bei dem die pönalisierte Handlung das geschützte Rechtsgut auch tatsächlich beeinträchtigen kann. ${ }^{919}$ Um dies festzustellen, ist eine Analyse der Deliktsstruktur der überprüften Strafnorm vor dem Hintergrund des von ihm geschützten Rechtsguts unerlässlich.

Gemäß diesen Vorgaben, die das verfassungsrechtliche Eignungserfordernis für ein dem Rechtsgüterschutz verpflichtetes Strafrecht konkretisieren, werden die $\$ \$ 265 c, 265 \mathrm{~d} S t G B$ im Folgenden überprüft. In die Rechtsgüter der Integrität des Sports und des Vermögens unterteilt hat eine gezielte Untersuchung beider Tatbestandsfassungen und denkbarer Implikationen ihrer gerade strafrechtlichen Qualifizierung zu zeigen, inwiefern von einer den Schutz des jeweiligen Rechtsguts fördernden Wirkung ausgegangen werden kann.

917 Vgl. Kargl Funktionen des Strafrechts, S. 21 ff.; Hefendehl Kritische Justiz 2016, 577 (579f.).

918 In diese Richtung aber BVerfGE 120, 224 (239), dem Gesetzgeber diesbezüglich geradezu einen Freibrief ausstellend.

919 Vgl. Hefendehl Kollektive Rechtsgüter, S.98f.; Sondervotum Graßhof zu BVerfGE 90, 145 (199, 204). 


\section{Hinsichtlich der Integrität des Sports}

Hinsichtlich der Geeignetheit der $\$ \$ \$ 265$ c, 265d StGB zum Schutz der nach Ansicht des Gesetzgebers beiden Tatbeständen als Rechtsgut zugrunde liegenden Integrität des Sports lassen sich bezüglich beider Vorgaben Bedenken vorbringen. Zum einen kann bereits auf einer allgemeinen Ebene ein unverträgliches Verhältnis zwischen der Wirkweise des Strafrechts und den Entstehungsbedingungen der für die Integrität des Sports konstitutiven Elemente vermutet werden, wodurch generalpräventive Effekte der vorgenommenen Kriminalisierung in Zweifel gezogen werden können (dazu a]). Zum anderen erscheint die notwendige Verbindung der jeweils tatbestandsmäßigen Unrechtsvereinbarung mit ihren speziellen Voraussetzungen und Einschränkungen zur aufgezeigten Konzeption des Rechtsguts zumindest auf den ersten Blick nicht evident und frei von Widersprüchen (dazu b]).

a) Allgemeine Untauglichkeit des Strafrechts zum Schutz der Integrität des Sports

Zunächst ist der Blick auf eine mögliche strukturelle Unvereinbarkeit der strafrechtlichen Wirkweise mit dem gesetzgeberischen Verständnis der Integrität des Sports zu richten, die einen positiven Beitrag zum Schutz des Rechtsguts schon losgelöst von der konkreten Ausformung der tatbestandlichen Angriffswege ausschlösse. In dieser Hinsicht zu untersuchen ist neben dem Verhältnis von strafrechtlicher Verhaltenssteuerung und der Entstehung sportethischer Werte zumindest ansatzweise auch die zu erwartende generalpräventive Wirkung einer Kriminalisierung im betroffenen Bereich.

aa) Systembedingte Untauglichkeit zur Förderung sportethischer Werte

Die Geltungskraft bestimmter sportethischer Werte wurde als zentraler Bestandteil der Konzeption der Integrität des Sports identifiziert. Die Gebotenheit eines strafrechtlichen Schutzes sportlicher Wettbewerbe wurde nicht zuletzt auf deren vorbildhafte Ausstrahlungswirkung zurückgeführt, die darauf gründe, dass die Sportler Fairness, Respekt und Toleranz verinnerlicht hätten und ihr kompetitives Leistungsstreben erkennbar dieser Richtschnur folge. Wird das schützenswerte Etwas folglich zumindest teil- 
weise in einer individuellen Einstellung bzw. einem inneren Bekenntnis des Sportlers zu einem bereichsspezifischen Wertekodex gesehen, stellt sich die grundsätzliche Frage, ob gerade das Strafrecht einen Beitrag zu deren Ausbildung oder Bewahrung zu leisten vermag.

Zweifel hieran erscheinen insofern angebracht, als das Strafrecht durch die Normierung von Verboten und der Androhung äußeren Zwangs allenfalls äußerlich normkonformes Verhalten erreichen kann, die Adressaten aber nicht zu positiven inneren Wertentscheidungen veranlasst. ${ }^{920}$ Die Bedeutung der Trennung von (Straf-)Recht und Moral auch auf eine Wirkungsanalyse stützend führte bereits Immanuel Kant aus, was durch die äußere Ordnung des Rechts erzwungen werde, könne nicht als sittlich wertvoll angesehen werden. ${ }^{921}$ Freilich könnte eine solche Sichtweise das Strafrecht überall dort in Begründungsprobleme bringen, wo sein Einsatz dem Integritätsschutz dienen soll. Allerdings ist dabei zwischen dem Sport und den anderen Bereichen des strafrechtlichen Integritätsschutzes zu differenzieren. Für Beamte, Ärzte und Parlamentarier existiert ein vergleichsweise klar umrissenes Berufsethos, das jeweils auch von detaillierten standesrechtlichen Vorgaben flankiert und geprägt wird. Es steht den Angehörigen dieser Berufsgruppen bei Ausübung ihrer Tätigkeit präsenter vor Augen, nicht zuletzt deshalb, weil sie sich ihm förmlich durch die Ableistung eines Eides verpflichtet haben. Da es ihnen gewährte Entscheidungskompetenzen bindet und Schutzwirkung zugunsten der ihren Befugnissen Ausgesetzten entfalten soll, ist es zudem stärker verhaltensbezogen und stellt geringere Anforderungen an die dahinterstehende Motivation.

Diese Merkmale begünstigen die Wirksamkeit eines am Berufsethos anknüpfenden und ebenfalls auf Verhaltenssteuerung ausgerichteten Strafrechts. Die sportethischen Prinzipien hingegen sind unbestimmter. Ihrem Anspruch nach kennzeichnen sie sich nicht als an den einzelnen Sportler herangetragene Forderungen, sondern vielmehr als freiwillig übernommene Handlungskriterien, die immanent als verbindlich angenommen werden. ${ }^{922}$ Am Beispiel des Fair Play wird deutlich, dass das eigenverantwortliche und zwanglose Bekenntnis der Sportler zu diesem Prinzip dessen Vorbildhaftigkeit und Wirkkraft überhaupt erst begründet. Der Verzicht auf eine vorteilhafte Position in einem kompetitiven Wettbewerb ist erst dann beeindruckend, wenn er nicht von einem übergeordneten Regelwerk vorgeschrieben wird, sondern aus einer rein intrinsischen Motivation erfolgt

920 Vgl. Momsen, in: Asmuth (Hrsg.), Entgrenzungen, 2012, S. 251 (252).

921 Kant Metaphysik (1797), Bd. VI, S. 230 f.

922 Schild FS Kargl, 2015, S. 507 (521). 
und die überzeugte Hingabe an eine abstrakte Idealvorstellung des Wettstreitens ausdrückt. ${ }^{923}$

Hiermit sind fast schon verhängnisvolle Ausgangsbedingungen für ein zur Herstellung sportlicher Fairness eingesetztes Strafrecht beschrieben. Denn es wäre mangels Zugriffs auf ebenjene intrinsische Motivation nicht nur wirkungslos, sondern geradezu kontraproduktiv. Die Erzwingung sportlicher Fairness durch die strafrechtliche Sanktionierung von VerstöBen droht das aufzulösen, was sie eigentlich schützen will. ${ }^{924}$ Faires Verhalten im Sport könnte nicht mehr länger als Ausfluss einer überzeugt eingenommenen Haltung wahrgenommen werden, sondern drückte lediglich die Anpassung an einen äußeren Zwang aus. Integrität würde durch bloße Rechtstreue ersetzt und verlöre jegliche inspirierende Faszination. ${ }^{925}$ In der Folge wird teilweise gar das Grundverständnis des Sports als gefährdet angesehen. Denn für seine Konstitution als autonome Eigenwelt komme ein externer Eingriff, der die Verantwortung für die sportethische Wertebildung einer staatlichen Kontrollinstanz zuweist, einem zerstörerischen Akt gleich. ${ }^{926}$

Ergibt sich hieraus zweifellos die Untauglichkeit des Strafrechts, Integrität im Sport zu produzieren, ${ }^{927}$ ist damit noch keine verbindliche Aussage über die Geeignetheit der $\$ \$ 265$ c, 265d StGB verbunden. Denn eine solche Zielrichtung entspräche einem aktivistischen Verständnis des Strafrechts, das dieses von vornherein überfordern würde. Norminternalisierungen verlaufen nicht über die Sanktionierung von Zuwiderhandlungen, sondern über die positive Vermittlung durch maßgebliche Sozialisationsinstanzen. ${ }^{928}$ Reduziert man den Anspruch also von einem aktiven Ausbau des Rechtsguts auf dessen Schutz, so ergeben sich Förderungsmöglichkeiten, die durchaus innerhalb des generalpräventiven Leistungsvermögens des Strafrechts liegen könnten. Wenngleich das Strafrecht die spezifische Sondermoral innerhalb der Eigenwelt nicht zu bestärken vermag, profitierte die Integrität des Sports in anderer Weise davon, dass ein äußeres Ver-

923 Valerius Jura 2018, 777 (778).

924 Schild Doping, S. 48.

925 Valerius Jura 2018, 777 (778); Pfister StraFo 2016, 441 (442); Schild Sportstrafrecht, S. $137 \mathrm{f}$.

926 Kauerhof Causa Sport 2014, 127 (133); in diese Richtung auch Schild Sportstrafrecht, S. 136.

927 So auch Stellungnahme des Deutschen Anwaltvereins Nr. 12/2016, S. 6; Dittrich ZWH 2017, 189 (190).

928 Hefendebl JA 2011, 401 (405). 
trauen in sie stabilisiert oder Außenstehende von Angriffen auf ihre Bestandteile abgehalten würden.

Dass ein öffentliches Vertrauen in die Integrität des Sports einen einigermaßen einheitlichen Gegenstand aufweist und eine tatsächlich handlungsleitende Funktion einnimmt, wurde bereits in Zweifel gezogen. ${ }^{929}$ Hält man es hingegen für existent, lässt sich strafrechtlichen Maßnahmen eine stabilisierende Wirkung nicht grundsätzlich absprechen. Natürlich bedarf der Nachweis dieses Wirkungszusammenhangs im Einzelnen einer deliktsstrukturellen Prüfung der Tatbestände. Auf einer allgemeinen Ebene ist jedoch zunächst zumindest nicht auszuschließen, dass das Wissen um die Pönalisierung des Match Fixing die Bereitschaft der Menschen erhöht, die jeweiligen Resultate als authentisch anzuerkennen - und sei es nur aufgrund der Annahme, der Druck strafrechtlicher Sanktionen würde die Sportler zu fairem Verhalten an- und Außenstehende von der Setzung von Anreizen zu Manipulationen abhalten. Kann allein diese Möglichkeit die niedrigen Anforderungen an eine generelle Eignung des Strafrechts ausreichend erfüllen, bestärkt sie gleichzeitig die bereits geäußerte Skepsis bezüglich der anknüpfenden Frage nach der Schutzwürdigkeit eines solchen Vertrauens. Denn gemäß den beschriebenen Entstehungsbedingungen und der Wirkkraft des Fair Play-Prinzips bezöge sich ein Vertrauen in eine gerade strafrechtlich verordnete Fairness letztlich auf eine Leerformel, die dem Sport unter Umständen zu einer höheren Ergebnis-Authentizität verhelfen könnte, darüber hinaus aber als gesellschaftlich inspirierende Vorlage und bestärkender Faktor eines sozialen Verantwortungsbewusstseins nicht in Betracht käme.

bb) Konkretisierte Zweifel an der generalpräventiven Wirkung des Strafrechts bei Match Fixing

Hinsichtlich des gezielt für die $\$ \$ 265 c$, 265d StGB überprüften Mechanismus der positiven Generalprävention lassen sich aus Vorstehendem ambivalente Schlüsse ziehen. Im Grundsatz verweist die Annahme einer positiven Generalprävention auf die Eignung der Kriminalstrafe als Mittel zur Erhaltung und Stärkung des Vertrauens in die Durchsetzungskraft der Rechtsordnung und die Bestandskraft der durch sie geschützten Werte. ${ }^{930}$ Wie erwähnt kann die strafrechtliche Verfolgung manipulationsbezogener

929 S. oben Teil 3 B. II. 2. d) cc) (2).

930 Roxin/Greco Strafrecht AT I $\$ 3$ Rn. 26. 
Absprachen unter gewissen Umständen das Vertrauen der Bevölkerung in die Authentizität sportlicher Wettbewerbe als ein Teilelement ihrer Integrität stärken. Eine präventiv wirkende Verankerung des Werts der Fairness in ihrer sportspezifischen und gesamtgesellschaftlichen Dimension im kollektiven Bewusstsein wird von Verurteilungen nach den $\$ \$$ 265c, 265d StGB hingegen kaum ausgehen. Bezogen auf die Tätergruppe der Sportakteure nährt das sich jenseits strafrechtlicher Verordnung ausbildende Bekenntnis zum Fair Play Zweifel an einem wesentlichen Beitrag der Kriminalstrafe zur Einübung diesbezüglicher Normtreue. Gerade durch die Tätigkeit der Strafjustiz angestoßene generalpräventive Lerneffekte könnten überdies von der zu erwartenden geringen rechtspraktischen Bedeutung der neuen Tatbestände abgeschwächt werden.

Um eine Verbesserung des Rechtsgutsschutzes demgegenüber in der vor angreifenden Verhaltensweisen abschreckenden Wirkung der konkreten Tatbestände festmachen zu können, müssen diesen negativ-generalpräventive Potenziale hinsichtlich ihres Adressatenkreises zugetraut werden. Diese für die $\$ \$ 265$ c, 265d StGB aufzuzeigen oder gar empirisch zu belegen, unterlässt der Gesetzgeber jedoch. ${ }^{931}$ Er kann sich dabei in gewisser Weise auf das Bundesverfassungsgericht berufen, das sich bezüglich der psychologischen Wirkung einer Strafandrohung auf den Standpunkt zurückzieht, eine solche könne regelmäßig zumindest nicht ausgeschlossen werden und ihr kritisches Hinterfragen den Gesetzgeber bereits aus „grundsätzlichen Erwägungen" heraus nicht an der Kriminalisierung eines sozialschädlichen Verhaltens hindern.932 Dies mag vor dem Hintergrund der durch das Gericht unterstrichenen Beweislastregel die Annahme der Geeignetheit der $\$ \$ 265 c, 265 d$ StGB insofern stützen, als der Forschungsstand zu abschreckenden Effekten von Straftatbeständen im Umfeld des Leistungssports nicht so eindeutig ausfällt, als dass ihm eine absolute Wirkungslosigkeit entnommen werden könnte. ${ }^{933}$ Umgekehrt sollten jedoch bereichsspezifische Indizien nicht ausgeblendet werden, die jedenfalls der allzu leichtfertig aus den gängigen Annahmen abgeleiteten Vermutung einer konkretisierten Präventionswirkung der Tatbestände im Wege stehen.

So wird zu deren Begründung insbesondere im Kontext des Wirtschaftsstrafrechts, in den die $\$ \$ 265$ c, 265d StGB aufgrund der wirtschaftlichen Verflechtungen des Spitzensports und der korruptionsnahen Ausgestal-

931 Die Geeignetheit der Delikte schon deswegen anzweifelnd Feltes/Kabuth NK 2017, 91 (97).

932 BVerfGE 120, 224 (249).

933 Vgl. Hauptmann/Rübenstabl HRRS 2007, 143 (147). 
tung der Tatbestände durchaus eingeordnet werden können, oftmals auf den bereits im Rahmen der Erklärungsansätze des Match Fixing eingeführten Rational Choice-Ansatz zurückgegriffen. ${ }^{934} \mathrm{Ihm}$ zufolge wird eine mit Wahlfreiheit ausgestattete Person sich für die Begehung einer kriminellen Handlung entscheiden, sofern die damit verbundenen Kosten und Erträge ein positiveres Saldo ergeben als die vergleichbaren Kosten und Erträge einer rechtstreuen Verhaltensweise. ${ }^{935}$ Abschreckungsmaßnahmen wie die Kriminalisierung eines Verhaltens, die Erhöhung der Strafschwere oder die Steigerung der Verfolgungsintensität würden dabei als Kosten-Variablen verbucht und verringerten als Produkt aus möglicher Strafhöhe und Verurteilungswahrscheinlichkeit den subjektiv erwarteten Nutzen einer kriminellen Handlung. ${ }^{936}$ Ungeachtet der grundsätzlichen Kritik an der Plausibilität des Ansatzes, die auch dessen Leistungsfähigkeit im Wirtschaftsstrafrecht relativiert, ${ }^{937}$ lassen sich hinsichtlich seiner Anwendung auf die $\$ \$ 265$ c, 265d StGB bereichsspezifische Bedenken an einer maßgeblichen Erhöhung der Kosten für rational agierende Normadressaten formulieren.

Für die als Vorteilsnehmer an der tatbestandsmäßigen Absprache nahezu ausnahmslos beteiligten Sportakteure wurden die auf Kostenseite einzustellenden Variablen bereits in einer allgemeinen, staatliche Strafen aufgrund ihrer landesabhängigen Existenz noch nicht berücksichtigenden Weise beschrieben. ${ }^{938}$ Teilweise wird nun in der hinzukommenden Androhung einer Kriminalstrafe und dem dank des Einsatzes strafprozessualer Zwangsmittel gesteigerten Entdeckungsrisiko getroffener Manipulationsabsprachen der ausschlaggebende Faktor für deren künftige Unterlassung gesehen. ${ }^{939}$ Diese Einschätzung verkennt jedoch, dass die in den Regelwerken der Verbände für die Beteiligung an Spielmanipulationen vorgesehenen Sanktionen in Form von Ausschlüssen oder jahrelangen Sperren den

934 S. oben Teil 2 A. III. 2.; allgemein zu Rational Choice bei Wirtschaftskriminalität Göppinger/Bock Kriminologie, $\$ 10$ Rn. 95.

935 Grundlegend Becker The Journal of Poitical Economy Vol. 76 (1968), 169 ff.; Wittig MSchrKrim 1993, 328 (331 f.).

936 Becker The Journal of Poitical Economy Vol. 76 (1968), 169 (177); vgl. Bock Kriminologie Rn. 178.

937 Göppinger/Bock Kriminologie $\mathbb{1} 10$ Rn.95; Boen MschrKrim 2001, 335 (350); Kunz/Singelnstein Kriminologie, $\mathbb{1} 12 \mathrm{Rn} .31 \mathrm{ff}$.

938 S. oben Teil 2 A. III. 2. a).

939 Adams/Rock ZfWG 2010, 381 (384); Maennig Vierteljahreshefte zur Wirtschaftsforschung 73, 263 (281); ähnlich für die Manipulationsform des Dopings Bannenberg/Rössner FS Schild, 2007, S. 59 (70). 
Sportakteur in seiner unmittelbaren Lebensgestaltung weitaus empfindlicher treffen können als eine für dasselbe Verhalten zu erwartende, staatlich verhängte Geld- oder Bewährungsstrafe. ${ }^{940}$ Auch die gerade für populäre Spitzensportler abwägungsrelevante Gefahr eines sozialen Reputationsverlustes schließt eher an die regelmäßig schneller verhängte verbandsrechtliche Rechtsfolge an. Demzufolge kann durchaus in Zweifel gestellt werden, ob mit einer bloß zusätzlichen und in der Gesamtwirkung untergeordneten strafrechtlichen Sanktion eine signifikante Erhöhung der Kosten für Sportakteure einhergeht. Denn der Annahme durchweg rational abwägender Akteure folgend werden diejenigen, die sich schon von der drohenden Erschütterung ihrer beruflichen Existenz nicht vom Ergreifen entsprechender Tatgelegenheiten haben abhalten lassen, hierauf auch nicht in Folge strafrechtlicher Konsequenzen verzichten.

Anders wäre dies freilich zu bewerten, wenn die Schaffung strafrechtlicher Tatbestände gerade das generelle Entdeckungsrisiko von Manipulationsabsprachen erhöhte. Die Möglichkeit eines Rückgriffs auf strafprozessuale Zwangsmittel dürfte hierfür aber kaum ausreichen. ${ }^{941}$ Ihr Einsatz mag zwar die Aufklärung eines Anfangsverdachts erleichtern. Dessen Bildung vollzieht sich aber regelmäßig über verbandsinterne Hinweisgeber oder die von Sportverbänden und Wettanbietern eingesetzten Kontrollsysteme des Wettmarkts und somit auch künftig außerhalb der Strafverfolgungsbehörden. ${ }^{942}$ Insbesondere für wettbezogenes Match Fixing erscheint daher die Ausgestaltung und Überwachung der Wettmärkte die wesentliche Determinante des empfundenen Entdeckungsrisikos zu sein. ${ }^{943}$

Kostensteigernde Effekte einer Kriminalisierung können sich dann allenfalls dergestalt auf die Einschätzung der Sanktionierungswahrscheinlichkeit auswirken, dass gerade durch die Kooperation von Sportverbänden, Wettanbietern und Strafverfolgungsbehörden eine effektivere Verfolgung ausgetauschter Verdachtsmomente verbandsintern und strafrechtlich erwartet wird. Angesichts des für Wettmanipulationen bereits einschlägigen $\$ 263$ StGB - diesbezüglich war eine drohende Kriminalstrafe für Sportakteure sowie externe Vorteilsgeber auch zuvor schon in die Kalkulation einzustellen - könnten solche gerade von den neu geschaffenen Straf-

940 Feltes/Kabuth NK 2017, 91 (100); Dury SpuRt 2005, 137 (140). Ausführlich zu Ausgestaltung und Wirkweise des verbandsinternen Sanktionsregimes s. unten Teil 3 C. II. 1. a) bb).

941 Eingehend hierzu s. unten Teil 3 C. II. 1. a) bb) (3) ( $\alpha$ ).

942 In ähnlicher Weise die Abschreckungswirkung der strafrechtlichen Sanktionierung des Selbstdopings bezweifelnd Norouzi/Summerer SpuRt 2015, 63 (64 f.).

943 Näher hierzu s. unten Teil 3 C. II. 1. a) aa) (2). 
tatbeständen ausgehende Wirkungen hauptsächlich auf den Bereich nichtwettbezogener Manipulationen i.S.d. $\$ 265 \mathrm{~d}$ StGB begrenzt sein. Selbst bei unkritischer Zugrundelegung des zur Unterstützung der generalpräventiven Wirkung des Strafrechts oftmals herangezogenen Rational Choice-Ansatzes sprechen verschiedene Aspekte dafür, dass die maßgebliche Abwägung der konkreten Normadressaten durch Einführung der $\$ \$ 265 \mathrm{c}, 265 \mathrm{~d}$ StGB nicht signifikant verändert wurde.

\section{cc) Zwischenergebnis}

Zusammenfassend kann festgehalten werden, dass die Förderung der Integrität des Sports durch strafrechtliche Maßnahmen bereits deshalb nicht überschätzt werden darf, weil diese schon strukturell in Widerstreit mit den Entstehungsbedingungen der geschützten Komponenten geraten. Die strafrechtliche Zwangswirkung schwächt gerade die Wesensmerkmale der konstitutiven sportethischen Werte, die ihre Übertragung in ein über den Sport hinausgehendes gesellschaftliches Verantwortungsbewusstsein bewirken könnten. Dem Ansatz des Gesetzgebers, gerade die Vorbildwirkung des sportethischen Wertekodex durch ihren strafrechtlichen Schutz zu bestärken, kann daher nicht gefolgt werden. Hinsichtlich der Stabilisierung eines in die Authentizität der Wettbewerbsresultate gesetzten öffentlichen Vertrauens und der Abschreckung der Normadressaten vor rechtsgutsbezogenen Angriffen können förderliche Effekte strafrechtlicher Regelungen trotz gewisser Bedenken im Einzelnen nicht ausgeschlossen werden. Insofern ist der Einsatz des Strafrechts nicht schon im Generellen als gänzlich ungeeignet zum Schutz der Integrität des Sports zu disqualifizieren.

b) Tatbestandsspezifische und deliktsstrukturelle Merkmale

Erwägungen zur allgemeinen Wirkweise des Strafrechts betreffen im Hinblick auf die Integrität des Sports eine notwendige, aber keine hinreichende Bedingung der Geeignetheit der untersuchten Strafnormen. Bezüglich der maßgeblichen Frage nach einer Förderung des Schutzes des Rechtsguts ist in erster Linie dessen nachweisbarer Zusammenhang mit dem konkreten Tatbestand entscheidend. Zielt dessen in objektiven und subjektiven Merkmalen beschriebene Angriffsrichtung an sämtlichen Elementen des geschützten Rechtsguts vorbei, führt dessen Verwirklichung zu keiner 
Schwächung des Rechtsguts. Im Umkehrschluss trägt die Kriminalisierung dann aber auch nichts zu seinem Schutz bei. Die in $\$ \$ 265$ c, 265d StGB beschriebenen Verhaltensweisen sind im Folgenden daher daraufhin zu überprüfen, ob und auf welche Weise sie Einbußen bei der Integrität des Sports hervorzurufen vermögen. Bedenken an der erforderlichen realen Verletzungskausalität ${ }^{944}$ können sich dabei zum einen aufgrund von Verkürzungen des tatbestandlichen Anwendungsbereiches ergeben, zum anderen an ihrer deliktsstrukturellen Ausgestaltung anknüpfen.

aa) Tatbestandliche Verkürzungen des Anwendungsbereiches

Vor dem Hintergrund des intendierten Schutzes der Integrität des Sports erstaunt die in bestimmten Bereichen über gewisse Tatbestandsmerkmale eintretende Verkürzung des Anwendungsbereiches der $\$ \mathbb{S} 265 \mathrm{c}, 265 \mathrm{~d}$ StGB. Diese realisiert sich in persönlicher wie sachlicher Hinsicht infolge der vorgenommenen Begrenzung des Täterkreises sowie der Beschränkungen der den Bezugspunkt der Unrechtsvereinbarung bildenden Manipulation, die sich sowohl auf leistungssportliche Wettbewerbe richten als auch zugunsten des Wettbewerbsgegners erfolgen muss. Hierin kann durchaus das Ausblenden rechtsgutsrelevanter Angriffswege und das Verfehlen integritätsschützender Potenziale erblickt werden.

Auf die Geeignetheit der Tatbestände schlägt das Ignorieren bestimmter rechtsgutsrelevanter Gefahren indes nicht durch. Entsprechend dem aufgezeigten Maßstab ist der Gesetzgeber im Rahmen der Festsetzung eines geeigneten Mittels von Verfassungs wegen gerade nicht dazu verpflichtet, einen allumfassenden Schutz des Rechtsguts zu gewährleisten. Der Einsatz eines geeigneten Mittels verlangt nicht nach der Ergreifung der effektivsten und weitreichendsten Option. ${ }^{945}$ Eine derartige Forderung würde gerade im Strafrecht auch nahezu zwangsläufig unlösbare Konflikte der getroffenen Regelung mit nachfolgenden Legitimationskriterien wie der Angemessenheit und Bestimmtheit hervorrufen. Die Entscheidung des Gesetzgebers, nur einer bestimmten von mehreren Gefahrenquellen zu begegnen, vermag Lücken des Rechtsgüterschutzes zu begründen, stellt die Eig-

944 Mit diesem Begriff werden die notwendigen Verknüpfungsmomente zwischen Tathandlung und Rechtsgut beschrieben, vgl. Hefendebl Kollektive Rechtsgüter, S. 148 f.; Jäger Rechtsgüterschutz, S. 17.

945 BVerfGE 67, 157 (175); 96, 10 (23). 
nung des realisierten Schutzes aber nicht in Frage. ${ }^{946}$ Eine die Geeignetheit erschütternde Wirkung käme den Einschränkungen daher allenfalls zu, wenn hierdurch die Schutzrichtung gänzlich falsch ausgelegt worden wäre und gerade die tatbestandlich adressierten Personenkreise, Institutionen und Verhaltenselemente von vornherein keinerlei Rechtsgutsbezug aufwiesen.

Dies kann für die konkrete tatbestandliche Ausgestaltung der $\mathbb{S} 265 \mathrm{c}$, 265d StGB jedoch verneint werden. Die folgende nähere Betrachtung der drei vor dem Hintergrund eines konsequenten Integritätsschutzes mitunter kritisierten tatbestandlichen Verkürzungen des Anwendungsbereiches legt zwar gewisse Widersprüche der gesetzgeberischen Begründung offen. Ebenso klar ist dabei aber festzustellen, dass sie die im Rahmen der Geeignetheitsprüfung geforderte Verbindung zwischen den Tatbeständen und dem geschützten Rechtsgut nicht in einer Weise auflösen, die die Geeignetheit der Vorschriften in Frage stellte.

\section{(1) Ausschluss tauglicher Täter}

Gemessen am Ziel eines möglichst lückenlosen Schutzes der Integrität des Sports wird der persönliche Anwendungsbereich der $\$ \$ 265 \mathrm{c}, 265 \mathrm{~d}$ StGB als zu eng kritisiert. Nachvollziehbar werde zwar die Fähigkeit zur Einflussnahme auf das Wettkampfgeschehen zur maßgeblichen Tätereigenschaft erklärt. Die sodann durch einschränkende Voraussetzungen geschaffene Fokussierung auf Sportler, Sportrichter, Trainer und einen kleinen Kreis von diesen gleichstehenden Personen werde den Realitäten des Hochleistungssports, der sich zunehmend als Produkt eines ausdifferenzierten Teams zeige, nicht gerecht. ${ }^{947}$

Tatsächlich kann beispielsweise der Ausschluss von Mechanikern, Service-Leuten oder familiär bzw. freundschaftlich verbundenen Beratern in bestimmten Sportarten zu Schutzlücken führen. Im Motor-, Ski- und Schlittensport hängt der Erfolg eines Teilnehmers erheblich von der Qualität seines Sportgeräts ab. Mechaniker oder Service-Leute haben demnach einen erheblichen Einfluss auf Verlauf und Ausgang eines Wettkampfes. Dennoch steht beispielsweise der Service-Mann, der sich gegen eine zugesagte Prämie dazu bereit erklärt, die Langlaufski seines als Favorit antreten-

946 BVerfG NJW 2020, 905 (913).

947 Löffelmann recht + politik 2/2016, 1 (3 f.); Stellungnahme Transparency International zu BT-Drs. 18/8831, S. 2; krit. auch Krack wistra 2017, 289 (293). 
den Athleten mit einer bremsenden Wachsmischung zu präparieren, auf dass dieser die vorderen Platzierungen verfehle, trotz der integritätsschädigenden Manipulation außerhalb des strafrechtlichen Anwendungsbereiches. Dort befinden sich auch Familienangehörige und Freunde eines Sportlers, die gerade in Einzelsportarten wie Tennis, Turnen oder Eiskunstlauf, in denen die Sportler oftmals schon in jungen Jahren in die internationale Spitze vorstoßen, trotz des Fehlens einer formalen Trainerrolle oftmals über genauso großen Einfluss auf die Einstellung und Taktik des Sportlers verfügen. Auch von ihnen initiierte manipulative Schlechtleistungen führen zu keiner strafrechtlichen Reaktion.

Für die Geeignetheit der $\$ \mathbb{S} 265 \mathrm{c}$, 265d StGB bleibt diese Fokussierung ohne Bedeutung. Der eingegrenzte Personenkreis, dem ein tauglicher Vorteilsnehmer i.S.d. $\$ \$ 265 \mathrm{c}, 265 \mathrm{~d}$ StGB entnommen werden muss, erfasst wenn auch nicht sämtliche, so doch die wahrscheinlichsten Akteure im Hinblick auf die manipulative Ausnutzung einer gegebenen Einflussmöglichkeit auf das tatsächliche Wettkampfgeschehen.

(2) Einschränkung auf Manipulationen leistungssportlicher bzw. berufssportlicher Wettbewerbe

Die $\$ \$ 265$ c, 265d StGB unterscheiden sich in der Bestimmung der sportlichen Wettbewerbe, die vor einer manipulativen Abrede geschützt werden sollen. Während die Voraussetzung eines berufssportlichen Wettbewerbs den Anwendungsbereich des $\$ 265 \mathrm{~d}$ StGB auf bestimmte hochklassige Ligen und Turniere beschränkt, zieht $\$ 265 \mathrm{c}$ StGB, der lediglich einen Wettbewerb des organisierten Sports verlangt, zu dem eine öffentliche Sportwette angeboten wird, den Kreis der in Betracht kommenden Manipulationsobjekte weiter. Dennoch bleiben Absprachen, die Manipulationen von Wettbewerben im großen Bereich des Breitensports beinhalten, ohne strafrechtliche Konsequenzen.

Aus dieser Fokussierung könnten sich insofern Zweifel an der rechtsgutsschützenden Eignung der Tatbestände ergeben, als gemeinhin gerade der ausgeschlossene Bereich des Breitensports als wichtige Sozialisationsinstanz im Sinne der Rechtsgutskonzeption angesehen wird. ${ }^{948}$ Dort findet für einen Großteil der Bevölkerung der erste unmittelbare Kontakt mit

948 Tsambikakis StV 2018, 319 (321); Stellungnahme des Deutschen Anwaltvereins Nr. 12/2016, S. 9; Krack ZIS 2016, 540 (545); Reinhart SpuRt 2016, 235 (238); Berberich ZfWG 2017, 347 (351). 
den sportethischen Werten statt. Die Erkenntnis ihrer Bedeutung und die Motivation zu ihrer Übernahme dürften von den selbst erlebten breitensportlichen Erfahrungen ungleich stärker beeinflusst werden als vom medialen Konsum eines Spitzensports, der sich hinsichtlich Fair Play und Leistungsbereitschaft oftmals als gespalten erweist. Für Kinder und Jugendliche verkörpert ihr Vereinstrainer, der sie Woche für Woche in Wettkämpfen dazu anhält, dem Schiedsrichter mit Respekt zu begegnen und den gegnerischen Spielern nach Abpfiff die Hand zu reichen, den Wert des Fair Play eher als ein Nationalspieler, der durch Theatralik und Zeitspiel auffällt. Der gemeinsam hart erkämpfte Gewinn einer Schul- oder Bezirksmeisterschaft im Basketball lehrt Teamgeist und Leistungsprinzip mit Sicherheit eindrücklicher als ein am TV verfolgtes Spiel in der Endphase der NBA-Saison, in dem bereits abgeschlagenen Teams einen eigenen Sieg möglichst vermeiden wollen, um ihre Chancen auf die Verpflichtung eines Talents nach der Saison zu erhöhen. Indem die $\$ \$ 265$ c, 265d StGB die Integrität des Sports also nur in einem vermögensrelevanten Ausschnitt des Sports schützen, in dem das konstitutive ethische Wertegerüst aber gerade brüchig und dessen inspirierendes Potenzial begrenzt zu sein scheint, könnten sie an ihrem Rechtsgut vorbeizielen.

Doch nicht nur der Breitensport wird ausgegrenzt. Auch die Erfassung des Leistungssports erfolgt lückenhaft. Dies drückt sich überraschenderweise gerade in $\$ 265 \mathrm{~d}$ StGB aus, wo der Integrität des Sports angesichts des gelockerten Vermögensbezuges eigentlich ein gesteigerter Stellenwert zukommen soll. ${ }^{949}$ Der Tatbestand verlangt die Betroffenheit eines Wettbewerbs des Berufssports, da ein solcher infolge seiner erhöhten Öffentlichkeitswirksamkeit in besonderer Weise die Glaubwürdigkeit des Sports determiniere. ${ }^{950}$ Mit der Eigenschaft der Berufssportlichkeit werden jedoch in vielen Sportarten, deren geringere Popularität keine umfangreiche Kommerzialisierung ausgelöst hat, Wettbewerbe selbst der obersten Ligen ausgeschlossen, da die Mehrheit der mitwirkenden Sportler keine wesentlichen Einnahmen aus ihrer Betätigung generiert. ${ }^{951}$ In diesen Sportarten, die gerade aufgrund ihrer von Kommerzialisierungserscheinungen noch weitgehend unbelasteten Natürlichkeit als geeignete Träger sportethischer Werte ausgemacht werden, selbst entscheidende Meisterschafts- oder Pokalspiele straffrei manipulieren zu können, mutet im Hinblick auf die zu

949 Vgl. Schönke/Schröder/Perron $₫ 265$ d Rn. 1; Fischer StGB $\$ 265$ d Rn. 2; zum bei $\$ 265$ d StGB gelockerten Vermögensbezug s. unten Teil 3 C. III. 2. b).

950 BT-Drs. 18/8831, S. 20.

951 Hierzu s. oben Teil 1 B. I. 3. 
schützende Integrität des Sports inkonsequent an. ${ }^{952}$ Und im zumindest teilweise von $\$ 265$ c StGB erfassten organisierten Amateurbereich steht $\$ 265$ d StGB für Fälle eindeutiger Spielmanipulationen, in denen der für $\$ 265$ c StGB notwendige Nachweis eines Zusammenhangs mit einer Wettsetzung in der Praxis misslingt, ${ }^{953}$ als Auffangtatbestand nicht zur Verfügung. 954

Allerdings untergräbt die beschriebene selektive Ausrichtung des sachlichen Schutzbereiches der $\$ \$ \$ 265 c$, 265d StGB auf den Leistungssport - im Falle des $\$ 265 \mathrm{~d}$ StGB gar dessen Verengung auf den Berufssport - nicht deren Geeignetheit zum Schutz der Integrität des Sports. Denn den erfassten Ausschnitten kann die Immanenz sportethischer Prinzipien nicht aufgrund gebildeter Extrembeispiele gänzlich abgesprochen werden. Auch die Repräsentanten des Leistungssports können als Integritätsträger wahrgenommen werden und eine Wertevermittlung anstoßen. Gerade vor dem Hintergrund des Integritätsverständnisses des Gesetzgebers, das auf der Annahme einer großen Reichweite und Vorbildwirkung des Leistungsund insbesondere des hochklassigen Berufssports basiert, kann nicht von einer unterbrochenen Verbindung zwischen Tatbestand und Rechtsgut ausgegangen werden. Zudem führte gerade die Ausdehnung des Tatbestandes auf den Breitensport, deren Notwendigkeit aus dem Anerkenntnis dessen überlegener wertebildender Funktion geschlossen werden könnte, zu einer weitflächigen Kriminalisierung, die im angedeuteten Sinne die Grenzen des Verhältnismäßigkeitsgrundsatzes an anderer Stelle überschreiten würde.

(3) Einschränkung auf Manipulationen zugunsten des Wettbewerbsgegners

Eine weitere Einschränkung erfahren die Tatbestände der $\$ \$ 265 c, 265 \mathrm{~d}$ StGB schließlich dadurch, dass die zugesagte Gegenleistung des Vorteilsnehmers darin bestehen muss, den Verlauf oder das Ergebnis eines sportlichen Wettbewerbs gerade zugunsten des Wettbewerbsgegners zu beeinflussen. Anreize für die Beeinflussung eines Wettbewerbs zu eigenen Guns-

952 Valerius Jura 2018, 777 (786f.); Reinhart SpuRt 2016, 235 (241); Fiedler DRiZ 2016, 17; Pfister StraFo 2016, 441 (447).

$953 \mathrm{Zu}$ dessen Schwierigkeit s. unten Teil 3 C. II. 2. a).

954 Vgl. Satzger Jura 2016, 1142 (1151); Kubiciel jurisPR-StrafR 3/2016 Anm. 1. 
ten wie beispielsweise Siegprämien werden ausgeschlossen. ${ }^{955}$ Für $\$ 265 \mathrm{~d}$ StGB hat die den Gegner begünstigende Manipulation darüber hinaus in wettbewerbswidriger Weise zu erfolgen. Auch dies erscheint vor dem intentionalen Hintergrund eines möglichst umfassenden Integritätsschutzes nicht schlüssig. Denn sämtliche ihrer Komponenten sind in gleicher Weise durch eine den Gegner benachteiligende Manipulation betroffen. ${ }^{956} \mathrm{Ob}$ diese nun in einer den Gegner zu ungewohnten Fehlern verleitenden Präparierung des Spielgeräts, der Verwendung unzulässiger Ausrüstung oder in der Verletzung eines Schlüsselspielers des gegnerischen Teams besteht, in allen Fällen kommt es zu einer schwerwiegenden Verzerrung des Wettkampfverlaufes, die den Geboten des Fair Play und des authentischen Leistungsvergleichs widerspricht, die Unvorhersehbarkeit des Ausgangs gefährdet und bei nachträglicher Offenlegung der Absichten das Publikum empört.

Zur Begründung der alleinigen Tatbestandsmäßigkeit der Verabredung von Manipulationen zugunsten des Wettbewerbsgegners führt der Gesetzgeber aus, nur diese seien sportuntypisch. ${ }^{957}$ Auch das Trachten nach Vorteilen und der Verbesserung der eigenen Siegchancen könne regelwidrige Ausprägungen annehmen, entspringe im Ausgangspunkt aber der sporttypischen Motivation, den Wettbewerb gewinnen zu wollen. Mit Blick auf die vom Gesetzgeber zur Ausfüllung des Rechtsguts herangezogene Sportethik kann dieses Abgrenzungskriterium nicht überzeugen. ${ }^{958}$ Vor deren Maßstab finden erfolgreiche sportliche Anstrengungen nur Anerkennung, wenn sie regelkonform erfolgen. Der durch eine mutwillige Verletzung erzwungene Ausschluss eines anderen Spielers vom Wettbewerb steht dem Sportsgeist nicht näher als die punktuelle Leistungsverweigerung. Auch der Einwand, die Beschränkung auf Manipulationen zugunsten des Wettbewerbsgegners sei insofern folgerichtig, als diese im Wettbewerb leichter zu realisieren seien, ${ }^{959}$ kann sich zwar auf einen Großteil der zuletzt insbesondere im Fußball und Tennis bekannt gewordenen Manipulationsfälle stützen, stellt aber allein auf praxisbezogene Umstände ab und vermag keine die tatbestandliche Differenzierung dogmatisch stützende Abweichung im Unwertgehalt herauszustellen.

955 S. oben Teil 1 B. I. 1.

956 Perron JuS 2020, 809 (813); Rübenstabl JR 2017, 264 (276); Krack ZIS 2016, 540 (546).

957 BT-Drs. 18/8831, S. 14; zust. Kubiciel WiJ 2016, 256 (259).

958 Rübenstabl JR 2017, 264 (276); Satzger Jura 2016, 1142 (1152 f.); Krack ZIS 2016, 540 (546f.).

959 Kubiciel WiJ 2016, 256 (259). 
Die problematische Ambivalenz des Abgrenzungskriteriums des Sporttypischen und die Widersprüchlichkeit der Einschränkung vor dem Hintergrund der Rechtsgutskonzeption lassen sich am Beispiel dreier Spieler des Fußballvereins VFL Osnabrück illustrieren. Diese traten am Ende der Drittliga-Saison 2014/2015 an Spieler bzw. Entscheidungsträger der sich ihrerseits im Abstiegskampf befindlichen Teams SV Werder Bremen II sowie Rot-Weiß Erfurt heran und forderten Geld von ihnen, damit sie sich im letzten, für Osnabrück tabellarisch bedeutungslosen Saisonspiel gegen den als schwächer eingeschätzten Abstiegskonkurrenten SC Paderborn ernsthaft um einen Sieg bemühten. Sie nutzten eine offenbar andere Vorstellung von sporttypischem Verhalten als Druckmittel, die bei bestimmten Tabellenkonstellationen am Ende einer Spielzeit eine gewisse Lustlosigkeit und einen automatischen Leistungsabfall bei der favorisierten Mannschaft erwarten lässt. Auch wenn das Verhalten der Spieler einen Angriff auf die Fairness und die sich nach dem Leistungsprinzip zusammensetzende Endtabelle mit potenziell weitreichenden Folgen für die betroffenen Teams darstellt, scheitert eine Strafbarkeit gemäß $\$ 265$ d StGB an der erforderlichen Beeinflussung zugunsten des Wettbewerbsgegners. ${ }^{960}$

In gewisser Weise erkennt der Gesetzgeber selbst an, dass die sporttypischen Motivationslagen komplexer sein können und nicht idealistisch mit ständiger Leistungsbereitschaft und einem bedingungslosen Streben nach dem Sieg beschrieben werden können. ${ }^{961}$ Nicht anders zu erklären ist das für $\$ 265 \mathrm{~d}$ StGB hinzukommende Erfordernis einer Beeinflussung in wettbewerbswidriger Weise. Hierdurch soll nämlich die Verabredung solcher Manipulationen aus der Strafbarkeit ausgeklammert werden, die zwar unmittelbar den Wettbewerbsgegner begünstigen, mittelbar jedoch auch auf die Verbesserung der eigenen Situation im Gesamtwettbewerb abzielen. Da sie zumindest vorrangig ein positives eigenes Endergebnis bezweckten, folgten sie letztlich einer übergeordneten sportimmanenten Wettkampflogik. ${ }^{962}$ Hiervon angesprochen werden die im Rahmen der phänomenologischen Übersicht kategorisierten Fälle des Match Fixing, in denen die Be-

960 Infolge einer staatsanwaltschaftlichen Nichtzulassungsbeschwerde gegen die zunächst abgelehnte Eröffnung des Hauptverfahrens ließ das LG Osnabrück die Anklage wegen des Verdachts der Manipulation von berufssportlichen Wettbewerben zwar zu. Der daraufhin erfolgte Freispruch der Angeklagten vom Vorwurf des $₫ 265$ d StGB wurde vom Landgericht bestätigt, da der gesetzliche Tatbestand in mehrfacher Hinsicht nicht erfüllt sei, LG Osnabrück vom 19.2.2019, Az. 7 Ns 188/18.

961 Vgl. Satzger Jura 2016, 1142 (1153); Pfister StraFo 2016, 441 (447 f.).

962 BT-Drs. 18/8831, S. 21. 
sonderheiten eines Gruppenmodus innerhalb eines Turniers zwei aufeinander treffende Teams dazu veranlassen, ihre jeweiligen Bemühungen um einen Sieg einzustellen, da nur ein Unentschieden die Qualifikation beider Teilnehmer für die nächste Runde garantiert. ${ }^{963} \mathrm{Da}$ derartige Intentionen aber für die Öffentlichkeit regelmäßig leicht durchschaubar sind, ihre evidente Umsetzung mitunter groteske Formen annehmen kann ${ }^{964}$ und zumeist zugleich die aufrichtigen Anstrengungen einer dritten Partei vergeblich werden lässt, werden gerade solche Manipulationen als frappierende Negierung sportethischer Werte empfunden. ${ }^{965}$

Dennoch schlägt sich auch die Straffreistellung von Manipulationen zu eigenen Gunsten nicht auf die Geeignetheit der $\$ \$ 265$ c, 265d StGB nieder. ${ }^{966}$ Diese stünde allenfalls in Frage, wenn die tatbestandlich erfassten Manipulationen zugunsten des Gegners isoliert betrachtet die zentralen sportethischen Prinzipien gar nicht tangierten. Für den Wert des Fair Play ließe sich zwar anführen, die Übervorteilung des Gegners stelle sich diesem gegenüber nicht als unfair dar. Dies würde aber sowohl den Adressatenkreis als auch den Begriffsgehalt des Fair Play verkürzen, das auch gegenüber Mitspielern und Zuschauern einzuhalten ist und die Bereitschaft zu Anstrengungen umschließt. ${ }^{967}$ Den Gegner begünstigende Manipulationen können die Integrität des Sports somit grundsätzlich beeinträchtigen.

bb) Ausgestaltung als abstraktes Gefährdungsdelikt

Mit der konkret erforderlichen Beschaffenheit der Manipulation wurde jedoch zunächst lediglich ein tatbestandsspezifischer Randaspekt angesprochen, der die Geeignetheit der $\$ \$ \$ 265$ c, 265d StGB zumindest nicht bereits ausschließt, die erforderliche Verbindungslinie zwischen Rechtsgut und

963 S. Teil 2 A. II. 3. b).

964 Vgl. das oben beschriebene Fallbeispiel des „Nichtangriffspakts“ zwischen der deutschen und österreichischen Nationalmannschaft bei der Fußball-WM von 1982, s. Teil 2 A. II. 3. b).

965 Stellungnahme des Deutschen Anwaltvereins Nr.12/2016, S. 9 f.; Perron JuS 2020, 809 (813); Swoboda/Bohn JuS 2016, 686 (689); Pfister StraFo 2016, 441 (448); Berberich ZfWG 2017, 347 (350); Satzger Jura 2016, 1142 (1152f.); Tsambikakis StV 2018, 319 (326), der im Merkmal der Wettbewerbswidrigkeit darüber hinaus die Herstellung einer die Rechtsfindung erschwerenden Akzessorietät zu den Regelwerken des internationalen Sports befürchtet.

966 Vgl.Jansen GA 2017, 600 (610).

967 Vgl. oben Teil 3 B. II. 2. d) aa) (1). 
Angriffswegen allerdings auch nicht eigenständig herzustellen vermag. Denn auf Tatbestandsebene handelt es sich bei der eigentlichen Wettbewerbsmanipulation lediglich um ein in Aussicht gestelltes künftiges Ereignis, dessen subjektive Inbezugnahme ausreicht. Auf den tatsächlichen Versuch oder gar die erfolgreiche Umsetzung einer Beeinflussung des sportlichen Wettbewerbs verzichten die $\$ \$ 265 c$, 265d StGB. Ihre Tathandlung erschöpft sich vielmehr in den Alternativen des Forderns, Sich-VersprechenLassens, Annehmens bzw. Anbietens, Versprechens oder Gewährens eines Vorteils als Gegenleistung für die Zusage einer Manipulation. Gerade dieses Verhalten muss sich unter Berücksichtigung der hinzutretenden subjektiven Voraussetzungen als verletzungstaugliche Angriffsform für die Integrität des Sports erweisen.

Dabei ist dessen institutionelle Konzipierung im Auge zu behalten, die einen spezifischen internen Wertekodex gerade im Hinblick auf ein hierauf gerichtetes äußeres Vertrauen abzusichern versucht, das wiederum die Grundlage einer positiven ideellen und ökonomischen Beeinflussung darstellen soll. Eine Beeinträchtigung dieses Funktionszusammenhangs verlangt aber bereits auf der ersten Stufe eine erkennbare Herabsetzung der sportethischen Werte während eines Wettbewerbs. Die sportspezifischen Gebote des Fair Play und der Leistungsbereitschaft beanspruchen allein für das unmittelbare Verhalten der teilnehmenden Akteure im Wettkampf Geltung und können durch bloße Manipulationsabsprachen im Vorfeld der sportlichen Betätigung nicht verletzt werden. Sofern eine Verletzungswirkung der bloßen Absprache aber im Hinblick auf das integritätsbezogene Vertrauen der Allgemeinheit angenommen und darauf gestützt wird, ein solches Vertrauen erleide bereits dann Einbußen, wenn Bürger von einzelnen Korruptionsfällen im Sport Kenntnis erlangten, ${ }^{968}$ ist dieser Ansicht eine Verkennung der kollektiven Dimension des Vertrauensrechtsguts entgegenzuhalten, deren Verletzung gerade nicht graduell durch die Beeinträchtigung des Vertrauens einzelner Bürger, sondern nur im Wege eines kollektiv verbreiteten Misstrauens begründbar erscheint. ${ }^{969} \mathrm{Da}$ tatbestandlich keine tatsächliche Manipulation verlangt wird und in übergeordneter Hinsicht auch ein misstrauensbedingter Attraktivitäts- und Bedeutungsverlust des Sports weder eingetreten sein noch konkret gedroht ha-

968 Mit diesem Argument für die vertrauensschützenden $\$ \mathbb{S} 331 \mathrm{ff}$. StGB als Verletzungsdelikte eintretend Graupe Systematik, S. 105.

969 Ebenfalls für die $\$ \$ 331 \mathrm{ff}$. StGB Zeiser Trafic, S. $177 \mathrm{f}$. 
ben muss, handelt es sich bei den $\$ \$ 265$ c, 265d StGB bezüglich der Integrität des Sports folglich um zwei abstrakte Gefährdungsdelikte. ${ }^{970}$

\section{(1) Grundlagen des abstrakten Gefährdungsdelikts und Notwendigkeit einer rechtsgutsabhängigen Differenzierung}

Das abstrakte Gefährdungsdelikt ist als Reaktion eines um effektiven Rechtsgüterschutz bemühten Strafrechts auf die komplexen, naturwissenschaftlich nicht vollends erfassbaren sowie zunehmend kollektivierten Risikozusammenhänge der modernen Gesellschaft mittlerweile zwar grundsätzlich anerkannt. ${ }^{971} \mathrm{Er}$ stellt an die hier vorgenommene Prüfung eines normlegitimierenden Zusammenhangs zwischen tatbestandlichem Verhalten und geschütztem Interesse allerdings besondere Anforderungen. Denn zunächst einmal lässt sich mit Blick auf die Tathandlung die erforderliche reale Verletzungskausalität nicht ausnahmslos annehmen. Die Strafbarkeit wird auch für Konstellationen angeordnet, in denen sich im konkreten Fall die Gefahr nicht realisiert und das Rechtsgut unversehrt bleibt.

Um einerseits den Rechtsgutsbezug aufrechtzuerhalten und andererseits eine Legitimation für die Pönalisierung letztlich folgenloser Handlungen zu schaffen, muss die Tathandlung in den Fokus gerückt werden und der von ihr beschriebenen Verhaltensweise als Mindestbedingung eine generell unerträgliche oder unangemessene Gefährlichkeit nachgewiesen werden. ${ }^{972}$ Bezogen auf die geschützten Elemente des Rechtsguts muss ihr in einer generalisierenden Perspektive die Neigung innewohnen, sich zu einer Schädigung auszuwachsen. Diese Qualität kann aber stets nur in Be-

970 Fischer StGB $\$ 265$ c Rn. 28; Rübenstabl JR 2017, 264 (269), 333 (334); Valerius Jura 2018, 777 (779); Stellungnahme des Deutschen Anwaltsvereins Nr. 12/2016, S. 8; auf die vereinzelte Kritik, der zufolge beim Schutz kollektiver Rechtsgüter mangels greifbarer Tatobjekte grundsätzlich nicht von einem abstrakten Gefährdungsdelikt ausgegangen werden könne (hierzu Tiedemann Wirtschaftsstrafrecht, Rn. 220; zweifelnd auch Krack ZIS 2016, 540 [543]) wird hier nicht weiter eingegangen.

971 Vgl. Schünemann GA 1995, 201 (211ff.); Kublen GA 1994, 347 (362ff.); Roxin/ Greco Strafrecht AT I $\$ 2$ Rn. 68 ff.; auch das Bundesverfassungsgericht hat festgestellt, dass der Rückgriff des Gesetzgebers auf abstrakte Gefährdungsdelikte „von Verfassungs wegen keinen Bedenken begegnet“ bzw. nicht „schlechterdings verfassungswidrig“ sei, BVerfGE 28, 175, 188; BVerfG NJW 1977, 2207; jüngst BVerfG NJW 2020, 905 (914).

972 Schünemann GA 1995, 201 (212); Kublen GA 1994, 347 (362 f.); Jakobs ZStW 107 (1995), 855 ff. stellt auf eine generelle Gefährlichkeit ab. 
zug auf das geschützte Rechtsgut bestimmt werden. Die verfassungsrechtlich erforderliche präzise deliktsstrukturelle Einordnung eines Tatbestandes ist somit stets abhängig von der Art des durch ihn geschützten Rechtsguts. ${ }^{973}$ Hierin zeigt sich das abstrakte Gefährdungsdelikt als Deliktstypus, der rechtsgutsbezogen einer weiteren Differenzierung bedarf.

Mit der bloßen Einordnung der $\$ \$ \$ 265 c$, 265d StGB als abstrakte Gefährdungsdelikte ist demnach noch keine die Anforderungen der Geeignetheitsprüfung ausfüllende Beziehung zwischen den Tathandlungen und der Integrität des Sports beschrieben. Gerade im Gegenteil erschwert der verfolgte Schutz eines kollektiven Interesses bei abstrakten Gefährdungsdelikten den erforderlichen Nachweis einer realen Verletzungskausalität. Neben der Schwierigkeit, angesichts seiner oftmals diffusen Komposition das Ausmaß einer Beeinträchtigung des kollektiven Rechtsguts überhaupt zu bestimmen, erscheint auch dessen ernsthafte Gefährdung durch eine einzelne Tat regelmäßig ausgeschlossen. ${ }^{974}$ Der für „klassische“ abstrakte Gefährdungsdelikte wie die Gefährdung des Straßenverkehrs ( $\$ 316$ StGB) oder die schwere Brandstiftung ( $\$ 306 \mathrm{~S}$ StGB) entwickelte Ansatz, die unmittelbare Rechtsgutsrelevanz der Tathandlungen fernab der Wahrscheinlichkeit einer eintretenden Rechtsgutsverletzung über die diesbezüglich grundsätzlich fehlende Vermeidemacht des Rechtsgutsträgers bzw. die mangelnde Beherrschbarkeit des dem Verhalten anhaftenden Risikos herzustellen, ${ }^{975}$ ist auf institutionell ausgerichtete und über eine Vertrauenskomponente materialisierte Kollektivrechtsgüter gerade nicht übertragbar. Denn die Beherrschungsmöglichkeit über ein Risiko geht bezüglich der rechtsgutsprägenden Zusammenhänge nicht so weit, als dass deren Verlust Rechtsgutrelevanz entfalten würde. ${ }^{976}$

Vor diesem Hintergrund stellt sich die Kategorie des abstrakten Gefährdungsdelikts in ihrem herkömmlichen Verständnis für kollektive Rechtsgüter zunächst als unpassend dar. Das aufgezeigte Problem der fehlenden realen Verletzungskausalität lässt sich auch nicht dadurch umgehen, eine Rechtsgutsverletzung bereits bei einzelnen punktuellen Verletzungen des kollektiven Interesses festzustellen, die das Gesamtsystem nicht notwendigerweise zu beeinträchtigen bräuchten. ${ }^{977}$ Hierdurch werden die das Kol-

973 Woblers Deliktstypen, S. 310.

974 Vgl. Tiedemann Wirtschaftsstrafrecht, Rn. 220.

975 Vgl. Hefendehl Kollektive Rechtsgüter, S. 157; Wohlers Deliktstypen, S. 309 ff. benennt die sich hierdurch charakterisierenden Delikte in seiner Differenzierung als konkrete Gefährlichkeitsdelikte.

976 Hefendebl Kollektive Rechtsgüter, S. 158, $198 \mathrm{f}$.

977 So Roxin/Greco Strafrecht AT I $\$ 2$ Rn. 83. 
lektivinteresse gerade zum schützenswerten Rechtsgut qualifizierenden ineinandergreifenden Wirkungszusammenhänge verkannt, die eben auch in diesem Freiheitsräume sichernden Mechanismus gestört werden müssen. Vielmehr ist der Befund einer sich verflüchtigenden realen Verletzungskausalität hinzunehmen und hinsichtlich der verfassungsrechtlich gleichwohl einzufordernden Beziehung von Tathandlung und Rechtsgut über materielle Äquivalente nachzudenken. ${ }^{978}$

In der streng rechtsgutsbezogenen Bestimmung der tathandlungsimmanenten Schadensneigung offenbart sich demnach eine Heterogenität abstrakter Gefährdungsdelikte. Die unterschiedlichen Formen der Gefahrvermittlung für bestimmte Arten von Rechtsgütern erfordern die Bildung von Unterkategorien, die eine genauere Systematisierung ermöglichen und bezüglich des unverzichtbaren Rechtsgutsbezugs der tatbestandsmäßigen Handlung spezifische Legitimationsbedingungen formulieren. Um diese im Anschluss auch für die präzise deliktsstrukturelle Einordnung der $\$ \mathbb{S} 265 \mathrm{c}, 265 \mathrm{~d}$ StGB und die Bewertung ihrer Eignung zum Rechtsgüterschutz nutzbar zu machen, sollen das Kumulationsdelikt sowie das Vorbereitungsdelikt näher betrachtet werden.

a) Die Unterkategorie des Kumulationsdelikts

Ausgangspunkt der Entwicklung des Kumulationsdelikts ist die Notwendigkeit, die beschriebene Verflüchtigung der realen Verletzungskausalität bei kollektiven Rechtsgütern zu ersetzen. Dem Kumulationsdelikt werden pönalisierte Verhaltensweisen zugeordnet, die zwar für sich gesehen ein rechtlich geschütztes Interesse nicht bzw. nicht in relevantem Maße zu beeinträchtigen vermögen, die aber im Zusammenhang mit anderen, gleichgerichteten Verhaltensweisen zu einer Beeinträchtigung führen können. ${ }^{979}$ Die fehlende Verletzungskausalität der Einzelhandlung wird durch das ihr immanente Risiko ersetzt, dass das Rechtsgut durch die massenhafte Vornahme der Tathandlung beeinträchtigt wird. Die diesem Ansatz zugrunde liegende hypothetische Erwägung - was wäre, wenn eine Handlung in großer Zahl vorgenommen würde? - betrifft dabei gerade kollektive Interessen und institutionelle Bedingungen, die als elementare Werte des Gemeinschaftslebens aufgefasst werden. Denn bei ihnen verwirklicht sich

978 Hefendehl Kollektive Rechtsgüter, S. 182 ff.

979 Grundlegend Kublen GA 1986, 389 (399 ff.); ferner Woblers Deliktstypen, S. 318 ff.; Hefendehl Kollektive Rechtsgüter, S. 183 ff. 
eine Gefahr häufig erst durch Massenverstöße. ${ }^{980}$ Isolierte deliktische Akte hingegen tangieren soziale Handlungsgefüge bzw. die sie tragenden Einstellungen regelmäßig weder auf Seiten des Repräsentanten der Institution selbst noch beim Publikum. ${ }^{981}$ In diesem Sinne greift teilweise auch der Gesetzgeber auf den Kumulationsgedanken zurück, wenn er etwa zur Begründung des Tatbestandes des Kapitalanlagebetrugs in $\mathbb{2} 264 \mathrm{a}$ StGB anführt, dass Individualschädigungen, wenn sie in einer gewissen Masse auftreten, geeignet seien, das Vertrauen der Anleger in den Kapitalmarkt zu erschüttern und das Funktionieren eines wesentlichen Bereichs der geltenden Wirtschaftsordnung zu gefährden. ${ }^{982}$

Der Typus des Kumulationsdelikts ist als legitim aufzufassen. Er lässt sich auf eine Pflicht des einzelnen Gesellschaftsmitglieds zur Mitwirkung an der Erhaltung kollektiver Rechtsgüter stützen, die Handlungen untersagt, die in einer prognostizierten Vielzahl zu gesellschaftlich nicht hinnehmbaren Folgen führen. ${ }^{983}$ Die gegen das Kumulationsdelikt erhobenen Einwände eines Verstoßes sowohl gegen das Schuld- als auch gegen das Bagatellprinzip greifen hingegen nicht durch. ${ }^{984}$ Die strafrechtliche Verantwortlichkeit des Einzelnen wird nicht über einen dem Schuldprinzip widersprechenden Verweis auf das Fehlverhalten Dritter begründet, sondern knüpft am eigenen Beitrag zu einer Gefährdung des Rechtsguts an. ${ }^{985}$ Der Kumulationsgedanke beschreibt eine im Rechtsgut selbst begründete Beeinträchtigungsmodalität, angesichts derer jede einzelne Handlung als unmittelbare Beeinträchtigung verstanden werden kann. ${ }^{986}$ Hierdurch werden auch keine für sich betrachtet bagatellartigen Verhaltensweisen unzulässig in den Bereich des Strafwürdigen hochgezogen. Das Bagatellprinzip kann etwa über den tatbestandlichen Ausschluss sozialadäquater Verhaltensweisen auch bei Kumulationsdelikten, für die ein minimales Eigengewicht des Beitrags gefordert wird, ${ }^{987}$ ausreichend Berücksichtigung finden. Der Kumulationsgedanke entfaltet sich vielmehr im nachgelagerten Nachweis der Relevanz der Tathandlung für das Rechtsgut, hat dabei von einem

980 Sondervotum Graßhof zu BVerfGE 90, 145, 199 (204).

981 Bezüglich des Beamtenapparates Loos FS Welzel, 1974, S. 879 (891).

982 BT-Drs. 10/318, S. 22.

983 Woblers Deliktstypen, S. 321; Tiedemann Tatbestandsfunktionen, S. $124 \mathrm{ff}$.

984 Die Einwände erhebend Kindhäuser, in: Schünemann (Hrsg.), Madrid-Symposium, S. 125 (129); abl. zum Kumulationsdelikt ferner Roxin/Greco Strafrecht AT I $\$ 2$ Rn. 80 ff.; Zieschang Gefährdungsdelikte, S. $241 \mathrm{ff}$.

985 Sondervotum Graßhof zu BVerfGE 90, 145, 199 (204).

986 Puschke Vorbereitungstatbestände, S. 95.

987 Kublen GA 1986, 389 (407 f.); Wohlers Deliktstypen, S. 324 ff. 
zunächst festzustellenden tatbestandlichen Erfolg auszugehen und betrifft die Ebene der Kriminalisierung. ${ }^{988}$

Voraussetzung einer legitimen Ersetzung der fehlenden Verletzungskausalität durch das Äquivalent eines Kumulationsbeitrages ist allerdings, dass bezogen auf die konkrete Verhaltensweise Kumulationseffekte zum einen realistischerweise auch zu erwarten sind und zum anderen von ihrer rechtsgutsbeeinträchtigenden Gesamtwirkung ausgegangen werden kann. ${ }^{989}$ Hinsichtlich der dabei zu treffenden Prognose, ob es zu einer hinreichenden Vielzahl von Einzelbeiträgen kommt, ist dem Gesetzgeber eine Einschätzungsprärogative einzuräumen, die sich jedoch an gegebenenfalls bestehenden empirischen Erkenntnissen zu orientieren hat. ${ }^{990}$ Das Vorliegen dieser Voraussetzungen muss für jede konkret untersuchte Verhaltensweise begründet werden.

\section{ß) Die Unterkategorie des Vorbereitungsdelikts}

Im Unterschied zum herkömmlichen abstrakten Gefährdungsdelikt ergibt sich das Gefährdungsunrecht des Vorbereitungsdelikts nicht aus einer rein objektiven und durch willentliches menschliches Verhalten unbeherrschbaren Gefährdung. Entsprechend der Feststellung beim Kumulationsdelikt können auch die von einem Vorbereitungsdelikt erfassten Tathandlungen für sich genommen keine Rechtsgutsschädigung bewirken. In Abgrenzung zum Kumulationsdelikt ist eine solche jedoch nicht einmal infolge des $\mathrm{Zu}$ sammenwirkens der pönalisierten Einzelhandlung mit einer Vielzahl anderer, gleichgerichteter Handlungen zu erwarten. Vielmehr werden der Kategorie des Vorbereitungsdelikts solche Verhaltensweisen zugeordnet, deren Risikopotenzial darin besteht, dass entweder der Handelnde selbst oder eine andere Person an das Ergebnis des in Frage stehenden Vorverhaltens anknüpft und die Rechtsgutsschädigung durch eine Zweithandlung eintritt. ${ }^{991}$ Kennzeichnend ist insofern gerade die intendierte Beherrschung einer späteren Rechtsgutsbeeinträchtigung durch den Vorbereitenden selbst oder einen Dritten.

988 Hefendehl Kollektive Rechtsüter, S. 188.

989 Kublen ZStW 105 (1993), 697 (716 Fn.91); Woblers Deliktstypen, S. 322 ff.; Hefendebl Kollektive Rechtsgüter, S. 185.

990 Wohlers Deliktstypen, S. 323.

991 Woblers GA 2002, 15 (19). 
Als Angriffsziel einer Vorbereitungshandlung drängen sich zunächst die in Umgrenzung und Reichweite und damit auch in ihrer Beeinträchtigung klarer fassbaren individuellen Rechtsgüter auf. Bestrafen etwa die $\$ \$ 263 \mathrm{a}$ Abs. 3, 234a Abs. 3 StGB die Vorbereitung eines Computerbetrugs bzw. einer Verschleppung, werden hierdurch entsprechend den Rechtsgütern der Hauptnormen in $\$ \$ 263$ a Abs. 1, 234a Abs. 1 StGB das Vermögen bzw. die Freiheit einer Person geschützt. ${ }^{992}$ Und pönalisiert $\ 89$ a Abs. 2 Nr. 1 Var. $1 \mathrm{StGB}$ das Unterweisen anderer in der Herstellung von oder im Umgang mit bestimmten Tatmitteln, werden durch die hierdurch vorbereiteten, anschließenden Gewalttaten das Leben sowie die persönliche Freiheit betroffen. ${ }^{993}$ Aber auch die Vorbereitung einer Beeinträchtigung kollektiver Rechtsgüter kann trotz ihres höheren Abstraktionsgrades als strafrechtlicher Anknüpfungspunkt dienen, wie das Delikt der Urkundenfälschung gemäß $₫ 267$ Abs. 1 Var. 1 und 2 StGB beispielhaft zeigt: ${ }^{994}$ Zum Schutz der Sicherheit und Zuverlässigkeit des Rechtsverkehrs oder des Vertrauens hierin wird bereits das Herstellen einer falschen Urkunde bestraft. Dieses begründet zwar weder einen alsbald in einer Schädigung mündenden Geschehensablauf noch ein berechenbares Risiko. Ist aber eine Urkunde erst einmal hergestellt, kann damit anschließend vereinfacht im Rechtsverkehr getäuscht werden.

Die Pönalisierung von derartigen Vorbereitungshandlungen ist nicht schlechthin illegitim. Sie lässt sich mit der Konzeption des Rechtsgüterschutzes im Wege einer Ableitung dergestalt begründen, dass die Strafbarstellung der Gefährdung eines Rechtsguts ihre Legitimation grundsätzlich aus der Strafwürdigkeit dessen Verletzung als dem eigentlich zu verhinderndem Ergebnis bezieht. ${ }^{995}$ Angesichts der Erstreckung des Strafrechts in das entfernte Vorfeld einer Rechtsgutsschädigung und der möglichen Zuordnung ihres tatsächlichen Eintritts in den primären Verantwortungsbereich eines Anschlusshandelnden trägt das Vorbereitungsdelikt jedoch auch im Vergleich zum Kumulationsdelikt eine erhöhte Rechtfertigungslast.

Zur Kompensation der aufgrund der Notwendigkeit beherrschbarer Zwischenschritte nur vermittelten Beziehung von pönalisierter Handlung

992 Puschke Vorbereitungstatbestände, S. 352.

$993 \mathrm{Zu}$ individuellem Rechtsgut des $₫ 89$ a StGB und dessen Einordnung als Vorbereitungsdelikt SK-StGB/Zöller $\$ 89$ a Rn. 10 f.; Puschke Vorbereitungstatbestände, S. 421 f.; aA zum geschützten Rechtsgut Fischer StGB $\$ 89$ a Rn. 5, der primär Bestand und Sicherheit eines Staats oder Organisation geschützt sieht.

994 Puschke Vorbereitungstatbestände, S. $94 \mathrm{f}$.

995 Vgl. Puschke Vorbereitungstatbestände, S. 106 ff., 124. 
und zukünftiger Rechtsgutsbeeinträchtigung ist ein zwischen beiden bestehender Gefährlichkeitszusammenhang zu verlangen, der über subjektive wie objektive Merkmale eine Risikoerhöhung für das geschützte Rechtsgut transportiert. ${ }^{996}$ Demnach kann eine Rechtsgutsbeeinträchtigung nur dann bereits in einer ihr objektiv weit entfernten Vorbereitungshandlung angelegt sein, wenn Vorbereitung und Beeinträchtigung vom Vorbereitenden in einem Planungszusammenhang verbunden werden. In subjektiver Hinsicht ist somit ein über den Vorsatz bezüglich der objektiven Modalitäten der Vorbereitung hinausgehendes, überschießendes subjektives Element zu fordern, das die Verletzung des Rechtsgutsobjekts oder dessen konkrete Gefährdung bei Vornahme der Vorbereitungshandlung einschließt. ${ }^{997}$ Die zur Distanzierung von einem Gesinnungsstrafrecht und für die Begründung des Gefährdungsunrechts zusätzlich erforderliche objektive Rechtsgutsbeziehung verlangt eine Tathandlung, die eine spätere unmittelbare Rechtsgutsbeeinträchtigung objektiv zu fördern vermag und von neutralen Alltagshandlungen abgrenzbar sein muss. ${ }^{998}$ Dieses Erfordernis erfüllen insbesondere Verhaltensweisen, die eine geradezu typische Vorbereitungshandlung für die geplante Rechtsgutsverletzung darstellen und keinem anderen, legalen Zweck dienen können.999

(2) Hinreichende Gefahrenwirkung der einzelnen Tathandlungen der $\mathbb{S} \$ 265 \mathrm{c}, 265 \mathrm{~d}$ StGB

Angesichts dieser Grundlagen und erforderlichen Differenzierungen des abstrakten Gefährdungsdelikts gilt es die Relation zwischen den Tathandlungen der $\$ \mathbb{S} 265 \mathrm{c}$, 265d StGB und dem Rechtsgut der Integrität des Sports zu untersuchen. Dabei stellt sich die Frage, ob den tatbestandlich beschriebenen Verhaltensweisen bereits für sich genommen oder zumindest unter den erweiterten Voraussetzungen ihrer prognostizierbaren $\mathrm{Ku}$ -

996 Puschke, in: Hefendehl (Hrsg.), Vorverlagerung, S. 9 (29ff.).

997 Puschke Vorbereitungstatbestände, S. 361 ff., demzufolge die erforderliche Intensität der subjektiven Rechtsgutsbeziehung gemäß einer Unterkategorisierung der Vorbereitungstatbestände zu differenzieren ist und in Tatbeständen, die nur über ein vom Vorbereitenden weitgehend eigenverantwortlich steuerbares Geschehen zur Rechtsgutsbeeinträchtigung führen können, mindestens dolus directus 2. Grades hinsichtlich der Beeinträchtigung vorausgesetzt sein muss; vgl. auch Woblers Deliktstypen, S. 329.

998 Vgl. Hefendehl, in: ders. (Hrsg.), Vorverlagerung, S. 89 (104).

999 Puschke, in: Hefendehl (Hrsg.), Vorverlagerung, S. 9 (33). 
mulation bzw. der gezielten Vorbereitung einer rechtsgutsbeeinträchtigenden Anschlusshandlung die geforderte Gefahrenwirkung für die Integrität des Sports zukommt.

Eine hinreichende Gefahrenwirkung der einzelnen tatbestandsmäßigen Manipulationsabsprache ist zunächst jedenfalls mit Blick auf das Rechtsgutselement des Sportethos abzulehnen. Für sich betrachtet zeigen sich die sportethischen Werte des Fair Play, der Chancengleichheit, der Leistungsbereitschaft, des Teamgeists und der Toleranz gegenüber korruptiven Abreden im Vorfeld eines Wettkampfes weitgehend resistent. ${ }^{1000}$ Es erfordert der Verbindung eines auch nach der Absprache aufrechterhaltenen Manipulationsentschlusses mit dem insbesondere bei Teamsportarten auch vom Zufall bestimmten Auftreten einer günstigen Gelegenheit im laufenden Wettbewerb, damit es zu einer tatsächlichen Manipulation und einer erkennbaren Verletzung der sportethischen Werte kommt. Und selbst wenn sich die in der tatbestandlichen Abrede zum Ausdruck kommende innere Abkehr eines einzelnen Akteurs vom sportethischen Verhaltenskodex später manifestiert, stellt dies zunächst nur eine sportinterne Pflichtverletzung dar. Der idealisierte Geltungsanspruch des Sportethos als eine innere Funktionsbedingung des institutionalisierten Leistungssports wird hiervon genauso wenig herabgesetzt wie von einzelnen groben Fouls oder von durch Kräfteschonung oder Lustlosigkeit motivierten Leistungsverweigerungen.

Aufgrund der beschriebenen Bedeutung des allgemeinen Vertrauens in die Integrität des Sports innerhalb der Rechtsgutskonzeption ist das Gefährdungspotenzial der Tathandlungsalternativen aber ohnehin gerade diesbezüglich zu untersuchen. Diese Komponente beschreibt das entscheidende Bindeglied innerhalb des vom Gesetzgeber zum Rechtsgut erklärten Funktionszusammenhangs und soll ihm die notwendige soziale Anbindung verleihen. ${ }^{1001}$ Die geäußerte Sorge beschreibt dabei eine von Manipulationsskandalen in ihrem Interesse am Spitzensport erschütterte Gesell-

1000 So auch Bohn KriPoz 2017, 88 (92); Stellungnahme des Deutschen Anwaltsvereins Nr. 12/2016, S. 8.

1001 Diese Relevanz verhindert auch die Qualifizierung des Vertrauens in die Integrität des Sports als ein durch soziale Anschauungen konstituiertes „vergeistigtes Zwischenrechtsgut“, dessen vorgelagerte Verletzbarkeit den strafrechtlichen Institutionenschutz mit einem "mediatisierten Erfolgsunrecht" versehe, vgl. bezüglich der staatlichen Bestechungsdelikte Wolter Zurechnung, S. 328 f.; Roxin/Greco Strafrecht AT I $\mathbb{1} 11$ Rn. 161; krit. Hefendebl Kollektive Rechtsgüter, S. 175 ff. Die sozialrelevante Funktionsfähigkeit der Institution Leistungssport wird in den Augen des Gesetzgebers gerade durch eine vertrauensvolle 
schaft, die sich daraufhin vom Sport als Ganzes abwendet und fortan seiner sozialisationsfördernder Funktionen entbehrt. Obschon sowohl bereits die Existenz eines derartigen Kollektivvertrauens als auch dessen hypothetisch handlungsleitende Bedeutung in Frage gestellt wurden, soll an dieser Stelle zum Zweck der Veranschaulichung der tatbestandlichen Angriffswirkung beides angenommen werden.

Zwar erscheint es hinsichtlich dieser Rechtsgutskonzeption zunächst schlüssig, mit der ggf. nur intendierten Abrede zwischen Vorteilsgeber und Vorteilsnehmer bereits die erste für die Glaubwürdigkeit des Sports potenziell bedrohliche Verhaltensweise strafrechtlich zu erfassen. Allerdings kann eine einzelne Tathandlung gemäß $\$ \$ 265 c$, 265d StGB nicht den vom Gesetzgeber prognostizierten Schadenseintritt eines derart erschütterten kollektiven Vertrauens bewirken, das ein umfangreiches SichAbwenden vom Sport auslöste. Selbst die medial über Wochen skandalisierte Aufdeckung der korruptionsbasierten und in dieser Form bis dato einmaligen Manipulationen durch Robert Hoyzer vermochte die Attraktivität der Fußball-Bundesliga nicht einmal kurzfristig zu schmälern. Ein schlagartig zu kollektivem Misstrauen gegenüber der Integrität des Sports führender Einzelfall ist kaum denkbar. Die einzelne verabredete Wettbewerbsmanipulation lässt sich stets mit ihren besonderen Begleitumständen erklären oder als ligen- bzw. sportartspezifisches Problem abtun, ohne dass hierdurch der Sport insgesamt als Interessensfeld und Werteträger in Verruf geriete. Das Rechtsgut wird im konkreten Einzelfall nicht einmal abstrakt gefährdet. Die Gefahr einer Schädigung des geschützten gesellschaftlichen Funktionszusammenhangs kann sich demnach allenfalls aus der Häufung entsprechender korruptiver Praktiken ergeben, die in ihrer Gesamtheit den Eindruck eines systemisch bedingten Wertekollapses vermittelten.

(3) Verletzungswirkung über den Kumulationsgedanken

Die erforderliche Verbindung von tatbestandlichem Verhalten und Rechtsgut kann den $\$ \mathbb{S} 265$ c, 265d StGB demnach allenfalls mithilfe des Kumulationsgedankens zukommen. Nur unter dessen erweiterten Voraussetzungen könnte die fehlende reale Verletzungskausalität der einzelnen

Hinwendung der Allgemeinheit vermittelt. Dieses Vertrauen als Zwischenrechtsgut auszulagern würde die Bestimmung des eigentlichen Rechtsguts entmaterialisieren. 
korruptiven Absprache im Hinblick auf den Ansehens- und Attraktivitätsverlust des Sports durch ihre Eignung als Mosaikstein ausgeglichen werden, der sich im Verbund mit gleichartigen Unrechtsvereinbarungen zum abschreckenden Gesamtbild eines korrumpierten Leistungssports formen kann.

Hierzu müssten bei der erfassten Verhaltensweise zunächst realistische Kumulationseffekte zu erwarten sein. Für den ebenfalls mit der Integrität des Sports in Verbindung gebrachten Bereich des Eigendopings wurden etwa gewisse Sog- und Spiralwirkungen festgestellt, ${ }^{1002}$ die die Annahme einer Häufung derartiger Sportmanipulationen stützen. Demnach veranlasst die begründete Vermutung gedopter Konkurrenten auch grundsätzlich nicht tatgeneigte Sportler zur Einnahme verbotener Substanzen, um im erbitterten Kampf um Nominierungen, vordere Platzierungen, Preisgelder und Sponsoren nicht ins Hintertreffen zu geraten.

Nun lässt sich eine solche Ansteckungswirkung der Einzelhandlung auf die hier untersuchten korruptiven Abreden einer Manipulation zugunsten des Gegners schon deswegen nicht übertragen, weil diese eben keinen sporttypischen Überbietungswettkampf fördern. Gleichwohl überschneidet sich die für die Prognose einer realistischen Kumulation maßgebliche Motivationslage der Akteure in gewisser Weise. Auch im Rahmen der

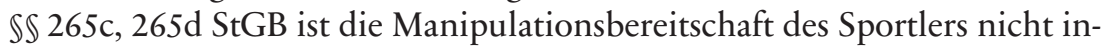
tentional gegen die Werte des Sports gerichtet, sondern durch die Erlangung des im Gegenzug zugesagten Vorteils primär egoistisch und ökonomisch motiviert. Wie bereits in der phänomenologischen Darstellung des Match Fixing gezeigt, wird dieser Antrieb durch eine infolge expandierender Sportwettenmärkte zunehmende Nachfrage nach Spielmanipulationen, daraus resultierende hohe Bestechungsprämien und eine in gewissen Sportarten und Verbänden vorgelebte Korruptionskultur insbesondere bei Sportakteuren mit geringerem bzw. unregelmäßigem Einkommen strukturell bestärkt. ${ }^{1003}$ Für die externen Vorteilsgeber steht zumindest bei den wettbezogenen Manipulationsabsprachen i.S.d. $\$ 265$ c StGB die persönliche Bereicherung ebenfalls im Vordergrund. Die Wettplatzierungsabsicht muss bereits Bestandteil der Unrechtsvereinbarung sein. Der Vorteilsgeber will sein ökonomisches Interesse mittels einer anschließenden Täuschungshandlung gegenüber dem Wettanbieter realisieren. Die Motivlage lässt sich also für beide an einer Abrede potenziell beteiligten Gruppen als eini-

1002 Bannenberg/Rössner FS Schild, 2007, S. 59 (68f.); Freund FS Rössner, 2015, S. 579 (592 f.); Schild Sportstrafrecht, S. 146 f.

1003 S. oben Teil 2 A. III. 
germaßen homogen beschreiben. Sie wird durch strukturelle Begleitumstände des Leistungssports begünstigt, ist profitorientiert und deswegen auch multiplizierbar. ${ }^{1004}$

Auf die von $\$ 265 \mathrm{~d}$ StGB erfassten Manipulationsabsprachen ohne Bezug zu einer Sportwette lässt sich diese Argumentation nicht uneingeschränkt übertragen. Hier wird der Vorteilsgeber nicht selten aus sportimmanenten Gründen agieren und gerade eine Verzerrung des authentischen sportlichen Wettbewerbs beabsichtigen, die einem Teilnehmer eine ihm allein aufgrund seiner Leistung nicht gebührende Position (den Einzug in die nächste Runde, den Klassenerhalt usw.) sichert. Ein intentionaler Angriff gegen die Integrität des Sports liegt hier näher. Allerdings dürfte es dem Vorteilsgeber auch hierbei letztlich eher um mit dem beeinflussten Wettbewerbsergebnis verbundene persönliche Vorteile materieller oder immaterieller Art gehen. Im öffentlichkeitswirksamen und kommerzialisierten Berufssport können auch einzelne Resultate und Platzierungen weitreichende finanzielle und emotionale Implikationen haben, was auch gehäufte sportimmanent motivierte Einwirkungen i.S.d. $\$ 265 \mathrm{~d}$ StGB als möglich erscheinen lässt. Gegen die Einschätzung des Gesetzgebers, wonach es in einer relevanten Anzahl von Einzelfällen zu tatbestandlichen Abreden im Sinne der $\$ \$ 265$ c, 265d StGB kommt, lassen sich somit keine durchschlagenden Einwände erheben. Die Prognose einer Kumulation ist realistisch.

Mit ihr allein geht jedoch nicht zwangsläufig auch eine Beeinträchtigung des geschützten Rechtsguts einher. Gerade wenn dieses sich über eine kollektive Vertrauenskomponente konstituieren soll, bleibt nachzuweisen, dass die tatbestandlich erfasste Verhaltensweise in ihrer realistischen Kumulation das beschriebene Vertrauen zu erschüttern vermag. Hierzu müssen die einzelnen Tathandlungen überhaupt in den Wahrnehmungskreis der Vertrauensträger gelangen. ${ }^{1005}$ Dies dürfte allerdings durch die umfangreiche mediale Sportberichterstattung, die bekannt gewordenes Match Fixing im internationalen Sport verlässlich aufgreift und in einen Zusammenhang mit vergleichbaren Fällen stellt, gewährleistet sein. Entscheidend ist demnach, ob die derart kommunizierte Vervielfältigung in ihrer Gesamtwirkung die Schwelle zu übersteigen vermag, jenseits derer ein Umschlagen des Vertrauens der Allgemeinheit in die Integrität des Sports in Misstrauen zu erwarten ist.

1004 S. hierzu Hefendehl Kollektive Rechtsgüter, S. 186 f., 280.

1005 Zu dieser Voraussetzung des Kumulationsdelikts Zeiser Trafic, S. 178. 
Grundsätzlich erscheint die Kenntnisnahme zahlreicher Fälle von Bestechlichkeit seiner Repräsentanten durchaus geeignet, ein kollektives Vertrauen in die Redlichkeit der entsprechenden Institution aufzulösen. ${ }^{1006}$ Für den Leistungssport ließe sich einwenden, dass die zur Begründung der prognostizierten Kumulationseffekte angeführten Faktoren Einbußen am geschützten spezifizierten Vertrauen geradezu zwangsläufig unwahrscheinlich werden lassen. Denn das schutzwürdige Vertrauen soll sich auf die Geltungskraft der sportethischen Werte im populären, medial präsenten und damit vorbildtauglichen Spitzensport beziehen und damit auf einen schmalen Sektor, dessen Akteure gerade wegen ihrer Popularität und der sich aus ihr ergebenden Vermarktungsmöglichkeiten finanziell unabhängig und für die ökonomischen Anreize einer korruptiv verabredeten Manipulation weniger empfänglich sind. Allerdings finden sich unter den in den vergangenen Jahren an Match Fixing beteiligten Sportlern wie gezeigt auch mehrere populäre Nationalspieler, die zwar teilweise aus persönlichkeitsabhängigen und kaum multiplizierbaren Motiven heraus handelten, zur Kumulationswirkung gleichwohl in einer Weise beigetragen haben könnten, Misstrauen nicht allein gegenüber den in puncto Wertevermittlung und Vorbildwirkung eher bedeutungslosen Randbereichen des Leistungssports entstehen zu lassen, sondern es auf die populärsten Sportarten und deren prominente Vertreter zu erweitern.

Für die These, der zufolge fortwährend publik werdende Manipulationsabsprachen im Sinne eines steten Tropfens die Glaubwürdigkeit und Vorbildwirkung des Spitzensports über einen Schwellenwert hinaus auszuhöhlen vermögen, jenseits dessen er als gesellschaftliches Interessensfeld und normbildende Institution kollabiert, ${ }^{1007}$ lassen sich in der Realität kaum verwertbare Belege finden. Der immer wieder angeführte Zuschauerschwund bei Fernsehübertagungen von Rundfahrten des Radsports nach den prominenten Dopingfällen der Jahre 2006 und 2007 ist für sich genommen in seinen Ursachen nicht eindeutig ${ }^{1008}$ und besitzt schon aufgrund der anderen Manipulationsform des Dopings hinsichtlich der Frage nach der tatsächlichen Kumulationswirkung der von $\$ \$ 265$ c, 265d StGB erfassten Verhaltensweisen kaum Aussagekraft. Ebenfalls nur eingeschränkt heranziehen lassen sich die erwähnten Beispiele asiatischer Fuß-

1006 Für den Beamtenapparat vgl. Hefendehl Kollektive Rechtsgüter, S. 322; Zeiser Trafic, S. $178 \mathrm{f}$.

1007 Die gesetzgeberische Konzeption in diesem Sinne unterstützend Jaleesi Kriminalisierung, S. $93 \mathrm{f}$.

1008 S. oben Teil 3 B. II. 2. d) cc) (2). 
ballligen, die in der Folge einer aufgedeckten Vielzahl von Spielmanipulationen in der sozialen und wirtschaftlichen Bedeutungslosigkeit verschwanden. ${ }^{1009} \mathrm{Da}$ der umfangreiche Zuschauerschwund in engem zeitlichen Zusammenhang mit der startenden Fernsehübertragung hochklassiger europäischer Fußballligen stand, können sie ebenso gut als Beleg einer fußballinternen Umlenkung der öffentlichen Nachfrage auf andere Wettbewerbe dienen. Ein durch Manipulationsenthüllungen ausgelöster Vertrauensverlust führte dann lediglich zu einem bereichsspezifischen SichAbwenden von einzelnen Sportarten oder gar nur einzelnen Ligen, das in eine Zuwendung zu anderen sportlichen Wettbewerben übergehen kann und den Spitzensport als vorbildhafte Sozialisationsinstanz nicht in Gänze disqualifizierte.

Noch vor der Annahme einer auch nur bereichsweise handlungsleitenden Kumulationswirkung müsste erklärt werden können, wieso sich Anziehungskraft und Identifikationspotenzial der großen europäischen Fußballligen von aufgedeckten Manipulationsserien bisher nahezu unbeeindruckt zeigen. Zum Teil tragen gewiss auch über den bloßen Fakt des Match Fixing hinausgehende ortsspezifische Besonderheiten wie etwa die in Asien öffentlich wahrgenommene Infiltration der Sportvereine mit Angehörigen der illegalen Wettszene zum Niedergang einer Liga bei. ${ }^{1010}$ Doch davon abgesehen drängen sich als den europäischen Top-Ligen Robustheit verleihende Faktoren wiederum ihre Spannung, Unterhaltung versprechende Inszenierung und die erlebte Gemeinschaft der Zuschauer auf, die sich von einem integritätsbezogenen Vertrauen in die verfolgten Wettbewerbe emanzipiert haben.

Dies führt zurück zur Kritik an der Konzeption der Integrität des Sports als Rechtsgut. Ein durch die Tathandlungen ausgelöster Bedeutungsverlust des Sports lässt sich auch mithilfe des Kumulationsgedankens allenfalls unter der oben bereits bezweifelten Prämisse eines tatsächlich existenten Vertrauens der Bevölkerung in die Integrität des Sports konstruieren. Der hilfsweise verfolgte Ansatz, der zwecks Untersuchung der tatbestandlichen Angriffswirkung der $\$ \$ 265$ c, 265d StGB die gesetzgeberischen Annahmen zum Vertrauenselement unterstellt hat, stößt hier an Grenzen. Denn die Bestimmung des relevanten Grenzwertes zwischen kollektivem Vertrauen und Misstrauen erfordert eine genaue Auseinandersetzung mit den realen Entstehungsbedingungen und der Anfälligkeit dieses Vertrauens, die an

1009 S. oben Teil 3 B. II. 2. d) cc) (2).

1010 ICSS/Sorbonne (Hrsg.) Part II, S. 23; Hill International Journal of Sports Marketing and Sponsorship 11 (2010), $221 \mathrm{ff}$. 
einem fingierten Platzhalter, dem angesichts der bloßen Behauptungen im Gesetzentwurf keine Konturen verliehen werden können, kaum zu leisten ist.

Selbst die kumulierte Vielzahl von Manipulationsabsprachen wird den behaupteten Mechanismus eines durch zerstörtes Vertrauen ausgelösten Rückzugs der Gesellschaft vom Sport und seiner Werte nicht auslösen, wenn nicht integritätsbezogene Glaubwürdigkeit die fortgesetzte Anteilnahme am Spitzensport bedingt, sondern der ohne sportethische Erwartungen auskommende Wunsch nach Zerstreuung und Unterhaltung. Die Kennzeichnung eines Vertrauens als existent, auf einen bestimmten Gegenstand bezogen und handlungsleitend definiert nicht nur dessen strafrechtliche Schutzwürdigkeit als Rechtsgut, sondern wirkt sich zwangsläufig auch auf die Wirkung etwaiger Angriffswege aus. Über das Fehlen dieser Merkmale kann der Kumulationsgedanke nicht hinweghelfen, da die zu multiplizierende Einzelhandlung dann gänzlich ohne Angriffsobjekt abirrt und auch in einer aufgerechneten Gesamtwirkung unschädlich bleiben muss.

Demnach ermöglicht der Kumulationsgedanke zwar eine Präzisierung der Einstufung der $\$ \$ 265 c$, 265d StGB als abstrakte Gefährdungsdelikte und zeigt eine Möglichkeit auf, die fehlende reale Verletzungskausalität der tatbestandlichen Verhaltensweisen im Hinblick auf die Integrität des Sports zu ersetzen. Dies verlangt aber eine weitgehend unkritische Übernahme ihrer voraussetzungsreichen und lediglich behaupteten Wirkungszusammenhänge, die sich in der Auseinandersetzung mit den Legitimationsbedingungen eines Kumulationsdeliktes einmal mehr als nicht greifbar erwiesen haben. Die spezifische deliktsstrukturelle Qualifizierung vermag den notwendigen Bezug von Tathandlung und Rechtsgut somit allenfalls unter gewichtigen Vorbehalten herzustellen.

(4) Einseitig bleibende Tathandlungen als Kumulations- oder Vorbereitungsdelikte?

Selbst eine sich über die dargestellten Zweifel hinwegsetzende Einordnung der $\$ \$ 265$ c, 265d StGB als Kumulationsdelikte im Hinblick auf die Integrität des Sports müsste sich schließlich fragen, ob diese deliktsstrukturelle Qualifizierung auf sämtliche Tatbestandsalternativen zutrifft. Denn die bisherige Prüfung der Kumulationswirkung bezog sich auf getroffene Manipulationsabsprachen. Tatbestandlich werden indes auch Konstellationen erfasst, in denen keine Unrechtsvereinbarung zustande kommt. Das 
bloße „Fordern“ bzw. „Anbieten“ eines Vorteils in den $\$ \$ 265$ c, 265d StGB beschreibt einseitig bleibende Korruptionshandlungen, deren rechtsgutsbeeinträchtigende Wirkung gesondert betrachtet werden muss, da sie selbst bei Unterstellung ihrer massenhaften Vornahme im Vergleich zur Kenntnisnahme geschlossener Manipulationsabsprachen einen geringeren Effekt auf das Vertrauen der Allgemeinheit in die Integrität des Sports haben könnten. Hielte man diesen nicht für ausreichend und verlangte das Eingehen der Gegenseite auf Vorteilsangebot oder -forderung als eine zur Rechtsgutsbeeinträchtigung erforderliche Anschlusshandlung, bliebe nur die Einordnung dieser Tatbestandsalternativen als Vorbereitungsdelikt mit den entsprechenden legitimationsbezogenen Konsequenzen.

Das unterstellte Kollektivvertrauen muss als ein hinreichend sensibles verstanden werden, damit es auch durch die Kumulation von nur einseitig intendierten korruptiven Vereinbarungen tangiert wird. Ein derart anfälliges Vertrauen wird etwa für den von den $\$ \$ 331 \mathrm{ff}$. StGB abgedeckten Bereich der gemeinwohlorientierten staatlichen Verwaltung angenommen, in dem bereits der Anschein der Unredlichkeit der Repräsentanten zu einer ernsthaften Funktionsstörung führen könne und daher zwischen dem Fordern bzw. Anbieten eines Vorteils und dem nachfolgenden Abschluss und der Umsetzung der Unrechtsvereinbarung allenfalls eine graduelle Unrechtssteigerung zu konstatieren sei. ${ }^{1011}$

Ob sich dieser Maßstab auch auf den Spitzensport übertragen lässt, kann zumindest bezweifelt werden. Seine abweichenden institutionellen Merkmale der autonomen Organisationsform, des individuellen Gewinnstrebens und der wirtschaftlichen Verflechtungen könnten ein in seine Authentizität gelegtes Vertrauen von vornherein vergleichsweise robuster ausgestalten, so dass es sich jedenfalls von einseitigen Anbahnungen einer Unrechtsvereinbarung unbeeindruckt zeigte. ${ }^{1012}$ Trotz der Plausibilität dieser Zweifel lässt sich aus ihnen aber keine evidente Ungefährlichkeit einer Kumulation der vorverlagerten Tathandlungen ableiten, die die im Rahmen der Geeignetheit grundsätzlich ausreichende Möglichkeit eines irgendwie geförderten Rechtsgüterschutzes zwingend von einer Anschlusshandlung abhängig machte. Das aktive Fordern eines Vorteils durch einen Sportak-

1011 Loos FS Welzel, 1974, S. 879 (888 ff.); Krack ZIS 2016, 540 (546).

1012 Vgl. Krack ZIS 2016, 540 (546); Rübenstahl JR 2017, 264 (267); in diese Richtung auch Kargl NStZ 2007, 489 (495), der dopingbezogen das ungenügende Gefahrenpotenzial einer vorgelagerten Tathandlung allerdings als Argument gegen die Bildung kollektiver Vertrauensrechtsgüter im Allgemeinen verwendet. 
teur signalisiert dessen Bereitschaft zur Abkehr von den vorbildhaften sportethischen Werten und vermag die öffentliche Einschätzung ihrer Verbindlichkeit grundsätzlich zu beeinflussen. Ein an einen Sportakteur gerichtetes Vorteilsangebot kann isoliert zwar gerade auch als Beleg der Standhaftigkeit des Wertekodex und ihres Repräsentanten im konkreten Fall aufgefasst werden. Die Kenntnis von der Existenz solcher Verlockungen kann umgekehrt aber auch Zweifel an den dauerhaft funktionsfähigen Abwehrkräften des Teilsystems veranlassen. Bei Befürwortung der Einordnung der $\$ \$ 265 c$, 265d StGB als Kumulationsdelikte ließe sich diese somit auf sämtliche Tatbestandsalternativen erstrecken.

\section{Hinsichtlich des Vermögensschutzes}

Auch hinsichtlich des jeweils verfolgten Schutzes von Vermögensinteressen sind die Tatbestände auf einen förderlichen Beitrag zu untersuchen. Der Einsatz des Strafrechts zum Schutz des individuellen Vermögens ist etabliert und findet zahlreiche, auch über die Delikte des 22. Abschnitts des StGB hinausgehende Ausdrucksformen. Die dabei erkennbaren, unterschiedlichen deliktsstrukturellen Ausgestaltungen zeigen, dass das Vermögen sowohl gegen Verletzungen als auch gegen bloße Gefährdungen strafrechtlich geschützt wird. Sein Schutz wird aber nicht lückenlos gewährleistet, sondern erstreckt sich hauptsächlich auf die Angriffswege der Täuschung, Drohung oder Pflichtverletzung in Kombination mit weiteren eigenständigen Tatbestandsmerkmalen. ${ }^{1013}$ Die Geeignetheit des Strafrechts zum Vermögensschutz begegnet dabei keinen grundsätzlichen Bedenken. Der Gesetzgeber kann im Rahmen seiner Einschätzungsprärogative der Strafandrohung als solcher auch bei vermögensschützenden Verhaltensnormen gewisse generalpräventive Effekte zutrauen.

Die tatbestandliche Ausgestaltung der $\$ \$ 265 c$, 265d StGB ist nun also zum intendierten Vermögensschutz in Bezug zu setzen. Dabei ist es zunächst ebenso wie hinsichtlich der Integrität des Sports unbeachtlich, dass nicht alle potenziell vermögensrelevanten Manipulationen erfasst werden und insbesondere Anreize für die Beeinflussung des Wettbewerbs zu eigenen Gunsten außen vor bleiben. So dürfte etwa eine außergewöhnliche Siegprämie, die einem aufgrund ihres zementierten Tabellenplatzes am Ende der Saison nicht mehr sonderlich motivierten Team in Aussicht gestellt wird, die Wahrscheinlichkeit des Ausgangs des nächsten Spiels in

1013 Tsambikakis StV 2018, 319 (320); Jansen GA 2017, 600 (612). 
einer von den Quoten der Wettanbieter nicht mehr realistisch abgebildeten Weise verändern. Für den konkreten Rechtsgutsbezug der tatbestandlich erfassten Angriffswege bleibt dies ohne Relevanz.

Den Tatbeständen ist weder das Erfordernis eines Vermögensschadens noch einer konkreten Gefährdung näher bestimmter Vermögensinteressen zu entnehmen. Auch bezüglich dieses Schutzgutes sind die $\$ \$ 265 \mathrm{c}, 265 \mathrm{~d}$ StGB somit als abstrakte Gefährdungsdelikte gefasst. ${ }^{1014}$ Die Prüfung der Geeignetheit verlangt wiederum eine nähere Bestimmung des der Verhaltensweise immanenten, rechtsgutsbezogenen Gefährdungspotenzials. Diesbezüglich ist im Ausgangspunkt für beide Delikte zu klären, auf welche Weise vom jeweiligen tatbestandlichen Verhalten angestoßene Kausalverläufe zu einer Beeinträchtigung bei den in Betracht kommenden Vermögensträgern führen können.

\section{a) Vermögensschutz durch $\$ 265$ c StGB}

Ausweislich des Gesetzentwurfs dient $\$ 265$ c StGB insbesondere dem Schutz des Vermögens von Wettanbietern. Wie bereits dargestellt können diese durch die Platzierung einer Wette auf einen manipulierten Sportwettbewerb einen Vermögensschaden erleiden. ${ }^{1015}$ Es bedarf dieser Wettplatzierung aber auch, um ein Manipulationsgeschehen überhaupt in die Sphäre der Wettanbieter zu überführen, in der vermögensmindernde Effekte denkbar sind. Die tatbestandsmäßige und der Wettplatzierung vorgelagerte Manipulationsabsprache kann für sich genommen keine Vermögensschädigung des Anbieters bewirken. Zwar beeinflusst bereits die zugesagte Manipulation eines Sportakteurs die sensiblen Wahrscheinlichkeiten des Ausgangs des betreffenden Wettbewerbs in einer von den Wettquoten nicht mehr abgebildeten Weise. Solange jedoch niemand überlegenes Wissen gegenüber dem Anbieter einsetzt, kalkulieren sämtliche Wettteilnehmer mit verzerrten Quoten, so dass allenfalls der keinen geschützten Vermögensbestandteil darstellende Umfang der ergebnisunabhängig einkalkulierten Gewinnmarge der Wettanbieter beeinträchtigt wird. Da die Realisierung der tathandlungsspezifischen Gefahr für das Vermögen der Wettanbieter also nicht dem unbeherrschbaren Zufall folgt, sondern in Form der Wettplatzierung eine bewusste Anschlusshandlung eines an der Ab-

1014 MüKo-StGB/Schreiner $₫ 265$ c Rn. 5; Rübenstabl JR 2017, 264 (269), 333 (334); Krack ZIS 2016, 540 (544); Valerius Jura 2018, 777 (779).

1015 S. Teil 2 B. III. 1. b). 
sprache Beteiligten voraussetzt, liegt eine Einordnung des $₫ 265$ c StGB als Vorbereitungsdelikt nahe. ${ }^{1016}$

Dessen sich aus einer subjektiven und objektiven Verklammerung von vorbereitender Tathandlung und Rechtsgutsbeeinträchtigung ergebendes Gefährdungsunrecht muss in der Geeignetheitsprüfung zumindest als Möglichkeit feststellbar sein. Indem $\$ 265$ c StGB das Erlangen eines rechtswidrigen Vermögensvorteils durch eine entsprechende Sportwette als Bestandteil der Unrechtsvereinbarung ausgestaltet, muss auch der Vorsatz über die objektiven Rahmenbedingungen der vorbereitenden Manipulationsabsprache hinausgehen und sich auf eine diese ausnutzende Wettplatzierung beziehen. Die unmittelbare Vermögensschädigung wird also in einen tatbestandlich vorausgesetzten Planungszusammenhang aufgenommen. Ferner sind die erfassten Tathandlungsvarianten der konkretisierten Manipulationsabsprache generell geeignet, eine nachfolgende vermögensschädigende Wettplatzierung durch einen an der Absprache Beteiligten vorzubereiten. Dies gilt auch für die einseitigen Tathandlungsvarianten des „Forderns“ und „Anbietens“, da geeignete Vorbereitungshandlungen nicht zwingend der direkte Anknüpfungspunkt für die unmittelbar beeinträchtigende Haupttat sein müssen, sondern auch nur ein Schritt zu einer Rechtsgutsschädigung sein können, dem weitere Vorbereitungshandlungen folgen müssen. ${ }^{1017}$

Aus den insofern feststellbaren Minimalvoraussetzungen eines subjektiven wie objektiven Rechtsgutsbezugs der Tathandlungen folgt noch keine abschließend positive Bescheidung des legitimierenden Gefährlichkeitszusammenhangs, dessen eingehende Prüfung der Stufe der Angemessenheit vorbehalten bleibt. Hinsichtlich der hier untersuchten Möglichkeit eines rechtsgutsbezogenen Gefährdungspotenzials des vorverlagerten tatbestandsmäßigen Verhaltens reicht der erkennbare Planungszusammenhang zwischen zweckgerichteter Manipulationsabsprache und Wettplatzierung aber aus, um die Annahme der Geeignetheit des $\$ 265$ c StGB als Vorbereitungsdelikt im Hinblick auf den primär verfolgten Vermögensschutz der Wettanbieter zu tragen.

Betrachtet man den vom Gesetzgeber ebenfalls erwähnten Vermögensschutz der redlichen Wettteilnehmer nicht als bloßen Reflex des Schutzes der Wettanbieter, ist differenzierend festzustellen, dass die womöglich vermögensrelevante Gefahr einer ihrer Wette zugrunde gelegten und infolge der ihnen unbekannten Manipulationsabsprache fehlerhaften Kalkulation 
der Ergebniswahrscheinlichkeiten jenseits einer erfolgenden Wettplatzierung durch den Vorteilsgeber besteht. Zudem verlangt $\$ 265$ c StGB keine subjektive Inbezugnahme der Beeinträchtigung gerade ihrer Gewinnchancen. Diesbezüglich ist also nicht von einem Vorbereitungsdelikt auszugehen, so dass sich die notwendige Verbindung zum Rechtsgut nur aus der objektiven Gefährlichkeit der Tathandlungen ergeben kann.

\section{b) Vermögensschutz durch $\$ 265 \mathrm{~d}$ StGB}

Hinsichtlich Sportlern, Sportvereinen, Veranstaltern und Sponsoren, die vom Gesetzgeber als die von $\$ 265 \mathrm{~d}$ StGB geschützten Vermögensträger benannt werden, ${ }^{1018}$ fällt das Aufzeigen schädigender Kausalverläufe infolge der erfassten Manipulationsabsprachen schwerer. Der Gesetzgeber unterstellt Match Fixing offenbar gerade im vielfältig kommerzialisierten Berufssport vermögensrelevante Auswirkungen für die involvierten Akteure, ohne diese im Einzelnen näher zu veranschaulichen. ${ }^{1019}$ Vermutlich den Bundesliga-Manipulationsskandal von 1970/1971 im Blick, verweist er einzig auf die Konstellation des durch manipulierte Spiele verursachten Abstiegs einer Mannschaft, der mit finanziellen Einbußen für den betroffenen Verein und seine Spieler einherginge. ${ }^{1020}$ Entnähme man diesem Beispiel eine auch bezüglich $\mathbb{2} 265 \mathrm{~d}$ StGB unzureichende Gefahrenwirkung der Manipulationsabsprache als solcher, die sich im kommerzialisierten Spitzensport immer erst mit Hinzutreten der wettbewerbsverzerrenden Manipulationsausführung vermögenswirksam niederschlagen könne, müsste das fragliche Gefährdungsunrecht über eine Einordnung auch des $\$ 265 \mathrm{~d}$ StGB als Vorbereitungsdelikt konstruiert werden.

Allerdings bleibt die tatsächliche Manipulation als potenziell vermögensschädigende Handlung straffrei. Sie stellt gerade keine deliktische Folgehandlung als Bezugspunkt der möglichen Vorbereitungshandlung dar. Zudem verlangt $\$ 265 \mathrm{~d}$ StGB keine Verknüpfung von Tathandlung und rechtsgutsbeeinträchtigender Manipulationsausführung im Sinne eines Planungszusammenhangs. Die Intention bei Antrag oder Abschluss der Manipulationsabsprache zielt beim Sportakteur auf die zugesagte Manipulationsprämie, beim Vorteilsgeber auf sportinterne Vorteile und somit auf beiden Seiten allein auf einen eigenen Vorteil, der im Unterschied zu

1018 BT-Drs. 18/8831, S. 10.

1019 Krit. Tsambikakis StV 2018, 319 (324).

1020 BT-Drs. 18/8831, S. 11; hierbei belässt es auch Kubiciel SpuRt 2017, 188 (190). 
\$265c StGB gerade nicht die Kehrseite der Verletzung der geschützten Vermögensträger in ihrem Rechtsgut bildet. Der Tatbestand enthält keine Voraussetzungen, die einen hinreichenden subjektiven Bezug zu einer künftigen Beeinträchtigung des geschützten Rechtsguts herstellen.

Verfehlt $\$ 265$ d StGB demnach mangels eines tatbestandlich vorausgesetzten subjektiven Rechtsgutsbezugs die Anforderungen an das spezifische Gefährdungsunrecht eines Vorbereitungsdelikts, kann sich seine untersuchte Geeignetheit allein aus einer hinreichenden Beziehung der objektiven Tathandlung zum Vermögen im Sinne einer objektiv-abstrakten Gefährdung ergeben. ${ }^{1021}$ Zumindest kann die Möglichkeit eines durch eine Manipulationsabsprache in Gang gesetzten Geschehensablaufs, der zur Vermögensschädigung eines wirtschaftlich am Sport partizipierenden und manipulationsbedingt benachteiligten Akteurs führt, nicht ausgeschlossen werden. Die Zusage eines zweckgebundenen Vorteils als Bestandteil der korruptiven Abrede kann einen beträchtlichen Anreiz für den Sportakteur darstellen, die verabredete Manipulation durchzuführen, die im kommerzialisierten Umfeld des Berufssports durchaus vermögensrelevant sein kann. Mag die Abhängigkeit dieser Vermögensrelevanz von einer tatsächlich ausgeführten Manipulation auch auf einen nur vermittelten Zusammenhang von tatbestandlicher Verhaltensweise und Rechtsgutsbeeinträchtigung hindeuten, entzieht dies dem $\$ 265 \mathrm{~d}$ StGB die Geeignetheit nicht, wird ihn aber im Rahmen der von Proportionalitätserwägungen geprägten Prüfungsstufe der Angemessenheit vor hohe Hürden stellen.

\section{Zwischenergebnis}

Überprüft man die $\$ \$ 265$ c, 265d StGB im Rahmen der Geeignetheit auf einen förderlichen Beitrag zum Schutz der Integrität des Sports, so kann dieser bereits aus grundsätzlichen Erwägungen zumindest nicht in der Bestärkung der Vorbildhaftigkeit sportethisch konformen Verhaltens liegen. Denn die über die Androhung äußeren Zwangs operierende Verhaltenssteuerung des Strafrechts relativiert Ausdrucksformen sportethischer Werte, die ihre Wirkkraft gerade aus Zwanglosigkeit und Selbstverpflichtung beziehen. Übersteigt es somit die Möglichkeiten des Strafrechts, Integrität im Sport aktiv zu produzieren, so verbleibt ihm der denkbare Schutz gewisser Rahmenbedingungen. Dank seiner auch in diesem Bereich nicht auszuschließenden abschreckenden Wirkung lassen sich möglicherweise

1021 Vgl. Puschke Vorbereitungstatbestände, S. 340 f. 
Angriffe externer Personen auf den Sport reduzieren und ein kollektives Vertrauen in die Authentizität der Wettbewerbe stabilisieren. Eine Förderung des Rechtsguts wäre damit aber nur verbunden, wenn in Form der unterlassenen Verhaltensweisen tatsächlich Angriffe auf die Bestandteile der Integrität des Sports abgewehrt würden.

Die in $\$ \$ \int 265$ c, 265d StGB beschriebenen Tathandlungen erweisen sich nicht bereits deshalb als ungeeignet, eine Beeinträchtigung der Integrität des Sports herbeizuführen, weil sie nur den Leistungssport erfassen und bestimmte Formen der Wettbewerbsmanipulation trotz ihres öffentlichen Empörungspotenzials ausschließen. Diese Einschränkungen setzen sie zwar den Einwänden aus, die Integrität des Sports nicht dort zu schützen, wo sich Wertevermittlung vollzieht, sondern nur dort, wo gleichzeitig vermögenswirksame Konsequenzen drohen und darüber hinaus widersprüchliche Differenzierungen vorzunehmen. Der Strafgesetzgeber hat das auserkorene Rechtsgut aber nicht allumfassend und bestmöglich zu schützen und die vorgenommene Fokussierung allein löst den Bezug zur Rechtsgutskonzeption nicht auf.

Dieser steht allerdings aufgrund des nicht ausreichenden Gefährdungsgrads der einzelnen tatbestandsmäßigen Manipulationsabsprache in Frage, die für sich genommen weder den Geltungsanspruch sportethischer Werte bedroht noch Erschütterungen eines hierauf gerichteten allgemeinen Vertrauens befürchten lässt. Eine tatsächliche Beeinträchtigung konstitutiver Rechtsgutselemente kann sich allenfalls aus einer Kumulation von Einzelhandlungen im Hinblick auf eine kollektive Vertrauenskomponente ergeben. Da jedoch schon deren Existenz eine Fiktion ist, lässt sich das Bedrohungspotenzial prognostizierbarer Kumulationseffekte kaum belastbar abschätzen. Zu einer ausreichenden Substitution der den abstrakten Gefährdungsdelikten in $\$ \mathbb{S} 265 \mathrm{c}, 265 \mathrm{~d}$ StGB zunächst grundsätzlich fehlenden Verletzungskausalität kann nur gelangen, wer der idealisierten Rechtsgutskonzeption des Gesetzgebers folgt und den zumindest sportartspezifisch feststellbaren Anschein einer folgenlosen Anhäufung von Manipulationsfällen zu entkräften versteht. Andernfalls muss konstatiert werden, dass die $\$ \mathbb{S} 265 \mathrm{c}$, 265d StGB letztlich auch als Kumulationsdelikt nicht geeignet sind, den Schutz der Integrität des Sports zu fördern.

Auch im Hinblick auf den intendierten Vermögensschutz sind die $\mathbb{S} \mathbb{S} 265 \mathrm{c}, 265 \mathrm{~d}$ StGB als abstrakte Gefährdungsdelikte ausgestaltet. Die tatbestandlich erfassten Verhaltensweisen liegen im Vorfeld einer manifesten Vermögensbeeinträchtigung. Ihre rechtsgutsbezogene Gefährdungswirkung kann sich in $\$ 265$ c StGB für die Wettanbieter nur über die deliktische Anschlusshandlung einer betrügerischen Wettplatzierung vollziehen. 
Diese Lockerung der Verbindung von Tathandlung und Rechtsgutsbeeinträchtigung wird jedoch durch einen subjektiv wie objektiv in $\$ 265 \mathrm{c}$ StGB angelegten Gefährlichkeitszusammenhang ausgeglichen, der eine Legitimierung als Vorbereitungsdelikt eröffnet. In $\$ 265 \mathrm{~d}$ StGB hingegen muss der notwendige Konnex zwischen Tathandlung und Vermögen mangels tatbestandlich vorausgesetzter intentionaler Rechtsgutsschädigung allein über eine objektive Gefährdung herstellbar sein. Für die Annahme der Geeignetheit reicht es insofern aus, dass die Einmündung spitzensportbezogener Manipulationsanträge und -absprachen in die Beeinträchtigung des Vermögens von Sportlern, Vereinen, Veranstaltern und Sponsoren zumindest denkbar erscheint.

Die legitimationsbezogene Bewertung der gleichwohl festgestellten Abschwächung der tatbestandsimmanenten Gefahr infolge der erforderlichen Vermittlung und teilweise unklarer Wirkungsmodalitäten bleibt der weiteren Prüfung des Verhältnismäßigkeitsgrundsatzes überlassen. In deren Rahmen wird der durch die $\$ \mathbb{S} 265$ c, 265d StGB erzielbare Vermögensschutz mit alternativen Schutzmaßnahmen zu vergleichen und in eine normative Abwägung mit den Freiheitsbereiche verkürzenden Auswirkungen der Vorverlagerung einzustellen sein. Zumindest für die Annahme der Geeignetheit der Tatbestände zum Vermögensschutz reicht das dargelegte vermögensbezogene Gefährdungspotenzial der korruptiven Abrede aus, deren generalpräventiv wirkende Pönalisierung somit im Umkehrschluss als förderlicher Beitrag zum Vermögensschutz begriffen werden kann.

\section{Erforderlichkeit}

Auf der nächsten Prüfungsebene des Verhältnismäßigkeitsgrundsatzes ist festzustellen, inwieweit die $\$ \$ 265$ c, 265d StGB zum Zweck des Schutzes ihrer Rechtsgüter erforderlich sind. Eine Strafnorm gilt dabei im Allgemeinen dann als erforderlich, wenn der Gesetzgeber nicht ein anderes, gleich wirksames, aber das Grundrecht nicht oder weniger stark einschränkendes Mittel hätte wählen können. ${ }^{1022}$ In dem hierbei vorzunehmenden Vergleich verschiedener geeigneter Regelungsregime und ihrer Effektivität findet in besonderer Weise die Forderung nach einem fragmentarischen Strafrecht ihren Ausdruck. ${ }^{1023}$ Ihrer konsequenten Durchsetzung steht allerdings die Schwierigkeit der zu treffenden mehrdimensionalen Progno-

1022 BVerfGE 90, 145 (172 ff.); 120, 224 (240).

1023 Hefendehl JA 2011, 401 (404 f.). 
sen entgegen. Diese müssen möglichst präzise nicht nur den Grad der zu erwartenden Schutzwirkung eines Mittels ausweisen, sondern auch dessen Eingriffstiefe. Denn dass das Strafrecht durchgehend die belastungsintensivste Maßnahme darstellt, ist angesichts der bereichsweise immensen Streubreite präventiver Maßnahmen des Zivil- oder öffentlichen Rechts nicht ausgemacht. ${ }^{1024}$ An die Stelle der diesbezüglich nicht zuletzt aufgrund eines Mangels an empirisch belastbaren Erkenntnissen bestehenden Unsicherheit treten wiederum verfassungsgerichtlich akzeptierte Beurteilungsspielräume des Gesetzgebers. ${ }^{1025}$

Wenngleich eine exakte Bestimmung von Wirksamkeit und Eingriffstiefe auch hier nicht geleistet werden kann, soll das kritische Potenzial der Erforderlichkeit insoweit ausgeschöpft werden, als alternative Formen des Schutzes der Rechtsgüter aufgezeigt und in ihrer Wirkweise dem durch die $\$ \mathbb{S} 265 \mathrm{c}, 265 \mathrm{~d}$ StGB gewährleisteten Schutz gegenübergestellt werden. Womöglich können auf diese Weise zumindest evidente Unzulänglichkeiten benannt oder eben ausgeschlossen und die Erforderlichkeit der Tatbestände über das Zusammentragen von Indizien annäherungsweise bewertet werden. Bezüglich der Integrität des Sports sollen bestimmte gesellschaftliche, privatrechtliche und verbandsinterne Maßnahmen vergleichsweise herangezogen werden. Da sich das Vermögen eines bereits bestehenden und ausdifferenzierten strafrechtlichen Schutzes versieht, ist vor allem dieser auf für die konkret zu schützenden Vermögensträger nachteilige Eigenschaften zu untersuchen, die eine Erweiterung des Schutzes in der Form der $\$ \$ 265$ c, 265d StGB angezeigt erscheinen lassen.

\section{Hinsichtlich der Integrität des Sports}

Aufgrund des vorzunehmenden Vergleichs gleich wirksamer Mittel setzt die Prüfung der Erforderlichkeit einer Strafnorm deren Eignung voraus. Diese wurde den $\$ \$ 265$ c, 265d StGB in Bezug auf das Rechtsgut der Integrität des Sports aber nur unter erheblichen Vorbehalten zugesprochen. Die Tatbestände verwirklichende Einzelhandlungen sind für sich genommen nicht imstande, die Bestandteile der Integrität des Sports zu verletzen. Ihre prognostizierbare Kumulation kann ein systemtragendes und handlungsleitendes Kollekivvertrauen überhaupt nur erschüttern, wenn dessen

1024 Für das Wirtschaftsstrafrecht etwa Tiedemann Wirtschaftsstrafrecht, Rn. 227 ff.; Schünemann GS Kaufmann, S. 629 (632).

1025 BVerfGE 45, 272 (289); 51, 60 (64); 80, 182 (185f.). 
Existenz entgegen den hier geäußerten Zweifeln angenommen wird. Eine bereits nicht geeignete Strafnorm kann unter keinen Umständen erforderlich sein. Es an dieser Stelle hierbei zu belassen, würde aber eine Auseinandersetzung mit alternativen Formen des sportbezogenen Integritätsschutzes unterbinden, aus deren Effektivität eine weitere ernst zu nehmende Schwächung der gesetzgeberischen Begründung des strafrechtlichen Handlungsbedarfs hervorgehen könnte. Um dies zu überprüfen, soll nicht nur der gesetzgeberischen Annahme gefolgt werden, ein durch Manipulationsverabredungen ausgehöhltes Sportethos führe zu einem Vertrauensverlust und einer Abwendung der Gesellschaft, in deren Folge sie für die sozialisationsfördernden Einflüsse des Sports nicht mehr empfänglich ist. Ferner wird die Eignung der $\$ \$ 265$ c, 265d StGB unterstellt, einem solchen Verlauf durch strafrechtliche Abschreckung und Vertrauensstabilisierung entgegenzuwirken.

Unter diesen Prämissen soll der Frage nachgegangen werden, ob dieser die Rechtsgutskonzeption auszeichnende Wirkungszusammenhang nicht auch durch außerstrafrechtliche Mittel hinreichend abgesichert werden könnte. So bemüht sich auch der organisierte Sport selbst darum, seine Akteure zu einem in Einklang mit sportethischen Werten stehenden Verhalten anzuhalten und seine Wettbewerbe vor unlauteren Einflussnahmen abzuschirmen. Die hierzu ergriffenen Maßnahmen sind auf ihre Tauglichkeit zur internen Stärkung integrer Wettbewerbe und der Stabilisierung eines hierauf gerichteten Vertrauens zu untersuchen (dazu a]). Die bedingungslose Annahme einer solchen Tauglichkeit würde vor dem Hintergrund strafrechtlicher Subsidiarität einen gewichtigen Einwand gegen die Kriminalisierung formen. Sollten sich die Sportverbände hingegen als mit dieser Aufgabe überfordert erweisen, wäre anschließend zu prüfen, inwiefern die dann als gestört zu betrachtende Funktion des Sports als wertvolle Sozialisationsinstanz nicht anderweitig gesellschaftlich substituiert werden kann (dazu b]). Denn auch eine solche Möglichkeit spräche gegen die Notwendigkeit des Einsatzes des Strafrechts zum Schutz einer allein über den Sport denkbaren Wertevermittlung. Sodann wird zu dem Vorschlag Stellung bezogen, die Tatbestände herabzustufen und für den Schutz der Integrität des Sports das als milder empfundene Ordnungswidrigkeitenrecht zu aktivieren (dazu c]). Angesichts der bereits herausgestellten Bedeutung des Sportwettenmarkts als Bedingungsfaktor des wettbezogenen Match Fixing werden schließlich die Realität und das integritätsschützende Potenzial dessen staatlicher Regulierung in den Blick genommen (dazu d]). 
a) Selbstregulierung durch die Sportverbände

Die Integrität des Sports ist nicht ausschließlich Regelungsobjekt des Strafrechts. Ihren Schutz verfolgen auch die einzelnen Sportverbände. Gerade bezüglich der Einhaltung sportethischer Werte im Wettbewerb fällt ihnen als Ausfluss der von Art. 9 Abs. 1 GG gewährten Verbandsautonomie auch die originäre Kompetenz zu. Ihre Definitionsmacht hinsichtlich dessen, was ein sportethisch konformes Verhalten auszeichnet, korrespondiert mit der Befugnis, deren Einhaltung zu überwachen und Verstöße zu ahnden. ${ }^{1026}$ Umgesetzt wird dies durch das jeweilige Verbandsrecht, das in Satzungen und Verordnungen Tatbestände sportethisch missbilligter Verhaltensweisen formuliert und das Verfahren ihrer Sanktionierung regelt. Noch bevor ein genauerer Blick auf die Bedingungen und Effekte verbandsrechtlicher Sanktionen zum Schutz der Integrität des Sports geworfen wird, soll ein zweites, der förmlichen Ahndung auch tatsächlich vorgeschaltetes Feld der verbandsinternen Schutzbemühungen beleuchtet werden. Mittels verschiedener Präventionsmaßnahmen versuchen die Sportverbände nämlich bereits dem Eintritt eines sanktionierbaren Satzungsverstoßes vorzubeugen. Dabei steht die Verhinderung von wettbezogenem Match Fixing besonders im Fokus. Eine Bewertung der Erfolgsaussichten derartiger präventiver Ansätze ist in die Erörterung der übergeordneten Frage nach einer ausreichenden Selbstregulierung durch die Sportverbände einzubeziehen.

aa) Schutzwirkung verbandlicher Präventionsmaßnahmen

Als institutionelle Reaktion auf Manipulationsfälle wurden in einigen Sportarten innerhalb der letzten Jahre spezialisierte Einrichtungen geschaffen und in die nationalen und internationalen Verbandsstrukturen eingefügt. So wurde beispielsweise im Tennis die Tennis Integrity Unit (TIU) ${ }^{1027}$ gegründet, der International Cricket Council schuf eine Anti Corruption Unit (ACU) ${ }^{1028}$ und im Fußball stellte der Weltverband FIFA ein Integritätsteam auf, während auf nationaler Ebene der DFB im Jahr 2011 einen externen Ombudsmann zum Schutz der Integrität installier-

1026 Vgl. Feltes/Kabuth NK 2017, 91 (99).

1027 Näheres unter: www.tennisintegrityunit.com.

1028 Näheres unter: www.icc-cricket.com/about/integrity/anti-corruption/about-us. 
te. ${ }^{1029}$ Mit im Einzelnen voneinander abweichenden Zuständigkeitsbereichen sollen diese Stellen präventive Maßnahmen gegen Match Fixing konzipieren und begleiten, als Ansprechpartner für Verbände und Sportler zur Verfügung stehen, teilweise aber auch verbandsinterne Disziplinarverfahren vorbereiten und durchführen. Zu diesem Zweck haben sie auch Hinweisgebersysteme implementiert, die Sportakteuren bei Kenntniserlangung von geplantem oder erfolgtem Match Fixing eine anonyme und vertrauliche Meldung garantieren und die Verbandsorgane gegebenenfalls zur Einleitung eines Verfahrens veranlassen. ${ }^{1030}$

Das Bündel der von den Verbänden und ihren spezialisierten Einrichtungen ergriffenen präventiven Maßnahmen gegen Match Fixing lässt sich grob nach den herkömmlich unterschiedenen Ebenen der Kriminalprävention kategorisieren. ${ }^{1031}$ Während einige Maßnahmen allgemein auf die Einstellung und Normbildung der Sportakteure einzuwirken versuchen und damit der primären, täterbezogenen Prävention zugeordnet werden können, reagieren andere auf konkretisierte Gefährdungsfaktoren und zielen darauf $a b$, die Bedingungen einer Manipulation situativ und technisch zu erschweren, wodurch sie der sekundären Prävention unterfallen. Die nachfolgende Fokussierung auf den Fußball rechtfertigt sich zum einen mit der erhöhten Aktivität der entsprechenden Verbände infolge publik gewordener Manipulationsfälle, zum anderen mit dessen allgemeiner Popularität, die ihm auch für die Rechtsgutskonzeption eine Sonderstellung einräumt.

\section{(1) Schulungs- und Informationsprogramme}

Zur ersten Kategorie zählen beispielsweise die von nationalen und internationalen Spitzenverbänden veranstalteten Seminare, in denen den aktiv am Profifußball Beteiligten die Bedeutung von Fair Play vermittelt und ihr Beitrag zu einem glaubwürdigen Sport aufgezeigt werden soll. So verschreibt sich etwa das von DFB und DFL aufgelegte Projekt „Spiel kein falsches Spiel“ dem Ziel, frühzeitig und vorbeugend über die von Spielmani-

1029 Näheres unter: www.dfb.de/gemeinsam-gegen-spielmanipulation/ombudsman n/; ausführlich zu dessen Möglichkeiten in der Korruptionsbekämpfung Lammert Korruption, S. $121 \mathrm{ff}$.

1030 Exemplarisch Deutscher Fußballbund (Hrsg.) Spiel kein falsches Spiel, S. 12.

1031 Übersicht der Ebenen der Kriminalprävention bei Meier Kriminologie $\mathbb{} 10$ Rn. 17. 
pulationen ausgehenden Gefahren aufzuklären. ${ }^{1032}$ Dies soll unter anderem in fachkundig geleiteten Präventionsschulungen geschehen. War deren Durchführung für die Nachwuchsleistungszentren der 36 Vereine der Bundesliga und Zweiten Bundesliga bereits seit 2014 verpflichtend, um gerade Jugendliche frühzeitig für das Thema zu sensibilisieren, gilt die Schulungspflicht seit Beginn der Saison 2018/2019 auch für die Lizenzmannschaften der Vereine. Die jährliche Teilnahme an einer Schulung zur Prävention von Match Fixing ist nun gar Voraussetzung für die Erteilung der Lizenz zur Teilnahme am Spielbetrieb. Flankiert werden sollen derartige Präsenzveranstaltungen durch ein eigens für die Spieler entwickeltes ELearning-Tutorial, das sie über die wichtigsten Verhaltensregeln, rechtliche Rahmenbedingungen und mögliche Konsequenzen von Verstößen informiert.

Vergleichbare Ansätze gehen auf internationaler Ebene aus der Kooperation der FIFA bzw. des IOC mit Interpol hervor. ${ }^{1033}$ Ebenfalls durch ELearning-Programme sowie durch eine ausgeteilte DVD sollen den Sportlern positive Vorbilder vorgestellt, Erkennungsanzeichen manipulativer Einwirkungsversuche erläutert und die Vertraulichkeit der Meldesysteme zugesichert werden. Den Verbänden wiederum werden durch erfahrene Ermittler bestimmte Interviewstrategien vermittelt, die bei der internen Verfolgung von Verdachtsfällen eingesetzt werden können. Im Rahmen der von Interpol gegründeten Match Fixing Task Force (IMFTF) kommt es überdies zu einem regelmäßigen Austausch zwischen den Sportverbänden und staatlichen Ermittlungsbehörden über erfolgversprechende Präventionsstrategien. Auf diese Weise sollen die maßgeblichen Akteure ein Bewusstsein für die Bedeutung eines integren Sports und seiner Gefährdung ausbilden und klare Handlungsmöglichkeiten für den Fall wahrgenommener Verdachtsmomente aufgezeigt bekommen.

Derartige Maßnahmen können wertvolle Effekte haben. Gerade die Adressierung von Nachwuchsspielern beugt der gelegentlich ausgemachten Gefahr vor, die Sportler würden das Übel der Manipulation gar nicht erkennen, weil sie es als akzeptiertes Mittel schon zu Beginn ihrer Laufbahn kennengelernt hätten. ${ }^{1034} \mathrm{Da}$ Schulungen und Beratungsangebote

1032 Auch zu den nachfolgend genannten Maßnahmen: www.gemeinsam-gegen-spi elmanipulation.de.

1033 Pressemitteilung von Interpol vom 30.10.2014, www.interpol.int/News-and-Ev ents/News/2014/FIFA-FIFPro-and-INTERPOL-launch-joint-campaign-to-fightmatch-manipulation; hierzu auch Mutschke, in: Höfling/Horst/Nolte (Hrsg.), Fußball, 2014, S. 41 (45).

1034 Vgl. Fiedler DRiZ 2016, 17. 
zudem lediglich einen minimalen Eingriffscharakter aufweisen, sind sie zweifelllos zu begrüßen. Für eine signifikante Stärkung integren Verhaltens im Sport und eines hierauf bezogenen kollektiven Vertrauens reichen sie aber nicht aus. Dies liegt zum einen an konkreten Umsetzungsdefiziten. So ging der im Fußball neu eingeführten Schulungspflicht für den Profibereich eine ernüchternde Bewertung der verbandlichen Präventionsbemühungen durch die Spielergewerkschaft VDV voraus. Diese hatte durch Befragungen von ausgewählten Spielern, Trainern und Managern ein gravierendes Schulungsdefizit ermittelt. ${ }^{1035}$ Die bereits vorhandenen Angebote einer qualitativen Schulung mittels abgestimmter Präventionsunterlagen seien von kaum einem Verein in Anspruch genommen worden, was zumindest auf dieser Ebene eine nach wie vor vorhandene Nachlässigkeit im Umgang mit dem Thema Match Fixing vermuten ließe. An der Umsetzung der nun existierenden Schulungspflicht kritisierte die VDV, dass DFB und DFL mit der Firma Sportradar ausgerechnet ein privates Unternehmen mit deren Ausrichtung beauftragt hätte, das selbst kommerzielle Interessen im Wettgeschäft verfolge und den Spielern keine vertraulichen Schutzräume anbieten könne. ${ }^{1036}$

Zum anderen kann allgemein bezweifelt werden, ob eine durch Schulungen angeregte theoretische Auseinandersetzung mit den ethischen Werten des Sports eine derart nachhaltige diesbezügliche Selbstverpflichtung auslöst, dass manipulativen Versuchungen künftig auch dann entschlossen widerstanden wird, wenn sie sich in einer unvorhergesehenen Lebenssituation konkretisieren. Schließlich bleibt negativ anzumerken, dass sich die Präventionsarbeit der Verbände - aus Gründen der Imagepflege womöglich durchaus in deren Interesse ${ }^{1037}$ - häufig abseits der medialen Berichterstattung vollzieht. Ein öffentliches Vertrauen in die verbandsinterne Integritätsstärkung kann so kaum gefördert werden.

1035 Vgl. Meldung auf der Homepage der VDV vom 16.2.2017, www.spielergewerk schaft.de/de/VDV/Aktuelles/Detail/641/Schulungsdefizit\%20im\%20Profi-berei ch.htm.

1036 Meldung auf der Homepage des VDV, www.spielergewerkschaft.de/de/VDV/A ktuelles/Detail/993/VDV\%20fordert\%20bessere\%20Pr\%C3\%A4ventionsarbeit \%20in\%20der\%20Bund.htm.

1037 So zumindest Feltes, in: Haberfeld/Sheehan (Hrsg.), Match-fixing, 2013, S. 15 (22f.). 
(2) Überwachung des Sportwettenmarkts durch Frühwarnsysteme

Neben solchen Bemühungen, die integres Verhalten im Wettbewerb durch einen aufklärerischen und erzieherischen Ansatz abzusichern versuchen, haben die Verbände auch Maßnahmen getroffen, die speziell wettbasiertes Match Fixing adressieren und darauf ausgerichtet sind, dessen Umsetzung zu erschweren und Anreize für die Sportakteure zu minimieren. Das Kernstück bildet dabei eine möglichst flächendeckende Überwachung des infolge moderner Kommunikationstechnologien expandierenden Sportwettenmarkts. Die Sensibilität der dynamischen Entwicklung der Wettquoten, die den Wettanbietern letztendlich für jedes denkbare Resultat eine Gewinnmarge garantieren soll, wird zur Aufdeckung wettbasierter Spielmanipulation genutzt. Dies geschieht in Kooperation mit privaten Dienstleistern, die im Auftrag der Sportverbände pausenlos und in Echtzeit die weltweiten Sportwettangebote und -quoten der bekannten Anbieter analysieren. Die dabei eingesetzte Software beruht auf einer gigantischen Datenbasis und soll über abgestimmte Algorithmen sowohl bei sog. Pre-Match-Wetten als auch bei Live-Wetten Unregelmäßigkeiten in Form von auffälligen Quotenverschiebungen und verdächtigen Wettmustern aufspüren. ${ }^{1038}$ Sinkt etwa die angebotene Quote für einen Sieg des Außenseiters augenblicklich rapide $a b$, deutet dies auf einen großvolumigen Einsatz auf ein solches Ergebnis hin. Dies kann ein Indiz für eine vorbereitete Manipulation darstellen. Der automatisch ausgelöste Alarm wird sodann in einem mehrstufigen Verfahren überprüft. ${ }^{1039}$ Zunächst suchen einzelne Mitarbeiter des Unternehmens nach rein technischen Erklärungen für den Quotensprung. Erscheinen solche nicht plausibel, wird der Fall intern in einer erweiterten Expertenrunde diskutiert, die Informationen über die Rahmenbedingungen des Spiels einzuholen versucht und im Falle eines bereits ausgetragenen Wettbewerbs verfügbares Videomaterial vom Spielverhalten der Akteure sichtet. Sofern sich der Manipulationsverdacht nicht ausräumen lässt, informiert das Unternehmen den entsprechenden Sportverband, der genauere Untersuchungen rund um den Wettbewerb einleiten und im Falle eines noch nicht ausgetragenen Wettbewerbs eine Absage in Erwägung ziehen kann.

1038 Zenglein, in: Kainz/Scherrer/Werner (Hrsg.), Sportfinanzierung, 2012, S. 171 (173 ff.) mit anschaulichen Beispielen zur Funktionsweise der Überwachung bei sog. Over-Under-Wetten.

1039 Hierzu Forrest/McHale Journal of Management Mathematics 2019, 1 (15); Lammert Korruption, S. 115. 
In der Hoffnung, mit ihrer Hilfe wettbezogenes Match Fixing effektiv aufdecken und somit auch präventiv eindämmen zu können, wird auf derartige Warnsysteme mittlerweile in nahezu allen großen Profiligen und Sportarten zurückgegriffen. ${ }^{1040}$ Einzelne Erfolgsmeldungen haben den Verwendungsoptimismus dabei offenbar gestärkt. So wurde der FIFA durch ihr Frühwarnsystem „Early-Warning-System (EWS)“ ein auffälliges Wettverhalten in Bezug auf die zwei bereits erwähnten "Geisterspiele“ zwischen dem lettischen und bolivianischen bzw. dem bulgarischen und estnischen Nationalteam angezeigt. ${ }^{1041}$ Am Ende der daraufhin eingeleiteten Untersuchung wurden die bosnischen Schiedsrichter von der FIFA-Disziplinarkommission wegen passiver Bestechung und unerlaubter Einflussnahme auf den Ausgang eines Spiels mit lebenslangen Sperren hinsichtlich jeglicher Tätigkeit im Zusammenhang mit Fußball belegt. ${ }^{1042}$

Auch beim Nachweis der Manipulation des Hinspiels zur Champions League-Qualifikation zwischen dem FK Pobeda und dem FC Pyunik am 13.7.2004 durch die UEFA lieferte das Monitoring entscheidende Hinweise. Es legte offen, dass der Umsatz bei Wetteinsätzen auf die betreffende Partie den gewöhnlich zu erwartenden Umsatz um das zehnfache überstieg. Es wurden zwischen drei und vier Millionen Euro an Wetteinsätzen getätigt, die weit überwiegend auf eine Niederlage des Favoriten FK Pobeda entfielen. Durch Zeugenaussagen konnte eine vom Clubpräsidenten des FK Pobeda initiierte Spielabsprache schließlich zweifelsfrei nachgewiesen werden. Gegen ihn erging eine durch das internationale Sportschiedsgericht CAS letztlich bestätigte lebenslange Sperre. ${ }^{1043}$ Darüber hinaus wurde der FK Pobeda für acht Jahre von allen UEFA-Vereinswettbewerben ausgeschlossen. Die Fälle belegen eine verfahrensrechtliche Bedeutung der Frühwarnsysteme innerhalb der Sportgerichtsverfahren. Der CAS bekräftigte jüngst auch bei den Bestätigungen des Ausschlusses des albanischen Fußballclubs KS Skenderbeu aus der Champions League sowie der lebenslangen Sperre des ghanaischen Schiedsrichters Joseph Lamptey ${ }^{1044}$ explizit

1040 Der Marktführer Sportradar setzt sein Kontrollsystem FDS nach eigenen Angaben für Dachorganisationen in 21 Sportarten (darunter das IOC, der DFB und die UEFA) ein, s. https://integrity.sportradar.com/anti-match-fixing/monitorin g-and-detection/.

1041 S. oben Teil 2 A. II. 5. a).

1042 Darstellung des Falles bei Ludwig, in: Kainz/Scherrer/Werner (Hrsg.), Sportfinanzierung, 2012, S. 181 (191).

1043 Auch ausführlich zum Sachverhalt CAS vom 15.4.2010, CAS 2009/A/1920, SpuRt 2010, $152 \mathrm{ff}$.

1044 Zum Sachverhalt s. oben Fn. 132. 
den Wert der Berichte des Frühwarnsystems zur Erreichung des notwendigen Beweismaßes zur Annahme von Spielmanipulationen. ${ }^{1045}$

Dennoch dürfen solche Einzelfälle nicht zu einer Überschätzung der Leistungsfähigkeit der Frühwarnsysteme führen. Zwar bescheinigte eine wissenschaftliche Evaluation etwa dem vom Marktführer Sportradar eingesetzten Fraud-Detection-System (FDS) auch dank der beschriebenen gewissenhaften Prüfung von Alarmmeldungen eine gute Spezifität, dank derer die Anzahl sog. falscher Positiver, also solcher Wettbewerbe, die zu Unrecht als verdächtig gemeldet wurden, erfreulich gering ausfällt. ${ }^{1046}$ Bezüglich der Sensitivität des Systems, also der Frage, wie viele aller tatsächlich manipulierten Wettbewerbe mit Wettbezug überhaupt identifiziert werden konnten, traf die Studie hingegen keine Aussage. Im Zeitraum zwischen Mai 2009 und November 2014 stufte das FDS insgesamt 1.625 weltweit ausgetragene Fußballspiele als höchst verdächtig ein, was einem Anteil von unter $1 \%$ aller von FDS überwachten Spiele entspricht. ${ }^{1047}$ Dass diesem Hellfeld ein beträchtliches Dunkelfeld manipulierter Spiele gegenüberstehen könnte, legen verschiedene augenfällige Schwachstellen der Frühwarnsysteme nahe.

So können Wettbetrüger das Auslösen eines Alarms umgehen, indem sie ihren Einsatz auf ein manipuliertes Spiel streuen. Tätigen sie zeitlich gestreckt viele kleine Einsätze bei unterschiedlichen Annahmestellen, kommt es zu keiner Quotenverschiebung, die den festgelegten Korridor des Regulären verlässt und das Spiel als potenziell gefährdet ausweist. Außerdem sind mit den auf das Verhältnis von Einsätzen und Wettquoten ausgerichteten Algorithmen sog. Manipulationen mit dem Markt schwer aufzudecken, bei dem der Wettende das schwächere Team im Einklang mit der allgemeinen Erwartung für eine sichere Niederlage besticht und hohe Einsätze auf den Favoriten platziert. ${ }^{1048}$ Dass solche hohen Einsätze nicht mehr zwangsläufig zur Meldung einer Auffälligkeit führen, hängt auch mit der immensen Zunahme der Liquidität des globalisierten Wettmarkts zusammen. ${ }^{1049}$

1045 CAS vom 21.12.2016, CAS 2016/A/4650 (Skenderbeu vs. UEFA); CAS 2017/A/ 5173 (Lamptey v. FIFA).

1046 Forrest/McHale Evaluation of Sportradar's Fraud Detection System, S. 4.

1047 Van Rompuy Spielmanipulationen, S. 25.

$1048 \mathrm{Zu}$ dieser Manipulationsform Hill Sichere Siege, S. 155 f.; Forrest/McHale/ McAuley International Journal of Sport Finance 2008, 156 (160).

1049 Ausführlich zur Zunahme der Liquidität der Wettmärkte und den damit zusammenhängenden Risiken für die Integrität des Sports s. oben Teil 2 A. III. 1. a). 
Wie bereits dargestellt hat das Internet auch grenzüberschreitend zugängliche Schwarzmärkte eröffnet, auf denen Sportwetten von nicht zugelassenen Anbietern ohne behördliche Erlaubnis angeboten werden. ${ }^{1050}$ An einer Zusammenarbeit mit Verbänden oder den Entwicklern von Kontrollsoftware sind sie naturbedingt nicht interessiert. Ihre Angebote und die sich daraufhin zutragenden Transaktionen sind für die Frühwarnsysteme schlicht nicht einsehbar. ${ }^{1051}$ Gleichzeitig werden Initiatoren von Spielmanipulationen aufgrund der vorangeschrittenen Regulierung und Überwachung des legalen Wettmarkts ihre Einsätze gerade bei illegalen Anbietern platzieren, um ihre Gewinne zu generieren. Auch die Vorgehensweise der 2011 im Zuge des zweiten „Fußball-Wettskandals“ verurteilten Ante Sapina und Mariko Curtak, denen es durch die Vermittlung zweier asiatischer Mitarbeiter einer englischen Wettfirma jahrelang gelang, von den Warnsystemen unbemerkt Einsätze in zweistelliger Millionenhöhe auf dem asiatischen Wettmarkt unterzubringen, lässt vermuten, dass die Lücken im System längst aufgedeckt und ausgenutzt werden. ${ }^{1052}$ Dies verleitet staatliche Ermittler aber auch Verbandsfunktionäre zunehmend dazu, die eingesetzten Frühwarnsysteme als ein weitgehend zahnloses Instrument zu bezeichnen, von dem im Kampf gegen Match Fixing kaum eine präventive Wirkung zu erwarten sei. ${ }^{1053}$

\section{(3) Wettverbote für Sportakteure}

$\mathrm{Zu}$ den verbandsinternen Vorkehrungsmaßnahmen gegen wettbasierte Manipulationen können auch die verbandsrechtlich verankerten Wettverbote gezählt werden. In etlichen Sportarten ist es Spielern, Trainern, Schiedsrichtern und Funktionsträgern von Vereinen verbandsrechtlich untersagt, Wetten auf den Ausgang oder den Verlauf solcher Wettbewerbe abzuschließen, an denen sie unmittelbar oder mittelbar beteiligt sind. ${ }^{1054}$

1050 S. oben unter Teil 2 A. III. 1. a); außerdem Reeckmann ZfWG 2015, 106 (108).

1051 Zenglein, in: Kainz/Scherrer/Werner (Hrsg.), Sportfinanzierung, 2012, S. 171 (177 f.).

1052 Vgl. ICSS/Sorbonne (Hrsg.) Part III, S. 368.

1053 S. die Einschätzungen der zitierten Experten bei Buschmann Wo Fifa und Uefa beim Wettbetrug versagt haben, Spiegel Online vom 4.2.2013, www.spiegel. $\mathrm{de} /$ sport/fussball/wettskandal-fruehwarnsysteme-von-fifa-und-uefa-ohne-chance -a-881417.html; krit. auch Giebel Causa Sport 2011, 254.

1054 Exemplarisch $₫ 1$ Nr. 2, 3 Rechts- und Verfahrensordnung des DFB, hierzu Hilpert Fußballstrafrecht, S. 44 f.; ferner $\$ 14 a$ Nr. 8 Rechtsordnung des Deutschen 
Ferner dürfen sie sich auf Sportwetten beziehendes Sonderwissen nicht an Dritte weitergeben. ${ }^{1055}$ Hierdurch soll ein von externen finanziellen Anreizen unbeeinflusstes Verhalten gemäß dem sportinternen Wertekodex gewährleistet und ein starkes individuelles Motiv für Match Fixing von vornherein ausgeschaltet werden. ${ }^{1056} \mathrm{Um}$ eine allzu leichte Umgehung dieser Vorgabe zu verhindern, ist auch die Anleitung oder Unterstützung der Wettsetzung eines Dritten, insbesondere eines Angehörigen, verboten. ${ }^{1057}$ Dies wird sich angesichts einer möglichen mehrfachen Vermittlung aber kaum aufdecken, geschweige denn verhindern lassen. Außerdem zeigen die Fälle des kollusiven Zusammenwirkens mit externen Vorteilsgebern, dass es keiner eigenen Wettsetzung des Sportakteurs bedarf, um von wettbasierten Manipulationen finanziell zu profitieren. Die Wettverbote dürften die Anreize einer Manipulation für tatgeneigte Sportler demnach kaum entscheidend einschränken.

(4) Schieds-, kampf- und wertungsrichterbezogene Maßnahmen

In Ansehung des großen Einflusses von Schieds-, Kampf- bzw. Wertungsrichtern auf Verlauf und Ergebnis eines Wettkampfes und als Reaktion auf von ihnen begangene Manipulationen wurde sich in verschiedenen Sportarten zum einen um einen erweiterten Schutz dieser Akteure vor externen Bestechungsversuchen, zum anderen um eine technische Erschwerung solcher Wettbewerbsmanipulationen bemüht. Als unmittelbare Konsequenz der verbandsinternen Aufarbeitung des „Falls Hoyzer“ 1058 beschloss der DFB unter anderem, die Vergütung von Schiedsrichtern im Spitzenbereich zu erhöhen, um die Schiedsrichter finanziell unabhängiger zu stellen und die Verlockungen eines korruptiv angebotenen Vorteils herabzusetzen. ${ }^{1059}$ Außerdem wurde die Betreuung von neu berufenen Schiedsrichtern intensiviert und das Verfahren der Ansetzung eines Schiedsrichters für ein Liga-

Handballbundes; $₫ 19$ Nr. 5 SR-Ordnung des Deutschen Basketballbundes; $\mathbb{7}$ Wettspielordnung des Deutschen Tennisbundes.

1055 Exemplarisch $₫ 1$ Nr. 2, 3 Rechts- und Verfahrensordnung des DFB; Tennis Anti-Corruption Program, Section D. 1. i).

1056 Lammert Korruption, S. $86 \mathrm{f}$.

1057 Exemplarisch $₫ 1$ Nr. 2, 3 Rechts- und Verfahrensordnung des DFB.

1058 Ausführlich zum Verlauf der Aufarbeitung und den hierbei ergriffenen Maßnahmen Sengle, in: Württembergischer Fußballverband (Hrsg.), Manipulation, 2008, S. 9 (22 ff.).

1059 Duyar Sportbeugung, S. 143. 
spiel dahingehend geändert, dass sie der Öffentlichkeit aber auch dem Schiedsrichter selbst erst zwei statt zuvor zehn Tage vor dem Spiel bekannt gegeben wird. ${ }^{1060}$ Die bis dahin bestehende Ungewissheit soll eine langfristige Planung von Manipulationen und eine den Kontrollsystemen entgehende kontinuierliche Platzierung kleinerer Wetteinsätze erschweren. ${ }^{1061}$

Auch die in vielen Sportarten mittlerweile implementierte unmittelbare Überprüfung neuralgischer Tatsachenentscheidungen eines Schiedsrichters durch videogestützte Zeitlupen der betreffenden Spielsituation leistet einen präventiven Beitrag. Wenngleich sich die Regeln der situativen Heranziehung eines sog. Videobeweises je nach Sportart im Einzelnen unterscheiden, ${ }^{1062}$ zwingt das Bildmaterial sportartübergreifend doch zumindest zur umgehenden Zurücknahme eklatanter Fehlentscheidungen, was den Einfluss des Feldschiedsrichters begrenzt und die Wahrscheinlichkeit einer erfolgreichen Manipulation im Sinne der bewussten Bevorzugung eines Wettbewerbsteilnehmers herabsetzt. ${ }^{1063}$ Gänzlich unmöglich werden manipulative Einflussnahmen durch Feldschiedsrichter jedoch schon aufgrund der im Sinne eines ungestörten Spielflusses zumeist nur begrenzt nutzbaren Überprüfungsmöglichkeiten nicht. Außerdem bleibt der Einsatz derartiger technischer Unterstützungssysteme aus Kostengründen in vielen Sportarten auf die oberste Wettkampfkategorie beschränkt.

In Sportarten, in denen Wertungsrichter unmittelbar per Votum über Qualität der erbachten Leistung und Platzierungen entscheiden, zielen durch Manipulationsfälle angestoßene Reformen des Wertungssystems ebenfalls auf eine Reduzierung ihrer Einflussmöglichkeiten. Als Reaktion auf den Manipulationsskandal bei den Olympischen Spielen $2002^{1064}$ werden beim Eiskunstlauf nun per Zufallsprinzip sieben aus den insgesamt

1060 Duyar Sportbeugung, S. 131; Weinbuch Sportwettmanipulationen, S. 97.

1061 Forrest/McHale/McAuley International Journal of Sport Finance 2008, 156 (165).

1062 In vielen europäischen Fußballligen und -wettbewerben werden Schiedsrichterentscheidungen, die die Gültigkeit eines Tores, die Zuweisung eines Strafstoßes oder die Vergabe eines Platzverweises betreffen, seit 2018 durch den sog. Video Assistant Referee (VAR) kontrolliert. Im Tennis und in ähnlicher Weise auch beim Kricket überprüft und veranschaulicht das von den Spielern situativ angerufene sog. Hawk-Eye, ob ein geschlagener Ball noch innerhalb des Feldes aufkam. Im Basketball kann ein Instant Replay zur Feststellung der Rechtzeitigkeit eines Wurfs, dessen Korbentfernung sowie zur Ahndung unsportlicher Fouls und bei Zuweisung eines Einwurfs genutzt werden.

1063 Vgl. Duyar Sportbeugung, S. 138 ff.; Momsen/Vaudlet, in: Emrich/Pierdzioch/ Pitsch (Hrsg.), Falsches Spiel, 2015, S. 219 (240 f.).

1064 Dazu s. oben Teil 2 A. II. 5. b). 
zwölf anonym abgegebenen Bewertungen ausgesucht, von denen noch einmal die jeweils beste und schlechteste Bewertung gestrichen wird. ${ }^{1065}$ Im Amateur-Weltboxverband AIBA kommt seit den Vorfällen bei den Olympischen Spielen $1988^{1066}$ eine Computersoftware zum Einsatz, die sämtliche Aktivitäten der fünf um den Ring platzierten Kampfrichter bezüglich der obligatorischen Zählung von Treffern vermerkt und auffällige Abweichungen unverzüglich ausweist. ${ }^{1067}$

Das Ausbleiben weiterer bekannt gewordener Spielmanipulationen durch deutsche Fußball-Schiedsrichter oder Wertungsrichter im Eiskunstlauf bzw. Boxen mag für den Erfolg derartiger Maßnahmen sprechen. Es darf aber nicht darüber hinwegtäuschen, dass der Schutz vor Manipulationen durch Schieds- oder Wertungsrichter in unteren Spielklassen nicht annähernd vergleichbar gewährleistet werden kann. Im Hinblick auf die Integrität des Sports im Ganzen können einem gestärkten Sportrichterwesen ohnehin zwar notwendige, aber allenfalls punktuelle positive Effekte zugeschrieben werden.

\section{(5) Kritik des widersprüchlichen Verhaltens}

Neben den konkreten Kritikpunkten an den einzelnen Maßnahmen sind die Präventionskonzepte der Verbände auch insgesamt nicht frei von Widersprüchen. Angesichts der Rolle des Sportwettenmarkts als wichtiger Bedingungsfaktor für wettbezogenes Match Fixing überraschen etwa die engen kommerziellen Verbindungen der Sportverbände und -vereine zur Wettindustrie. Derzeit unterhalten 14 der 18 Vereine der Fußball-Bundesliga wirtschaftliche Partnerschaften mit privaten Wettanbietern, die ca. 50 Millionen Euro jährlich in Sportsponsoring investieren. ${ }^{1068}$ Der DFB selbst kooperiert mit dem Anbieter Bwin und sichert ihm vielfältige Werbeflächen in den vom DFB organisierten Spielen der 3. Liga, der Frauen-Bun-

1065 Eingehend zum neuen Wertungssystem Waldeck, in: Krähe/Vieweg (Hrsg.), Schiedsrichter, 2008, S. $15 \mathrm{ff}$.

1066 Dazu s. oben Teil 2 A. II. 5. b).

1067 Hierzu ausführlich Koch/Maennig in: Der Bürger im Staat 1/2006, S. 50 (53).

1068 Krit. Haberl Wetten dass...?, Süddeutsche Zeitung Magazin vom 14.3.2019, szmagazin.sueddeutsche.de/ sport/sportwetten-fussball-werbung-tipico-bwin-869 74? reduced=true; Schrum Geschäfte im halblegalen Bereich, Deutschlandfunk vom 26.11.2019, www.deutschlandfunkkultur.de/sportwetten-geschaefte-im-ha lblegalen-bereich.976.de.html?dram:article_id=464349. 
desliga sowie des DFB-Pokals zu. ${ }^{1069}$ In Österreich tritt der Anbieter Tipico gar als namensgebender Sponsor der Ersten Liga auf. Schon grundsätzlich führen derartige Partnerschaften zur Frage nach auftretenden Interessenskonflikten, wenn der Anbieter, der als Sponsor am Erfolg eines Teams interessiert ist, Wetten auf dessen Spiele anbietet. ${ }^{1070}$ Darüber hinaus treten prominente Spieler in Werbespots von Wettanbietern auf, die in hoher Frequenz die Live-Übertragung von Bundesligaspielen einrahmen und dem Zuschauer unter Adressierung von Identifikationswünschen suggerieren, durch die Platzierung von Wetten selbst Teil des unterstützten Teams werden zu können. ${ }^{1071}$

Die den Wettanbietern hierdurch eingeräumte Präsenz kann zwar positiv im Sinne einer Kanalisierung des Wettverhaltens der Bevölkerung in legale und überwachte Bahnen wirken. Der massive Aufforderungscharakter erhöht aber auch das spielbezogene Wettaufkommen, dessen Resultat einer gesteigerten Liquidität des Wettmarkts einen bedeutenden Anreiz für Manipulatoren darstellt. Gerade unbedeutende Freundschaftsspiele oder kleinere Turniere, die aufgrund geringer sportlicher Relevanz bzw. eines niedrigeren Verdienstes der Teilnehmer für Manipulationen anfällig sind, werden durch ihre geringe Sichtbarkeit und ein infolgedessen moderates Wettaufkommen demnach auch geschützt. Vor diesem Hintergrund erstaunt die Entscheidung von Tennisverbänden und Turnierveranstaltern umso mehr, die Übertragungsrechte für kleinere Turniere teilweise gerade an Wettanbieter zu verkaufen, die die Spiele online auf ihrer Homepage nebst den passgenauen Wettangeboten ausstrahlen. ${ }^{1072}$

\section{(6) Zwischenergebnis}

Indem sie die verschiedenen Akteure auf unterschiedliche Weise anzusprechen und bekannte Risikofaktoren eines korruptiven Verhaltens einzuschränken versuchen, dokumentieren die mit unterschiedlichen Kooperationspartnern entwickelten Präventionsmaßnahmen die ernsthaften An-

1069 S. Meldung auf der Homepage des DFB vom 20.1.2019, www.dfb.de/verbandss truktur/partner-des-dfb/bwin/.

1070 S. ICSS/Sorbonne (Hrsg.) Part II, S. 12 Fn. 22.

1071 S. etwa die mit martialischer Musik unterlegten Aufforderungen in einem mit populären Nationalspielern des FC Bayern München besetzten Werbespot des Wettanbieters Tipico: „Du kannst Zuschauer sein oder Zeuge, im Publikum sitzen oder mit uns in die Schlacht ziehen“.

1072 S. ICSS/Sorbonne (Hrsg.) Part II, S. 12. 
strengungen der Sportverbände, Angriffen auf die Integrität des Sports vorzubeugen. Mit der Entwicklung von Schulungsprogrammen, der Benennung von Ombudspersonen bzw. Integrity Officer, der Implementierung vertraulicher Meldesysteme zur Ermutigung und zum Schutz von Hinweisgebern, der Einführung strengerer Vorgaben bei der Ansetzung von Schiedsrichtern sowie einem intensivierten Informationsaustausch mit Wettanbietern und Strafverfolgungsbehörden wurde zumindest durch die nationalen und internationalen Fußballverbände der auf der MINEPS VKonferenz der Sportminister an den organisierten Sport gerichtete Forderungskatalog ${ }^{1073}$ nahezu vollständig umgesetzt. Im Sinne des beschriebenen ökonomischen Erklärungsansatzes zu Match Fixing zielen die Maßnahmen dabei erkennbar darauf ab, durch eine akteurspezifische Verringerung der Erfolgswahrscheinlichkeiten einer Manipulation deren erwarteten Nutzen zu senken und durch verbesserte Aufdeckungsmöglichkeiten und die Ausbildung einer robusten moralischen Haltung die Kosten zu erhöhen.

Aufgrund der jeweils festgestellten Defizite kann diesen Maßnahmen allein allerdings nicht zugetraut werden, authentische Wettbewerbe im Sinne des Sportethos hinreichend zu gewährleisten. Ihr allgemein-erzieherischer Ansatz wird auf die Willensbildung situativ tatgeneigter Sportakteure wohl ebenso wenig hemmenden Einfluss haben wie die problemlos überwindbaren technischen Schutzvorkehrungen auf die Manipulationsabsicht externer Vorteilsgeber und ihre Umsetzung. Der aus theoretischen Modellen und empirischen Erkenntnissen hervorgehende Risikofaktor eines geringen und unregelmäßigen Verdienstes bestimmter Sportler könnte durch eine verbandsrechtliche Sanktionierung von Gehältern zurückhaltenden Vereinen oder eine gleichmäßigere Verteilung von Preisgeldern konsequenter abgeschwächt werden. Durch umfangreiche kommerzielle Partnerschaften mit privaten Sportwettenanbietern werden hingegen manipulationsbezogene Risiken selbst erhöht, die man mittels der Maßnahmen eigentlich präventiv einzudämmen versucht. ${ }^{1074}$

Ein weiterer Widerspruch besteht zwischen einer durch solche präventiven Initiativen den Sportlern gegenüber propagierten Integritätskultur und dem regelmäßig publik werdenden Fehlverhalten exponierter Spitzen-

1073 Vgl. Aufruf 3.41 der Berliner Erklärung der 5. UNESCO-Weltkonferenz der Sportminister (MINEPS V).

1074 Daher etwa auch die Empfehlung von Lewis/Wilkinson/Henzelin Integrity in Tennis, S. 68, Wettanbieter als Sponsoren aus dem Tennis gänzlich zu verbannen. 
funktionäre auf der Führungsebene der Verbände und Vereine. ${ }^{1075}$ Bereits im Rahmen der Bedingungsfaktoren von Match Fixing wurde der indirekte Zusammenhang von Verbandskorruption und direkter Wettkampfkorruption aufgezeigt. Die Annahme teurer Uhren durch Verbandspräsidenten oder Vereinsvorsitzende ${ }^{1076}$ oder das Angebot von Gefälligkeiten, um auf das Vergabeverfahren großer Sportveranstaltungen einzuwirken, tragen jedenfalls nicht dazu bei, die Ernsthaftigkeit des von den Verbänden ausgegebenen Bekenntnisses zu den eigenen ethischen Standards vorbildhaft zu unterstreichen.

\section{bb) Ordnungs- und Strafgewalt der Verbände}

Die Präventionsarbeit stellt aber nur eine Säule der sportethischen Selbstregulierung der Verbände dar. Daneben ist die eigenständige Verfolgung und Sanktionierung von konkreten Fällen normwidrigen Verhaltens durch die Verbände von großer Bedeutung. Die Festlegung von Verhaltenspflichten und ihre Durchsetzung mittels einer eigenen Ordnungs- und Strafgewalt folgt dabei grundsätzlich aus der durch $\$ 25$ BGB und Art. 9 Abs. 1 GG garantierten Verbandsautonomie. ${ }^{1077}$ Hiervon Gebrauch machend pflegen die einzelnen Sportverbände ein jeweils ausdifferenziertes Verbandsrecht, das zum einen verfolgbare Tatbestände enthält, zum anderen bestimmte verbandsinterne Organe mit der Befugnis ausstattet, tatbestandsmäßiges Verhalten mit einer der hierfür vorgesehenen Sanktionen zu ahnden.

Trotz der Verbandsautonomie und der fehlenden unmittelbaren Bindung an die Grundrechte sind die Verbände bei der Ausgestaltung ihrer Regelwerke aber nicht gänzlich frei. Dies folgt auch aus der nicht unumstrittenen Rechtsnatur der Verbandsstrafe, die trotz ihres zivilrechtlichen Ursprungs mittlerweile überwiegend nicht mehr als Vertragsstrafe, sondern als ein eigenständiges, verbandsrechtliches Institut aufgefasst wird,

1075 Krit. hierzu Schenk, in: Kainz/Scherrer/Werner (Hrsg.), Sportfinanzierung, 2012, S. 139 (144 f.); Weinbuch Sportwettmanipulationen, S. 88.

1076 Dies sorgte in den vergangenen Jahren etwa zum Rücktritt des DFB-Präsidenten Reinhard Grindel bzw. zum Erlass eines Strafbefehls wegen einer Steuerstraftat gegen den Vorstandsvorsitzenden der FC Bayern München AG KarlHeinz Rummenigge.

1077 Grundlegend BGHZ 21, 370 (373); auf Sportverbände gewendet s. Sengle FS Röhricht, 2005, S. 1205 (1206f.); Nolte, in: Württembergischer Fußballverband (Hrsg.), Manipulation, 2008, S. 61 (66). 
das auch zu präventiven Zwecken intensive Eingriffe in die Freiheitsrechte der Mitglieder gewährt und somit eine Nähe zu staatlichen Strafmaßnahmen aufweist. ${ }^{1078}$ Verstärkt wird dieser Eindruck durch die pyramidale Struktur des Sportverbandswesens, die die Sportler in ein Abhängigkeitsverhältnis setzt und eine der staatlichen Machtposition nicht unähnliche Monopolstellung der jeweils übergeordneten Verbände begründet. Die Etablierung einer solchen Strafgewalt auf zivilrechtlicher Grundlage erscheint aber nur bei gleichzeitiger Berücksichtigung gewisser grundrechtlicher und strafrechtlicher Prinzipien hinnehmbar, die die privatautonome Gestaltungsfreiheit der Verbände beschränken. ${ }^{1079}$ Neben der Adaption bestimmter strafverfahrensrechtlicher Garantien beanspruchen etwa die aus Art. 103 Abs. 2 GG abgeleiteten Gesetzlichkeitsprinzip und Bestimmtheitsgrundsatz auch im Vereinsrecht Geltung. ${ }^{1080}$ Sanktionstatbestände samt Rechtsfolgen müssen jedem Sportler klar vor Augen führen, ob und wie ein Fehlverhalten geahndet wird. Die letztlich verhängte Sanktion hat ferner verhältnismäßig zu sein. ${ }^{1081}$

\section{(1) Rechtsgrundlagen und Verfahren}

Die im Verbandsrecht verwendete Regelungstechnik verlangt häufig eine Zusammenschau der einzelnen Regelwerke und weicht daher von derjenigen einer Vorschrift des staatlichen Kernstrafrechts ab, die das tatbestandliche Verhalten und die Rechtsfolge gleichermaßen enthält. Zwar gehören sowohl die Verbotsvorschriften als auch die angedrohten Sanktionen zu den wesentlichen Grundsätzen des Verbandes und müssen daher zwingend in der Satzung geregelt sein. ${ }^{1082}$ Diesem Erfordernis kommen die Verbände aber oftmals durch Generalklauseln nach, in denen sie zwar enumerativ die Strafarten aufzählen, ihre Strafgewalt aber häufig mit dem unbestimmten Rechtsbegriff eines unsportlichen, unethischen oder verbandsschädigenden Verhaltens begründen, dessen Konkretisierung dann in den erlassenen Ethik-Kodizes, Rechts-, Verfahrens-, Disziplinar- oder Spielord-

1078 Vgl. Rössner FS Meyer-Gossner, 2001, S. 741 (742); Weinbuch Sportwettmanipulationen, S. 48.

1079 Eingehend Rössner FS Meyer-Gossner, 2001, S. 741 (742 f.); PHB-SportR/Summerer 3. Kap. Rn. 465 ff.; Hilpert Fußballstrafrecht S. 130 f.

1080 BGHZ 96, 249 f.; U. Steiner FS Lutter, 1994, S. 213 (218); Weinbuch Sportwettmanipulationen, S. $48 \mathrm{ff}$.

1081 U. Steiner, FS Lutter, 1994, S. 213 (218).

1082 PHB-SportR/Summerer 3. Kap. Rn. 331. 
nungen erfolgt. ${ }^{1083}$ Es handelt sich insofern um Blankett-Vorschriften, die angesichts des erwähnten Bestimmtheitsgrundsatzes nicht frei von Kritik sind. ${ }^{1084}$ In den in Bezug genommenen Statuten finden sich neben den bereits erwähnten Wettverboten dann auch eigenständige Verbote von Spielmanipulationen, die als zweiter konkretisierter Sonderfall eines unsportlichen Verhaltens neben dem Doping explizit hervorgehoben werden.

Gemäß \6a S. 1 der Rechts- und Verfahrensordnung des DFB (RuVODFB $)^{1085}$ begeht eine Spielmanipulation, wer es, insbesondere als Spieler, Schiedsrichter, Trainer oder Funktionsträger, unternimmt, auf den Verlauf und/oder das Ergebnis eines Fußballspiels und/oder den sportlichen Wettbewerb durch wissentlich falsche Entscheidungen oder andere unbefugte Beeinflussung einzuwirken in der Absicht, sich oder einem anderen einen Vorteil zu verschaffen. Dies gilt nach S. 2 nicht für Spieler, die beim Spiel oder im Zusammenhang mit diesem durch Verletzung einer Fußballregel ausschließlich einen spielbezogenen sportlichen Vorteil anstreben. Gemäß den strafrechtlichen Unternehmensdelikten (vgl. $\$ 11$ Abs. 1 Nr. 6 StGB) führt die Beschreibung der Tathandlung mit „unternehmen“ zu einem frühen Vollendungszeitpunkt des Tatbestandes. ${ }^{1086}$ Erfasst werden sowohl die tatsächliche Einwirkung als auch deren Versuch und verschiedene Formen der zielgerichteten Vorbereitung etwa durch Eingehen einer diesbezüglichen Abrede. Satz 2 dient dabei der Klarstellung, dass etwa eine „Schwalbe" im Spiel keine Spielmanipulation im Sinne der Vorschrift ist. Neben dieser Legaldefinition der Spielmanipulation ermöglicht es das in $\$ 1 \mathrm{Nr} .1$ RuVO-DFB abgelegte Bekenntnis zu den Grundsätzen der Integrität, Loyalität und Fairness, manipulationsnahe, die Voraussetzungen des $\$ 6 \mathrm{a} \mathrm{Ru}-$ VO-DFB aber nicht erfüllende Sachverhalte im Einzelfall mithilfe des Auffangtatbestandes des $₫ 1 \mathrm{Nr} .4$ RuVO-DFB als unsportliches Verhalten zu ahnden. Auf kontinentaler und globaler Ebene werden die Match Fixing erfassenden Verbandsregelungen im Fußball durch Art. 2 Abs. 1 e) der UEFA Statuten bzw. Art. 69 des FIFA-Disziplinarreglements ergänzt, wobei

1083 So etwa in $₫ 44$ Nr. 1 DFB-Satzung; $\$ 6$ Satzung des Deutschen Basketballbundes; $\mathbb{5} 5$ Satzung des Deutschen Handballbundes; $\mathbb{1 1}$ Satzung des Deutschen Hockeybundes; $\$ 7$ Ziff. 11 Satzung des BDR.

1084 PHB-SportR/Summerer 3. Kap. Rn. 468 f.

$1085 \mathrm{Zu}$ dessen Entstehung als Reaktion des DFB auf den Wettskandal um Robert Hoyzer s. Sengle, in: Württembergischer Fußballverband (Hrsg.), Manipulation, 2008, S. 9 (24); normanalytisch ausführlich Hilpert Fußballstrafrecht, S. 155 ff.; Lammert Korruption, S. $86 \mathrm{ff}$.

1086 Zur Vorverlagerung der Strafbarkeit bei Unternehmensdelikten MüKo-StGB/ Radtke $₫ 11$ Rn. $133 \mathrm{f}$. 
erstere generalklauselartig gefasst und nur letztere explizit auf Spielmanipulationen ausgerichtet ist. ${ }^{1087}$

In Form einer klaren tatbestandlichen Trennung noch deutlicher bringt $\$ 14 \mathrm{a}$ der Rechtsordnung des DHB (RO-DHB) die geschlossene Erfassung von tatsächlicher Manipulation und korruptiven Vorfeldhandlungen zum Ausdruck. Nach Abs. 1 wird sanktioniert, wer den Verlauf oder das Ergebnis eines Spiels und/oder eines sportlichen Wettbewerbs durch unbefugte Einflussnahme, eine vorsätzlich falsche Entscheidung oder eine vorsätzliche Benachteiligung beeinflusst. Abs. 2 verwirklicht hingegen, wer einen Vorteil für sich oder einen Dritten als Gegenleistung dafür fordert, sich versprechen lässt oder dafür annimmt, dass er verspricht, einen anderen im sportlichen Wettbewerb zu bevorzugen und damit einen anderen Teilnehmer zu benachteiligen, wobei es auf das tatsächliche Vorliegen und den Nachweis der Bevorzugung bzw. Benachteiligung nicht ankommt. Die aktive Bestechung ist schließlich in Abs. 3 geregelt.

Ein Vergleich dieser beiden Vorschriften mit $\$ 265$ d StGB weist für die verbandsrechtlichen Tatbestände bezogen auf die hieran gebundenen Sportakteure einen persönlich wie sachlich weiteren Anwendungsbereich aus. Verhaltensweisen, die $\$ 265 \mathrm{~d}$ StGB verwirklichen, lassen sich lückenlos auch unter die verbandsrechtlichen Verbote subsumieren. Letztere erfahren indes keine Einschränkung durch die Voraussetzungen von berufssportlichen Wettbewerben und einer Manipulation zu Gunsten des Wettbewerbsgegners und werden durch Auffangtatbestände für sportwidriges und unfaires Verhalten flankiert. Demnach können etwa auch das Angebot vereinsfremder Siegprämien oder deren entsprechende Forderung durch Spieler als unbefugte Beeinflussung gewertet und als unsportliches Verhalten geahndet werden. Der Unterschied lässt sich am bereits erwähnten Fall der drei Spieler des VFL Osnabrück veranschaulichen, ${ }^{1088}$ die vom Amtsgericht rechtskräftig vom Vorwurf der Manipulation berufssportlicher Wettbewerbe freigesprochen wurden, vom DFB-Sportgericht im Juli 2017 hingegen zu Sperren von bis zu drei Monaten und zusätzlichen Geldstrafen verurteilt wurden. ${ }^{1089}$

Das verbandsinterne Verfahren der Feststellung und Sanktionierung eines Verstoßes gegen die Verbote der Spielmanipulation verläuft trotz ein-

1087 Ausführlich hierzu Lammert Korruption, S. 97 ff.

1088 S. oben Teil 3 C. I. 1. b) aa) (3).

1089 DFB sperrt Osnabrücker Spieler, Spiegel Online vom 10.7.2017, www.spiegel. $\mathrm{de} /$ sport/fussball/dfb-sperrt-spieler-vom-vfl-osnabrueck-wegen-betrugsversuch-a $-1157087 . h t m l$. 
zelner sportartspezifischer Abweichungen, die etwa die unterschiedliche Bezeichnung der sportgerichtlichen Spruchkörper betreffen, ${ }^{1090}$ in seinen Grundzügen vergleichbar und soll am Beispiel des Fußballs skizziert werden. Sobald dem Verband etwa durch Meldungen von Mitwissern oder Hinweise der Frühwarnsysteme entsprechende Verdachtsmomente bekannt werden, leitet der gemäß $\$ 50$ Nr. 1 DFB-Satzung mit der Überwachung der Einhaltung der Satzung und Ordnungen betraute Kontrollausschuss ein förmliches verbandsrechtliches Ermittlungsverfahren ein, in dessen Rahmen er den Sachverhalt aufzuklären versucht. ${ }^{1091}$ Hierzu kann er die Beteiligten befragen oder zu Stellungnahmen auffordern. Je nach Erhärtung des Verdachts kann er das Verfahren einstellen oder Anklage beim Sportgericht als dem erstinstanzlich zuständigen Rechtsorgan des DFB erheben, $\mathbb{} 13 \mathrm{Nr} .1$ a) RuVO-DFB. ${ }^{1092}$

Bei Anklageerhebung wird das Sportgericht zumeist durch den Einzelrichter im schriftlichen Verfahren entscheiden. Bei komplexeren Gegenständen wird es in erweiterter Besetzung eine mündliche Verhandlung ansetzen, in der Zeugen vernommen und andere Beweismittel eingebracht werden können. Sieht das Sportgericht infolgedessen die in der Anklage erhobenen Vorwürfe als erwiesen an, verurteilt es den Beschuldigten und spricht eine Sanktion aus. Diese muss dem in der Satzung niedergelegten Sanktionskatalog entnommen sein. Im Falle des DFB kommen gemäß $\$ 44$ Nr. 2 DFB-Satzung Verwarnungen, Verweise, Geldbußen, Platzverbote, Verlust der Ämterbekleidung, Sperren auf Dauer oder auf Zeit, Ausschlüsse auf Dauer oder auf Zeit, der Entzug der Trainerzulassung, Punktabzüge und Zwangsabstiege in Betracht. ${ }^{1093}$ Es können auch mehrere Sanktionen nebeneinander verhängt werden. Die ausgesprochene Verbandssanktion stellt dabei nach herrschender Meinung keine Vertragsstrafe i.S.d. $\$ \$ 339 \mathrm{ff}$. BGB dar, sondern ein eigenständiges, verbandsrechtliches Instru-

1090 Diese heißen im Fußball und im Handball Bundesgericht und Sportgericht, im Tennis sind der Disziplinarausschuss und das Sportgericht für Disziplinarangelegenheiten und Regelverstöße zuständig, in der Leichtathletik und im Skisport der verbandseigene Rechtsausschuss.

1091 Hilpert Fußballstrafrecht, S. 56; zur sehr ähnlichen Vorgehensweise beim Fußballweltverband FIFA s. Villiger, in: Kainz/Scherrer/Werner (Hrsg.), Sportfinanzierung, 2012, S. 119 (128 ff.).

1092 Die Stellung des DFB-Kontrollausschusses als eigenständige Anklageinstanz stellt in den verbandsgerichtlichen Verfahren dabei eine Besonderheit dar, vgl. Hilpert SpuRt 1996, 50 ff.

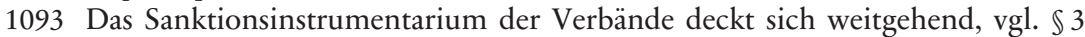
Abs. 1 RO-DHB; $\$ 9$ Disziplinarordnung des Deutschen Tennisbundes; $\mathbb{2} 23$ Rechtsordnung des Deutschen Basketballbundes. 
ment. ${ }^{1094}$ Gerade bei Match Fixing im Fußball lässt sich dabei als Ausprägung der von den Verbänden ausgerufenen Null-Toleranz-Strategie gegen Korruption und Manipulation eine strenge Sanktionspraxis beobachten, die etwa in den bereits erwähnten Fällen um Robert Hoyzer, den FK Pobeda und die bosnischen Schiedsrichter jeweils zu lebenslangen Sperren der Beteiligten durch DFB, UEFA bzw. FIFA führte.

Gegen die Urteile des Sportgerichts können die Betroffenen sowie der Kontrollausschuss unter Beachtung bestimmter Form- und Fristvorgaben das Rechtsmittel der Berufung einlegen, über das das Bundesgericht als das zweite Rechtsorgan des DFB entscheidet, $\mathbb{S} 24 \mathrm{ff}$. RuVO-DFB. Ist der verbandsinterne Rechtsweg ausgeschöpft, kann der Betroffene ein echtes Schiedsgericht i.S.d. $\$ \$ 1025 \mathrm{ff}$. ZPO anrufen. Echte Schiedsgerichte sind von den meisten Verbänden gegründet worden, um verbandsinterne Streitigkeiten schnell, sachkundig, mit einer flexiblen Verfahrensgestaltung und vor allem unter Ausschluss des Rechtsweges zu den ordentlichen Gerichten zu entscheiden. ${ }^{1095}$ So umfasst die durch eine Schiedsklausel der Betroffenen rechtsgeschäftlich eröffnete Zuständigkeit des vom DFB eingerichteten Ständigen Schiedsgerichtes eben auch die Überprüfung der Wirksamkeit einer durch die Verbandsorgane endgültig verhängten Sanktion ( $\$ 1$ Abs. 1 des Anhangs I zu RuVO-DFB). Der am Ende des Schiedsverfahrens ergehende Schiedsspruch ist letztgültig und kann nur unter engen Voraussetzungen durch ein für das konkrete Schiedsgericht zuständiges staatliches Gericht aufgehoben werden. ${ }^{1096}$

Die nationale Schiedsgerichtsbarkeit des organsierten Sports findet ihre Entsprechung auf internationaler Ebene durch den Court of Arbitration for Sport (CAS) mit Sitz in Lausanne, der von den nationalen Verbänden und ihren Mitgliedern als unabhängige richterliche Instanz anerkannt wird (vgl. $\$ 14$ Nr. 1 e] DFB-Satzung) und in Form des sog. Appeals Arbitration Procedure etwa über die Rechtmäßigkeit der Sanktionierung eines Vereins oder Sportlers durch die internationalen Verbände entscheidet (Art. R47 ff. CAS-VerfO). Blickt man auf die überschaubare Judikatur des CAS zu Fällen der Spielmanipulation, so werden die strengen Sanktionen der Verbände häufig bestätigt. Zur Rechtfertigung kennzeichnet der Gerichtshof in seinem Urteil zum FK Pobeda Match Fixing als „einen der verwerflichsten Verstöße gegen die Integrität des Sports“ und verweist auf die Bedeutung der abschreckenden Wirkung derartiger Sanktionen, so dass

1094 BGHZ 21, 373; 87, 337; PHB-SportR/Summerer 3. Kap. Rn. 331.

1095 Momsen KriPoZ 2018, 21 (24).

1096 Momsen KriPoZ 2018, 21 (24); Grunsky FS Röhricht, 2005, S. 1137 (1139). 
selbst der achtjährige Wettbewerbsausschluss des Clubs und die lebenslange Sperre seines Präsidenten angemessen seien. ${ }^{1097}$ Gleichzeitig werden aber bestimmte verfahrensbezogene Probleme beim Nachweis einer wettbezogenen Spielmanipulation konstatiert. ${ }^{1098}$ Der die sanktionierenden Sportverbände treffenden Darlegungs- und Beweislast sei gerade bei mutmaßlichen Manipulationen durch Schiedsrichter schwer beizukommen, da das konkrete Motiv einer Fehlentscheidung kaum zu ermitteln sei. ${ }^{1099}$ Außerdem verweigerten sich durch kriminelle Organisationen bedroht fühlende Zeugen häufig die Aussage, wenn ihnen keine Anonymität zugesichert werden könne, die aber wiederum die Rechte des Beweisgegners tangieren würde.

Auch wenn gerade das Zusammenwirken von internationalen Dachverbänden und CAS bei der Sanktionierung von Sportlern und deren gerichtlicher Überprüfung jüngst in die Kritik geriet, ${ }^{1100}$ zeigt die vorstehende Schilderung des verbandsrechtlichen Verfahrens doch insgesamt den Versuch, prägende Prinzipien des staatlichen Strafprozesses, die im Sinne eines rechtsstaatlichen Verfahrens insbesondere eine Stärkung der Position des Beschuldigten bezwecken, in die verbandsinternen Verfahrensordnungen zu integrieren. ${ }^{1101}$ Dies lässt sich in der satzungsmäßig weitgehend vollzogenen Trennung zwischen Anklageorgan und Gericht, der Eröff-

1097 CAS vom 15.4.2010, CAS 2009/A/1920, SpuRt 2010, 152 ff.

1098 Villiger, in: Kainz/Scherrer/Werner (Hrsg.), Sportfinanzierung, 2012, S. 119 (133 ff.).

1099 Anschaulich wird dies im Verfahren gegen den russischen Schiedsrichter Oleg Oriekhov, dessen lebenslange Sperre der CAS nur durch Rückgriff auf die Verletzung des Gebots, Einwirkungsversuche zwecks Spielmanipulation unverzüglich der UEFA mitzuteilen, halten konnte, CAS vom 18.1.2011, 2010/A/ 2172.

1100 Insbesondere der Fall der wegen Dopings gesperrten Eisschnellläuferin Claudia Pechstein ließ aufgrund der Monopolstellung der Verbände und der Abhängigkeit der Athleten Zweifel an der Wirksamkeit der Schiedsvereinbarung und ausreichenden Garantien in der Verfahrensordnung des CAS zur Wahrung der Rechte der Athleten aufkommen, vgl. LG München SchiedsVZ 2013, 100 ff.; diese nicht vollends überzeugend ausräumend dann BGH NJW 2016, 2266 ff.; die Kritik zusammenfassend PHB-SportR/Pfister/Summerer 3. Kap. Rn. $514 \mathrm{ff.}$

1101 Vgl. Rössner FS Meyer-Gossner, 2001, S. 741 (745 ff.); Sengle FS Röhricht, 2005, S. 1205 (1207 f.); PHB-SportR/Summerer 3. Kap. Rn. 465 ff.; Scherrer/Muresan/ Ludwig Sportrecht, S.363; eine umfassende Übernahme von Prinzipien des staatlichen Prozessrechts wird mit Verweis auf die den Verbänden als Körperschaften des Privatrechts fehlenden hoheitlichen Befugnisse wiederum nicht als adäquat angesehen, s. Villiger, in: Kainz/Scherrer/Werner (Hrsg.), Sportfinanzierung, 2012, S. 119 (130). 
nung eines Rechtsmittelverfahrens, den auch im Vereinsrecht geltenden Maximen der Unschuldsvermutung sowie des Verbots der Doppelbestrafung, der Möglichkeit der Ablehnung eines Mitglieds des Rechtsorgans wegen Befangenheit ( $\$ 19$ RuVO-DFB) sowie den dem Beschuldigten in der mündlichen Verhandlung gewährten Rechten der Frage und des letzten Wortes ( $\$ 54$ Nr. 11, 13 RuVO-DFB) erkennen. Auch Legalitäts- und Opportunitätsprinzip finden ihre Ausprägung. ${ }^{1102}$

Im Falle erwiesenermaßen ergebnisbeeinflussender Spielmanipulationen bleibt schließlich zu beachten, dass sich die sportgerichtlichen Verfahren nicht auf die Sanktionierung der Beteiligten beschränken. Zum Zwecke der Gewährleistung der größtmöglichen Chancengleichheit innerhalb der Wettbewerbe sind unter Umständen Spielwertungen zu annullieren und Spielwiederholungen anzuordnen (vgl. $\$ \$ 17 \mathrm{f}$. RuVO-DFB). Sollten zum Zeitpunkt der Aufdeckung der Manipulation aber bereits weitere Spiele oder gar ganze Runden eines Pokalwettbewerbs ausgetragen worden sein, kann sich die Zurücksetzung des Wettbewerbs als schwierig erweisen. ${ }^{1103}$ Der unter Umständen diffizile Ausgleich zwischen Gerechtigkeit im Einzelfall und der Sicherung des Spielbetriebs drückt sich in den einschränkenden Voraussetzungen der Fristenregelung, der Präklusionswirkung und des strengen Kausalitätsnachweises eines Einspruches gegen die Spielwertung aus. ${ }^{1104}$

\section{(2) Eingriffsintensität verbandsinterner Sanktionen}

Die Fähigkeit der Sportverbände, integritätsverletzende Angriffe auf ihre Wettbewerbe eigenständig zu verfolgen und mit individuellen Sanktionen und wettbewerbssichernden Korrekturen zu beantworten, stützt sich somit auf ein ausdifferenziertes und mehrstufiges System aus Regelwerken und

1102 Beispielhaft in $\$ 73 \mathrm{RVO}$ des Deutschen Leichtathletikverbandes für Bagatellsachen; $₫ 5$ Nr. 5 RuVO-DFB.

1103 Dies betraf das von Robert Hoyzer manipulierte Spiel des Hamburger SV gegen den SC Paderborn in der ersten Runde des DFB-Pokals. Da zum Zeitpunkt der Aufdeckung des Falles bereits zwei weitere Runden gespielt waren, wurde die durch den Hamburger SV beantragte Spielwiederholung erstinstanzlich abgelehnt. Doch erst gegen Zahlung einer Entschädigung in Höhe von 500.000 Euro und der zusätzlichen Überweisung von Einnahmen aus einem Länderspiel zog der Hamburger SV seinen Einspruch schließlich zurück.

1104 Vgl. Sengle, in: Württembergischer Fußballverband (Hrsg.), Manipulation, 2008, S. $9(25)$. 
verbands- bzw. schiedsgerichtlichen Entscheidungen. Auch und gerade die von den $\$ \$ 265 c$, 265d StGB erfassten Verhaltensweisen lassen sich hierüber regulieren. Die über spezifische Tatbestände im Verbandsrecht begründete Ordnungsgewalt ist diesbezüglich keine rein theoretische, sondern äußert sich regelmäßig in der Verhängung langfristiger Spielsperren gegen in Match Fixing involvierte Verbandsmitglieder. Damit dieser Befund jedoch maßgeblich gegen die Erforderlichkeit einer Kriminalisierung angeführt werden kann, müsste es sich bei der verbandsrechtlichen Verfolgung und Sanktionierung von Match Fixing zunächst um einen im Vergleich zur Aktivierung des Strafrechts weniger gravierenden Eingriff in die Rechte der hiervon Betroffenen handeln.

Zweifel hieran könnten sich aus den durchaus drastischen Folgen einer verbandsrechtlichen Sanktion für den Betroffenen ergeben. Die bei Match Fixing nicht unübliche Aussprache einer lebenslangen Sperre verschließt den Verurteilten nicht nur dauerhaft ein Tätigkeitsfeld, dem sie sich jahrelang hingebungsvoll gewidmet haben, sondern ist für dem Sport hauptberuflich Nachgehende unter Umständen sogar von existenzieller Wucht. Mit einem solchen verbandsrechtlichen Urteilsspruch gehen zumeist unmittelbar arbeitsvertragliche Konsequenzen einher. ${ }^{1105}$ Eingestellte Gehaltszahlungen oder ausbleibende Wettkampfprämien werden verschärft durch die zurückgezogene finanzielle Unterstützung durch Sportförderung oder Sponsoren. Und neben solchen materiellen Einbußen erfahren die Betroffenen häufig auch soziale Ächtung zumindest innerhalb der Sportwelt, die mit dem Abbruch sozialer Kontakte und ihrem gänzlichen Ausschluss aus dem Sportgeschehen verbunden sein kann.

Aus dem Vergleich mit einer denkbaren strafgerichtlichen Verurteilung wegen desselben Verhaltens wird teilweise eine höhere Eingriffsintensität der verbandsrechtlichen Sanktion abgeleitet. ${ }^{1106}$ Deren Folgen träfen den Sportakteur weitaus härter als eine auch für die $\$ \$ 265 c$, 265d StGB im Regelfall zu erwartende strafgerichtliche Geldstrafe, die zudem gerade aufgrund einer nach $\$ 46$ Abs. 2 StGB berücksichtigungsfähigen Verbandssanktion noch herabgesetzt werden könne. Für den Bereich des Dopings wird diese Einschätzung zusätzlich durch die Eingriffstiefe des Verfahrens untermauert, das der verbandsrechtlichen Sanktionierung vorausgeht. Insbesondere das in Übereinstimmung der Sportverbände mit der Nationalen Anti-Doping-Agentur etablierte System der Trainingskontrollen erlegt den

1105 Vgl. Bepler, in: Nolte (Hrsg.), Persönlichkeitsrechte, 2011, S. 9 (17).

1106 Feltes/Kabuth NK 2017, 91 (100); Dury FS Röhricht, 2005, S. 1097 (1110 ff.); U. Steiner ZRP 2015, 51 (52 f.). 
Athleten engmaschige Meldepflichten bezüglich ihres gegenwärtigen Aufenthaltsortes auf (vgl. Art. 6.1.1 NADA-Code) und führt zu nahezu lückenlosen Bewegungsprofilen, die auch datenschutzrechtliche Probleme aufwerfen. ${ }^{1107}$ Die allzeitige Verfügbarkeit für den unangekündigten Besuch eines Kontrolleurs und die für jedes Quartal vorab anzugebenden täglichen Aufenthaltsorte schränken die private Lebensführung erheblich ein. ${ }^{1108}$

Die strafrechtlichen Sanktionen unter Verweis auf das individuelle Strafempfinden im Einzelfall als milderes Mittel zu betrachten, verkennt allerdings den qualitativen Unterschied der verglichenen Sanktionsarten. Der strafgerichtlichen Verurteilung wohnt eine sozialethische Missbilligung des Verhaltens inne, die eine letztlich privatrechtlich fundierte Disziplinarmaßnahme nicht transportiert. ${ }^{1109}$ Gerade diese Konnotation begründet aber das im Rahmen der Erforderlichkeit zum Ausdruck kommende Prinzip der Subsidiarität des Strafrechts, dessen Anforderungen nicht durch eine einzelfallabhängige und berufsspezifische Strafempfindlichkeit überspielt werden dürfen. Gleiches gilt für womöglich eingriffsintensive verbandsrechtliche Präventionsmaßnahmen. Diesen kommt im Bereich des Match Fixing ohnehin keine vergleichbar belastende Wirkung zu wie dem Dopingkontrollsystem. Darüber hinaus kann ihre Eingriffstiefe aber allenfalls zu ihrer eigenen Unverhältnismäßigkeit führen, ohne dass sie gerade dadurch den Weg für als milder erachtete strafrechtliche Maßnahmen bereiten darf. ${ }^{1110}$ Die verbandsrechtliche Verfolgung und Sanktionierung von Match Fixing ist demnach von geringerer Eingriffsintensität als ihre strafrechtliche Ahndung.

1107 Ausführlich hierzu Niewalda Persönlichkeitsrecht, S. 488 ff.; Nolte, in ders. (Hrsg.): Persönlichkeitsrechte, 2011, S. 59 ff.

1108 U. Steiner ZRP 2015, 51 (52).

1109 Ott Selbstdoping, S. 196 Fn. 772.

1110 Allgemein Hefendebl JA 2011, 401 (405). Auch die hinsichtlich der härteren Sanktionswirkung der verbandsrechtlichen Entscheidungen in Fn. 1106 zitierten Autoren leiten hieraus - anders als dies teilweise für das Wirtschaftsstrafrecht vertreten wird - nicht die Forderung des Einsatzes des Strafrechts als eines milderen Mittels ab, sondern befürworten aufgrund einer überlegenen abschreckenden Wirkung gerade die ausschließlich sportautonome Sanktionierung. 
(3) Rechtsgutsbezogene Wirksamkeit verbandsinterner Sanktionen

Von maßgeblicher Bedeutung ist somit die Frage, inwiefern den verbandsrechtlich gegen Match Fixing eingesetzten Mitteln mindestens die gleiche Eignung zum Schutz der Integrität des Sports zugesprochen werden kann wie den strafrechtlichen Schutzvorschriften der $\$ \$ S 265 c, 265 d$ StGB. Gewisse Kennzeichen des beschriebenen verbandsrechtlichen Verfahrens könnten dabei sogar zu Gunsten dessen struktureller Überlegenheit gegenüber einem staatlichen Strafverfahren angeführt werden. In den verbandsrechtlichen Verfahren werden nicht nur auf die Bedingungen integrer Sportwettbewerbe spezialisierte und daher sachkundigere Entscheidungsträger vermutet. ${ }^{111}$ Die Verfahren sind auch an die Bedürfnisse des schnelllebigen Wettkampfsports angepasst und werden selbst bei Einlegung von Rechtsmitteln und der Einholung eines Schiedsspruches innerhalb weitaus kürzerer Zeit zu einer letztgültigen Entscheidung geführt als entsprechende Strafverfahren, deren Fortgang durch die Belastung der staatlichen Justiz verzögert wird. ${ }^{1112}$ Das sportinterne Unwerturteil folgt der korruptiven oder manipulativen Tathandlung somit als unmittelbare Reaktion, was die Wehrhaftigkeit der Sportverbände unterstreicht und die Integrität der Wettbewerbe augenblicklich vor weiteren Angriffen der betroffenen Person absichert. Zumal den von internationalen Dachverbänden und dem internationalen Sportschiedsgericht ausgesprochenen Sanktionen die direkte und weltweite Durchsetzbarkeit zukommt, die etwa beim Urteil eines deutschen Amtsgerichts zumindest fraglich ist. ${ }^{1113}$

Trotz dieser kaum zu bestreitenden Vorzüge wird beständig eingewendet, das Kontroll- und Sanktionensystem der Verbände hätte sich insgesamt als unzureichend erwiesen. ${ }^{114}$ Dies jedoch auf einen bereits fehlenden Aufklärungswillen der Verbände zurückzuführen, die an einer konsequenten Aufdeckung und Verfolgung manipulativer Einflussnahmen schon aus Imagegründen nicht ernsthaft interessiert seien, ${ }^{1115}$ stellt eine offenbar stark unter dem Eindruck der Verwicklung des Weltradsportverbandes UCI in die Dopingskandale der Jahrtausendwende und der zahlreichen Fälle von Funktionärskorruption stehende Pauschalisierung dar.

1111 Jansen GA 2017, 600 (611).

1112 PHB-SportR/Pfister/Summerer 3. Kap. Rn. 506 ff.

1113 Bach ZRP 2006, 239.

1114 Stellvertretend Heger SpuRt 2007, 153; Rössner FS Mehle, 2009, S. 567 (570, 575).

1115 Feltes/Kabuth NK 2017, 91 (98); Jansen GA 2017, 600 (611); Kubiciel jurisPRStrafR 3/2016 Anm. 1. 
Hierdurch werden die beschriebenen präventiven und verbandsrechtlichen Bemühungen der Verbände zur Eindämmung von Match Fixing in Form von ernsthaften Kampagnen und Kooperationen mit Wettanbietern, Nichtregierungsorganisationen und Polizeibehörden negiert. Es sind demnach auch vielmehr im Verbandsrecht selbst angelegte spezifische Schwachpunkte, die den durch die Verbände realisierbaren Schutz der Integrität des Sports in den Augen des Gesetzgebers entscheidend hinter einem strafrechtlichen Schutz zurückbleiben lässt. Wenngleich der Gesetzentwurf keine differenzierte Auseinandersetzung mit dem Kriterium der Erforderlichkeit und der verbandseigenen Regulierung enthält,, ${ }^{1116}$ decken sich die dort zumindest angedeuteten Einwände gegen die gleiche Eignung einer sportautonomen Selbstregulierung mit denjenigen der insoweit ebenfalls skeptischen Literaturstimmen. Sie werden im Folgenden auf ihre Berechtigung überprüft.

\section{(a) Fehlen strafprozessualer Ermittlungsbefugnisse}

Wie bereits in der Diskussion um ein Anti-Doping-Gesetz wird auch hinsichtlich der Ahndung von Match Fixing im Fehlen effektiver Aufklärungsmittel ein zentrales Defizit der verbandsrechtlichen Disziplinarverfahren gesehen. ${ }^{1117}$ Die komplexen Sachverhalte der Initiierung und Umsetzung von Spielmanipulationen könnten allein durch Befragungen der Beschuldigten und möglicher Zeugen durch Verbandsorgane im Regelfall nicht im erforderlichen Umfang festgestellt werden. Fehlt es an Zeugen und zeigen sich die Beschuldigten nicht kooperationsbereit bzw. streiten die Vorwürfe ab, wird es den Verbänden kaum gelingen, die belastbaren Nachweise eines satzungswidrigen Verhaltens zu erbringen, die für eine wirksame Rechtsdurchsetzung nötig wären. ${ }^{1118}$ Insbesondere die Manipulationen mit Wettbezug seien in größere Organisationszusammenhänge und Netzwerke eingebettet, die das Verbandsrecht schlicht überforderten. ${ }^{1119} \mathrm{Um}$ sie auszuleuchten, müssten Durchsuchungen und Beschlagnahmen angeordnet, Geldflüsse zurückverfolgt, die Telekommunikation überwacht und Zeugen zur Aussage verpflichtet werden können. Es be-

1116 Krit. Pfister StraFo 2016, 441 (442); Stellungnahme des Deutschen Anwaltvereins Nr. 12/2016, S. 6 f.

1117 Rössner FS Mehle, 2009, S. 567 (570, 575 f.); Kubiciel SpuRt 2017, 188 (189).

1118 BT-Drs. 18/8831, S. 9.

1119 Kubiciel WiJ 2016, 256 (262); Rössner FS Mehle, 2009, S. 567 (570). 
dürfte also Zwangsmittel, die nur den staatlichen Ermittlungsbehörden bei verfolgbaren Straftatbeständen zur Verfügung stünden. Ihr Einsatz stärke auch die generalpräventive Wirkung der Korruptions- und Manipulationsverbote, da strafrechtlicher Ermittlungsdruck die Einschätzung des Entdeckungs- und Verfolgungsrisikos entscheidend beeinflusse. ${ }^{1120}$

Auf der anderen Seite können sich aus dem Fehlen eingriffsintensiver Zwangsmittel aber auch gewisse förderliche Effekte für eine verbandsinterne Ahndung von Spielmanipulationen ergeben. Denn mit den beschränkten Möglichkeiten bei der Beweismittelbeschaffung und -erhebung korreliert ein größerer Spielraum bei der Evaluation der Beweise bzw. deren Würdigung. ${ }^{1121}$ So trifft die Verbände keine mit staatlichen Behörden vergleichbare Sorgfaltspflicht, die Herkunft und Authentizität einer Videoaufnahme zu belegen, um sie als zulässiges Beweismittel in das Verfahren einzuführen. Auch löst der Umstand, dass eine Gesprächsaufzeichnung ohne Wissen des Betroffenen angefertigt wurde, nicht per se ein diesbezügliches Verwertungsverbot aus. ${ }^{1122}$ Gleichwohl zeigt ein Blick auf die Sanktionspraxis der Sportverbände im Bereich des Match Fixing, dass verhältnismäBig vielen Verdachtsfällen eine eher geringe Anzahl an Verurteilungen gegenübersteht. ${ }^{1123}$ Dies allein ist zwar noch kein untrügliches Indiz für die strukturelle Unzulänglichkeit der verbandsrechtlichen Verfahren. Schließlich sind im Konkurrenzkampf des Leistungssports auch falsche Anschuldigungen oder nicht durch Fakten belegte mediale Skandalisierungen nicht auszuschließen. Allerdings wurden mehrere Verurteilungen durch die Sportverbände erst durch einen Rückgriff auf Erkenntnisse ermöglicht, die im Rahmen eines Strafverfahrens eben durch den Einsatz von Zwangsmitteln gewonnen wurden. Die lebenslangen Sperren gegen die die Manipulationsvorwürfe abstreitenden Schiedsrichter Oleg Oriekhov und Novo Panic konnten letztlich nur ausgesprochen werden, weil beide aufgrund von im Rahmen der Ermittlungen der deutschen Polizei gegen die Brüder Sapina abgefangenen Telefongesprächen und SMS-Nachrichten mit deren

1120 Bannenberg Korruption, S. 438 f.; Rössner FS Mehle, 2009, S. 567 (576).

1121 Villiger, in: Kainz/Scherrer/Werner (Hrsg.), Sportfinanzierung, 2012, S. 119 (135 f.).

1122 Villiger, in: Kainz/Scherrer/Werner (Hrsg.), Sportfinanzierung, 2012, S. 119 (136).

1123 So auch Ludwig, in: Kainz/Scherrer/Werner (Hrsg.), Sportfinanzierung, 2012, S. 181 (197). 
auf Wettbetrug ausgelegtem Netzwerk unzweifelhaft in Verbindung gebracht werden konnten. ${ }^{1124}$

Möchte man darin nun den Beleg der Abhängigkeit einer funktionsfähigen Verbandskontrolle von einer strafrechtlichen Flankierung sehen, gälte es aber darüber hinaus darzulegen, inwiefern eine solche nicht bereits mit $\$ 263$ StGB ausreichend vorhanden ist. Auch das angesprochene Strafverfahren gegen die Brüder Sapina fußte auf einem Betrugsvorwurf. Zwar wird behauptet, eigenständige Tatbestände i.S.d. $\$ \$ 265$ c, 265d StGB würden die Annahme eines Anfangsverdachts und somit die Verfahrenseinleitung für die Strafverfolgungsbehörden erleichtern. ${ }^{1125}$ Doch selbst für Manipulationsabsprachen gemäß $\$ 265 \mathrm{~d}$ StGB darf allein die äußerlich wahrnehmbare krasse Fehlentscheidung eines Schiedsrichters, die überraschende Leistungsschwäche eines Favoriten oder das Aufstellen einer sog. BMannschaft durch den Trainer aufgrund ihrer sportinternen Geläufigkeit künftig keinen Anfangsverdacht i.S.d. $\$ 152$ Abs. 2 StPO begründen. ${ }^{1126}$ Eine gegenüber $\$ 263 \mathrm{StGB}$ erleichterte Verdachtsannahme ist mit den neuen Tatbeständen nicht zwingend verbunden, zumal die Staatsanwaltschaften in der Vergangenheit bisweilen auch bei geringen Anzeichen einer Manipulation und noch ungeklärtem Wettbezug Ermittlungen aufgenommen haben. ${ }^{1127}$ Für die Aufdeckung von Match Fixing werden sie wie beim im Gesetzgebungsverfahren immer wieder herangezogenen „Fall Hoyzer" aber auch künftig auf Anstöße aus dem Sport selbst angewiesen sein. ${ }^{1128}$ Die spezifizierten und erweiterten Ermittlungsbefugnisse werden die Abhängigkeit der Strafverfolgungsbehörden von verbandsintern implementierten Kommunikationswegen und Meldesystemen bei Sammlung der für einen Anfangsverdacht notwendigen Indizien nicht auflösen.

Noch grundsätzlicher ließe sich der Einwand entkräften, indem geschaffenen strafprozessualen Eingriffsmöglichkeiten auch im Rahmen der Er-

$1124 \mathrm{Zu}$ den Sachverhalten Ludwig, in: Kainz/Scherrer/Werner (Hrsg.), Sportfinanzierung, 2012, S. 181 (194f.).

1125 Haug/Martin Causa Sport 2014, 345 (354); Mintas, in: Kainz/Scherrer/Werner (Hrsg.), Sportfinanzierung, 2012, S. 97 (99); Mutschke, in: Höfling/Horst/Nolte (Hrsg.), Fußball, 2014, S. 41 (43).

1126 S. BeckOK-StGB/Bittmann/Nuzinger/Rübenstabl $\$ 265$ d Rn. 5.6; Dittrich ZWH 2017, 189 (191).

1127 Vgl. Sengle, in: Württembergischer Fußballverband (Hrsg.), Manipulation, 2008, S. 9 (27 ff.).

1128 Die Aufklärung wurde seinerzeit durch eine Meldung des Schiedsrichterkollegen Manuel Gräfe beim DFB in Gang gesetzt, s. Gräfe/Abrens Abpfiff, 11 Freunde vom 2.4.2019, www.11freunde.de/artikel/wie-manuel-graefe-den-hoyzer-ska ndal-aufdeckte. 
forderlichkeit eine die Kriminalisierung von Verhaltensweisen stützende Argumentationskraft zur Verhinderung einer Umkehr des Begründungszusammenhangs von Strafrecht und Strafprozessrecht abgesprochen wird. ${ }^{1129}$ Dass sich Sachverhalte mittels ausgedehnter Ermittlungsbefugnisse genauer rekonstruieren lassen, dürfte für etliche Bereiche heimlichen Verhaltens gelten und stellt in seiner Selbstverständlichkeit einen legitimationsbezogenen Non-Faktor dar.

\section{( $\beta$ ) Beschränkte Bindungswirkung}

Attestiert der Gesetzgeber den Verbänden unzureichende Eingriffsbefugnisse, spricht er neben den fehlenden Aufklärungsmitteln auch die nur beschränkte Bindungswirkung der verbandsrechtlichen Ordnungsgewalt an. Da eine einseitige Rechtssetzung nur dem Staat vorbehalten ist, bedarf es ihrer rechtsgeschäftlichen Anerkennung. Diese erfolgt bei Sportlern, Trainern und Schiedsrichtern durch ihre Mitgliedschaft in einem Verein bzw. Verband. Mit ihr unterliegen sie auch der Ordnungsgewalt des jeweiligen Dachverbandes, sofern dieser eine sog. Durchgriffsanordnung ausspricht und ihr unmittelbarer Verein auf die Dachverbandssatzung verweist. ${ }^{1130}$ Dritte können nur in engen Ausnahmefällen als mittelbare Mitglieder Adressat einer Sanktion der Vereine oder Verbände sein, etwa wenn sie sich der Sanktionsgewalt vertraglich unterworfen haben oder ein Verein beispielsweise zur Erteilung eines Stadionverbotes von seinem Hausrecht Gebrauch macht. ${ }^{1131}$ Wirkten Dritte hingegen auf das Verhalten von Sportakteuren unlauter ein und verfolgten auf Kosten des Sports eigene Interessen, stünden den Verbänden keine Sanktionsmöglichkeiten zur Verfügung. ${ }^{132}$ Sie wären bei Kenntniserlangung auf die Mitteilung an die staatlichen Behörden beschränkt. ${ }^{133}$

Zumindest für Manipulationsversuche außerhalb des Kontextes einer Sportwette, wie sie $\$ 265 \mathrm{~d}$ StGB erfasst, fällt die fehlende Handhabe gegen Externe aber schon deswegen nicht sonderlich ins Gewicht, weil die regelmäßig ideelle oder sportimmanente Motivation hinter diesen Handlungen

1129 Vgl. Jahn SpuRt 2013, 90 f.; hierzu bereits oben unter Teil 3 B. I. 3.

$1130 \mathrm{Zu}$ dieser sog. Doppelverankerung s. Weinbuch Sportwettmanipulationen, S. 52.

1131 S. PHB-Sportrecht/Summerer 3. Kap. Rn. 338.

1132 BT-Drs. 18/8831, S. 9.

1133 Villiger, in: Kainz/Scherrer/Werner (Hrsg.), Sportfinanzierung, 2012, S. 119 (126). 
auch Vorteilsgeber aus dem erweiterten Umfeld des Sports erwarten lässt und somit keine Lücke in der sportinternen Selbstregulierung offenbart. ${ }^{1134}$ Während Vereinsverantwortliche, die Sportlern Prämien für absichtliche Niederlagen in Aussicht stellen, dem Verbandsrecht unterliegen, kann auf ein entsprechendes Verhalten etwa von Sponsoren seitens der Vereine mit der Kündigung der Geschäftsbeziehung reagiert werden. Davon abgesehen ist ein Vorgehen gegen externe Dritte im theoretischen Idealfall zum Schutz der Integrität des Sports gar nicht notwendig. Denn diese kann letztlich nur durch die Akteure auf dem Spielfeld tangiert werden. Sie sind unverzichtbarer Bestandteil einer korruptiven Abrede. Wird ihr Fehlverhalten durch die Verbände konsequent verfolgt und sanktioniert, reduzieren sich auch die Aussichten für externe Dritte, das Geschehen in ihrem Sinne zu beeinflussen.

\section{$(\gamma)$ Machtlosigkeit gegenüber der Organisierten Kriminalität}

Als besonders misslich werden das Fehlen spezifischer strafprozessualer Ermittlungsbefugnisse und der unzulängliche Zugriff auf Externe mitunter angesichts der bei wettbedingten Manipulationen zunehmend ausgemachten Täterstrukturen empfunden. In der Form breiter Kapitalflüsse, die unter Ausnutzung eines hierarchisch organisierten und arbeitsteilig operierenden Netzwerkes über Landesgrenzen hinweg gesteuert würden, trügen diese häufig die Erkennungsmerkmale der sog. Organisierten Kriminalität. ${ }^{1135} \mathrm{Im}$ über das Internet leicht und anonym zugänglichen, schwer zu überwachenden und gleichzeitig umsatzstarken Sportwettenmarkt finde sie nahezu perfekte Bedingungen vor, um in größerem Umfang unbemerkt Gelder zu waschen und beträchtliche rechtswidrige Gewinne zu erzielen, die dann teilweise wiederum als Bestechungssummen eingesetzt werden könnten. ${ }^{1136}$ Die Bezeichnung dieser vermuteten Gruppierungen changiert dabei von Organisierter Kriminalität über Syndikate bis hin zum

1134 Vgl. Feltes/Kabuth NK 2017, 91 (99f.).

1135 Jaleesi Kriminalisierung, S. 28 f.; Momsen/Vaudlet, in: Emrich/Pierdzioch/Pitsch (Hrsg.), Falsches Spiel, 2015, S. 219 (222 ff.); Kubiciel WiJ 2016, 256 (257).

1136 Berliner Erklärung der 5. UNESCO-Weltkonferenz der Sportminister (MINEPS V), Aspekt 3.15; vgl. auch das Zitat des Leiters der Abteilung Sportintegrität bei Interpol John Abbot in Mustroph Millionen von der Mafia?, Der Freitag vom 25.5.2013, www.freitag.de/autoren/der-freitag/millionen-von-der-mafi a; Kubiciel WiJ 2016, 256 (257); Mutschke, in: Höfling/Horst/Nolte (Hrsg.), Fußball, 2014, S. 41 (42 f.). 
medial häufig verwendeten und daher wohl auch die öffentliche Meinung prägenden Begriff der sog. Wett-Mafia, der mit den Adjektiven „osteuropäisch“ bzw. „asiatisch“ zumeist noch eine geographische Herkunftsbeschreibung beigefügt wird. ${ }^{1137}$

Damit dieser Aspekt einer gefestigten und elaborierten täterschaftlichen Vorgehensweise überhaupt in die Diskussion um die Erforderlichkeit eines strafrechtlichen Schutzes eingebracht werden kann, müsste es sich um mehr als eine bloße Behauptung handeln. Andernfalls ließe sich dem Gesetzgeber der plumpe Versuch vorwerfen, allein durch die ungeprüfte Übernahme der Bezeichnung eines Phänomens (Organisierte Kriminalität) die einzig passende Reaktionsform (Kriminalstrafe) indizieren zu wollen. ${ }^{1138} \mathrm{Im}$ Gesetzentwurf belässt er es bei der nicht näher ausgeführten Feststellung, dass die Täter der zuletzt bekannt gewordenen Wettbetrugsfälle teilweise der Organisierten Kriminalität entstammten. ${ }^{1139}$ Werden zum Beleg vor allem die beiden abgeurteilten Manipulationskomplexe um Ante Sapina herangezogen, ${ }^{1140}$ kann gerade an dessen gerichtlich aufgeklärter Vorgehensweise die Berechtigung der Zuordnung zur Organisierten Kriminalität überprüft werden.

Bei Zugrundelegung allein der polizeilichen Arbeitsdefinition, wonach Organisierte Kriminalität neben einer von Gewinnstreben motivierten planmäßigen Begehung bedeutender Straftaten lediglich ein arbeitsteiliges Zusammenwirken von mindestens zwei Personen unter Verwendung geschäftsähnlicher Strukturen voraussetzt, ${ }^{1141}$ erscheint eine Zuordnung des wettbezogenen Match Fixing zur Organisierten Kriminalität so naheliegend wie wenig aussagekräftig. Aus dem Umstand, dass bereits die Tatbegehung eines Wettbetrugs in Form von Verbindungen zu manipulationsbereiten Sportakteuren und gegebenenfalls bei der Platzierung der Wetten behilflichen Mittelsmännern einen gewissen Organisationsgrad erfordert und somit nahezu zwangsläufig die maßgeblichen Kennzeichen aufweist, ergibt sich eher eine Kritik an der mangelnden Trennschärfe der Definiti-

1137 S. bereits Fn. 4. Auch in wissenschaftlichen Publikationen wird der Begriff der „Wettmafia“" mitunter ohne nähere Auseinandersetzung mit den Kennzeichen gerade mafiöser Strukturen gebraucht, s. Jaleesi Kriminalisierung, der nach anfänglicher Verwendung des Begriffs in An- und Abführzeichen (S. 29) auch auf diese später verzichtet, S. 119, 207, 209.

1138 Tsambikakis StV 2018, 319 (324).

1139 BT-Drs. 18/8831, S. 11.

1140 Kubiciel WiJ 2016, 256 (257 Fn. 15).

1141 Bundeskriminalamt (Hrsg.) Bundeslagebild Organisierte Kriminalität 2018, S. 10. 
onsmerkmale als ein gesteigertes phänomenologisches Bedrohungspotenzial. ${ }^{1142}$

Ein solches kann grundsätzlich erst durch einen Abgleich mit präzisierten Indikatoren Organisierter Kriminalität festgestellt werden. Diese haben gerade nicht am $\mathrm{Ob}$ eines organisierten Vorgehens anzuknüpfen, sondern am Wie. So erachtet es der BGH für kennzeichnend, dass sich die organisierten Gruppierungen aus beliebig austauschbaren und ersetzbaren Randtätern, die keinen Einblick in den Aufbau und die Zusammensetzung der Gesamtorganisation haben und den Hauptverantwortlichen, die als Drahtzieher und Financiers im Hintergrund verbleiben, zusammensetzen. ${ }^{1143}$ Die spezifische Gefährlichkeit der Organisierten Kriminalität liegt demnach in der Verkörperung einer gewissen Macht, vermöge derer kriminelle Ziele unabhängig vom jeweiligen Willen der Mitglieder durchgesetzt werden können. ${ }^{1144}$ Inhaltlich stellt sich die Organisierte Kriminalität häufig als Ausdruck einer ökonomischen Parallelwelt mit gewerbeähnlicher Teilnahme an einem illegalen Marktgeschehen dar. ${ }^{1145}$ Dabei sollen Profite durch das Angebot solcher Konsumgüter oder Dienstleistungen erwirtschaftet werden, hinsichtlich derer eine große private Nachfrage auf staatliche Restriktionen in Form von strafrechtlich flankierten Verboten oder Steuern trifft. ${ }^{1146}$

Wendet man diese Indikatoren nun auf Ante Sapina an, so muss zwischen dessen Vorgehensweise im Manipulationskomplex rund um Robert Hoyzer und dem sog. zweiten Manipulationsskandal („Bochum-Fall“) differenziert werden. Schon im ersten Fall kommt ihm zwar die Rolle einer Zentralgestalt zu, die mit einem Kreis an Gehilfen unter Ausnutzung gewisser Kontakte in die Fußballszene aus fortgesetzten Spielmanipulationen erhebliche Gewinne erzielte. Sein vergleichsweise eindimensionales Netzwerk war dabei aber stark auf ihn zugeschnitten. ${ }^{1147}$ Unter gelegentlicher Mitwirkung seines Bruders platzierte er selbst die Wetten bei ausschließlich legalen Anbietern, trug allein deren finanzielles Risiko und knüpfte

1142 Zur allgemeinen Kritik an der Begriffsdefinition der Organisierten Kriminalität s. Hefendebl StV 2005, $156 \mathrm{f}$.

1143 BGH NJW 1984, 247.

1144 Hefendehl StV 2005, 156 (158).

1145 Kirkpatrick wistra 2016, 378 (386).

1146 Herzog/Achtelik/Herzog/Achtelik GWG Einl. Rn. 106.

1147 Vgl. auch die Einschätzung von Milan Sapina, nach der sein Bruder Ante und Robert Hoyzer „kleine Fische“ gewesen seien, zitiert bei Hill Sichere Siege, S. 180. 
und pflegte auch die Kontakte zu den Sportakteuren. ${ }^{1148}$ Die aufgebauten Strukturen beschränkten sich somit auf das zur Durchsetzung des Wettbetrugs Notwendige. Eine vom Willen der Einzelpersonen losgelöste Organisationsgefahr lässt sich hierin ebenso wenig erkennen wie ein illegaler Handelsgegenstand. Die vorgenommene Zuordnung zur Organisierten Kriminalität überzeugt hier nicht.

Anderes könnte für seine veränderte und transnationale Vorgehensweise im zweiten Manipulationskomplex gelten. Um die Restriktionen auf dem deutschen Wettmarkt zu umgehen, schloss er gemeinsam mit Mariko Cvrtak Wetten auf von ihm beeinflusste Spiele auf dem asiatischen Wettmarkt $\mathrm{ab}$, die ihnen durch englische Buchmacher vermittelt worden und in Deutschland illegal gewesen waren. ${ }^{1149}$ Schon die isolierte Betrachtung der pyramidalen Strukturen des illegalen asiatischen Wettmarkts weist diesen als Erscheinungsform der Organisierten Kriminalität aus. Die Einsätze der Wettenden gelangen dabei über die sog. „Runner“ eines lokalen Buchmachers und Strohmänner, die zur Verschleierung großer Geldströme eingesetzt werden, zu regionalen Rechenzentren, von wo sie zunächst gebündelt und dann in bestimmten Tranchen bei verschiedenen Anbietern platziert werden. ${ }^{1150}$ Dieses komplexe System wird auf dem Geschäftsfeld der Sportwetten errichtet, das sich durch hohe Nachfrage und auch in Asien staatliche Restriktionen auszeichnet, der Profitmaximierung dient und somit die kennzeichnenden Züge einer ökonomischen Parallelwelt trägt. Es erreicht ein abstraktes Organisationsniveau, das den einzelnen Repräsentant austauschbar werden lässt.

Mit Blick auf Sapina ist nun jedoch zu beachten, dass er lediglich als Nutznießer dieses illegalen Angebots aufgetreten ist, ohne selbst in die Strukturierung des illegalen Marktgeschehens eingebunden gewesen zu sein. Sein grenzüberschreitendes und auf unterschiedlichen Organisationsebenen mehrere Personen involvierendes Vorgehen ist kein Ausdruck spezifischer Macht, sondern stellt lediglich eine Anpassung an die ihm bereiteten Hindernisse dar. ${ }^{1151}$ So diente auch die Einbindung der englischen Buchmacher nicht etwa primär der Verschleierung, sondern ermöglichte ihm überhaupt erst den Zugang zu den illegalen asiatischen Märkten. Trotz zweifelsfrei vorhandener Schnittstellen liegt es demnach nahe, in seinem Vorgehen eher einen lediglich mit einem außergewöhnlichen Organi-

1148 LG Berlin Urteil vom 17.11.2005 - (512) 68 Js 451-05 Kls (42/05).

1149 LG Bochum Urteil vom 19.05.2011 Az. 12 KLs 35 Js 141/10 - 16/11.

1150 Hierzu ausführlich Hill Sichere Siege, S. $66 \mathrm{ff}$.

1151 Vgl. Feltes, in: Haberfeld/Sheehan (Hrsg.), Match-fixing, 2013, S. 15 (26). 
sationsgrad einhergehenden Betrug zu sehen als eine Ausprägung der Organisierten Kriminalität.

Von einer Infiltrierung des Sports durch die Organisierte Kriminalität ließe sich demnach allenfalls dann sprechen, wenn die Hintermänner der illegalen Wettmärkte ihre Aktivität stärker auf die eigene Initiierung von Spielmanipulationen lenkten. Hierfür lassen sich mit den Singapurern Eng Set Tan, genannt Dan Tan, bzw. Wilson Raj Perumal, die als Zentralfiguren des calcioscomesse-Skandals bzw. zahlreicher allein zum Wettbetrug arrangierter Fußballspiele syndikatsähnliche Unternehmensstrukturen zur systematischen Verknüpfung von Wettmöglichkeiten auf asiatischen Märkten und Match Fixing schufen, zwar vereinzelte Beispielsfälle anführen. ${ }^{1152}$ Aus Berichten übergeordneter Strafverfolgungsbehörden ergibt sich indes kein klarer Beleg einer solchen Infiltrierung. Im vom Bundeskriminalamt jährlich herausgegebenen Lagebild zur Organisierten Kriminalität findet der Sportwettbetrug im Rahmen der einschlägigen Kategorie „Kriminalität im Zusammenhang mit dem Wirtschaftsleben“ bislang jedenfalls keine explizite Erwähnung. Auf internationaler Ebene endete jüngst eine Konferenz der von INTERPOL gegründeten Match Fixing Task Force (IMFTF) mit dem Aufruf an die Mitgliedsstaaten, mehr Informationen zu teilen, um das unklare Bild der mit Match Fixing in Verbindung stehenden Gruppen der Organisierten Kriminalität zu schärfen. ${ }^{1153}$

Alles in allem erweist sich der vom Gesetzgeber zur Begründung der Kriminalisierung vorgebrachte Zusammenhang von Match Fixing und Organisierter Kriminalität als nicht sonderlich tragfähig. Doch selbst bei Annahme derartiger Strukturen auf Vorteilsgeberseite überzeugt die Herausstellung des Strafrechts als adäquates Gegenmittel nicht. Stünden hinter einem Großteil der Fälle des Sportwettbetrugs tatsächlich weit ausgebaute und vielschichtige kriminelle Netzwerke, so wäre das Strafrecht mit deren Aufdeckung und der Sanktionierung der maßgeblichen Drahtzieher genauso überfordert wie die Sportverbände. Denn selbst mit den im Zuge der $\mathbb{S} \mathbb{S} 265 \mathrm{c}$, 265d StGB verfügbaren Zwangsmitteln der Durchsuchung und Überwachung der Telekommunikation (vgl. $\mathbb{\$} 100 \mathrm{a}$ Abs. 2 Nr. 1 p]

1152 Zum calcioscomesse-Manipulationskomplex bereits Fn. 130; zur Rolle Dan Tans als Drahtzieher und seiner Verbindung zu Perumal (zu diesem bereits Fn. 133) s. Buncombe Dan Tan: The man who fixed football, The Independent vom 29.3.2013, www.independent.co.uk/news/world/asia/dan-tan-the-man-who-fixe d-football-8554751.html.

1153 Pressemitteilung Interpol vom 12.9.2018, www.interpol.int/News-and-Events/ News/2018/INTERPOL-Match-Fixing-Task-Force-closes-ranks-on-organized-cri me. 
StPO) würden sich allenfalls die Gruppenmitglieder unterer Hierarchieebenen überführen lassen, die tatsächlich selbst Absprachen über die Manipulation von Sportwettbewerben träfen. Die einflussreichen Entscheidungsträger im Hintergrund, die die Wettstrukturen geschaffen hätten und an ihnen verdienten, würden von den Strafverfolgungsmaßnahmen hingegen allenfalls zufällig erfasst. ${ }^{1154}$ Die zur Begründung der Überlegenheit des Strafrechts gegenüber den verbandsrechtlichen Verfahren angeführte Leistungsfähigkeit bei der umfangreichen Aufklärung krimineller Strukturen ist somit erheblich einzuschränken. Und sofern es um die Verhinderung einer Ausnutzung des Sportwettenmarkts zur Geldwäsche geht, versprechen alternative Maßnahmen wie die Eindämmung des illegalen Glücksspiels über eine Ausweitung der strafbewehrten Verbote in $\$ \mathbb{S} 284$, 285 StGB mehr Erfolg. ${ }^{1155}$

( $\delta$ ) Signalwirkung der Kriminalstrafe

Als letzten Einwand gegen die gleiche Eignung der verbandsrechtlichen Regulierung bringt der Gesetzentwurf vor, verbandsinterne Sanktionen blieben mit ihrem Unwerturteil hinter strafrechtlichen Verurteilungen zurück und könnten daher nicht in gleicher Weise den Unrechtsgehalt von korruptiven Verhaltensweisen zum Ausdruck bringen. ${ }^{1156}$ Damit sich hieraus ein tatsächlich erweiterter Schutz der Integrität des Sports ergibt, müsste die angesprochene Signalwirkung der Kriminalstrafe mit einer Stärkung des Unrechtsbewusstseins ${ }^{1157}$ und darüber hinaus allgemein mit überlegenen generalpräventiven Potenzialen verbunden sein. Dass sich diese für die Gruppe tatgeneigter Sportakteure zumindest nicht in Form einer effektiveren Abschreckung durch die veränderte Rechtsnatur der Sanktion entfalten dürften, wurde bereits angedeutet. Die psychologische Zwangswirkung, die bereits von der Androhung solcher verbandsrechtlicher Sanktionen ausgeht, die die Lebenswirklichkeit unmittelbar und schmerzlich verändern, wird allein durch die rechtstheoretische Aufwertung des Sanktionsregimes nicht forciert. Wird in anderen korruptionsnahen Lebensberei-

1154 Swoboda/Bohn Jus 2016, 686 (689); für Jaleesi Kriminalisierung, S. 139 Fn. 621 liegt dieser Befund hingegen im Wesen der Orgnaisierten Kriminalität begründet und bleibt für die Bewertung der Tatbestände folgenlos.

1155 Stellungnahme des Deutschen Richterbundes Nr. 2/2016, S. 3.

1156 BT-Drs. 18/8831, S. 9; unterstützend Waßmer ZWH 2019, 6 (9).

1157 Hierzu Bannenberg/Rössner, in: Weinreich (Hrsg.), Korruption im Sport, 2006, S. $214(223)$. 
chen eine über die hinnehmbar erscheinenden Geld- oder Bewährungsstrafen hinausgehende negative Abschreckungswirkung gerade in der öffentlichen Wahrnehmung eines Strafverfahrens ausgemacht, ${ }^{1158}$ so wird sich dieser Effekt bei Fällen des Match Fixing, die ihre Publizität zumeist bereits durch eine täterbezogene Medienberichterstattung erfahren, in engen Grenzen halten. Nicht zuletzt wegen der Belastung der Justiz werden die Strafverfahren erst zu einem verzögerten Zeitpunkt durchgeführt werden, zu dem die medial bereits ausreichend informierte Öffentlichkeit das Interesse an dem zugrunde liegenden Fall weitgehend wieder verloren haben dürfte.

Jedoch könnte die signalhafte Definition von Manipulationsabsprachen als kriminelles Unrecht im Sinne der positiven Generalprävention das gesamtgesellschaftliche Bewusstsein von der Bedeutung eines integren Sports erweitern. Ein dem Spitzensport entgegengebrachtes kollektives Vertrauen vorausgesetzt, ließe sich dieses durch eine zentrale staatliche Strafverfolgung wohl eher stärken als durch die sportinternen Verfahren der diversen Verbände, deren Konsequenz und Effektivität selbst für weite Teile der am Leistungssport interessierten Bevölkerung nicht klar ersichtlich sind. Auf eine solche übergeordnete Funktion des Strafrechts stellt auch das Bundesverfassungsgericht $a b$, wenn es in anderem Zusammenhang darauf verweist, nicht-strafrechtliche Maßnahmen zielten eher auf die Verhinderung der Normverletzung und die Beseitigung ihrer Folgen, hätten aber keine normstabilisierende Wirkung. ${ }^{1159}$

Eine Verlagerung der überlegenen Wirkung des Strafrechts in den Bereich der allgemeinen Normbestärkung ist insofern problematisch, als sie empirisch kaum feststellbar ist. Vor dem Hintergrund der hier überprüften Rechtsgutskonzeption ist sie aber zumindest nachvollziehbar. Die notwendige Sozialbindung soll die Integrität des Sports über ihre Außenwirkung als glaubwürdiges Vorbild erstrebenswerter Werte erlangen. Trotz der bereits vorgebrachten Zweifel an der inspirierenden Kraft eines strafrechtlich abgesicherten Sportethos, kann sich das Strafrecht aufgrund seiner vergleichsweise exponierten Schutzwirkung und der damit ausgelösten Erwartung in die effektivere Abwehr äußerer korruptiver Einwirkungen hinsichtlich des Schutzes des Vertrauens in die Integrität sportlicher Wettbe-

1158 Dieses Argument wurde insbesondere für die Aufwertung des Verbots von Submissionsabsprachen von der Ordnungswidrigkeit zur Straftat angeführt, vgl. LK-StGB/Tiedemann zu $\$ 298 \mathrm{Rn} .5$ und wird auch auf den Bereich des Sports angewendet, s. Rössner FS Mehle, 2009, S. 567 (575).

1159 BVerfGE 120, 224 (251 f.). 
werbe tatsächlich als geeigneter erweisen. Auf der Basis des der Rechtsgutskonzeption zugrunde liegenden, vermuteten Wirkungszusammenhangs würde es damit die Vorbedingung des Wertetransfers zwischen Spitzensport und Gesellschaft schaffen.

\section{(4) Zwischenergebnis}

Vorstehend wurden die Versuche des organisierten Sports beschrieben, die Integrität seiner Wettbewerbe auch im Rahmen seiner Verbandsgewalt zu schützen. Hierzu wurde ein ausdifferenziertes Verbandsrecht entwickelt, dessen sanktionsbegleitete Verbote der manipulativen Einflussnahme von den zuständigen Verbandsorganen in der Praxis auch tatsächlich durchgesetzt werden. Trotz einer im Einzelfall möglichen hohen Eingriffsintensität stellen die dabei ausgesprochenen Sanktionen als letztlich zivilrechtlich begründete Ordnungsmaßnahmen ein milderes Mittel im Vergleich zur Kriminalstrafe dar, so dass dem verbandsrechtlichen Verfahren eine im Vergleich zum Einsatz des Strafrechts defizitäre Eignung nachgewiesen werden müsste, um die Erforderlichkeit der $\$ \$ 265$ c, 265d StGB zum Schutz der Integrität des Sports zu begründen.

Die vom Gesetzgeber diesbezüglich nur schlagwortartig vorgebrachten Aspekte verfangen bei näherer Auseinandersetzung nur bedingt. Der Rückgriff auf strafprozessuale Zwangsmittel würde die Aufklärung von Manipulationsfällen zwar erleichtern, darf aber kein Selbstzweck sein. Ihn angesichts der vermeintlichen Unzulänglichkeit der verbandsrechtlichen Verfahren bei der Abschreckung von externen Vorteilsgebern bzw. der Aufdeckung komplexer krimineller Netzwerke für unverzichtbar zu halten, überschätzt zum einen den realen Bedarf nach einem Vorgehen gegen Dritte, das über die bereits von $\$ 263$ StGB eröffneten Möglichkeiten hinausgeht. Zum anderen wird ein Phänomen herangezogen, dessen Existenz sich anhand der bisher in Erscheinung getretenen Täterstrukturen nicht eindeutig belegen lässt, dem in seiner behaupteten Form durch die von den $\$ \$ 265$ c, 265d StGB eröffneten Ermittlungsbefugnisse aber auch hypothetisch nicht entscheidend entgegengetreten werden könnte.

Für die Sportler selbst ist weder aufgrund des größeren Unwertgehalts der Sanktionsform der Kriminalstrafe noch aufgrund der Publizität des ihr vorangehenden Strafverfahrens mit abschreckenden Effekten zu rechnen. Lediglich im Hinblick auf die Stabilisierung eines gesellschaftlichen Normvertrauens zeigen die sportinternen Verfahren gewisse Schwächen. Allenfalls diesbezüglich ist einer Kriminalisierung ein überlegener Beitrag 
zuzutrauen. Allerdings dürfte er empirisch kaum nachzuweisen sein. Bezieht man die gegenübergestellten Effekte von verbandsrechtlicher und strafrechtlicher Ahndung manipulationsbezogener Absprachen demnach auf die beschriebenen Merkmale des Rechtsguts, so zeichnet sich nur hinsichtlich der als Voraussetzung der Norminternalisierung begriffenen öffentlichen Wahrnehmung eines integren Spitzensports eine bessere Eignung des Strafrechts ab.

b) Soziale Kontrolle und Substitute der Norminternalisierung

Mag sich diese verbandsrechtliche Lücke auch mit der gesetzgeberischen Sorge decken, gerade Einbußen im kollektiven Vertrauen in die Integrität des Sports bewirkten einen Interessens- und Zuschauerschwund und entzögen dem Spitzensport seine ideellen Potenziale, lässt sich hieraus noch keine Ableitung über die Erforderlichkeit strafrechtlicher Mittel zur Sicherung dieses wertbildenden Zusammenhangs treffen. Denn die Gesellschaft selbst könnte fernab strafrechtlicher oder verbandsrechtlicher Regulierung über eigene Reaktionsmöglichkeiten und Potenziale verfügen, um Beschädigungen der Glaubwürdigkeit des Spitzensports in moralischer Hinsicht auszugleichen. Trifft die Annahme des Gesetzgebers zu, wonach die sportinteressierte Öffentlichkeit ihre Gunst entsprechend dem Maß an im Sport verkörperter Integrität verteilt, wird sie sich immerzu den Sportarten zuwenden, die sie noch als authentische Träger sportethischer Werte und damit identifikationsstiftende Vorbilder anerkennt. Solange solche Sportarten zu finden sind, wäre zum einen die als schützenswert herausgestellte Wertevermittlung durch den Sport intakt, zum anderen sorgte eine derartige Orientierung der Öffentlichkeit sportintern für einen natürlichen Wettbewerb der Integrität, in dem die einzelnen Verbände beständig um die Ausrichtung glaubwürdiger Wettkämpfe bemüht sein müssten, um nicht mit Missachtung gestraft zu werden. ${ }^{1160}$ Ironischerweise ließe sich somit gerade auf Grundlage der Prämissen des Gesetzentwurfs auf eine funktionsfähige soziale Kontrolle des Sports deuten, die dessen immaterielle Werte auch ohne strafrechtlichen Schutz hervorkehre und bedeutsame Impulse zur sportartspezifischen Selbstreinigung liefere.

Und selbst wenn sich die Öffentlichkeit nicht nur partiell von Sportarten, sondern doch umfassend vom Sport abwendete - sei es, weil keine einzige Sportart einen hinreichend glaubwürdigen Eindruck erwecken

1160 Tsambikakis StV 2018, 319 (322); Jansen GA 2017, 600 (608). 
kann, sei es, weil eben doch der Unterhaltungsfaktor das Interesse auf wenige manipulationsanfällige Sportarten kanalisiert -, würde damit das durch den strafrechtlichen Schutz der Integrität des Sports verfolgte Ziel einer Vermittlung positiver Werte gesellschaftlich keineswegs außer Reichweite geraten. Denn mögen die Prinzipien von Fair Play, Teamgeist und Leistungswillen auch eine besondere sportspezifische Prägung erfahren haben, so fungiert der Sport nicht als ihre exklusive Veranschaulichung. Deren Ausbildung kann auch über andere Formen der Interaktion in anderen gesellschaftlichen Subsystemen erfolgen. ${ }^{1161}$ Lässt sich der Sport aber problemlos hinwegdenken, ohne dass der Gesellschaft ideelle Einbußen drohen, kann sein strafrechtlicher Schutz auch nicht auf seine Rolle als vermeintlich unverzichtbare Sozialisationsinstanz gestützt werden. Einem Abwenden der Öffentlichkeit von manipulationsbelasteten Sportarten ist nicht mit strafrechtlichen Mitteln entgegenzuwirken, wenn die hierdurch befürchtete Störung einer Wertevermittlung entweder bereits sportintern oder aber durch alternative gesellschaftliche Mechanismen kompensiert werden kann. Hinsichtlich des zentralen Rechtsgutselements einer durch den Sport angestoßenen Normbildung erweisen sich die $\$ \mathbb{S} 265 \mathrm{c}, 265 \mathrm{~d}$ StGB somit nicht als erforderlich.

\section{c) Etablierung des Ordnungswidrigkeitenrechts}

Als weitere Alternative zu einer strafrechtlichen Erfassung manipulationsbezogener Absprachen wird eine Aktivierung des Ordnungswidrigkeitenrechts vorgeschlagen. ${ }^{1162}$ Tatsächlich wäre im Falle einer skeptischen Einschätzung des ausreichenden Schutzes der Integrität des Sports durch verbandsrechtliche und gesellschaftliche Reaktionsformen im Sinne des Subsidiaritätsprinzips noch vor einer Kriminalisierung die Einführung von Bußgeldvorschriften zu erwägen. Da auf Rechtsfolgenseite kein Freiheitsentzug droht und die Verhängung eines Bußgeldes keine nur der Kriminalstrafe immanente sozialethische Missbilligung, sondern eine ethisch neutrale Pflichtenmahnung transportiert, stellt das Ordnungswidrigkeitenrecht das grundsätzlich mildere Sanktionsregime dar. ${ }^{1163}$

1161 Vgl. Reinhart SpuRt 2016, 235 (237); Tsambikakis StV 2018, 319 (322); Jansen GA 2017, 600 (607 f.).

1162 Stellungnahme des Deutschen Anwaltvereins Nr. 12/2016, S. 12; Trüg FS Rössner, 2015, S. 686 (699 f.).

1163 Vgl. Stächelin Strafgesetzgebung, S. $154 \mathrm{f}$. 
Auch aufgrund seines strukturellen Zuschnitts wird es für die Aufnahme von Tatbeständen, die den Sport vor korruptiven Angriffen absichern sollen, als passend empfunden. Die Intention eines verstärkten staatlichen Schutzes der gesellschaftlichen und wirtschaftlichen Dimension des Sports betreffe nicht den dem Strafrecht vorbehaltenen Kernbereich unmittelbarer Individualrechtsgutsverletzungen und lasse sich eher in einem Rechtsgebiet realisieren, dessen genuine Funktion es sei, soziale Teilsysteme zu schützen. ${ }^{1164}$ Außerdem kennzeichne es sich grundsätzlich durch die Erfassung von in ihrer Wirkung schwächeren Angriffsweisen und enthalte daher mehrheitlich abstrakte Gefährdungsdelikte, ${ }^{1165}$ in die sich die für den Sport ebenfalls nur abstrakt gefährlichen manipulationsbezogenen Absprachen einfügen würden. Diese stellten letztlich bloße Regelverstöße in einem institutionellen Rahmen dar, dessen Störung nicht zwangsläufig auch mit der Beeinträchtigung von Individualrechtsgütern korreliere, was wiederum dem herabgesetzten Unrechtsgehalt einer Ordnungswidrigkeit entspreche. ${ }^{1166}$

Eine derart begründete Zuordnung beruht jedoch auf materiellen Abgrenzungskriterien, die ihrerseits nicht unumstritten sind. In ihrem Verweis auf die ultima ratio-Funktion des Strafrechts und den geringeren Schweregrad der Sportkorruption folgt sie dem sog. qualitativ-quantitativen Ansatz, der sich in Abkehr von einer das geltende Recht nicht mehr widerspiegelnden, rein qualitativen Unterscheidung zwischen einem rechtsgüterschützenden Strafrecht und einem auf bloßes „Verwaltungsunrecht" ${ }^{\text {“ }}$ beschränkten Ordnungswidrigkeitenrecht ${ }^{1167}$ herausgebildet hat. Dieser mittlerweile als herrschend bezeichneten Betrachtungsweise ${ }^{1168} \mathrm{zu}^{\mathrm{zu}}$ folge soll grundsätzlich eine quantitative Steigerung des Unrechts und der Vorwerfbarkeit maßgeblich sein, wobei Verhaltensweisen jenseits eines bestimmten Grads der Missbilligung das sozialethische Unwerturteil der Kriminalstrafe herausforderten. ${ }^{1169}$ Einem solchen Kernbereich unterfielen Interessen, deren Verletzung besonders schwerwiegend sei, was insbesondere auf die unmittelbare Verletzung von Individualrechtsgütern zutreffe. Kollektive Interessen hingegen seien nicht unmittelbar verletzbar und wie-

1164 Hierzu im Allgemeinen Trüg Insiderstrafrecht, S. 112 ff.

1165 Arzt/Weber/Heinrich/Hilgendorf Strafrecht BT $\$ 35$ Rn. 48 f.

1166 Vgl. Stellungnahme des Deutschen Anwaltvereins Nr.12/2016, S. 11; Trüg FS Rössner, 2015, S. 686 (699 f.); Ott Selbstdoping, S. 207.

1167 Hierzu Schmidt JZ 1951, 101 (102 f.).

1168 Vgl. KK-OWiG/Mitsch Einl. Rn. 113; Schönke/Schröder/Kinzig vor $\$ 38$ Rn. 37.

1169 BVerfGE 27, 18 (29f.). 
sen traditionell eine Nähe zum Ordnungsrecht auf, so dass diesbezügliche Störungen mit Bußgeldern zu ahnden seien. ${ }^{1170}$

An der Vagheit einer derart zu bestimmenden Grenzlinie Kritik übend, möchte eine Gegenansicht die Abgrenzung anhand der Art der geschützten Rechtsgüter bzw. der Verbindung zwischen der tatbestandlichen Handlung und dem geschützten Rechtsgut vornehmen. ${ }^{1171}$ Dieses Vorgehen knüpfe an den Ausgangspunkt einer qualitativ-quantitativen Betrachtung an, verspreche aber eine präzisere Handhabung der Kriterien im Grenzbereich. Hiernach sei gerade der Kreis legitimer Kollektivrechtsgüter ausschließlich dem Strafrecht zu überantworten. Schon an deren grundsätzliche Anerkennung seien strenge Legitimationsanforderungen zu richten, die sie als essenzielle Rahmenbedingungen für ein Funktionieren von Staat oder Gesellschaft auswiesen. Erfüllte ein überindividuelles Interesse diese Mindestbedingungen, müsse sein Schutz dann aber auch über das Strafrecht erfolgen. Für das Ordnungswidrigkeitenrecht verblieben Fälle der abstrakten Gefährdung von Individualrechtsgütern.

Gerade am Beispiel der Integrität des Sports zeigt sich im Sinne der letzten Ansicht, dass das Ordnungswidrigkeitenrecht zum Schutz kollektiver Rechtsgüter eher einen unstimmigen Kompromiss als einen goldenen Mittelweg verspricht. Die Gesetzesbegründung stützt das Rechtsgut maßgeblich auf eine sich vollziehende Interaktion zwischen der Gesellschaft und dem Ethos des Leistungssports, die die moralische Konstitution der Gesellschaft beeinflusse. Demzufolge bedürfe es gerade einer starken Betonung des Verbots korruptiver Verhaltensweisen, die nur das Strafrecht in seiner positiv-generalpräventiven Wirkweise verkörpern kann. Das Ordnungswidrigkeitenrecht erscheint vor dem Hintergrund einer solchen Rechtsgutskonzeption zwangsläufig ungeeignet. Insofern verfängt auch der Verweis auf das bewehrte Kartellordnungswidrigkeitenrecht nicht. ${ }^{1172}$ Denn dort geht es ausschließlich um die Absicherung der Regularien einer wirtschaftlichen Wettbewerbsform. Da die Annahmen des Gesetzgebers die Sozialrelevanz nicht ausreichend begründen, die Integrität des Sports die Hürden eines legitimen Kollektivrechtsguts folglich nicht überspringt, ${ }^{1173}$ muss die Konsequenz in der Annahme eines Verhaltens liegen, dessen staatliche

1170 Vgl. KK-OWiG/Mitsch Einl. Rn. 115.

1171 Hefendehl ZIS 2016, 636 (641 ff.).

1172 Dieses als Beispiel für die Aktivierung des Ordnungswidrigkeitenrechts heranziehend Stellungnahme des Deutschen Anwaltvereins Nr. 12/2016, S. 11.

1173 S. oben Teil 3 B. II. 2. e). 
Sanktionswürdigkeit insgesamt nicht mit der Integrität des Sports begründet werden kann.

d) Veränderte staatliche Regulierung des Sportwettenmarkts

Schließlich ist bei der Bewertung staatlicher Maßnahmen zum Schutz der Integrität des Sports außerhalb des eingriffsintensiven Strafrechts auch die Regulierung des Glücksspielsektors in den Blick zu nehmen. Da die Bedingungen der Wettmärkte entscheidenden Einfluss auf das von $\$ 265$ c StGB adressierte wettbezogene Match Fixing nehmen, könnte ihre regulative Gestaltung einen erheblichen Beitrag zu seiner Verhinderung leisten und die Integrität des Sports vor derartigen Angriffen effektiv schützen. Aus diesem Potenzial könnte sich ein weiteres Indiz für die fehlende Erforderlichkeit einer strafrechtlichen Intervention zumindest im Hinblick auf $\$ 265 \mathrm{c}$ StGB ergeben, das sich auch durch einen Rückgriff auf die bereits erwähnte ökonomische Kriminalitätstheorie festigen ließe.

Ihr zufolge ist der vom Täter erwartete Nutzen einer wettbezogenen Spielmanipulation eng verbunden mit dem erzielbaren Wetterlös, während die entgegenstehende Größe der Kosten erheblich vom Entdeckungsrisiko geprägt wird. ${ }^{1174}$ In Form der Beschränkung bestimmter Wettformen, Höchstgrenzen für Einsätze und der Ermöglichung des Aufspürens verdächtiger Wettmuster stehen der Sportwettenregulierung durchaus geeignet erscheinende Steuerungsinstrumente zur Einflussnahme auf beiden Seiten zur Verfügung. Ließe sich bereits durch glücksspielregulatorische Maßnahmen ausreichend auf die Abwägung einwirken, so dass sich wettbezogenes Match Fixing rationalen Akteuren nicht mehr als lohnenswert darstellte, bedürfte es keiner mit der Erhöhung der Kostenvariable begründete Kriminalstrafe mehr. Um dies zu ermitteln, werden der Zusammenhang von Wettenregulierung und Integritätsschutz theoretisch genauer beschrieben und die praktische Umsetzbarkeit anhand der gegenwärtigen Rechtslage in Deutschland und möglicher alternativer Regulierungsmodelle überprüft.

1174 S. oben Teil 2 A. III. 2. a). 
aa) Intendierter Integritätsschutz durch den Glücksspielstaatsvertrag

Ausweislich $\ 1$ des Glücksspielstaatsvertrages, der ein Übereinkommen der 16 Bundesländer zur Schaffung bundeseinheitlicher Rahmenbedingungen für die Veranstaltung von Glücksspielen darstellt, zählt auch die Vorbeugung von Gefahren für die Integrität des sportlichen Wettbewerbs zu dem Bündel an Zielen, die mit den getroffenen Regelungen gleichrangig verfolgt werden. Im Schnittfeld von staatlichem Interesse an einer Glücksspielregulierung und Integritätsschutz im Sport befindet sich dabei insbesondere die Bekämpfung illegaler Wettmärkte. Deren Gefährdungspotenzial für authentische sportliche Wettbewerbe wurde bereits angedeutet. ${ }^{1175}$ Erkennt man in der Aussicht auf hohe finanzielle Gewinne bei gleichzeitig geringem Entdeckungsrisiko maßgebliche motivationale Antriebsfaktoren einer durch sportferne Akteure initiierten Spielmanipulation, ${ }^{1176}$ so bieten zugängliche, den verbandsinternen Überwachungssystemen aber entzogene Schwarzmärkte ohne Einsatzlimits die nahezu idealen Bedingungen. Ihre Zurückdrängung zielt somit auf einen gewichtigen kriminogenen Anreiz und könnte durchaus Manipulationsabsprachen verhindern.

Da sich das Problem existenter Schwarzmärkte mit dem ursprünglich für den Bereich des Glücksspiels etablierten staatlichen Veranstaltungsmonopol nicht nur nicht lösen ließ, sondern gar zu wachsen drohte, wurde dieses mit dem am 1. Juli 2012 in Kraft getretenen Ersten Glücksspieländerungsvertragsgesetz (1. GlüÄndStV) für das Segment der Sportwetten zu Gunsten einer gewissen Marktöffnung gelockert, nach der für eine Probephase von 7 Jahren insgesamt 20 Konzessionen für Sportwettanbieter erteilt werden sollten $\left(\mathbb{1 0 a}\right.$ i.V.m. $\$ \int \mathbb{S} 4 \mathrm{ff}$. GlüStV aF). ${ }^{1177}$ Ein solches Konzessionsmodell mit Höchstzahlbegrenzung sollte den nicht mehr beherrschten natürlichen Spieltrieb der Bevölkerung wieder in geordnete und überwachte Bahnen lenken und hierdurch die unverzichtbare Vorbedingung für das Eingreifen weiterer im GlüStV enthaltener Regelungen zum unmittelbaren Integritätsschutz schaffen, die ihrerseits nur auf lizensierte Anbieter Anwendung finden. ${ }^{1178}$

1175 S. oben Teil 2 A. III. 1. a) bb).

1176 Vgl. Weinbuch Sportwettmanipulationen, S. $15 \mathrm{f}$.

1177 Neunzehntes Hauptgutachten der Monopolkommission, BT-Drs. 17/10365, S. 54.

1178 Zur grundlegenden Bedeutung der Kanalisierung der Spielnachfrage hin zu legalen Glücksspieltätigkeiten Haucap/Nolte/Stöver (Hrsg.) Faktenbasierte Eva- 
$\mathrm{Zu}$ jenen zählen vor allem die in $₫ 21 \mathrm{Abs.} 1$ und $4 \mathrm{GlüStV}$ verankerten inhaltlichen Restriktionen über Art und Umfang zulässiger Sportwetten. Demnach sind solche Wetttypen, denen eine erhöhte Manipulationsanfälligkeit zugeschrieben wird, aus dem Sortiment der Wettanbieter zu entfernen. Da etwa einzelne Ereignisse während eines sportlichen Wettbewerbs aufgrund ihrer nicht zwangsläufigen Ergebnisrelevanz technisch und moralisch leichter manipulativ herbeigeführt und die hierin liegende Integritätsverletzung schwieriger nachgewiesen werden könnten, treffe dies auf Wetten auf einzelne Vorgänge wie etwa Torschützen, Eckbälle, Strafstöße oder gelbe Karten (sog. Ereigniswetten) ebenso zu wie auf Wetten während des laufenden Sportereignisses (sog. Live-Wetten), die sich nicht allein auf das Endergebnis bezögen und bei denen sich Manipulatoren stärkere Schwankungen der Quoten und eine schwierigere Erfassung verdächtiger Wettmuster zunutze machten. ${ }^{1179}$ Daneben ordnet $\$ 21$ Abs. 3 S. 1 GlüStV eine organisatorische, rechtliche, wirtschaftliche und personelle Trennung zwischen der Veranstaltung von Sportwetten und der Veranstaltung von Sportereignissen an, um bereits dem Anschein von Interessenskollisionen und dem Entstehen von Manipulationsrisiken entgegenzuwirken. Außerdem wird in $\$ 5 \mathrm{GlüStV}$ die Werbung für Sportwetten insofern eingeschränkt, als es hierfür grundsätzlich einer durch die Länder ausgestellten Befugnis bedarf, die sich auf die schlechthin unzulässige Werbung für Sportwetten im Fernsehen unmittelbar vor oder während der LiveÜbertragung von Sportereignissen nicht erstrecken kann.

bb) Ausbleibender Vollzug und zweifelhafte Geeignetheit

Gerade die den Bereich der Sportwetten betreffenden Regelungen des 1. GlüÄndStV gerieten schnell nach Inkrafttreten zum Gegenstand zahlreicher Rechtsstreitigkeiten. So wies etwa der hessische Verwaltungsgerichtshof das vorgesehene Verfahren der Lizenzvergabe durch ein eigens eingerichtetes Glücksspielkollegium als intransparent und gegen Bundesstaats-

luierung, S.95; Neunzehntes Hauptgutachten der Monopolkommission, BTDrs. 17/10365, S. 54.

1179 Vgl. die amtliche Erläuterung zum Ersten Glücksspieländerungsstaatsvertrag zu $\ 21$, abgedruckt in: Uwer Glücksspielrecht S. 69; zust. Streinz/Liesching/ Hambach/Bolay/Pfütze $\$ 21$ GlüStV Rn. 22. Zu den spezifischen Integritätsrisiken dieser Wetttypen ferner Forrest/McHale/McAuley International Journal of Sport Finance 2008, 156 (161 f.). 
und Demokratieprinzip verstoßend zurück. ${ }^{1180}$ Auch der Europäische Gerichtshof erklärte das sportwettenbezogene Schutzkonzept des Glücksspieländerungsstaatsvertrags für inkonsistent und mit europäischem Recht unvereinbar. ${ }^{1181} \mathrm{Da}$ Bemühungen um einen Zweiten Glücksspieländerungsstaatsvertrag, der unter Berücksichtigung dieser höchstrichterlichen Rügen und einer weiteren kritischen Stellungnahme der Europäischen Kommission ${ }^{1182}$ eine weitere Liberalisierung des Sportwettenmarkts in Form des Wegfalls der Höchstzahlbegrenzung der vergebenen Lizenzen vorsah, ${ }^{1183}$ am Widerstand von Schleswig-Holstein und Nordrhein-Westfalen vorerst scheiterte, ist bis Ende des Jahres 2019 keine einzige Konzession auf Grundlage des GlüStV erteilt worden. Stattdessen operierten die Wettanbieter teilweise mittels ihnen vorläufig ausgestellter Erlaubnisse, teilweise unter bloßer Berufung auf die Dienstleistungsfreiheit auf dem deutschen Markt, ohne dass die Aufsichtsbehörden auf Einhaltung der auf Integritätsschutz abzielenden Vorschriften in den $\$ \$ 4,5,23$ GlüStV drängten. ${ }^{1184}$

Der Ablauf der im 1. GlüÄndStV auf sieben Jahre beschränkten Experimentierphase am 30. Juni 2019 ließ eine neue Regelung für den Bereich der Sportwetten erforderlich werden, die in Form eines im März 2019 beschlossenen Dritten Glücksspieländerungsstaatsvertrages (3. GlüÄndStV) am 1. Januar 2020 in Kraft trat. Dieser hebt durch Streichung des Abs. 3 in $\$ 10 \mathrm{a}$ GlüStV aF die Begrenzung der Zahl der Sportwettenkonzessionen nun tatsächlich auf. Anstelle des dadurch obsolet gewordenen Auswahlverfahrens zwischen mehreren geeigneten Erlaubnisbewerbern sieht das vom Regierungspräsidium Darmstadt durchzuführende neue Erlaubnisverfahren vor, jedem Bewerber, der nachweislich die unverändert gebliebenen Erlaubnisanforderungen ( $\$ \$ 4 \mathrm{ff}$. GlüStV) erfüllt, eine Konzession zu erteilen. Diese wird allerdings nur bis zum 30. Juni 2021 befristet erteilt werden. An diesem Datum endet die Laufzeit des aktuellen GlüStV. Eine Anschlussregelung ist gegenwärtig noch nicht absehbar. ${ }^{1185}$ Es handelt sich daher bloß um eine der Überbrückung dienende Verlängerung der Experi-

1180 VGH Hessen vom 16.10.2015 - 8 B 1028/15, NVwZ 2016, $171 \mathrm{ff}$.

1181 EuGH vom 4.2.2016 - C-336/14, NVwZ 2016, 369 ff.

1182 Empfehlung der Europäischen Kommission vom 14. Juli 2014 (2014/478/EU).

1183 Vgl. Art. 1 Nr. 4 b) des Entwurfs zum Zweiten Glücksspieländerungsstaatsvertrags vom 16. März 2017; zu den Änderungen im Einzelnen und hieran zu übender verfahrensbezogener Kritik Becker ZfWG 2017, 446 (447ff.); Hilf) Umbach ZfWG 2017, 234 (237 ff.).

1184 Haucap/Nolte/Stöver (Hrsg.) Faktenbasierte Evaluierung, S. 97 f.; Hilf/Umbach ZfWG 2017, 234 (236).

1185 Zu vagen Reformüberlegungen Hilf/Umbach ZfWG 2019, 337 (339). 
mentierphase mit abermals offenem Schicksal. Ein klares und Rechtssicherheit versprechendes Konzept ist für den Bereich der Sportwetten weiterhin nicht erkennbar.

Unabhängig von seinem ausgebliebenen Vollzug bestanden aber auch begründete Zweifel an der theoretischen Geeignetheit des limitierten Konzessionsmodells und seiner flankierenden Maßnahmen zur Vorbeugung von Gefahren für die Integrität des Sports. So deuten empirische Erkenntnisse gar auf kontraproduktive Effekte des verfolgten Ansatzes hinsichtlich des postulierten Ziels der Schwarzmarktbekämpfung hin. Eine nahezu willkürlich festgesetzte quantitative Begrenzung von Konzessionen ungeachtet der hohen Anzahl eintrittswilliger Anbieter in den Markt der Sportwetten schließt per se zahlreiche Anbieter aus und bildet damit eine wesentliche Mitursache für einen anwachsenden Grau- und Schwarzmarkt. ${ }^{1186}$

Diese Bedenken haben sich im Zuge der Aufhebung der Kontingentierung durch den 3. Glücksspieländerungsstaatsvertrags und der Verlängerung der Experimentierphase nicht verflüchtigt. Es ist unklar, ob sich Wettanbieter, die in den vergangenen Jahren unter Ausnutzung der entstandenen juristischen Grauzone ihr Angebot weitgehend ohne Reglementierungen zur Verfügung stellen konnten, durch die Aussicht auf eine zeitlich eng befristete Konzession dazu bewegen lassen, in den regulierten Bereich überzutreten. ${ }^{1187}$ Abschreckend dürfte dabei auch die Unsicherheit bezüglich der künftigen behördlichen und gerichtlichen Vollzugspraxis der weiterhin vorgesehenen erheblichen Einschränkungen des Wettprogramms - Verbot von Livewetten auf bestimmte Spielereignisse in $\$ 21$ Abs. 4 S. 2 GlüStV, starres gesetzliches Einsatzlimit für Wetten im Internet in Höhe von monatlich 1.000 Euro in $\$ 4$ Abs. 5 Nr. 2 S. 2 GlüStV - wirken, denen konzessionierte Anbieter grundsätzlich unterworfen wären. ${ }^{1188}$ Gerade die sog. Live-Wetten erfreuen sich großer Beliebtheit und erreichen einen Anteil von bis zu $70 \%$ aller über das Internet getätigten Einsätze. ${ }^{1189}$ Ihre stärkere Reglementierung und der gänzliche Ausschluss von Ereigniswetten kann zur Abwanderung hieran interessierter Wettspieler in illegale Märkte führen. ${ }^{1190}$

1186 Neunzehntes Hauptgutachten der Monopolkommission, BT-Drs. 17/10365, S. 21; Becker/Hilf/Nolte/Uwer/Hilf/Nolte \$10a GlüStV Rn. 32.

1187 Skeptisch etwa die Europäische Kommission in einer Stellungnahme zum 3. GlüÄndStV, Aktenzeichen GD GROW/B/2 - N105 04/63.

1188 Hilf/Umbach ZfWG 2019, 337 (339).

1189 ICSS/Sorbonne (Hrsg.) Part 1, S. 104.

1190 Haucap/Nolte/Stöver (Hrsg.) Faktenbasierte Evaluierung, S. 192 (206 f.). 
Kritisch zu bewerten ist dies insofern, als der zur Rechtfertigung der Restriktionen angeführte Grund des erhöhten Gefährdungspotenzials dieser Wettformen sowohl für die Authentizität sportlicher Wettbewerbe als auch für die Suchtprävention klarer empirischer Belege entbehrt. Die Annahme eines bei Live- und Ereigniswetten erhöhten Manipulationsrisikos erscheint mit Blick auf die leichtere Umsetzung des Vereinbarten im laufenden Wettbewerb zunächst zwar nachvollziehbar, verkürzt die Einschätzung aber unzulässig auf die Angebotsseite und lässt Faktoren außer Betracht, die die Nachfrage nach diesen Wettformen bei Vorteilsgebern hemmen. Den maßgeblichen Anreiz einer Manipulationsabsprache setzt das Produkt aus erzielbarer Gewinnsumme und möglichst geringem Entdeckungsrisiko. Aufgrund von Einsatzlimitierungen dürfte die Manipulation von Live- oder Ereigniswetten potenziellen Vorteilsgebern aber weniger profitabel und in Folge des insgesamt weniger liquiden Wettmarkts auch als leichter identifizierbar erscheinen, was sich auch auf die bisher erwiesenen Fälle wettbezogener Spielmanipulationen stützen lässt. Diesen lagen überwiegend weiterhin zulässige Pre-Match-Wetten auf das Endergebnis eines Spiels oder die Anzahl der erzielten Tore zugrunde. ${ }^{1191}$ Da die von Live-Wetten ausgehende erhöhte Suchtgefahr ebenfalls in Zweifel steht, ${ }^{1192}$ wird die durch die Beschränkung des Angebots trotz erheblicher Nachfrage drohende Abwanderung in nicht-reglementierte Wettmärkte ohne überzeugende Rechtfertigung in Kauf genommen. Diese Tendenz könnte auch durch das angesprochene Werbeverbot gefestigt werden, das die Lenkung der Aufmerksamkeit einer großen Zielgruppe auf legale Anbieter erschweren dürfte.

Insgesamt sind somit weder der gegenwärtige Schwebezustand noch das Konzept eines vielfach limitierten Konzessionsmodells geeignet, das integritätsschützende Ziel der Kanalisierung zu verwirklichen. Im Gegenteil scheinen sich die befürchteten kontraproduktiven Effekte in der seit Inkrafttreten des 1. GlüÄndV im Jahr 2012 nachvollzogenen Marktentwicklung niederzuschlagen, die ein rasantes Wachstum des nicht-regulierten

1191 Van Rompuy Spielmanipulationen, S. 15 ff.; Haucap/Nolte/Stöver (Hrsg.) Faktenbasierte Evaluierung, S. 205 f.; ICSS/Sorbonne Part 1, S. 103.

1192 Diese wird mit der höheren Ereignisfrequenz begründet, die schnell zu einem Verlust der Kontrolle über das eigene Wettverhalten führen könne, s. Pressemitteilung der Bundeszentrale für gesundheitliche Aufklärung Nr. 604/2010; ausführlich zur Widerlegung dieser Annahme mit Rückgriff auf Studien Haucap/Nolte/Stöver (Hrsg.) Faktenbasierte Evaluierung, S. 45 ff. 
Markts in Anteil und Gesamtmarktvolumen zu erkennen gibt. ${ }^{1193}$ Im internationalen DICE-Kanalisierungsindex, der anhand des Vergleichs von sechs europäischen Staaten untersucht, wie geeignet gesetzgeberische Maßnahmen sind, Glücksspiele aus dem Grau- oder Schwarzmarkt in den regulierten Bereich zu überführen, belegt Deutschland den letzten Rang. ${ }^{1194}$

cc) Verbesserter Integritätsschutz durch alternative Regulierungsmodelle

Kritik an einer unzureichenden Bekämpfung von Schwarzmärkten durch die gegenwärtige Regulierungsform entfaltete im Rahmen der Erforderlichkeitsprüfung aber nur dann ein gegen $\$ 265$ c StGB einsetzbares argumentatives Potenzial, wenn alternative Regulierungsmodelle diesbezüglich eine überlegene Wirkung versprächen und gesetzgeberisch unproblematisch umsetzbar wären. Entsprechend der vorstehenden Analyse wäre hierbei zuvörderst an eine vollständige Marktfreigabe zu denken, die noch immer eine an qualitative Kriterien gebundene staatliche Genehmigung vorsehen könnte, die zahlenmäßige Beschränkung zugelassener Anbieter aber entfallen ließe. Eingriffe in deren jeweilige Angebotsgestaltung könnten abgebaut bzw. evidenzbasierter ausgestaltet werden. Statt des Verbots besonders beliebter Wettformen ließe sich ein Ausschluss bewettbarer Veranstaltungen in Erwägung ziehen, die aufgrund einer leichteren Verführbarkeit der teilnehmenden Akteure und einer geringeren medialen Kontrolle als anfälliger für Manipulationen gelten dürfen. Fokussiert werden könnten hierbei neben Wettbewerben, an denen überwiegend Amateure oder Minderjährige teilnehmen, ${ }^{1195}$ und unterklassige Ligen in Einzelsportarten wie Tennis, in denen das Ergebnis immer nur von einer Person abhängt, ${ }^{1196}$ auch tabellarisch bedeutungslose Ligaspiele am Ende einer Sai-

1193 Zuletzt Glücksspielaufsichtsbehörden der Länder (Hrsg.) Jahresreport 2017, S. $3 \mathrm{f} ., 13 \mathrm{f}$.

1194 Vgl. die Darstellung bei Haucap/Nolte/Stöver (Hrsg.) Faktenbasierte Evaluierung, S. $158 \mathrm{ff}$.

1195 Haucap/Nolte/Stöver (Hrsg.) Faktenbasierte Evaluierung, S. 210; s. hierzu auch die auffordernden Beschlüsse des Europäischen Parlaments vom 14. März 2013 (2013/2567[RSP]) sowie vom 10. September 2013 (2012/2322[INI]), die in ersten Reformüberlegungen zur Anschlussregelung des Mitte 2021 in seiner aktuellen Fassung auslaufenden GlüStV zumindest auch diskutiert werden, s. Hilf/Umbach ZfWG 2019, 337 (342).

1196 Für ein Ausschluss von Wetten auf unterklassige Tennis-Ligen eintretend Becker ZfWG 2017, 2 (7). 
son. ${ }^{1197}$ Eine derartige Marktöffnung setzte Anreize für Anbieter, ihre Wetten im legalen und kontrollierten Bereich anzubieten. Gleichzeitig würden Wettspieler ihre präferierten Wettformen auch im legalen Wettmarkt vorfinden. ${ }^{1198}$ Neben diesen wirkungsbezogenen Vorteilen fügte sich ein solcher Ansatz auch in die europa- bzw. verfassungsrechtlichen Vorgaben zur Dienstleistungs- (Art. 56 AEUV) und Berufsfreiheit (Art. 12 GG) ein. ${ }^{1199}$

Obschon das Wachstum der Schwarzmärkte durch eine derartige Regulierung zweifelsohne ausgebremst würde, wird deren gänzliche Auflösung angesichts der globalisierten Dimensionen des Sportwettenmarkts und der territorial begrenzten Reichweite eines staatlichen Regulierungskonzeptes indes kaum zu erwarten sein. ${ }^{1200}$ Gerade wenn Manipulatoren aus den genannten Gründen der Gewinnmaximierung und Entdeckungsreduzierung gezielt nach Anbietern suchen, die keine Einsatzlimits vorschreiben und der staatlichen oder sportverbandlichen Kontrolle entzogen sind, werden sie diese insbesondere im asiatischen Raum auch finden. Staatliche Versuche, über die Implementierung von Internetsperren oder das Blockieren von in diese Richtung fließenden Zahlungen den Zugang zu solchen Schwarzmärkten zu versperren, bergen zum einen rechtliche Probleme und geben viele Möglichkeiten der technischen Umgehung preis. ${ }^{1201}$

Davon unabhängig stellt sich die Frage, ob sich eine unbeschränkte Marktöffnung im Sportwettensegment auch mit den übrigen Zielen der Glücksspielregulierung vereinbaren ließe. So bedeutend die Zurückdrängung von Schwarzmärkten als Grundbedingung weiterer Maßnahmen auch sein mag, wird in der plötzlichen Vielzahl lizensierter Anbieter teilweise auch eine Gefahr für die Integrität des Sports gesehen. Ein großes

1197 Diese Einschränkung wurde etwa von der französischen Online-Glücksspielaufsichtsbehörde ARJEL eingeführt, nachdem verdächtige Wettmuster insbesondere bei Spielen festgestellt worden waren, bei denen aus sportlicher Sicht für eine Mannschaft wenig auf dem Spiel stand, vgl. Van Rompuy Spielmanipulationen, S. 7.

1198 Sich für eine solche Marktöffnung ohne zahlenmäßige Beschränkung aussprechend Weinbuch Sportwettmanipulationen, S. 200 ff.; Vesper/Nolte, in: Württembergischer Fußballverband (Hrsg.), Sportwette, 2013, S.9 (12); aA Adams/ Rock ZfWG 2010, 381 (385 f.).

1199 Zum Verstoß einer festgelegten Höchstzahl der Konzessionen gegen die Dienstleistungsfreiheit gemäß Art.56 AEUV vgl. VG Wiesbaden vom 15.4.2016 - 5 K 1431/14. WI, ZfWG 2016, 275.

1200 So wohl auch Weinbuch Sportwettmanipulationen, S. 198 ff.; Forrest/McHale/ McAuley International Journal of Sport Finance 2008, 156 (164).

1201 Vgl. zum Access-Blocking Ennuschat/Klestil ZfWG 2009, 389 (391ff.); Brugger/ Leven ZfWG 2007, $302 \mathrm{ff}$. 
Angebot senke zwangsläufig das staatliche Kontrollniveau der im Markt aktiven Anbieter einschließlich ihrer Verpflichtung zur Umsetzung integritätsschützender Maßnahmen und könne zudem die Gefahr von Spielsucht erhöhen, die wiederum bei Sportlern als Anreiz der Manipulationsbeteiligung ausgemacht wurde. ${ }^{1202}$ Bei der Prognose des integritätsschützenden Potenzials der Sportwettenregulierung bleiben deren vielfältige und teilweise gegenläufige Zielvorgaben einschränkend zu berücksichtigen. Konkret auf die Reduzierung der Anreize für Manipulatoren zielende Maßnahmen sind zwangsläufig von restriktiver Art und erschweren somit die Kanalisierung des Spieltriebs. So würde die Vorgabe von Einsatzlimits und einer zu führenden Sperrdatei für verdächtige Spieler einerseits die Aussicht auf durch Manipulationen erzielbare hohe Wettgewinne schmälern, andererseits gerade eine Abwanderung in illegale Märkte ohne Beschränkungen auslösen, die von den Überwachungssystemen nicht erfasst werden. Ein im Sinne der Kanalisierung auf weitreichende Marktöffnung und den Abbau inhaltlicher Beschränkungen und Werbeverbote setzendes Konzept könnte hingegen mit den gleichrangigen Regelungszwecken der Suchtprävention und des Jugendschutzes konfligieren. ${ }^{1203}$

Solange der Gesetzgeber diese Ziele in einem Gleichgewicht auszutarieren hat, erscheinen gewisse Abstriche beim Schutz der Integrität des Sports unvermeidlich. Dennoch hat er sich um ihre wechselseitige Optimierung im Sinne praktischer Konkordanz zu bemühen. Vor diesem Hintergrund vermag aber weder die unübersichtliche gegenwärtige Rechtslage noch das zuvor präferierte Konzessionsmodell zu überzeugen. Ihre genannten Schwachpunkte eröffnen einem alternativen Regulierungsansatz durchaus erhebliche Potenziale eines verbesserten Schutzes der Integrität des Sports. Diese dürften vor allem in der Unterstützung der von Sportverbänden und Wettanbietern geleisteten Präventionsarbeit liegen, indem ein zurückgedrängter Schwarzmarkt die Effektivität der eingesetzten Überwachungssysteme schärft. ${ }^{1204}$ Eine unmittelbare Einflussnahme auf die Abwägung manipulationsgeneigter Akteure erscheint hingegen allenfalls in Einzelfällen denkbar.

Trotz der möglichen Reduzierung wirtschaftlicher Anreize bleiben solche sowohl auf dem regulierten Markt als auch in weiterhin bestehenden

1202 Weinbuch Sportwettmanipulationen, S. $132 \mathrm{f}$.

1203 Einem solchen Ansatz daher kritisch gegenüber stehend Hayer ZfWG 2017, 445 f.; allgemein zum Zielkonflikt Haucap/Nolte/Stöver (Hrsg.) Faktenbasierte Evaluierung, S. 111.

1204 Sinner FS Neumann, 2017, S. 1222 (1240). 
illegalen Rückzugsräumen präsent. Eine vollständige Entwertung motivierender Faktoren und ein hierdurch prognostizierbarer drastischer Rückgang von Manipulationsabsprachen liegen demnach außerhalb der Erreichbarkeit einer nationalen glücksspielrechtlichen Regulierung. ${ }^{1205}$ Auch eine signalhafte und wirkungsvolle Bekräftigung der gesellschaftlichen Bedeutung sportethischer Werte ist in diesem Kontext nur schwer möglich. Die staatliche Regulierung des Sportwettenbereiches kann in veränderter Form durchaus zum Schutz der Integrität des Sports beitragen, liefert angesichts der beschriebenen Unzulänglichkeiten aber kein weiteres Indiz gegen die Erforderlichkeit einer strafrechtlichen Erfassung wettbezogener Manipulationsabsprachen.

\section{Hinsichtlich des Vermögensschutzes}

Von den dargestellten verbandsinternen Präventionsmaßnahmen beabsichtigen insbesondere die in Kooperation mit den Sportwettanbietern entwickelten und eingesetzten Wett-Monitoring-Systeme auch den Schutz des Vermögens der Sportwettenanbieter. Werden infolge der Feststellung eines verdächtigen Wettverhaltens Spiele abgesagt oder aus dem Angebot der Wettanbieter entfernt, sollen dadurch gerade auch der Abschluss von Wetten zu verzerrten Quoten sowie die Auszahlung illegitimer Wettgewinne verhindert werden. Aufgrund der aufgezeigten Umgehungsmöglichkeiten ist der den Wettanbietern hierdurch garantierte Vermögensschutz jedoch beschränkt und vermag gerade die Erforderlichkeit des ihrem Schutz dienenden $₫ 265$ c StGB nicht in Frage zu stellen. Im Gegensatz zur Integrität des Sports wird das Vermögen allerdings auch vielfältig strafrechtlich geschützt. Da im Rahmen der Erforderlichkeit neu geschaffener Normen nicht nur außerstrafrechtliche Alternativmittel vergleichsweise heranzuziehen sind, sondern auch zum Schutz des gleichen Interesses bereits existierende strafrechtliche Regelungen Berücksichtigung finden müssen, sind die $\$ \$ 265$ c, 265d StGB zunächst auf diesbezügliche Überschneidungen zu überprüfen.

Solche lassen sich für die spezifische Schutzrichtung des Sportwettbetrugs gemäß $₫ 265$ c StGB auch feststellen. So wurde gezeigt, dass der Ab-

1205 Ähnlich skeptisch im Hinblick auf das Fehlen einer transnationalen Harmonisierung der Glücksspielregulierung Van Rompuy Spielmanipulationen, S. 38; Forrest/McHale/McAuley International Journal of Sport Finance 2008, 156 (159). 
schluss eines Wettvertrags unter Täuschung des Wettanbieters über eine zuvor verabredete Spielmanipulation dessen Vermögen schädigen und den Tatbestand des $\$ 263$ StGB bzw. $\$ 263$ a StGB verwirklichen kann. ${ }^{1206}$ Etabliert aber bereits das klassische Vermögensstrafrecht ein rechtsgutsbezogenes Schutzniveau, das von der neu geschaffenen Strafnorm nicht erweitert wird, erweist sich letztere als überflüssig. Aufgrund der im Vergleich zu den $\$ \$ 263$, 263a StGB vorverlagerten Tathandlung stellt $\$ 265$ c StGB einen intensiveren Eingriff dar. Der Bereich der straffreien Ausübung der allgemeinen Handlungsfreiheit wird nicht erst durch die Täuschung bei Abschluss eines Wettvertrages verlassen, sondern bereits mit der vorangehenden korruptiven Abrede mit einem Akteur des Sports. Erforderlich wäre diese erweiterte Freiheitsbeschränkung nur, wenn sich hierdurch gleichzeitig der verfolgte Zweck des Vermögensschutzes signifikant verbesserte.

Weist eine Vereinbarung von Manipulationen berufssportlicher Wettbewerbe hingegen keinen Bezug zu einer Sportwette auf, greifen im prognostizierbaren weiteren Verlauf zumeist mangels Anhaltspunkte einer Täuschung weder $\$ \$ 263,263 \mathrm{a}$ StGB ein, noch eröffnen die $\$ \$ 266,299,331 \mathrm{ff}$. StGB strafrechtliche Reaktionen. Da sich die Tathandlungen gemäß $\$ 265 \mathrm{~d}$ StGB auf einen bisher straflosen Bereich erstrecken, ist zu prüfen, inwieweit die hiervon potenziell betroffenen Vermögensinteressen von Sportlern, Vereinen, Veranstaltern und Sponsoren womöglich bereits einen ausreichenden außerstrafrechtlichen Schutz erfahren.

a) Effektivierung des strafrechtlichen Vermögensschutzes durch $\$ 265 \mathrm{c}$ StGB?

Insbesondere die strafgerichtliche Aufarbeitung der Manipulationskomplexe um Ante Sapina unterstrich in den Augen des Gesetzgebers offenbar gewisse Unzulänglichkeiten des klassischen Vermögensstrafrechts in der Konfrontation mit wettbezogenem Match Fixing. Die beträchtlichen Schwierigkeiten, sowohl eine auf den manipulierten Wettbewerb bezogene Wettsetzung als auch einen konkreten Vermögensschaden in der Praxis nachzuweisen, sorgten dafür, dass der Betrugstatbestand nicht auf alle als strafwürdige Angriffe auf das Vermögen der Wettanbieter und redlichen

1206 S. oben Teil 2 B. III. 1. und 2. 
Wettteilnehmer erachteten Konstellationen angewendet werden könne. ${ }^{1207}$ Seine Voraussetzungen und die hiermit korrespondierenden und höchstrichterlich zuletzt verschärften Nachweispflichten erschwerten eine wirksame Strafverfolgung der Beteiligten. ${ }^{1208}$ Indem $\$ 265$ c StGB nun auf einen eingetretenen und nachzuweisenden Vermögensschaden verzichtet und die Tathandlung von der Platzierung der Wette auf das eigentliche Match Fixing verlagert, verspricht er diesbezüglich auf den ersten Blick Erleichterungen für Gerichte und Strafverfolgungsbehörden.

Anders als ein Vermögensschaden muss der in $\$ 265$ c StGB verlangte angestrebte Vermögensvorteil nicht beziffert werden, da dessen Höhe letztlich von Wettquoten und anderen Faktoren abhängt und zum Zeitpunkt des Eingehens der Unrechtsvereinbarung noch gar nicht kalkulierbar ist. ${ }^{1209}$ Und anstatt womöglich verschleierte Verbindungslinien zwischen einer vereinbarten Manipulation und einer nachfolgenden Wettsetzung nachziehen zu müssen, könnten sich die Ermittlungsbehörden fortan auf den einen, zeitlich wie räumlich eng umgrenzten Handlungskomplex der korruptiven Abrede fokussieren. ${ }^{1210}$ Resultierten hieraus eine erhöhte Aufdeckungswahrscheinlichkeit und konsequente Strafverfolgung für den Bereich manipulierter Sportwetten, ließe sich auch im Sinne einer Stärkung der generalpräventiven Wirkung des strafrechtlichen Verbots von einem verbesserten Vermögensschutz ausgehen.

Umgekehrt begründen allerdings gerade die grundsätzliche Erscheinungsform einer korruptiven Abrede sowie die voraussetzungsreiche Tatbestandsfassung Zweifel daran, ob mithilfe des $\$ 265$ c StGB Nachweisschwierigkeiten tatsächlich überwunden werden können. Bereits in anderen Bereichen des Korruptionsstrafrechts stehen die Ermittlungsbehörden regelmäßig vor dem Problem, eine Absprache zwischen Vorteilsgeber und Vorteilsnehmer nachzuweisen, die nur in seltenen Ausnahmefällen dokumentiert wird oder vor möglichen Zeugen erfolgt. ${ }^{1211}$ Bei $\$ 265 \mathrm{c}$ StGB kommt hinzu, dass mangels sprachlicher Präzision des Normtextes Unklar-

1207 BT-Drs. 18/8831, S. 11; Nolte Stellungnahme zu BT-Drs. 18/8831, S. 2 f.; Giebel Causa Sport 2011, 254 (256); Mintas, in: Kainz/Scherrer/Werner (Hrsg.), Sportfinanzierung, 2012, S. 97 (99).

1208 Momsen/Vaudlet, in: Emrich/Pierdzioch/Pitsch (Hrsg.), Falsches Spiel, 2015, S. 219 ( 225 ff.).

1209 Kubiciel WiJ 2016, 256 (259).

1210 Kubiciel Wij 2016, 256 (258 f.); ähnlich Jaleesi Kriminalisierung, S. 109.

1211 S. Hetzer NJW 2004, 3746 (3747 f.); Wabnitz/Janovsky/Schmitt/Bannenberg 13. Kapitel Rn. 22; zur Vermutung einer hohen Dunkelziffer bei Korruptionsdelikten Bundeskriminalamt (Hrsg.) Bundeslagebild Korruption 2018, S. 23. 
heit über die einzelnen Bezugspunkte der erforderlichen Unrechtsvereinbarung herrscht, ${ }^{1212}$ die die zielgerichtete Ausrichtung von Ermittlungen erschweren kann.

Unabhängig von einer Behandlung des Sportwettbezuges als Gegenstand der Unrechtsvereinbarung hat sich jedenfalls der Vorsatz des Sportakteurs auf die Ausnutzung seiner Manipulationshandlung zu einer betrügerischen Wettsetzung zu richten. Bei dessen Nachweis dürfte es jedoch erhebliche Mühe bereiten, den Einwand des Vorteilsnehmers zu entkräften, ihm sei nicht bewusst gewesen, dass die Manipulationsabsprache der Platzierung einer Wette dienen sollte. ${ }^{1213}$ Oftmals wird tatsächlich nicht ausdrücklich über den Wettbetrug als antreibendes Motiv gesprochen worden sein. Dieser angelegten Beweisproblematik ist sich der Gesetzgeber offenbar auch selbst bewusst, wenn er sie mit der Hilfestellung für die Praxis abzumildern versucht, bei Ermittlung des Vorsatzes des Vorteilsnehmers könne berücksichtigt werden, ob allein die Platzierung einer Sportwette die Manipulationsabsprache aus Sicht der an ihr Beteiligten als wirtschaftlich sinnvoll erscheinen lasse. ${ }^{1214}$ Eine solche Vorgehensweise birgt jedoch die Gefahr, dass eine vom Vorsatz erfasste Unrechtsvereinbarung losgelöst von einem tatsächlich geführten Nachweis allein aufgrund der Plausibilität anderer Ziele überprüft wird und somit quasi als ein dem Strafrecht fremder Anscheinsbeweis zu widerlegen wäre. ${ }^{1215}$ Zumal ähnliches auch hinsichtlich der als Gegenleistung eines Sportrichters von den $\$ \mathbb{S} 265 \mathrm{c}$, 265d Abs. 3, 4 StGB geforderten Unterordnung der Neutralitätspflicht unter die Interessen des Vorteilsgebers droht. Der kaum zu führende Nachweis eines entsprechenden Willens hierzu dürfte in der Praxis wohl regelmäßig direkt aus der Vorteilsgewährung gefolgert werden. ${ }^{1216}$

1212 S. oben Teil 1 B. I. 2.

1213 Löffelmann recht + politik 2/2016, 1 (2); Stellungnahme der Bundesrechtsanwaltskammer Nr. 8/2016, S. 8; Stellungnahme des Deutschen Richterbundes Nr.2/16, S. 4; Bohn KriPoZ 2017, 88 (94); Kubiciel jurisPR-StrafR 3/2016 Anm. 1.

1214 BT-Drs. 18/8831, S. 15; dem im Ergebnis folgend Jaleesi Kriminalisierung, S. 237 ff. sowie Stam NZWiSt 2018, 41 (45), denen zufolge von der äußeren Tatsache des Forderns, Sich-Versprechen-Lassens oder Annehmens eines Vorteils durch den Vorteilsnehmer weitgehend unproblematisch auf dessen Billigung eines rechtswidrigen Vermögensvorteils aus einer Sportwette geschlossen werden könne.

1215 Pfister StraFo 2016, 441 (446f.); Stellungnahme der Bundesrechtsanwaltskammer Nr. 8/2016, S. 8; Rübenstabl JR 2017, 264 (278f.); aA Jaleesi Kriminalisierung, S. $238 \mathrm{f}$.

1216 Pfister StraFo 2016, 441 (446f.). 
Auch der auf der Komplementärseite des Vorteilsgebers erforderliche Nachweis einer zum Zeitpunkt der Abrede bestehenden Absicht zur Platzierung einer entsprechenden Sportwette wird regelmäßig allein als Ableitung aus der später tatsächlich abgeschlossenen Wette erbracht werden können. Erst sie kann die zuvor kaum erschütterbare Einlassung des Vorteilsgebers widerlegen, die Abrede hätte gar nicht auf eine öffentliche Sportwette gezielt. ${ }^{217}$ Damit aber löst sich der für $\$ 265$ c StGB ausgemachte ermittlungstechnische Vorteil einer Trennung von Manipulationsvereinbarung und Wettsetzung gleich wieder auf. Die Vorverlagerung des Vermögensschutzes geht folglich mit einer hochkomplexen Tatbestandsstruktur einher, deren objektive wie subjektive Voraussetzungen die Nachweisund Anwendungsschwierigkeiten generieren, die sie überwinden wollte.

Auch die beanstandeten Nachweisschwierigkeiten beim Vermögensschaden im Rahmen der $\$ \mathbb{S} 263$, 263a StGB stellen kein im Sinne eines effektiven Vermögensschutzes zwingend auszugleichendes Defizit dar. Die bei einer solchen Argumentation des Gesetzgebers häufig mitschwingende Implikation, wonach ein bestimmtes Verhalten von grundsätzlich rechtsgutsbeeinträchtigender Qualität sei, was bedauerlicherweise nur nicht in jedem Einzelfall bewiesen werden könne, ist einzuschränken. Denn ein nicht zu erbringender Nachweis kann genauso auch die Fehlerhaftigkeit der Anfangshypothese offenlegen. ${ }^{1218}$ Übertragen auf die Strafbarkeit von Wettmanipulationen ließe sich etwa anführen, die Anwendungsschwierigkeiten der $\mathbb{S} 263$, 263a StGB infolge des schwer nachzuweisenden Schadens der Wettanbieter belegten gerade die Funktionsfähigkeit des bisherigen Vermögensstrafrechts, da es abgesehen von wenigen Institutionen von unumstrittener gesamtgesellschaftlicher Relevanz ${ }^{1219}$ keines strafrechtlichen Sondervermögensschutzes bedürfe, wo ein konkreter Vermögensschaden eben nicht beweisbar sei. ${ }^{1220}$ Prozessuale Beweisschwierigkeiten infolge einer verfassungsrechtlich gebotenen Schadensbestimmung sind als notwendige Konsequenz einer am Bestimmtheitsgrundsatz orientierten Rechtspflege hinzunehmen. ${ }^{1221}$ Für eine strafrechtliche Erfassung von Verhaltensweisen, die im Vorfeld der Rechtsgutsverletzung liegen, aber gleichwohl strafrechtliches Unrecht darstellen, existiert überdies die Möglichkeit

1217 Tsambikakis StV 2018, 319 (323).

1218 Tsambikakis StV 2018, 319 (323).

1219 Zum Vergleich des $\$ 265$ c StGB mit den $\$ \$ 264$, 264a, 265b StGB eingehend Teil 3 C. III. 2. a).

1220 Stellungnahme der Bundesrechtsanwaltskammer Nr. 8/2016, S. 5.

1221 Sinner FS Neumann, 2017, S. 1229 (1236); Stellungnahme des Deutschen Anwaltsvereins Nr. 12/2016, S. 8. 
der Bestrafung wegen eines versuchten Betrugs. Auch insofern bedarf es als Reaktion auf Beweisschwierigkeiten keiner tatbestandlichen Vorverlagerung des Vermögensschutzes der Wettanbieter, die dann eine Grenzziehung zum versuchten Betrug erschwert. ${ }^{1222}$

Wird vom Gesetzgeber an der Erfassung der Wettmanipulationsfälle allein über $\mathbb{S} 263$, 263a StGB ferner kritisiert, dass sich das Verhalten der manipulationsbereiten Sportler, Trainer oder Schiedsrichter allenfalls als Teilnahmehandlung bestrafen ließe, was ihre im kriminellen Gesamtkontext essenzielle Rolle nicht ausreichend widerspiegele, ${ }^{1223}$ so folgt aus der mit $₫ 265$ c StGB nun geschaffenen Möglichkeit ihrer täterschaftlichen Bestrafung keine Verbesserung des Vermögensschutzes. Die unterschiedliche Bewertung von externem Vorteilsgeber und sportinternem Vorteilsnehmer kann allenfalls mit Blick auf das Rechtsgut der Integrität des Sports als unbillige Privilegierung der Sportakteure aufgefasst werden, da diese die dem Sportethos widerstrebende Spielmanipulation letztlich ausführen sollen. Gewendet auf das Vermögen der Wettanbieter erscheint sie hingegen sachgerecht, da der diesbezügliche Angriff in der Platzierung der Wette liegt und die fördernde Mitwirkung des Sportlers in Form der Durchführung der Manipulation hieran nicht zwingend Tatherrschaft begründen muss. ${ }^{1224}$

Nach diesem Vergleich lässt sich also festhalten, dass bereits das klassische Vermögensstrafrecht bezogen auf die Interessen der Sportwettanbieter ein Schutzniveau bereitstellt, das sich dogmatisch einfügt und auch in puncto Effektivität nicht zwangsläufig hinter $\$ 265$ c StGB zurückbleibt. Der Verzicht auf einen nachweisbaren Verletzungserfolg und die Vorverlagerung der Tathandlung in $\$ 265$ c StGB führt entgegen der Erwartung des Gesetzgebers nicht zwangsläufig zu einem Gewinn an Anwendungssicherheit. Stattdessen steht zu befürchten, dass die im Rahmen der $\$ \$ 263$, 263a StGB identifizierten tatbestandsbezogenen Nachweisschwierigkeiten lediglich durch neue ersetzt wurden. Abgesehen davon, dass die korruptive Absprache in der erforderlichen Form faktisch kaum nachzuweisen sein wird, reicht es aus, wenn der strafrechtliche Schutz zum Zeitpunkt der Platzierung der Wette einsetzt. Die einzelnen Beiträge zu einem gegen das Vermögen der Wettanbieter geführten Angriff lassen sich sachgerecht bestrafen. Die Wettanbieter werden hierdurch auch in ihren Möglichkeiten des

1222 Bohn KriPoZ 2017, 88 (93); Satzger Jura 2016, 1142 (1155); i. Erg. auch MüKoStGB/Schreiner $\$ 265$ c Rn. 3.

1223 BT-Drs. 18/8831, S. 11; zust. Kubiciel WiJ 2016, 256 (259).

1224 Tsambikakis StV 2018, 319 (324). 
Selbstschutzes nicht beeinträchtigt. Sie können unter Ausnutzung der privatrechtlichen Vertragsfreiheit die Bedingungen der Wettplatzierung so ausgestalten, dass manipulationsbezogene und für sie tatsächlich vermögensschädigende Täuschungen strafrechtliche Folgen nach sich ziehen. ${ }^{1225}$ Auch unter Berücksichtigung der Aspekte, die die Begründung des Bedarfs nach einem spezifischen Tatbestand des Sportwettbetrugs prägen, lässt sich durch die Einführung des $\$ 265$ c StGB kein signifikant verbesserter strafrechtlicher Vermögensschutz bezüglich der Wettanbieter feststellen. Ein solcher könnte dann allenfalls noch allein über die Vermögensinteressen der als mitgeschützt benannten redlichen Wettteilnehmer begründet werden, deren mögliche Beeinträchtigung jenseits einer Wettplatzierung des manipulationsbeteiligten Wettspielers von $\$ 263$ StGB nicht abgebildet wird.

b) Außerstrafrechtlicher Vermögensschutz im Berufssport

Es wurde bereits angedeutet, dass angesichts des weit gezogenen Kreises der im wirtschaftlichen Umfeld des Berufssports aktiven Vermögensträger eine manifeste Vermögensbeeinträchtigung durch eine korruptive Abrede i.S.d. $\$ 265 \mathrm{~d}$ StGB häufig nur durch (mehrfache) Vermittlung vorstellbar ist. Dies bedingt zum einen die Nicht-Anwendbarkeit des klassischen Vermögensstrafrechts, da der potenziell Geschädigte regelmäßig weder selbst Adressat einer Täuschung ist, noch sich zu einem solchen in einer Nähebeziehung befindet und auch die Voraussetzungen des Vermögensschadens und der Stoffgleichheit nicht erfüllt sein dürften. ${ }^{1226}$ Es beschränkt darüber hinaus auch die zivilrechtlichen Schutzmöglichkeiten. Nur in seltenen Fällen wird der Vermögensträger in einer vertraglichen Beziehung zu den verantwortlichen Akteuren einer vermögenswirksamen Spielmanipulation stehen, die es ihm einerseits erlaubt, sich präventiv gegen derlei Risiken abzusichern, im Schadensfall aber auch als Grundlage einer Regulierung herangezogen werden kann. Für Veranstalter und Sponsoren mag man diese Möglichkeit der Gestaltung der Geschäftsbeziehung inklusive bestimmter Verhaltenserwartungen an den teilnehmenden oder unterstützten Einzelsportler oder Verein noch annehmen können. ${ }^{1227}$ Für Vereine, die aufgrund der Manipulation eines anderen Spiels aus einem Turnier

1225 Tsambikakis StV 2018, 319 (324).

1226 Vgl. Valerius SpuRt 2005, $90 \mathrm{f}$.

1227 Tsambikakis StV 2018, 319 (324). 
ausscheiden oder in eine untere Liga absteigen und infolgedessen finanzielle Einbußen erleiden, kommen zivilrechtliche Ausgleichsansprüche ebenso wenig in Betracht wie für jenseits des Sponsorings wirtschaftlich am Sport beteiligte Unternehmen, deren Umsatz von der allgemeinen Attraktivität der Sportart abhängt.

Die mittelbare und von externen Faktoren abhängige Wirkweise von Manipulationen ohne Wettbezug erschwert bereits die Feststellung kausaler Beeinträchtigungen fremder Vermögensinteressen. Hält man diese aber zumindest nicht für ausgeschlossen, so führt die Mittelbarkeit auf der Prüfungsstufe der Erforderlichkeit dazu, dass den in Betracht kommenden Vermögensinteressen kein hinreichender Schutz durch bereits existierende strafrechtliche oder außerstrafrechtliche Maßnahmen gewährt werden kann.

\section{Zwischenergebnis}

In der Auseinandersetzung mit außerstrafrechtlichen Maßnahmen stellen sich die $\$ \$ 265$ c, 265d StGB als nicht erforderlich zum Schutz der Integrität des Sports heraus. Zunächst vermag es der Sport selbst, seinen eigenen Integritätsanspruch zumindest bis zu einem gewissen Grad durchzusetzen. Folge eines zunehmenden Problembewusstseins der Verbände sind häufig kooperativ entwickelte Maßnahmen der primären und situativen Prävention, die aufgrund spezifischer Schwachstellen in ihrer Wirkung nicht überschätzt werden sollten, denen bei der Ausbildung eines sportethischen Bewusstseins und der Erschwerung der konkreten Bedingungen von Match Fixing aber durchaus gewisse positive Effekte zugetraut werden können. Daneben steht ein ausdifferenziertes Verbandsrecht zur Verfügung, auf dessen Grundlage bereits manipulationsbezogene Absprachen der verbandsrechtlich gebundenen Sportakteure mit empfindlichen Sanktionen beantwortet werden können, denen bisweilen auch arbeitsrechtliche Konsequenzen folgen. Mit Schulungen und Erziehungsprogrammen als präventiven Elementen, Warn- und Hinweisgebersystemen als Kontrolleinrichtungen und den verbandsrechtlichen Disziplinarorganen als Ermittlungsinstanzen steht die Selbstregulierung des Sports trotz Effektivitätszweifeln im Einzelnen grundsätzlich in Einklang mit dem als erfolgsver- 
sprechend bewerteten Drei-Säulen-Modell der Korruptionsbekämpfung. ${ }^{1228}$

Die festgestellten immanenten Grenzen der verbandsrechtlichen Verfahren sind insofern hinnehmbar, als Sportarten, denen eine nach außen hin verlässliche Gewährleistung ihrer Authentizität nicht gelingt, unter gesellschaftlichem Druck stehen. Dieser müsste die für das Rechtsgut konstitutive Wertevermittlung durch den Sport entweder weiterhin durch eine integritätsgesteuerte Umverteilung der Zuschauergunst garantieren oder aber den Sport insgesamt als Transporteur von Fairness, Leistungsbereitschaft und Teamgeist durch andere Interaktionsfelder ersetzen, ohne dass hierdurch gesamtgesellschaftlich ein Engpass vorbildhafter Sozialisationsinstanzen entstünde. In beiden Fällen erweist sich eine zusätzliche strafrechtliche Absicherung der immateriellen Werte des Leistungssports als überflüssig.

Insofern verfangen auch die zum Beleg der vermeintlich überlegenen Schutzwirkung einer strafrechtlichen Verfolgung vorgebrachten Argumente insgesamt nicht. Dass die Sportverbände bei der konsequenten Ahndung von Match Fixing gelegentlich von den ihnen durch Strafverfolgungsbehörden zur Verfügung gestellten staatlichen Ermittlungsergebnissen profitieren, ist unbestritten. Dieser Austausch hat sich in der Vergangenheit aber auch bereits über herkömmliche Betrugsverfahren vollzogen und wird sich durch die $\$ \$ 265 \mathrm{c}, 265 \mathrm{~d}$ StGB auch aufgrund knapper justizieller Ressourcen nicht signifikant intensivieren lassen. Den strafrechtlichen Handlungsbedarf über das Schlagwort der Organisierten Kriminalität begründen zu wollen, hieße, deren tatsächliche Ausprägung im Bereich des Match Fixing in gleicher Weise zu überschätzen wie davon losgelöst die grundsätzliche Eignung der neuen Tatbestände zu deren effektiver Bekämpfung. Der hier als ausreichend erachtete Schutz der Integrität des Sports durch verbandsinterne, privatrechtliche und gesellschaftliche Regelungsmechanismen steht schließlich auch einer Aktivierung des Ordnungswidrigkeitenrechts entgegen, das wohl schon grundsätzlich nicht zum Schutz kollektiver Funktionszusammenhänge berufen ist und eine kollektive Vertrauensbildung als Vorbedingung eines Wertetransfers auch nicht festigen könnte.

In Bezug auf den verfolgten Zweck des Vermögensschutzes ist nach den Tatbeständen und den von ihnen jeweils einbezogenen Vermögensträgern zu differenzieren. Der von $\$ 265$ c StGB angestrebte Schutz des Vermögens

1228 Schenk, in: Kainz/Scherrer/Werner (Hrsg.), Sportfinanzierung, 2012, S. 139 (143). 
der Wettanbieter und redlichen Wettteilnehmer lässt sich zwar durch die insoweit ineffektiven außerstrafrechtlichen Präventionsmaßnahmen nicht hinreichend realisieren. In Form der $\$ \$ \$ 263$, 263a StGB existieren jedoch bereits gegen die Erscheinungsform des Sportwettbetrugs einsetzbare strafrechtliche Sanktionsmöglichkeiten. Die an deren eingeschränkter Anwendbarkeit anknüpfende Kritik des Gesetzgebers verfängt insofern nicht, als jene dogmatisch betrachtet ein systemkonformer Ausfluss des fragmentarischen Vermögensstrafrechts ist und praktisch betrachtet durch die Schaffung eines abstrakten Gefährdungsdeliktes von hochkomplexer Tatbestandsstruktur auch nicht überwunden werden kann. Der primär verfolgte Schutz des Vermögens der Wettanbieter erfährt durch $\$ 265$ c StGB keine Effektivierung. Die Vorschrift ist diesbezüglich somit nicht erforderlich und könnte allenfalls noch über den ausschließlichen Schutz des Vermögens der redlichen Wettteilnehmer legitimiert werden.

Dieses Ergebnis lässt sich auf $₫ 265 \mathrm{~d}$ StGB schon deswegen nicht übertragen, weil das bereits vorhandene strafrechtliche Instrumentarium gegen Manipulationen berufssportlicher Wettbewerbe ohne Bezug zu einer Sportwette nicht zum Einsatz gebracht werden kann. Potenziell betroffene Sportler, Vereine, Verbände oder Unternehmen können ihre Interessen auch weder durch verbandsinterne Vorkehrungen selbst absichern noch im Nachhinein durch privatrechtliche Ausgleichsansprüche kompensieren. Fehlende strafrechtliche wie außerstrafrechtliche Maßnahmen begründen somit die Erforderlichkeit des $\$ 265 \mathrm{~d}$ StGB zum Vermögensschutz.

\section{Angemessenheit}

Obwohl sich somit hinsichtlich des intendierten Schutzes der Integrität des Sports beide Strafvorschriften und hinsichtlich des intendierten Vermögensschutzes zumindest $\$ 265$ c StGB bereits als nicht erforderlich herausgestellt haben, sind sie zwecks vollständiger Bewertung der im Rahmen der Geeignetheitsprüfung aufgeworfenen deliktsstrukturellen Besonderheiten schließlich auch auf ihre Verhältnismäßigkeit im engeren Sinne (Angemessenheit) zu untersuchen. Danach darf die staatliche Reaktion nicht außer Verhältnis zum angestrebten Zweck stehen. ${ }^{1229}$ Auf die Prüfung einer Strafbewehrung gewendet muss diese unter Berücksichtigung der von ihr ausgehenden Grundrechtsbeschränkungen der Betroffenen im Rahmen einer Gesamtwürdigung noch in angemessenem Verhältnis zu

1229 Vgl. etwa BVerfGE 44, 353 (373). 
dem durch sie erzielbaren Rechtsgüterschutz stehen und der Strafanlass den Straffolgen entsprechen. ${ }^{1230}$ Hieraus folgt insbesondere eine Beschränkung der Vorverlagerung des Strafrechts, die relational an zu respektierende Freiheitssphären und einen vermittelten Zuwachs des Rechtsgüterschutzes angebunden wird. Indem sich mit zunehmender Entfernung der pönalisierten Verhaltensweise vom geschützten Rechtsgut auch der Begründungsaufwand der geforderten Proportionalität zwischen dem angestrebten Zweck des Straftatbestandes und der Beeinträchtigung der Freiheitssphäre erhöht, setzt die Prüfungsstufe einen Kontrapunkt zum reinen Schutzgedanken. ${ }^{1231}$

Vor diesem Hintergrund sind die bereits beschriebenen Rechtsgutsbeziehungen der Tathandlungen aufzugreifen, gegebenenfalls zu präzisieren und mit potenziell betroffenen Freiheitsansprüchen des Individuums sowie dem Gewicht und der Dringlichkeit der beiden verfolgten Schutzzwecke in Abwägung zu bringen. Insbesondere im Hinblick auf die festgestellte Vorverlagerung des strafrechtlichen Vermögensschutzes durch die $\$ \$ 265 c, 265 d$ StGB verlangt die Angemessenheit eine normative Betrachtung der im Rahmen der Geeignetheit für ausreichend erachteten vermögensbezogenen Gefährdungswirkung der Tathandlungen unter Berücksichtigung ihrer deliktsstrukturellen Einordnung. Außerdem ist der Strafrahmen der $\$ \$ 265 c$ c, 265d StGB in die Bewertung einzubinden. Denn eine Strafnorm ist nur dann verhältnismäßig im engeren Sinne, wenn auch Tatbestand und Rechtsfolge sachgerecht aufeinander abgestimmt sind und die Strafandrohung nach Art und Maß dem unter Strafe gestellten Verhalten nicht schlechthin unangemessen ist. ${ }^{1232}$

\section{Hinsichtlich der Integrität des Sports}

In Bezug auf Sportethos und Authentizität der Wettbewerbe als innere Funktionsbedingungen der Integrität des Sports weisen die einem Korruptionsdelikt nachempfundenen Tathandlungen der $\$ \$ 265$ c, 265d StGB die für diese Deliktsgruppe typische Vorverlagerungstendenz auf. Denn eine sportethische Werte erst verletzende und die Authentizität des Wettbewerbs beeinträchtigende Manipulation muss zur Vollendung der Tatbestände weder eingetreten sein noch einzutreten drohen. Das Ausmaß der

1230 BVerfGE 90, 145 (185).

1231 Hefendehl Kollektive Rechtsgüter, S. 104.

1232 BVerfGE 120, 224 (241). 
Vorverlagerung vor den Zeitpunkt einer so bestimmten Interessensverletzung variiert dabei nach den unterschiedlichen Tathandlungen und ist bei einem einseitigen „Fordern“ oder „Anbieten“, das das Zustandekommen einer manipulationsbezogenen Unrechtsvereinbarung offen lässt, am stärksten ausgeprägt. ${ }^{1233} \mathrm{Im}$ Hinblick auf das in dieser Arbeit für die gesetzgeberische Rechtsgutskonzeption für maßgeblich erachtete Kollektivvertrauen erbringt eine nur einseitig intendierte Manipulationsabsprache im Vergleich zu deren einvernehmlicher Vereinbarung einen geringeren Beitrag zur rechtsgutsbeeinträchtigenden Kumulationswirkung. Angesichts des Eindrucks in ihrem Gefährdungsgrad reduzierter Tathandlungen ist zu prüfen, ob sich die tatbestandliche Ausgestaltung der integritätsbezogenen Angriffsformen in Gegenüberstellung mit Konstitution und Gewicht des geschützten Rechtsguts sowie dem festgesetzten Strafmaß als angemessen darstellt.

Hierzu eignet sich ein Vergleich mit den Korruptionsdelikten der $\$ \$ 331 \mathrm{ff}$. StGB, an deren integritätsbezogene Schutzrichtung, korruptiven Angriffsformen und Strafrahmen die $\$ \$ 265$ c, 265d StGB erkennbar angeglichen wurden. Wird im Rahmen der $\$ \$ 331 \mathrm{ff}$. StGB der tatbestandliche Einbezug einseitiger Willenserklärungen (auch hier: „fordern“ bzw. „anbieten") damit begründet, dass es angesichts der essenziellen Bedeutung eines vertrauenswürdigen, gemeinwohlorientierten Verwaltungshandelns schon den Anschein der Käuflichkeit amtlicher Entscheidungen zu verhindern gelte, ${ }^{1234}$ fällt die Feststellung einer vergleichbaren Interessenslage bei

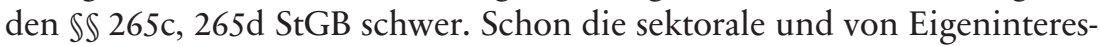
sen bestimmte Eigenart des Leistungssports dürfte ein unterstelltes Vertrauen in dessen Integrität robuster gegenüber bloßen Anscheinsmeldungen von Bestechung und Bestechlichkeit ausgestalten. Selbst bei Anerkennung des Rechtsguts unter entsprechender Annahme eines Kollektivvertrauens kommt der Integrität des Sports keine mit der Funktionsfähigkeit der öffentlichen Verwaltung vergleichbare Bedeutung zu, die die Erstreckung auf vorgelagerte Handlungen mit herabgesetztem Kumulationsbeitrag auszugleichen vermag. ${ }^{1235}$

Das geringere Gewicht des vermeintlichen Vertrauensgegenstands und damit verbunden auch die robustere Konstitution des vermeintlich aufgebrachten Vertrauens untersagt die uneingeschränkte Übertragung der Annahme, schon das Fordern oder Anbieten eines Vorteils füllten das Un-

1233 Vgl. Krack ZIS 2016, 540 (543).

1234 Vgl. NK-StGB/Kublen $\$ 331$ Rn. 13; BGH NStZ 2005, 334 (335).

1235 Rübenstabl JR 2017, 264 (267). 
recht der Tat hinreichend aus, das von nachfolgenden Annahmehandlungen allenfalls noch graduell gesteigert würde. Vor dem Hintergrund dieser strukturellen Unterschiede stößt auch die mit der Vorteilsannahme und

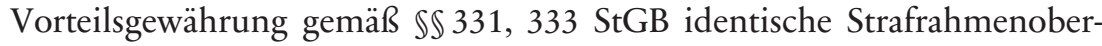
grenze der $\$ \$ 265 c$, 265d StGB von einer Freiheitsstrafe von bis zu drei Jahren auf durchgreifende Bedenken. Über die bereits begründete Ablehnung vorangehender Legitimitätsanforderungen hinaus bestehen mindestens hinsichtlich der Tatbestandsmäßigkeit einseitig angestrebter Unrechtsvereinbarungen auch erhebliche Zweifel an der Proportionalität von Eingriffswirkung und integritätsbezogenem Schutzzweck der $\$ \$ \$ 265$ c, 265d StGB. ${ }^{1236}$

\section{Hinsichtlich des Vermögensschutzes}

Die jeweilige Beziehung zwischen den Tathandlungen der $\$ \mathbb{S} 265 \mathrm{c}, 265 \mathrm{~d}$ StGB und dem Vermögen als zweitem geschütztem Rechtsgut wurde in einer deliktsstrukturellen Einordnung bereits skizziert. Dabei wurde für beide Delikte eine Verlagerung der Strafbarkeit in das Vorfeld einer manifesten Beeinträchtigung geschützter Vermögensträger festgestellt. Im Rahmen der Angemessenheit gilt es deren Ausmaß auch anhand eines Vergleichs mit dem systematischen Umfeld der Delikte nachzuzeichnen und eine unzulässige Überschreitung eines verfassungsrechtlich fundierten und dem Strafrecht entzogenen Kernbereichs privater Lebensgestaltung auszuschließen. ${ }^{1237} \mathrm{Im}$ Sinne der geforderten Abwägung bleibt sodann zu überprüfen, inwieweit die durch die Vorverlagerung jedenfalls intensivierte Beeinträchtigung der allgemeinen Handlungsfreiheit der Betroffenen ausgeglichen wird. Als Kompensationsfaktoren kommen die durch die Gefährdungswirkung der Tathandlungen vermittelte Dringlichkeit des Rechtsgutsschutz sowie dessen Stärkung durch eine signifikante Effizienzsteigerung oder die Einbeziehung eines zusätzlichen Schutzgutes in Betracht. Die gefundenen Abwägungsergebnisse sind schließlich mit dem Strafrahmen der $\$ \mathbb{S} 265 \mathrm{c}$, 265d StGB in Bezug zu setzen.

1236 So auch Krack ZIS 2016, 540 (546).

$1237 \mathrm{Zu}$ dessen Herleitung Hefendehl Kollektive Rechtsgüter, S. 104 ff. 
a) Ausmaß der Vorverlagerung und Ausgleich in $\$ 265$ c StGB

Im Hinblick auf den Vermögensschutz der Wettanbieter wurde $\$ 265 \mathrm{c}$ StGB als Vorbereitungsdelikt qualifiziert. Das Ausmaß der Vorverlagerung des strafrechtlichen Vermögensschutzes verdeutlicht ein Abgleich des $\$ 265$ c StGB mit seinem Deliktsumfeld im 22. Abschnitt des StGB. Im Vergleich zu seinem grammatischen Anknüpfungspunkt des Betrugs gemäß $\$ 263$ StGB ist für die durch $\$ 265$ c StGB bewirkte Vorverlagerung nicht der bloße Verzicht auf den Nachweis eines Vermögensschadens entscheidend. Dieser ist etwa auch für den sog. Submissionsbetrug nach $\$ 298$ StGB prägend, ohne dass dieser auf die Abgabe eines rechtswidrig entstandenen Angebots abstellende Tatbestand die Strafbarkeit im Vergleich zur im Rahmen des Betrugs erforderlichen Täuschungshandlung wirklich nach vorne verlagern würde. ${ }^{1238}$ Indem $\$ 265$ c StGB nun aber die bloße Abrede zwischen Vorteilsgeber und Vorteilsnehmer ausreichen lässt, bestimmt er kein Äquivalent zur Täuschungshandlung, sondern ein diese lediglich vorbereitendes Verhalten zum strafrechtlichen Anknüpfungspunkt.

Die tatbestandsstrukturelle Orientierung des $\$ 265$ c StGB an einem Korruptionsdelikt, durch die schon die erste für die Integrität des Sports für gefährlich gehaltene Verhaltensweise erfasst werden soll, bewirkt im Hinblick auf den Vermögensschutz einen Grad an Vorverlagerung, der auch denjenigen der ebenfalls als abstrakte Gefährdungsdelikte ausgestalteten sog. Kranzdelikte des Betrugs übertrifft. Denn sie entkoppelt ihn von jeglicher Art der Kommunikationsbeziehung zwischen Täter und Getäuschtem, wie sie beim Subventionsbetrug gemäß $\$ 264$ StGB mit dem potenziellen Subventionsgeber, beim Kapitalanlagebetrug gemäß $\$ 264$ a StGB mit einem Kreis von potenziellen Kapitalanlegern und beim Kreditbetrug gemäß $₫ 265$ b StGB mit dem potenziellen Kreditgeber erforderlich ist. ${ }^{2239}$ Einer entsprechenden Kontaktaufnahme mit dem Wettanbieter bedarf es für $\$ 265$ c StGB nicht, worin sich dessen Charakter als Vorbereitungsdelikt äußert. Als weiterer Unterschied zu den Sonderbetrugsvorschriften fällt zudem der Verzicht auf eine Regelung zur tätigen Reue in den $\$ \$ 265 c$, 265d StGB ins Auge. Dieser ist zwar bezüglich des Schutzes des kollektiven Rechtsguts konsequent, ${ }^{1240}$ erweitert den Eingriffscharakter der Pönalisie-

1238 Hefendehl Kollektive Rechtsgüter, S. 278.

1239 Valerius Jura 2018, 777 (780); Berberich ZfWG 2017, 347 (349).

1240 Zur Abhängigkeit der Systemkonformität einer Vorschrift über die tätige Reue vom geschützten Rechtsgut Hefendehl Kollektive Rechtsgüter, S. 267, 280. 
rung des Vermögensangriffs angesichts des frühen Vollendungszeitpunktes und der Irrelevanz der Aufgabe des Tatplans aber beträchtlich. ${ }^{1241}$

Trotz der weiten Vorverlagerung der Strafbarkeit respektiert $\$ 265$ c StGB den verfassungsrechtlich vor strafrechtlichen Eingriffen geschützten Kernbereich privater Lebensgestaltung. Die pönalisierten Verhaltensweisen unterfallen keiner zwingend staatsfreien Intimsphäre. Diese hat bereits verlassen, wer mit einem auf ein regelverletzendes Verhalten abzielenden Angebot an eine andere Person herantritt oder für die unlautere Verzerrung eines sportlichen Wettbewerbs aktiv einen persönlichen Vorteil fordert. Gleichwohl liegt in der Vorverlagerung der Strafbarkeit eine Beschränkung der allgemeinen Handlungsfreiheit, die in der vorzunehmenden Abwägung eines Ausgleichs auf Schutzgutseite bedarf. Bei den Kranzdelikten des Betrugs wird die strafrechtliche Erfassung abstrakter Vermögensgefahren mit dem das Vermögen ergänzenden Schutz zusätzlicher Kollektivinteressen begründet, die dem insgesamt verfolgten Schutzkonzept zusätzliches Gewicht verleihen. An diesem Ansatz soll wohl auch für $\$ 265$ c StGB angeknüpft werden, wenn der Gesetzgeber die Bezeichnung des Sportwettbetrugs explizit an den Kreditbetrug gemäß $\$ 265$ b StGB anlehnt ${ }^{1242}$ und die Unzulänglichkeit eines strafrechtlichen Schutzes über $\$ 263$ StGB damit begründet, der Unrechtsgehalt von Manipulationsabsprachen gehe über die vom Betrugstatbestand abgebildete Verletzung fremder Vermögensinteressen hinaus. ${ }^{1243}$

Doch der Versuch einer aus der Anlehnung an die $\mathbb{S}$ 264, 264a, 265b StGB abgeleiteten Legitimität blendet zum einen die an der Vorverlagerung dieser Sonderbetrugsvorschriften ihrerseits geübte Kritik aus ${ }^{1244}$ und übersieht zum anderen, dass neben dem bereits festgestellten Unterschied im Vorverlagerungsgrad auch die jeweils herangezogenen Kollektivrechtsgüter keine Gleichsetzung erlauben. Mit dem allgemeinen Interesse an einer wirksamen staatlichen Wirtschaftsförderung ( $\$ 264$ StGB), ${ }^{1245}$ der Funktionsfähigkeit des Kapitalmarkts $(\mathbb{2} 264 \mathrm{a} \mathrm{StGB})^{1246}$ sowie der Kredit-

1241 Krit. zum Fehlen einer Regelung zur tätigen Reue Bohn KriPoz 2017, 88 (94); Stam NZWiSt 2018, 41 (47).

1242 BT-Drs. 18/8831, S. 12.

1243 BT-Drs. 18/8831, S. 11.

1244 Vgl. etwa Wohlers Deliktstypen, S. 173 ff., 340; zu $\$ 264$ StGB Schünemann, in: Hefendehl/von Hirsch/Wohlers (Hrsg.), Rechtsgutstheorie, 2003, S. 133 (149 f.); zu $\$ 264 a$ StGB Zieschang GA 2012, 607 ff.; Jacobi Kapitalanlagebetrug S. 263; zu $\$ 265$ b StGB Hefendehl Kollektive Rechtsgüter, S. 260 ff.

1245 OLG Hamburg NStZ 1984, 218; Eisele Strafrecht BT II Rn. 725.

1246 Schönke/Schröder/Perron $\$ 264 a$ Rn. 1; Rengier Strafrecht BT I $₫ 17$ Rn. 9. 
wirtschaft $(\$ 265 \text { b StGB })^{1247}$ werden volkswirtschaftlich bedeutsame Systeme geschützt, die individuelle Verwirklichungspotenziale garantieren. Zudem stehen sie in direktem Zusammenhang mit dem Ein- oder Umsatz von Vermögenswerten und sind daher an das mitgeschützte Rechtsgut des Vermögens angebunden. Beides trifft auf die Integrität des Sports nicht zu. ${ }^{1248}$ Diese ist bereits nicht als schutzwürdiges Rechtsgut anzuerkennen und in gesamtgesellschaftlicher Hinsicht kein vergleichbar essenzielles Subsystem. ${ }^{1249}$ Zum Vermögensschutz weisen die Bestandteile der Integrität des Sports keine natürliche Verbindung auf, da sich im Sinne der Sportethik authentische Wettbewerbe unabhängig von Kommerzialisierungserscheinungen vollziehen, während die ökonomische Seite des Sports wiederum dessen Integrität nicht zwingend voraussetzt. ${ }^{1250}$

Erfährt der mit der Pönalisierung verfolgte Zweck aus der Integrität des Sports somit keine Aufwertung, hat sich die Vorverlagerung des $\$ 265 \mathrm{c}$ StGB allein im Hinblick auf das Vermögen und die Dringlichkeit dessen Schutzes zu legitimieren. Diese wird bei Vorbereitungsdelikten durch einen hinreichenden Gefährlichkeitszusammenhang indiziert, der die Tathandlung subjektiv wie objektiv in Verbindung zum Rechtsgut setzt. Dessen im Rahmen der Geeignetheit bereits eingeschränkt vorgenommene Prüfung ist dabei aufzugreifen und zu erweitern. ${ }^{1251}$ In subjektiver Hinsicht verlangen sämtliche dort enthaltenen Tatbestände eine überschießende Innentendenz, die die Vorbereitungshandlung und die daran anknüpfende Rechtsgutsbeeinträchtigung in einem Planungszusammenhang verknüpft. Unabhängig von der Eigenschaft des tauglichen Täters als Vorteilsgeber oder -nehmer stellt die in seinen Vorsatz zwingend aufzunehmende, über die unmittelbare Manipulationsprämie hinausgehende Vorteilserlangung im Zuge einer Sportwette die Kehrseite des Vermögensschadens der Wettanbieter dar. In der Vorstellung des Vorteilsgebers tritt die künftige Betrugstat dabei aufgrund der zwingenden Kongruenz von zu manipulierendem und zu bewettendem Wettbewerb einigermaßen konkret hervor.

1247 LK-StGB/Tiedemann $\$ 265$ b Rn. 9 ff.; Fischer StGB $\$ 265$ b Rn. 3; Lackner/Kühl/ Heger/Heger $\$ 265$ b Rn. 1.

1248 Valerius Jura 2018, 777 (779); wohl auch Matt/Renzikowski/Sinner $\$ 265 c$ Rn. 4.

1249 Krack ZIS 2016, 540 (544); Stellungnahme des Deutschen Anwaltsvereins Nr. 12/2016, S. 8; Stellungnahme der Bundesrechtsanwaltskammer Nr. 8/2016, S. 5 f.; Rübenstabl JR 2017, 264 (267); Sinner FS Neumann, 2017, S. 1229 (1236); Kretschmer FS Rössner, 2015, S. 628 (644 f.).

1250 Valerius Jura 2018, 777 (779).

1251 S. oben Teil 3 C. I. 2. a). 
Damit wird auch den erhöhten Anforderungen an die subjektive Rechtsgutsbeziehung entsprochen, die für Konstellationen formuliert werden, in denen es allein beim Vorbereitenden selbst - wie eben in $\$ 265$ c Abs. 2, 4 StGB beim Vorteilsgeber - liegt, die Rechtsgutsbeeinträchtigung durch eine eigenverantwortliche Folgehandlung herbeizuführen. ${ }^{1252}$

In objektiver Hinsicht ist die Minimalvoraussetzung einer generellen Eignung der erfassten Tathandlungen zur Vorbereitung einer späteren Rechtsgutsbeeinträchtigung bereits festgestellt worden. Auch eine schlechthin unzulässige Beschreibung der tatbestandsmäßigen Vorbereitungshandlung mit einer sozial indifferenten, dem Kernbereich privater Lebensgestaltung zuzuordnenden Verhaltensweise wurde ausgeschlossen. Darüber hinaus kann auch die für das spezifische Gefährdungsunrecht konstitutive Typizität der Tathandlungen angenommen werden, der zufolge nur bestimmte, in Bezug auf die Rechtsgutsbeeinträchtigung als bedeutungsvoll zu wertende Eignungsbeziehungen als tatbestandsmäßig erfasst sein dürfen. ${ }^{1253}$ Zwar können mittels Manipulationsabsprachen auch andere, vor allem sportinterne Zwecke verfolgt werden. Nach $\$ 265$ c StGB ist das Verhältnis von Vorteil und intendierter Wettkampfmanipulation aber in Kenntnis der Beteiligten gerade in den Dienst einer Sportwette mit rechtswidrigem Vermögensvorteil zu stellen. Durch diese spezifizierte Zweckbestimmung, die sich bereits objektiv auszuprägen hat, ${ }^{1254}$ bereiten die Tathandlungen typischerweise eine Wettsetzung vor, bei der ein mit der Schädigung des Wettanbieters einhergehender Wettvorteil angestrebt wird.

Mitunter wird abschließend gefordert, nur solche Handlungen könnten als Vorbereitung begriffen werden, die die spätere Haupttat objektiv erleichterten oder förderten. ${ }^{1255}$ Dies müsste bei Tathandlungen, die sich in einem bloßen Sich-bereit-Erklären zu einer künftigen Tat erschöpfen, in Frage gestellt werden, da dem Sich-Erbietenden eigenverantwortliche Handlungsoptionen verblieben und der ein Erbieten Annehmende lediglich einen bereits bestehenden Tatentschluss festige. ${ }^{1256}$ Auch wenn sich die Tathandlungen des Sportakteurs nach $\$ 265$ c Abs. 1, 3 StGB auf den ersten Blick unter den Begriff des Sich-bereit-Erklärens fassen lassen, bezie-

$1252 \mathrm{Zu}$ den erhöhten Anforderungen bei sog. Vorbereitungsdelikten im engeren Sinn Puschke Vorbereitungstatbestände, S. $361 \mathrm{ff}$.

1253 Vgl. Jakobs Strafrecht AT, S. 708; Stratenwerth/Kublen Strafrecht AT $\$ 11$ Rn. 9;

Puschke Vorbereitungstatbestände, S. $264 \mathrm{f} ., 380 \mathrm{f}$.

1254 S. oben Teil 1 B. I. 2.

1255 S. etwa Puschke Vorbereitungstatbestände, S. 343.

1256 So Puschke Vorbereitungstatbestände, S. $343 \mathrm{f}$. 
hen sie sich anders als etwa in $\$ 30$ Abs. 2 StGB nicht auf die künftige Straftat, sondern auf eine straflose Manipulation. Die ihnen immanente Förderung muss aber hinsichtlich der vermögensschädigenden Wettplatzierung vorliegen. Das Fordern eines Vorteils durch einen Sportakteur bzw. seine Manipulationszusage bestärkt nicht nur einen beim Vorteilsgeber bereits ausgeprägten betrugsbezogenen Tatentschluss, sondern ermöglicht erst dessen Umsetzung. Spiegelbildlich liegt der objektive Förderungsbeitrag eines Vorteilsangebots des Vorteilsgebers gemäß $\$ 265$ c Abs. 2, 4 StGB in der Hinwirkung auf den Eintritt einer notwendigen Bedingung der anschließenden Vermögensschädigung des Wettanbieters.

Der sich aus diesen Kriterien zusammensetzende Gefährlichkeitszusammenhang ist jedoch nur eine notwendige, aber keine hinreichende Bedingung der Angemessenheit des $\$ 265$ c StGB als Vorbereitungsdelikt. Denn die als Kompensationsfaktor der Vorverlagerung herangezogene Dringlichkeit des Rechtsgüterschutzes verlangt neben einer hinreichend rechtsgutsgefährdenden Verhaltensweise auch eine mit deren Pönalisierung verbundene Effizienzsteigerung des Rechtsgüterschutzes. ${ }^{1257}$ Eine solche ist jedoch im Rahmen der Prüfung der Erforderlichkeit bereits verneint worden. ${ }^{1258}$ Die Beeinträchtigung des Vermögens der Wettanbieter erfordert den Abschluss einer Wette auf ein manipuliertes Spiel, der bei Platzierung durch den Vorteilsgeber, Vorteilsnehmer oder einen von der Manipulationsabsprache in Kenntnis gesetzten Dritten automatisch Täuschungscharakter zukommt. Eine Anhebung des durch den allgemeinen Betrugstatbestand gewährleisteten Schutzniveaus durch eine frühzeitige strafrechtliche Intervention ist angesichts der komplexen und mit Nachweisschwierigkeiten verbundenen Tatbestandsstruktur des $\$ 265$ c StGB nicht zu erwarten. ${ }^{1259}$ Sofern das Bundesverfassungsgericht den durch Vorbereitungsdelikte geleisteten Zuwachs an Rechtsgüterschutz schon durch den Mechanismus der Generalprävention vermittelt sieht, ${ }^{1260}$ ist diese generalisierende Auffassung aufgrund ihrer mangelnden Überprüfbarkeit und bedenklichen strafrechtlichen Ausweitungstendenz abzulehnen. ${ }^{1261}$

Der sachliche Grund der Vorverlagerung kann demnach nicht darin gesehen werden, das Schutzgut des Vermögens der Wettanbieter erfahre allein durch die Pönalisierung der späteren Verletzungshandlung keinen

1257 Hefendehl Kollektive Rechtsgüter, S. $106 \mathrm{f}$.

1258 S. oben Teil 3 C. II. 2. a).

1259 AA Jaleesi Kriminalisierung, S. 109.

1260 BVerfGE 90, 145 (185).

1261 Sondervotum Sommer zu BVerfGE 90, 145 (224 ff.); Zeiser Trafic, S. 153. 
ausreichenden Schutz. Da durch das Anknüpfen an der spezifischen Gefährlichkeit einer Vorbereitungshandlung der strafrechtlich etablierte Vermögensschutz der Wettanbieter nicht gestärkt wird, erweist sich die durch $\$ 265$ c StGB bewirkte Vorverlagerung des Strafrechts als unverhältnismäBig im engeren Sinne.

Auch der bereits angedeutete Alternativweg einer Legitimierung des $\$ 265$ c StGB über die ausschließlichen Ausrichtung des Vermögensschutzes auf die redlichen Wettteilnehmer endet spätestens bei der Angemessenheitsprüfung. Unbekannte Manipulationsabsprachen können zwar die Kalkulationen der übrigen Wettteilnehmer verzerren und die Gewinnchancen der auf ein anderes Ereignis setzenden Wettspieler reduzieren. Um allein hierüber aber einen Zusammenhang des tatbestandsmäßigen Verhaltens zur Beeinträchtigung manifester Vermögensinteressen herzustellen, verlaufen die Kalkulationen von Wettteilnehmern zum einen zu vielfältig, zum anderen bleibt der Bezugspunkt der Gesamtheit der redlichen Wettteilnehmer zu diffus. Denn einige werden - von der Manipulationsabsprache begünstigt - gerade verbesserte Gewinnchancen zu niedrigeren Preisen erwerben, andere womöglich selbst bei Kenntnis der geplanten Manipulation auf einen anderen Wettbewerbsausgang setzen. Ein so vermitteltes vermögensbezogenes Gefährdungspotenzial bleibt zu abstrakt, um die Angemessenheit des $\$ 265$ c StGB hierauf zu stützen.

\section{b) Ausreichend objektiv-abstrakte Gefährdung in $\$ 265 \mathrm{~d}$ StGB}

Mangels vergleichbar verlässlicher Aktivierung des Betrugstatbestands zum Schutz der Vermögensinteressen von Sportlern, Vereinen, Veranstaltern oder Sponsoren könnte $\$ 265 \mathrm{~d}$ StGB hingegen bei Manipulationsabsprachen ohne Wettbezug grundsätzlich eine Effektivierung des Vermögensschutzes gewährleisten. Da eine tatbestandlich hinreichend vorausgesetzte subjektive Rechtsgutsbeziehung jedoch fehlt, eine Legitimation des $\$ 265 \mathrm{~d}$ StGB als Vorbereitungsdelikt daher ausscheidet, ${ }^{1262}$ müsste sich die zum Ausgleich der Vorverlagerung erforderliche Dringlichkeit des Rechtsgüterschutzes aus der objektiven Gefährlichkeit der erfassten Verhaltensweisen ergeben. Zweifel hieran gründen auf der indirekten Wirkungsmodalität der Tathandlungen, deren vermögensbezogenes Gefährdungspotenzial von

1262 S. oben Teil 3 C. I. 2. b). 
eigenverantwortlichen Folgehandlungen und spezifischen Wettbewerbskonstellationen abhängt. ${ }^{1263}$

Finanzielle Einbußen drohen Vereinen oder Sportlern überwiegend erst durch tatsächlich ausgeführte und wettbewerbsverzerrende Manipulationen. Im Anschluss des tatbestandsmäßigen Verhaltens bedarf es somit der Aufrechterhaltung des gefassten Manipulationsentschlusses des Sportakteurs sowie dessen absprachegemäßer Umsetzung im Wettkampfgeschehen. ${ }^{1264}$ Die Notwendigkeit eigenverantwortlicher Anschlusshandlungen schwächt die objektive Gefahrenwirkung einer vorgelagerten Tathandlung. Hierüber kann bei $\$ 265 \mathrm{~d}$ StGB auch der bei $\$ 30$ Abs. 2 StGB fruchtbar gemachte Gedanke der Selbstbindung nicht hinweghelfen, wonach die Gefährlichkeit etwa eines nach $₫ 265 \mathrm{~d}$ Abs. 2, 4 StGB tatbestandsmäßigen Manipulationsangebots („Fordern“) durch einen Sportakteur in dessen durch die Erwartung einer Annahme eintretenden Selbstbindung gesehen werden könne, die die tatsächliche Vornahme der Manipulation wahrscheinlicher mache. ${ }^{1265}$ Denn das Ausreichen der Möglichkeit einer solchen Selbstbindung wird bei $\$ 30$ Abs. 2 StGB auch auf die Qualität eines Verbrechens als Bezugspunkt der Zusage gestützt, während die bei $₫ 265 \mathrm{~d}$ StGB in Rede stehende Manipulation nicht einmal eine strafbare Folgehandlung darstellt.

Neben dem Erfordernis ihrer eigenverantwortlichen und voraussetzungsreichen Vornahme führt die Unsicherheit über die tatsächlich vermögensbeeinträchtigende Wirkung einer Manipulation zu einer weiteren Verflüchtigung der rechtsgutsbezogenen Gefährlichkeit. ${ }^{1266}$ Selbst in berufssportlichen Wettbewerben sind einzelne Resultate nicht zwangsläufig, sondern allenfalls in wettbewerbsspezifischen Sonderkonstellationen (z.B. in über Auf- und Abstieg entscheidenden Relegationsspielen oder Ausscheidungsspielen in Turnieren) mit vermögenswerten Exspektanzen ihrer Teilnehmer verbunden. ${ }^{1267}$ Wettbewerbe, deren Resultat für beteiligte Vereine und Sportler keine unmittelbare Vermögensrelevanz entfaltet, dürften auch im Berufssport die Mehrzahl bilden. Und im Hinblick auf die in

1263 Vgl. Krack ZIS 2016, 540 (544); Jansen GA 2017, 600 (612); Satzger Jura 2016, 1142 (1153); Hdb-StR/Kindhäuser/Schumann \$34 Rn. 200 f.

1264 S. oben Teil 3 C. I. 2. b).

1265 Vgl. MüKo-StGB/Joecks/Scheinfeld \$30 Rn. 43.

1266 Jaleesi Kriminalisierung, S. 98 Fn. 433 spricht diesbezüglich von einer „zweifachen Abstraktionsebene", wobei er aufgrund der ökonomischen Durchdringung berufssportlicher Wettbewerbe gleichwohl eine Gefahr für Vermögensinteressen erkennt.

1267 Vgl. Tsambikakis StV 2018, 319 (324). 
den Schutzbereich einbezogenen Veranstalter und Sponsoren hat der Eintritt einer manifesten Vermögensbeeinträchtigung regelmäßig noch weitere Stufen zu überwinden, da Ticketverkäufe, Rechtevermarktung und Werbewert stark von der multifaktoriellen Attraktivität einer Sportart insgesamt beeinflusst werden.

Die vermögensbezogene Wirkungsmodalität der tatbestandsmäßigen Verhaltensweisen lässt sich am Beispiel des Anbietens eines Vorteils gemäß $\$ 265$ d Abs. 4 StGB veranschaulichen: Zunächst müsste etwa ein adressierter Schiedsrichter auf das Angebot des Vorteilsgebers eingehen, es dann zweitens während des Wettbewerbs immer noch umsetzen wollen und drittens hierzu auch die Gelegenheit finden, bevor die Möglichkeit besteht, dass sich seine Manipulation viertens verzerrend auf das Ergebnis auswirkt und fünftens gerade dieses manipulierte Ergebnis den Gehalt einer vermögenswerten Exspektanz eines Sportlers oder Vereins etwa in Form der konkretisierten Aussicht auf Preisgelder oder ligaabhängige Vermarktungsprämien mindert. ${ }^{1268}$ Bei Einbeziehung der von der allgemeinen Attraktivität einer Sportart abhängigen Begleitindustrie gestaltet sich die Kausalbeziehung von Manipulationsabsprachen und Vermögensbeeinträchtigungen noch diffuser.

Ein derartiger, mehrfach vermittelter Zusammenhang von Tathandlung und Rechtsgutsbeeinträchtigung transportiert allenfalls eine hochabstrakte Gefährdung des Vermögens, die keinen ausreichenden Beitrag zur Legitimierung des $\$ 265 \mathrm{~d}$ StGB leistet. ${ }^{1269}$ Die Abwendung diffuser Gefahren von Vermögensträgern, die zum Teil - etwa in Gestalt von Veranstaltern und Sponsoren - bei ihrem wirtschaftlichen Engagement im Berufssport durchaus übliche Risiken eingehen und über gewisse Selbstschutzmöglichkeiten verfügen, kann keine Dringlichkeit des Rechtsgutsschutzes begründen, die zum Ausgleich der bewirkten Vorverlagerung des Strafrechts aber notwendig wäre. Auch $\$ 265 \mathrm{~d}$ StGB erweist sich zum Schutz des Vermögens als nicht angemessen.

1268 S. Krack wistra 2017, 289.

1269 So auch MüKo-StGB/Schreiner $\$ 265$ d Rn. 3; Schönke/Schröder/Perron $\$ 265 d$ Rn. 1; Hdb-StR/Kindhäuser/Schumann \$34 Rn. 200 f.; Satzger Jura 2016, 1142 (1153); Bohn KriPoZ 2017, 88 (93); aA Waßmer ZWH 2019, 6 (8). 
c) Proportionalität von Tatbestand und Strafrahmen

Bedenken gegen die Angemessenheit der $\$ \$$ 265c, 265d StGB lassen sich auch auf der Ebene der Strafrahmengestaltung formulieren. Bei einem Vergleich der Strafrahmen fällt auf, dass auf die erhebliche Unrechtsverdünnung der $\$ \$ 265 \mathrm{c}$, 265d StGB gegenüber $\$ 263$ StGB als Vermögensverletzungsdelikt, aber auch gegenüber den einen engeren Vermögensbezug aufweisenden Sonderbetrugsvorschriften nicht angemessen reagiert wurde.

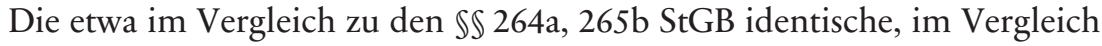
zu den einen nachweisbaren Vermögensschaden erfordernden $\$ \$ 263,266$ StGB um lediglich zwei Jahre reduzierten Höchststrafe einer dreijährigen Freiheitsstrafe spiegelt den herabgesetzten Unrechtsgehalt nicht ausreichend wieder, zumal ein verletztes legitimes Zweitrechtsgut fehlt. ${ }^{1270} \mathrm{Ob}$ angesichts des diesbezüglich bestehenden Beurteilungsspielraums des Gesetzgebers bereits die Festsetzung eines solchen Strafrahmens als unangemessen anzusehen ist, erscheint zwar fraglich. Jedenfalls tragen aber auch Zweifel an der sachgerechten Anpassung der Rechtsfolge an die Besonderheiten der tatbestandlichen Struktur dazu bei, die $\$ \$ 265$ c, 265d StGB als insgesamt nicht angemessen zum Schutz des Vermögens zu bewerten.

\section{Zwischenergebnis}

In der abzulehnenden Angemessenheit der $\$ \$ 265 \mathrm{c}$, 265d StGB drückt sich in besonderer Weise das unstimmige Verhältnis der parallel verfolgten Schutzgüter aus. Die Schutzrichtung der Integrität des Sports verlangt eine korruptionsartige Ausgestaltung der Tatbestände, die die Beziehung der pönalisierten Verhaltensweisen zum Individualrechtsgut des Vermögens weitgehend lockert. Doch anstatt hierdurch einen zumindest punktuell nachweisbar effizienteren strafrechtlichen Vermögensschutz zu etablieren, wird dieser im Hinblick auf Vermögensgefährdungen in eine bisher unbekannte Abstraktionshöhe getrieben. $\mathrm{Zu}$ deren normativem Ausgleich vermag die Integrität des Sports selbst bei Anerkennung ihrer Rechtsgutsqualität mangels konzeptionellen Zusammenhangs mit dem Rechtsgut Vermögen wenig beizutragen. Und im Hinblick auf den verfolgten Integritätsschutz steht ihre vergleichsweise reduzierte gesamtgesellschaftliche Bedeutung einer beträchtlichen Eingriffsintensität gegenüber, die durch vorver-

1270 Krack ZIS 2016, 540 (544 f.); Bohn KriPoz 2017, 88 (92 f.). 
lagerte, in ihrem Gefährdungsgrad herabgesetzte Tathandlungen und ein strenges Strafmaß vermittelt wird.

\section{Ergebnis}

In ständiger Rückbeziehung auf die Zwecksetzung des Rechtsgüterschutzes ermöglichte der Verhältnismäßigkeitsgrundsatz unter Ausnutzung des gesetzgebungskritischen Potenzials seiner Kategorien eine eingehende und verfassungsrechtlich begründete Analyse der $\$ \$ 265 \mathrm{c}$, 265d StGB im Hinblick auf die allgemein-strafrechtliche und spezifisch deliktsstrukturelle Wirkweise, deren Vergleich mit alternativen strafrechtlichen und außerstrafrechtlichen Mitteln sowie deren normative Bewertung. Gemessen an ihrem Zweck des Schutzes der Integrität des Sports und des Vermögens haben sich die überprüften Straftatbestände dabei jeweils als unverhältnismäßig erwiesen.

Bezüglich der Integrität des Sports wurden der Prüfung des Verhältnismäßigkeitsgrundsatzes die vorab zurückgewiesenen Annahmen zugrunde gelegt, die die strafrechtliche Schutzwürdigkeit der Integrität des Sports in der Rechtsgutskonzeption des Gesetzgebers begründen. Unter der Prämisse der Maßgeblichkeit eines integritätsbezogenen Vertrauens für den sozial wertvollen Funktionserhalt des Sports können beide Vorschriften mithilfe eines Rückgriffs auf den Kumulationsgedanken zwar noch als geeignet angesehen werden. Da aber die sportethischen Werte und die Authentizität sportlicher Wettbewerbe bereits durch verbandsrechtliche Präventionsund Sanktionierungsmaßnahmen ein gewisses Schutzniveau erfahren, dessen verbleibende Defizite durch strafrechtliche Regelungen nicht zwangsläufig kompensiert würden, und da ein gestörter ideeller Wertetransport entweder sportintern durch einen Integritätswettlauf der Sportarten oder durch gänzlich andere gesellschaftliche Interessensfelder substituiert werden könnte, sind sie jedenfalls nicht erforderlich. Zudem begründet die vergleichsweise hohe Strafandrohung der $\$ \$ \$ 265$ c, 265d StGB Zweifel an ihrer Angemessenheit.

Der parallel bezweckte Vermögensschutz wird in beiden Vorschriften über eine Ausweitung ihrer Struktur als abstrakte Gefährdungsdelikte auf Vorfeldhandlungen verfolgt. Diese stellt sich zwar noch jeweils als geeignet dar, scheitert aber aus unterschiedlichen Gründen an den übrigen Voraussetzungen einer verhältnismäßigen Strafvorschrift. Eine Legitimierung des $\$ 265$ c StGB als Vorbereitungsdelikt scheitert trotz hinreichend vorausgesetztem Gefährlichkeitszusammenhang daran, dass der bereits durch 
$\$ 263$ StGB gewährleistete strafrechtliche Schutz der bei einem Sportwettbetrug tangierten Vermögensinteressen der Wettanbieter nicht effektiver ausgestaltet wird. Die diesbezügliche Behauptung einer nun ermöglichten Überwindung von Nachweisschwierigkeiten, die eine verlässliche Anwendung des $\$ 263$ StGB auf einschlägige Fallkonstellationen hinderten, ist ein bloßes Scheinargument. Ohne mit ihr einhergehende Effektivierung des strafrechtlichen Vermögensschutzes erweist sich die Ausdehnung des Strafrechts in das Vorfeld der betrugsrelevanten Täuschungshandlung einer Wettplatzierung weder als erforderlich noch als angemessen.

Dem durch $\$ 265 \mathrm{~d}$ StGB verfolgten Vermögensschutz ist schließlich die Angemessenheit abzusprechen. Ohne die erforderlichen Merkmale eines Vorbereitungsdelikts kommt eine Legitimierung nur über eine hinreichende objektive Vermögensgefährdung in Betracht. Dieser Voraussetzung genügt die indirekte und mehrfach vermittelte Wirkmodalität der tatbestandsmäßigen Verhaltensweisen, die allenfalls in Kombination mit einer Reihe von Folgebedingungen Relevanz für die ihrerseits nur diffus umschriebenen Vermögensinteressen im Berufssport entfalten können, nicht. Insofern verfehlt $\$ 265 \mathrm{~d}$ StGB die Anforderungen, die zum Ausgleich der Vorverlagerung des strafrechtlichen Eingriffs an Gewicht und Dringlichkeit des Schutzzwecks zu stellen sind. Den Vermögensinteressen der Sportwirtschaft, die im Gegensatz zu den Schutzgegenständen der ähnlich strukturierten Delikte im Umfeld des $\$ 265 \mathrm{~d}$ StGB nicht der Absicherung eines volkswirtschaftlich bedeutsamen Systems dient, strafrechtlichen Schutz vor hochabstrakten und nicht belegten Gefährdungen zu gewähren, lässt sich mit der Ausrichtung und Begrenzung des Vermögensstrafrechts nicht vereinbaren.

\section{Bestimmtheitsgrundsatz}

Als Ausprägung des in $\$ 1$ StGB und Art. 103 Abs. 2 GG verankerten Gesetzlichkeitsprinzips zieht der Bestimmtheitsgrundsatz sämtlichen Straftatbeständen eine unumstrittene verfassungsrechtliche Grenze. Die Prüfung einer Übereinstimmung der $\$ \$ 265 \mathrm{c}, 265 \mathrm{~d}$ StGB mit den Anforderungen des Bestimmtheitsgrundsatzes betrifft dabei unmittelbar deren konkrete tatbestandliche Ausgestaltung, steht übergeordnet aber auch in Zusammenhang mit der gesetzgeberisch erhofften negativ-generalpräventiven Wirkung der Pönalisierung. Denn Mindestbedingung möglicher abschre- 
ckender Effekte ist die klare Erkennbarkeit des verhaltensbezogenen Normbefehls für die Adressaten. ${ }^{1271}$

Gemäß dem Gehalt der verfassungsrechtlichen Garantie müssen sowohl der Kreis der adressierten Personen als auch das strafrechtlich erfasste Verhalten und weitere Voraussetzungen der Strafbarkeit im Wortlaut einer Strafnorm so präzise beschrieben werden, dass sich deren Tragweite und Anwendungsbereich verlässlich einschätzen und durch Auslegung ermit-

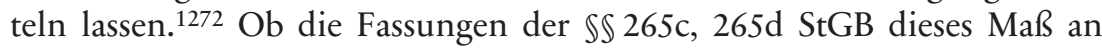
Rechtssicherheit gewährleisten, erscheint mit Blick auf einige Tatbestandselemente fraglich. Sowohl bei der Beschreibung des in beiden Normen deckungsgleichen Täterkreises als auch bei der Qualifizierung der von Tathandlungen i.S.d. $\$ 265 \mathrm{~d}$ StGB in Bezug genommenen Sportwettbewerben bedient sich der Gesetzgeber unbestimmter Rechtsbegriffe, die in Einzelfällen eine vorhersehbare Subsumtion erschweren könnten.

Dabei bleibt jedoch zu beachten, dass die Verwendung unbestimmter Rechtsbegriffe für sich genommenen grundsätzlich noch keinen verfassungswidrigen Verstoß gegen den Bestimmtheitsgrundsatz begründet. In einer Gesetzestechnik, die bei der Beschreibung von Gefahren für das geschützte Rechtsgut entwicklungsoffen die Vielgestaltigkeit des Lebens wiederspiegelt, sich dabei aber nicht in kleinteiliger Kasuistik verlieren will, ist der Bezug eines gewissen Abstraktionsniveaus stellenweise unvermeidbar. Dies erkennt auch das Bundesverfassungsgericht an, das die Verwendung unbestimmter, konkretisierungsbedürftiger Begriffe bis hin zu Generalklauseln so lange für mit dem Bestimmtheitsgrundsatz vereinbar hält, wie sich mit Hilfe der üblichen Auslegungsmethoden, insbesondere durch Heranziehung anderer Vorschriften desselben Gesetzes, durch Berücksichtigung des Normzusammenhangs oder aufgrund einer gefestigten Rechtsprechung eine zuverlässige Grundlage für eine präzisierende Auslegung und Anwendung der Norm gewinnen lässt. ${ }^{1273}$ Der Grad der für eine Norm jeweils erforderlichen Bestimmtheit lasse sich dabei nicht abstrakt festlegen, sondern hänge von den Besonderheiten des jeweiligen Tatbestandes einschließlich der Umstände ab, die zur gesetzlichen Regelung geführt hätten. ${ }^{1274}$ Der Bestimmtheitsgrundsatz wird demnach von einer nahezu unvermeidbaren inneren Spannung zwischen dem Anspruch rechtsstaatlicher Normenklarheit und pragmatischen Zugeständnissen an die

1271 S. Hefendehl JA 2011, 401 (403).

1272 BVerfGE 126, 170 (196).

1273 BVerfGE 45, 363 (371f.); 86, 288 (311); 131, 268 (307).

1274 BVerfGE 28, 175 (183); 86, 288 (311); 126, 170 (196); 134, 33 (81f.). 
Gesetzestechnik geprägt, die im Rahmen der konkreten Bewertung der in $\$ \mathbb{S} 265 \mathrm{c}, 265 \mathrm{~d}$ StGB identifizierten unbestimmten Rechtsbegriffe eine differenzierte Auseinandersetzung mit deren Auslegungsfähigkeit erfordert.

\section{Adressatenkreis und persönlicher Anwendungsbereich}

Vor dem Ziel eines möglichst umfassenden Rechtsgüterschutzes wurde der tatbestandliche Adressatenkreis der $\mathbb{S} 265 \mathrm{c}$, 265d StGB mitunter noch als zu eng kritisiert, da er bestimmte Akteure aus dem Umfeld des Sports ausschließe, die durchaus auf die letztlich erbrachte Leistung eines Sportlers einwirken könnten. ${ }^{1275}$ Vor dem Hintergrund des Bestimmtheitsgrundsatzes fällt hingegen auf, dass für die auf Vorteilsnehmerseite der tatbestandsmäßigen Unrechtsvereinbarungen zwingend zu involvierenden Personen eine besondere Eigenschaft vorausgesetzt wird, deren genaue Definition unterbleibt. Dies gilt angesichts ihrer zahlenmäßigen Bedeutung in brisanter Weise für die Gruppe der Sportler. Aber auch der von $\$ 265$ c Abs. 6 S. 2 StGB angeordnete Einbezug solcher Personen, die einem Trainer gleichstehen, führt zu einer Unschärfe bei der Bestimmung des Kreises tauglicher Täter bzw. Vorteilsnehmer.

\section{Sportler}

Die Personengruppe der Sportler erfährt gesetzlich lediglich durch das Kriterium der Teilnahme an einem Wettbewerb des organisierten Sports in $\$ 265$ c Abs. 5 bzw. $\$ 265$ d Abs. 5 eine geringfügige formale Eingrenzung. Ihre Eigenschaft als Vorteilsnehmer und potenzielle Täter gründet auf einer Betätigung (Sport), die trotz ihrer zahlreichen tatbestandlichen Aufnahme (Sportwetten, Sportorganisationen, Sportveranstaltungen, sportliche Wettbewerbe) gesetzlich ohne nähere Erläuterung und somit zunächst bedeutungsoffen bleibt. Der bereits beschriebene Verzicht auf eine eigens eingeführte oder in Bezug genommene materielle Sportdefinition ${ }^{1276}$ wird gerade angesichts deren offensichtlicher Bedeutung für die tatbestandliche Weite vor dem Hintergrund des Bestimmtheitsgrundsatzes als problematisch empfunden. Er ignoriere die bereits in anderen rechtlichen Zusammenhängen kaum zu leistende Abgrenzung zwischen Sport und Spiel und

1275 S. oben Teil 3 C. I. 1. b) aa) (1).

1276 S. oben Teil 3 B. II. 2. c) aa). 
könnte bei Ausübenden solcher Tätigkeiten, deren Verständnis als Sport nicht auf einem ungeteilten gesellschaftlichen Konsens beruht - den bereits thematisierten Beispielsfällen entsprechend ist etwa an die Teilnehmer einer Skatmeisterschaft oder eines professionell organisierten eSportTurniers zu denken -, die Unsicherheit begründen, vom Adressatenkreis der strafbewehrten Verbote in $\$ \$ 265 c, 265 \mathrm{~d}$ StGB erfasst zu sein. ${ }^{1277}$

Hinsichtlich des Sportbegriffs stand dem Gesetzgeber keine sportwissenschaftlich unstrittige und anschlussfähige Definition zur Verfügung. ${ }^{1278}$ Die Abhängigkeit des Sportbegriffs von dynamischen gesellschaftlichen Anschauungen und seine selbst beanspruchte Aufnahmefähigkeit von neu aufkommenden Spiel- und Bewegungsformen erlaubt allenfalls die Festsetzung bestimmter Begriffskriterien. Schon die Eigenart des von den $\$ \$ \$ 265 c$, 265d StGB geregelten Lebensbereiches und die Intention eines auch zukünftig zeitgemäßen Anwendungsbereiches erfordert somit eine begriffliche Öffnung der Tatbestände in Form eines nicht näher erläuterten Sportbegriffs. ${ }^{1279}$ Der Verzicht des Gesetzgebers auf eine Legaldefinition und das stattdessen durchscheinende Verständnis des Sports als Typusbegriff, der sich über verschiedene sporttypische Indizien, die disjunktiv aber auch komparativ miteinander verknüpft werden können, materialisiert, erscheint insofern nachvollziehbar. ${ }^{1280}$

Allerdings verlangt der Bestimmtheitsgrundsatz auch hinsichtlich einer in Kauf zu nehmenden gesetzlichen Weite die Möglichkeit einer gewissen Eingrenzung durch eine präzisierende Auslegung, die zumindest von verwandten Vorschriften oder der Rechtsprechung im vorliegenden Fall kaum zu erwarten ist. Die strafrechtliche Bezugnahme des Sports in $\mathbb{3} 3$ Abs. 3 Anti-Doping-Gesetz ist in gleicher Weise unbestimmt gehalten. ${ }^{1281}$ Die dortige Einschränkung des persönlichen Anwendungsbereichs des Selbstdopings über eine erforderliche Zugehörigkeit der Sportler zu sog. Testpools des Dopingkontrollsystems (vgl. $\mathbb{} 3$ i.V.m. $\mathbb{} 4$ Abs. 1 Nr.4, 5,

1277 Ausführlich Jaleesi Kriminalisierung, S. 151 ff.; ferner Momsen KriPoZ 2018, 21 (26); Satzger Jura 2016, 1142 (1148); Pfister StraFo 2016, 441 (443); Stellungnahme des Deutschen Richterbundes Nr. 2/2016, S. 5; s. auch Rübenstabl JR 2017, $264(275)$.

1278 S. oben Teil 3 B. II. 2. a) bb).

1279 S. Kubiciel WiJ 2016, 256 (257).

1280 Grundlegend zum Typusbegriff Puppe GS Kaufmann, 1989, S. 25 ff.; zu dessen Anwendung auf den Sport Krack wistra 2017, 289 (291); Lehner/Nolte/Putzke/ Nolte AntiDopG $₫ 1$ Rn. 27; Schörner HRRS 2017, 407 (412).

1281 Zur Kritik hieran s. Lehner/Nolte/Putzke/Putzke AntiDopG $₫ 3$ Rn. 46. 
Abs. 7 Nr. 1 AntiDopG) greift für die $\$ \$ 265 c$, 265d StGB nicht. ${ }^{1282}$ Aufgrund der noch kurzen Geltungsdauer der sportbezogenen Straftatbestände hat sich bisher keine schärfende Rechtsprechung zum strafrechtlichen Sportbegriff herausgebildet und ist angesichts der zu prognostizierenden geringen praktischen Relevanz der Normen auch nicht zu erwarten. Und eine sich aus dem Normzusammenhang ergebende Eingrenzung des Sportbegriffs über das Erfordernis der Teilnahme an einer in $\$ 265$ c Abs. 5 definierten Veranstaltung des organisierten Sports erweist sich insofern als untauglich, als sich entsprechende Organisationsstrukturen und Turnierformen eben auch bei Brett- oder Computerspielen feststellen lassen. ${ }^{1283}$

Zur Konkretisierung unbestimmter Tatbestandsmerkmale kann grundsätzlich ferner eine am Rechtsgut ausgerichtete teleologische oder eine die Gesetzesbegründung miteinbeziehende historische Auslegung beitragen. Der intendierte Schutz der Integrität des Sports und der von ihr umfassten sportethischen Werte hätte zwar theoretisch das Potenzial einer Eingrenzung des Sportbegriffs auf Tätigkeiten, in denen diese Werte auch zum Ausdruck kommen. Unter den Gesichtspunkten der Fairness und des Respekts gegenüber dem Gegner könnte dies etwa zum Ausschluss des mitunter virtuelle Gewalt billigenden eSports, ${ }^{1284}$ unter dem Aspekt eines aufrichtigen Leistungsvergleichs zum Ausschluss von Showveranstaltungen wie Wrestling führen. Abgesehen davon, dass der Gesetzeswortlaut der

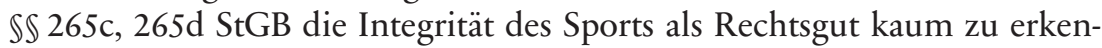
nen gibt, erfolgt ihre Materialisierung gerade durch die sportethischen Werte wie gezeigt wurde aber zu diffus, erscheint auch die Ausprägung der Werte im Sport selbst zu widersprüchlich, um aus einem hierauf fokussierten Abgleich eine verlässliche Präzisierung des Sportbegriffs abzuleiten. ${ }^{1285}$

Die am Willen des Gesetzgebers orientierte Auslegung knüpft am vorherrschenden gesellschaftlichen Verständnis von Sport an. ${ }^{1286}$ Dieses mag auf den ersten Blick ebenfalls schwer zu greifen sein, ${ }^{1287}$ enthält jedoch zumindest gewisse präzisierende Parameter. Seine Maßgeblichkeit unterstreicht zunächst die Irrelevanz individueller Selbsteinschätzungen und

1282 S. Schönke/Schröder/Perron $\$ 265$ c Rn. 4; BeckOK-StGB/Bittmann/Nuzinger/ Rübenstabl $\$ 265$ c Rn. 51.

1283 S. Pfister StraFo 2016, 441 (444).

1284 Hierzu Schörner HRRS 2017, 407 (410); für eine grundsätzliche Einbeziehung Kubiciel ZRP 2019, 200 (202).

1285 Skeptisch hinsichtlich der Integrität des Sports als Auslegungshilfe auch Pfister StraFo 2016, 441 (443 f.).

1286 BT-Drs. 18/8831, S. 19.

1287 Krit. vor allem Pfister StraFo 2016, 441 (443). 
führt im Sinne des Verständnisses des Sports als Typusbegriff einvernehmliche Begriffsmerkmale wie ein Mindestmaß an körperlicher Anstrengung, die Abhängigkeit des Erfolgs von Leistung und nicht vom Zufall und traditionelle Unterscheidungen wie die von Sport und reinen Gesellschaftsspielen bzw. Showveranstaltungen in die Auslegung ein. Zur Ermittlung der gesellschaftlichen Anschauung lässt sich außerdem auf Entscheidungen nationaler wie internationaler disziplinübergreifender Sportverbände zurückgreifen, bestimmte Betätigungen als Sportart anzuerkennen. Solche Anerkennungsakte privater Stellen dürfen angesichts des Gesetzesvorbehalts in Art. 103 Abs. 2 GG zwar nicht allein ausschlaggebend für die Weite eines Straftatbestandes sein. ${ }^{1288}$ Als ihrerseits gesellschaftliche Anschauungen aufgreifendes Indiz können sie dem maßgeblichen gesellschaftlichen Sportverständnis aber Konturen verleihen und hierüber einem ausufernden strafrechtlichen Sportbegriff entgegenwirken. ${ }^{1289}$ So lässt sich der tatbestandliche Ausschluss des beispielhaft genannten Grenzfalles eSport auf die gesellschaftlich (noch) vorherrschende und auch von Sportverbänden wie dem DOSB oder IOC getragene Weigerung zurückführen, diese bewegungsarme Betätigung als Sport zu verstehen.

Wenngleich es nicht immer leicht fallen dürfte, über die Anerkennung durch Sportverbände hinausgehende Kriterien der Ermittlung zu finden, ist der durch ein Abstellen auf das gesellschaftliche Sportverständnis erzielbare Präzisierungsgrad des unbestimmten Rechtsbegriffs des Sports geeignet, Normadressaten der $\$ \$ 265$ c, 265d StGB zumindest das sich aufdrängende Risiko einer Strafbarkeit aufzuzeigen. Hierin kann zwar allenfalls die Erfüllung der Mindestbedingung einer bestimmten Strafrechtsvorschrift gesehen werden. ${ }^{1290}$ Unter Berücksichtigung der wandelbaren Dynamik des geregelten Lebensbereiches und der für derartige Fälle verfassungsrechtlich zulässigen Herabsetzung des Bestimmtheitsmaßstabes reicht dies für eine Vereinbarkeit mit Art. 103 Abs. 2 GG aber aus.

\section{Einem Trainer gleichgestellte Personen}

Die Kritik an einem zu unbestimmt beschriebenen Täterkreis bezieht sich ferner auf die durch $\$ 265$ c Abs. 6 S. 2 StGB angeordnete Erweiterung auf

1288 Vgl. Rübenstahl JR 2017, 333 (336); Valerius Jura 2018, 777 (783).

1289 S. Hdb-StR/Kindhäuser/Schumann $\$ 34$ Rn. 186; Stam NZWiSt 2018, 41 (42); Kubiciel WiJ 2016, 256 (257).

1290 S. BVerfGE 48, 48 (56f.); 92, 1 (12). 
Personen, die einem Trainer gleichstehen. Die für die Gleichstellung als maßgeblich erklärte Möglichkeit, vermöge einer beruflichen oder wirtschaftlichen Stellung Einfluss auf den Einsatz oder die Anleitung von Sportlern zu nehmen, lasse sich etwa bei Angehörigen des medizinischen Betreuerstabs eines Sportteams mitunter nur situationsabhängig feststellen und drohe bei der gesetzgeberisch offenbar intendierten Einbeziehung von Personen aus dem Sponsorenumfeld ${ }^{1291}$ gar die Wortlautgrenze zu überschreiten. ${ }^{1292}$

Die vorgebrachten Bedenken tragen jedoch die Annahme eines Verstoßes gegen Art. 103 Abs. 2 GG nicht. Gerade im Leistungssport ist das die Sportler umgebende Umfeld komplexer geworden. Trainerstäbe werden mit Assistenz- und Spezialtrainern ausdifferenziert und treffen spieltaktische Entscheidungen häufig unter Einbeziehung medizinischer Empfehlungen ärztlicher Betreuer oder der Einschätzung von Teammanagern oder Sportdirektoren. Auch für spieltaktische Fragen eigentlich nicht zuständige Funktionsträger wie Präsidenten, Vorstände, geldgebende Mäzene oder Sponsoren besitzen in besonders strukturierten oder wirtschaftlich abhängigen Sportvereinen mitunter eine dominante Machtposition, die sich faktisch auf die Bestimmung der personellen oder taktischen Ausrichtung des Teams über den Kopf eines nur als Marionette eingesetzten Trainers hinweg erstreckt.

Um diesen Gegebenheiten Rechnung zu tragen und den tatbestandlich vertypten Gefahren der manipulativen Einflussnahme im Sport effektiv zu begegnen, ist es daher angezeigt, den Täterkreis über die klassischen Rollen der unmittelbar an einem Wettbewerb teilnehmenden Sportler, Schiedsrichter und Trainer hinaus auszuweiten. Hierbei auf die Fähigkeit zur wesentlichen Einflussnahme auf Einsatz und Anleitung von Sportlern abzustellen, erscheint angesichts des Regelungsziels schlüssig. Auch werden Grundlage (berufliche oder wirtschaftliche Stellung) und Bezugsgegenstand (Einsatz und Anleitung von Sportlern) des Einflusses klar umrissen. Forderungen nach deren Ausweitung, die durch die ermöglichte tatbestandliche Einbeziehung weiterer Akteure zu einem verbesserten Schutz vor Manipulationen führen soll, würden die Bestimmtheit hingegen überstrapazieren. ${ }^{1293}$

1291 S. BT-Drs. 18/8831, S. 20.

1292 Satzger Jura 2016, 1142 (1146); ebenfalls krit. Momsen KriPoZ 2018, 21 (26); Dittrich ZWH 2017, 189 (193).

1293 Vgl. Löffelmann recht + politik 2/2016, 1 (3 f.). 
Die erforderliche Wesentlichkeit transportiert zwar eine gewisse Unbestimmtheit, die jedoch im Normzusammenhang mit dem Vergleichsmaßstab der Einflussmöglichkeiten eines Trainers begrenzend und trennscharf ausgelegt werden kann. ${ }^{1294}$ Danach sind Personen, die innerhalb einer von klarer Aufgabenteilung geprägten Vereinsstruktur lediglich im Vorfeld eines Wettkampfs unverbindliche spieltaktische Empfehlungen an den Trainer oder die Sportler herantragen, im Gegenteil zu solchen aus dem Täterkreis auszugrenzen, deren unmittelbare Vorgaben von Sportlern als ebenso bindend angenommen und befolgt werden, als stammten sie vom Trainer. Da die Betroffenen im Regelfall um die Inhaberschaft einer derartigen spieltaktischen Entscheidungskompetenz wissen, erschließt sich ihnen die eigene Zugehörigkeit zum Täterkreis und das entsprechende Risiko einer Strafbarkeit ausreichend aus dem Wortlaut des Gesetzes.

\section{Berufssportlicher Wettbewerb i.S.d. $\$ 265 \mathrm{~d}$ StGB}

Einen Bezug zu einer Wette nicht voraussetzend grenzt $\$ 265 \mathrm{~d}$ StGB den von der Manipulationsabsprache betroffenen Kreis an Sportwettbewerben durch das Merkmal „berufssportlich“ ein. Das für den Anwendungsbereich der Vorschrift insofern wesentliche Kriterium wird in Abs. 5 gesetzlich definiert. Demnach erhält eine Sportveranstaltung die Bezeichnung berufssportlich, wenn sie von einem Sportbundesverband oder einer internationalen Sportorganisation veranstaltet oder in deren Auftrag oder mit deren Anerkennung organisiert wird, verpflichtende Regeln einer Sportorganisation einzuhalten sind und an ihr überwiegend Sportler teilnehmen, die durch ihre sportliche Betätigung unmittelbar oder mittelbar Einnahmen von erheblichem Umfang erzielen.

Die Begriffsklärung erfolgt somit unter Verwendung ihrerseits unbestimmter Rechtsbegriffe, die ein klares Umreißen des Anwendungsbereichs des $\$ 265 \mathrm{~d}$ StGB und damit die Vorhersehbarkeit der Strafbarkeit erschweren. ${ }^{1295}$ Denn welche Einnahmen als mittelbar durch die sportliche Betätigung erzielt gelten, lässt sich dem Gesetzestext ebenso wenig entnehmen wie eine konkrete Schwelle für die Qualifizierung der Gesamteinnah-

1294 So auch Jaleesi Kriminalisierung, S. 132 f.; Hdb-StR/Kindhäuser/Schumann $\$ 34$ Rn. 180.

1295 Zur Kritik vgl. Waßmer ZWH 2019, 6 (10 f.); Valerius Jura 2018, 777 (786); Tsambikakis StV 2018, 319 (326); Rübenstabl JR 2017, 333 (336); Schönke/ Schröder/Perron $\$ 265$ d Rn. 5 ff.; Dittrich ZWH 2017, 189 (194). 
men als erheblich bzw. die als Bezugsgröße heranzuziehende Wettbewerbsform für ein festzustellendes Überwiegen teilnehmender Berufssportler. Mag der Gesetzgeber hinsichtlich der einzubeziehenden Einnahmen auch nachschieben, dass es sich um eine Einnahmequelle im Sinne eines wiederholten Erlangens wirtschaftlicher Vorteile etwa durch Start- und Preisgelder, Leistungen der Sportförderung, Sponsoren- oder Arbeitsvergütungen handeln müsse, die über eine bloße Kostenerstattung hinausgehe, ${ }^{1296}$ bleibt etwa unklar, inwiefern auch Einnahmen von Sportlern aus privaten Werbeverträgen oder Vortragsvergütungen noch als mittelbar aus der sportlichen Betätigung hervorgehend einzuschließen sind. ${ }^{1297}$ Hinsichtlich des Umfangs der Einnahmen stellt sich überdies die Frage, ob dessen Erheblichkeit relativ unter Berücksichtigung der Verdienstverhältnisse innerhalb einer Sportart oder gar der wirtschaftlichen Situation im Heimatland des einzelnen Sportlers oder absolut und sportartübergreifend festzusetzen ist. ${ }^{1298}$

Der vom Gesetzgeber zur Begriffsschärfung des berufssportlichen Wettbewerbs angeregte Rückgriff auf die Gesetzesbegründung zur Vorbildregelung in $\$ 4$ Abs. 7 Nr. 2 AntiDopG ${ }^{1299}$ verschafft bezüglich der aufgeworfenen Fragen keinen Gewinn an tatbestandlicher Bestimmtheit. ${ }^{1300}$ Auch eine Präzisierung durch die Strafgerichte hat sich noch nicht entwickelt. Eine an der Gewährleistung der Anwendungsfähigkeit der Norm orientierte Auslegung spricht jedoch dafür, die berücksichtigungsfähigen Einnahmen auf mit der sportlichen Tätigkeit in direktem Zusammenhang stehende Vergütungen zu beschränken ${ }^{1301}$ und diesbezüglich eine absolute Erheblichkeitsschwelle festzusetzen. ${ }^{1302}$ Der andernfalls erforderliche Nachweis verschiedenster Einnahmen und sportart- und länderspezifischer Ver-

1296 BT-Drs. 18/8831, S. 22.

1297 Stellungnahme des Deutschen Richterbundes Nr.2/16, S. 6; Rübenstabl JR 2017, 333 (336).

1298 Rübenstahl JR 2017, 333 (336); Stellungnahme Transparency International zu BT-Drs. 18/8831, S. 4.

1299 BT-Drs. 18/8831, S. 22.

1300 Perron JuS 2020, 809 (812); Valerius Jura 2018, 777 (786); Dittrich ZWH 2017, 189 (194); kritisch gegenüber der Bestimmtheit des $\$ 4$ Abs. 7 AntiDopG Norouzi/Summerer SpuRt 2015, 63 (64); Graf/Jäger/Wittig/Eschelbach $\$ 4$ AntiDopG Rn. 23.

1301 Was allerdings auch Schwarzgeldzahlungen und Vergütungen einschließt, die pro forma für eine anders deklarierte Arbeitsleistung gezahlt werden, s. Schönke/Schröder/Perron $\$ 265$ d Rn. 6.

1302 Rübenstabl JR 2017, 333 (336); Stam NZWiSt 2018, 41 (46); Jaleesi Kriminalisierung, S. 261 ff.; aA wohl Fischer StGB $\$ 265$ d Rn. 6. 
gütungsstrukturen, der mitunter bei einer Vielzahl von Athleten zu erbringen wäre, zwänge Ermittlungsbehörden und Gerichte zur Kapitulation. Hinsichtlich der Konkretisierung der Erheblichkeitsschwelle ließe sich in Orientierung an dem übergeordneten Merkmal der Berufsmäßigkeit auf deren allgemeinen Zweck der Absicherung des Lebensunterhalts verweisen und in Anlehnung an den gesetzlichen Mindestlohn für Vollzeitsportler eine Mindestsumme von 1.500 Euro pro Monat ansetzen. ${ }^{1303}$

Dieser Wert müsste von der überwiegenden Zahl der Teilnehmer an einem Wettkampf erreicht werden, wobei dies nach allgemeinem Sprachgebrauch einen Anteil an Berufssportlern von $50 \%+1$ erfordert. ${ }^{1304}$ Aus dem Anwendungsbereich der Norm entfallen somit Wettkämpfe, bei denen ein Berufssportler bzw. ein aus Berufssportlern bestehendes Team gegen einen Amateur bzw. ein ausschließlich aus Amateuren bestehendes Team antritt. Wie oft eine solche Konstellation in der Realität des Sports auftritt, ist schwer zu sagen. Sofern Beispiele aber dem Herrenfußball mit Verweis auf dort bei bestimmten Wettbewerbsformen auftretende größere Professionalisierungsdifferenzen zwischen den Kontrahenten entnommen werden - genannt wird etwa ein Spiel der WM-Qualifikation zwischen Deutschland und San Marino ${ }^{1305}$-, wird das insgesamt erreichte Professionalisierungsniveau im Herrenfußball unterschätzt. In dessen Folge befindet sich selbst im Kader eines in Spielen des DFB-Pokals antretenden Viertligisten oder eben einer kleinen Nation mittlerweile mindestens ein Spieler, der den Grenzwert der erheblichen Einnahmen aus der sportlichen Betätigung überschreitet. ${ }^{1306}$

Fehlt es in anderen Sportarten in konkreten Spielen oder Wettbewerben an der mehrheitlichen Beteiligung von Berufssportlern, sollen diese nach Ansicht des Gesetzgebers wohl durch eine Verlagerung der Bezugsgröße doch noch dem Anwendungsbereich des $₫ 265 \mathrm{~d}$ StGB zugeordnet werden können, sofern die Voraussetzung für den das einzelne Spiel überwölben-

1303 Überzeugend Stam NZWiSt 2018, 41 (46); Jaleesi Kriminalisierung, S. 263 f.; Waßmer ZWH 2019, 6 (11); ebenfalls um eine am Mindestlohn ausgerichtete, absolute Zahl bemüht, diese aufgrund der „Erheblichkeit“ der Einnahmen aber auf 25.000 Euro jährlich (2.100 Euro monatlich) heraufsetzend BeckOKStGB/Bittmann/Nuzinger/Rübenstabl \$265d Rn. 39-41.

1304 Fischer StGB $\$ 265$ d Rn. 10; Schönke/Schröder/Perron $\$ 265$ d Rn. 5.

1305 S. das entsprechende Beispiel bei Reinhart SpuRt 2016, 235 (239).

1306 Im aktuellen Kader der Fußball-Nationalmannschaft San Marinos, die den letzten Platz der FIFA-Weltrangliste belegt, befinden sich drei Spieler, die bei italienischen Drittligisten unter Vertrag stehen und dort mit großer Wahrscheinlichkeit erhebliche Einnahmen im oben genannten Sinne erzielen. 
den Gesamtwettbewerb vorliegt. ${ }^{1307}$ Dies erscheint insofern bestimmtheitsfördernd und im Hinblick auf das Rechtsgut der Integrität des Sports nachvollziehbar, als es dann nicht auf die Zufälligkeit der Zusammensetzung der im konkreten Spiel eingesetzten Sportler ankommt, sondern auf die Hochklassigkeit und Medienpräsenz eines Pokalwettbewerbs oder einer Liga insgesamt. ${ }^{1308}$ Ein Spiel der Hockey-Bundesliga fällt demnach in den Anwendungsbereich des $\$ 265$ d StGB, wenn über die Hälfte der im Kader eines Erstligavereins stehenden Spieler durch ihre sportliche Betätigung Einnahmen von erheblichem Umfang erzielt. Bei sportlichen Großveranstaltungen wie Leichtathletik-Meisterschaften oder Olympischen Spielen, die mehrere Disziplinen oder gar Sportarten umschließen, muss hingegen jede Disziplin, in der ein Sieger ermittelt wird, für sich betrachtet werden. Die Festlegung des Gesamtwettbewerbs als maßgebliche Referenzgröße für ein Überwiegen teilnehmender Berufssportler wäre in diesen Fällen wiederum mit einem kaum zu leistenden Ermittlungsaufwand verbunden. ${ }^{1309}$

Der durch die Merkmale „mittelbare Einnahmen“, „erheblicher Umfang" und „überwiegende Teilnahme“ erhöhte Unbestimmtheitsgrad der Legaldefinition des den Anwendungsbereich des $\$ 265$ d StGB prägenden berufssportlichen Wettbewerbs lässt sich insgesamt nur mit Mühe und einer an Praktikabilitätserwägungen orientierten Auslegung eingrenzen. Selbst bei reduzierter Berücksichtigung mittelbarer Einnahmen und einer absolut bestimmten und konkretisierten Erheblichkeitsschwelle wird der Nachweis der Berufssportlichkeit bei bestimmten Wettbewerben in Randsportarten mit einem Teilnehmerfeld, das Sportler umschließt, die sich unterschiedlich finanzieren, wie es sich etwa bei Meisterschaften im Triathlon oder Rudern oder Spielen der Hockey-Bundesliga darstellt, ${ }^{1310}$ Probleme bereiten. Entsprechend schwer dürfte auch den Normadressaten eine verlässliche Einschätzung der Einkommensverhältnisse der Teilnehmer und somit die Vorhersehbarkeit einer potenziellen Strafbarkeit fallen, wo-

1307 BT-Drs. 18/8831, S. 22 äußert sich hinsichtlich der relevanten Bezugsgröße unklar, wenn zunächst gefordert wird, die Voraussetzungen müssten bezogen auf den konkret von der Manipulationsabsprache erfassten Wettbewerb vorliegen, um direkt nachzuschieben, dies könne der einzelne Wettkampf oder ein aus mehreren einzelnen Veranstaltungen bestehender Gesamtwettbewerb sein.

1308 Schönke/Schröder/Perron $\$ 265$ d Rn. 5; s. auch Jaleesi Kriminalisierung, S. 269; aA Hdb-StR/Kindhäuser/Schumann $\$ 34$ Rn. 205.

1309 Hierzu ausführlich Reinhart SpuRt 2016, 235 (239); Krack wistra 2017, 289 (296).

1310 Vgl. Stellungnahme Transparency International zu BT-Drs. 18/8831, S. 4. 
bei diesbezügliche Irrtümer in einer konkreten Strafbarkeitsprüfung zu einem Ausschluss des Vorsatzes führten. ${ }^{1311}$ Wenn sie auch aufgrund der aufgezeigten Möglichkeit einer gewissen auslegungsgesteuerten Präzisierung keinen verfassungswidrigen Verstoß begründen, dürften die $\$ 265 \mathrm{~d}$ StGB immanenten Bestimmtheits- und Nachweisdefizite für eine faktische Eingrenzung der Strafbarkeit auf Wettkämpfe sorgen, an denen bekanntermaßen ganz überwiegend Berufssportler teilnehmen.

1311 Dazu Pfister StraFo 2016, 441 (447); Stam NZWiSt 2018, 41 (46). 


\section{Zusammenfassung und Fazit}

Ziel der Untersuchung war die Bewertung der Legitimation der in den $\$ \mathbb{S} 265 \mathrm{c}, 265 \mathrm{~d}$ StGB geschaffenen Straftatbestände des Sportwettbetrugs bzw. der Manipulation von berufssportlichen Wettbewerben. Als Grundlage erforderte diese eine phänomenologische Auseinandersetzung mit den tatbestandlich in Bezug genommenen Manipulationsformen im Sport und ihren Rahmen- und Entstehungsbedingungen, eine Darstellung der diesbezüglichen strafrechtlichen Reaktionsmöglichkeiten vor Inkrafttreten der $\mathbb{S} \$ 265 \mathrm{c}, 265 \mathrm{~d}$ StGB sowie die Festlegung eines gleichermaßen fundierten wie operationalisierbaren allgemeinen Maßstabes zur Legitimationsprüfung strafrechtlicher Tatbestände. Die hinsichtlich dieser unerlässlichen Vorfragen und bei der anschließenden konkreten Legitimationsprüfung gefundenen Ergebnisse lassen sich in den zehn folgenden Aussagen zusammenfassen:

- Von einem weiten Verständnis des Begriffs der Sportmanipulation ausgehend, adressieren die $\mathbb{S} \mathbb{2} 265 \mathrm{c}$, 265d StGB als Bezugspunkt der tatbestandsmäßigen Absprache nur einen Teilbereich der im Sport auftretenden manipulativen Verhaltensweisen, dessen zwei erfasste Erscheinungsformen dem Begriff Match Fixing unterfallen und sich anhand der Kriterien Bezugspunkt der manipulativen Einwirkung, angestrebter Wettbewerbseffekt, Motivlage des Sportakteurs und Quelle des materiellen Vorteils von anderen Erscheinungsformen abgrenzen lassen.

- Anknüpfend an der Kommerzialisierung bestimmter Bereiche des Leistungssports und den Besonderheiten der ihn begleitenden Wettmärkte, können ökonomische Erklärungsansätze (Rational Choice) relevante Anreize und hieraus ableitbare situative und sportartspezifische Manipulationsrisiken aufzeigen, ohne das Auftreten der fokussierten Manipulationsformen überzeugend aus sich heraus erklären zu können.

- Die öffentliche Meinung einer weiten und zunehmenden Verbreitung von wettbedingtem und sportintern motiviertem Match Fixing beruht im Wesentlichen auf von der Aufdeckung einzelner Manipulationskomplexe beeinflussten Vermutungen, deren Plausibilität angesichts des Mangels an empirisch verlässlichen Befunden zu Ausmaß und Entwicklung des entsprechenden Hell- und Dunkelfeldes kaum zu überprüfen ist. 
- Von wenigen unwahrscheinlichen Konstellationen abgesehen, beschränkt sich die jenseits der $\$ \$ 265 c$, 265d StGB bestehende strafrechtliche Reaktionsmöglichkeit auf die Ahndung wettbedingten Match Fixing als Betrug gemäß $\$ 263 \mathrm{StGB}$, steht dabei jedoch in Abhängigkeit einer tatsächlichen Wettplatzierung und eines gelingenden Schadensnachweises und erfasst den involvierten Sportakteur nach herrschender Meinung bloß als Teilnehmer.

- Die Legitimation der $\$ \mathbb{S} 265 \mathrm{c}, 265 \mathrm{~d}$ StGB bemisst sich insbesondere nach dem verfassungsrechtlichen Verhältnismäßigkeitsgrundsatz, der einen nicht vorgeformten, sondern seinerseits verfassungsrechtlich materialisierten Rechtsgutsbegriff als zentralen Bezugspunkt integriert und dessen weitere Prüfungsstufen eine Analyse der Deliktsstruktur und hiervon ausgehend eine Bewertung des rechtsgutsbezogen realisierten Schutzniveaus erfordern.

- Da die vom Gesetzgeber aus der idealisierten Annahme eines sportethischen Wertekodex und bloß vermuteten Wirkungszusammenhängen konfigurierte Integrität des Sports aufgrund ihrer unbestimmten, ethisierten und unzureichend sozialgebundenen Bestandteile den an ein strafrechtlich schutzwürdiges Rechtsgut zu stellenden Anforderungen nicht entspricht, kommt allenfalls das Vermögen als legitimer Schutzzweck der $\$ \$ 265$ c, 265d StGB in Betracht.

- Die Kriminalisierung der tatbestandlich beschriebenen Verhaltensweisen, die die $\$ \mathbb{S} 265$ c, 265d StGB als abstrakte Gefährdungsdelikte ausweisen, vermag zum Schutz von Vermögensinteressen beizutragen, was trotz diesbezüglich vorgebrachter Zweifel an der allgemeinen Eignung des Strafrechts und das Schutzniveau absenkender tatbestandlicher Einschränkungen auch hinsichtlich der Integrität des Sports im gesetzgeberischen Verständnis angenommen werden kann.

- An der Erforderlichkeit, die den $\$ \mathbb{S} 265 \mathrm{c}, 265 \mathrm{~d}$ StGB im Hinblick auf die Integrität des Sports aufgrund funktionierender Selbstregulierungsmechanismen in Sport und Gesellschaft abzusprechen ist, fehlt es zumindest $\$ 265$ c StGB auch in Bezug auf den Vermögensschutz, der bei wettbedingtem Match Fixing bereits durch $\$ 263$ StGB gewährleistet wird, ohne dass die Vorverlagerung der Tathandlung diesbezüglich eine Effektivierung bewirkt.

- Die Vorverlagerung der strafrechtlichen Interventionsmöglichkeit auf nicht ausreichend rechtsgutsgefährdende Verhaltensweisen zum Schutz lediglich diffuser Vermögensinteressen kennzeichnet $₫ 265 \mathrm{~d}$ StGB als unangemessen. 
- Die Kumulation unbestimmter Rechtsbegriffe steigert insbesondere im Rahmen des $\$ 265$ d StGB den Ermittlungsaufwand und lässt Anwendungsschwierigkeiten erwarten, führt aufgrund noch hinreichend präzisierender Auslegungsmöglichkeiten aber nicht zu einem Verstoß gegen den Bestimmtheitsgrundsatz nach Art. 103 Abs. 2 GG.

Nach dem hier angelegten Prüfungsmaßstab sind die $\$ \$ 265$ c, 265d StGB somit als verfassungswidrig zu bezeichnen. Sie sind weder als Kumulationsdelikte zum Schutz der Integrität des Sports noch als Vorfelddelikte zum Schutz des Individualvermögens zu legitimieren. Der im Gesetzentwurf unzureichend über angenommene, aber nicht belegte Wirkungszusammenhänge begründete Schutz der Integrität des Sports stellt keinen legitimen Zweck dar. Schon gegen das zugrunde gelegte Kollektivrechtsgut bestehen demnach durchgreifende Bedenken, während sich der vorverlagerte Vermögensschutz in den erfassten Bereichen, in denen er nicht bereits ausreichend durch $₫ 263$ StGB gewährleistet werden kann, als unangemessen herausstellt. Die selbständige Pönalisierung von Vorbereitungshandlungen durch $\$ 265$ c StGB ist aufgrund der verlässlich eintretenden Strafbarkeit der späteren Verletzungshandlung ebenso unverhältnismäßig wie der durch $\$ 265 \mathrm{~d}$ StGB intendierte Schutz teilweise diffuser Vermögensinteressen vor Verhaltensweisen, deren rechtsgutsbezogene objektive Gefährlichkeit erheblich gemindert ist. Abseits unmittelbar legitimationsbezogener Aspekte wirken die Tatbestandsfassungen mitunter nicht abgestimmt, könnten zu Beeinträchtigungen der sportinternen Verbandsgerichtsbarkeit führen und neue Haftungsrisiken für Sportverbände und Sportvereine hervorrufen. ${ }^{1312}$

In gewisser Hinsicht stehen die legitimationsbezogenen Defizite der $\mathbb{S} \mathbb{S} 265 \mathrm{c}$, 265d StGB dabei sinnbildlich für problematische Tendenzen in der neueren Strafgesetzgebung. Die Ausdehnung der Strafbarkeit weit ins Vorfeld einer manifesten Rechtsgutsverletzung wird durch die Heranziehung eines konstruierten Allgemeininteresses zu legitimieren versucht, das vage und abstrakt bleibt und über keinerlei nachweisbar freiheitssichernde Funktion verfügt. ${ }^{1313}$ Anstatt die Legitimationsbasis des Tatbestandes zu solidieren, transportiert eine solche Dopplung des vermeintlichen Rechtsgüterschutzes oftmals zu Auslegungs- und Anwendungsschwierigkeiten führende Systemwidrigkeiten, wie sie die $\$ \$ 265$ c, 265d StGB als ins Vermögensstrafrecht gesetzte Korruptionstatbestände verdeutlichen. Die infol-

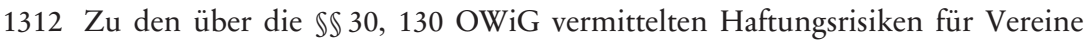
Kubiciel SpuRt 2017, 188 (192 f.).

$1313 \mathrm{Zu}$ dieser Tendenz Roxin/Greco Strafrecht AT I $₫ 2$ Rn. 75. 
gedessen zu konstatierende praktische Bedeutungslosigkeit dieser Tatbestände bezeugt die veränderte allgemeine Ausrichtung eines Strafrechts, das der ihm aufgebürdeten Erwartungslast eines Bekämpfungsinstruments sozialer Missstände (beispielsweise der Korruption) und eines allgemeinen Erziehungsmittels (beispielsweise zu mehr Fairness) hauptsächlich symbolisch und als Türöffner strafprozessualer Ermittlungen nachkommt. ${ }^{1314}$

Wünschenswert und verfassungsrechtlich angezeigt wäre indes eine Rückführung des Strafrechts auf den verhältnismäßig ausgestalteten Schutz klar umrissener und gesamtgesellschaftlich werthaltiger Rechtsgüter. Ob diese Vorgaben jedoch noch Raum für eine strafrechtliche Erfassung leistungssportlicher Wettkampfmanipulationen belassen, muss grundsätzlich und von ihrer etwaigen korruptiven Dimension unabhängig bezweifelt werden. Denn ein über $\$ 263$ StGB hinausgehender Sondervermögensschutz für Wettanbieter und einzelne mit dem Leistungssport verbundene Berufsgruppen erscheint dann genauso wenig begründbar wie der institutionelle Schutz eines gesellschaftlichen Teilbereiches, der weder aus der breitflächigen, aber passiv und beliebig bleibenden öffentlichen Anteilnahme noch aus seiner sektoral begrenzten wirtschaftlichen Bedeutung eine freiheitssichernde Funktion bezieht und zur Stabilisierung seines selbst definierten Wertekodex auf eigene Schutzmechanismen zurückgreifen kann.

Der demnach hier befürwortete Verzicht auf einen spezifizierten Einsatz des Strafrechts gegen Match Fixing zwingt indes nicht zu deren fatalistischer Hinnahme. Neben der bewährten Möglichkeit einer strafrechtlichen Verfolgung des vermögensschädigenden Wettbetrugs und seiner Begleithandlungen nach $\$ 263$ StGB konnten hier auf verschiedenen Ebenen noch nicht hinreichend ausgenutzte integritätsschützende Potenziale jenseits des Strafrechts aufgezeigt werden. Sie eröffnen sich Staat und Sportverbänden gleichermaßen. Durch eine klare und streng an empirischen Erkenntnissen ausgerichtete Sportwettenregulierung, durch die verbandsrechtliche Gewährleistung einer verlässlichen Bezahlung der Sportakteure, durch die Implementierung verbandsinterner Hinweisgebersysteme und die konsequente verbandsrechtliche Verfolgung hierdurch gewonnener Verdachtsmomente ließen sich bestimmte Risikofaktoren adressieren, die die Aufdeckungswahrscheinlichkeit vor allem des wettbedingten Match Fixing erhöhen und deren Anreize abschwächen. Noch wirkungsvoller wä-

1314 Bezeichnend insoweit die Einlassung des MdB Wellenreuther, dem es bei der Einführung der $\$ \$ 265 \mathrm{c}, 265 \mathrm{~d}$ StGB offenbar primär darum ging, ein „deutliches Signal“" zu setzen, s. BT-PIPr. 18/221, S. 22255 (C). 
ren indes glaubhafte und tatkräftige Bemühungen der Verbände, der Herausbildung interner korruptionsbegünstigender Strukturen ganzheitlich entgegenzuwirken und auf allen Ebenen des eigenen Wirkungsbereiches eine auf Transparenz, Sachlichkeit und Fairness basierende Organisationskultur zu etablieren. Hierdurch würde nicht nur dem einzelnen manipulationsgeneigten Sportakteur der Rückgriff auf Neutralisationstechniken entzogen, sondern auch das allgemeine Vertrauen in die Integrität des Sports und seiner Akteure gestärkt.

Selbst die Ausschöpfung dieser außerstrafrechtlichen Potenziale wird nicht sämtliche manipulativen Einwirkungen auf das sportliche Wettkampfgeschehen verhindern. Die in einem vielfach kommerzialisierten Umfeld nicht gänzlich zu beseitigenden sportlichen und wirtschaftlichen Manipulationsanreize lassen auch in Zukunft Meldungen über bestochene Schiedsrichter oder absprachegemäß die eigene Niederlage herbeiführende Sportler erwarten. Eine hieraus resultierende nachhaltige Beschädigung der Glaubwürdigkeit des Spitzensports kann durch die beschriebenen Maßnahmen - vor allem durch eine entschlossene verbandsinterne Corporate Governance - zumindest abgefedert werden. Sollten sich dennoch Teile der am Spitzensport interessierten Öffentlichkeit in ihrem medialen Konsumvergnügen beeinträchtigt fühlen oder gar enttäuscht anderen Inhalten zuwenden, so beschreibt dies eine Gefahr, die von der Gesellschaft durchaus getragen werden kann. Die gesellschaftlich wirklich bedeutsame Funktionsfähigkeit des Sports liegt in der Bereitstellung eines Raumes für spielerische und gesundheitsfördernde Betätigung, für sozialen Austausch und für das prägende aktive Erleben der Vereinigungsfähigkeit von Leistungsstreben, Fairness und Toleranz. Sie kann von leistungssportlichen Vorbildern verstärkt werden, ist auf diese aber nicht zwingend angewiesen. Ihre Störung steht daher selbst bei deren Wegfall nicht zu befürchten. 


\section{Literaturverzeichnis}

Alle angegebenen URLs wurden zuletzt am 31.01.2021 abgerufen.

Achenbach, Hans/Ransiek, Andreas/Rönnau, Thomas (Hrsg.) Handbuch Wirtschaftsstrafrecht, 5. Aufl., Heidelberg 2019 (zit. Achenbach/Ransiek/Rönnau/Bearbeiter).

Adams, Michael/Rock, Jan-Phillip Sportwetten und Spielmanipulation, ZfWG 2010, S. 381-386.

Adolphsen, Jens Regierungsentwurf eines Anti-Doping-Gesetzes: Wer die Musik bezahlt, bestimmt die Melodie, Legal Tribune Online vom 22.5.2015, www.lto.de/ $\mathrm{recht} / \mathrm{hintergruende/h/gesetzgebung-regierungsentwurf-anti-doping-gesetz-schie}$ dsgerichte.

Adolphsen, Jens/Nolte, Martin/Lehner, Michael/Gerlinger, Michael (Hrsg.) Sportrecht in der Praxis, Stuttgart 2012 (zit. Adolphsen/Nolte/Lehner/Gerlinger/Bearbeiter).

Ablert, Gerd/an der Heiden, Iris/Repenning, Sven Die ökonomische Bedeutung des Sports - Sportsatellitenkonto (SSK) 2016, Osnabrück 2019, www.bmwi.de/Reda ktion/DE/Publikationen/Wirtschaft/sportsatellitenkonto-2016.pdf?_blob=publi cationFile\&v $=8$.

Albrecht, Peter-Alexis Erosionen des rechtsstaatlichen Strafrechts, KritV 1993, S. 163182.

Amelung, Knut Rechtsgüterschutz und Schutz der Gesellschaft, Frankfurt a.M. 1972 (zit. Amelung Rechtsgüterschutz).

An der Heiden, Iris/Meyrahn, Frank/Ablert, Gerd Bedeutung des Spitzen- und Breitensports im Bereich Werbung, Sponsoring und Medienrechte, Forschungsbericht vom 17. Januar 2012, www.bmwi.de/Redaktion/DE/Publikationen/Studien/bed eutung-des-spitzen-und-breitensports.pdf?_blob=publicationFile\&v $=5$.

Andreff, Wladimir Complexity triggered by Economic Globalisation - the issue of on-line betting-related Match Fixing, Systems 2017, 5, 12.

- Different Types of Manipulation in Sport, in: Breuer, Markus/Forrest, David (Hrsg.), The Palgrave Handbook on the Economics of Manipulation in Sports, Cham 2018, S. 13-35 (zit. Andreff, in: Breuer/Forrest [Hrsg.], Palgrave Handbook).

Appel, Ivo Verfassung und Strafe, Berlin 1998 (zit. Appel Verfassung und Strafe).

Arzt, Gunther/Weber, Ulrich/Heinrich, Bernd/Hilgendorf, Eric Strafrecht Besonderer Teil, 3. Aufl., Bielefeld 2015 (zit. Arzt/Weber/Heinrich/Hilgendorf Strafrecht BT).

Ashelm, Michael Olympia ist am Boden, Faz.net vom 30.7.2016, www.faz.net/aktuel 1/wirtschaft/das-ioc-in-der-krise-olympia-ist-am-boden-14363340.html.

Bach, Thomas Bekämpfung des Dopings mittels eines Anti-Doping-Gesetzes?, ZRP 2006, S. 239. 
Bach, Florian Vereinsfremde Siegprämien für Fußballspieler, JR 2008, S. 57-59.

Bachmann, Mario/Goeck, Ferdinand Ein Blick in den Abgrund? - Strafrecht auf dem Prüfstand von Verfassung und Kriminologie, in: Brunhöber, Beatrice/Höffler, Katrin/Kaspar, Johannes/Reinbacher, Tobias/Vormbaum, Moritz (Hrsg.), Strafrecht und Verfassung, Baden-Baden 2013, S.37-56 (zit. Bachmann/Goeck in: Brunhöber/Höffler/Kaspar/Reinbacher/Vormbaum [Hrsg.], Strafrecht und Verfassung).

Bannenberg, Britta Korruption in Deutschland und ihre strafrechtliche Kontrolle, Neuwied 2002 (zit. Bannenberg Korruption).

Bannenberg, Britta/Schaupensteiner, Wolfgang Korruption in Deutschland: Porträt einer Wachstumsbranche, 3. Aufl., München 2007 (zit. Bannenberg/Schaupensteiner Korruption).

Bannenberg, Britta/Rössner, Dieter Straftat gegen den Wettbewerb. Plädoyer für den Einsatz des Strafrechts bei Dopingverstößen, in: Weinreich, Jens (Hrsg.), Korruption im Sport. Mafiose Dribblings, Organisiertes Schweigen, Leipzig 2006, S. 214-227.

- Manipulationen im Leistungssport als strafwürdige Sachverhalte, in: Kretschmer, Bernhard (Hrsg.), Rechts- als Geisteswissenschaft: Festschrift für Wolfgang Schild zum 60. Geburtstag, 2007, S. 59-74 (zit. Bannenberg/Rössner FS Schild).

Baumann, Jürgen/Weber, Ulrich/Mitsch, Wolfgang/Eisele, Jörg Strafrecht Allgemeiner Teil, 12. Aufl., Bielefeld 2016 (zit. Baumann/Weber/Mitsch/Eisele Strafrecht AT).

Beckemper, Katharina Das Rechtsgut „Vertrauen in die Funktionsfähigkeit der Märkte“, ZIS 2011, S. 318-323.

Becker, Gary S. Crime and Punishment: An Economic Approach, Journal of Political Economy 76 (1968), S. 169-217.

Becker, Florian Zur Weiterentwicklung der Glücksspielregulierung, ZfWG 2017, S. 2-13.

- Rechtliche Bewertung der Änderungen des Glücksspielstaatsvertrages, ZfWG 2017, S. 446-451.

Becker, Florian/Hilf, Juliane/Nolte, Norbert/Uwer, Dirk Glücksspielregulierung Kommentar zum Glücksspielstaatsvertrag und Nebengesetzen, Köln 2017 (zit. Becker/Hilf/Nolte/Uwer/Bearbeiter).

Belzer, Jason Thanks to Roger Goodell, NFL revenues projected to surpass \$13 billion in 2016, Forbes Online vom 29.2.2016, www.forbes.com/sites/jasonbelzer/20 16/02/29/thanks-to-roger-goodell-nfl-revenues-projected-to-surpass-13-billion-in-2 016/\#1beda2f01cb7.

Bender, Juliane Mannigfaltige Manipulationen, Die Tageszeitung vom 14.9.2010, S. 19, taz.de/!384899/.

Bepler, Klaus Gefahren für die Persönlichkeitsrechte von Sportlern durch arbeitsvertragliche Regelungen, in: Nolte, Martin (Hrsg.), Neue Bedrohungen für die Persönlichkeitsrechte von Sportlern, Stuttgart 2011, S.9-26 (zit. Bepler, in: Nolte [Hrsg.], Persönlichkeitsrechte).

Berberich, Bernd Sportwettbetrug und Manipulation von berufssportlichen Wettbewerben, ZfWG 2017, S. 347-352. 
Betting Integrity Association (ESSA) ESSA 2018 Annual Integrity Report, ibia.bet/wpcontent/uploads/2019/05/ESSA-2018-Annual-Integrity-Report.pdf (zit. ESSA).

Beuckelmann, Stefan Das Strafrecht und die Lauterkeit des sportlichen Wettbewerbs, NJW-Spezial 2010, S. 56-57.

Binding, Karl Lehrbuch des Gemeinen Deutschen Strafrechts, BT 1. Band, 2. Aufl., 1902 (zit. Binding Lehrbuch des Gemeinen Deutschen Strafrechts, BT I).

Bittmann, Folker Wettbetrug: Intersubjektiv bestimmter Quotenschaden, ZWH 2013, S. 137-141.

Bock, Michael Kriminologie, 5. Aufl., München 2019 (zit. Bock Kriminologie).

Boen, Klaus Wirtschaftskriminologie. Vom Versuch, mit einem blinden Fleck umzugehen, MschrKrim 2001, S. 335-356.

Bösing, Jan Manipulationen im Sport und staatliche Sanktionsmöglichkeiten: zur Notwendigkeit eines neuen Straftatbestandes gegen Bestechlichkeit und Bestechung im Sport, Marburg 2014 (zit. Bösing Manipulationen).

Bohn, André Die fortschreitende Ausweitung des materiellen Strafrechts am Beispiel der zukünftigen Strafbarkeit des Sportwettbetrugs und der Manipulation berufssportlicher Wettbewerbe, KriPoZ 2017, S. 88-94.

Bouhs, Daniel Das böse D-Wort, Die Tageszeitung vom 3.2.2011, taz.de/!5127417/.

Brauneisen, Achim Das deutsche Recht des Sportwettenbetrugs de lege lata und de lege ferenda, in: Württembergischer Fußballverband e.V. (Hrsg.), Das Recht der Sportwette und des Wettbetruges: Tagungsband des wfv-Sportrechtsseminars vom 30. September bis 2. Oktober 2011 in Wangen/Allgäu, Baden-Baden 2013, S. 43-68 (zit. Brauneisen, in: Württembergischer Fußballverband [Hrsg.], Sportwette).

Breuer, Christoph/Wicker, Pamela/Dallmeyer, Sören/Ilgner, Michael Die Lebenssituation von Spitzensportlern und -sportlerinnen in Deutschland, Sonderpublikation des Bundesinstituts für Sportwissenschaft (Hrsg.), Stand Oktober 2018, www.sp orthilfe.de/fileadmin/pdf/Studien/Breuer_et_al._2018_Lebenssituation_Spitze nsportler.pdf.

Breuer, Christoph/Feiler, Svenja (Hrsg.) Sportentwicklungsbericht für Deutschland 2017/2018 - Teil 1, Bonn 2019, www.dosb.de/sportentwicklung/sportentwicklu ngsbericht.

Breuer, Markus/Kaiser, Sebastian Match-fixing and manipulation in sport, in: Schulenkorf, Nico/Frawley, Stephen (Hrsg.) Critical Issues in Global Sport Management, London 2016, S. 64-76 (zit. Breuer/Kaiser in: Frawley/Schulenkorf [Hrsg.], Critical Issues).

Brodowski, Dominik Diskussionsbeiträge der 36. Tagung der deutschsprachigen Strafrechtslehrerinnen und Strafrechtslehrer 2015 in Augsburg, ZStW 127 (2015), S. 691-736.

Brugger, Christina/Leven, Marius Die technische Umsetzbarkeit des Verbots von Sportwetten im Internet - zugleich eine Anmerkung zum Beschluss des VGH Bayern vom 7.5.2007 - 24 C S 07/10, ZfWG 2007, S. 302-307. 
Buncombe, Andrew Dan Tan - the man who fixed football, The Independent vom 29.3.2013, www.independent.co.uk/news/world/asia/dan-tan-the-man-who-fixed -football-8554751.html.

Bund Deutscher Radfahrer (Hrsg.) Jahresberichte 2017, vorgelegt beim Hauptausschuss am 29. April 2018, static.rad-net.de//html/bdr/bekanntmachungen/2018/ 20180413_berichtsheft_ha_2018.pdf.

Bundeskriminalamt (Hrsg.) Polizeiliche Kriminalstatistik 2019, Jahrbuch, Band IV: Einzelne Straftaten/ -gruppen und ausgewählte Formen der Kriminalität, www.bka.de/SharedDocs/Downloads/DE/Publikationen/PolizeilicheKriminalsta tistik/2019/Jahrbuch/pks2019Jahrbuch4Einzelne.pdf?_blob=publicationFile\&v $=4$.

- Bundeslagebild Organisierte Kriminalität 2018, www.bka.de/SharedDocs/Downl oads/DE/Publikationen/JahresberichteUndLagebilder/OrganisierteKriminalitaet /organisierteKriminalitaetBundeslagebild2018.pdf?_blob=publicationFile\&v=4 .

- Bundeslagebild Korruption 2018, abrufbar unter: www.bka.de/SharedDocs/Dow nloads/DE/Publikationen/JahresberichteUndLagebilder/Korruption/korruption Bundeslagebild2018.html.

Bundesministerium des Innern (Hrsg.) Fragenkatalog zum Expertentreffen am 19. Mai 2014 im Bundesministerium des Innern, Bonn: Schriftliche Antworten der Expertinnen und Experten, Juli 2014, www.bmi.bund.de/SharedDocs/downl oads/DE/veroeffentlichungen/2014/stellungnahmen-experten-spielmanipulation .pdf?_blob=publicationFile\&v=1.

Bundesministerium für Wirtschaft und Energie (Hrsg.) Wirtschaftsfaktor Sportwetten - Sportfaktor Lotterie, Dezember 2014, www.bmwi.de/Redaktion/DE/Publikati onen/Wirtschaft/wirtschaftsfaktor-sportwetten.pdf?_blob=publicationFile\&v=1 4.

- Sportwirtschaft: Fakten \& Zahlen, Ausgabe 2018, Berlin 2018, www.bmwi.de/Re daktion/DE/Publikationen/Wirtschaft/sportwirtschaft-fakten-und-zahlen.pdf? blob=publicationFile $\& \mathrm{v}=12 /$.

Bundesrechtsanwaltskammer (BRAK) Stellungnahme zum Referentenentwurf des Bundesministeriums der Justiz und für Verbraucherschutz zur Strafbarkeit von Sportwettbetrug und der Manipulation berufssportlicher Wettbewerbe vom 3.11.2015, Nr. 8/2016, www.brak.de/zur-rechtspolitik/stellungnahmen-pdf/stellu ngnahmen-deutschland/2016/april/stellungnahme-der-brak-2016-8.pdf.

Bunzel, Michael Die Potenz des verfassungsrechtlichen Verhältnismäßigkeitsprinzips als Grenze des Rechtsgüterschutzes in der Informationsgesellschaft, in: Hefendehl, Roland/von Hirsch, Andrew/Wohlers, Wolfgang (Hrsg.), Die Rechtsgutstheorie - Legitimationsbasis des Strafrechts oder dogmatisches Glasperlenspiel?, Baden-Baden 2003, S. 96-118 (zit. Bunzel, in: Hefendehl/von Hirsch/ Wohlers [Hrsg.], Rechtsgutstheorie).

Burchard, Christoph Strafverfassungsrecht - Vorüberlegungen zu einem Schlüsselbegriff, in: Tiedemann, Klaus/Sieber, Ulrich/Satzger, Helmut/Burchardt, Christoph/Brodowski, Dominik (Hrsg.), Die Verfassung moderner Strafrechtspflege: Erinnerung an Joachim Vogel, Baden-Baden 2016, S. 27-62 (zit. Burchard, in: Tiedemann/Sieber/Satzger/Burchardt/Brodowski [Hrsg.], Strafrechtspflege). 
- Strafrechtslimitation als Motor der Strafrechtsexpansion, in: Kuhli, Milan/Asholt, Martin (Hrsg.), Strafbegründung und Strafeinschränkung als Argumentationsmuster, Baden-Baden 2017, S. 21-44 (zit. Burchard, in: Kuhli/Asholt [Hrsg.], Strafbegründung).

Buschmann, Rafael Wo FIFA und UEFA beim Wettbetrug versagt haben, Spiegel Online vom 4.2.2013, www.spiegel.de/sport/fussball/wettskandal-fruehwarnsyste me-von-fifa-und-uefa-ohne-chance-a-881417.html.

Caceres, Javier „Jeder hätte an deiner Stelle das Gleiche getan“, Sueddeutsche.de vom 13.1.2020, www.sueddeutsche.de/sport/real-madrid-supercopa-foul-notbre mse-valverde-1.4755141.

Carpenter, Kevin Match Fixing: The biggest threat to sport in the 21st Century? International Sports Law Review Vol. 12 Issue 2 (2012), S. 13-24.

Cherkeh, Rainer/Momsen, Carsten Doping als Wettbewerbsverzerrung? Möglichkeiten der strafrechtlichen Erfassung des Dopings unter besonderer Berücksichtigung der Schädigung von Mitbewerbern, NJW 2001, S. 1745-1752.

Dann, Matthias/Scholz, Karsten Der Teufel steckt im Detail - Das neue Anti-Korruptionsgesetz für das Gesundheitswesen, NJW 2016, S. 2077-2081.

Deutsche Fußballiga (DFL), Report 2018, abrufbar unter: www.dfl.de/de/dfl-report2018/.

Deutscher Anwalt Verein (DAV) Stellungnahme des Deutschen Anwaltsvereins durch den Ausschuss Strafrecht zum Referentenentwurf eines Gesetzes zur Änderung des Strafgesetzbuches: Strafbarkeit von Sportwettbetrug und der Manipulation berufssportlicher Wettbewerbe, Nr. 12/2016.

Deutscher Fußballbund (Hrsg.) Spiel kein falsches Spiel - Informationsbroschüre, 3. Aufl. 2017.

Deutscher Olympischer Sportbund (DOSB) Bestandserhebung 2020, abrufbar unter: www.dosb.de/medienservice/statistiken.

Deutscher Olympischer Sportbund (DOSB)/Deutscher Fußball-Bund (DFB)/Deutsche Fußball Liga (DFL) Gemeinsame Stellungnahme zum Entwurf eines Gesetzes zur Änderung des Strafgesetzbuches - Strafbarkeit von Sportwettbetrug und der Manipulation von berufssportlichen Wettbewerben, www.bmjv.de/SharedDocs/ Gesetzgebungsverfahren/Stellungnahmen/2016/Downloads/01152016_Stellung nahme_DOSB_DFB_DFL_RefE_Sportwettbetrug_und_Manipulation_berufssp ortlicher_Wettbewerbe.pdf?_blob=publicationFile $\& \mathrm{v}=\overline{1}$.

Deutscher Richterbund Stellungnahme des Deutschen Richterbundes zum Gesetzentwurf zur Strafbarkeit des Sportwettbetrugs und der Manipulation berufssportlicher Wettbewerbe, Nr. 2/2016, www.drb.de/fileadmin/DRB/pdf/Stellung nahmen/2016/DRB_160111_Stn_Nr_02_Sportwettbetrug.pdf.

Di Ronco, Anna/Lavorgna, Anita Fair Play? Not so much: Corruption in the Italian football, Trends in Organized Crime 2015, S. 176-195.

DIE ZEIT (Hrsg.), Das Lexikon in 20 Bänden, Band 9: Leum-mits, Hamburg 2005. 
Diedrich, Tobias Bedarf und Nutzen eines Gesetzes zur Bekämpfung des Dopings im Sport, in: Asmuth, Christoph (Hrsg.), Entgrenzungen des Machbaren? Doping zwischen Recht und Moral, Bielefeld 2012, S. 271-289 (zit. Diedrich, in: Asmuth [Hrsg.], Entgrenzungen).

Dittrich, Joachim Die Integrität des Sports - Schutzzweck oder Gesetzesziel?, ZWH 2017, S. 189-196.

Drape, Joe N.C.A.A. survey reveals athletes' gambling habits, New York Times Online vom 13.5.2004, www.nytimes.com/2004/05/13/sports/colleges-ncaa-survey-r eveals-athletes-gambling-habits.html.

Duden - Das Fremdwörterbuch, 11. Aufl., Berlin 2015.

Duggan, Mark/Levitt, Steven Winning Isn't Everything: Corruption in Sumo Wrestling, American Economic Review 92 (2002), S. 1594-1605.

Dury, Walter Kann das Strafrecht die Doping-Seuche ausrotten?, SpuRt 2005, 137-141.

- Lösung des Doping-Problems durch den Staatsanwalt?, in: Crezelius, Georg (Hrsg.), Festschrift für Volker Röhricht zum 65. Geburtstag, Köln 2005, S. 10971114 (zit. Dury FS Röhricht).

Duttig, Andreas Comfortably satisfied? Das Beweismaß in internationalen Dopingund Spielmanipulationsverfahren vor dem Internationalen Sportgerichtshof CAS unter besonderer Berücksichtigung des Standards comfortable satisfaction, Baden-Baden 2019 (zit. Duttig Beweismaß).

Duyar, Zübeyde Sportbeugung: Manipulationsverhalten von Schiedsrichtern im Fußballsport als strafbares Unrecht und die Bedeutung der allgemeinen Täuschung für das Strafrecht, Frankfurt a.M. 2014 (zit. Duyar Sportbeugung).

Eisele, Jörg Strafrecht - Besonderer Teil - Band 2: Eigentumsdelikte und Vermögensdelikte, 5. Aufl., Stuttgart 2019 (zitiert als: Eisele Strafrecht BT II).

Elaad, Guy/Grumer, Alex/Kantor, Jeffrey Corruption and Sensitive Soccer Games: Cross-Country Evidence, Journal of Law, Economics and Organization 34 (2018), S. 364-394.

Engländer, Armin Anmerkung zu BGH vom 15.12.2006 - 5 StR 181/06 (Fall Hoyzer), JR 2007, S. 477-479.

- Revitalisierung der materiellen Rechtsgutslehre durch das Verfassungsrecht?, ZStW 127 (2015), S. 616-634.

Ehrlich, Isaac Crime, Punishment, and the Market for Offenses, Journal of Economic Perspectives Volume 10, No. 1, 1996, S. 43-67.

Emrich, Eike/Pierdzioch, Christian Theoretische Rahmung, in: Emrich, Eike/Pierdzioch, Christian/Pitsch, Werner (Hrsg.), Falsches Spiel im Sport. Analysen zu Wettbewerbsverzerrungen, Saarbrücken 2015, S.15-44 (zit. Emrich/Pierdzioch, in: Emrich/Pierdzioch/Pitsch [Hrsg,], Falsches Spiel).

Ennuschat, Jörg/Klestil, Stephanie Sperrverfügungen gegenüber dem Access-Provider als Instrument zur Bekämpfung des illegalen Online-Glücksspiels?, ZfWG 2009, S. 389-395. 
Erbs, Georg (Begr.)/Kohlhaas, Max/Häberle, Peter (Hrsg.) Strafrechtliche Nebengesetze - Kommentar, München, Stand: 233. EL Oktober 2020 (zit. Erbs/Kohlhaas/ Häberle/Bearbeiter).

Fahl, Christian Sportverbandsgerichtsbarkeit und Doppelbestrafungsverbot, SpuRt 2001, S. 181-183.

Feltes, Thomas Match Fixing in Western Europe, in: Haberfeld, Maria/Sheehan, Dale (Hrsg.), Match-Fixing in International Sports: Existing Processes, Law Enforcement and Prevention Strategies, Cham 2013, S. 15-30 (zit. Feltes, in: Haberfeld/Sheehan [Hrsg.], Match-Fixing).

Feltes, Thomas/Kabuth, Detlef Die Politik schützt den Sport vor Wettmanipulationen. Warum?, Neue Kriminalpolitik 2017, S. 91-101.

Fiedler, Adrian Ein großer Wurf gegen Wettbetrug? Pro und Contra, DRiZ 2016, S. 17.

FIFPro (Hrsg.) Black Book Eastern Europe - The problems professional footballers encounter: research, 2012, www.lefigaro.fr/assets/pdf/fifpro.pdf (zit. FIFPro [Hrsg.], Black Book).

Fischer, Thomas Strafgesetzbuch mit Nebengesetzen, 67. Aufl., München 2020 (zit. Fischer StGB).

Fisman, Raymond/Miguel, Edward Corruption, Norms, and Legal Enforcement: Evidence from Diplomatic Parking Tickets, Journal of Political Economy 115 (2007), S. 1020-1048.

Forrest, David Match Fixing, in: Breuer, Markus/Forrest, David (Hrsg.), The Palgrave Handbook on the Economics of Manipulation in Sports, Cham 2018, S.91114 (zit. Forrest, in: Breuer/Forrest [Hrsg.], Palgrave Handbook).

Forrest, David/McHale, Ian An Evaluation of Sportradar's Fraud Detection System, 2015, integrity.sportradar.com/wp-content/uploads/sites/22/2018/11/Sportradar-I ntegrity-Services_University-of-Liverpool_An-Evaluation-of-the-FDS.pdf.

- Using statistics to detect match fixing in sport, IMA Journal of Management Mathematics (2019) 00, S. 1-19.

Forrest, David/McHale, Ian/McAuley, Kevin „Say It Ain't So“: Betting-Related Malpractice in Sport, International Journal of Sport Finance 2008, S. 156-166.

Fritzweiler, Jochen/Pfister, Bernhard/Summerer, Thomas Praxishandbuch Sportrecht, 3. und 4. Aufl., München 2014 bzw. 2020 (zit. PHB-SportR/Bearbeiter).

Frisch, Wolfgang Ausschluss und Ablehnung des Staatsanwalts. Möglichkeiten und Grenzen richterlicher Rechtsfortbildung und sachgerechter Gesetzgebung, in: Frisch, Wolfgang (Hrsg.), Festschrift für Hans-Jürgen Bruns, Köln 1978 S. 385414 (zit. Frisch FS Bruns).

- Rechtsgut, Recht, Deliktsstruktur und Zurechnung im Rahmen der Legitimation staatlichen Strafens, in: Hefendehl, Roland/von Hirsch, Andrew/Wohlers, Wolfgang (Hrsg.), Die Rechtsgutstheorie - Legitimationsbasis des Strafrechts oder dogmatisches Glasperlenspiel?, Baden-Baden 2003, S. 215-238 (Frisch, in: Hefendehl/von Hirsch/Wohlers [Hrsg.], Rechtsgutstheorie). 
- An den Grenzen des Strafrechts, in: Küper, Wilfried (Hrsg.), Beiträge zur Rechtswissenschaft: Festschrift für Walter Stree und Johannes Wessels zum 70. Geburtstag, Heidelberg 1993, S. 69-106 (Frisch FS Stree/Wessels).

- Voraussetzungen und Grenzen staatlichen Strafens, NStZ 2016, S. 16-24.

Freund, Georg Verfassungswidrige Dopingstrafbarkeit nach $\$ 95$ Abs. 1 Nr. 2a AMG, in: Bannenberg, Britta/Brettel, Hauke (Hrsg.), Über allem: Menschlichkeit: Festschrift für Dieter Rössner, Baden-Baden 2015, S. 579-598 (zit. Freund FS Rössner).

Funck, Michael Täuschungsbedingter Betrugsschaden, Baden-Baden 2018 (zit. Funck Betrugsschaden).

Gaede, Karsten Betrug durch den Abschluss durch den Abschluss manipulierter Fußballwetten: Das Hoyzer-Urteil als Sündenfall der Ausdehnung des Betrugstatbestandes. Anmerkung zu BGH-Urteil vom 15.12.2006 - 5 StR 181/06 („Hoyzer"), HRRS 2007, S. 18-22.

Gärditz, Klaus Ferdinand Demokratizität des Strafrechts und Ultima Ratio-Grundsatz, JZ 2016, S. 641-650.

Gebauer, Gunter Korruption im Sport, in: Wagner, Elisabeth/Wolf, Burkhard, Korruption, Berlin 2011, S. 136-147 (zit. Gebauer, in: Wagner/Wolf [Hrsg.], Korruption).

- Die Mythen-Maschine, in: Caysa, Volker (Hrsg.), Sportphilosophie, Leipzig 1997, S. 290-317 (zit. Gebauer, in: Caysa [Hrsg.], Sportphilosophie).

Giebel, Christoph Strafrechtlicher Schutz für die Lauterkeit des Sports in Deutschland, Causa Sport 2011, S. 254-256.

Gienger, Eberhard Ein großer Wurf gegen Wettbetrug? Pro und Contra, DRiZ 2016, S. 16.

Gieselmann, Dirk Die Betrogenen vom Polarkreis, 11 freunde.de vom 12.1.2016, www.11freunde.de/artikel/der-finnische-klub-rops-im-bann-der-wettmafia.

Glücksspielaufsichtsbehörden der Länder (Hrsg.) Jahresreport: Der deutsche Glücksspielmarkt 2018 - Eine ökonomische Darstellung vom 22.10.2019, innen.hessen .de/sites/default/files/media/hmdis/jahresreport_2018_0.pdf.

- Jahresreport: Der deutsche Glücksspielmarkt 2014 - Eine ökonomische Darstellung vom 22.12.2015, innen.hessen.de/sites/default/files/media/hmdis/jahresrep ort_2014.pdf.

Göppinger, Hans/Bock, Michael (Hrsg.) Kriminologie, 6. Aufl., München 2008 (zit. Göppinger/Bock Kriminologie).

Gorse, Samantha/Chadwick, Simon The Prevalence of Corruption in International Sport, 2011, www.jogoremoto.pt/docs/extra/G3jsJk.pdf.

Grabitz, Markus/Stolz, Christopher Skandal im belgischen Fußball: Lug und Trug, Tagesspeigel.de vom 14.10.2018, www.tagesspiegel.de/sport/fc-bruegge-rsc-ander lecht-und-co-im-fokus-skandal-im-belgischen-fussball-lug-und-trug/23183652.ht $\mathrm{ml}$.

Gräfe, Manuel/Abrens, Tobias Abpfiff, 11 Freunde vom 2.4.2019, www.11freunde.de /artikel/wie-manuel-graefe-den-hoyzer-skandal-aufdeckte. 
Graf, Jürgen-Peter/Jäger, Markus/Wittig, Petra (Hrsg.) Wirtschafts- und Steuerstrafrecht, 2. Aufl., München 2017 (zit. Graf/Jäger/Wittig/Bearbeiter).

Graupe, Johannes Die Systematik und das Rechtsgut der Bestechungsdelikte, München 1988 (zit. Graupe Systematik).

Greco, Luis Was lässt das Bundesverfassungsgericht von der Rechtsgutslehre übrig? Gedanken anlässlich der Inzestentscheidung des Bundesverfassungsgerichts, ZIS 2008, S. 234-238.

- Lebendiges und Totes in Feuerbachs Straftheorie, Berlin 2009 (zit. Greco Straftheorie).

- Zur Strafwürdigkeit des Selbstdopings im Leistungssport, GA 2010, S. 622-638.

- Verfassungskonformes oder legitimes Strafrecht? Zu den Grenzen einer verfassungsrechtlichen Orientierung der Strafrechtswissenschaft, in: Brunhöber, Beatrice/Höffler, Katrin/Kaspar, Johannes/Reinbacher, Tobias/Vormbaum, Moritz (Hrsg.), Strafrecht und Verfassung, Baden-Baden 2013, S. 13-36 (zit. Greco, in: Brunhöber/Höffler/Kaspar/ Reinbacher/Vormbaum [Hrsg.], Strafrecht und Verfassung).

- Zur Bestimmung des Vermögensschadens beim Sportwettenbetrug, NZWiSt 2014, S. 334-338.

Grunsky, Wolfgang Schiedsgerichtsbarkeit im deutschen Fußball, in: Crezelius, Georg (Hrsg.), Festschrift für Volker Röhricht zum 65. Geburtstag, Köln 2005, S. 1137-1148 (zit. Grunsky FS Röhricht).

- Persönlichkeitsrecht und Verbandsautonomie bei der Dopingbekämpfung, SpuRt 2007, S. 188-192.

Grupe, Ommo/Mieth, Dietmar Lexikon der Ethik im Sport, 3. Aufl., Schorndorf 2001 (zit. Grupe/Mieth/Bearbeiter Lexikon der Ethik im Sport).

Gustke, Axel „Deflategate“ in der NFL: viel Wind um wenig Luft, Tagesspiegel.de vom 22.1.2015, www.tagesspiegel.de/sport/big-four-die-us-sport-kolumne-deflate gate-in-der-nfl-viel-wind-um-wenig-luft/11266304.html.

Guttmann, Allen Vom Ritual zum Rekord: das Wesen des modernen Sports, Schorndorf 1979 (zit. Guttmann Rekord).

Haberl, Tobias Wetten, dass...?, Süddeutsche Zeitung Magazin Nr.11/2019 vom 14.3.2019, sz-magazin.sueddeutsche.de/sport/sportwetten-fussball-werbung-tipic o-bwin-86974? reduced=true.

Häublein, Anja Korruption im Profifußball in Deutschland, Wiesbaden 2014 (zit. Häublein Korruption).

Haft, Fritjof Freiberufler sind keine Amtsträger, NJW 1995, S. 1113-1118.

Hanack, Ernst-Walter Empfiehlt es sich, die Grenzen des Sexualstrafrechts neu zu bestimmen?, Gutachten für den 47. Deutschen Juristentag, in: Ständige Deputation des Deutschen Juristentages (Hrsg.), Verhandlungen des siebenundvierzigsten Deutschen Juristentages. Nürnberg 1968, Band I (zit. Hanack Gutachten für den 47. Deutschen Juristentag).

Hartmann, Bernd/Niehaus, Holger Zur strafrechtlichen Einordnung von Wettmanipulationen im Fußball, JA 2006, S. 432-435. 
Harvey, Andrew/ Levy, Harvey Don't fix it! Players Questionnaire: Results and Analysis, 2014, abrufbar unter: https:/fifpro.org/en/rights/match-fixing/match-fixing -don-t-fix-it.

Hassemer, Winfried Theorie und Soziologie des Verbrechens: Ansätze zu einer praxisorientierten Rechtsgutslehre, Frankfurt a.M. 1980 (zit. Hassemer Theorie und Soziologie).

- Einführung in die Grundlagen des Strafrechts, 2. Aufl., München 1990 (zit. Hassemer Einführung).

- Kennzeichen und Krisen des modernen Strafrechts, ZRP 1992, S. 378-383.

- Darf es Straftaten geben, die ein strafrechtliches Rechtsgut nicht in Mitleidenschaft ziehen? in: Hefendehl, Roland/von Hirsch, Andrew/Wohlers, Wolfgang (Hrsg.), Die Rechtsgutstheorie - Legitimationsbasis des Strafrechts oder dogmatisches Glasperlenspiel?, Baden-Baden 2003, S. 57-64 (zit. Hassemer, in: Hefendehl/von Hirsch/Wohlers [Hrsg.], Rechtsgutstheorie).

Haug, Tanja/Martin, Anja Schutz des Sports vor Manipulation: Ist das geplante Anti-Doping-Gesetz wirksam?, Causa Sport 2014, S. 345-355.

Hauptmann, Markus/Rübenstahl, Markus Zur verfassungsrechtlichen Unbedenklichkeit einer Doping-Besitzstrafbarkeit de lege ferenda - insbesondere gemessen am „Cannabis-Urteil“ des BVerfG, HRRS 2007, S. 143-151.

Haucap, Justus/Nolte, Martin/Stöver, Heino (Hrsg.) Faktenbasierte Evaluierung des Glücksspielvertrages, Köln 2017, www.dshs-koeln.de/fileadmin/redaktion/Instit ute/Sportrecht/Dokumente/Faktenbasierte_Evaluierung_des_GlueStV.pdf (zit. Haucap/Nolte/Stöver [Hrsg.] Faktenbasierte Evaluierung).

Hayer, Tobias Die Regulation von Sportwetten - Quo vadis?, ZfWG 2017, S. $445-$ 446.

Heilemann, Tina Bestechlichkeit und Bestechung im sportlichen Wettbewerb als eigenständiges Strafdelikt, Stuttgart u.a. 2014 (zit. Heilemann Bestechlichkeit).

Heintschel-Heinegg, Bernd von (Hrsg.) Beck'scher Online-Kommentar Strafgesetzbuch, 45. Ed., München 2020 (zit. BeckOK-StGB/Bearbeiter).

Hefendebl, Roland Kollektive Rechtsgüter im Strafrecht, Köln 2002 (zit. Hefendehl Kollektive Rechtsgüter).

- Die Materialisierung von Rechtsgut und Deliktsstruktur, GA 2002, S. 21-28.

- Organisierte Kriminalität als Begründung für ein Feind- oder Täterstrafrecht?, StV 2005, S. 156-161.

- Mit langem Atem: Der Begriff des Rechtsguts - Oder: Was seit Erscheinen des Sammelbandes über die Rechtsgutstheorie geschah, GA 2007, S. 1-14.

- Außerstrafrechtliche und strafrechtliche Instrumentarien zur Eindämmung der Wirtschaftskriminalität, ZStW 119 (2007), S. 816-847.

- Der fragmentarische Charakter des Strafrechts, JA 2011, S. 401-406.

- Ein Wolf im Schafspelz? Ein ganzes Wolfsrudel! Herrschaftsstabilisierung über Strafrecht und juristische Ausbildung, Kritische Justiz 2016, S. 577-589.

- Ordnungswidrigkeiten: Legitimation und Grenzen, ZIS 2016, S. 636-645. 
- Eine soziale Rechtsgutstheorie, in: Herzog, Felix/Schlothauer, Reinhold/Wohlers, Wolfgang/Wolter, Jürgen (Hrsg.), Rechtsstaatlicher Strafprozess und Bürgerrechte - Gedächtnisschrift für Edda Weßlau, Berlin 2016 S. 579-593 (zit. Hefendehl GS Weßlau).

Heger, Martin Zum Rechtsgut einer Strafnorm gegen Selbst-Doping, SpuRt 2007, S. 153-155.

- NJW-Editorial 4/2016.

Henning-Bodewig, Frauke Das europäische Wettbewerbsrecht: Eine Zwischenbilanz, GRUR Int 2002, S. 389-398.

Herzog, Felix/Achtelik, Olaf Christoph (Hrsg.) Geldwäschegesetz - Kommentar, 4. Aufl., München 2020 (zit. Herzog/Achtelik/Bearbeiter GWG).

Hetzer, Wolfgang Korruptionsbekämpfung in Europa, NJW 2004, S. 3746-3750.

Hilf, Juliane/Umbach, Klaus Neues zum Sportwettkonzessionsverfahren, ZfWG 2017, S. 234-239.

- Update zum Sportwettenrecht, ZfWG 2019, S. 337-343.

Hilgendorf, Eric/Kudlich, Hans/Valerius, Brian (Hrsg.) Handbuch des Strafrechts, Band 5: Strafrecht Besonderer Teil II, Heidelberg 2020 (zit. Hdb-StR/Bearbeiter).

Hill, Declan Sichere Siege: Fußball und organisiertes Verbrechen oder wie Spiele manipuliert werden, Köln 2008 (zit. Hill Sichere Siege).

- A critical mass of corruption: why some football leagues have more match-fixing than others, International Journal of Sports Marketing and Sponsorship, Vol. 11 No. 3 (2010), S. 221-235.

- Jumping into Fixing, Trends in Organised Crime 2015, S. 212-228.

- Why Sport is losing the war to match fixers, in: Transparency International (Hrsg.), Global Corruption Report: Sport, New York 2016, S. 231-235 (zit. Hill, in: Transparency International [Hrsg.], Corruption Report).

Hilpert, Horst Notwendigkeit einer Anklageinstanz in Sportverbandsgerichtsverfahren?, SpuRt 1996, S. 50-53.

- Fußballstrafrecht, 2. Aufl., Berlin 2018 (zit. Hilpert Fußballstrafrecht).

Hirsch, Hans-Joachim Zu strafrechtlichen Fragen des Sportrechts, in: Joerden, Jan/ Scheffler, Uwe/Sinn, Arndt/Wolf, Gerhard (Hrsg.), Vergleichende Strafrechtswissenschaft: Frankfurter Festschrift für Andrzej J. Szwarc zum 70. Geburtstag, Berlin 2009, S. 559-584 (zit. Hirsch FS Szwarc).

Hörnle, Tatjana Grob anstößiges Verhalten: strafrechtlicher Schutz von Moral, Gefühlen und Tabus, Frankfurt a.M. 2005 (zit. Hörnle Anstößiges Verhalten).

- Das Verbot des Geschwisterinzests - Verfassungsrechtliche Bestätigung und verfassungsrechtliche Kritik, NJW 2008, S. 2085-2088.

Hohmann, Olaf Das Rechtsgut der Umweltdelikte, Frankfurt a.M. 1991 (zit. Hohmann Umweltdelikte).

Holzhäuser, Felix/Bagger, Tim/Schenk, Maximilian Ist E-Sport „echter“ Sport?, SpuRt 2016, S. 94-97. 


\section{Literaturverzeichnis}

Hürner, Thomas Neymar und das Financial Foul Play, FAZ.net vom 8.8.2017, www.faz.net/aktuell/sport/fussball/neymars-rekord-transfer-financial-fair-play-ge scheitert-15138608.html.

Hutz, Christopher/Kaiser, Martin Aspekte der Spielmanipulationen und des Sportwettbetruges in Deutschland und der Schweiz, NZWiSt 2013, S. 379-385.

Interpol/International Olympic Comitee (Hrsg.) Handbook on Protecting Sport from Competition Manipulation, 2016 (zit. Interpol/IOC [Hrsg.] Handbook).

International Centre for Sport Security (ICSS)/Université Paris 1 - Sorbonne (Hrsg.) Fighting against the Manipulation of Sports Competitions, Final Report, Part 1-3, 2014 (zit. ICSS/Sorbonne [Hrsg.] Part).

Institut des Relations Internationales et Strategiques/European Commission (Hrsg.) Preventing Criminal Risks linked to the sports betting market, Final Report June 2017, abrufbar unter: www.iris-france.org/preventing-the-criminal-risks-linke d-to-the-sports-betting-market/ (zit. IRIS [Hrsg.] Preventing).

Ivanov, Petar/Köpferl, Georg Wo zwei wetten, muss einer verlieren, Jura 2016, S. 554-566.

Jacobi, Christoph Der Straftatbestand des Kapitalanlagebetrugs ( $\$ 264 \mathrm{a}$ StGB), Baden-Baden 2000 (zit. Jacobi Kapitalanlagebetrug).

Jacques, Henning Die Bestechungstatbestände unter besonderer Berücksichtigung des Verhältnisses der $\$ \$ 331 \mathrm{ff}$. StGB zu $\mathbb{} 12$ UWG, Bern 1996 (zit. Jacques Bestechungstatbestände).

Jäger, Herbert Strafgesetzgebung und Rechtsgüterschutz bei Sittlichkeitsdelikten: eine kriminalsoziologische Untersuchung, Stuttgart 1957 (zit. Jäger Rechtsgüterschutz).

Jaeger, Christian Wettbetrug - nicht nur ein Schaden für den Sport, sondern auch für das Vermögen, Anm. zu BGH vom 20.12.2012 - 4 StR 55/12, JA 2013, S. 868-871.

Jahn, Matthias Doping zwischen Selbstgefährdung, Sittenwidrigkeit und staatlicher Schutzpflicht, ZIS 2006, S. 57-62.

- Die Strafbarkeit des Besitzes nicht geringer Mengen von Dopingmitteln, GA 2007, S. 579-589.

- Strategien und Instrumente in Dopingverfahren aus Sicht des deutschen Strafrechts, SpuRt 2013, S. 90-94.

- Strafverfassungsrecht: Das Grundgesetz als Herausforderung für die Dogmatik des Straf- und Strafverfahrensrechts, in: Tiedemann, Klaus/Sieber, Ulrich/Satzger, Helmut/Burchard, Christoph/Brodowski, Dominik(Hrsg.), Die Verfassung moderner Strafrechtspflege: Erinnerungen an Joachim Vogel, Baden-Baden 2016, S. 63-86 (Zit.Jahn Vogel-Symposium).

Jahn, Matthias/Brodowski, Dominik Krise und Neuaufbau eines verfassungsrechtlichen Ultima Ratio-Prinzips, JZ 2016, S. 969-980.

Jahn, Matthias/Meier, Stefan Der Fall Hoyzer - Grenzen der Normativierung des Betrugstatbestandes JuS 2007, S. 215-219. 
Jaleesi, Mani Die Kriminalisierung von Manipulationen im Sport - Eine Untersuchung zum Sportwettbetrug und der Manipulation von berufssportlichen Wettbewerben gem. $\$ 265$ c und $\$ 265$ d StGB, Baden-Baden 2020 (zit. Jaleesi Kriminalisierung).

Jakobs, Günther Strafrecht Allgemeiner Teil, 2. Aufl., Berlin 1991 (zit. Jakobs Strafrecht AT).

- Das Strafrecht zwischen Funktionalismus und „alteuropäischem Prinzipiendenken“, ZStW 107 (1995), S. 843-876.

- Kriminalisierung im Vorfeld von Rechtgutsverletzungen, ZStW 97 (1985), S. 751-785.

Jansen, Scarlett Der Schutz der „Integrität des Sports“ durch das Strafrecht?, GA 2017, S. 600-614.

Jescheck, Hans-Heinrich/Weigend, Thomas Lehrbuch des Strafrechts - Allgemeiner Teil, 5. Aufl., Berlin 1996 (zit. Jescheck/Weigend Strafrecht AT).

Jetter, Michael/Walker, Kay Good Girl, Bad Boy? Evidence Consistent with Collusion in Professional Tennis, Southern Economic Journal 84, Vol. 1 (2017), S. 155180.

Joecks, Wolfgang/Miebach, Klaus (Hrsg.), Münchener Kommentar zum Strafgesetzbuch, 3. und. 4. Aufl., München 2017-2020 (zit. MüKo-StGB/Bearbeiter).

Kalb, Adrian/Herrmann, Konstantin/Emrich, Eike Die Darstellung von Wettbewerbsverzerrungen im Sport in den Printmedien, in: Emrich, Eike/Pierdzioch, Christian/Pitsch, Werner (Hrsg.), Falsches Spiel im Sport. Analysen zu Wettbewerbsverzerrungen, Saarbrücken 2015, S. 109-156 (zit. Kalb/Herrmann/Emrich, in: Emrich/Pierdzioch/Pitsch [Hrsg.], Falsches Spiel).

Kant, Immanuel Metaphysik der Sitten, Akademieausgabe, Bd. VI (zit. Kant Metaphysik).

Kargl, Walter Die Funktionen des Strafrechts in rechtstheoretischer Sicht, Heidelberg 1995 (zit. Kargl Funktionen des Strafrechts).

- Über die Bekämpfung des Anscheins der Kriminalität bei der Vorteilsannahme ( $\$ 331$ StGB), ZStW 114 (2002), S. 763-793.

- Begründungsprobleme des Dopingstrafrechts, NStZ 2007, S. 489-496.

- Vertrauen als Rechtsgutsbestandteil, in: Neumann, Ulfried/Prittwitz, Cornelius (Hrsg.), „Personale Rechtsgutslehre“ und „Opferorientierung im Strafrecht“, Frankfurt a.M. 2007, S. 41-84 (zit. Kargl, in: Neumann/Prittwitz [Hrsg.], Personale Rechtsgutslehre).

Kasiske, Peter Die konkludente Täuschung bei $\$ 263$ StGB zwischen Informationsrisiko und Informationsherrschaft GA 2009, S. 360-370.

Kauerhof, Rico Strafrecht zwischen Sanktions- und Interventionsrecht: Eine Systemanalyse anhand der Dopingproblematik, in: Asmuth, Christoph (Hrsg.), Entgrenzungen des Machbaren? Doping zwischen Recht und Moral, Bielefeld 2012, S. 291-269 (zit. Kauerhof, in: Asmuth [Hrsg.], Entgrenzungen).

- Anti-Doping-Kampf: Sport als Strafrechtsgut?, Causa Sport 2014, S. 127-135. 
KEA (Hrsg.) Match-fixing in sport - A mapping of criminal law provisions in EU 27, 2012, ec.europa.eu/assets/eac/sport/library/studies/study-sports-fraud-final-ver sion_en.pdf.

Kerner, Hans-Jürgen/Trüg, Gerson Referendarexamensklausur Strafrecht - Betrugsstrafrechtliche Relevanz des Dopings, JuS 2004, S. 140-145.

Ketteler, Gerd Sport als Rechtsbegriff, SpuRt 1997, S. 73-77.

Kindhäuser, Urs Voraussetzungen strafbarer Korruption in Staat, Wirtschaft und Gesellschaft, ZIS 2011, S. 461-469.

Kindhäuser, Urs/Neumann, Ulfried/Paeffgen, Hans-Ulrich (Hrsg.) Strafgesetzbuch, 5. Aufl., Baden-Baden 2017 (zit. NK-StGB/Bearbeiter).

Kindhäuser, Urs/Schumann, Kay Strafprozessrecht, 5. Aufl., Baden-Baden 2019 (zit. Kindhäuser/Schumann Strafprozessrecht).

Kirkpatrick, David Ryan Organisierte Kriminalität - Wirtschaftskriminalität, wistra 2016, S. 378-386.

Kleffmann, Gerald Doppelfehler im System, Sueddeutsche.de vom 27.12.2019, www.sueddeutsche.de/sport/tennis-betrug-koepfer-itf-1.4736915.

Kloepfer, Michael Verfassungsrecht Band I - Grundlagen, Staatsorganisationsrecht, Bezüge zum Völker- und Europarecht, München 2011 (zit. Kloepfer Verfassungsrecht I).

Kistner, Thomas Fifa Mafia - Die schmutzigen Geschäfte mit dem Weltfußball, München 2014 (zit. Kistner Fifa Mafia).

- „Idiot! 4:1 sollte es sein.“, Sueddeutsche.de vom 8.4.2017, www.sueddeutsche.de/s port/schiebung-im-fussball-idiot-4-1-sollte-es-sein-1.3456478.

Knauer, Christoph/Kudlich, Hans/Schneider, Hartmut (Hrsg.) Münchener Kommentar zur Strafprozessordnung, 1. Aufl., München 2018 (zit. MüKo-StPO/Bearbeiter).

Koalitionsvertrag zwischen CDU, CSU und SPD für die 18. Legislaturperiode Deutschlands Zukunft gestalten, 27.11.2013, www.bundestag.de/resource/blob/ 194886/696f36f795961df200fb27fb6803d83e/koalitionsvertrag-data.pdf.

Koch, Rainer/Maennig, Wolfgang Spiel- und Wettmanipulationen - und der AntiKorruptionskampf im Fußball, Der Bürger im Staat 1/2006, www.buergerimstaa t.de/1_06/spiel.htm.

Ködel, Mario Jonas Warum NBA-Teams absichtlich verlieren, Sueddeutsche.de vom 12.4.2018, www.sueddeutsche.de/sport/tanking-im-basketball-warum-nba-teamsabsichtlich-verlieren-1.3939451-0\#seite-2.

König, Peter Sportschutzgesetz - Pro und Contra. Argumente für ein Sportschutzgesetz, SpuRt 2010, S. 106-107.

Krack, Ralf Betrug durch Wettmanipulationen. Das Urteil des BGH zum Schiedsrichterskandal, ZIS 2007, S. 103-112.

- Bestechlichkeit und Bestechung von Sportschiedsrichtern - eine Straftat?, ZIS 2011, S. 475-481.

- Sportwettbetrug und Manipulation von berufssportlichen Wettbewerben, ZIS 2016, S. 540-551. 
- Sportwettbetrug und Manipulation von berufssportlichen Wettbewerben, wistra 2017, S. 289-297.

Krauß, Detlev Rechtsgut und kein Ende. Zur Strafbarkeit des Geschwisterinzests (BVerfGE 120, 224), in: Herzog, Felix/Neumann, Ulfried (Hrsg.), Festschrift für Winfried Hassemer zum 70. Geburtstag, Heidelberg 2010, S. 423-437 (zit. Krauß FS Hassemer).

Kretschmer, Bernhard Sportmanipulation als Strafrechtsproblem, in: Bannenberg, Britta/Brettel, Hauke (Hrsg.), Über allem: Menschlichkeit: Festschrift für Dieter Rössner, Baden-Baden 2015, S. 628-645 (zit. Kretschmer FS Rössner).

Kreuzer, Arthur Kriminalisierung des „Eigendoping“ von Sportlern?, ZRP 2013, S. 181-183.

Krähe, Christian Techno-Doping und der Fall Pistorius, SpuRt 2008, S. 149-154.

Krüger, Matthias/Hilbert, Sven/Wengenroth, Lenard Strafbarkeit von Spielmanipulationen, Causa Sport 2013, S. 188-198.

Kube, Edwin/Vahlenkamp, Werner Korruption - hinnehmen oder handeln?, VA 85 (1994), S. 432-449.

Kubiciel, Michael Wetten und Betrug - Zur konkludenten Täuschung. Anmerkungen zu BGH-Urteil vom 15.12.2006, BGH 5 StR 181/06 („Hoyzer“), HRRS 2007, S. 68-71.

- Freiheit, Institutionen, abstrakte Gefährdungsdelikte. Ein neuer Prototyp des Wirtschaftsstrafrechts? in: Kempf, Eberhard/Lüderssen, Klaus/Volk, Klaus (Hrsg.), Strafverfolgung in Wirtschaftsstrafsachen. Strukturen und Motive, Frankfurt a.M. 2015, S. 158-171 (zit. Kubiciel, in: Kempf/Lüderssen/Volk [Hrsg.], Prototyp).

- Legitimation, Umfang und Interpretation der Straftatbestände gegen Sportwettbetrug und Manipulation von berufssportlichen Wettbewerben, WiJ 2016, S. 256-266.

- Bekämpfung der Korruption im Sport - Die Straftatbestände gegen den Sportwettbetrug und die Manipulation berufssportlicher Wettbewerbe, jurisPRStrafR 3/2016 Anm. 1.

- Schriftliche Fassung der Stellungnahme in der öffentlichen Anhörung vor dem Rechtsausschuss am 28.9.2016 zum Regierungsentwurf BT-Drs. 18/8831, www.bundestag.de/blob/461382/64f767b3aaf287ec4caaa53f201926d2/kubiciel-d ata.pdf.

- Neue Haftungsrisiken für Vereine: Die Straftatbestände gegen Sportwettbetrug und Spielmanipulation, SpuRt 2017, S. 188-193.

- Integrität des Sports - Konkretisierung eines Begriffs, KriPoZ 2018, S. 29-31.

- Entwicklung des eSports und Schutz seiner Integrität, ZRP 2019, S. 200-203.

Kudlich, Hans An den Grenzen des Strafrechts, JA 2007, S. 90-95.

- Sportschutzgesetz - Pro und Contra. Argumente gegen ein Sportschutzgesetz, SpuRt 2010, S. 108-109.

- Wissenschaftsbetrug als Straftatbestand? Pro und Contra, DRiZ 2013, S. 361. 
- Die Relevanz der Rechtsgutstheorie im modernen Verfassungsstaat, ZStW 127 (2015), S. 635-653.

Kühl, Kristian Strafrecht Allgemeiner Teil, 8. Aufl., München 2017 (zit. Kübl Strafrecht AT).

Kublen, Lothar Zum Strafrecht der Risikogesellschaft, GA 1994, S. 347-367.

- Der Handlungserfolg der strafbaren Gewässerverunreinigung ( $\$ 324$ StGB), GA 1986, S. 389-408.

- Umweltstrafrecht - auf der Suche nach einer neuen Dogmatik, ZStW 105 (1993), S. 697-726.

Kulhanek, Tobias Oliver Bilanzrechtsorientierung und Quotenschaden als Beispiele einer modernen Schadensdogmatik, NZWiSt 2013, S. 246-251.

Künast, Renate Doping im Sport? Braucht es das Strafrecht, DRiZ 2015, S. 301.

Kunz, Karl-Ludwig/Singelnstein, Tobias Kriminologie: eine Grundlegung, 7. Aufl., Bern 2016 (zit. Kurz/Singelnstein Kriminologie).

Lackner, Kar/Kühl, Kristian/Heger, Martin (Hrsg.) Strafgesetzbuch - Kommentar, 29. Aufl., München 2018 (zit. Lackner/Kühl/Heger/Bearbeiter).

Lagodny, Otto Strafrecht vor den Schranken der Grundrechte, Tübingen 1996 (zit. Lagodny Schranken).

Lammert, Katharina Korruption im Sport: zugleich ein Beitrag zur rechtlichen Verantwortungsteilung zwischen Sport und Staat, Köln 2014 (zit. Lammert Korruption).

Lampe, Ernst Joachim Rechtsgut, kultureller Wert und individuelles Bedürfnis, in: Stratenwerth, Günther (Hrsg.) Festschrift für Hans Welzel zum 70. Geburtstag, Berlin 1974, S. 151-166 (zit. Lampe FS Welzel).

Landau, Herbert Die jüngere Rechtsprechung des Bundesverfassungsgerichts zu Strafrecht und Strafverfahrensrecht, NStZ 2015, S. 665-671.

Laufhütte, Heinrich W./Rissing-van Saan, Ruth/Tiedemann, Klaus (Hrsg.) Strafgesetzbuch - Leipziger Kommentar, 12. und 13. Aufl., Tübingen 2008-2020 (zit. LK$\mathrm{StGB} /$ Bearbeiter).

Lehner, Michael/Nolte, Martin/Putzke, Holm Anti-Doping-Gesetz - Kommentar, 1. Aufl., Baden-Baden 2017 (zit. Lehner/Nolte/Putzke/Bearbeiter AntiDopG).

Lenk, Hans Aspekte einer Pragmatisierung der Ethik - auch für die Sportethik, in: Cachay, Klaus/Digel, Helmut/Drexel, Gerhard (Red.), Sport und Ethik. Symposium der deutschen Vereinigung für Sportwissenschaft Sektion Sportsoziologie, Clausthal-Zellerfeld 1985, S.1-20 (zit. Lenk, in: Cachay/Digel/Drexel [Hrsg.], Pragmatisierung).

- Sportethik und Wirtschaftsethik: Konkurrenz und Fairness in Sport und Wirtschaft, in: Maring, Matthias (Hrsg.), Bereichsethiken im interdisziplinären Dialog, Karlsruhe 2014, S. 301-322 (zit. Lenk, in: Maring [Hrsg.], Bereichsethiken).

Lewis, Adam/Wilkinson, Beth/Henzelin, Marc Independent Review of Integrity in Tennis, Final Report vom 19.12.2018, www.atptour.com/-/media/files/independ ent-review-of-integrity-in-tennis-interim-report-2018.pdf (zit. Lewis/Wilkinson/ Henzelin Integrity in Tennis). 
Löffelmann, Markus Strafbarkeit des Sportwettbetrugs, recht + politik Nr. 2/2016, S. $1-5$.

Loos, Fritz Zum Rechtsgut der Bestechungsdelikte, in: Stratenwerth, Günther (Hrsg.) Festschrift für Hans Welzel zum 70. Geburtstag, Berlin 1974, S. 879-896 (zit. Loos FS Welzel).

Ludwig, Kai Internationale Fußballsanktionspraxis bei Verfehlungen im Sportwettenbereich, in: Kainz, Florian/Scherrer, Urs/Werner, Christian (Hrsg.), Sportfinanzierung und Sportwetten, Zürich u.a. 2012, S.181-198 (zit. Ludwig, in: Kainz/Scherrer/Werner [Hrsg.], Sportfinanzierung).

Lüderssen, Klaus Die Symbiose von Markt und Staat - auseinanderdividiert durch Strafrecht?, StV 1997, S. 318-323.

- Das Strafrecht zwischen Funktionalismus und alteuropäischem Prinzipiendenken, ZStW 107 (1995), S. 877-906.

Lutz, Judith Die Kriminalisierung des Sports - Anti-Doping-Maßnahmen des Strafrechts und der Sportverbände im Vergleich, HRRS 2016, S. 21-28.

Maas, Heiko Wann darf der Staat strafen? NStZ 2015, S. 305-309.

Maennig, Wolfgang Korruption im internationalen Sport: Ökonomische Analyse und Lösungsansätze, Vierteljahreshefte zur Wirtschaftsforschung 73 (2004) 2, S. 263-291.

Matt, Holger/Renzikowski, Joachim Strafgesetzbuch - Kommentar, 2. Aufl., München 2020 (zit. Matt/Renzikowski/Bearbeiter).

Maurach, Reinhart/Schroeder, Friedrich-Christian/Maiwald, Manfred Strafrecht - Teilband 2: Straftaten gegen Gemeinschaftswerte, 10. Aufl., Heidelberg 2012 (zit. Maurach/Schroeder/Maiwald Strafrecht BT II).

Maurach, Reinhart/Zipf, Hans Strafrecht - Teilband 1: Grundlehren des Strafrechts und Aufbau der Straftat, 8. Aufl., Heidelberg 1992 (zit. Maurach/Zipf Strafrecht $\mathrm{AT} / 1)$.

McKinseydCompany (Hrsg.) Wachstumsmotor Bundesliga: Die ökonomische Bedeutung des professionellen Fußballs in Deutschland - Ergebnisse 2015, www.dfl.de/de/mckinsey_2015/.

Meier, Bernd-Dieter Kriminologie, 5. Aufl., München 2016 (zit. Meier Kriminologie).

Meier, Heiko/Riedl, Lars/Kukuk, Marc Soziologische Herausforderungen durch Migration, Inklusion und Integration im Sport, in: Meier, Heiko/Riedl, Lars/Kukuk, Marc (Hrsg.), Migration, Inklusion und Integration: soziologische Beobachtungen im Sport, Baltmannsweiler 2016, S. 1-14 (zit. Meier/Riedl/Kukuk, in: Meier/ Riedl/Kukuk, Migration).

Mintas, Laila „Match Fixing“ - Klare Abseitsposition des deutschen Gesetzgebers, in: Kainz, Florian/Scherrer, Urs/Werner, Christian (Hrsg.), Sportfinanzierung und Sportwetten, Zürich u.a. 2012, S.97-102 (zit. Mintas, in: Kainz/Scherrer/ Werner [Hrsg.], Sportfinanzierung).

Mitsch, Wolfgang (Hrsg.) Karlsruher Kommentar zum Gesetz über Ordnungswidrigkeiten, 5. Aufl., München 2018 (zit. KK-OwiG/Bearbeiter). 
Momsen, Carsten Fairneß im Sport als Rechtsproblem, in: Ghosh-Schellhorn, Martina /Marti, Roland (Hrsg.), Playing by the rules of the game - Materialien der internationalen Transcultura-Konferenz 2006, Berlin 2008, S. 73-92 (zit. Momsen, in: Ghosh-Schellhorn/Marti [Hrsg.], Spielregeln).

- Strafrecht - ein effizientes Instrument im Anti-Doping-Kampf?, in: Asmuth, Christoph (Hrsg.), Entgrenzungen des Machbaren? Doping zwischen Recht und Moral, Bielefeld 2012, S. 251-269 (zit. Momsen, in: Asmuth [Hrsg.], Entgrenzungen).

- Integrität des Sports - Was sollen die neuen Tatbestände schützen?, KriPoZ 2018, S. 21-28.

Momsen, Carsten/Vaudlet, Marie Korruption und Spielmanipulation im Fußball rechtliche Überlegungen, in: Emrich, Eike/Pierdzioch, Christian/Pitsch, Werner (Hrsg.), Falsches Spiel im Sport. Analysen zu Wettbewerbsverzerrungen, Saarbrücken 2015, S. 219-248 (zit. Momsen/Vaudlet, in: Emrich/Pierdzioch/Pitsch [Hrsg.], Falsches Spiel).

Momsen-Pflanz, Gundula Die sportethische und strafrechtliche Bedeutung des Dopings: Störung des wirtschaftlichen Wettbewerbs und Vermögensrelevanz, Frankfurt a.M. 2005 (zit. Momsen-Pflanz Doping).

Müller-Dietz, Heinz Strafe und Staat, Frankfurt a.M. 1973 (zit. Müller-Dietz Strafe und Staat).

Muresan, Remus Die Europaratskonvention über die Manipulation von Sportwettkämpfen, Causa Sport 2016, S. 3-9.

Mustroph, Tom Millionen von der Mafia?, Der Freitag vom 25.5.2013, www.freitag. de/autoren/der-freitag/millionen-von-der-mafia.

Mutschke, Ralf Integrität im Weltfußball, in: Höfling, Wolfram/Horst, Johannes/ Nolte, Martin (Hrsg.), Fußball - Motor des Sportrechts, Tübingen 2014, S. 4153 (zit. Mutschke, in: Höfling/Horst/Nolte [Hrsg.], Fußball).

Naber, Ibrahim Wettskandal im Tennis weitet sich aus - Deutscher Spieler involviert, Die Welt Online vom 15.12.2019, www.welt.de/vermischtes/article204340 410/Wettskandal-im-Tennis-Ermittlungsverfahren-gegen-deutschen-Spieler.htm 1.

Niewalda, Johannes Dopingkontrollen im Konflikt mit allgemeinem Persönlichkeitsrecht und Datenschutz, Berlin 2011 (zit. Niewalda Persönlichkeitsrecht).

Nolte, Martin Sport und Recht: ein Lehrbuch zum internationalen, europäischen und deutschen Sportrecht, Schorndorf 2004 (zit. Nolte Sport und Recht).

- Freiheitsrechte der Freizeit- und Berufssportler im Widerstreit mit staatlichem recht und Verbandsrecht, in: Württembergischer Fußballverband e.V. (Hrsg.), Die Manipulation sportlicher Wettbewerbe als Herausforderung für das Recht des Staates und der Verbände, Baden-Baden 2008, S. 61-74 (zit. Nolte, in: Württembergischer Fußballverband [Hrsg.], Manipulation).

- Anti-Doping-Meldepflichten im Lichte des Datenschutzrechts, in: Nolte, Martin (Hrsg.), Neue Bedrohungen für die Persönlichkeitsrechte von Sportlern, Stuttgart 2011, S. 59-74 (zit. Nolte, in: ders. [Hrsg.], Persönlichkeitsrechte). 
- Schriftliche Stellungnahme zur Anhörung als Sachverständiger im Rechtsausschuss zu BT-Drs. 18/8831 am 28.9.2016, www.bundestag.de/blob/461384/8d6de 671c6c66e8371dfdeb71f3e231e/nolte-data.pdf.

Norouzi, Ali B./Summerer, Thomas DAV-Stellungnahme zum Anti-Doping-Gesetz, SpuRt 2015, S. 63-65.

Nuzinger, Thomas/Rübenstabl, Markus/Bittmann, Folker Stellungnahme zum Referentenentwurf des Bundesministeriums der Justiz und für Verbraucherschutz zur Strafbarkeit von Sportwettbetrug und der Manipulation berufssportlicher Wettbewerbe, WiJ 2016, S. 34-37.

Obly, Ansgar/Sosnitza, Olaf Kommentar zum Gesetz gegen den unlauteren Wettbewerb, 7. Aufl., München 2016 (zit. Obly/Sosnitza UWG).

Oldigs, Dirk Möglichkeiten und Grenzen der strafrechtlichen Bekämpfung von Submissionsabsprachen, Heidelberg 1998 (zit. Oldigs Submissionsabsprachen).

Ortiz de Urbina Gimeno, Inigo Korruption im Sport im Lichte des spanischen Strafrechts: Ungeschick, Unmoral oder Kalkül des Gesetzgebers?, in: Kuhlen, Lothar/ Kudlich, Hans/Gómez Martín, Victor/ Martin/Ortiz de Urbina Gimeno, Ínigo (Hrsg.), Korruption und Strafrecht, 2018, S. 101-121 (zit. Ortiz de Urbina Gimeno, in: Kuhlen/Judlich/Gomez Martin/Ortiz de Urbina Gimeno [Hrsg.], Korruption und Strafrecht).

Ostermeier, Peter Die strafrechtliche Bewertung der Wettmanipulation nach dem Wettskandal-Urteil, ZfWG 2007, S. 253-261.

Ott, Konrad Grundelemente der Gerechtigkeit im Sport, in: Pawlenka, Claudia (Hrsg.), Sportethik, Paderborn 2004, S. 133-148 (zit. Ott, in: Pawlenka [Hrsg.], Sportethik).

Ott, Steffen Strafwürdigkeit und Strafbedürftigkeit des Selbstdopings im Leistungssport, Baden-Baden 2013 (zit. Ott Selbstdoping).

Otto, Harro Rechtsgutsbegriff und Deliktstatbestand, in: Müller-Dietz, Heinz (Hrsg.), Strafrechtsdogmatik und Kriminalpolitik, Köln 1971, S. 1-20 (zit. Otto, in: Müller-Dietz [Hrsg.], Strafrechtsdogmatik).

- Strafwürdigkeit und Strafbedürftigkeit als eigenständige Deliktskategorien? Überlegungen zum Deliktsaufbau, in: Stree, Walter (Hrsg.), Gedenkschrift für Horst Schröder, München 1978, S. 53-72 (zit. Otto GS Schröder).

- Der Mißbrauch von Insider-Informationen als abstraktes Gefährdungsdelikt, in: Schünemann, Bernd/Tiedemann, Klaus (Hrsg.), Bausteine des europäischen Wirtschaftsstrafrechts - Madrid-Symposium vom 14. bis 17. Oktober 1992, Köln 1994, S. 447-462 (zit. Otto, in: Schünemann/Tiedemann [Hrsg.], Madrid-Symposium).

- Wettbewerbsbeschränkende Absprachen bei Ausschreibungen, $\$ 298$ StGB, wistra 1999, S. 41-46.

Paringer, Martin Korruption im Profifußball: eine Überprüfung unlauteren Verhaltens von Vereinsfunktionär und Spieler unter dem Aspekt der $\$ \$ 263$ und $\$ \$ \$ 298$ ff. StGB am Beispiel des sog. Bundesligaskandals, Frankfurt a.M. 2001 (zit. Paringer Korruption). 
Pawlenka, Claudia Angewandte Ethik im Kontext von Sportethik und Bioethik, in: Maring, Matthias (Hrsg.), Bereichsethiken im interdisziplinären Dialog, Karlsruhe 2014, S. 277-300 (zit. Pawlenka, in: Maring [Hrsg.], Bereichsethiken).

Perron, Walter Sportwettbetrug und Manipulation von berufssportlichen Wettbewerben $(\$ \$ 265 c-265$ e StGB) - gelungene Gesetzgebung oder überflüssiges Strafrecht?, JuS 2020, S. 809-815.

Pieth, Mark Internationale Harmonisierung von Strafrecht als Antwort auf transnationale Wirtschaftskriminalität, ZStW 109 (1997), S. 756-776.

Pieth, Mark/Zerbes, Ingeborg Sportverbände und Bestechung: Sachgerechte Grenzen des Korruptionsstrafrechts?, ZIS 2016, S. 619-625.

Pitsch, Werner/Emrich, Eike/Pierdzioch, Christian Match Fixing im deutschen Fußball: Eine empirische Analyse mittels der Randomized-Response-Technik, in: Emrich, Eike/Pierdzioch, Christian/Pitsch, Werner (Hrsg.), Falsches Spiel im Sport. Analysen zu Wettbewerbsverzerrungen, Saarbrücken 2015, S. 157-172 (zit. Pitsch/Emrich/Pierdzioch, in: Emrich/Pierdzioch/Pitsch [Hrsg.], Falsches Spiel).

Pitsch, Werner/Frenger, Monika/Emrich, Eike/Pierdzioch, Christian Prävalenzen von Wettbewerbsverzerrungen unter Kaderathleten und Einstellungen zum Fair Play, in: Emrich, Eike/Pierdzioch, Christian/Pitsch, Werner (Hrsg.), Falsches Spiel im Sport. Analysen zu Wettbewerbsverzerrungen, Saarbrücken 2015, S.181-201 (zit. Pitsch/Frenger/Emrich/Pierdzioch, in: Emrich/Pierdzioch/Pitsch [Hrsg.], Falsches Spiel).

Pfister, Andreas Die geplanten Straftatbestände „zur Bekämpfung der Korruption im Sport“, StraFo 2016, S. 441-448.

Pollmann, Arnd Integrität: Aufnahme einer sozialphilosophischen Personalie, 2. Aufl., Bielefeld 2018 (zit. Pollmann Integrität).

Pragal, Oliver Die Korruption im privaten Sektor und ihre strafrechtliche Kontrolle durch $\$ 298$ StGB, Köln 2006 (zit. Pragal Privater Sektor).

- 2299 StGB - keine Straftat gegen den Wettbewerb!, ZIS 2006, S. 63-80.

Prittwitz, Cornelius Das deutsche Strafrecht: Fragmentarisch? Subsidiär? Ultima ratio? Gedanken zu Grund und Grenzen gängiger Strafrechtsbegrenzungspostulate, in: Institut für Kriminalwissenschaften (Hrsg.), Vom unmöglichen Zustand des Strafrechts, Frankfurt a.M. 1995, S. 387-405 (zit. Prittwitz, in: Institut für Kriminalwissenschaften [Hrsg.], Zustand).

- Straftat Doping, in: Lüderssen, Klaus/Volk, Klaus/Wahle, Eberhard, Festschrift für Wolf Schiller zum 65. Geburtstag, Baden-Baden 2014, S. 512-537 (zit. Prittwitz FS Schiller).

Puppe, Ingeborg Vom Umgang mit Definitionen in der Jurisprudenz, in: Dornseifer, Gerhard (Hrsg.), Gedächtnisschrift für Armin Kaufmann, Köln 1989, S. 15-35 (zit. Puppe GS Kaufmann).

Puschke, Jens Grund und Grenzen des Gefährdungsstrafrechts am Beispiel der Vorbereitungsdelikte, in: Hefendehl, Roland (Hrsg.), Grenzenlose Vorverlagerung des Strafrechts? Berlin 2010, S. 9-40 (Puschke, in: Hefendehl [Hrsg.], Vorverlagerung). 
- Legitimation, Grenzen und Dogmatik von Vorbereitungstatbeständen, Tübingen 2017 (zit. Puschke Vorbereitungstatbestände).

Radtke, Henning Sportwettenbetrug und Quotenschaden, Jura 2007, S. 445-451.

Rawls, John Eine Theorie der Gerechtigkeit, Frankfurt a.M. 1975 (zit. Rawls Theorie der Gerechtigkeit).

- Gerechtigkeit als Fairneß. Ein Neuentwurf, Frankfurt a.M. 2006 (zit. Rawls Gerechtigkeit als Fairneß).

Rebeggiani, Luca/Rebeggiani, Fatma Which Factors Favor Betting Related Cheating in Sports? Some Insights from Political Economy, in: Haberfeld, Maria/Sheehan, Dale (Hrsg.), Match-Fixing in International Sports: Existing Processes, Law Enforcement and Prevention Strategies, Cham 2013, 15-30, S. 157-176 (zit. Rebeggiani/Rebeggiani, in: Haberfeld/Sheehan [Hrsg.], Match-fixing).

Rehmet, Marco $₫ 5$ Nr. 10a StGB auf dem völkerrechtlichen Prüfstand, HRRS 2017, S. 518-523.

Reeckmann, Martin Illegales Glücksspiel - Forschung und Handlungsbedarf, ZfWG 2015, S. 106-111.

Reinhart, Michael Sportverbandsgerichtsbarkeit und Doppelbestrafungsverbot, SpuRt 2001, S. 45-48.

- Das „Hoyzer-Urteil“ des BGH: Genugtuung für den Sport oder Gefahr für die Betrugsdogmatik?, SpuRt 2007, S. 52-56.

- Der Straftatbestand der Manipulation von berufssportlichen Wettbewerben - absichtliches Foulspiel des Gesetzgebers?, SpuRt 2016, S. 235-240.

Rengier, Rudolf Die Unterscheidung von Zwischenzielen und unvermeidlichen Nebenfolgen bei der Betrugsabsicht, JZ 1990, S. 321-326.

- Strafrecht Allgemeiner Teil, 12. Aufl., München 2020 (zit. Rengier Strafrecht AT).

- Besonderer Teil - Band I: Vermögensdelikte, 22. Aufl., München 2020 (zit. Rengier Strafrecht BT I).

Reschke, Eike Erwiderung auf Reinhart (SpuRt 2001, 45), SpuRt 2001, S. 183-184.

Reuther, Christian Zur Strafbarkeit des Blutdopings nach $\$ 95$ i.V.m. $\$ 6$ a AMG, SpuRt 2008, S. 145-148.

Rieble, Volker Strafbare Arbeitgeberfinanzierung gelber Arbeitnehmervereinigungen, ZIP 2009, S. 1593-1601.

Römer, Jörg/Niestedt, Michael Unerlaubte Substanz im Fahrrad, Spiegel Online vom 28.3.2018, www.spiegel.de/wissenschaft/technik/e-doping-wie-man-elektromotor en-in-rennraedern-versteckt-a-1091641.html.

Rönnau, Thomas Untreue als Wirtschaftsdelikt ZStW 119 (2008), S. 887-926.

Rönnau, Thomas/Soyka, Till Der „Quotenschaden“ im Fall „Hoyzer“ - ein Verstoß gegen das Bestimmtheitsgebot, NStZ 2009, S. 12-15.

Röthig, Peter/Probl, Robert Sportwissenschaftliches Lexikon, 7.Aufl., Schorndorf 2003. 


\section{Literaturverzeichnis}

Rössner, Dieter Die Verbandsstrafe im Sport. Strafverfahrensrechtliche Prinzipien im Zivilrecht?, in: Eser, Albin (Hrsg.), Strafverfahrensrecht in Theorie und Praxis: Feschtschrift für Lutz Meyer-Gossner zum 65. Geburtstag, München 2001, S. 741-753 (zit. Rössner FS Meyer-Gossner).

- „Sportbetrug“ und Strafrecht - Notwendige Differenzierungen und kriminalpolitische Überlegungen, in: Hiebl, Stefan/Kassebohm, Nils/Lilie, Hans (Hrsg.), Festschrift für Volkmar Mehle zum 65. Geburtstag, 2009, S. 567-579 (zit. Rössner FS Mehle).

Roxin, Claus Zur Strafbarkeit des Geschwisterinzests - Zur verfassungsrechtlichen Überprüfung materiellrechtlicher Strafvorschriften, StV 2009, S. 544-550.

- Strafrecht und Doping, in: Joecks, Wolfgang u. a. (Hrsg.), Recht - Wirtschaft Strafe: Festschrift für Erich Samson zum 70. Geburtstag, Heidelberg 2010, S. 445-454 (zit. Roxin FS Samson).

- Zur neueren Entwicklung der Rechtsgutsdebatte, in: Herzog, Felix/Neumann, Ulfried (Hrsg.), Festschrift für Winfried Hassemer zum 70. Geburtstag, Heidelberg 2010, S. 573-597 (zit. Roxin FS Hassemer).

- Der gesetzgebungskritische Rechtsgutsbegriff auf dem Prüfstand, GA 2013, S. 433-453.

Roxin, Claus/Greco, Luis Strafrecht Allgemeiner Teil, Band 1: Grundlagen. Der Aufbau der Verbrechenslehre, 5. Aufl., München 2020 (zit. Roxin/Greco Strafrecht AT I).

Roxin, Claus/Schünemann, Bernd Strafverfahrensrecht, 29. Aufl., München 2017 (zit. Roxin/Schünemann Strafverfahrensrecht).

Rübenstabl, Markus $\$ \$ 265$ c und 265 d StGB - (Para-)Korruptionsstrafrecht zur Bekämpfung des Sportwettbetrugs und der Manipulation von Berufssportwettbewerben?, JR 2017, S. 264-279 (Teil 1), S. 333-338 (Teil 2).

Rudoplphi, Hans-Joachim/Samson, Erich/Schreiber, Hans-Ludwig (Begr.), Wolter, Jürgen (Hrsg.) Systematischer Kommentar zum Strafgesetzbuch, 9. Aufl., Köln 20172019 (zit. SK-StGB/Bearbeiter).

Sachs, Michael Grundgesetz - Kommentar, 8. Aufl., München 2018 (zit. Sachs/Bearbeiter GG).

Satzger, Helmut Der Submissionsbetrug, Berlin 1994 (zit. Satzger Submissionsbetrug).

- Das deutsche Strafanwendungsrecht ( $\$ \$ 3$ ff. StGB) - Teil 1, Jura 2010, S. 108116.

- „Sportwettbetrug“ und „Manipulation von berufssportlichen Wettbewerben“ zwei neue Tatbestände mit zweifelhafter Existenzberechtigung, Jura 2016, S. 1142-1155.

Saliger, Frank Die Normativierung des Schadensbegriffes in der neueren Rechtsprechung zu Betrug und Untreue, in: Joecks, Wolfgang u. a. (Hrsg.), Recht - Wirtschaft - Strafe: Festschrift für Erich Samson zum 70. Geburtstag, Heidelberg 2010, S. 455-483 (zit. Saliger FS Samson).

- Juristischer und wirtschaftlicher Schaden, HRRS 2012, S. 363-368. 
- Das Unrecht der Korruption, in: Albrecht, Peter-Alexis/Kirsch, Stefan/Neumann, Ulfried/Sinner, Stefan (Hrsg.), Festschrift für Walter Kargl zum 70. Geburtstag, Berlin 2015, S. 493-505 (zit. Saliger FS Kargl).

Saliger, Frank/Rönnau, Thomas/Kirch-Heim, Claudio Täuschung und Vermögensschaden beim Sportwettenbetrug durch Spielteilnehmer - Fall „Hoyzer“, NStZ 2007, S. 361-368.

Sax, Walter Grundsätze der Strafrechtspflege, in: Bettermann, Karl August/Nipperdey, Hans Carl/Scheuner, Ulrich (Hrsg.) Die Grundrechte - Bd. 3, Halbbd. 2: Rechtspflege und Grundrechtsschutz, 2. Aufl., Berlin 1972, S. 909-1014 (zit. Sax, in: Bettermann/Nipperdey/Scheuner [Hrsg.], Grundrechte III/2).

Schäfers, Beatrice Das Meinungsspektrum zum „Hoyzer-Fall“ - Eine Bestandsaufnahme, ZfWG 2008, S. 236-246.

Schattmann, Matthias Betrug des Leistungssportlers im Wettkampf, Frankfurt a.M. 2008 (zit. Schattmann Betrug).

Schiemann Sportwettenbetrug durch Spielmanipulationen - Schadensermittlung. Anmerkung zu BGH-Urteil vom 20.12.2012 - 4 StR 55/12, NJW 2013, S. 888.

Schenk, Sylvia Der Kampf gegen Manipulationen im Sport, in: Kainz, Florian/ Scherrer, Urs/Werner, Christian (Hrsg.), Sportfinanzierung und Sportwetten, Zürich u.a. 2012, S. 139-150 (zit. Schenk, in: Kainz/Scherrer/Werner [Hrsg.], Sportfinanzierung).

Scherrer, Urs/Muresan, Remus/Ludwig, Kai Sportrecht, 3. Aufl., Zürich 2014 (zit. Scherrer/Muresan/Ludwig Sportrecht).

Schild, Wolfgang Sportstrafrecht, Baden-Baden 2002 (zit. Schild Sportstrafrecht).

- Strafbarer Wettbetrug - zur Entscheidung des BGH im Fall Sapina/Hoyzer, ZfWG 2007, S. 10-14.

- Korruption und Manipulation im Sport als Strafrechtsprobleme, in: Wagner, Elisabeth/Wolf, Burkhard, Korruption, Berlin 2011, S.158-192 (zit. Schild, in: Wagner/Wolf [Hrsg.], Korruption).

- Doping, Studienbrief der Fernuniversität Hagen 2014 (zit. Schild Doping).

- Doping, Sportethos und rechtliche Sanktionierung, in: Albrecht, Peter-Alexis/ Kirsch, Stefan/Neumann, Ulfried/Sinner, Stefan (Hrsg.), Festschrift für Walter Kargl zum 70. Geburtstag, Berlin 2015, S. 507-522 (zit. Schild FS Kargl).

Schlösser, Jan Der „Bundesliga-Wettskandal“ - Aspekte einer strafrechtlichen Bewertung, NStZ 2005, S. 423-429.

Schlöter, Jan-Friedrich Bekämpfung des Dopings im professionellen Sport mithilfe des Strafrechts, Baden-Baden 2017 (zit. Schlöter Doping).

Schmidt, Eberhard Straftaten und Ordnungswidrigkeiten, JZ 1951, S. 101-104.

Schmitt, Jörg/Wulzinger, Michael Spur nach Warschau, Der Spiegel Nr. 5/2010 vom 1.2.2010, S. $136 \mathrm{ff} .$, www.spiegel.de/spiegel/print/d-68885129.html.

Schönau, Birgit Juventus fürchtet um die Trophäen, Sueddeutsche.de vom 19.5.2010, www.sueddeutsche.de/sport/wett-skandal-juventus-fuerchtet-um-die-t rophaeen-1.886152. 
Schörner, Christian ESport und Strafrecht - Zum Sportbegriff der $\$ \$ 265$ c und 265d StGB und deren Anwendbarkeit auf kompetitives Computerspielen, HRRS 2017, S. 407-413.

Schramm, Edward Die Amtsträgereigenschaft eines freiberuflichen Planungsingenieurs - Entscheidungsbesprechung zu BGHSt 43, 96, JuS 1999, S. 333-337.

Schreiber/Beulke, Werner Untreue durch Verwendung von Vereinsgeldern zu Bestechungszwecken - BGH NJW 1975, 1234, JuS 1977, S. 656-661.

Schröder, Christian Handbuch Kapitalmarktstrafrecht, 4. Aufl., Köln 2020 (zit. Schröder Kapitalmarktstrafrecht).

Schrum, Anja Geschäfte im halblegalen Bereich, Deutschlandfunk vom 26.11.2019, www.deutschlandfunkkultur.de/sportwetten-geschaefte-im-halblegalen-bereich. 976.de.html?dram:article_id=464349.

Schünemann, Bernd Alternative Kontrolle der Wirtschaftskriminalität, in: Dornseifer, Gerhard (Hrsg.), Gedächtnisschrift für Armin Kaufmann, Köln 1989, S. 629-650 (zit. Schünemann GS Kaufmann).

- Kritische Anmerkungen zur geistigen Situation der deutschen Strafrechtswissenschaft, GA 1995, S. 201-229.

- Das Rechtsgüterschutzprinzip als Fluchtpunkt der verfassungsrechtlichen Grenzen der Straftatbestände und ihrer Interpretation, in: Hefendehl, Roland/von Hirsch, Andrew/Wohlers, Wolfgang (Hrsg.), Die Rechtsgutstheorie - Legitimationsbasis des Strafrechts oder dogmatisches Glasperlenspiel?, Baden-Baden 2003, S. 133-154 (zit. Schünemann, in: Hefendehl/von Hirsch/Wohlers [Hrsg.], Rechtsgutstheorie).

Schürmann, Volker Natürlichkeit oder Fairness? Begründungsstrategien zum Dopingverbot im Spannungsfeld zwischen Recht und Moral, in: Asmuth, Christoph (Hrsg.), Entgrenzungen des Machbaren? Doping zwischen Recht und Moral, Bielefeld 2012, S. 75-88 (zit. Schürmann, in: Asmuth [Hrsg.], Entgrenzungen).

Schwab, Rouven Das zivilrechtliche Nachspiel im Fall Hoyzer, NJW 2005, S.938940.

Schwier, Jürgen Zur Moralität des sportlichen Wettkampfspiels, Sportwissenschaft 1990, S. 390-405.

Sengle, Alfred Verbandsgerichtsbarkeit und Schiedsgerichtsbarkeit im nationalen Fußball, in: Crezelius, Georg (Hrsg.), Festschrift für Volker Röhricht zum 65. Geburtstag, Köln 2005, S. 1205-1224 (zit. Sengle FS Röhricht).

- Formen der Manipulation (Doping, Wettbetrug, sonstige manipulative Verhaltensweise bzw. Absprachen) in Theorie und Praxis, in: Württembergischer Fußballverband e.V. (Hrsg.), Die Manipulation sportlicher Wettbewerbe als Herausforderung für das Recht des Staates und der Verbände, Baden-Baden 2008, S. 938 (zit. Sengle, in: Württembergischer Fußballverband [Hrsg.], Manipulation).

Siep, Ludwig Arten und Kriterien der Fairness im Sport, in: Gerhardt, Volker/ Lämmer, Manfred (Hrsg.), Fairneß und Fair play: eine Ringvorlesung an der deutschen Sporthochschule Köln, 2. Aufl., Köln 1995, S. 87-102 (zit. Siep, in: Gerhardt/Lämmer [Hrsg.], Fairneß). 
Sinner, Stefan Zum Begriff des Wettbewerbs und zum „Vorteil großen Ausmaßes“ in $\$ \$ 299,300$ StGB, HRRS 2016, S. 196-201.

- Korruption im Sport - strafwürdiges Unrecht, Verzerrung des Wettbewerbs oder bloß unfaires Spiel?, in: Saliger, Frank u.a. (Hrsg.), Rechtsstaatliches Strafrecht: Festschrift für Ulfried Neumann zum 70. Geburtstag, Heidelberg 2017, S. 12291241 (zit. Sinner FS Neumann).

Spapens, Tobine/Olfers, Marjan Match-fixing: The Current Discussion in Europe and the Case of the Netherlands, European Journal of Crime, Criminal Law and Criminal Justice 2015, S. 333-358.

Spöring, Thomas Von „Asian Handicap“ bis „Zweierkombi“: Einführung in die Theorie der Sportwetten, in: Kainz, Florian/Scherrer, Urs/Werner, Christian (Hrsg.), Sportfinanzierung und Sportwetten, Zürich u.a. 2012, S. 103-107 (zit. Spöring, in: Kainz/Scherrer/Werner [Hrsg.], Sportfinanzierung).

Sportradar (Hrsg.) World Match Fixing: The Problem and the solution, 2014, online zugänglich über: www.yumpu.com/en/document/view/40384161/sportrada r-security-services-world-match-fixing-the-problem-and-the-solution.

Stächelin, Gregor Strafgesetzgebung im Verfassungsstaat: normative und empirische materielle und prozedurale Aspekte der Legitimation unter Berücksichtigung neuerer Strafgesetzgebungspraxis, Berlin 1998 (zit. Stächelin Strafgesetzgebung).

Stam, Fabian Die Straftatbestände des Sportwettbetrugs ( $\$ 265$ c StGB) und der Manipulation von berufssportlichen Wettbewerben ( $\$ 265 \mathrm{~d}$ StGB), NZWiSt 2018, S. 41-48.

Steiner, Dirk Das Fairnessprinzip im Strafprozess, Frankfurt a.M. 1995 (zit. D. Steiner Fairnessprinzip).

Steiner, Udo Verfassungsfragen des Sports, NJW 1991, S. 2729-2735.

- Aktuelle Entwicklungen des Verhältnisses von Sport und Recht, in: Altenberger, Helmut/Haimerl, Bernhard (Hrsg.), Sport im Spiegel - Festschrift für Heinz Lutter, Regensburg 1994, S. 213-225 (zit. U. Steiner FS Lutter).

- Die Autonomie des Sports, München 2003 (zit. U. Steiner Autonomie).

- Deutschland als Antidopingstaat, ZRP 2015, S. 51-53.

Steinsiek, Marc/Vollmer, Philipp Anmerkung zu BVerfG-Beschluss vom 7.12.2011 - 2 BvR 2500/09, ZIS 2012, S. 586-590.

Sternberg-Lieben, Detlev Rechtsgut, Verhältnismäßigkeit und die Freiheit des Strafgesetzgebers, in: Hefendehl, Roland/von Hirsch, Andrew/Wohlers, Wolfgang (Hrsg.), Die Rechtsgutstheorie - Legitimationsbasis des Strafrechts oder dogmatisches Glasperlenspiel?, Baden-Baden 2003, S. 65-82 (zit. Sternberg-Lieben, in: Hefendehl/von Hirsch/Wohlers [Hrsg.], Rechtsgutstheorie).

Stratenwerth, Günter/Kublen, Lothar Strafrecht - Allgemeiner Teil. Die Straftat, 6. Aufl., München 2011 (zit. Stratenwerth/Kublen Strafrecht AT).

Streinz, Rudolf/Liesching, Mark/Hambach, Wulf Glücks- und Gewinnspielrecht in den Medien - Kommentar, München 2014 (zit. Streinz/Liesching/Hambach/Bearbeiter).

Stuckenberg, Carl-Friedrich Grundrechtsdogmatik statt Rechtsgutslehre, GA 2011, S. 653-661. 
Sutherland, Edwin Hardin White Collar Crime, New Haven 1983 (zit. Sutherland White Collar).

Swoboda, Sabine/Bohn, André Aktuelles Gesetzgebungsvorhaben: Neue Straftatbestände zum Sportwettbetrug und zur Manipulation berufssportlicher Wettbewerbe, JuS 2016, S. 686-689.

Sykes, David/Matza, Gresham Techniken der Neutralisierung: Eine Theorie der Delinquenz, in: Sack, Fritz/König, Rene (Hrsg.), Kriminalsoziologie, Wiesbaden 1979, S. 360-371 (zit. Sykes/Matza, in: Sack/König [Hrsg.], Kriminalsoziologie).

Szebrowski, Nickel Kick-Back, Köln 2005 (zit. Szebrowski Kick-Back).

Taylor, Beck/Trogdon, Justin Losing to Win: Tournament Incentives in the National Basketball Association, Journal of Labor Economics 2002, S. 23-41.

Tenter, Dieter/Thomas, Klaus Die „Schwalbe“ auf dem Fußballfeld oder ist die Zeitlupenstudie für den Staatsanwalt Anlass zu Einleitung von Ermittlungen, JA 1996, S. 855-856.

Tettinger, Peter Fairness als Rechtsbegriff im deutschen Recht, Der Staat 36 (1997), S. 575-595.

Tiedemann, Klaus Tatbestandsfunktionen im Nebenstrafrecht: Untersuchungen zu einem rechtsstaatlichen Tatbestandsbegriff, entwickelt am Problem des Wirtschaftsstrafrechts, Tübingen 1968 (zit. Tiedemann Tatbestandsfunktionen).

- Der Entwurf eines ersten Gesetzes zur Bekämpfung der Wirtschaftskriminalität, ZStW 87 (1975), 253-296.

Tiedemann, Klaus Wirtschaftsstrafrecht, 5.Aufl., München 2017 (zit. Tiedemann Wirtschaftsstrafrecht).

Timm, Frauke Die Legitimation des strafbewehrten Dopingverbots, GA 2012, S. 732-746.

Thurn, John Phillip Eugenik und Moralschutz durch Strafrecht? Verfassungsrechtliche Anmerkungen zur Inzestverbotsentscheidung des Bundesverfassungsgerichts, KJ 2009, S. 74-83.

Transparency International e.V. (Hrsg.) Stellungnahme zum Gesetzentwurf der Bundesregierung (BT-Drs. 18/8831, Stand: 20.06.2016): „Entwurf eines Gesetzes zur Änderung des Strafgesetzbuches - Strafbarkeit von Sportwettbetrug und der Manipulation von berufssportlichen Wettbewerben“ vom 26. September 2016, www.bundestag.de/resource/blob/461388/18383ae7cbb1431618e11c80dbdc 8a6 2/tid_fiedler-data.pdf.

- Jahresbericht 2018, www.transparency.de/fileadmin/Redaktion/Publikationen/20 19/Jahresbericht_2018_Transparency_Deutschland.pdf.

Triffterer, Otto Vermögensdelikte im Bundesligaskandal, NJW 1975, S. 612-617.

Trüg, Gerson Konzeption und Struktur des Insiderstrafrechts, Tübingen 2014 (zit. Trüg Insiderstrafrecht).

- Umrisse eines Sportsanktionenrechts - Gedanken zur Subsidiarität des Strafrechts, in: Bannenberg, Britta/Brettel, Hauke (Hrsg.), Über allem: Menschlichkeit: Festschrift für Dieter Rössner, Baden-Baden 2015, S. 686-700 (zit. Trüg FS Rössner). 
Trumpyte, Rugile The gap between sport institutions and the public will, in: Transparency International (Hrsg.), Global Corruption Report: Sport, New York 2016, S. 250-253 (zit. Trumpyte, in: Transparency International [Hrsg.], Corruption Report).

Tsambikakis, Michael Überflüssiges Strafrecht: Sportwettbetrug und Manipulation berufssportlicher Wettbewerbe, StV 2018, S. 319-325.

UNESCO (Hrsg.) Berliner Erklärung der 5. UNESCO-Weltkonferenz der Sportminister (MINEPS V) in Berlin am 30. Mai 2013, abrufbar unter: www.bmi.bund. de/SharedDocs/downloads/EN/news/berlin-declaration.html.

Uwer, Dirk Glücksspielrecht - Textsammlung, 2. Aufl., 2013 (zit. Uwer Glücksspielrecht).

Van Reeth, Daam TV Demand for the tour de France: The Importance of Stage Characteristics versus Outcome Uncertainty, Patriotism and Doping, International Journal of Sport Finance 2013, Volume 8, Issue 1, S. 39-60.

Valerius, Brian Schneller, höher, weiter? Strafbarkeit von Wett-Betrugsfällen im Sport, SpuRt 2005, S. 90-93.

- Sportwettbetrug $(\$ 265$ c StGB) und Manipulation von berufssportlichen Wettbewerben ( $\$ 265$ d StGB), Jura 2018, S. 777-788.

Van Rompuy, Ben Die Wahrscheinlichkeit von Spielmanipulationen - Fakten \& Zahlen zum Integritätsrisiko bestimmter Sportwetten, 2015, www.asser.nl/medi a/2691/die-warscheinlichkeiten-von-spielmanipulation-studie-2015.pdf (zit. Van Rompuy Spielmanipulationen).

- The Role of the Betting Industry, in: Transparency International (Hrsg.), Global Corruption Report: Sport, New York 2016, S. 236-241 (zit. Van Rompuy, in: Transparency International [Hrsg.], Corruption Report).

Vesper, Michael/Nolte, Martin Sportwetten und Wettbetrug aus Sicht des organisierten Sports, in: Württembergischer Fußballverband (Hrsg.), Das Recht der Sportwette und des Wettbetruges: Tagungsband des wfv-Sportrechtsseminars vom 30. September bis 2. Oktober 2011 in Wangen/Allgäu, Baden-Baden 2013, S. 918 (zit. Vesper/Nolte, in: Württembergischer Fußballverband [Hrsg.], Sportwette).

Vieweg, Klaus „Techno-Doping“- Regelungs- und Durchsetzungsmöglichkeiten der Sportverbände, in: ders. (Hrsg.), „Techno-Doping“ Leistungssteigerung durch technische Hilfsmittel aus naturwissenschaftlicher und juristischer Perspektive, Stuttgart 2015, S. 47-64 (zit. Vieweg, in: ders. [Hrsg.], Techno-Doping).

Vieweg, Klaus/Staschik, Paul Lex sportiva und Fairness-Prinzip, SpuRt 2013, S. 227 234.

Villiger, Marco Der Kampf der Verbände gegen Spielmanipulationen, in: Kainz, Florian/Scherrer, Urs/Werner, Christian (Hrsg.), Sportfinanzierung und Sportwetten, Zürich u.a. 2012, S. 119-137 (zit. Villiger, in: Kainz/Scherrer/Werner [Hrsg.], Sportfinanzierung).

Vogel, Joachim Strafrechtsgüter und Rechtsgüterschutz durch Strafrecht im Spiegel der Rechtsprechung des Bundsverfassungsgericht, StV 1996, S. 110-119. 
Vogler, Theo Möglichkeiten und Wege einer Entkriminalisierung, ZStW 90 (1978), S. 132-172.

Volk, Klaus Marktmissbrauch und Strafrecht, in: Herzog, Felix/Neumann, Ulfried (Hrsg.), Festschrift für Winfried Hassemer zum 70. Geburtstag, Heidelberg 2010, S. 915-928 (zit. Volk FS Hassemer).

Volkwein, Karin Sport und Gesellschaft - Ursachen für ethische Probleme im Sport, Olympische Jugend 1995, Heft 2, S. 4-8.

Von Hirsch, Andrew/ Woblers, Wolfgang Rechtsgutstheorie und Deliktsstruktur - zu den Kriterien fairer Zurechnung, in: Hefendehl, Roland/von Hirsch, Andrew/ Wohlers, Wolfgang (Hrsg.), Die Rechtsgutstheorie - Legitimationsbasis des Strafrechts oder dogmatisches Glasperlenspiel?, Baden-Baden 2003, S. 196-214 (zit. Von Hirsch/Wohlers, in: Hefendehl/von Hirsch/Wohlers [Hrsg.], Rechtsgutstheorie).

Von Mangoldt, Hermann/Klein, Friedrich/Starck, Christian (Hrsg.) Grundgesetz Band 3: Artikel 83-146, 7. Aufl., München 2018 (zit. Von Mangoldt/Klein/ Starck/Bearbeiter).

Von Komorowski, Alexis/Bredemeier, Barbara Fußball, Vermögensstrafrecht und Schiedsrichterverhalten, SpuRt 2005, S. 181-184.

Vormbaum, Thomas Fragmentarisches Strafrecht in Geschichte und Dogmatik, ZStW 123 (2011), S. 660-690.

Wabnitz, Heinz-Bernd/Janovsky, Thomas (Hrsg.) Handbuch des Wirtschafts- und Steuerstrafrechts, 4. Aufl., München 2014 (zit. Wabnitz/Janovsky/Bearbeiter).

Wabnitz, Heinz-Bernd/Janovsky, Thomas/Schmitt, Lothar (Hrsg.) Handbuch des Wirtschafts- und Steuerstrafrechts, 5. Aufl., München 2020 (zit. Wabnitz/Janovsky/ Schmitt/Bearbeiter).

Waldeck, Volker Wertungssysteme im Eiskunstlaufen, in: Krähe, Christian/Vieweg, Klaus (Hrsg.), Schiedsrichter und Wettkampfrichter im Sport, Stuttgart 2008, S. 15-30 (zit. Waldeck, in: Krähe/Vieweg [Hrsg.], Schiedsrichter).

Walter, Tonio Angestelltenbestechung, internationales Strafrecht und Steuerstrafrecht, wistra 2001, S. 321-327.

Waßmer, Martin Paul Auslegungsprobleme der Strafvorschrift der „Manipulation von berufssportlichen Wettbewerben“( $\$ 265 \mathrm{~d}$ StGB), ZWH 2019, S. 6-14.

Weigend, Thomas Über die Begründung der Straflosigkeit bei Einwilligung des Betroffenen, ZStW 98 (1986), S. 44-72.

Weinbuch, Christian Verhinderung von Sportwettmanipulationen und Autonomie des Sports, Konstanz 2015 (zit. Weinbuch Sportwettmanipulationen).

Weinreich, Jens Die globale Spezialdemokratie, in: ders. (Hrsg.), Korruption im Sport. Mafiose Dribblings, Organisiertes Schweigen, Leipzig 2006, S. $22-66$ (zit. Weinreich, in: ders. [Hrsg.], Korruption).

- Ghana in der Hölle, Uruguay im Paradies, Spiegel Online vom 3.7.2010, www.spi egel.de/sport/fussball/elfmeterdrama-im-wm-viertelfinale-ghana-in-der-hoelle-ur uguay-im-paradies-a-704428.html. 
Westermann, Harm Peter Fairness als Rechtsbegriff, in: Württembergischer Fußballverband e.V. (Hrsg.), Fairness-Gebot, Sportregeln und Rechtsnormen, Stuttgart 2004, S. 79-97 (zit. Westermann, in: Württembergischer Fußballverband [Hrsg.], Fairness-Gebot).

Wessels, Johannes/Hillenkamp, Thomas/Schuhr, Jan Strafrecht Besonderer Teil - Band 2: Straftaten gegen Vermögenswerte, 43. Aufl., Heidelberg 2020 (zit. Wessels/ Hillenkamp/Schuhr Strafrecht BT II).

Widmaier, Gunter (Begr.)/ Satzger, Helmut/Schluckebier, Wilhelm (Hrsg.) Strafgesetzbuch - Komentar, 4. Aufl., Köln 2019 (zit. SSW-StGB/Bearbeiter).

Wilke, Matthias Das Ende der Fairness? - ethische Werte aus dem Sport im Spiegel der Gesellschaft, Köln 2009 (zit. Wilke Fairness).

Wilmroth, Jan So viel verwetten die Deutschen bei der WM, Sueddeutsche.de vom 14.7.2018, www.sueddeutsche.de/wirtschaft/gluecksspiel-so-viel-verwetten-die-de utschen-bei-der-wm-1.4052568.

Wissenschaftliche Dienste des Deutschen Bundestages Ist E-Sport Sport? Sachstand vom 9. Juni 2017, WD 10-3000-036/17, www.bundestag.de/resource/blob/515426/c2a 9373a582f7908c090a658fdff1af8/wd-10-036-pdf-data.pdf.

- Sport als Staatsziel im Grundgesetz, Ausarbeitung vom 6. September 2018, WD 10-3000-069/18, www.bundestag.de/resource/blob/591832/139b6646e66df754ac8 907697bfb2683/WD-10-069-18-pdf-data.pdf.

Wissenschaftlicher Parlamentsdienst des Abgeordnetenhauses von Berlin Gutachten über Voraussetzungen und Auswirkungen der Anerkennung von eSport als Sportart vom 18. März 2016, abrufbar unter: www.parlament-berlin.de/de/Verwaltung/ Wissenschaftlicher-Dienst/Gutachten.

Wittig Der ökonomische Ansatz zur Erklärung kriminellen Verhaltens, MSchrKrim 1993, S. 328-335.

- Die Absicht der rechtswidrigen Bereicherung, JA 2013, 401-407.

Woblers, Wolfgang Deliktstypen des Präventionsstrafrechts - zur Dogmatik „moderner" Gefährdungsdelikte, Berlin 2000 (zit. Wohlers Deliktstypen).

- Rechtsgutstheorie und Deliktsstruktur, GA 2002, S. 15-20.

- Die Tagung aus der Perspektive eines Rechtsgutsskeptikers, in: Hefendehl, Roland/von Hirsch, Andrew/Wohlers, Wolfgang (Hrsg.), Die Rechtsgutstheorie Legitimationsbasis des Strafrechts oder dogmatisches Glasperlenspiel?, BadenBaden 2003, S. 281-285 (zit. Woblers, in: Hefendehl/Von Hirsch/Wohlers [Hrsg.], Rechtsgutstheorie).

- Insiderhandel und Kursmanipulation - Prüfstein der Frage, wie weit sich Strafrechtsnormen an den Realitäten des Marktes zu orientieren haben, ZStW 125 (2013), S. 443-480.

Wojdyla, Jacek Folgerungen aus den jüngsten Manipulationsvorfällen in Italien, Causa Sport 2014, S. 201-204.

Wolfers, Justin Point Shaving: Corruption in NCAA Basketball, American Economic Review 96 (2006), S. 279-283. 


\section{Literaturverzeichnis}

Wolter, Jürgen Objektive und personale Zurechnung von Verhalten, Gefahr und Verletzung in einem funktionalen Straftatsystem, Berlin 1981 (zit. Wolter Zurechnung).

Youssef, Omar Abo/Godenzi, Gunhild Diskussionsbeiträge der Strafrechtslehrertagung 2013 in Zürich, ZStW 125 (2013), S. 659-700.

Zeiser, Roland Trafic d'Influence: Der Straftatbestand des missbräuchlichen Handels mit Einfluss als Modell der Schließung von Strafbarkeitslücken?, Berlin 2012 (zit. Zeiser Trafic).

Zenglein, Detlev Möglichkeiten und Grenzen von Überwachungssystemen zur Sicherung der Integrität des Sports, in: Kainz, Florian/Scherrer, Urs/Werner, Christian (Hrsg.), Sportfinanzierung und Sportwetten, Zürich u.a. 2012, S. $171-$ 179 (zit. Zenglein, in: Kainz/Scherrer/Werner [Hrsg.], Sportfinanzierung).

Zieschang, Frank Die Gefährdungsdelikte, Berlin 1998 (zit. Zieschang Gefährdungsdelikte).

- Der Kapitalanlagebetrug gemäß $\$ 264$ a StGB - eine überflüssige Vorschrift?, GA 2012, S. 607-616.

Zuck, Rüdiger Doping, NJW 1999, S. 831-833.

- Wider die Kriminalisierung des Sports NJW 2014, S. 276-281.

Zuck, Rüdiger/Gerhardt, Rudolf Fairer Sport, Integrität der Wissenschaft, enttäuschtes Vertrauen - Hilft das Strafrecht weiter, ZRP 2014, S. 28-30.

Zurawski, Nils/Scharf, Marcel Das Anti-Doping-Gesetz: Doping, Sport und Überwachung aus AthletInnen-Sicht, NK 2015, S. 399-413. 